PROGRAMA DE DOCTORADO EN INGENIERÍA QUÍMICA Y AMBIENTAL

TESIS DOCTORAL:

\title{
VIABILIDAD DEL PROCESO DE GASIFICACIÓN DE RESIDUOS CON ALTO CONTENIDO EN MATERIAL PLÁSTICO
}

Presentada por Jorge Arenales Rivera para optar al

grado de

Doctor/a por la Universidad de Valladolid

Dirigida por:

Dra. Raquel Ramos Casado 

A mi familia y amigos 


\section{AGRADECIMIENTOS}

Agradezco al Centro de Investigaciones Energéticas, Medioambientales y Tecnológicas (CIEMAT), al centro de Desarrollo de Energías Renovables (CEDER) y a su director, D. Miguel Latorre Zubiri, por permitirme utilizar los medios experimentales para la realización de esta tesis.

Así mismo, quiero mostrar mi agradecimiento a la Comunidad Autónoma de Madrid por el proyecto "Prolipapel", y al Ministerio de Ciencia e Innovación por el proyecto "Gasreur", sin los cuales no hubiera sido posible la realización de esta tesis.

La realización de esta tesis jamás hubiera sido posible sin la ayuda y colaboración de multitud de profesionales, por tanto, quiero expresarles mi agradecimiento y gratitud, ya que sin su colaboración directa e indirecta, hubiera sido un reto inasumible afrontar este trabajo.

A mi directora de tesis, Dra. Raquel Ramos Casado, principalmente, por su orientación en la realización de esta tesis.

Al Director de la División de Combustión y Gasificación, D. Juan Otero Becerra, en su momento, por poner a disposición las instalaciones.

A los profesionales de la Unidad de Procesos de Conversión Térmica: Virginia, Elena, Ricardo, Santiago y Alfonso, por su ayuda y colaboración.

A Chema e Isabel, de la Unidad de Valoración Energética de Combustibles y Residuos, por su ayuda y dedicación.

A todo el equipo que ha colaborado en los diferentes ensayos: Miguel, Iván, Rubén, Ramiro, Andrés y Gonzalo.

Al personal de laboratorio, Ruth y Miguel, por su gran ayuda.

Y por último, quiero mostrar mi agradecimiento, a toda mi familia y amigos. 


\section{RESUMEN}

La recuperación energética de residuos no reciclables con contenido en materiales plásticos se ha convertido en una alternativa viable a la mera eliminación de residuos vía vertedero o incineración. Ante las nuevas normativas europeas, cada vez más restrictivas, en tanto a la eliminación en vertedero de residuos, se abre la posibilidad de aprovechar estos residuos para la producción de combustibles aptos para su transformación energética en instalaciones de conversión térmica, como gasificación.

En esta Tesis Doctoral se muestra la obtención de combustibles derivados de residuos no peligrosos, denominados combustibles sólidos recuperados, a partir de residuos de origen doméstico: fracciones de rechazo de residuos sólidos urbanos, fracciones de rechazo de la clasificación y selección de envases llevados a plantas de tratamientos de residuos sólidos, y a partir de residuos de origen industrial: rechazos del papelote que llega a la industria papelera y de los lodos generados en el proceso. El estudio de la viabilidad técnica de estos combustibles se ha llevado a cabo en plantas de gasificación de lecho fluidizado burbujeante (LFB) de $0,1 \mathrm{MW}_{\text {th }}$ y circulante (LFC) de $0,5 \mathrm{MW}_{\text {th }}$.

En primer lugar, se ha estudiado la caracterización de las fracciones residuales de partida, tanto de origen doméstico, como industrial. La normativa seguida para plasmar esta caracterización ha sido la suministrada a través de la normativa europea sobre combustibles sólidos recuperados (CSR). Respecto a las fracciones residuales de origen doméstico, éstas fueron analizadas suministrándose datos relevantes sobre la procedencia de cada una de ellas, su caracterización y su idoneidad o no como materia prima en la producción de combustibles. Los estudios que se han llevado a cabo engloban desde análisis cuantitativos del residuo a la determinación del contenido en biomasa del mismo. El proceso de peletizado, para dotar a los combustibles de unas características físicas adecuadas para su alimentación en procesos de conversión térmica, fue estudiado a través de una matriz plana, donde se modificó la relación de compresión con objeto de optimizar el producto peletizado, de 37 a $40 \mathrm{~mm}$. En esta etapa se observó la aparición de fundidos de material plástico, que empeoraron la calidad del pélet. En cuanto a las fracciones residuales procedentes de la industria papelera, éstas fueron estudiadas en distintos turnos de trabajo para conocer la variabilidad del material. Al igual que ocurrió con el residuo de origen doméstico, se caracterizaron química y físicamente cada una de las fracciones para su posterior empleo como materia prima en la producción de combustibles, dando lugar a cuatro, obtenidos de la mezcla de residuos con alto contenido en material plástico y lodos de destintado.

Finalmente, se estudió y evaluó la viabilidad de un proceso de gasificación empleando los combustibles preparados. El CSR de origen doméstico fue evaluado en el gasificador LFB con aire como agente gasificante, donde el parámetro clave fue la relación de equivalencia ER, 0,19-0,23. La composición del gas de proceso y su poder calorífico fueron analizados, al igual que los subproductos generados: alquitranes y cenizas, resultando en un combustible adecuado para este tipo de proceso. Respecto a los CSR de origen industrial, se analizó su idoneidad en un gasificador LFB, donde se obtuvieron buenos resultados con cada uno de ellos, analizándose composición de gas, alquitranes y cenizas generadas en el proceso en función de la proporción de lodo de destintado (5-35\%). Además, el CSR con menor contenido en ceniza fue gasificado en un gasificador LFC variando ER, obteniéndose un gas de buena calidad en términos de poder calorífico inferior al emplear aire como agente gasificante para un $\mathrm{ER}=0,3$. 
ÍNDICE

PUBLICACIONES.........................................................................................................XV

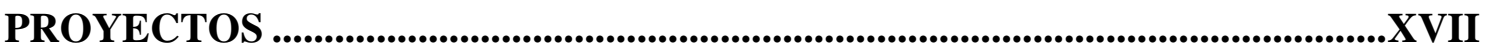

PRESENTACIÓN ..........................................................................................XVIII

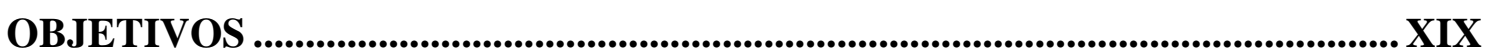

ORGANIZACIÓN ..................................................................................................

1 CAPÍTULO I. ANTECEDENTES ….............................................................. 1

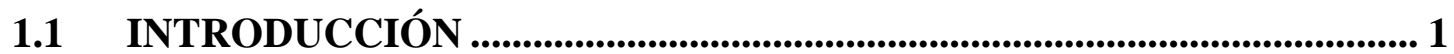

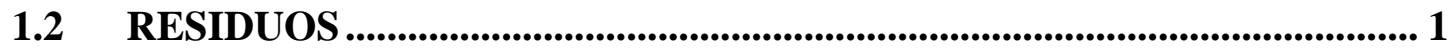

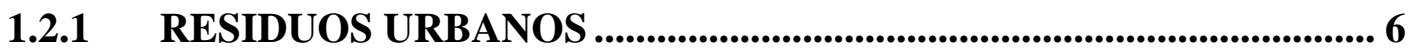

1.2.2 INDUSTRIA PAPELERA ....................................................................... 8

1.2.3 PRODUCCIÓN DE COMBUSTIBLES DE RESIDUOS ........................9

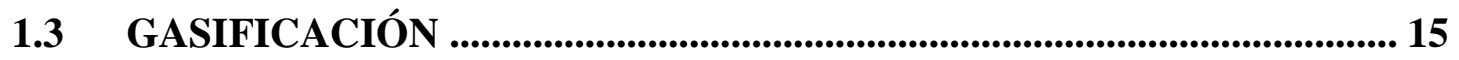

1.3.1 INTRODUCCIÓN ............................................................................. 15

1.3.2 FUNDAMENTOS DEL PROCESO DE GASIFICACIÓN................... 16

1.3.3 ETAPAS DE LA GASIFICACIÓN ......................................................... 17

1.3.4 TECNOLOGÍAS DE GASIFICACIÓN...................................................... 19

1.3.5 PARÁMETROS DE OPERACIÓN....................................................... 25

1.4 GAS DE GASIFICACIÓN..................................................................... 26

1.4.1 CAPACIDAD DE GASIFICACIÓN ..................................................... 26

1.4.2 APLICACIONES COMERCIALES DE LA GASIFICACIÓN ......... 28

1.4.3 GASIFICACIÓN DE CDR/CSR ........................................................ 31

1.4.4 SUBPRODUCTOS .................................................................................. 32

2 CAPÍTULO II. MATERIALES Y MÉTODOS ................................................... 38

$2.1 \quad$ INTRODUCCIÓN ................................................................................38

2.2 MATERIALES A ESTUDIO...........................................................38

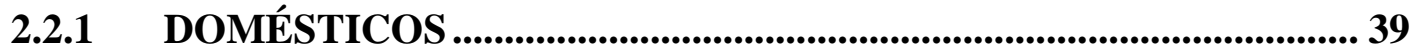

2.2.2 COMERCIALES E INDUSTRIALES ................................................... 43

2.3 CARACTERIZACIÓN DE LOS MATERIALES....................................... 45

2.3.1 MÉTODOS DE ANÁLISIS GENERALES............................................... 45

2.4 INSTALACIONES DE PRETRATAMIENTO .......................................... 55

2.4.1 SECADO …………........................................................................................ 55

2.4.2 ELIMINACIÓN DE IMPROPIOS .........................................................56 
2.4.3 TRITURACIÓN Y MOLIENDA........................................................56

2.4.4 PELETIZACIÓN ..............................................................................57

2.4.5 MÉTODOS DE PREPARACIÓN....................................................... 59

2.5 INSTALACIONES DE GASIFICACIÓN.....................................................60

2.5.1 PLANTA PILOTO DE LECHO FLUIDIZADO BURBUJEANTE.. 60

2.5.2 PLANTA PILOTO DE LECHO FLUIDIZADO CIRCULANTE..... 65

2.5.3 TRATAMIENTO DE LOS DATOS EXPERIMENTALES................. 74

2.5.4 ANÁLISIS DEL GAS DE GASIFICACIÓN .......................................... 76

2.6 INSTALACIONES PARA ESTUDIO DE LA FLUIDIZACIÓN ............... 79

2.6.1 MODELO UNIDAD CIRCULANTE A TEMPERATURA

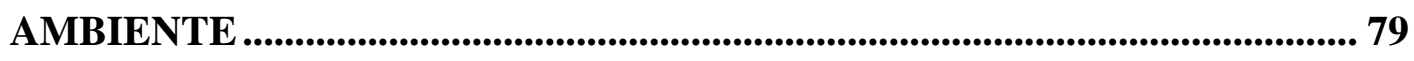

2.6.2 MODELO VÁLVULA NO-MECÁNICA CLÁSICA TIPO "LOOPSEAL" 84

2.6.3 TRATAMIENTO DE LOS DATOS EXPERIMENTALES................. 86

3 CAPÍTULO III. COMBUSTIBLES SÓLIDOS RECUPERADOS.................... 87

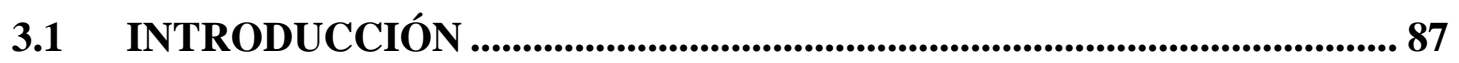

3.2 RESIDUOS SÓLIDOS URBANOS (RSU) .................................................. 87

3.2.1 CARACTERIZACIÓN DE RECHAZOS DE PLANTA DE TRATAMIENTO DE RESIDUOS SÓLIDOS ...................................................... 88

3.2.2 PREPARACIÓN DEL COMBUSTIBLE.............................................90

3.2.3 CARACTERIZACIÓN DEL COMBUSTIBLE DERIVADO DE RESIDUOS ..................................................................................................94

3.2.4 ANÁLISIS TERMOGRAVIMÉTRICO DEL COMBUSTIBLE ...... 97

3.2.5 CLASIFICACIÓN DEL COMBUSTIBLE SÓLIDO RECUPERADO 100

$3.3 \quad$ RESIDUOS INDUSTRIALES .............................................................. 104

3.3.1 CARACTERIZACIÓN DE LOS RESIDUOS INDUSTRIALES.... 104

3.3.2 ANÁLISIS TERMOGRAVIMÉTRICO DE RECHAZOS DE

INDUSTRIA PAPELERA................................................................................. 107

3.3.3 PREPARACIÓN DEL COMBUSTIBLE............................................ 109

3.3.4 CARACTERIZACIÓN DEL COMBUSTIBLE DERIVADO DE

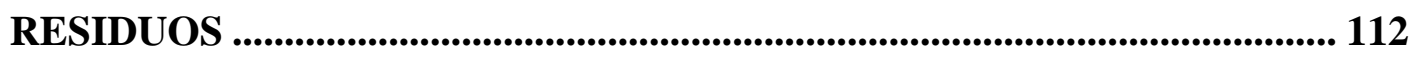

3.3.5 ANÁLISIS TERMOGRAVIMÉTRICO DEL COMBUSTIBLE .... 116

3.3.6 ESTUDIO CINÉTICO.............................................................................. 117 
3.3.7 CLASIFICACIÓN DEL COMBUSTIBLE SÓLIDO RECUPERADO 120

4 CAPÍTULO IV. TECNOLOGÍA DE LECHO FLUIDIZADO ....................... 131

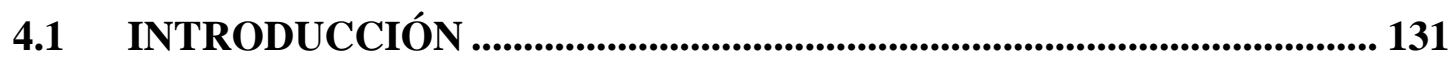

4.2 ASPECTOS FLUIDO-DINÁMICOS......................................................... 132

4.2.1 FLUDIZACIÓN.................................................................................. 132

4.2.2 MATERIAL DE LECHO .................................................................. 133

4.2.3 MÍNIMA FLUIDIZACIÓN................................................................ 135

4.2.4 VELOCIDAD TERMINAL ................................................................ 139

4.3 LECHO FLUIDIZADO CIRCULANTE............................................... 143

4.3.1 INTRODUCCIÓN............................................................................. 143

4.3.2 FLUJO DE SÓLIDOS AXIAL Y LATERAL EN EL RISER .......... 144

4.4 MODELO UNIDAD CIRCULANTE A TEMPERATURA AMBIENTE 165

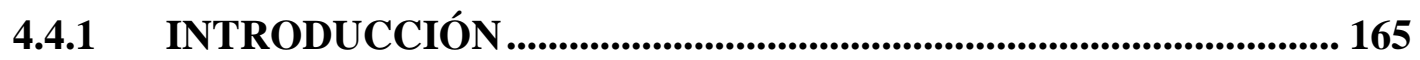

4.4.2 UNIDAD CIRCULANTE CON VÁLVULA TIPO L .......................... 165

4.5 MODELO VÁLVULA NO-MECÁNICA TIPO LOOP-SEAL A

TEMPERATURA AMBIENTE ..................................................................... 172

4.5.1 INTRODUCCIÓN ........................................................................... 172

4.5.2 SISTEMA DE RECIRCULACIÓN ...................................................... 172

4.5.3 VÁLVULA NO-MECÁNICA LOOP-SEAL TIPO U.......................... 173

4.6 SIMULACIÓN GASIFICADOR LECHO FLUIDIZADO CON VÁLVULA NO-MECÁNICA TIPO LOOP-SEAL .............................................. 177

5 CAPÍTULO V. VIABILIDAD DE LA GASIFICACIÓN CON CSR .............. 179

5.1 CSR DE ORIGEN DOMÉSTICO. RSU Y ENVASES ............................. 182

5.1.1 INFLUENCIA DEL ER ......................................................................... 182

5.2 CSR DE ORIGEN INDUSTRIAL. INDUSTRIA PAPELERA................. 189

5.2.1 INFLUENCIA DEL LODO DE DESTINTADO................................. 189

5.2.2 INFLUENCIA DEL TIPO DE GASIFICADOR................................. 196

6 CAPÍTULO VI. RESUMEN DE RESULTADOS Y CONCLUSIONES........ 204

6.1 RESUMEN DE RESULTADOS ................................................................... 204

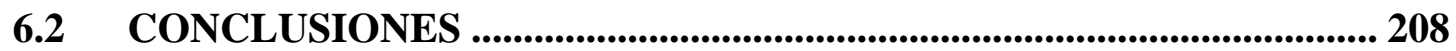

6.3 FUTUROS TRABAJOS ......................................................................... 209

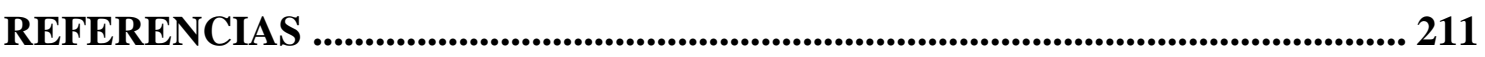


ANEXO I. Determinación de la velocidad de mínima fluidización

ANEXO II. Determinación de la velocidad terminal ............................................ 228

ANEXO III. Simulación gasificador de LFC con válvula loop-seal ...................... 230

ANEXO IV. Granulometría de las cenizas volantes del CSR de origen doméstico 


\section{LISTA DE FIGURAS}

Figura 1.1. Residuos generados en miles de toneladas en 2014, Eurostat. ..................... 2

Figura 1.2. Jerarquía europea en la gestión de residuos ............................................. 3

Figura 1.3. Tratamiento de residuos en porcentaje en 2014, Eurostat. ............................ 4

Figura 1.4. Tecnologías de conversión de residuos a energía para RSU y CDR [31]..... 5

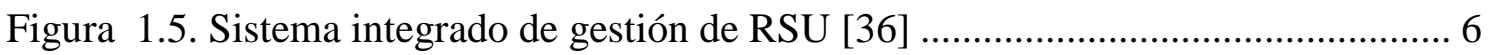

Figura 1.6. Utilización de papel reciclado país por país en Europa en 2015, CEPI........ 8

Figura 1.7. Tasa de reciclado de papel en Europa en 2015, CEPI................................. 9

Figura 1.8. Diagrama de Venn indicando la terminología usada para las fracciones

energéticas susceptibles de poder usarse para recuperación energética tras su pretratamiento en plantas de tratamiento mecánico biológico (TMB) [51] ............. 12

Figura 1.9. Origen de los CSR, ERFO ...................................................................... 13

Figura 1.10. Fábricas cementeras en España a 31 de Diciembre de 2013 [59].............. 14

Figura 1.11. Porcentaje de energía por tipo de combustible alternativo en cementeras

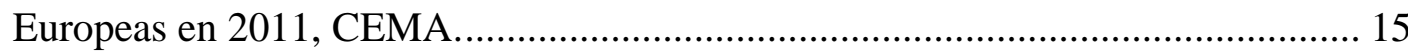

Figura 1.12. Gasificador de lecho de flujo ascendente ............................................. 21

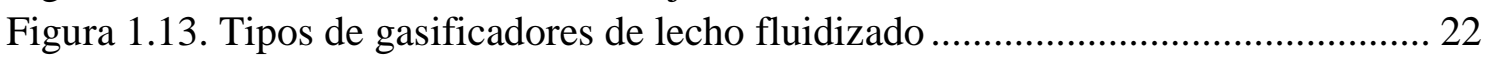

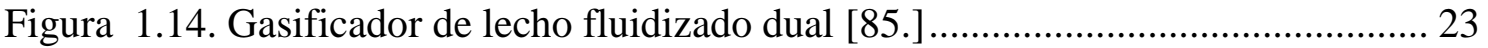

Figura 1.15. Producción de gas de gasificación por continentes [97].......................... 27

Figura 1.16. Capacidad de gasificación mundial y crecimiento acumulado por año [97].

Figura 1.17. Combustibles empleados para la producción de gas de gasificación a nivel

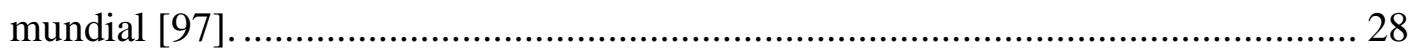

Figura 1.18. Número de gasificadores en función del combustible empleado [97]...... 28

Figura 1.19. Aplicaciones del gas de gasificación [100] .............................................. 29

Figura 1.20. Requerimientos del gas de gasificación para proceso Fisher-Tropsch,

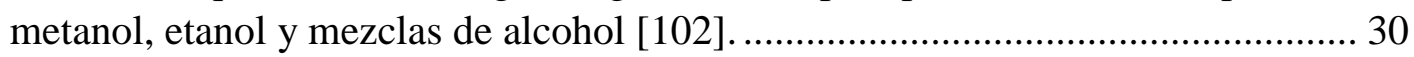

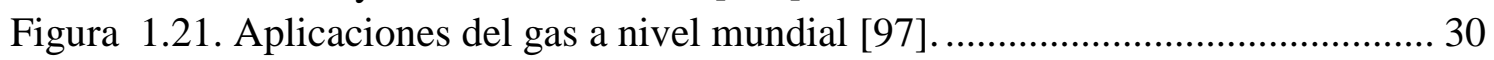

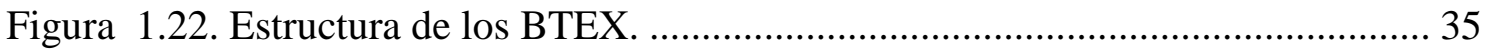

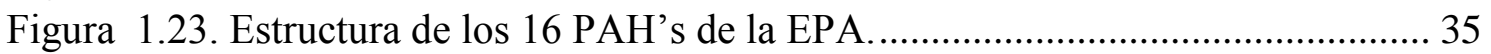

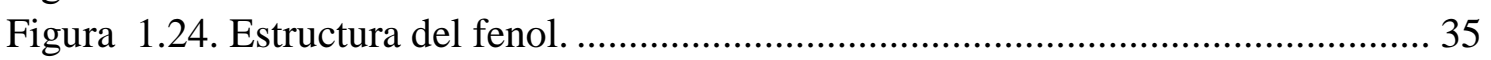

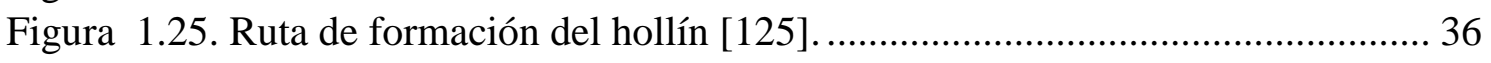

Figura 2.1. Rechazo de la clasificación de papelote y del proceso de pulpado.............. 38

Figura 2.2. Corriente de rechazo de la selección de la materia orgánica en la planta de

TMB.

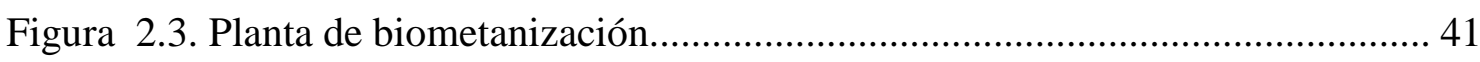

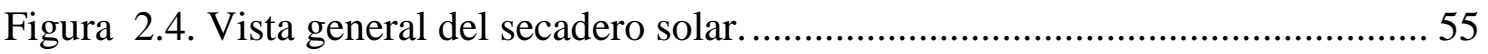

Figura 2.5. Vista general de los equipos de trituración. ...............................................56

Figura 2.6. Vista general de la planta piloto de densificación......................................57

Figura 2.7. Esquema de la planta piloto de densificación. ............................................. 57

Figura 2.8. Croquis de una prensa de matriz plana. ..................................................... 58

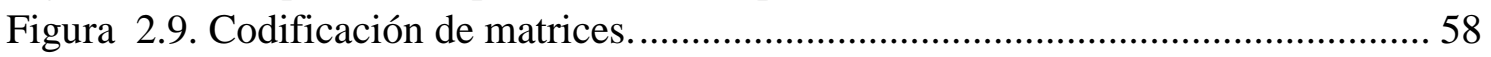

Figura 2.10. Residuo sólido urbano y residuo de la clasificación y selección de envases.

Material molido a $25 \mathrm{~mm}$ y $8 \mathrm{~mm}$ en la parte superior. Imagen aumentada de material molido a $25 \mathrm{~mm}$ y pélets en la parte inferior. 
Figura 2.11. Vista general de la planta piloto de gasificación de lecho fluidizado burbujeante.

Figura 2.12. Diagrama P\&I de la planta piloto de gasificación de lecho fluidizado burbujeante.

Figura 2.13. Distribuidor de gas utilizado en el gasificador de lecho fluidizado burbujeante.

Figura 2.14. Pantalla principal del SCADA usado en la planta piloto de gasificación de lecho fluidizado burbujeante

Figura 2.15. Vista general de la planta piloto de gasificación de lecho fluidizado circulante.

Figura 2.16. Diagrama P\&I de la planta piloto de gasificación de lecho fluidizado circulante.

Figura 2.17. Distribuidores de gas utilizados en el gasificador de lecho fluidizado circulante.

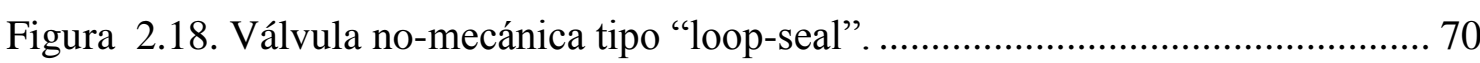

Figura 2.19. Esquema del gasificador de lecho fluidizado circulante......................... 71

Figura 2.20. Pantalla principal del SCADA usado en la planta piloto de gasificación de lecho fluidizado circulante.

Figura 2.21. Evolución de las temperaturas en el interior del reactor durante el ensayo de gasificación en lecho fluidizado circulante.

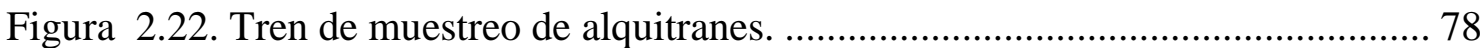

Figura 2.23. Tren de muestreo de cloro para cromatografía iónica................................79

Figura 2.24. Vista general de la planta piloto modelo de unidad circulante a temperatura ambiente.

Figura 2.25. Diagrama de flujo del modelo de unidad circulante a temperatura ambiente. 80

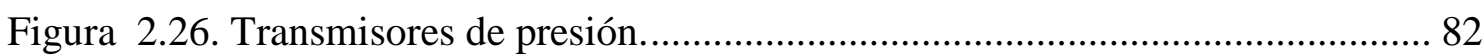

Figura 2.27. Vista general del modelo de válvula no-mecánica tipo "loop-seal”. ........ 84

Figura 2.28. Esquema modelo válvula no-mecánica tipo "loop-seal” .......................... 85

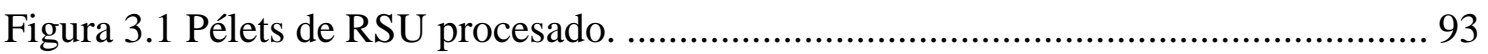

Figura 3.2 Análisis de la humedad y el contenido en cenizas de distintas muestras...... 94

Figura 3.3 Curva TG suministrada tras el ensayo en la termobalanza en atmósfera inerte.

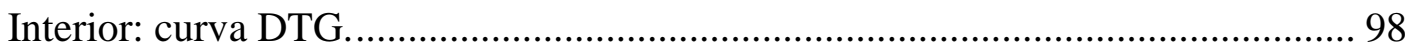

Figura 3.4 Curva TG suministrada tras el ensayo en la termobalanza en atmósfera

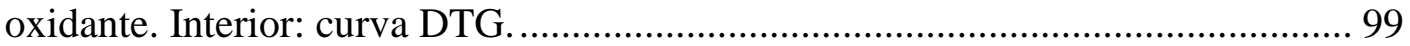

Figura 3.5 Método Coats-Redfern CSR doméstico.................................................. 100

Figura 3.6 Parte 1 Anexo A (normativo)_Obligatorio de especificar. .......................... 101

Figura 3.7 Parte 1 Anexo A (normativa)_no obligatorio de especificar. ...................... 102

Figura 3.8 Parte 1 Anexo A (normativo)_preparación................................................. 103

Figura 3.9. Composición química de la corriente residual de lodos. ........................... 105

Figura 3.10. Composición química de la fracción rechazo de clasificación de papelote y

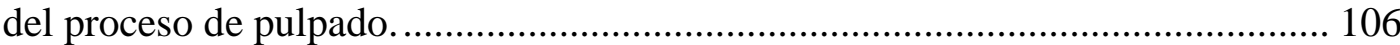

Figura 3.11. Curvas TG para la fracción rechazo a $20^{\circ} \mathrm{C} / \mathrm{min}$. Interior: Curva DTG... 108

Figura 3.12. Curva TG para lodo a $20^{\circ} \mathrm{C} / \mathrm{min}$. Interior: Curva DTG. ........................ 109

Figura 3.13. Consumo energético durante el proceso de molienda y peletizado de las mezclas fracción rechazo/lodo. ........................................................................... 110 
Figura 3.14. Evaluación del efecto de la humedad de la muestra en el índice de durabilidad y la densidad a granel para M3.

Figura 3.15. Metales en las cenizas en forma de óxidos de las mezclas lodo/fracción rechazo.

Figura 3.16 Curvas TG para las mezclas combustible rechazo/lodo $20^{\circ} \mathrm{C} / \mathrm{min}$. Interior: Curva DTG.

Figura 3.17. Método Coats-Redfern para la fracción rechazo........................................ 118

Figura 3.18. Método Coats-Redfern para lodo........................................................ 118

Figura 3.19 Ejemplo de la representación gráfica usando los métodos FWO and KAS, respectivamente, para la mezcla combustible $85 / 15$ para diferentes valores de conversión.

Figura 3.20. M1: Parte 1 Anexo A (normativo)_Obligatorio de especificar................ 122

Figura 3.21. M1: Parte 1 Anexo A (normativo)_No obligatorio de especificar........... 123

Figura 3.22. M2: Parte 1 Anexo A (normativo)_Obligatorio de especificar................. 124

Figura 3.23. M2: Parte 1 Anexo A (normativo)_No obligatorio de especificar........... 125

Figura 3.24. M3: Parte 1 Anexo A (normativo)_Obligatorio de especificar................ 126

Figura 3.25. M3: Parte 1 Anexo A (normativo)_No obligatorio de especificar........... 127

Figura 3.26. M4: Parte 1 Anexo A (normativo)_Obligatorio de especificar................. 128

Figura 3.27. M4: Parte 1 Anexo A (normativo)_No obligatorio de especificar........... 129

Figura 3.28. Mezclas (M1, M2, M3, M4): Parte 1 Anexo A (normativo)_preparación.

Figura 4.1. Variaciones de un lecho de partículas sólidas en un reactor por contacto con

un fluido ascendente [166]

Figura 4.2. Clasificación de partículas sólidas desarrolladas por Geldart [74]........... 134

Figura 4.3. Relación entre la clasificación de partículas sólidas propuesta por Geldart y

la velocidad de fluidización [74]

Figura 4.4. Coeficiente de rozamiento frente al número de Reynolds [174]

Figura 4.5. Comparación de correlaciones para el cálculo de la velocidad terminal de partículas sólidas aisladas [168].

Figura 4.6. Perfiles laterales en el riser [167]...................................................... 145

Figura 4.7. Flujo de partículas sólidas en la zona de transporte de un lecho fluidizado.

Figura 4.8. Tipos de configuraciones de las conexiones de salida del riser junto con los

valores de la tasa de reflujo de cada una de ellas [197].

Figura 4.9. Mecanismo físico del reflujo de sólidos debido a la conexión de salida del riser [196].

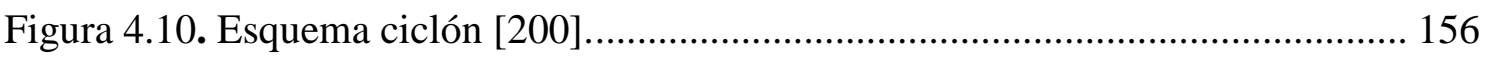

Figura 4.11. Correlaciones para la estimación de la pérdida de carga en un ciclón..... 158

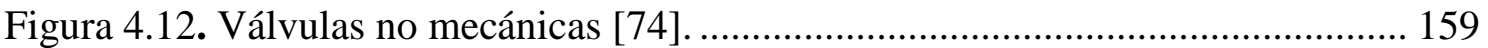

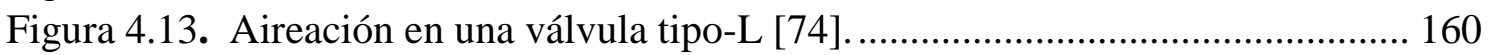

Figura 4.14. Patrones de flujo en una válvula L con diferentes tasas de aireación [74].

Figura 4.15. Modelo unidad circulante a temperatura ambiente (salida abrupta; válvula de mariposa; válvula tipo-L). ........................................................................... 166

Figura 4.16. Estudios de circulación de sólidos de Knowlton con una válvula tipo-L. 167

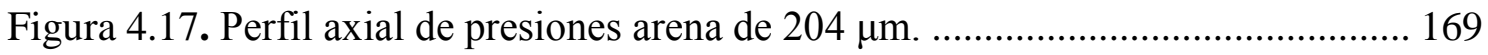

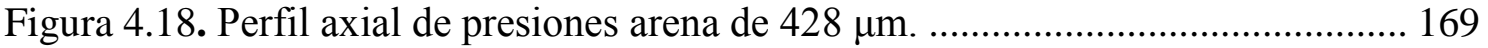




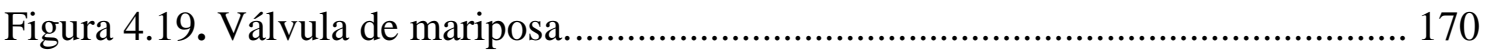

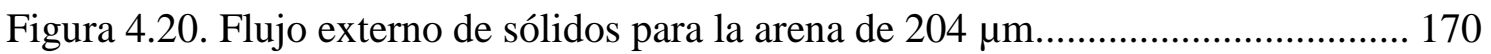

Figura 4.21. Flujo externo de sólidos para la arena de $428 \mu \mathrm{m}$..................................... 171

Figura 4.22. Sonda no-isocinética para la medida de flujo interno de sólidos............. 171

Figura 4.23. Loop-seal clásico con tramo horizontal. ............................................ 173

Figura 4.24. Distribuidor de aire mediante tuberías perforadas. ............................... 173

Figura 4.25. Modelo válvula loop-seal tipo U a temperatura ambiente. ...................... 174

Figura 4.26. Instalación de las tuberías largas perforadas en el modelo. ...................... 175

Figura 4.27. Instalación del punto de aireación sobre la rama de retorno en el modelo.

Figura 4.28. Tasas de circulación de placa perforada en función de los caudales de aire de la rama de retorno y salida........................................................................... 176

Figura 4.29. Tasas de circulación de placa porosa de borosilicato en función de los caudales de aire de la rama de retorno y salida............................................... 177

Figura 4.30. Perfil de presiones en el lecho fluidizado circulante_simulación............. 178

Figura 4.31. Perfil de presiones en el lecho fluidizado circulante 0,5 $\mathrm{MW}_{\text {th. }}$.............. 178

Figura 5.1. Composición del gas de proceso en función del ER en el gasificador de LFB para el CSR de origen doméstico...................................................................... 183

Figura 5.2. Producción de gas y PCI en función del ER para el CSR de origen doméstico en el gasificador de LFB para el CSR de origen doméstico.

Figura 5.3. EFG y conversión de carbono para el CSR de origen doméstico en el gasificador de LFB para el CSR de origen doméstico. ........................................ 185

Figura 5.4. Borboteadores tras un tren de alquitranes. ........................................... 185

Figura 5.5. Alquitranes según clasificación del ECN en el gasificador de LFB para el CSR de origen doméstico.

Figura 5.6. Alquitranes según clasificación del ECN en el gasificador de LFB para el CSR de origen doméstico.

Figura 5.7. EFG y conversión de carbono para las mezclas combustibles en el gasificador de LFB para los CSR de origen industrial.

Figura 5.8. Alquitranes según clasificación del ECN en el gasificador de LFB para los CSR de origen industrial.

Figura 5.9. Composición del gas en función del ER en el gasificador de LFC para el CSR de origen industrial M1

Figura 5.10. Producción de gas en función del ER en el gasificador de LFC para el CSR de origen industrial M1.

Figura 5.11. EFG y conversión de carbono en función del ER en el gasificador de LFC para el CSR de origen industrial M1.

Figura 5.12. Alquitranes según clasificación ECN en el gasificador de LFC para el CSR de origen industrial M1. 200

Figura 5.13. Concentración de contaminantes minoritarios en el gas de proceso del gasificador de LFC para el CSR de origen industrial M1. 201 


\section{LISTA DE TABLAS}

Tabla 1.1. kg de RSU generados y tratados por persona, incluidos porcentajes en sus tratamientos en 2014, Eurostat ......................................................................... 7

Tabla 1.2. Clases de CSR en Finlandia según norma SFS 5875 [46] ............................ 10

Tabla 1.3. Especificaciones CDR de calidad media y alta según la norma UNI 9903 [47]

Tabla 1.5. Plantas de gasificación de residuos operativas en 2016 [98] ....................... 32

Tabla 1.6. Clasificación de compuestos representativos por familias [122] ................... 34

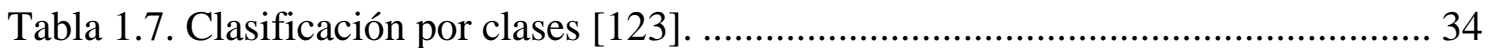

Tabla 2.1. Corrientes residuales obtenidas en el complejo de tratamiento de residuos de la Mancomunidad de la Ribera Baja (Navarra)....................................................... 39

Tabla 2.2. Composición de la corriente de rechazo de la selección de inertes de la fracción orgánica y resto.................................................................................. 42

Tabla 2.3. Composición de los rechazos de la planta de selección y clasificación de

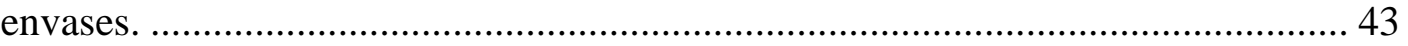

Tabla 2.4. Normativa empleada para la caracterización de los CSR .............................. 49

Tabla 2.5. Poder calorífico inferior de compuestos del gas de proceso. ........................ 75

Tabla 2.6. Rangos de análisis del FTIR para los distintos gases de gasificación............ 77

Tabla 2.7. Propiedades físicas de las partículas sólidas empleadas en los experimentos: distribución de tamaño de partícula, densidad aparente y densidad de partícula.... 82

Tabla 3.1. Comparación de la composición de RSU en distintas áreas de estudio dentro

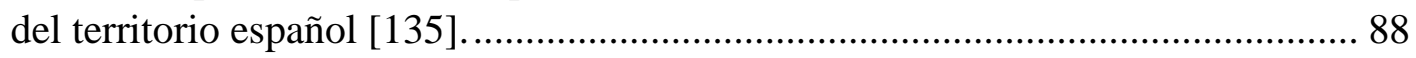

Tabla 3.2. Caracterización de las fracciones de rechazo de la planta de tratamiento de

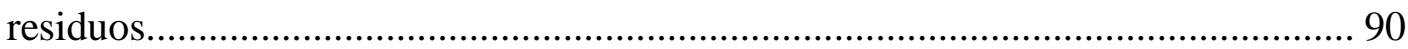

Tabla 3.3. Consumo energético durante el proceso de molienda y peletizado del RSU

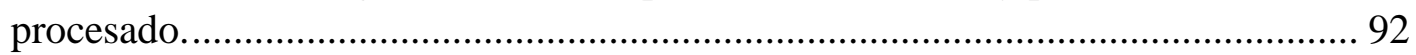

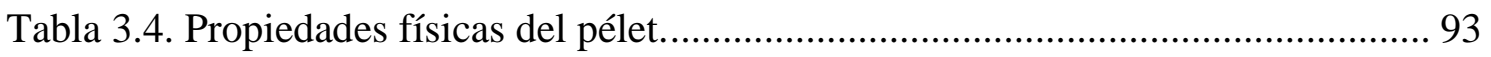

Tabla 3.5. Caracterización del CSR de origen doméstico. .......................................... 95

Tabla 3.6. Metales en las cenizas en forma de óxidos................................................... 95

Tabla 3.7. Índices de ensuciamiento y formación de escorias [145] .............................. 96

Tabla 3.8. Fusibilidad de las cenizas del CSR de origen doméstico. ............................ 97

Tabla 3.9. Determinación del contenido en biomasa para el CSR doméstico................ 97

Tabla 3.10. Datos de los análisis termogravimétricos correspondientes a las etapas de

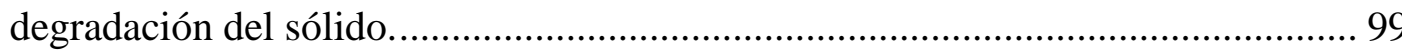

Tabla 3.11. Caracterización de las corrientes residuales procedentes de la industria

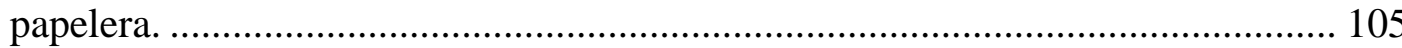

Tabla 3.12. Composición en metales de las cenizas de las corrientes residuales de la industria papelera en forma de óxidos............................................................. 107

Tabla 3.13. Contenido en biomasa de la fracción rechazo de la clasificación de papelote

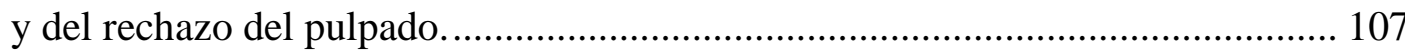

Tabla 3.14. Calidad del pélet de las mezclas lodo/fracción rechazo............................ 111

Tabla 3.15. Caracterización de las mezclas combustibles de la industria papelera...... 113

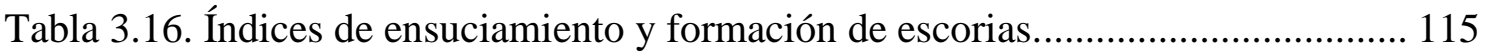

Tabla 3.17. Fusibilidad de las cenizas de las diferentes mezclas producidas................ 115 
Tabla 3.18. Determinación del contenido de biomasa en las mezclas fracción rechazo/lodo por disolución selectiva.

Tabla 3.19 Etapas de degradación de las mezclas combustible rechazo/lodo.

Tabla 3.20 Parámetros cinéticos de las mezclas combustibles rechazo/lodo mediante el método Coats-Redfern

Tabla 3.21 Parámetros cinéticos de las mezclas combustible rechazo/lodo para la degradación del material plástico mediante los métodos FOW y KAS.

Tabla 4.1. Correlaciones para estimar la velocidad de mínima fluidización. 138

Tabla 4.2. Factores de forma para la ecuación de Brauer modificada por Muschelknautz.

Tabla 4.3. Correlaciones para la determinación de la velocidad terminal.................... 142

Tabla 4.4. Valores recomendados para n por Richardson y Zaki................................ 143

Tabla 4.5. Condiciones de operación en los ensayos con la unidad circulante............ 167

Tabla 4.6. Comparativa medida flujo interno de sólidos y externo de sólidos para un inventario de sólidos de $30 \mathrm{~kg}$

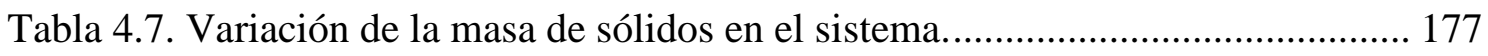

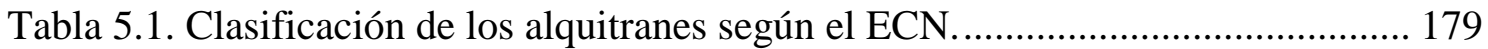

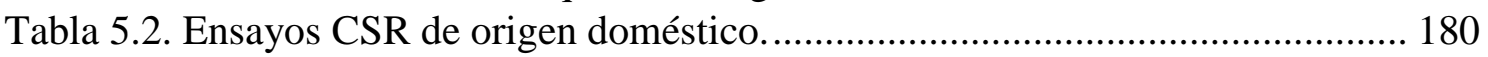

Tabla 5.3. Ensayos CSR de origen industrial. ........................................................... 181

Tabla 5.4. Composición de las cenizas de ciclón y del lecho de los CSR de origen doméstico tras los ensayos de gasificación. ....................................................... 188

Tabla 5.5. Composición y PCI del gas de proceso para los CSR de origen industrial. 190

Tabla 5.6. Concentración de especies minoritarias en el gas de proceso para los CSR de

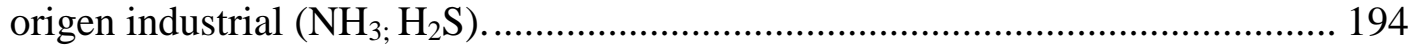

Tabla 5.7. Análisis de cloro de los CSR de origen industrial.................................... 195

Tabla 5.8. Cenizas de los CSR de origen industrial tras los ensayos de gasificación. . 196

Tabla 5.9. Análisis de cloro en función del ER......................................................... 201

Tabla 5.10. Cenizas del ciclón secundario del CSR industrial M1 tras los ensayos de gasificación 


\section{PUBLICACIONES}

\section{$\underline{\text { Artículos }}$}

Arenales Rivera, J., López Pérez, V., Ramos Casado, R., Sánchez Hervás, J.M. Thermal degradation of paper industry wastes from a recovered paper mill using TGA. Characterization and gasification test. Waste Management, Volume 47, Part B, January 2016, pages 225-235.

$>$ Ramos Casado, R., Arenales Rivera, J., Borjabad Garcia, E., Escalada Cuadrado, R., Fernandez Llorente, M., Bados Sevillano, R., Pascual Delgado, A. Classification and characterisation of SRF produced from different flows of processed MSW in the Navarra region and its co-combustion performance with olive tree pruning residues. Waste Management, Volume 47, Part B, January 2016, pages 206-216.

\section{$\underline{\text { Congresos }}$}

$>$ Arenales, J., Murillo, J.M., Perez, V., Ortiz, I., Ramos, R., Esteban, L., Bados, R., Perez, P., Fernandez, M. and Sanchez, J.M. Thermal conversion of wastes from recycling paper industry by means of gasification. Proceedings ANQUE International Congress of Chemical Engineering, 24-27 June, 2012, Sevilla (Spain).

> Arenales, J., Pérez, V., Sanchez, J.M., Esteban, L.S., Perez, P., Fernández, M., Ramos, R., Cólera, M. and Alcalde, C. Preparation and characterisation of refuse derived fuels (RDFs) from plastic wastes for gasification. Proceedings WasteEng, $4^{\text {th }}$ International Conference on Engineering for Waste and Biomass Valorisation, September 10-13, 2012, Porto (Portugal). [ISBN 979-10-9152600-5 Mines d'Albi Campus Jarlard Route de Teillet Albi 81013 Cedex 09 France].

$>$ Pérez, V., Sanchez, J.M., Arenales, J., Ortiz, I., Pascual, A., Sanchez, J.M. and Ramos, R. Gasification of plastic wastes in acirculating fluidized bed pilot plant. Proceedings WasteEng, $4^{\text {th }}$ International Conference on Engineering for Waste and Biomass Valorisation, September 10-13, 2012, Porto (Portugal). [ISBN 97910-91526-00-5 Mines d'Albi Campus Jarlard Route de Teillet Albi 81013 Cedex 09 France].

$>$ Arenales Rivera, J. Valorización energética de la fracción resto de residuos domésticos, comerciales e industriales. Jornadas de Investigación y Difusión de la Ciencia, Ciclo de Seminarios "Jóvenes Investigadores" CIEMAT, 13-14June, 2014, Madrid (Spain).

$>$ Arenales Rivera, J. Gas solid flow in a CFB with L-valve and impat of gas distribution changes in the design. $69^{\text {th }}$ Meeting of the IEA Fluidized Bed Conversion Implementing Agreement, 25-26 September, 2014, Aix en Provence (France).

$>$ Arenales, J., Perez, V., Ramos, R. and Sánchez, J.M. Thermal degradation of paper industry wastes from a recovered paper mill using TGA. Proceedings Venice $2014,5^{\text {th }}$ International Symposium on Energy from Biomass and Waste, 17-20 November, 2014, San Servolo, Venice (Italy) [@ 2014 CISA Publisher, Italy]. 
Arenales, J., Ramos, R., Barro, R. Solid recovered fuels for energy recovery. Proceedings Soria 2016, $1^{\text {st }}$ Conference on Bioenergy and Climate Change Towards a Sustainable Development, 6-7 June, 2016, Soria (Spain). 


\section{PROYECTOS}

Los estudios llevados a cabo en la presente tesis han sido financiados mediante los proyectos que se muestran a continuación:

"Aprovechamiento energético mediante gasificación del rechazo procedente del tratamiento de residuos urbanos" (Proyecto GASREUR)

- Entidad financiadora: Ministerio de Ciencia e Innovación.

- Entidades participantes: CIEMAT, NAMAINSA, FIDIMA

- Duración: Enero 2009-Diciembre 2011

- Investigador responsable: Raquel Ramos Casado (CIEMAT)

"Producción limpia de papel reciclado: Hacia la sostenibilidad en la producción de papel en la Comunidad de Madrid" (Proyecto PROLIPAPEL II)

- Entidad financiadora: Consejería Educación CAM, S2009/AMB-1480

- Entidades participantes: UCM, INIA, CSIC-CIB, CIEMAT, UC3M

- Duración: Enero 2010-Diciembre 2013

- Investigador responsable: Ángeles Blanco Suárez (UCM) 


\section{PRESENTACIÓN}

La presente tesis doctoral se encuentra enmarcada dentro de las líneas de investigación que la unidad de Procesos de Conversión Térmica (Combustión y Gasificación) del Departamento de Energía, perteneciente al Centro de Investigaciones Energéticas, Medioambientales y Tecnológicas (CIEMAT), está llevando a cabo en materia de valorización energética de residuos.

La línea de investigación de la valorización energética por vía térmica de residuos con alto contenido en material plástico nace a raíz del proyecto de investigación: "Aprovechamiento energético mediante gasificación del rechazo procedente de residuos urbanos (GASREUR)", financiado por el Ministerio de Ciencia e Innovación a través del Plan Nacional de Investigación Científica, Desarrollo e Innovación Tecnológica 2008-2011. El objeto de estudio del citado proyecto fue la viabilidad técnica del empleo de los rechazos de residuos sólidos urbanos como combustible en un proceso de gasificación, que incluye las fases de recogida, pretratamiento y densificación del material objeto de estudio, así como la aplicación energética del gas generado mediante los ensayos realizados en una planta piloto de lecho fluidizado circulante.

También se produjo la incorporación a la línea de investigación de valorización energética de residuos con alto contenido en material plástico, del proyecto de investigación: "Producción limpia de papel reciclado: hacia la sostenibilidad en la producción de papel en la Comunidad de Madrid (PROLIPAPEL)", financiado por la Comunidad de Madrid. Su objetivo fue la valorización energética de residuos industriales procedentes de una fábrica de papel recuperado, subdividido en dos fases, realizándose ensayos de combustión en una planta piloto de lecho fluidizado burbujeante (PROLIPAPEL I, 2006-2009) y ensayos de gasificación en una planta piloto de lecho fluidizado circulante (PROLIPAPEL II, 2010-2013), respectivamente.

Los estudios llevados a cabo en esta tesis han servido para el desarrollo de la tecnología de gasificación de residuos con alto contenido en material plástico empleando tecnologías de lecho fluidizado, es decir: lecho fluidizado burbujeante y lecho fluidizado circulante, ambos a presión atmosférica, de forma que los resultados obtenidos en planta piloto ayuden a la integración de estos procesos en instalaciones industriales, que generen este tipo de residuos. 


\section{OBJETIVOS}

El objetivo principal que se persigue en este estudio es evaluar la viabilidad técnica del proceso de gasificación de residuos con contenido en material plástico. La consecución de este objetivo global se desarrolla por medio de objetivos parciales que abarcan desde la generación del material objeto de estudio hasta la valorización energética del producto tratado. La evaluación de la viabilidad de esta tecnología para aprovechamiento y valorización térmica de residuos de tipo doméstico, residuos urbanos o industriales se lleva a cabo con actuaciones que permiten la optimización del proceso de gasificación en operación autotérmica en plantas piloto de lecho fluidizado. El desarrollo de este objetivo se pretende llevar a cabo por medio de las siguientes etapas:

Obtención de combustibles sólidos recuperados (CSRs) a partir de rechazos de una planta de tratamiento de residuos sólidos y de residuos de la industria papelera, que incluye el estudio y desarrollo de su preparación, así como la caracterización completa de los combustibles obtenidos para su evaluación y clasificación conforme a la normativa actual.

$\checkmark$ Estudio y caracterización de los rechazos provenientes de planta de tratamientos de residuos sólidos (rechazos de tratamiento mecánico biológico y rechazos de recogida selectiva de envases plásticos).

$\checkmark$ Estudio y caracterización de los rechazos provenientes de la industria papelera (rechazos de la clasificación de papelote, rechazos del proceso de pulpado y lodos de destintado).

$\checkmark$ Pretratamiento de las fracciones rechazo obtenidas de cada uno de los residuos con objeto de prepararlos para el proceso de densificación posterior en forma de pélets, que incluye eliminación de impropios, proceso de molienda y secado.

$\checkmark$ Evaluación del proceso de densificación de los combustibles seleccionados en base al consumo energético, las características del material a peletizar y a las propiedades físicas de los pélets.

$\checkmark$ Cinética de la pirolisis y combustión de los CSR por métodos termogravimétricos.

$\checkmark$ Evaluación y clasificación de los combustibles obtenidos en base a la normativa desarrollada para CSRs.

Estudio del proceso de gasificación a través de la tecnología de lecho fluidizado.

$\checkmark$ Estudio de los aspectos fluido-dinámicos y de operación de una unidad circulante a temperatura ambiente construida a semejanza de la planta piloto de gasificación de lecho fluidizado circulante (LFC) usada para la evaluación del proceso de gasificación de los CSRs.

$\checkmark$ Estudio y operación de una válvula no-mecánica loop-seal tipo U construida con iguales dimensiones a la disponible en la planta piloto de gasificación.

$\checkmark$ Desarrollo de un modelo fluido-dinámico de un gasificador de lecho fluidizado circulante con una válvula no-mecánica loop-seal tipo U. 
Evaluación de la gasificación de los CSRs, deteniéndonos en los siguientes puntos de estudio y evaluación:

$\checkmark$ Desarrollo del proceso de gasificación en reactores de lecho fluidizado a escala piloto y en operación autotérmica mediante la optimización del proceso en condiciones de operación conocidas por evaluación de la calidad del gas obtenido.

$\checkmark$ Caracterización del gas de proceso generado durante el proceso de gasificación en reactores de lecho fludizado a escala piloto.

$\checkmark$ Caracterización de algunos contaminantes del gas con determinación de calidad energética y medioambiental. 


\section{ORGANIZACIÓN}

La organización del presente estudio de investigación se desarrolla en seis capítulos. En el capítulo I, se presentan los antecedentes sobre la generación de residuos domésticos, comerciales e industriales en los países desarrollados y su posible transformación en combustibles derivados de residuos (CDRs), para su empleo como combustible para recuperación energética mediante procesos térmicos, en concreto gasificación. Además, se muestra el trasfondo del proceso de gasificación y los subproductos generados durante el mismo, así como las tecnologías de gasificación existentes. En el capítulo II, se muestra el desarrollo metodológico y experimental empleados durante dicho estudio de investigación, incluyendo descripciones de equipos, materiales y plantas piloto.

El trabajo de investigación se desarrolla en tres grandes bloques, que se corresponden con la preparación y caracterización del combustible generado de residuos, el estudio de la tecnología de gasificación y el estudio de gasificación de combustibles derivados de residuos, es decir: la optimización del proceso de gasificación.

En el primer bloque, capítulo III, se realiza un estudio de las fracciones de rechazo susceptibles de ser transformadas en CSRs. La caracterización de cada fracción se realiza mediante diferentes análisis de laboratorio de manera que se produzca una caracterización completa (análisis elemental, análisis inmediato, poder calorífico, contenido en metales, cenizas y fusibilidad), discutiendo su adecuación al proceso de gasificación (problemas medioambientales y técnicos) y necesidad de pretratamientos. La densificación del material se lleva a cabo en una planta piloto de peletización, donde se estudia la optimización del proceso de densificación en base a parámetros que reflejarán la calidad del pélet producido. Este estudio finaliza con la evaluación y clasificación de los combustibles obtenidos en base a la normativa europea sobre CSRs.

El segundo bloque, capítulo IV, versa sobre aspectos fundamentales de la hidrodinámica para las tecnologías de fluidización, que se estudian mediante un modelo de unidad circulante a temperatura ambiente y un modelo de válvula no-mecánica tipo "loop-seal".

En el tercer bloque, capítulo V, se presenta el estudio de gasificación de los CSRs de origen doméstico (rechazos de planta de tratamiento de residuos sólidos) e industrial (industria papelera). Este estudio ahondará en la viabilidad del proceso de gasificación, la optimización del mismo, y la formación de alquitranes durante el proceso de gasificación.

Finalmente, en el capítulo VI, se presentan las conclusiones derivadas de la presente tesis, así como las futuras actuaciones a considerar. 


\section{CAPÍTULO I. ANTECEDENTES}

\subsection{INTRODUCCIÓN}

El aumento de los requerimientos energéticos a nivel mundial ha provocado escasez en los combustibles tradicionales, surgiendo la necesidad de realizar búsquedas de vías alternativas para la obtención de energía. Por tanto, el desarrollo de las energías renovables es una elección obligada, que puede evitar problemas de disponibilidad futura, al no ser fuentes de energía fósil [1]. Además, los problemas de calentamiento global y cambio climático han contribuido al desarrollo e investigación de fuentes alternativas de producción de energía [2,3].

En este sentido, la biomasa ha experimentado un importante auge, que puede convertirla en una de las principales fuentes de energía primaria a nivel mundial [4]. Aunque el empleo de biomasa goce de ventajas muy competitivas como son: una elevada disponibilidad de recursos, una reducción de los gases de efecto invernadero y una importante aceptación social, ya que reduce el calentamiento global y fomenta el desarrollo económico en áreas rurales, los elevados costes asociados a recolección y transporte unidos al almacenamiento previo al procesamiento para su aprovechamiento energético, debidos a su baja producción por área cultivada, hacen que la viabilidad económica de su empleo se reduzca $[5,6]$.

Estos hechos, unidos al aumento del coste de muchas de las biomasas, que se utilizan actualmente en la producción de energía mediante procesos de conversión térmica, ha fomentado la búsqueda de combustibles alternativos que pudieran sustituir a la biomasa convencional. A tenor de las desventajas propias del empleo de biomasa como son: la estacionalidad, los costes de transporte, los costes de almacenamiento y la dificultad de tener una estabilidad de suministro, de manera que permita disponer de un combustible con ciertas garantías, hacen que ciertos combustibles alternativos como subproductos o residuos, hayan cobrado una notable importancia como sustitutos potenciales, reforzados, al tener coste bajo, cero o incluso negativo [7]. No obstante, los residuos tienen otra componente añadida, que es su abundancia, además de los costes de tratamiento y eliminación.

\subsection{RESIDUOS}

La generación de residuos sólidos urbanos (RSU), y de residuos derivados de actividades industriales en los países desarrollados, ha provocado que se disponga de elevadas cantidades de residuos que deben ser gestionadas, por ejemplo en la Unión Europa, ver Figura 1.1. En base a la normativa de residuos existente en la Unión Europea, se está priorizando el desarrollo de un sistema de gestión de residuos eficaz que englobe el aprovechamiento, minimización y valorización de los residuos y subproductos derivados de actividades humanas.

Estos residuos contienen restos de materia orgánica, textiles, papel y cartón, madera, plásticos, etc. Se pretende lograr la integración de los sistemas de gestión de residuos con el normal funcionamiento de plantas de tratamiento de residuos e industrias, de manera que se logren los objetivos indicados anteriormente, es decir una reducción y un 
aprovechamiento del residuo generado. Este aprovechamiento de los residuos generados redunda en una reducción de costes de manipulación de los residuos, e incluso en la obtención de un producto procesado que tenga interés económico en el mercado.

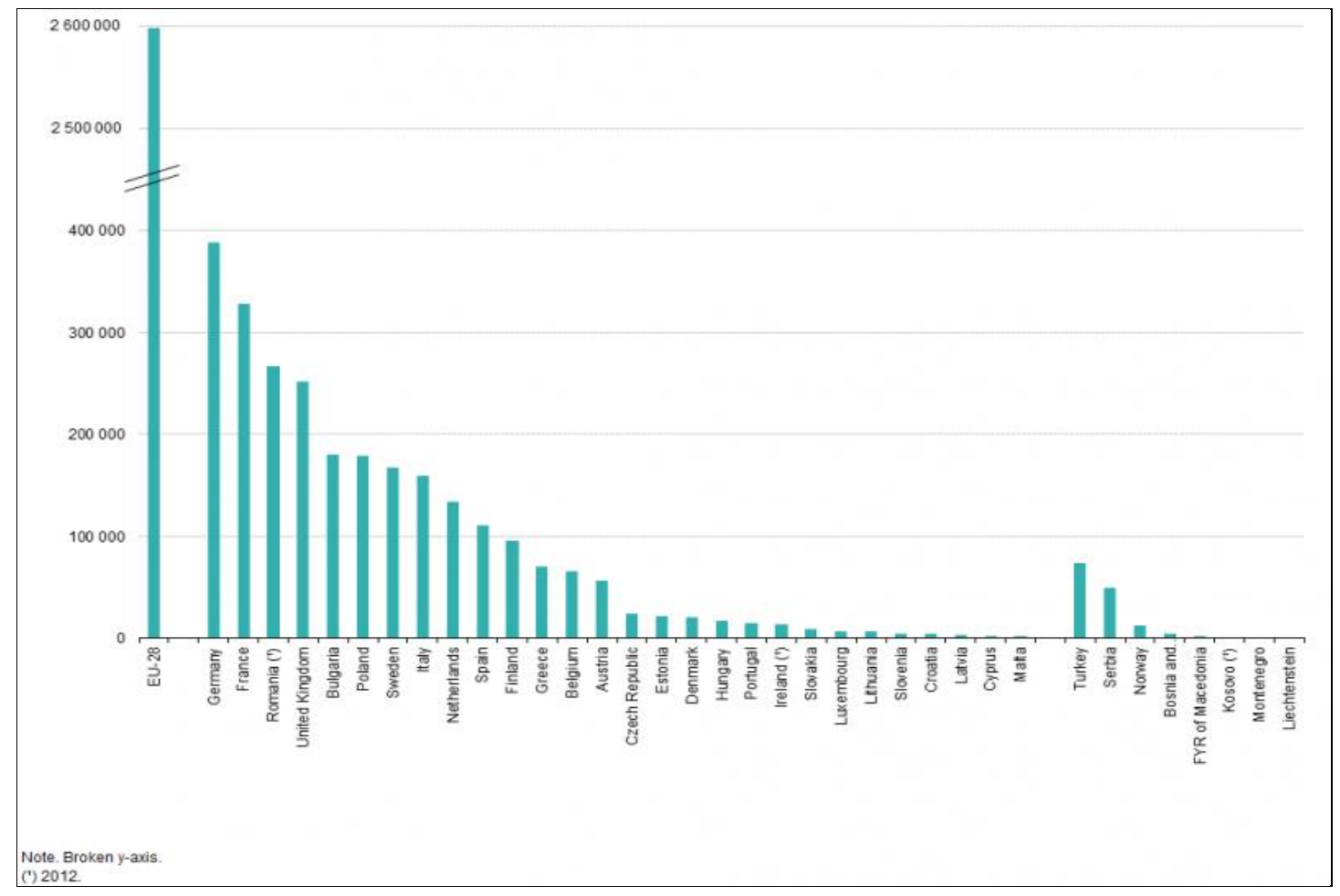

Figura 1.1. Residuos generados en miles de toneladas en 2014, Eurostat.

El término residuo se aplica a cualquier sustancia, perteneciente a una de las categorías recogidas en el anexo I de la Directiva 2006/12/CE [8], de la cual su poseedor se desprenda o tenga la intención u obligación de desprenderse. Además, las fracciones biodegradables de residuos de origen biológico de la agricultura, forestales $\mathbf{o}$ industriales con actividades relacionadas con la pesca y la acuicultura, así como la fracción biodegradable de residuos sólidos urbanos e industriales, se denominan "biomasa" [9]. Por tanto, en lo sucesivo se hablará de contenido en biomasa en referencia a la fracción biodegradable de los residuos a estudio.

La elevada cantidad de residuos de tipo doméstico, comercial e industrial que se generan en los países desarrollados ha derivado en la necesidad de disponer de sistemas de gestión eficiente. La gestión adecuada de los residuos generados en actividades humanas permite la consecución de un desarrollo sostenible, que se fundamenta en tres pilares básicos: desarrollo económico, desarrollo social y protección del medio ambiente. La Asamblea General de las Naciones Unidas define el desarrollo sostenible como: "la satisfacción de las necesidades de la generación presente sin comprometer la capacidad de las generaciones futuras para satisfacer sus propias necesidades".

Existen diferentes iniciativas con el fin de alcanzar un desarrollo sostenible, que van desde la promoción del uso de energías limpias hasta la minimización de los residuos y de las emisiones de gases de efecto invernadero que se generan. En este perfil se enmarca la iniciativa Horizonte 20/20, que tiene como objeto reducir un 20\% la energía primaria consumida en la Unión Europea y las emisiones de gases de efecto invernadero, así como aumentar un $20 \%$ el consumo de energías renovables [10, 11]. 
En las sociedades avanzadas, la continua generación de residuos ha generado un problema de tal envergadura que su reducción, bien por re-utilización o reciclaje a cualquier nivel es necesaria, como puede inferirse de los diferentes programas que se han implementado a tal efecto en España: Plan Nacional Integrado de Residuos (PNIR), 2008-2015, y Plan Estatal Marco de Gestión de Residuos (PEMAR), 2014-2020, o a través de leyes europeas como la Directiva 2008/98/CE. Siendo el objetivo de estos programas nacionales y leyes europeas convertir a los países de la Unión Europea en "sociedades del reciclaje", pudiendo reducir los residuos generados y usarlos como fuente para diferentes procesos [12-18]. En este contexto, las estrategias de gestión de residuos se centran en un incremento de la recogida selectiva, por ejemplo: implementando sistemas de recogida de residuos por vacío, que mejoran la eficiencia en la gestión de residuos $[19,20]$.

La directiva europea 2008/98/CE, ha establecido una jerarquía en el tratamiento de residuos: prevención, reutilización, reciclado, valorización y eliminación, que proporciona el mejor resultado medioambiental global, minimizando los métodos de eliminación que no contribuyen a la valorización, ver Figura 1.2. No obstante, el término valorización hace referencia tanto obtención de materias primas secundarias, es decir: reciclado o recuperación, como a los métodos que permiten obtener un producto destinado a fines diversos como pueda ser la valorización energética.

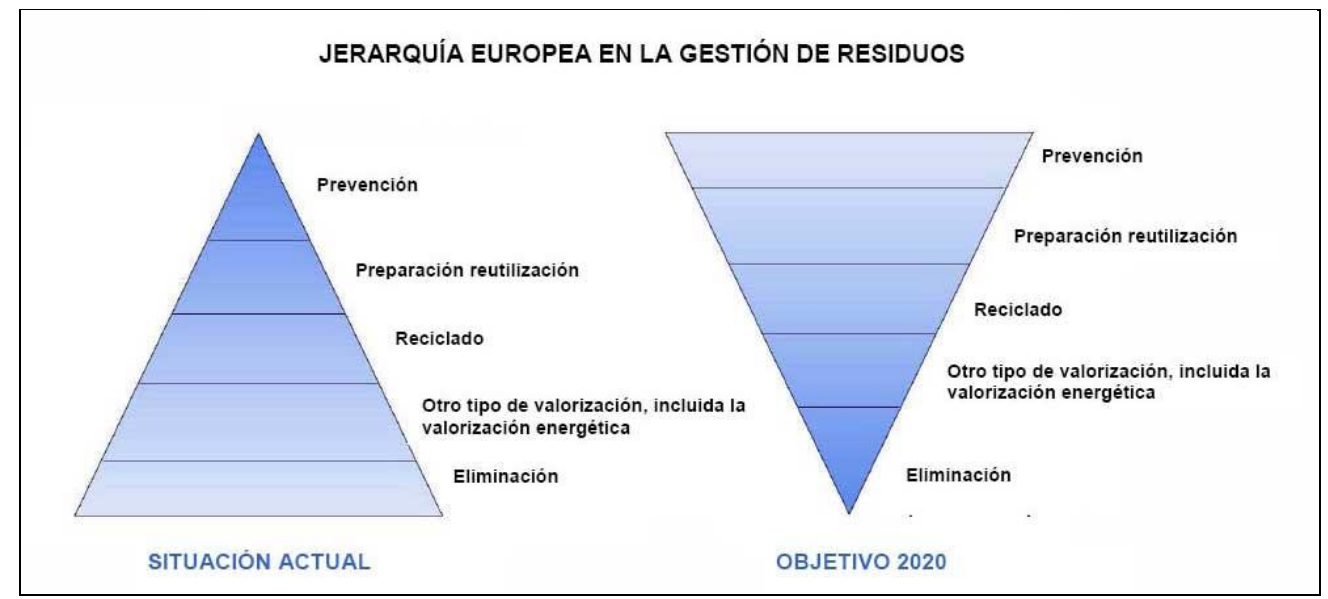

Figura 1.2. Jerarquía europea en la gestión de residuos

Además, la directiva europea 1999/31/CE, ha dictaminado importantes restricciones en cuanto a la eliminación en vertedero de materia biodegradable, reduciéndolo a residuos con un poder calorífico inferior a $13 \mathrm{MJ} / \mathrm{kg}$. Por tanto, la valorización energética de las fracciones residuales no reciclables con elevado poder calorífico se muestra como una opción de recuperación de residuos, pudiendo ofrecer oportunidades de negocio para las compañías de gestión de residuos [21]. La eliminación es el destino final de los residuos que no han podido ser valorizados.

Existen diferentes métodos de eliminación de residuos, como puedan ser la incineración sin recuperación de calor o el depósito en vertedero, siendo la alternativa más habitual esta última, ver Figura 1.3. Sin embargo, la .actual normativa europea obliga a los países miembros a una drástica reducción de la materia biodegradable que se deposita en vertedero, del 75\% al 35\% sobre niveles del 1995 para los años 2006 al 2016, respectivamente [22]. 
El depósito en vertedero de residuos con contenido elevado de materia orgánica genera efluentes, tanto líquidos como gaseosos. En cuanto a las emisiones líquidas, se produce un lixiviado con alto contenido en metales pesados, mientras que para las emisiones gaseosas, éstas corresponden principalmente a compuestos orgánicos volátiles, dióxido de carbono y metano [23, 24]. Estas emisiones se producen de manera continuada a consecuencia de la actividad microbiológica bacteriana, incluso después de su clausura, pero la implementación de sistemas de recogida de gas metano solamente es viable económicamente en vertederos de gran capacidad [25-27].

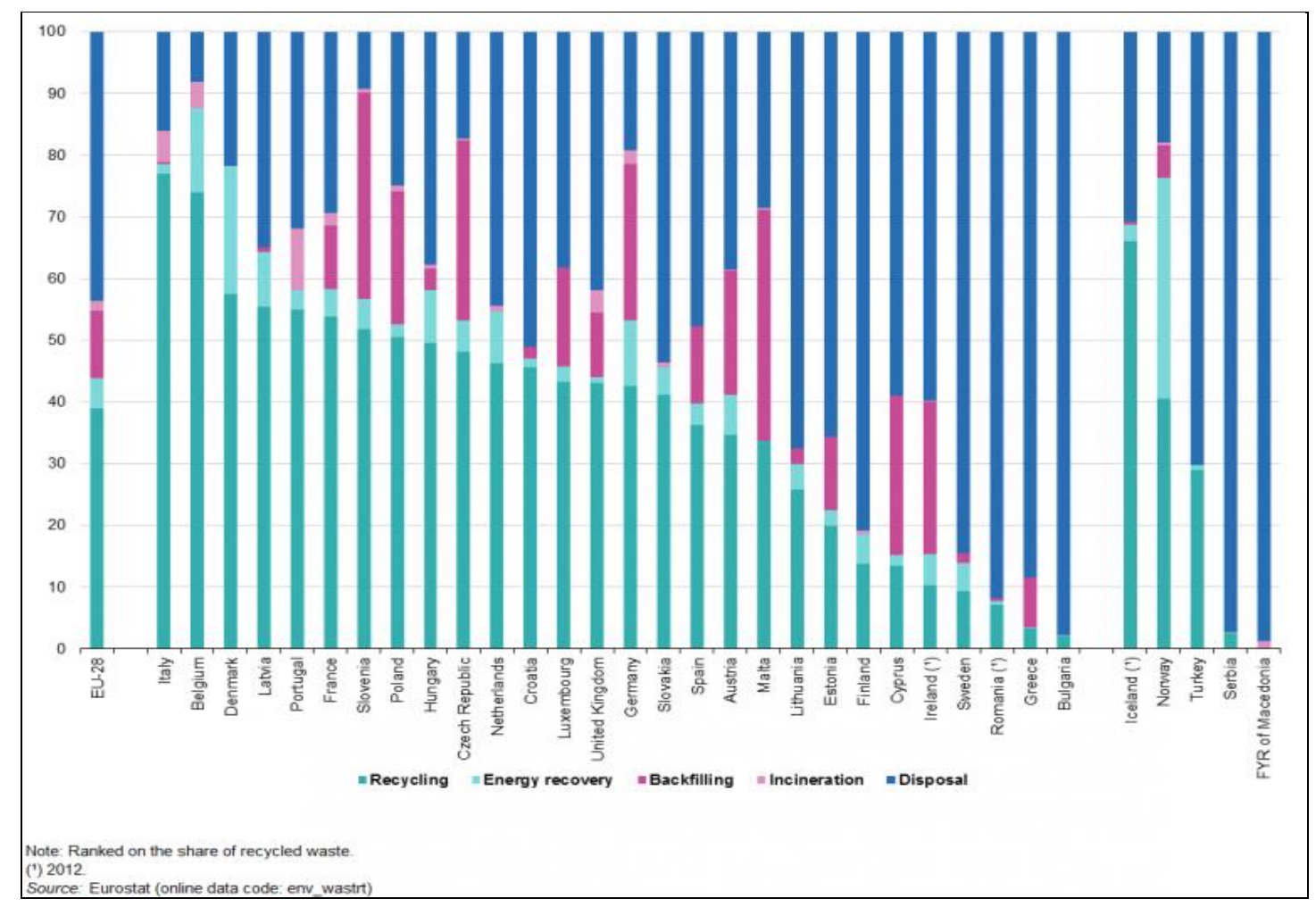

Figura 1.3. Tratamiento de residuos en porcentaje en 2014, Eurostat.

Existen diferentes opciones de recuperación de las fracciones que no han podido ser recicladas o de las que no es económicamente viable su reciclaje, siendo la recuperación energética mediante procesos de conversión térmica una opción aceptable, que permite valorizar los residuos energéticamente [28]. Algunos procesos térmicos, como son combustión, pirólisis o gasificación generan productos potenciales para su empleo como combustibles o para la obtención de productos secundarios.

La existencia de otros métodos de valorización de residuos, como son aquellos que emplean procesos biológicos, permiten también la obtención de gases combustibles mediante procesos de digestión o de productos que se empleen para actividades agrícolas como el compost, mediante un proceso aerobio, que puede ser comercializable $[29,30]$. Por tanto, las fracciones destinadas a su depósito en vertedero deben limitarse a aquellos residuos con bajo poder calorífico o con materia orgánica biodegradable estabilizada, ya que mediante métodos de valoración se puede obtener un aporte energético y se logra una reducción del volumen de residuos generados en cualquier actividad doméstica, comercial o industrial. 
Los sistemas de procesamiento de residuos pretenden alcanzar el objetivo de cierre del ciclo residual, es decir: conseguir un menor impacto y un grado de valorización mayor para los residuos derivados de las actividades humanas, evitando la eliminación mediante vertido o incineración de residuos, en la medida de lo posible. Con este objetivo, se están implementando tecnologías de conversión de residuos a energía, pudiéndose realizar de manera directa o indirecta, mediante tratamientos previos, ver Figura 1.4 [31]. Estas tecnologías se basan en la recuperación energética de residuos en forma de electricidad y calor. La recuperación energética puede ser llevada a cabo de manera directa a través de un horno convencional de parrillas o de manera indirecta a través de un tratamiento mecánico-biológico, seguido de un proceso de recuperación energética (combustión, pirólisis, gasificación, ect.). No obstante, las refinerías de residuos se muestran como una alternativa a estos sistemas de valorización [32, 33].

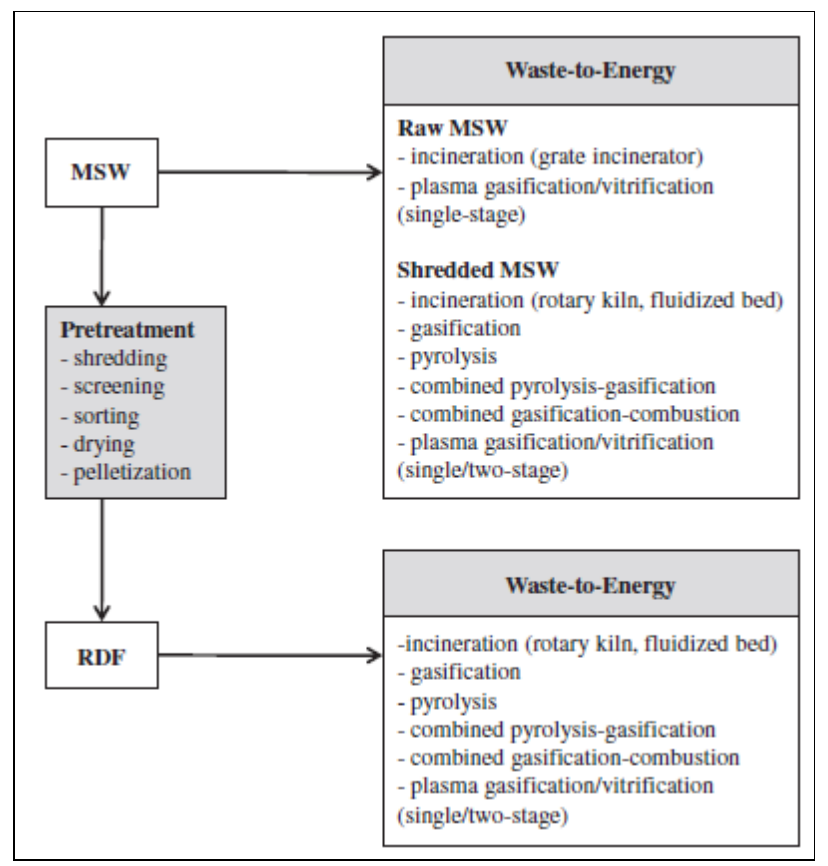

Figura 1.4. Tecnologías de conversión de residuos a energía para RSU y CDR [31]

El tratamiento indirecto consta de tres etapas. La primera etapa, consta de un pretratamiento de los residuos previo a la recuperación energética, ya que existe la necesidad de procesamiento de las fracciones residuales, separando las fracciones nocombustibles y procesando las fracciones combustibles, generando un producto denominado combustible derivado de residuo (CDR), que tiene una distribución de partículas uniforme, una composición química y física más homogénea que el residuo de partida y un poder calorífico superior [34]. Los pre-tratamientos se clasifican en:

- Pre-tratamiento mecánico-biológico con compostaje de la fracción orgánica

- Pre-tratamiento mecánico-biológico con digestión anaerobia

- Pre-tratamiento mecánico-biológico con estabilización del residuo (biosecado)

- Pre-tratamiento mecánico convencional.

La segunda etapa, que consiste en la recuperación energética mediante procesos de conversión térmica, requiere de una preparación del material procesado que facilite su alimentación, en forma de pélets o briquetas. Y por último, una tercera etapa, que consiste en la eliminación final del remanente residual. 


\subsubsection{RESIDUOS URBANOS}

Las plantas de tratamiento de RSU generan gran cantidad de fracciones rechazo. Estas fracciones de rechazo se generan a partir de los rechazos en las plantas de selección de envases, en las que se incorporan los envases ligeros del contenedor amarillo, y, principalmente, de la fracción resto, es decir de los residuos que resultan una vez realizado el triaje de los materiales reciclables (fracción orgánica, papel y cartón, vidrio, envases y metales) mediante recogida separada. Las fracciones rechazo, que consisten principalmente en una mezcla de plásticos y deshechos biodegradables, están catalogados como residuos en la Lista Europea de Residuos:

- Código LER 19 12, Residuos del tratamiento mecánico de residuos (por ejemplo, clasificación, trituración, compactación, peletización) no especificados en otra categoría, que incluyen Residuos combustibles (combustible derivado de residuos), Código LER 191210.

- Código LER 1905 Residuos del tratamiento aeróbico de residuos.

- Código LER 1906 Residuos del tratamiento anaeróbico de residuos.

Sin embargo, la composición de los RSU no es constante, ya que es dependiente de la estacionalidad y de la variabilidad geográfica, lo que provoca una reducción en las posibilidades de empleo como combustible para obtención energética. Por tanto, es necesaria una adecuada caracterización del residuo [35].

La Figura 1.5 muestra un sistema de gestión tipo de residuos sólidos urbanos (RSU), desde la recogida de residuos hasta su valorización final en términos de recuperación de material, reciclaje y compostaje, y de recuperación energética. El procesamiento de los residuos permite la obtención de un producto combustible, homogéneo, basado en carbono, que podrá ser empleado en instalaciones de conversión térmica en forma de pélets o briquetas para su valorización energética [36].

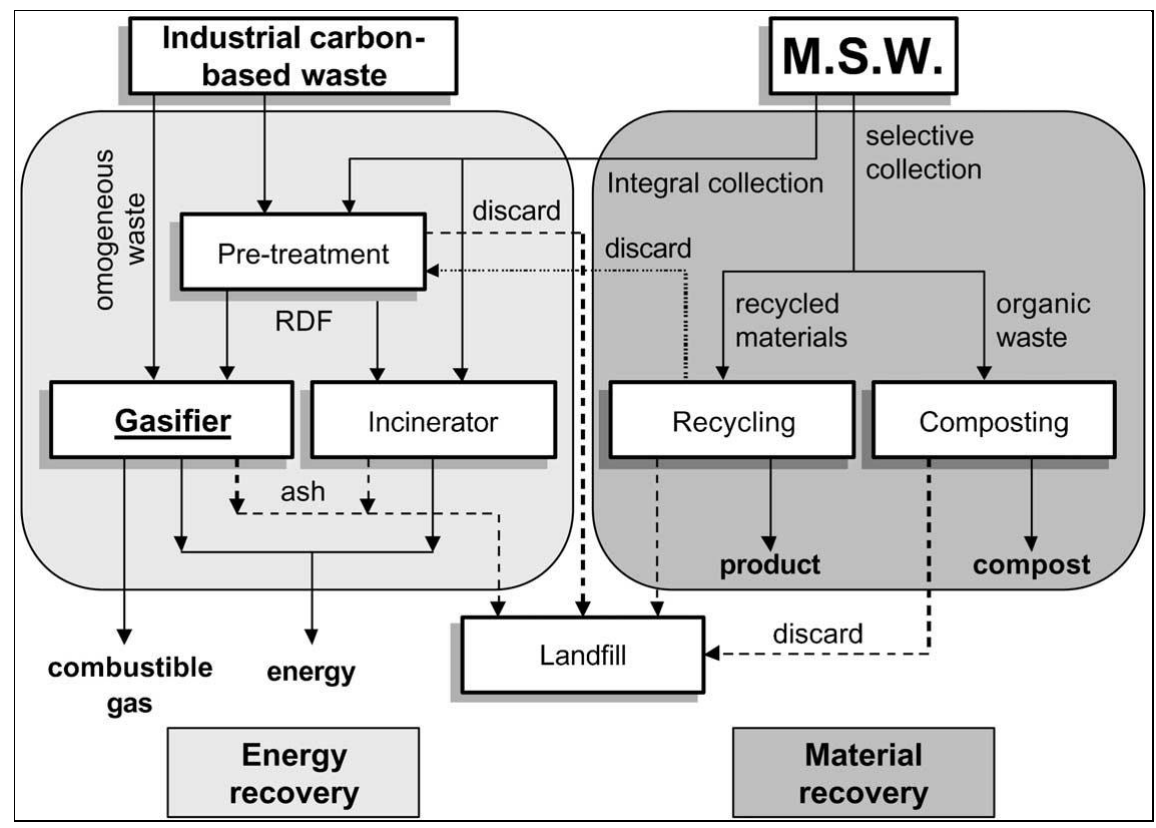

Figura 1.5. Sistema integrado de gestión de RSU [36]

La gestión de los residuos sólidos urbanos (RSU), deben encarar tanto problemas de tipo medioambiental como aspectos de índole económica y social [37]. La generación de residuos sólidos urbanos fue en la Europa de los 28 de 242.64 millones de toneladas 
en 2014, ver Tabla 1.1, y existe una previsión de incremento alrededor de 338 millones de toneladas para el 2020 [38]. La tendencia actual en los países europeos es reducir la cantidad de materia biodegradable que se envía a vertedero para su posterior eliminación. Actualmente, España envía un 55\% del RSU generado, que fue de 20,83 millones de toneladas en 2014, por tanto, es necesario poner énfasis en el reciclaje y valorización de residuos con el objeto de convertirnos en una sociedad respetuosa con el medio ambiente.

\begin{tabular}{|c|c|c|c|c|c|c|}
\hline \multicolumn{7}{|c|}{ Municipal waste, 2014} \\
\hline & \multirow{2}{*}{$\begin{array}{c}\text { Generated, } \\
\text { (kg per person) }\end{array}$} & \multirow{2}{*}{\begin{tabular}{|c|}
$\begin{array}{c}\text { Treated, } \\
\text { (kg per person) }\end{array}$ \\
\end{tabular}} & \multicolumn{4}{|c|}{ Municipal waste treated, $\%$} \\
\hline & & & Recycled & Composted & Incinerated & Landfilled \\
\hline $\mathrm{EU}^{\star}$ & 475 & 465 & $28 \%$ & $16 \%$ & $27 \%$ & $28 \%$ \\
\hline Belgium & 435 & 439 & $34 \%$ & $21 \%$ & $44 \%$ & $1 \%$ \\
\hline Bulgaria & 442 & 416 & $23 \%$ & $2 \%$ & $2 \%$ & $74 \%$ \\
\hline Czech Republic & 310 & 310 & $23 \%$ & $3 \%$ & $19 \%$ & $56 \%$ \\
\hline Denmark & 759 & 759 & $27 \%$ & $17 \%$ & $54 \%$ & $1 \%$ \\
\hline Germany & 618 & 618 & $47 \%$ & $17 \%$ & $35 \%$ & $1 \%$ \\
\hline Estonia & 357 & 303 & $31 \%$ & $6 \%$ & $56 \%$ & $8 \%$ \\
\hline Ireland $^{* \star}$ & 586 & 531 & $34 \%$ & $6 \%$ & $18 \%$ & $42 \%$ \\
\hline Greece $^{\star *}$ & 509 & 509 & $16 \%$ & $4 \%$ & $0 \%$ & $81 \%$ \\
\hline Spain & 435 & 435 & $16 \%$ & $17 \%$ & $12 \%$ & $55 \%$ \\
\hline France & 511 & 511 & $22 \%$ & $17 \%$ & $35 \%$ & $26 \%$ \\
\hline Croatia & 387 & 374 & $15 \%$ & $2 \%$ & $0 \%$ & $83 \%$ \\
\hline Italy & 488 & 455 & $28 \%$ & $18 \%$ & $21 \%$ & $34 \%$ \\
\hline Cyprus & 626 & 626 & $13 \%$ & $12 \%$ & $0 \%$ & $75 \%$ \\
\hline Latvia & 281 & 281 & $3 \%$ & $5 \%$ & $0 \%$ & $92 \%$ \\
\hline Lithuania & 433 & 425 & $21 \%$ & $10 \%$ & $9 \%$ & $60 \%$ \\
\hline Luxembourg & 616 & 616 & $28 \%$ & $18 \%$ & $35 \%$ & $18 \%$ \\
\hline Hungary & 385 & 376 & $25 \%$ & $6 \%$ & $10 \%$ & $59 \%$ \\
\hline Malta & 600 & 545 & $8 \%$ & $4 \%$ & $0 \%$ & $88 \%$ \\
\hline Netherlands & 527 & 527 & $24 \%$ & $27 \%$ & $48 \%$ & $1 \%$ \\
\hline Austria & 565 & 547 & $26 \%$ & $32 \%$ & $38 \%$ & $4 \%$ \\
\hline Poland & 272 & 272 & $21 \%$ & $11 \%$ & $15 \%$ & $53 \%$ \\
\hline Portugal & 453 & 453 & $16 \%$ & $14 \%$ & $21 \%$ & $49 \%$ \\
\hline Romania $^{* *}$ & 254 & 214 & $5 \%$ & $11 \%$ & $2 \%$ & $82 \%$ \\
\hline Slovenia & 432 & 257 & $49 \%$ & $12 \%$ & $0 \%$ & $39 \%$ \\
\hline Slovakia & 321 & 282 & $6 \%$ & $6 \%$ & $12 \%$ & $76 \%$ \\
\hline Finland & 482 & 482 & $18 \%$ & $15 \%$ & $50 \%$ & $17 \%$ \\
\hline Sweden & 438 & 438 & $33 \%$ & $16 \%$ & $50 \%$ & $1 \%$ \\
\hline United Kingdom & 482 & 473 & $28 \%$ & $17 \%$ & $27 \%$ & $28 \%$ \\
\hline Iceland $^{* *}$ & 345 & 345 & $38 \%$ & $7 \%$ & $6 \%$ & $49 \%$ \\
\hline Norway & 423 & 414 & $27 \%$ & $17 \%$ & $54 \%$ & $3 \%$ \\
\hline Switzerland & 730 & 730 & $33 \%$ & $21 \%$ & $46 \%$ & $0 \%$ \\
\hline Montenegro $^{\star *}$ & 508 & 451 & $1 \%$ & $0 \%$ & $0 \%$ & $99 \%$ \\
\hline FYR of Macedonia & 370 & 370 & $:$ & : & : & $100 \%$ \\
\hline Serbia & 302 & 236 & $1 \%$ & $0 \%$ & $0 \%$ & $99 \%$ \\
\hline Turkey & 405 & 363 & $0 \%$ & $0 \%$ & $0 \%$ & $100 \%$ \\
\hline Bosnia \& Herzegovina & 349 & 234 & $0 \%$ & $0 \%$ & $0 \%$ & $100 \%$ \\
\hline \multicolumn{7}{|c|}{$\begin{array}{l}\text { The treatment operations may not add up to } 100 \% \text { due to rounding. } \\
\text { Data for the Czech Republic, Germany, Spain, Cyprus, Luxembourg and Poland are estimated and may be revised. } \\
\text { Data not available } \\
\text { EU aggregate is estimated based on } 2013 \text { data for those Member States for which } 2014 \text { data are not available. } \\
2013 \text { data instead of } 2014 \text {. } \\
\text { The source dataset can be found here. }\end{array}$} \\
\hline
\end{tabular}

Tabla 1.1. kg de RSU generados y tratados por persona, incluidos porcentajes en sus tratamientos en 2014, Eurostat 


\subsubsection{INDUSTRIA PAPELERA}

La industria del papel recuperado genera gran cantidad de residuos sólidos y lodos. Los residuos sólidos se generan en operaciones de clasificación de papel recuperado a la entrada de la industria papelera y en el proceso de pulpado [37]. Los lodos generados en la industria constan de lodo de destintado generado en las operaciones en las unidades de destintado, lodo primario generado en la clarificación de efluentes líquidos y lodo secundario generado en las operaciones de tratamientos biológicos de aguas residuales.

Los residuos y lodos provenientes de la industria del papel recuperado están catalogados como residuos en la Lista Europea de Residuos:

- Código LER: 0303 Residuos de la producción y transformación de pasta de papel, papel y cartón

- 030305 Lodos de destintado procedentes del reciclado de papel.

- 030308 Residuos procedentes de la clasificación de papel y cartón destinados al reciclado.

○ 030310 Desechos de fibras y lodos de fibras, de materiales de carga y de estucado, obtenidos por separación mecánica.

- 030311 Lodos del tratamiento in situ de efluentes, distintos de los especificados en el código 030310.

Actualmente, la industria papelera produce gran cantidad de residuos, los cuales se eliminan llevándolos a vertedero o incinerándolos. En 2015, la producción de papel en Europa se situó en torno a 90,9 millones de toneladas, que generaron 8,8 millones de toneladas de residuos, mostrando un reducción respecto a las 11 millones de toneladas generadas en 2005 .

Además, la producción de papel reciclado, durante el mismo periodo, fue de 47,7 millones de toneladas, generando 8,2 millones de toneladas de residuos sólidos. España es uno de los países que más papel reciclado emplea, ver Figura 1.6., alrededor de un $11 \%[37,38]$.

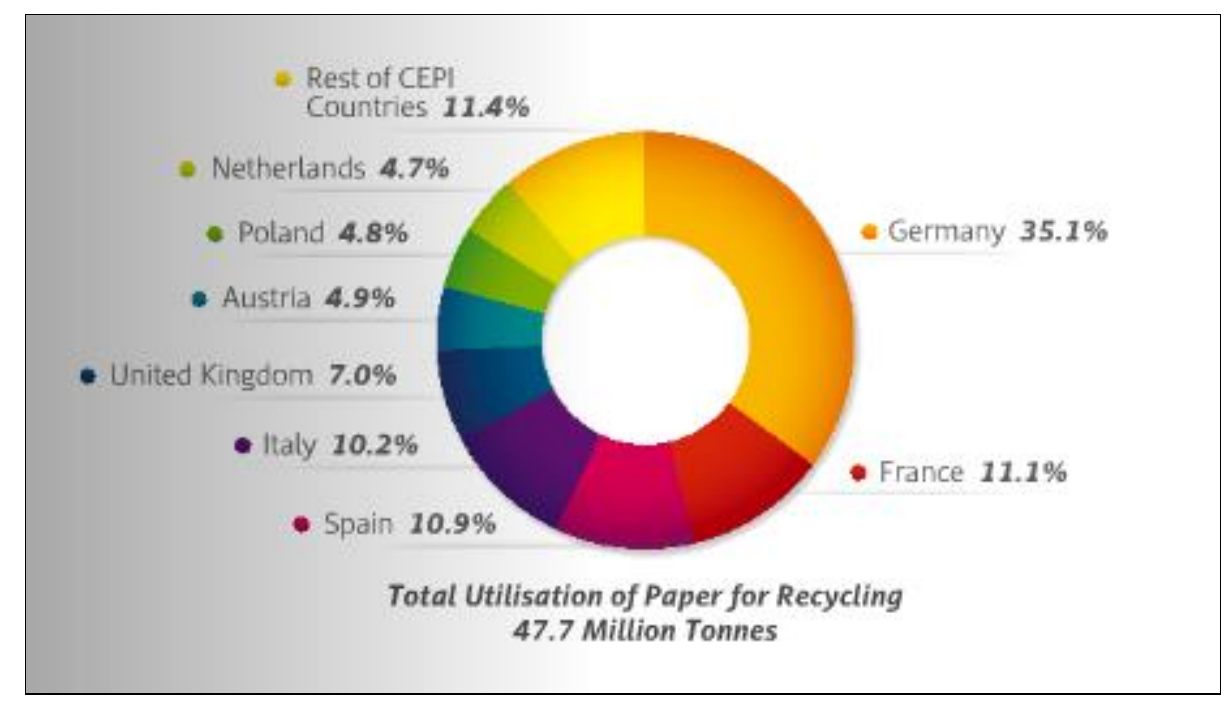

Figura 1.6. Utilización de papel reciclado país por país en Europa en 2015, CEPI. 
La industria papelera que utiliza papelote para producir papel reciclado, genera principalmente lodo de destintado, alrededor del $90 \%$ del total, y una menor cantidad de rechazos de la clasificación del papelote. Con anterioridad a la crisis económica, el lodo de destintado fue usado en cantidades significativas como relleno en la industria cementera, sin embargo, actualmente es enviado a vertedero, ya que a consecuencia de la crisis económica surgida en 2012, la industria cementera ha reducido su uso [39, 40, 41]. Debido a que la generación de residuos sólidos se encuentra en torno a 1,7 millones de toneladas para el año 2014, se buscan vías alternativas para su tratamiento en vez de su envío a vertedero.

Además, la industria papelera se fija para 2020 el objetivo de recoger para su reciclaje en Europa el $74 \%$ del papel que consume para evitar generar una elevada cantidad de residuos, siendo en España esta tasa de reciclaje del $71 \%$, un $0.5 \%$ menor que a nivel europeo, ver Figura 1.7 [42].

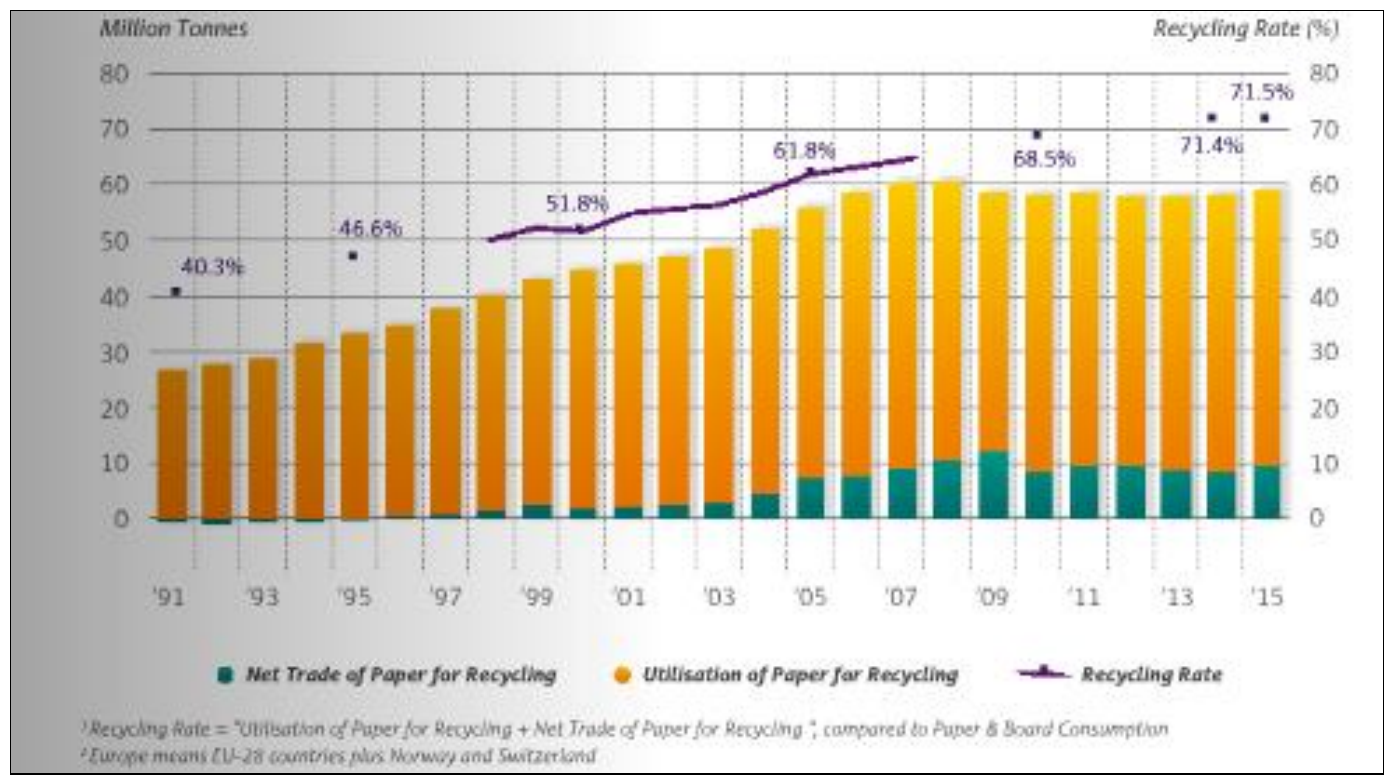

Figura 1.7. Tasa de reciclado de papel en Europa en 2015, CEPI.

\subsubsection{PRODUCCIÓN DE COMBUSTIBLES DE RESIDUOS}

\subsubsection{CDR}

El término combustible derivado de residuo (CDR), fue inicialmente introducido por el Dr. Jerome Collins en 1973, para referirse a residuos sólidos urbanos pretratados, es decir: homogeneizados y procesados [43]. No obstante, la "American Society for Testing Materials" (ASTM) define varias categorías que engloban a los CDR, basados en el tamaño de partícula, interrelacionados con los métodos de preparación, y en su estado físico. Los CDR son divididos en siete categorías, siendo la quinta categoría, la correspondiente a un residuo combustible densificado en forma de pélets, briquetas, lingotes y cubetas [44]. 
Los CDR engloban un amplio abanico de materiales de deshecho que han sido procesados para cumplir con las directrices, especificaciones normativas o industriales con el objeto de obtener un producto con un elevado poder calorífico. Los combustibles derivados de residuos incluyen residuos de tratamiento de residuo sólido urbano, residuos industriales, residuos comerciales, lodos de depuradora, residuos industriales peligrosos, residuos de biomasa, etc.

El término CDR, ha sido empleado en países anglófonos para referirse a las fracciones de rechazo con alto poder calorífico provenientes del procesamiento de residuos sólidos urbanos. Existe otra terminología aplicada a los combustibles obtenidos con fracciones rechazo de residuos sólidos urbanos como son combustibles recuperados, combustible derivado de envases, fracciones de papel y plástico y combustible procesado [45].

Los CDR son combustibles sólidos, líquidos pastosos o gaseosos preparados a partir de residuos peligrosos, no peligrosos e inertes, para su valoración energética en plantas de incineración y co-incineración y que habitualmente solo cumplen las especificaciones establecidas entre el productor del combustible y el usuario. Por tanto, solamente son de aplicación los parámetros fijados en las autorizaciones ambientales por parte de las administraciones pertinentes y los requisitos particulares de las empresas usuarias.

Aunque, los CDR no cumplen ninguna normativa, ni ninguna especificación, algunos países dentro de la Unión Europea sí que han establecido su propia normativa para englobarlos:

- Finlandia: Norma SFS 5875 Solid Recovered Fuel (SRF)-Quality Control System, 2000, ver Tabla 1.2.

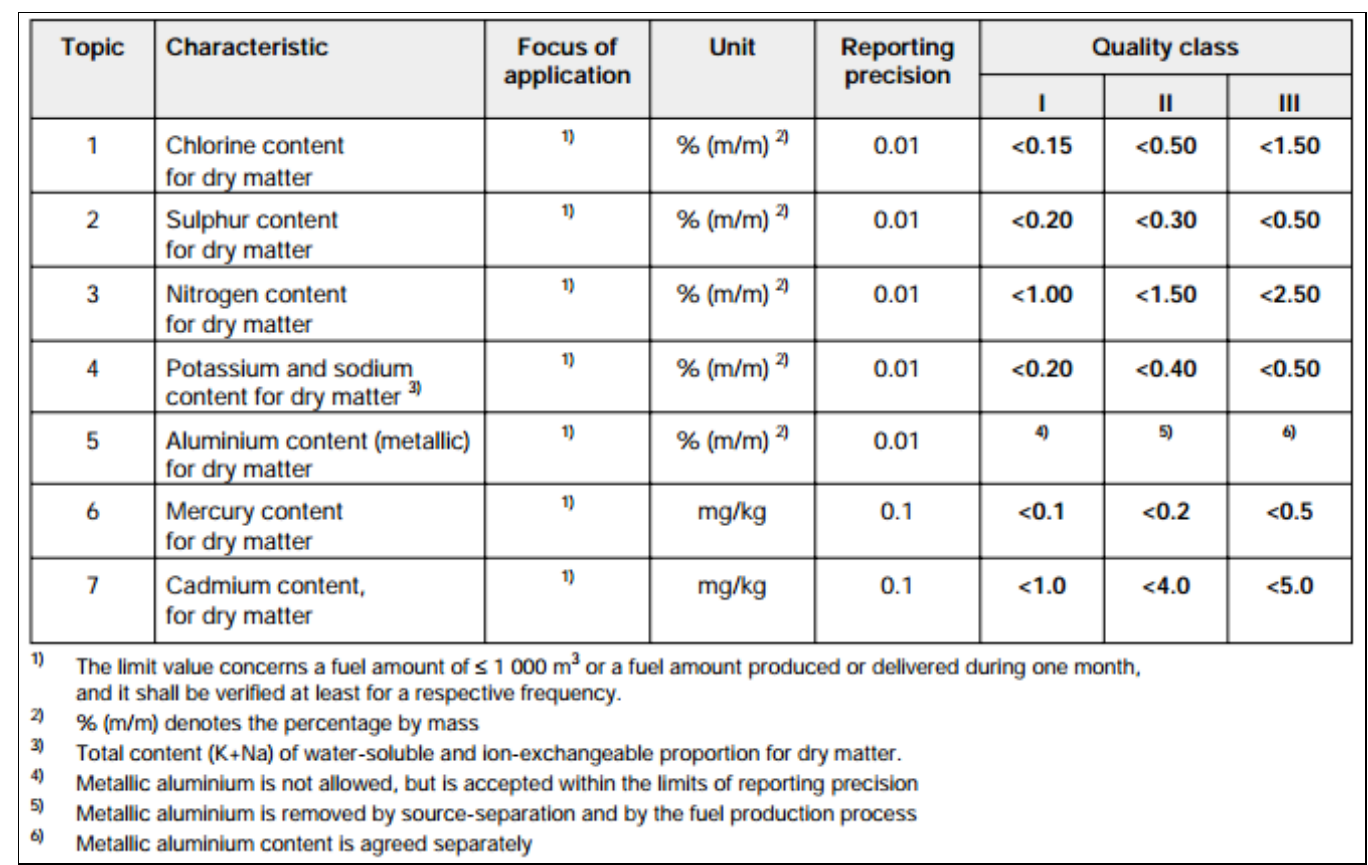

Tabla 1.2. Clases de CSR en Finlandia según norma SFS 5875 [46] 
- Italia: CSR de calidad media y alta según la norma UNI 9903 Non mineral refuse derived fuels, 1992, ver Tabla 1.3.

\begin{tabular}{|c|c|c|c|}
\hline Caratteristica & $\begin{array}{l}\text { unità di } \\
\text { misura }\end{array}$ & $\begin{array}{c}\text { limite di accettazione } \\
\text { Qualità normale }\end{array}$ & $\begin{array}{c}\text { limite di accettazione } \\
\text { Qualità elevata }\end{array}$ \\
\hline Umidità & $\%$ t.q. & $\max 25$ & $\max 15$ \\
\hline $\mathrm{PCI}$ & $\mathrm{kJ} / \mathrm{kg}$ t.q. & $\min 15.000$ & $\min 20.000$ \\
\hline Contenuto di ceneri & $\%$ s.s. & $\max 20$ & $\max 15$ \\
\hline As & mg/kg s.s. & $\max 9$ & $\max 5$ \\
\hline $\mathrm{Cd}+\mathrm{Hg}$ & mg/kg s.s. & $\max 7$ & $\max 3$ \\
\hline $\mathrm{Cd}+\mathrm{Hg}$ & mg/kg s.s. & $\max 7$ & $\max 1$ \\
\hline Cl totale & $\%$ t.q. & $\max 0,9$ & $\max 0,7$ \\
\hline $\mathrm{Cr}$ & mg/kg s.s. & $\max 100$ & $\max 70$ \\
\hline $\mathrm{Cu}$ solubile & mg/kg s.s. & $\max 300$ & $\max 50$ \\
\hline $\mathrm{Mn}$ & mg/kg s.s. & $\max 400$ & $\max 200$ \\
\hline $\mathrm{Ni}$ & mg/kg s.s. & $\max 40$ & $\max 30$ \\
\hline $\mathrm{Pb}$ volatile & mg/kg s.s. & $\max 200$ & $\max 100$ \\
\hline $\mathrm{S}$ & $\%$ t.q. & $\max 0,6$ & $\max 0,3$ \\
\hline Contenuto di vetro & $\%$ s.s & $*$ & $*$ \\
\hline $\mathrm{Fe}$ & $\%$ s.s & * & $*$ \\
\hline Fluoro & $\%$ s.s & 水 & $*$ \\
\hline Al & $\%$ s.s & * & $*$ \\
\hline $\mathrm{Sn}$ & $\%$ s.s & * & $*$ \\
\hline $\mathrm{Zn}$ & $\%$ s.s & * & $*$ \\
\hline aspetto esteriore & & * & $*$ \\
\hline pezzatura & $\mathrm{mm}$ & * & $*$ \\
\hline rammollimento ceneri & ${ }^{\circ} \mathrm{C}$ & * & $*$ \\
\hline
\end{tabular}

Tabla 1.3. Especificaciones CDR de calidad media y alta según la norma UNI 9903 [47]

- Alemania: Los residuos se dividen, generalmente, en CSR y fracciones con elevado poder calorífico. Las fracciones con un elevado poder calorífico recibían un menor tratamiento, siendo simplemente separadas en fracciones en función de su composición y características en lugar de generar una mezcla de residuos, mientras que los CSR se ampararon bajo la norma: RAL-GZ 724 Quality Assurance of Solid Recovered Fuels, 2001. Estos CSR debían asegurar un poder calorífico definido, un bajo contenido en cloro, un cierto tamaño de partícula y densidad a granel, así como un bajo contenido en metales pesados, ver Tabla 1.4, además de la disponibilidad de suministro cuando se requiera.

\begin{tabular}{|l|c|c|}
\hline Parameter & $\begin{array}{c}\text { Median } \\
\text { [mg/MJ DS] }\end{array}$ & $\begin{array}{c}\text { "80.-Percentile!" } \\
\text { [mg/MJ DS] }\end{array}$ \\
\hline Cadmium & 0.25 & 0.56 \\
\hline Mercury & 0.038 & 0.075 \\
\hline Thallium & 0.063 & 0.13 \\
\hline Arsenic & 0.31 & 0.81 \\
\hline Cobalt & 0.38 & 0.75 \\
\hline Nickel & 5.0 & 10 \\
\hline Antimony & 3.1 & 7.5 \\
\hline Lead & 12 & 25 \\
\hline Chromium & 7.8 & 16 \\
\hline Copper & - & - \\
\hline Manganese & 16 & 31 \\
\hline Vanadium & 0.63 & 1.6 \\
\hline Tin & 1.9 & 4.4 \\
\hline
\end{tabular}

Tabla 1.4. Concentración límite de metales pesados para co-incineración [48] 
Estas normativas han sido precursoras en relación al desarrollo de nuevas regulaciones europeas. Dichas regulaciones han venido acompañadas del desarrollo de una normativa específica, logrando un reconocimiento el término Combustible Sólido Recuperado (CSR), no obtenido por los CDR a nivel europeo [49, 50]. No obstante, los CSR pertenecen a una categoría, residuos no peligrosos, que se engloba dentro de los CDR, ver Figura 1.8.

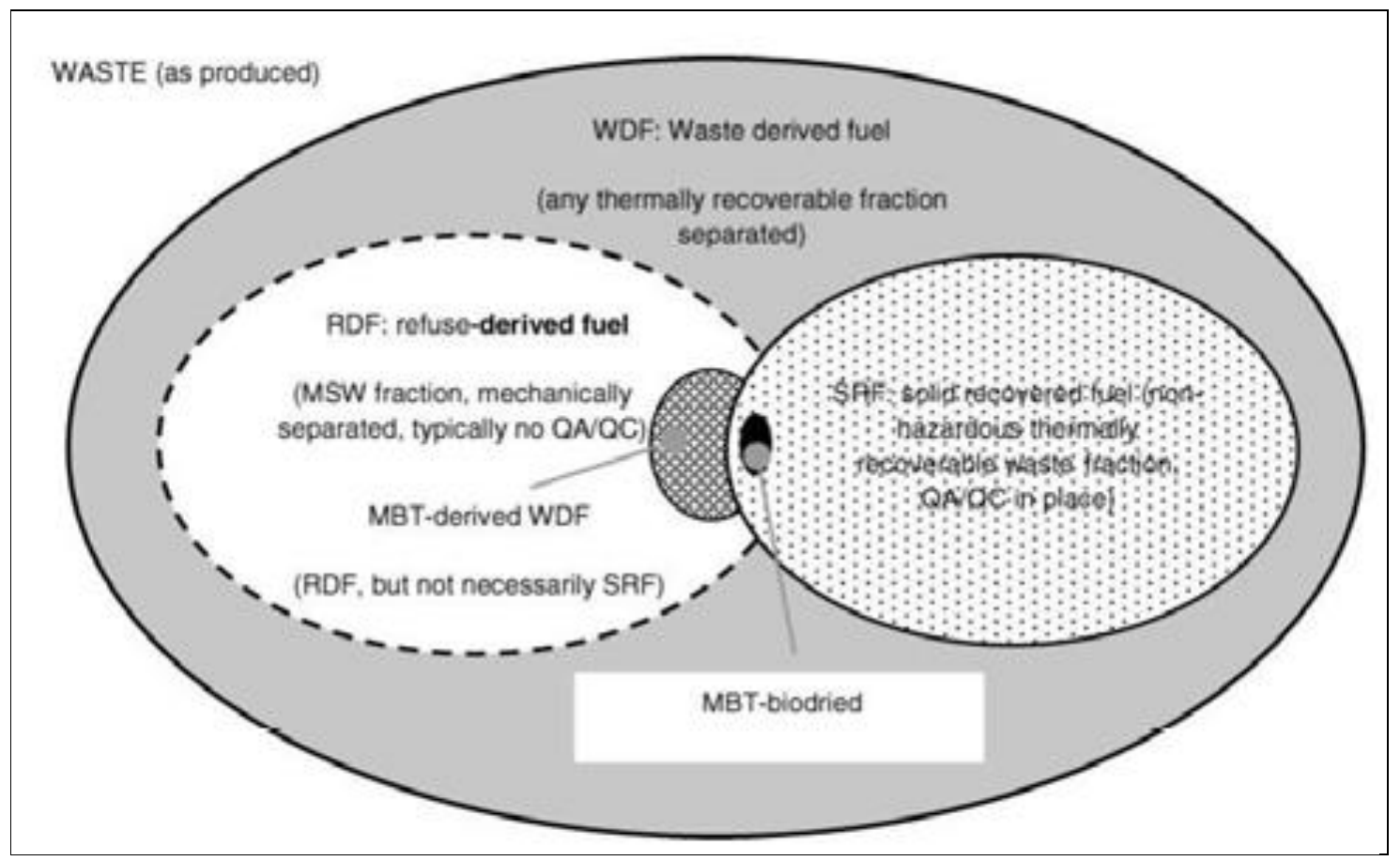

Figura 1.8. Diagrama de Venn indicando la terminología usada para las fracciones energéticas susceptibles de poder usarse para recuperación energética tras su pretratamiento en plantas de tratamiento mecánico biológico (TMB) [51]

\subsubsection{CSR}

Los CSR son combustibles sólidos preparados a partir de residuos no peligrosos destinado a ser utilizado para la recuperación energética en plantas de incineración o coincineración, de acuerdo a la norma UNE-EN 15357: 2012, y que cumplen con los requisitos de clasificación y de especificación establecidos en la norma UNE- EN 15359:2012 del Comité Europeo de Normalización (CEN) [52, 53].

Este sistema de clasificación está basado en tres indicadores: indicador económico (poder calorífico neto), indicador operacional (contenido en cloro) e indicador medioambiental (contenido en mercurio). Además, las fracciones biogénicas de estos combustibles pueden ser estimadas mediante la determinación del contenido de biomasa bajo la norma UNE-EN 15440: 2012 [54, 55]. 
En la figura 1.9 puede observarse el origen de los CSR, que pueden ser producidos a partir de RSU o de residuos comerciales e industriales.

\section{Origin of SRF}

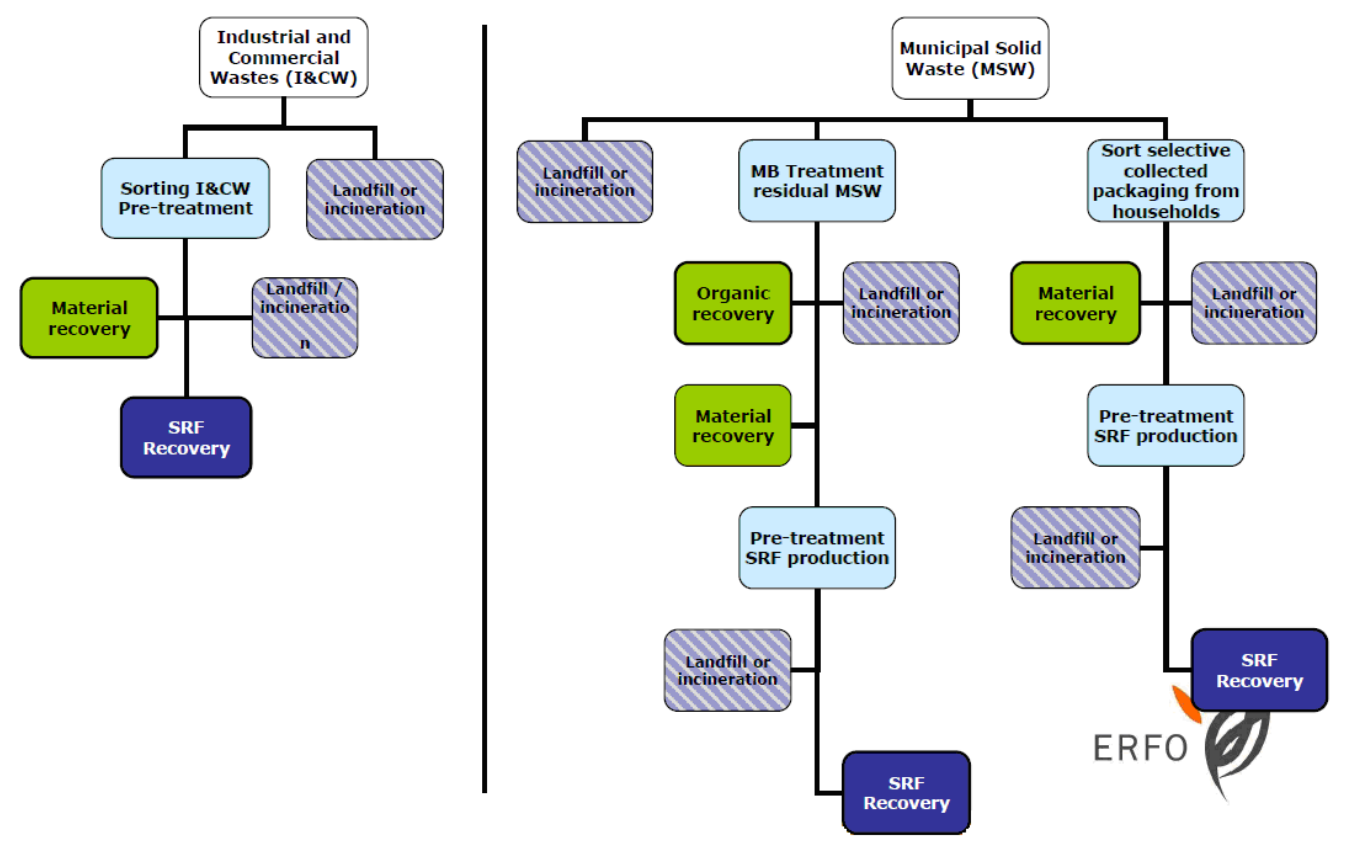

Figura 1.9. Origen de los CSR, ERFO

\subsubsection{Situación de los CDR/CSR en España}

En 2001, se fundó ERFO, que es una asociación sin ánimo de lucro que aglutina a las empresas productoras de CSR a nivel Europeo [56]. No obstante, la producción de CSR en España se encuentra en fase preliminar, aunque existen algunos productores de este tipo de combustible, cuyos usuarios potenciales son las cementeras. Las empresas productoras más relevantes en España fueron en el año 2016:

- Holcim España, Geocycle [229]

○ Albox, Almeria: Capacidad 40.000 T/año

- Estella, Navarra

- Grupo Griñó Ecologic, Sanea [230]

○ Constantí (Tarragona): Capacidad 16.000 T/año

- Enusa Industrias Avanzadas [233]

○ Cervera del Maestre (Castellón): Capacidad 120.000 T/año

- CEMEX [231]

○ Castillejo de Yepes (Toledo): Capacidad 35.000 T/año

- Crevillente (Alicante): Cerrada

- Reciplasa [228, 234]

○ Onda (Castellón): Capacidad 70.000 T/año

- Parque tecnológico de Valdemingómez, Las Lomas (Madrid): 900 T/dia [235]

- OSALAN [232]

○ Monte Arráiz (Bilbao): Capacidad 180.000 T/año

- CESPA [236] 
- PI Zona Franca de Barcelona: Capacidad 40.000 T/año [236]

- Ecoparque el Aceituno (Toledo) 250.000 T/año [240]

- Cañada Hermosa (Murcia): Capacidad 500.000 T/año [240]

- Ecoparqque de Can Mata (Barcelona)

- SOGAMA

○ Cerceda (La Coruña): Capacidad 500.000-550.000 T/año [237]

- FCC

○ Castellbisbal (Barcelona): Capacidad 30.000 T/año [238]

- PROMSA (Barcelona): Capacidad 50.000 T/año [239]

- PIRSA, EVEREST (Sabadell) [228]

- Trans Sabater S.L., Ribarroja del Turia (Valencia) [228]

El principal usuario de CDR o CSR en España es el sector cementero según muestra la fundación CEMA en sus publicaciones sobre producción, consumo y calidad de los CSR. En España solamente un 4,2\% (porcentaje energético) respecto al consumo total de combustibles utilizados por la industria del cemento proceden de residuos, mientras que en el conjunto de la UE esta cifra se eleva hasta el $18 \%[57,58]$.

En España la cantidad de CSR utilizado como combustible en el sector del cemento es de un 22,4\%, siendo la media de la Unión Europea del 30,5\%, y en países como Holanda inclusive se llega al $83 \%$. Este hecho hace que la valorización energética de CSR sea una opción de interés. En España a 31 de diciembre de 2013, la producción de cemento la acaparan 13 empresas, ver Figura 1.10., a través de 34 fábricas. Además, existen plantas donde solamente se realiza la molienda del cemento.

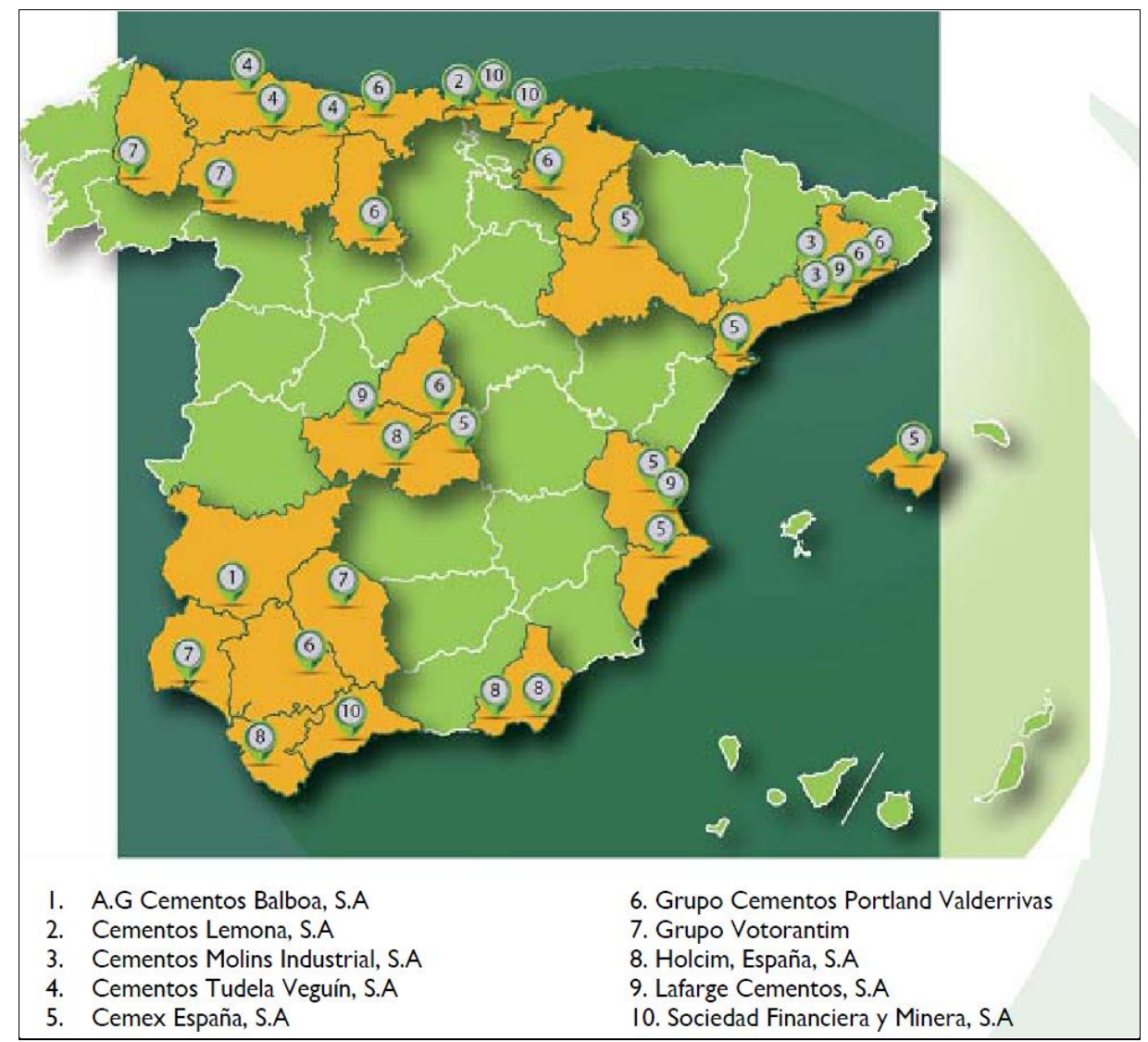

Figura 1.10. Fábricas cementeras en España a 31 de Diciembre de 2013 [59]. 
Según un estudio realizado por el IDAE para la elaboración del Plan de Energías Renovables 2011-2020 sobre el potencial de la valorización energética directa de residuos, el potencial de producción de CDR a partir del tratamiento de la fracción resto en España es de 1,2 millones de toneladas. Su objetivo es el empleo de residuos en substitución de combustibles tradicionales [60]. En la Figura 1.11 se puede observar el porcentaje de residuos que se emplean como combustibles alternativos en las cementeras europeas.

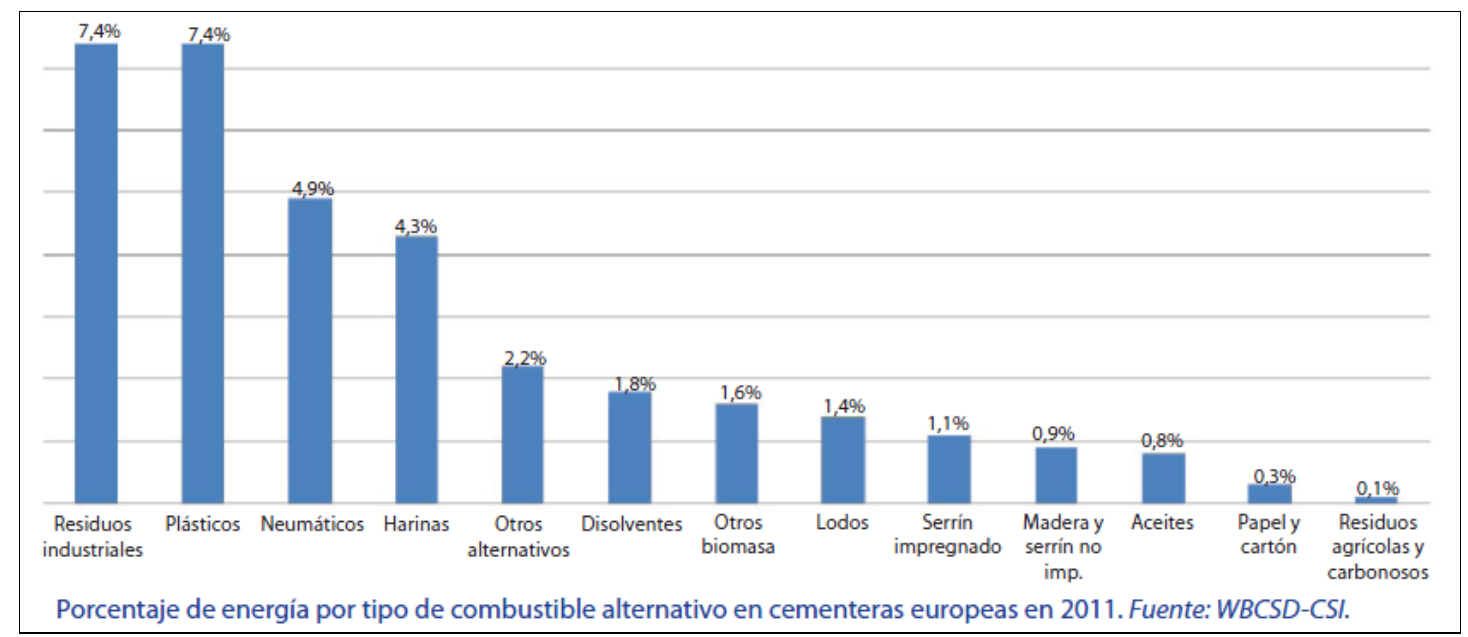

Figura 1.11. Porcentaje de energía por tipo de combustible alternativo en cementeras Europeas en 2011, CEMA.

\subsection{GASIFICACIÓN}

\subsubsection{INTRODUCCIÓN}

La recuperación de energía mediante residuos ha incrementado el desarrollo de tecnologías de conversión residuo a energía [61]. Muchos autores han investigado el potencial de los CSR para recuperación energética empleando tecnologías avanzadas de tratamiento térmico [62-65]. La conversión de residuos para su aprovechamiento energético puede ser llevada a cabo a través de distintos procesos. El proceso de conversión empleado depende de factores tales como: el tipo y la cantidad de la materia prima empleada o la forma de energía requerida en función de consideraciones medioambientales y requerimientos de uso final.

El empleo de residuos como combustible o como materia prima para su aprovechamiento requiere de tratamientos para su utilización. La conversión en portadores energéticos, bien sea en estado gaseoso o líquido, permite una mayor aplicabilidad y una manipulación más sencilla. La transformación de residuos en un combustible con un cierto valor añadido puede llevarse a cabo mediante procesos biológicos, producción de etanol o metano, o a través de procesos termoquímicos, que permiten obtener combustibles gaseosos, líquidos y sólidos, a partir de los cuales se pueden obtener una amplia variedad de productos secundarios, lo cual denota que las tecnologías de conversión térmica pueden ser empleadas de cara a la producción de productos secundarios, más allá de la mera generación de calor y electricidad [66]. 
La producción de enrgía a través de procesos térmicos (gasificación, combustión y pirolisis) reducen el impacto ambiental que otros procesos de producción de energía ocasionan [67]. Por tanto, el aumento de la demanda energética, unido a la necesidad de reducir la contaminación ambiental y limitar la formación de gases de efecto invernadero, ha provocado que las energías renovables hayan experimentado un auge, y en particular aquellas que emplean combustibles sólidos para generar un gas producto destinado a la obtención de calor y energía [68].

La utilización de diferentes residuos para su aprovechamiento térmico mediante procesos de conversión térmica, es una tecnología que se encuentra en pleno proceso de desarrollo a nivel de investigación y experimentación. Estos residuos presentan una elevada heterogeneidad en su composición, lo que dificulta su salida al mercado. Además, suelen presentar unas características singulares en su composición, que se corresponden con elevadas cantidades de material inorgánico (cloro, azufre y nitrógeno), que generan ciertos contaminantes que deben ser eliminados para evitar inconvenientes operacionales y riesgos medioambientales.

La posibilidad de explorar vías alternativas de eliminación de residuos, tras su conversión en un combustible adecuado para emplear en las tecnologías de conversión térmica existentes, genera gran controversia socialmente. Algunos procesos como la incineración son poco aceptados, debido a la posibilidad de generar altas concentraciones de dioxinas y furanos en función del tipo de residuo empleado como combustible. Sin embargo, el proceso de gasificación al emplear una menor cantidad de oxígeno (atmósfera reductora), limita la formación de dichas especies resultando en una tecnología más adecuada por su menor impacto ambiental $[69,96]$.

\subsubsection{FUNDAMENTOS DEL PROCESO DE GASIFICACIÓN}

El aprovechamiento energético de un combustible sólido a través de procesos termoquímicos permite obtener combustibles gaseosos, líquidos y sólidos, a partir de los cuales se pueden obtener una amplia variedad de productos secundarios. Los principales procesos de conversión térmica para obtener energía a partir de residuos y subproductos son combustión, pirólisis y gasificación.

La combustión es un proceso que se basa en la transformación de la energía química presente en un combustible en calor sensible, al obtener un gas a elevada temperatura. En este proceso se ponen en contacto un combustible y un comburente, que generalmente es aire debido a su menor coste económico.

Por el contrario, la pirólisis es un proceso de descomposición térmica en ausencia de oxígeno, que produce la aparición de tres fracciones: una fracción sólida compuesta básicamente de carbono, una líquida consistente en una mezcla de hidrocarburos pesados y una gaseosa formada por gases ligeros no condensables [70].

En cuanto al proceso de gasificación, es un proceso que genera un gas combustible a temperatura elevada, por tanto se genera un gas con una cierta proporción de energía química, gas combustible, y calor sensible, que dependerá de las condiciones de operación del proceso de gasificación. 
El agente gasificante que se emplea para el control del proceso de gasificación, que permite llevar a cabo la oxidación en condiciones subestequiométricas, puede ser aire, oxígeno, aire enriquecido de oxígeno y vapor de agua.

La gasificación es una oxidación parcial, que produce una elevada cantidad de productos gaseosos (dióxido de carbono, monóxido de carbono, hidrógeno, agua, hidrocarburos gaseosos y especies reducidas como amoníaco o sulfuro de hidrógeno), un residuo sólido con cierto poder calorífico (residuo carbonoso o char), cenizas y componentes condensables (alquitranes) [66]. El gas combustible generado durante el proceso puede ser llevado a combustión directa en calderas o tras una limpieza adecuada en motores de combustión interna y turbinas de gas.

Los subproductos que se generan tras el proceso de gasificación son principalmente: alquitranes, residuos carbonosos, cenizas volantes e inquemados, que requieren ser gestionados como residuos. La producción de alquitranes es inevitable, aunque puede ser reducida mediante el empleo de medidas primarias, modificaciones en operación in situ, o medidas de final de línea, empleando sistemas de limpieza a tal efecto. La limpieza del gas de proceso dependerá del destino final, pudiéndose emplear para combustión directa, o para la obtención de diferentes combustibles secundarios [71]. No obstante, el empleo del gas de gasificación en motores de combustión interna y turbinas de gas requiere de una adecuada limpieza del gas para evitar daños al equipo [72].

\subsubsection{ETAPAS DE LA GASIFICACIÓN}

Durante la gasificación ocurren un gran número de procesos que se agrupan generalmente a través de distintas etapas. La primera etapa, denominada secado, es donde tiene lugar el secado inicial del combustible que se introduce en el gasificador. La segunda etapa, que consiste en un proceso de devolatilización o pirólisis rápida, que se produce a temperaturas bajas, es donde se produce la liberación de la materia volátil y la generación del residuo carbonoso remanente. La tercera etapa que tiene lugar, es la combustión de la materia volátil y del residuo carbonoso generado, siendo la última etapa que consiste en la gasificación del residuo carbonoso restante [73]. Estas etapas ocurren de manera conjunta en el interior del gasificador, con la salvedad de que se produzcan en zonas diferenciadas del mismo, gasificadores de lecho fijo, o que tengan lugar de manera simultánea, gasificadores de lecho fluidizado.

En la primera etapa, se produce el calentamiento y secado de las partículas del combustible, que ocurre a temperaturas por encima de $100^{\circ} \mathrm{C}$. En esta etapa se produce la desaparición del agua contenida en el combustible sólido en forma de vapor. La siguiente etapa es la devolatilización, también conocida como pirólisis o descomposición térmica, que comienza lentamente a $150^{\circ} \mathrm{C}$, hasta alcanzar una velocidad casi instantánea por encima de $700^{\circ} \mathrm{C}$ [74].

En la segunda etapa, se producen reacciones de craqueo térmico, transferencias de masa y calor, liberación de gases ligeros no condensables (tales como $\mathrm{H}_{2}, \mathrm{CO}, \mathrm{CO}_{2}, \mathrm{CH}_{4}, \mathrm{O}_{2}$, $\mathrm{N}_{2} \mathrm{y}$ otros hidrocarburos ligeros), vapores de hidrocarburos condensables, que se liberan de la matriz sólida del combustible en fase gaseosa o líquida en forma de nieblas, y un residuo carbono sólido. 
La composición de los productos generados tras la devolatilización depende de la temperatura, la presión, la composición del gas que rodea al sólido durante la devolatilización y de la velocidad de calentamiento impuesta por el tipo de gasificador empleado [62]. Además, la naturaleza y la composición del sólido influyen notablemente en la composición del gas [75]. Durante la etapa de gasificación ocurren diversas reacciones bajo un ambiente reducido, ya que se lleva a cabo en presencia de menor cantidad de oxígeno que el requerido para oxidación completa.

El proceso de gasificación lleva asociado una serie de etapas, donde se producen reacciones exotérmicas y endotérmicas [74, 76, 77]. En el caso de un proceso de gasificación autotérmico, la oxidación parcial del gas combustible y del residuo carbonoso produce el calor necesario para el craqueo térmico de los hidrocarburos condensables y la gasificación del residuo carbonoso mediante vapor de agua y dióxido de carbono. Este calor aportado durante el proceso de gasificación sirve para mantener una temperatura de operación constante en el gasificador. Sin embargo, en un proceso de gasificación alotérmico, el calor necesario para las reacciones endotérmicas se suministra mediante fuentes externas, tales como resistencias eléctricas, combustión del residuo carbonoso generado o gases combustibles de manera exterior con el subsiguiente aporte de calor.

Dentro del gasificador se produce la combustión del residuo carbonoso, siendo esta reacción la que más energía térmica aporta para las reacciones endotérmicas, y la oxidación del hidrógeno contenido en el combustible para generar vapor de agua:

Oxidación del carbono: $\mathrm{C}+\mathrm{O}_{2} \rightarrow \mathrm{CO}_{2} \Delta \mathrm{H}_{0}=+393.77 \mathrm{~kJ} / \mathrm{mol}$

Oxidación del hidrógeno: $\mathrm{H}_{2}+\frac{1}{2} \mathrm{O}_{2} \rightarrow \mathrm{H}_{2} \mathrm{O} \Delta \mathrm{H}_{0}=+742 \mathrm{~kJ} / \mathrm{mol}$

Las reacciones de gasificación heterogéneas, que son endotérmicas, producen la gasificación del residuo carbonoso mediante vapor de agua y dióxido de carbono, siendo las denominadas reacciones de Boudard y reacción de gasificación con vapor, respectivamente:

Boudard: $\mathrm{C}+\mathrm{CO}_{2} \rightarrow 2 \mathrm{CO} \Delta \mathrm{H}_{0}=-172.58 \mathrm{~kJ} / \mathrm{mol}$

Gasificación con vapor: $\mathrm{C}+\mathrm{H}_{2} \mathrm{O} \rightarrow \mathrm{H}_{2}+\mathrm{CO} \Delta \mathrm{H}_{0}=-131.38 \mathrm{~kJ} / \mathrm{mol}$

La reacción de metanación puede ser considerada solamente con la presencia de catalizadores y en procesos a alta presión.

Metanación: $\mathrm{C}+2 \mathrm{H}_{2} \mathrm{O} \rightarrow \mathrm{CH}_{4} \Delta \mathrm{H}_{0}=+74.90 \mathrm{~kJ} / \mathrm{mol}$

Existen otra serie de reacciones de reformado con vapor, heterogéneas y homogéneas, que generalmente son endotérmicas [7], como la reacción de desplazamiento con agua:

Desplazamiento con agua: $\mathrm{CO}+\mathrm{H}_{2} \mathrm{O} \rightarrow \mathrm{H}_{2}+\mathrm{CO}_{2} \Delta \mathrm{H}_{0}=-41.98 \mathrm{~kJ} / \mathrm{mol}$

El predominio de alguna de las reacciones anteriores es función del tipo de contacto existente en el reactor, la concentración de las especies que se generan en el proceso, la temperatura de operación, la presión de operación, la actividad catalítica del material de lecho empleado, la presencia de catalizadores, el agente gasificante empleado, etc. 


\subsubsection{TECNOLOGÍAS DE GASIFICACIÓN}

La transformación de un determinado combustible en un portador energético se puede llevar a cabo mediante diferentes procesos de conversión térmica. Existen diversas tecnologías de gasificación, cuyo desarrollo se inició hace décadas, aunque aún son susceptibles de mejora y optimización. No obstante, la aparición de tecnologías prometedoras en el campo de la gasificación está modificando la percepción convencional de este tipo de procesos, tanto en las condiciones de operación necesarias, como en la generación de sustancias no deseables como alquitranes, partículas sólidas, etc. La selección de la tecnología de gasificación depende de los requerimientos necesarios, que contemplan aspectos tan variados como el tipo de combustible empleado, la cantidad de alquitranes generados, etc.

Los gasificadores se pueden clasificar en base a diferentes criterios, es decir: en función del agente gasificante empleado (aire, aire enriquecido con oxígeno, oxígeno, vapor de agua o plasma), la presión de operación (atmosféricos o presurizados), la temperatura (baja temperatura o alta temperatura), la forma de aporte el calor al reactor (gasificadores directos, autotérmicos, o gasificadores indirectos, alotérmicos) o del diseño del reactor. En cuanto a la fuente de calentamiento, alotérmico se refiere a aquellos gasificadores, que reciben el calor necesario para mantener el proceso de gasificación, mediante una fuente externa mediante una resistencia eléctrica, un intercambiador de calor o mediante un proceso indirecto. Por el contrario, autotérmico se refiere a aquellos gasificadores que reciben el aporte energético en forma de calor mediante la combustión parcial del material a gasificar.

La clasificación de los reactores en función del diseño, que hace referencia a aspectos como la forma de contacto gas-sólido, la forma de alimentación del combustible respecto al agente gasificante o la velocidad relativa gas-sólido, se subdivide en función de la tecnología empleada: tecnología de lecho móvil, lecho fluidizado, lecho arrastrado, horno rotatorio, parrilla móvil y plasma $[62,74,78]$.

La aplicabilidad de cada una de estas tecnologías depende de la variedad de combustibles a emplear y de los requerimientos finales del gas de proceso generado, ya que el contenido de alquitranes en el gas influye en la necesidad de limpieza, para su empleo en motores de combustión interna alternativos, turbinas de gas o en la producción de productos secundarios.

\subsubsection{Tipos de gasificadores}

\section{- Gasificadores rotatorios}

Los gasificadores rotatorios disponen de una parte mecánica que permite el desplazamiento de los sólidos, facilitando la operación en continuo. Los sólidos se mueven a través del reactor para, finalmente, entrar en la zona de mayor temperatura [79]. Este tipo de gasificador emplea tiempos de residencia bajos, sin embargo generan gran cantidad de alquitranes durante el proceso debido a la baja temperatura de gases a la salida [80]. 


\section{- Gasificadores de lecho móvil}

En los reactores de lecho móvil, se dispone de un lecho móvil formado por un flujo de partículas de combustible sólidas a lo largo de un reactor, a través del cual avanza el agente gasificante y el gas de proceso [81]. Los gasificadores que emplean esta tecnología se clasifican en función de la dirección de avance del agente gasificante y del gas de proceso, es decir: movimiento de flujo ascendente (reactor de lecho fijo en contracorriente), movimiento de flujo descendente (reactor de lecho fijo en isocorriente) y movimiento de flujo cruzado.

La terminología "lecho fijo" utilizada para este tipo de gasificadores se debe al movimiento lento descendente que experimenta el combustible por acción de la fuerza de gravedad. La construcción de estos equipos es sencilla, ya que constan de un sistema de alimentación para el combustible, un reactor cilíndrico que contiene al combustible y un sistema de extracción de cenizas. La utilidad de estos reactores está condicionada al grado de humedad, tamaño y tipo de combustible.

\section{- Gasificadores de lecho fijo de flujo ascendente}

En los gasificadores de lecho fijo de flujo ascendente, el agente gasificante se precalienta previamente a su introducción a través de un distribuidor de gas en la parte inferior del reactor. La alimentación del material a gasificar se realiza desde la parte superior del reactor [82]. El gas de proceso experimenta un ascenso a lo largo del reactor de forma que se recoge en la parte superior del mismo.

En los gasificadores de lecho fijo, las reacciones que tienen lugar se estratifican a lo largo del reactor, aunque esta estratificación depende del tipo de reactor de lecho fijo empleado. En este caso como se observa en la Figura 1.12, el agente gasificante a la entrada al reactor entra en contacto con el residuo carbonoso y con la ceniza, que se encuentran a elevada temperatura, correspondiendo esta zona a la etapa de combustión donde se alcanza la temperatura de ignición del combustible, produciéndose una reacción de combustión que aporta el calor necesario al gas ascendente para llevar a cabo el proceso de gasificación.

Las siguientes etapas en sentido ascendente son: reducción, pirólisis y secado. El gas que asciende caliente entra en contacto con el combustible, produciéndose las reacciones que tienen lugar en un proceso de gasificación, de manera que se obtiene un gas de proceso con una temperatura moderada. En la etapa de combustión se consume prácticamente la totalidad del oxígeno del comburente, lo que permite las siguientes etapas de reducción y pirólisis. El secado del combustible a gasificar se realiza mediante la cesión de calor residual del gas de proceso a la salida del reactor.

Este tipo de reactores presentan elevadas tasas de conversión de carbono, debido al elevado tiempo de residencia del sólido, y una elevada eficiencia térmica, debido a la temperatura baja del gas de proceso, aunque el gas generado tiene un alto contenido en alquitranes, cenizas y partículas sólidas, que requiere una excesiva limpieza del gas para su empleo en motores de combustión interna alternativos. Además, presenta desventajas como son la limitación de escalado y una baja capacidad específica, que es ligeramente superior a $250 \mathrm{~kW}$. 
En los gasificadores de lecho fijo descendente, el agente gasificante se introduce por un costado del reactor, de manera que se mezcla con los gases generados en la etapa de pirólisis. La alimentación se realiza desde la parte superior del reactor como ocurría para el reactor de lecho fijo ascendente. El flujo de la fase gaseosa, formado por el agente gasificante y el gas de pirolisis, avanzan paralelamente a la fase sólida, formada por el residuo carbonoso y las cenizas, hacia la parte inferior del reactor, donde de manera descendente se producen las etapas de combustión y reducción. La combustión de parte del gas de pirólisis aporta el calor necesario para las etapas de secado, pirólisis y gasificación, conociéndose este fenómeno como llama pirolítica [82]. El flujo de gas caliente se mueve hacia la zona de reducción, donde se encuentra el residuo carbonoso remanente del proceso, lo que genera un gas de proceso con un poder calorífico y un contenido en alquitranes bajos.

Este tipo de reactores presentan elevadas tasas de conversión de carbono, pero su eficiencia térmica es algo menor que en el caso anterior, debido a la mayor temperatura del gas de proceso obtenido, aunque este hecho reduce la cantidad de alquitranes que acompañan al gas a la salida del reactor gracias al craqueo térmico. Al igual que para el gasificador de lecho fijo ascendente, presenta desventajas en cuanto al potencial de escalado, que es limitado, y a la baja capacidad específica, entre 20-200 kW.

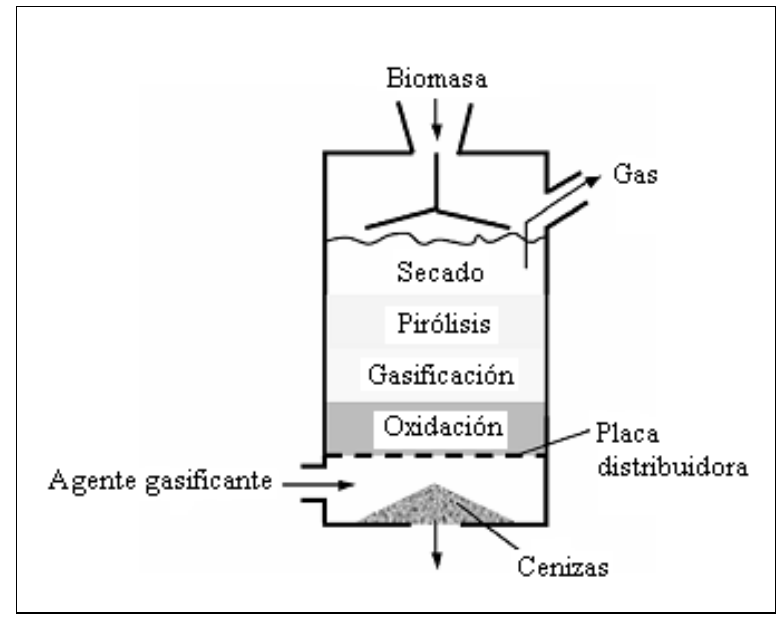

Figura 1.12. Gasificador de lecho de flujo ascendente

\section{- Gasificadores de lecho fluidizado}

La tecnología de fluidización se basa en mantener un lecho de partículas sólidas, denominado material de lecho, que puede tener actividad catalítica o no, sito en el interior del reactor en condiciones de fluidización mediante el empleo de un agente gasificante, que es introducido a través de una caja de vientos. La distribución del agente gasificante se lleva a cabo mediante un distribuidor de gas, que permite lograr una fluidización homogénea evitando fenómenos de formación de canales preferentes o de estratificación del lecho. El agente gasificante, se introduce en la parte inferior del reactor con una velocidad ascensional suficiente para fluidizar el material de lecho. 
La tecnología de lecho fluidizado consta de dos tipos de gasificadores: unidades de lecho fluidizado burbujeante y unidades de lecho fluidizado circulante, ver Figura 1.13. Este tipo de unidades se basan en la generación de una retromezcla en el interior del reactor, que permite una adecuada transferencia de materia y energía entre el combustible y el agente gasificante [83].

Las principales ventajas de las unidades de lecho fluidizado son: facilidad y flexibilidad de operación a cargas distintas a las de diseño, posibilidad de sustitución o variación del tamaño del combustible, buen control de temperatura, buen contacto gas-sólido, elevadas velocidades de reacción, buen potencial de escalado, alta capacidad específica y elevada conversión de carbono, aunque menor que para los reactores de lecho móvil. Como desventajas más apreciables se encuentran una moderada generación de alquitranes y de partículas sólidas que acompañan al gas de proceso.

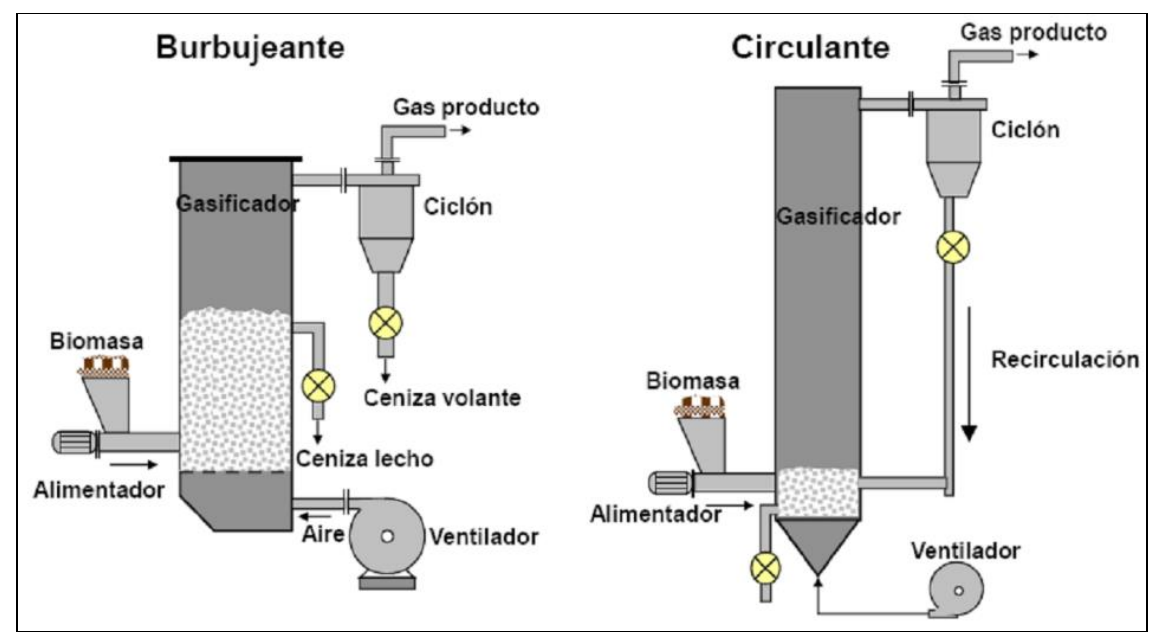

Figura 1.13. Tipos de gasificadores de lecho fluidizado

\section{- Lecho fluidizado burbujeante}

Las unidades de gasificación de lecho fluidizado burbujeante constan de un reactor cilíndrico, un sistema de alimentación y para los combustibles con un elevado contenido en cenizas se requiere de un sistema de extracción de las mismas. Las partículas sólidas se retienen mediante el empleo de un separador gas-sólido, ciclón. La velocidad ascensional que alcanza el agente de fluidización en las unidades burbujeantes es menor que en las unidades circulantes, ya que no requiere arrastre de material.

\section{- Gasificador de lecho fluidizado circulante}

Las unidades circulantes constan de un ciclón primario que permite la captura de las partículas sólidas arrastradas, que son devueltas al reactor a través de un sistema de recirculación, formado por una válvula no-mecánica y una rama de retorno, que posibilita el paso de partículas sólidas desde una zona de baja presión, ciclón, a una zona de alta presión, reactor.

Existen diferentes tipos de válvulas no mecánicas que posibilitan la recirculación de sólidos dentro del sistema como son: válvula tipo $\mathrm{L}$, válvula tipo $\mathrm{V}$, válvula tipo $\mathrm{J}, \mathrm{y}$ diferentes sellos hidráulicos como "loop-seal" o "seal-pot". El movimiento de los sólidos aumenta el tiempo de residencia del residuo carbonoso generado, por tanto aumenta la eficacia de conversión. 
Las partículas sólidas que no son capturadas por el ciclón primario, escapando del sistema de recirculación, son recogidas mediante un ciclón secundario. La necesidad de la existencia de un sistema de extracción de cenizas se encuentra ligada al contenido en cenizas del combustible alimentado.

\section{- Gasificador de lecho fluidizado dual}

Actualmente, la tecnología de fluidización está experimentando un auge en cuanto a configuración se refiere, ya que este tipo de tecnología permite la circulación de partículas sólidas entre reactores. De esta manera pueden usarse para aplicaciones de craqueo catalítico donde se dispone de reactor y regenerador o para captura de carbono entre calcinador y carbonatador [84].

Y con respecto a la gasificación, la conexión entre un reactor de gasificación y un combustor, que podrá utilizar los inquemados y el residuo carbonoso para generar el calor necesario para mantener el proceso de gasificación. El gasificador produce una cierta cantidad de inquemados y residuos carbonosos que son enviados, junto con material de lecho al combustor, donde se recalentarán con el objeto de que aumenten la temperatura del material de lecho antes de volver a enviarlo hacia el gasificador, ver Figura 1.14 [85].

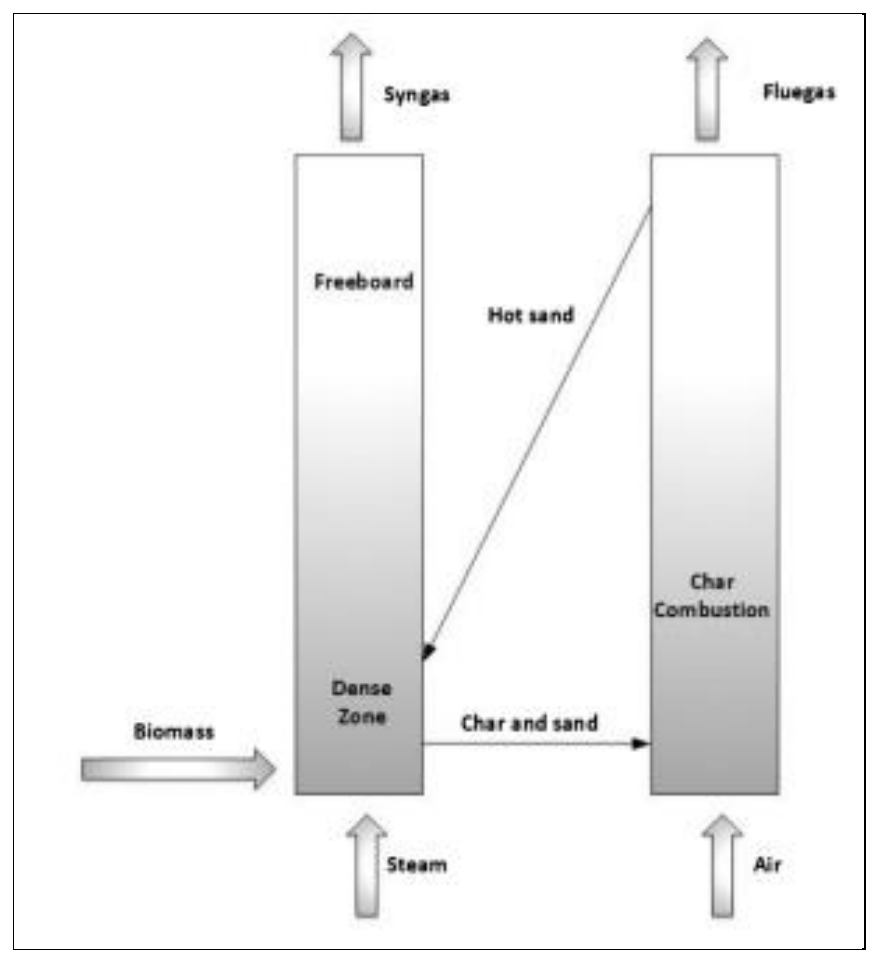

Figura 1.14. Gasificador de lecho fluidizado dual [85.]

\section{- Gasificador de lecho arrastrado}

Los reactores de lecho arrastrado operan en corrientes paralelas de manera que el sólido es arrastrado por el agente gasificante (generalmente oxígeno o vapor), generando un gas de proceso con un contenido en alquitranes prácticamente nulo y con altas conversiones de carbono debido a la elevada temperatura de salida del gas $\left(1400^{\circ} \mathrm{C}\right)$. 
Existen dos configuraciones para este tipo de gasificadores en función de la forma de alimentación, es decir: alimentación por la parte superior o alimentación lateral del agente gasificante y del combustible. El material a gasificar se alimenta molido finamente para lograr una elevada conversión del combustible sólido, ya que los tiempos de residencia en el reactor son reducidos [86]. La alimentación de las partículas sólidas de combustible puede realizarse de manera pneumática o bombeada en forma de pasta al reactor presurizado, siendo esta última la opción menos eficiente desde el punto de vista energético, ya que se requiere energía térmica para el calentamiento y evaporación del agua que acompaña al combustible.

Este tipo de gasificadores, al igual que los gasificadores ciclónicos, permiten la operación a elevadas temperaturas favoreciendo el craqueo de los alquitranes [87], por tanto hace que esta tecnología siga en estado de desarrollo e investigación debido a la posibilidad de reducción del contenido en alquitranes del gas de proceso, lo que evitaría sobrecostes adicionales derivados de la limpieza del gas.

\section{- Otras tecnologías}

Existen otra serie de tecnologías de gasificación que se encuentran en pleno desarrollo como son la gasificación por plasma, la gasificación con agua supercrítica o la gasificación en reactor de lecho de chorro.

\section{- Gasificación por plasma}

La gasificación por plasma es una tecnología que descompone la fracción orgánica del combustible generando un gas combustible y transforma la fracción inorgánica en un material vítreo conocido como escoria vitrificada [88]. Esta tecnología permite variabilidad en el combustible alimentado, pero debe ser molido antes de su inyección en el reactor.

El sistema consiste en un reactor conectado a un equipo de generación de plasma, que suministra la energía necesaria para el proceso de gasificación, y un sistema que permite la extracción del material vítreo formado. En este proceso parte de los átomos o moléculas del gas son parcial o totalmente ionizados, ya que se alcanzan temperaturas del orden de $2000-3000^{\circ} \mathrm{C}$ [89]. Debido a las elevadas temperaturas que se alcanzan en dicho proceso, los componentes no deseables que acompañan al gas de proceso son eliminados, obteniéndose un gas limpio, sin rastro de ta, alquitranes, residuo carbonoso y cenizas [90].

\section{- Gasificador con agua supercrítica}

La gasificación con agua supercrítica permite obtener un gas combustible con elevado contenido en hidrógeno. En este proceso se alcanzan las condiciones supercríticas del agua a temperaturas y presiones superiores a $374,15^{\circ} \mathrm{C}$ y $22,1 \mathrm{MPa}$, respectivamente. Las ventajas de esta tecnología son la posibilidad de trabajar con combustibles húmedos [91] y la reducción del contenido en alquitrán y residuo carbonoso generado debido al particular medio de reacción [92]. 
Los reactores de lecho de chorro consiguen un buen contacto gas-sólido, ya que el gas se inyecta verticalmente, de manera ascendente a través de un orificio sencillo en el interior de un reactor, que contiene un lecho de partículas sólidas.

La ascensión del gas provoca la expansión del lecho de partículas, haciendo que se genere una corriente de gas con elevada porosidad ( $>5 \%)$, que circula por el centro del reactor. Con una caída de presión y velocidad ascensional suficientes, el gas vence los requerimientos necesarios para que el chorro de gas rompa en la parte superior de la superficie, produciendo la formación del patrón de flujo característico [93], que consiste en la generación de una fuente de partículas sólidas que cae en forma de flujo descendente en las proximidades de la pared del reactor, formándose una corriente con una menor porosidad $(\sim 40-50 \%)$.

\subsubsection{PARÁMETROS DE OPERACIÓN}

Las condiciones de operación dependen de la tecnología de gasificación de que se disponga para la obtención del gas de proceso. La selección del tipo de gasificador va a influir notablemente, aunque existen una serie de parámetros de operación, que son claves para determinar el correcto funcionamiento del proceso de gasificación cualquiera que sea el tipo de reactor seleccionado.

Los parámetros más importantes son: la relación de equivalencia (ER), los perfiles de temperatura y presión en el reactor, el tiempo de residencia del combustible, las características químicas y físicas del combustible, el agente gasificante empleado y el material de lecho seleccionado. Estos parámetros cobran mayor o menor importancia dependiendo del tipo de gasificador seleccionado, aunque la necesidad de tener en cuenta más de un parámetro para determinar y evaluar la correcta operación del proceso son debidas a la mayor complejidad de este proceso de conversión térmica en comparación con otros procesos más convencionales como pueda ser la combustión.

Relación de equivalencia (ER): Es la proporción entre la ratio aire/combustible en el proceso y la ratio aire/combustible para completa combustión, ya que en este proceso se trabaja bajo condiciones subestequiométricas. La variación de la relación de equivalencia influye en multitud de parámetros como: temperatura de gasificación, contenido en alquitranes y poder calorífico del gas de proceso, es decir: la energía química contenida en el gas combustible generado. Un ER elevado provoca la oxidación de parte del gas de proceso y la reducción del poder calorífico del mismo, mientras que un ER bajo provoca el aumento del contenido en alquitranes y del remanente del residuo carbonoso generado. En condiciones de gasificación el rango de trabajo se sitúa en torno a $0,25-0,5$.

Temperatura y presión en el reactor: Los perfiles axiales de temperatura a lo largo del reactor indican la variación de temperatura que se origina en el mismo de manera que se obtienen datos relevantes sobre el proceso de gasificación. En cuanto a la presión, es un parámetro clave para la operación, siendo de gran utilidad para controlar la recirculación que se produce en gasificadores de lecho fluidizado circulante al poder disponer de un perfil de presiones de la instalación. 
Tiempo de residencia: El tiempo de residencia se define como el tiempo medio que permanecen las partículas sólidas de combustible en el interior del gasificador debiendo ser el adecuado para asegurar que se producen las reacciones de gasificación y que se obtiene un gas de proceso con unas características adecuadas. El tiempo de residencia se define en función del tipo y diseño del reactor. Sin embargo, se pueden hacer pequeñas variaciones en las condiciones de operación, que posibilitan un aumento del tiempo de residencia, por ejemplo: disminución de velocidad superficial del gas en un reactor de lecho fluidizado o modificando la velocidad en un gasificador de parrilla [62].

Agente gasificante: El agente gasificacnte empleado afecta a la composición del gas de proceso. En el caso de gasificación con aire, este provoca la dilución en nitrógeno del gas obtenido, resultando en un gas con un poder calorífico bajo, 4-7 $\mathrm{MJ} / \mathrm{Nm}^{3}$. La posibilidad de emplear otros agentes gasificantes, implica una opción de aumentar el poder calorífico del gas de proceso, como con el caso de vapor de agua (10-16 $\mathrm{MJ} / \mathrm{Nm}^{3}$ ) o aire enriquecido con oxígeno $\left(10-12 \mathrm{MJ} / \mathrm{Nm}^{3}\right)$ [94].

La interrelación entre los parámetros operacionales, que se mencionan en este apartado, muestra la dificultad de determinar un criterio efectivo acerca de la calidad del proceso basándose solamente en parámetros de rendimiento, como los aquí mencionados, por tanto, son solamente indicativos de la eficiencia del proceso de gasificación. La calidad final del gas de proceso va a depender de la utilidad futura del gas, estableciéndose los requisitos necesarios.

El desarrollo del proceso de gasificación depende del tipo de tecnología empleada, ya que está estrechamente ligado a las características operacionales, que van a ser clave en la formación de los alquitranes. El gas de proceso generado tras la gasificación contiene alquitranes, partículas sólidas e impurezas, que acompañan al gas combustible que se pretende obtener. La aplicación final del gas de proceso determina el grado de limpieza de gas requerido. Por tanto, la limpieza del gas afecta al balance económico del proceso de gasificación, ya que los costes de inversión y operación dependerán de los requerimientos necesarios en cuanto a la limpieza del gas [95].

\subsection{GAS DE GASIFICACIÓN}

\subsubsection{CAPACIDAD DE GASIFICACIÓN}

La distribución geográfica de la capacidad de gasificación a nivel mundial se muestra en la Figura 1.15 en el año 2015. En la producción de gas de gasificación destaca la región de Asia/Oceanía por encima del resto de regiones, que muestran capacidades similares. Además, esta región está planificando un considerable aumento en su capacidad de producción como se observa en la siguiente figura. Este espectacular aumento en los países asiáticos, tiene a China a la cabeza. 


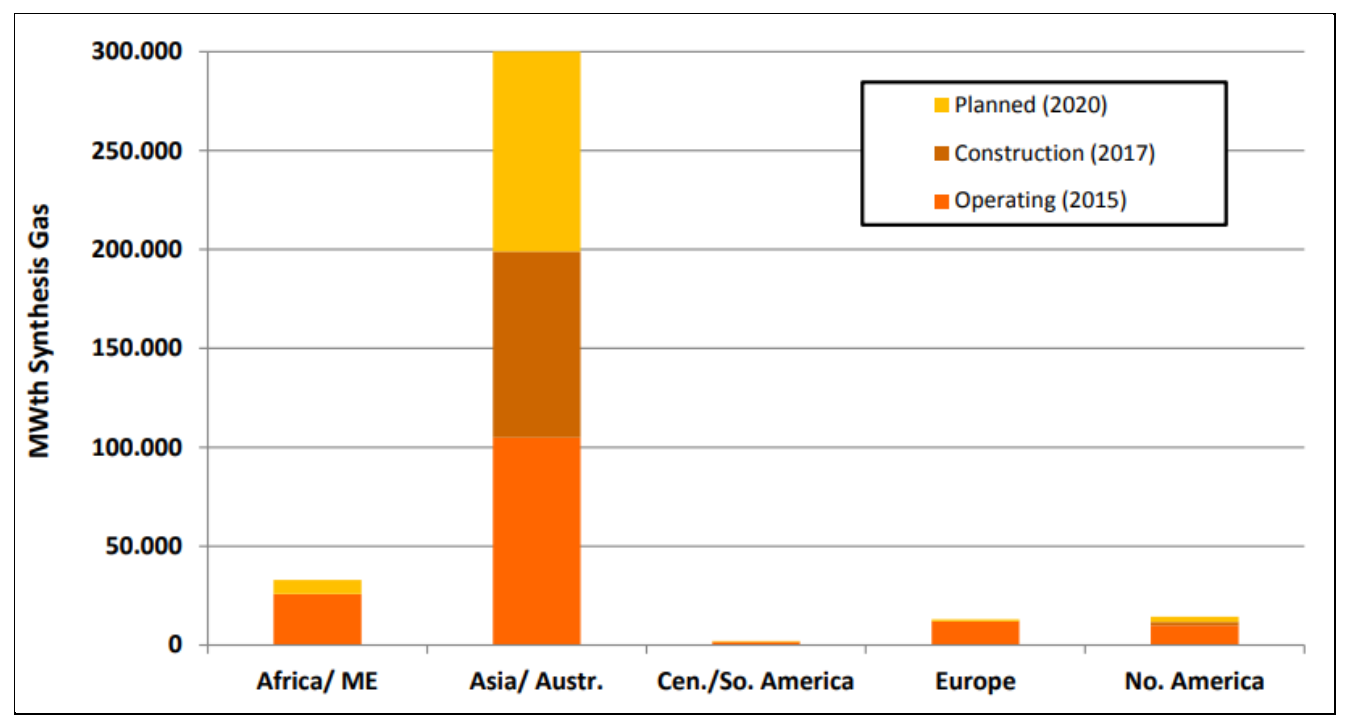

Figura 1.15. Producción de gas de gasificación por continentes [97].

En el año 2016, existían 356 proyectos operativos, construidos o planeados, que se corresponden con 863 gasificadores, con una capacidad de gasificación de más de 154 $\mathrm{GW}_{\mathrm{t}}$. En la Figura 1.16 se observa la capacidad de producción mundial acumulada desde 1970 a 2020. Las previsiones de crecimiento auguran un aumento de la capacidad de gasificación entre los años 2017 y 2020, con un incremento del número de gasificadores hasta 1870 y de la capacidad de gasificación llegando a $370 \mathrm{GW}_{\text {th }}$ [97, 98].

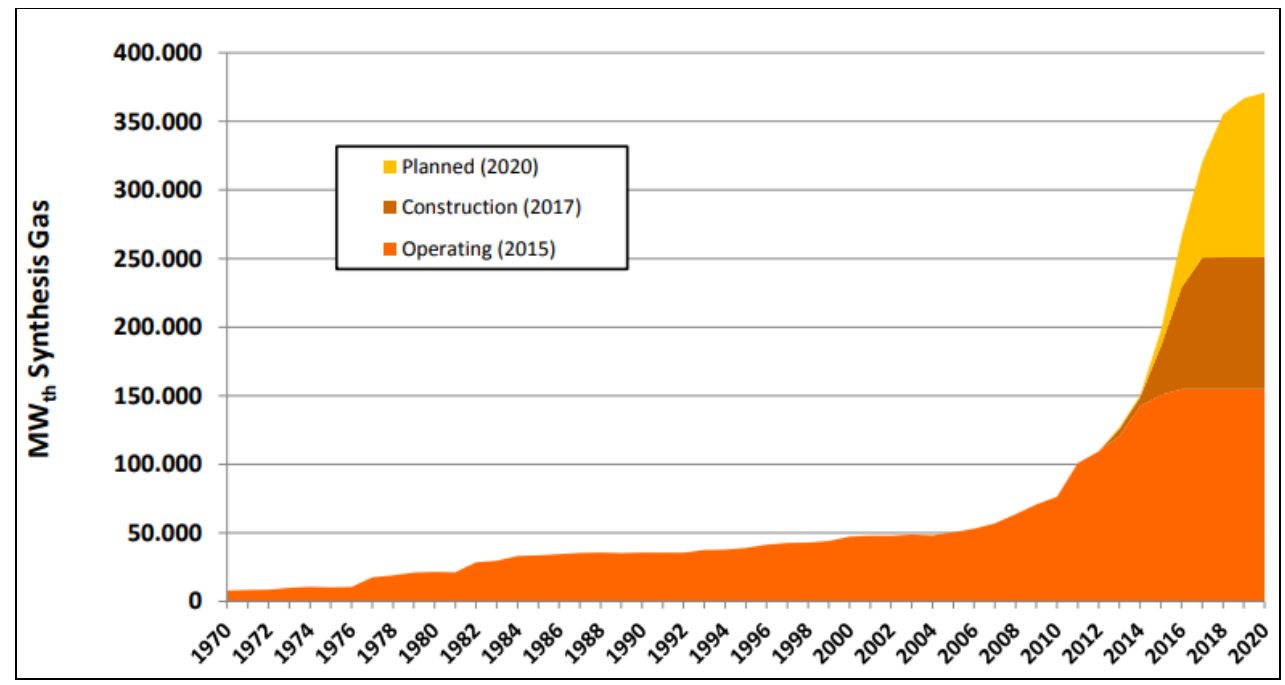

Figura 1.16. Capacidad de gasificación mundial y crecimiento acumulado por año [97].

El combustible mayoritario empleado en las plantas de gasificación a nivel mundial en el año 2016 fue carbón, $57 \%$ de la producción total de gas de síntesis, seguidas de petróleo, gas, coque de petróleo, ver Figura 1.17. En comparación, la utilización de otros combustibles alternativos, como biomasa o residuos ha sido muy escasa, siendo un $0,3 \%$ de la producción total de gas de síntesis [96]. 


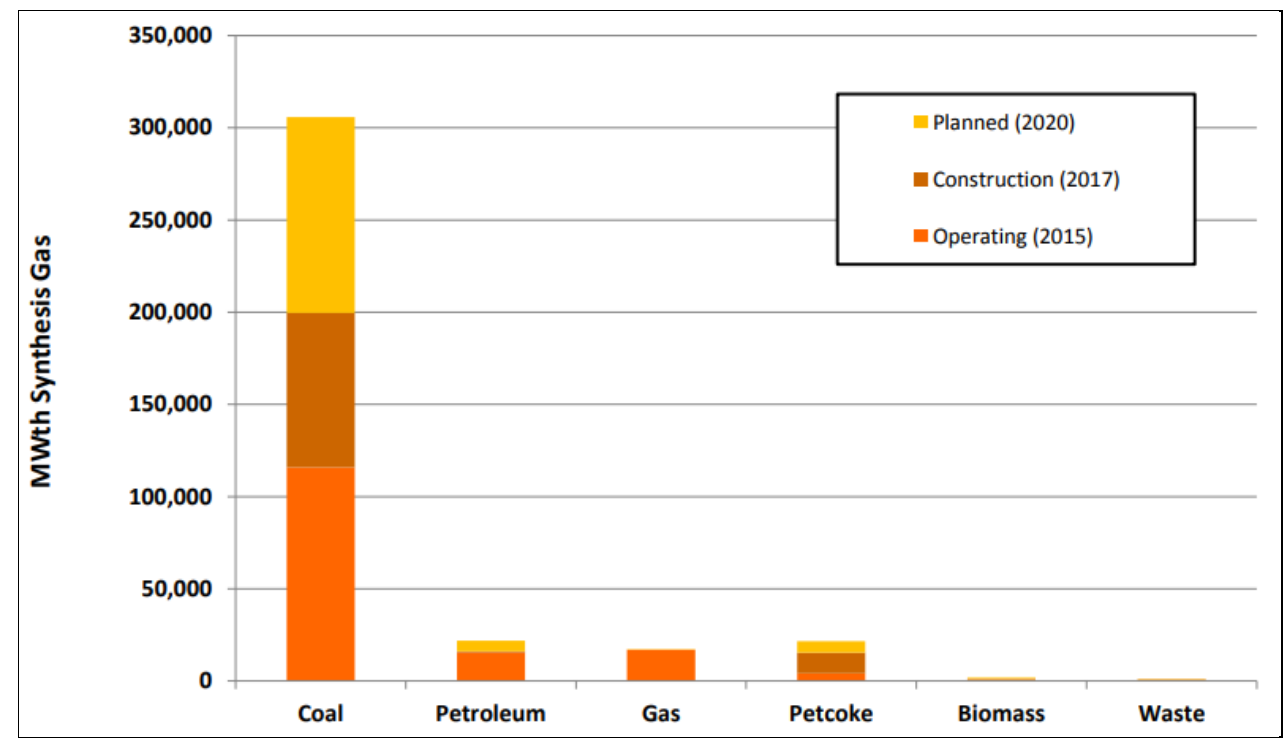

Figura 1.17. Combustibles empleados para la producción de gas de gasificación a nivel mundial [97].

Sin embargo, el número de gasificadores que emplearon combustibles alternativos, biomasa o residuos como combustibles no fue tan bajo, a pesar de que la explotación comercial de residuos en un proceso de gasificación presenta una serie de inconvenientes, tanto tecnológicos, como de estabilidad en el suministro, ver Figura 1.18 [99].

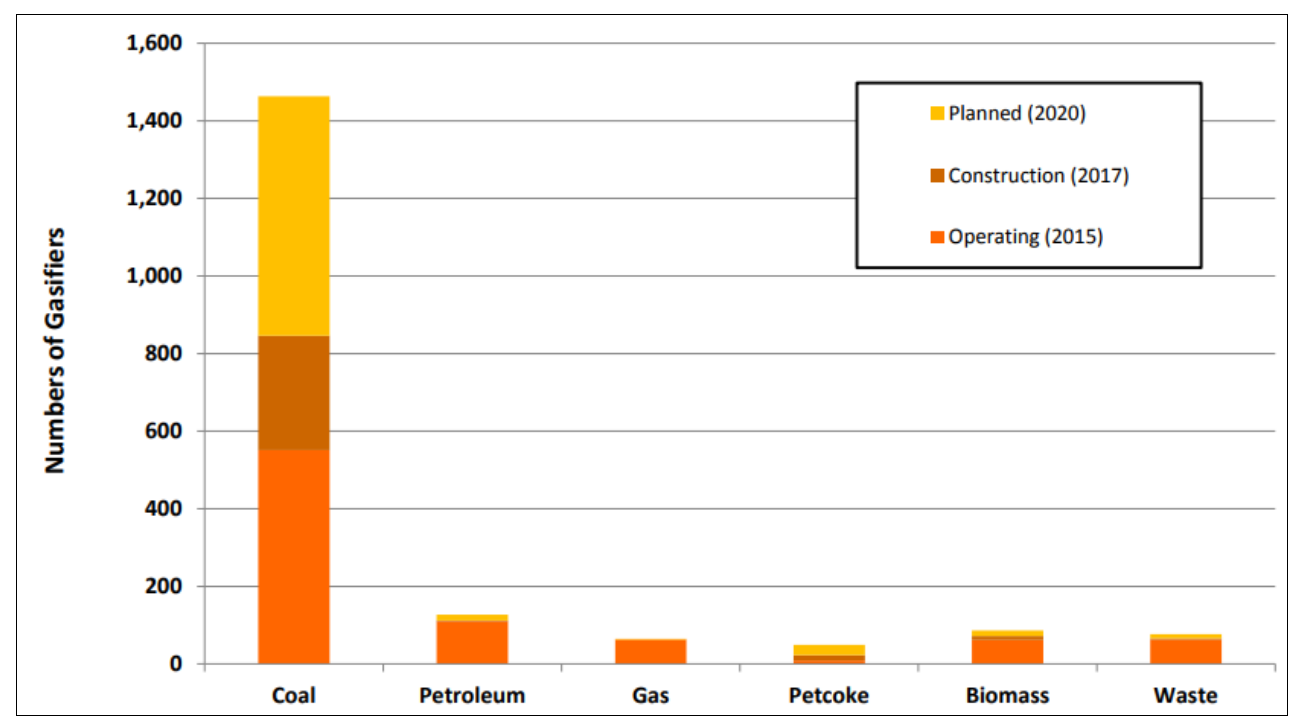

Figura 1.18. Número de gasificadores en función del combustible empleado [97].

\subsubsection{APLICACIONES COMERCIALES DE LA GASIFICACIÓN}

El gas de gasificación puede ser empleado en multitud de aplicaciones para obtener diferentes productos, ver Figura 1.19. Algunas de estas aplicaciones permiten obtener: amoniaco, alcoholes, combustibles líquidos (gasolina y diésel), combustibles gaseosos (metano e hidrógeno), combustión del gas producido en hornos y calderas, producción de energía eléctrica mediante motores y turbinas. 


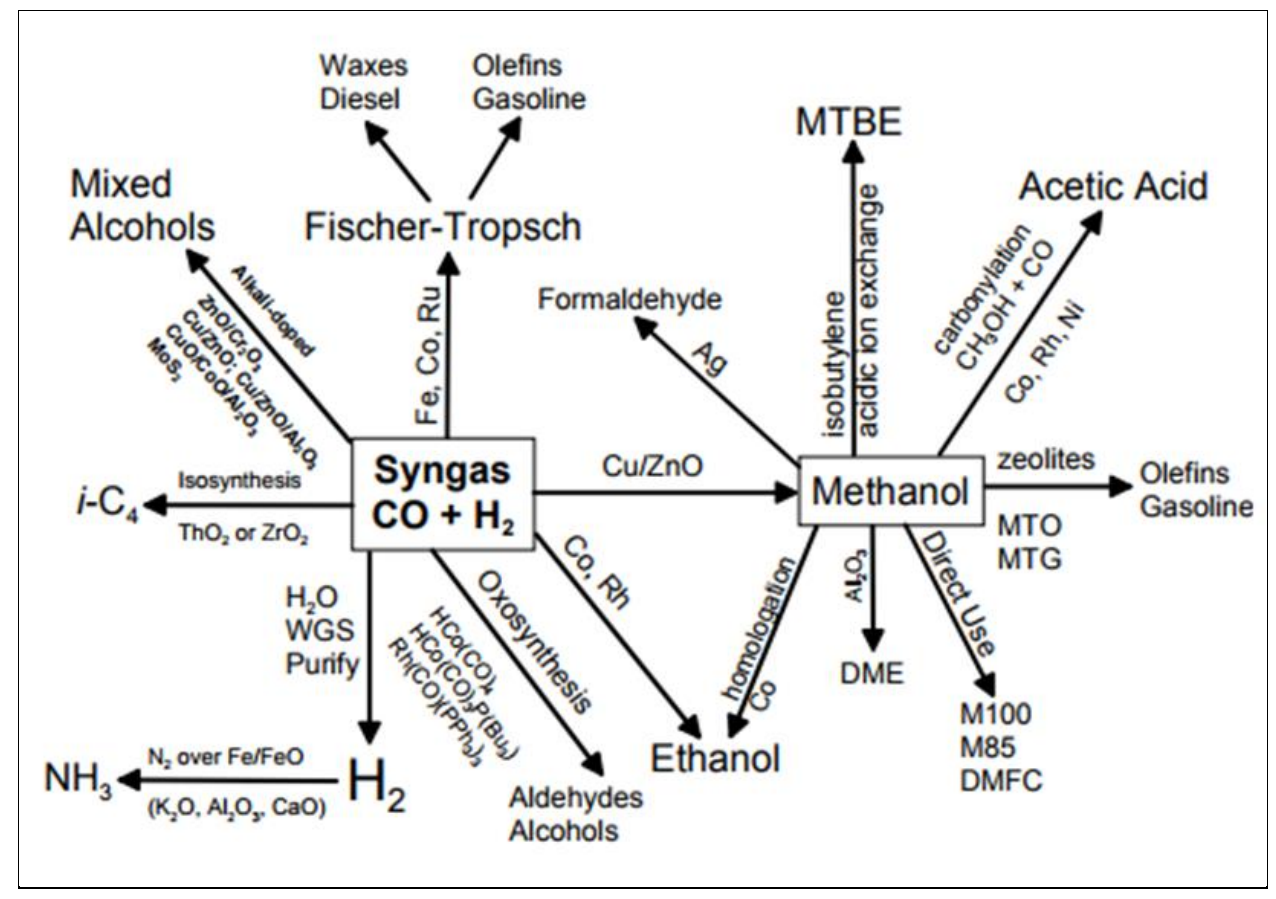

Figura 1.19. Aplicaciones del gas de gasificación [100].

El gas de gasificación contiene impurezas como: partículas, alquitranes, hollín, compuestos nitrogenados, sulfuro de hidrógeno, cloruro de hidrógeno, compuestos alcalinos y cenizas. El grado de limpieza del gas de gasificación es función de los requerimientos a cumplir en las distintas aplicaciones finales, así como del proceso de gasificación [103].

En algunas aplicaciones, los requerimientos de limpieza del gas son menores, como en la combustión del gas de gasificación directamente en hornos y calderas, ya que admite una mayor concentración de alquitranes. Sin embargo, otras aplicaciones tienen más requerimientos. La limpieza del gas para su aplicación en motores de combustión interna y turbinas de gas requiere de una concentración de alquitranes comprendida entre $50-100 \mathrm{mg} / \mathrm{Nm}^{3}$ y de partículas $<50 \mathrm{mg} / \mathrm{Nm}^{3}$ para motores de combustión interna y $<30 \mathrm{mg} / \mathrm{Nm}^{3}$ para turbinas de gas, respectivamente, con un tamaño menor a $10 \mu \mathrm{m}$. Además, la concentración de amoniaco para ambos debe ser inferior a 50 ppm [99, 101]. En la Figura 1.20 se observan los requerimientos del gas de gasificación para su transformación en alcoholes o su aplicación en un proceso de Fisher-Tropsch. 


\begin{tabular}{|c|c|c|c|c|c|c|c|c|c|}
\hline \multirow{3}{*}{$\begin{array}{l}\text { Conversion } \\
\text { Products } \\
\text { Catalyst }\end{array}$} & \multicolumn{2}{|c|}{ Fischer-Tropsch } & \multicolumn{2}{|l|}{ Methanol } & \multicolumn{4}{|c|}{ Mixed Alcohol } & \multirow{3}{*}{$\begin{array}{l}\text { Fermentation } \\
\text { Ethanol } \\
\text { Biological }\end{array}$} \\
\hline & Olefins $+\mathrm{CO}_{2}$ & Paraffins $+\mathrm{H}_{2} \mathrm{O}$ & Methanol & Methanol & \multicolumn{4}{|c|}{ Mixture of ethanol and higher alcohols } & \\
\hline & $\mathrm{Fe}$ & Co & 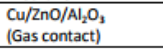 & $\begin{array}{l}\mathrm{Cu} / \mathrm{ZnO} \\
\text { (Liquid contact) }\end{array}$ & $\begin{array}{l}\text { Alkali//Cu } \\
/ / 2 n O\left(\mathrm{Al}_{2} \mathrm{O}_{3}\right)\end{array}$ & $\begin{array}{l}\text { Alkali/ZnO } \\
/ \mathrm{Cr}_{2} \mathrm{O}_{3} \\
\end{array}$ & $\begin{array}{l}\text { Alkali/CuO } \\
\text { /CoO }\end{array}$ & Alkali/MoS 2 & \\
\hline Temp ("C) & $300-350$ & $200-250$ & $220-275$ & $225-265$ & $275-310$ & $300-425$ & $260-340$ & $260-350$ & $20-40$ \\
\hline Pressure (bar) & $20-40$ & $10-40$ & $50-100$ & 50 & $50-100$ & $125-300$ & $60-200$ & $30-175$ & $1-2$ \\
\hline $\mathrm{H}_{2} / \mathrm{CO}$ ratio & $0.6-1.7$ & Slightly $>2$ & Unimportant & & \multicolumn{4}{|l|}{$1-1.2$} & Not sensitive \\
\hline $\begin{array}{l}\left(\mathrm{H}_{2}-\mathrm{CO}_{2}\right) / \\
\left(\mathrm{CO}+\mathrm{CO}_{2}\right) \text { ratio }\end{array}$ & \multicolumn{2}{|l|}{ Unimportant } & Slightly $>2$ & Low ratios $\sim 0.68$ & \multirow{17}{*}{$\begin{array}{l}\text { Same as } \\
\text { methanol } \\
\text { (gaseous) }\end{array}$} & \multirow{17}{*}{$\begin{array}{l}\text { Same as } \\
\text { methanol } \\
\text { (gaseous) }\end{array}$} & \multirow{17}{*}{$\begin{array}{l}\text { Same as FT } \\
\text { (Co } \\
\text { catalyst) }\end{array}$} & Unimportant & Unimportant \\
\hline $\mathrm{CO}_{2}$ & \multicolumn{2}{|l|}{$<5 \%$} & \multicolumn{2}{|c|}{$\begin{array}{l}4-8 \% \text { (very slow reaction without any } \mathrm{CO}_{2} \text {, but } \\
\text { also inhibited if too much present) }\end{array}$} & & & & $\begin{array}{l}<5 \% \text { (avoid } \\
\text { promotion of } \\
\text { methanol) }\end{array}$ & Aids initial growth rates \\
\hline $\mathrm{H}_{2} \mathrm{O}$ & \multicolumn{2}{|c|}{$\begin{array}{l}\text { Low (slowly oxidises catalysts, } \\
\text { very large amounts inhibit Fe } \\
\text { based FT synthesis) }\end{array}$} & \multicolumn{2}{|c|}{$\begin{array}{l}\text { Low (excessive amounts block active sites, } \\
\text { reducing activity but increasing selectivity) }\end{array}$} & & & & \multirow{8}{*}{$\begin{array}{l}\text { Same as } \mathrm{FT} \\
\text { (Co catalyst) }\end{array}$} & $\begin{array}{l}\text { Most reactors use an } \\
\text { aqueous solution }\end{array}$ \\
\hline Hydrocarbons & \multicolumn{2}{|c|}{$\begin{array}{l}\text { Recycle to produce smaller } \\
\text { molecules (to improve efficiency) }\end{array}$} & \multicolumn{2}{|c|}{$\begin{array}{l}\text { Recycle to produce smaller molecules (to } \\
\text { improve efficiency) }\end{array}$} & & & & & None \\
\hline $\mathrm{C}_{2} \mathrm{H}_{2}$ & & & Low (inert) & $<5 p p m v$ & & & & & Unknown \\
\hline $\mathrm{CH}_{6}$ & \multicolumn{2}{|l|}{$<2 \%$ (inert) } & \multicolumn{2}{|l|}{ Low (inert) } & & & & & Low (inert) \\
\hline $\mathrm{N}_{2}$ & \multicolumn{2}{|l|}{ Low (inert) } & \multicolumn{2}{|l|}{ Low (inert) } & & & & & Low (inert) \\
\hline $\mathrm{HCN}$ & \multirow{2}{*}{\multicolumn{2}{|c|}{$\begin{array}{l}<10 \mathrm{ppb} \text { (poison) } \\
<10 \mathrm{ppb} \text { (poison) }\end{array}$}} & \multirow{2}{*}{\multicolumn{2}{|c|}{$\begin{array}{l}<10 \mathrm{ppb} \text { (poison) } \\
<10 \mathrm{ppb} \text { (poison) }\end{array}$}} & & & & & Unknown \\
\hline $\mathrm{NH}_{3}$ & & & & & & & & & Can help organism growth \\
\hline No. & \multicolumn{2}{|c|}{$<100 \mathrm{ppb}$ (poison) } & \multicolumn{2}{|l|}{$<100 \mathrm{ppb}$ (poison) } & & & & & $\begin{array}{l}\text { <40ppmv, since >150ppmv } \\
\text { inhibits bacterial enzymes }\end{array}$ \\
\hline $\begin{array}{l}\text { Sulphur } \\
\left.\text { (COS, } \mathrm{H}_{2} \mathrm{~S}, \mathrm{CS}_{2}\right)\end{array}$ & $\begin{array}{l}<100 p p b \\
\text { (most } \\
\text { important } \\
\text { poison) }\end{array}$ & $\begin{array}{l}<60 \mathrm{ppb} \text { (most } \\
\text { important } \\
\text { poison) }\end{array}$ & \multicolumn{2}{|c|}{$\begin{array}{l}<100 \mathrm{ppb} \text { (poison, permanent activity loss) } \\
\text { coS only a poison in liquid phase } \\
\mathrm{Zn} \text { can scavenge } 0.4 \% \text { of its weight in } \mathrm{S} \text { while } \\
\text { maintaining } 70 \% \text { activity }\end{array}$} & & & & $\begin{array}{l}\text { Resistant, } \\
\text { 50-100ppmv } \\
\text { is actually } \\
\text { needed }\end{array}$ & $\begin{array}{l}\text { Tolerant (up to } 2 \% \mathrm{H}_{2} \mathrm{~S} \text { ), } \\
\text { since } \mathrm{S} \text { can help certain } \\
\text { organisms' growth }\end{array}$ \\
\hline $\begin{array}{l}\text { Halides } \\
\text { (HCl, Br, F) }\end{array}$ & \multicolumn{2}{|c|}{$\begin{array}{l}\text { <10ppb (poison, can lead to } \\
\text { structural changes in the catalyst) }\end{array}$} & $\begin{array}{l}\text { <1ppb (poison, leads } \\
\text { to sintering) }\end{array}$ & $\begin{array}{l}<10 \mathrm{ppb} \text { (poison, leads } \\
\text { to sintering) }\end{array}$ & & & & \multirow{5}{*}{$\begin{array}{l}\text { Same as } \mathrm{FT} \\
\text { (Co catalyst) }\end{array}$} & $\begin{array}{l}\text { Should be removed, } \\
\text { although some organisms } \\
\text { tolerant to Cl compounds }\end{array}$ \\
\hline $\begin{array}{l}\text { Alkali metals } \\
(\mathrm{Na}, \mathrm{K})\end{array}$ & \multicolumn{2}{|c|}{$\begin{array}{l}<10 \mathrm{ppb} \text { (promotes mixed alcohol } \\
\text { reaction) }\end{array}$} & \multicolumn{2}{|c|}{$\begin{array}{l}\text { Low (avoid due to promotion of mixed alcohol } \\
\text { reaction) }\end{array}$} & & & & & Unknown \\
\hline Tars & \multirow{2}{*}{\multicolumn{2}{|c|}{$\begin{array}{l}\text { Concentration below dew point } \\
\text { (otherwise condense on surfaces) }\end{array}$}} & \multicolumn{2}{|c|}{$\begin{array}{l}\text { Concentration below dew point (otherwise tars } \\
\text { will condense on catalyst and reactor surfaces) }\end{array}$} & & & & & $\begin{array}{l}\text { Must be removed }- \text { similar } \\
\text { requirements to FT }\end{array}$ \\
\hline Particulates & $<0.1 \mathrm{ppm}$ & & $<0.1 \mathrm{ppm}$ & $<0.1 \mathrm{ppm}$ & & & & & Must be removed \\
\hline Particulate size & $<2 \mu \mathrm{m}$ & & Unknown & Low & & & & & Must be removed \\
\hline $\begin{array}{l}\text { Other trace } \\
\text { species: }\end{array}$ & Unimportant & & $\begin{array}{l}\text { Avoid: As, } \mathrm{P}, \mathrm{Pb} \text { (lowe } \\
\text { heavy metals), Co (for } \\
\mathrm{SiO}_{2} \text { (promotes wax w } \\
\mathrm{Al}_{2} \mathrm{O}_{3} \text { (promotes DME) }\end{array}$ & $\begin{array}{l}\text { ctivity, as with other } \\
\text { CH4, activity reduced), } \\
\text { h surface area loss), free } \\
\text { Ni and fe (promote FT) }\end{array}$ & & & & $\begin{array}{l}\text { Co (beneficial } \\
\text { methanol to } \\
\text { ethanol } \\
\text { conversion) }\end{array}$ & Must be removed \\
\hline
\end{tabular}

Figura 1.20. Requerimientos del gas de gasificación para proceso Fisher-Tropsch, metanol, etanol y mezclas de alcohol [102].

La utilización del gas de gasificación a nivel mundial puede observarse en la Figura 1.21. En esta figura se muestra el uso final del gas en el año 2015 para diferentes aplicaciones: fabricación de productos químicos, producción de combustibles líquidos, producción de combustibles gaseosos y producción eléctrica. El $65 \%$ del gas de gasificación producido se emplea para la fabricación de productos químicos, $19 \%$ para combustibles líquidos, el $10 \%$ para combustibles gaseosos y el $6 \%$ restante para producción de energía eléctrica. No obstante, las previsiones de aumento para el año 2017 también vienen recogidas, al igual que los planes futuros de ampliación hasta el año 2020. Estas previsiones indican un aumento significativo de la producción de combustibles gaseosos y productos químicos.

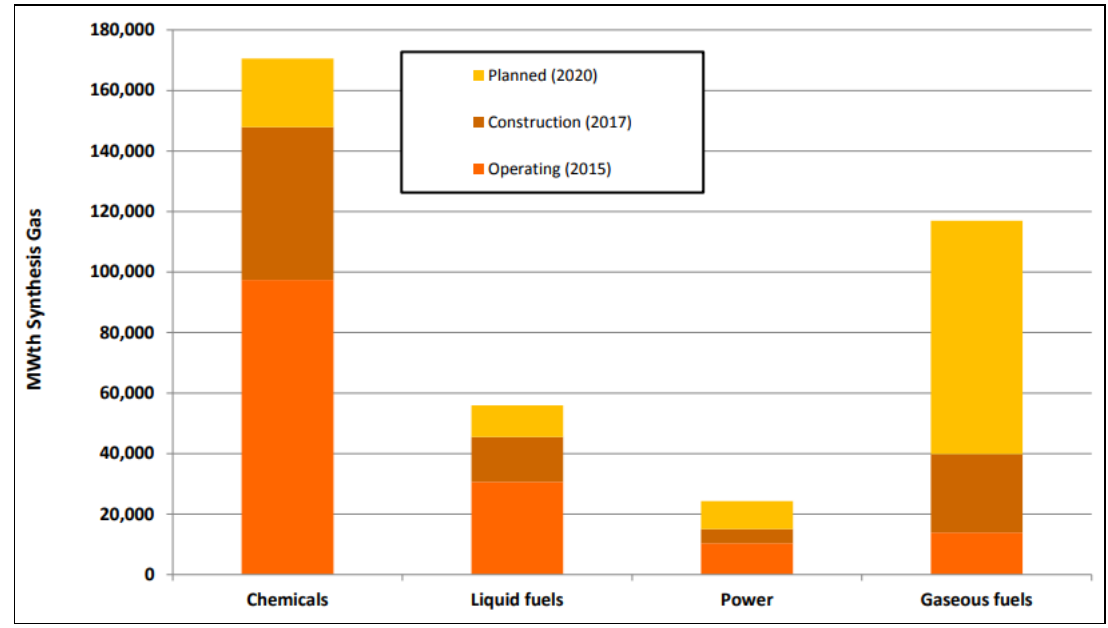

Figura 1.21. Aplicaciones del gas a nivel mundial [97]. 


\subsubsection{GASIFICACIÓN DE CDR/CSR}

El aprovechamiento de residuos para valorización energética se ha incrementado a medida que las restricciones medioambientales han aumentado en severidad. Esto ha resultado en un aumento en la investigación sobre residuos sólidos [104]. Los residuos sólidos comenzaron a considerarse combustibles a partir de la aparición del término CDR, para hacer referencia a los RSU homogeneizados y tratados [43]. Sin embargo, este término se ha empleado para englobar a residuos de muy diversa procedencia: RSU, residuos industriales, lodos de depuradora, residuos de biomasa, etc. Actualmente, la Unión Europea ha desarrollado un sistema de clasificación de los combustibles de origen residual, bajo el término CSR, siendo el origen de estos residuos: RSU, comercial e industrial [56].

Aunque tradicionalmente se utiliza la incineración para la recuperación energética de residuos $[57,58,105]$, el aprovechamiento de residuos en procesos de gasificación data de los años 80 [106]. Actualmente, la recuperación energética de residuos mediantes procesos de gasificación, ha experimentado un auge con las nuevas reglamentaciones medioambientales, ya que permite reducir el volumen de residuos eliminados vía vertedero o incineración. Además, la gasificación es más atractiva que la incineración al producir una menor contaminación, ser más eficiente y generar un gas limpio y transportable $[15,96]$.

En la literatura se pueden encontrar muchos trabajos publicados sobre gasificación de residuos a nivel laboratorio $[64,7,63,107,108]$ o planta piloto $[12,109,110]$ empleando CSR como combustible en lechos fluidizados, sin embargo, pocos de estos trabajos corresponden al empelo de gasificadores de LFC. La mayor parte de las investigaciones se llevaron a cabo en reactores alotérmicos a nivel laboratorio [63] o a escala piloto [111, 112, 113], sin embargo, a escala piloto en condiciones autotérmicas se encuentra menos información, reactor en operación autotérmica con CDR [114].

Aunque existen multitud de estudios sobre la aplicación de residuos en gasificación de lechos fluidizados, solamente unos pocos hacen referencia al empleo de residuos de la industria papelera. La mayor parte de las investigaciones se centran en la gasificación de lodos de papelera $[113,115,116]$. Sin embargo, otros estudios, emplearon mezclas de rechazos y lodo de destintado de papelera junto con astillas para su co-gasificación en un gasificador de flujo descendente [117].

Actualmente se dispone de varias plantas que operan con residuos, ver Tabla 1.5. La planta Kymijärvi II situada en Lathi (Finlandia) fue la primera en operar con CSR para producción de energía eléctrica y calor en el año 2012. El CSR está formado por plásticos, madera y residuos de papel, cuya procedencia es residuo comercial, doméstico e industrial. Esta planta dispone de gasificadores de lecho fluidizado. La cantidad de combustible empleado, CSR y madera, es de 250.000 Ton/año, equivalente a 170.000 Ton/año de carbón. No obstante, en la planta Kymijärvi I ya se había utilizado CSR como combustible auxiliar con carbón desde 1998. A parte de esta planta, la planta de M\&W en Lanark (Escocia) utiliza gasificadores de lecho fluidizado para obtención de electricidad a partir de CDR. 


\begin{tabular}{|c|c|c|c|}
\hline Planta & Localización & Combustible & Producto final \\
\hline $\begin{array}{l}\text { Kymijärvi II, } 160 \\
\text { MW }\end{array}$ & Lathi (Finlandia) & $\begin{array}{l}\text { CSR y madera } \\
(250000 \text { Ton/año) }\end{array}$ & $\begin{array}{l}\text { Electricidad y } \\
\text { calefacción }\end{array}$ \\
\hline Bilsthorpe plant & $\begin{array}{l}\text { Nottinghamshire } \\
\text { (Reino Unido) }\end{array}$ & Residuos & Electricidad \\
\hline $\begin{array}{l}\text { Energy Works } \\
\text { Hull, } 28 \mathrm{MW}\end{array}$ & $\begin{array}{l}\text { Hull, Esat Yorkshire } \\
\text { (Reino Unido) }\end{array}$ & Residuos & Electricidad \\
\hline $\begin{array}{l}\text { GreenSky London } \\
\text { Solena }\end{array}$ & $\begin{array}{l}\text { Londres (Reino } \\
\text { Unido) }\end{array}$ & $\begin{array}{l}\text { Residuos } \\
\text { (575000 Ton/año) }\end{array}$ & $\begin{array}{l}120000 \text { Ton/año } \\
\text { de combustible } \\
\text { para aviación }\end{array}$ \\
\hline $\begin{array}{l}\text { M\&W WTE } \\
\text { Gasification } \\
\text { Project, } 12.5 \mathrm{MW}\end{array}$ & Lanark (Escocia) & $\begin{array}{l}\text { CDR } \\
\text { (RSU) } \\
(40000 \text { Ton/año) }\end{array}$ & Electricidad \\
\hline $\begin{array}{l}\text { Tees Valley } \\
\text { Renewable Energy } \\
\text { Facility, } 200 \mathrm{MW}\end{array}$ & $\begin{array}{l}\text { Teesside/Billingham } \\
\text { (Reino Unido) }\end{array}$ & $\begin{array}{l}\text { RSU } \\
\text { (700000 Ton/año) }\end{array}$ & Electricidad \\
\hline $\begin{array}{l}\text { Bombardier } \\
\text { Aerospace, } 14.85 \\
\text { MW }\end{array}$ & Belfast (Irlanda) & $\begin{array}{l}\text { Residuos } \\
\text { domésticos y } \\
\text { comerciales } \\
(180000 \text { Ton/año) }\end{array}$ & $\begin{array}{l}\text { Electricidad y } \\
\text { calefacción) }\end{array}$ \\
\hline $\begin{array}{l}\text { Green3Power } \\
\text { WTL Plant }\end{array}$ & $\begin{array}{l}\text { St. Lucie County, } \\
\text { California (USA) }\end{array}$ & $\begin{array}{l}\text { RSU } \\
(1000 \text { Ton/d) }\end{array}$ & $\begin{array}{l}\text { Combustible } \\
\text { líquido (diésel) }\end{array}$ \\
\hline $\begin{array}{l}\text { ICM/JUM } \\
\text { Gasification } \\
\text { Demonstration }\end{array}$ & California (USA) & $\begin{array}{l}\text { Residuo biomásico } \\
(10 \mathrm{~T} / \mathrm{d})\end{array}$ & Gas de síntesis \\
\hline $\begin{array}{l}\text { Lake County } \\
\text { Waste-to-Ethanol }\end{array}$ & $\begin{array}{l}\text { Lake County, } \\
\text { Indiana (USA) }\end{array}$ & $\begin{array}{l}\text { RSU } \\
(10 \mathrm{~T} / \mathrm{d}) \\
\end{array}$ & Etanol \\
\hline $\begin{array}{l}\text { Sierra BioFuels } \\
\text { Plant }\end{array}$ & $\begin{array}{l}\text { McCarran, Storey } \\
\text { County, Nevada } \\
\text { (USA) }\end{array}$ & $\begin{array}{l}\text { RSU (200000 } \\
\text { Ton/año) }\end{array}$ & $\begin{array}{l}\text { Combustibles } \\
\text { líquidos (diésel y } \\
\text { queroseno) }\end{array}$ \\
\hline $\begin{array}{l}\text { Lebanon WTE } \\
\text { Gasification } \\
\text { Project }\end{array}$ & $\begin{array}{l}\text { Lebanon, Tennessee } \\
\text { (USA) }\end{array}$ & $\begin{array}{l}\text { Residuos de } \\
\text { madera, trozos de } \\
\text { goma, lodos de } \\
\text { sumideros } \\
(64 \text { Ton } / d)\end{array}$ & $\begin{array}{l}\text { Electricidad } \\
(300 \mathrm{~kW})\end{array}$ \\
\hline
\end{tabular}

Tabla 1.5. Plantas de gasificación de residuos operativas en 2016 [98].

\subsubsection{SUBPRODUCTOS}

El gas de gasificación genera una serie de subproductos como: partículas sólidas, alquitranes, hollín, compuestos nitrogenados, sulfuro de hidrógeno, cloruro de hidrógeno, compuestos alcalinos y cenizas. En función del uso final del gas de gasificación será necesario un determinado grado de limpieza del gas, reduciendo la posible formación de estos subproductos o eliminándolos completamente mediante medidas de abatimiento de contaminantes. Respecto a las cenizas, la concentración de metales en las cenizas dependerá del combustible gasificado (residuos, biomasa, carbón, etc.), siendo necesario su tratamiento y posterior eliminación mediante vertedero controlado. 
El resto de subproductos se analizan en continuo en cualquier proceso de gasificación de manera que pueda controlarse la calidad del gas obtenido. Sin embargo, el subproducto más perseguido en el proceso de gasificación es el alquitrán, ya que su producción limita el uso final del gas de gasificación en diversas aplicaciones.

\subsubsection{Alquitranes}

\subsection{Introducción}

La mezcla de alquitranes presentes en el gas de proceso es uno de los subproductos que se forman durante la gasificación. Cuando la mezcla de alquitranes se enfría por debajo de su temperatura de rocío, se genera un líquido denso y viscoso, que puede llegar a solidificarse. La temperatura de rocío se alcanza cuando la presión parcial de la mezcla de alquitranes se iguala a la presión de saturación, la cual se estima mediante modelos, ya que es una mezcla de componentes compleja [118]. La principal desventaja de la formación de alquitranes en el proceso radica en la posible obstrucción de equipos que puede producir. Estas obstrucciones se deben a que condensan en las partes internas de los equipos: tuberías, filtros, motores, etc.

En la literatura se pueden encontrar diversas definiciones para el término alquitrán, aunque en este estudio se empleará como referencia la dada por en el Comité Europeo de Normalización (CEN), en su guía para el muestreo y análisis de los alquitranes y partículas en gases de proceso, donde define a los alquitranes como: "término genérico e inespecífico para la entidad de todos los compuestos orgánicos presentes en un gas producto de gasificación excluyendo los hidrocarburos gaseosos (C1 al C6)" [119]. Algunos autores consideran al benceno un alquitrán, algo que no contempla la anterior definición. Su inclusión es debida a su categorización como sustancia cancerígena por la Agencia de Protección Medioambiental [120] y a los problemas que genera en aplicaciones posteriores del gas de proceso como puede ser en una posterior conversión catalítica del gas [121].

La formación de alquitranes se produce durante la despolimerización, en la etapa de pirólisis, formándose los denominados alquitranes primarios, que están formados por moléculas condensables, orgánicas y oxigenadas [82, 122]. Los alquitranes primarios experimentan reacciones adicionales de reformado, craqueo, oxidación y polimerización, formándose a temperaturas superiores a $500^{\circ} \mathrm{C}$, gases ligeros no condensables y moléculas pesadas denominadas alquitranes secundarios, siendo los compuestos olefínicos y fenólicos sus más importantes constituyentes. El aumento de temperatura resulta en una destrucción de los alquitranes primarios, pero en una incipiente formación de alquitranes terciarios, compuestos poliaromáticos de gran tamaño, que se generan a temperaturas superiores a $750^{\circ} \mathrm{C}$.

\subsection{Clasificación}

Bajo el término alquitrán se engloban multitud de compuestos con gran variedad de propiedades físicas y químicas, por tanto, una simplificación se hace necesaria para su estudio. Además, la cantidad y composición de los alquitranes formados depende de factores tales como: tecnología de gasificación, combustible o condiciones de operación. Existen diferentes clasificaciones para los alquitranes que se van formando durante el proceso de gasificación, como la desarrollada por Milne y otros [122], basada en las condiciones de temperatura y de tiempo de residencia a la que se generaran los 
alquitranes. Esta clasificación divide los alquitranes en primarios, secundarios y terciarios. La segunda clasificación se basa en la estructura de las moléculas alquitranadas formadas, que distingue cinco clases diferentes de alquitranes [123].

La clasificación propuesta por Milne y Evans agrupa a los alquitranes en tres familias, ver Tabla 1.6, atendiendo a las condiciones que han dado lugar a su formación. La primera familia corresponde a las moléculas formadas tras la fragmentación del combustible, cuya estructura química es semejante al combustible original, formándose en la etapa de devolatilización del combustible. Estos compuestos tienen un tiempo de vida corto debido a su elevada reactividad, siendo prácticamente insignificantes a elevada temperatura o tiempo de residencia. La segunda y tercera familia está compuesta por moléculas aromáticas y por moléculas poliaromáticas, respectivamente.

\begin{tabular}{|l|l|}
\hline Familia & Compuestos representativos \\
\hline Primarios & Ácido propanoico, ácido benzoico \\
\hline Secundarios & Ciclopentadieno, estireno, cresoles \\
\hline Terciarios & Benceno, naftaleno, fenantreno, pireno \\
\hline
\end{tabular}

Tabla 1.6. Clasificación de compuestos representativos por familias [122].

Por otro lado, la clasificación propuesta por Van Paasen y Kiel divide a los alquitranes en cinco grupos en función del número de anillos aromáticos de cada molécula, ver Tabla 1.7. Esta clasificación permite detectar fácilmente las características de condensación o solubilidad del gas que los contiene. Los alquitranes que no pueden detectarse por cromatografía de gases, bien por su peso molecular o por su elevada polaridad, se engloban en la clase 1, requiriendo un análisis gravimétrico para su estimación. La presencia en esta agrupación, clase 1, de compuestos con una elevada polaridad, puede afectar a las estimaciones sobre solubilidad en agua de la mezcla, y la presencia de compuestos de elevado peso molecular no cuantificables por cromatografía, puede afectar a la estimación del punto de rocío, subestimándolo.

\begin{tabular}{|l|l|}
\hline Clase & Descripción \\
\hline Clase I & No detectables por cromatografía gaseosa (columna no-polar) \\
\hline Clase II & Compuestos heteroatómicos \\
\hline Clase III & Aromáticos de 1 anillo excluyendo al benceno \\
\hline Clase IV & Aromáticos de $2-3$ anillos \\
\hline Clase V & Aromáticos de 4-7 anillos \\
\hline
\end{tabular}

Tabla 1.7. Clasificación por clases [123].

\subsection{Propiedades}

En función de sus características los alquitranes se pueden dividir en cuatro grupos:

- BTEX: El acrónimo BTEX hace referencia a benceno, tolueno, etilbenceno y xilenos, ver Figura 1.22. Son compuestos volátiles que pueden utilizarse en motores y en turbinas, ya que aumentan el poder calorífico. Sin embargo, son compuestos tóxicos, como el benceno que es cancerígeno. 


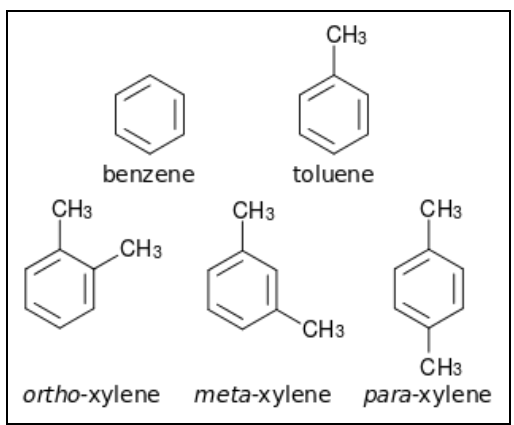

Figura 1.22. Estructura de los BTEX.

- PAHs: Son hidrocarburos aromáticos policíclicos formados por condensados de dos o más anillos de benceno. Son compuestos planos con elevados puntos de fusión y bajas presiones de vapor. Son sustancias bastante estables, por tanto, se engloban dentro de los compuestos orgánicos persistentes. A pesar de que su toxicidad depende de su estructura, se pueden considerar genotóxicos (mutagénicos o carcinogénicos). La EPA ha designado como contaminantes prioritarios los 16 PAH's, cuyas estructuras se muestran en la Figura 1.23.

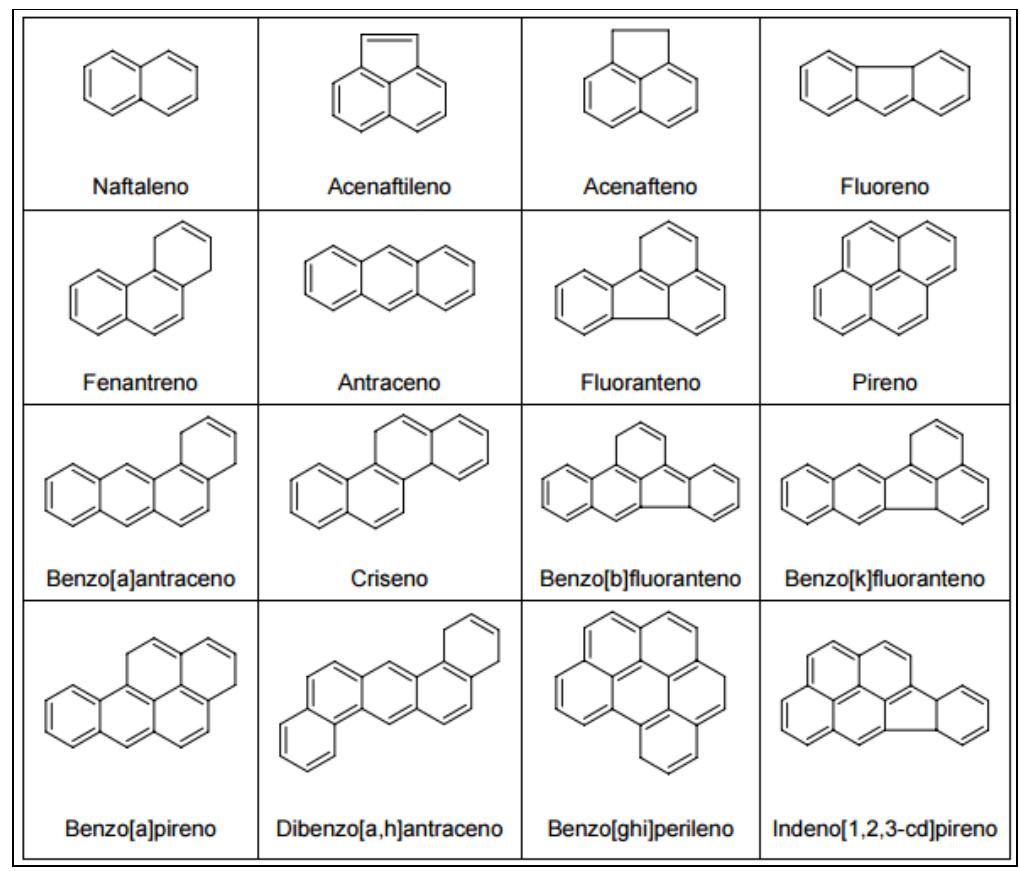

Figura 1.23. Estructura de los 16 PAH's de la EPA.

- Fenoles: Son compuestos aromáticos con al menos un grupo hidroxilo, ver Figura 1.28. La importancia en la determinación de estos compuestos se debe a que son corrosivos para los motores de combustión interna y tóxicos, que unidos a su solubilidad en agua puede originar contaminación en las aguas.

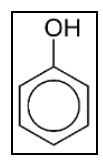

Figura 1.24. Estructura del fenol. 
- Otros compuestos: Son los compuestos nitrogenados, es decir: aminas, amidas o nitrilos.

\subsection{Determinación}

La determinación de alquitranes en el gas de gasificación puede realizarse a través de la especificación técnica CEN/TS 15439:2006. Es un método discontinuo, que consiste en la absorción de los alquitranes en isopropanol para su posterior análisis por GC-MS. Análogamente, existe la posibilidad de emplear adsorbentes en fase sólido (SPA), que es al igual que el anterior un método discontinuo. Las metodologías en continuo se hallan en un grado de desarrollo menor. Se basan en la medida del punto de rocío o en la detección de ionización de llama (FID) [124].

\subsubsection{Hollín}

El principal mecanismo de conversión térmica de los alquitranes, principalmente PAHs, incluso en presencia de vapor, es la formación de hollín. Su formación es idéntica a los mecanismos de formación de PAHs seguido de un proceso de coagulación, ya que se produce una adsorción con partículas finas, ver Figura 1.29.

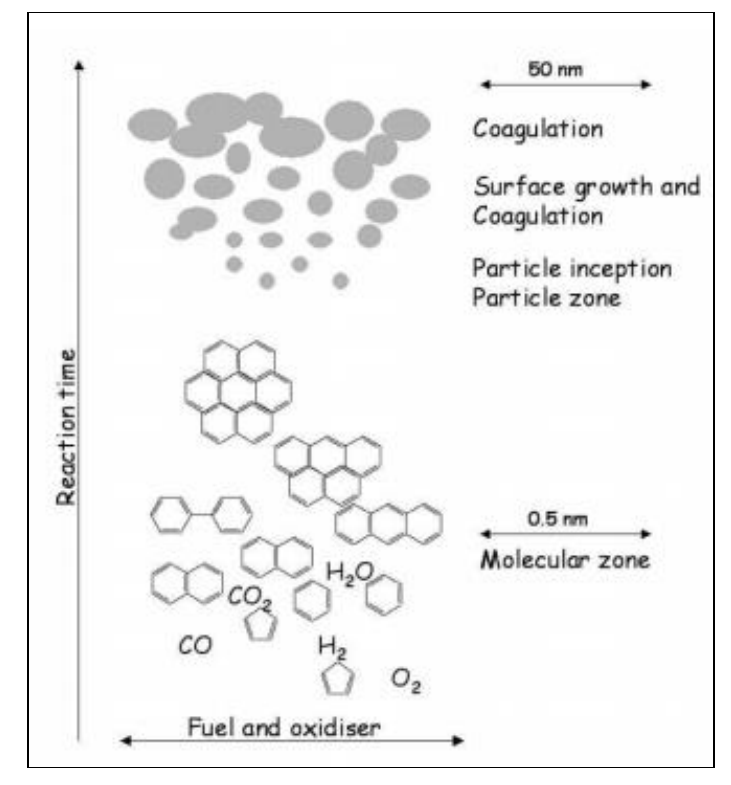

Figura 1.25. Ruta de formación del hollín [125].

\subsubsection{Medidas de reducción de alquitranes}

La reducción del contenido de alquitranes en las instalaciones de gasificación puede realizarse de dos formas completamente diferentes: eliminación de alquitranes de la corriente gaseosa y conversión por reformado o craqueo. La reducción del contenido de alquitranes se realiza a través de dos métodos diferenciados, métodos primarios, aquellos que se implementan en el interior del gasificador, y métodos secundarios, aquellos que se llevan a cabo aguas abajo del proceso de gasificación. La conversión por reformado y craqueo puede realizarse en diferentes ubicaciones de la instalación, es decir: aguas abajo mediante los denominados métodos secundarios y en el interior del reactor a través de los denominados métodos primarios. 
Los métodos primarios se desarrollan in situ, es decir en el interior del propio gasificador, resultando atractivos, ya que se reduce el coste económico de manera considerable en comparación con los métodos secundarios. Sin embargo, su eficacia como método de reducción de alquitranes se encuentra en fase de investigación.

Los métodos primarios, tienen como objeto la reducción del contenido de alquitranes, de manera que se siga obteniendo un gas de proceso con una calidad adecuada, en base a la optimización en el funcionamiento del gasificador mediante modificaciones en el diseño y cambios en las condiciones de operación. Los métodos primarios empleados se clasifican de la siguiente manera:

- Modificación de las condiciones de operación

- Empleo de aditivos en operación

- Re-diseño del gasificador

La selección del tipo de gasificador va a determinar la posibilidad de emplear una mayor o menor variedad de medidas primarias que permitan la reducción del contenido en alquitranes del gas de proceso generado.

Las modificaciones en el diseño del gasificador suelen estar blindadas de antemano, ya que la selección del gasificador se realiza en base a aspectos tales como: aplicación final del gas, tipo de combustible, etc. Las modificaciones en el gasificador son mínimas pudiéndose actuar sobre el freeboard con la incorporación de entradas secundarias o terciarias de aire durante el proceso de gasificación.

Una de las medidas primarias que se ha mostrado más efectiva es el uso de aditivos que catalicen el gas formado durante el proceso de gasificación, implementándose para algunos tipos de tecnologías como las de fluidización [227]. Sin embargo, las opciones más habituales de implementación de medidas primarias se basan en la modificación de las condiciones de operación, modificándose tiempos de residencia, perfiles de temperatura, etc.

Los métodos secundarios son aquellos que se realizan aguas abajo del gasificador. Estos métodos secundarios son aplicables para exigencias de limpieza de gas elevadas, ya que su excesivo coste reduce su posibilidad de uso. Estos métodos son efectivos, bien de manera individual o complementando a métodos primarios de reducción de alquitranes. Los métodos secundarios se subdividen en: reformado y craqueo de alquitranes, eliminación mecánica de alquitranes y eliminación física de alquitranes [126]. Dentro de los métodos de reformado y craqueo se dispone de craqueo térmico, craqueo térmico mejorado con plasma y craqueo catalítico. En el caso de métodos de eliminación física de alquitranes se emplean precipitadores electrostáticos, ciclones, filtros, separadores de partículas giratorios y lavadores. 


\section{CAPÍTULO II. MATERIALES Y MÉTODOS}

\subsection{INTRODUCCIÓN}

Las instalaciones empleadas durante el desarrollo de la presente tesis se encuentran situadas en el Centro de Desarrollo de Energías Renovables (CE.D.E.R.), sito en la salida 56 de la autovía de Navarra A-15. Este centro pertenece al Centro de Investigaciones Energéticas, Medioambientales y Tecnológicas (CIEMAT). Entre los diversos laboratorios e instalaciones existentes en el CEDER se han empleado en este estudio: planta piloto de peletización, gasificador de lecho fluidizado circulante, gasificador de lecho fluidizado burbujeante, modelo de unidad circulante a temperatura ambiente y modelo de válvula no-mecánica tipo "loop-seal" a temperatura ambiente.

En este capítulo se describen las instalaciones que han sido utilizadas de manera pormenorizada y los procedimientos operacionales llevados a cabo durante la experimentación. Además, se adjunta una descripción de los combustibles empleados, ya que su caracterización química y física se explica con mayor profundidad en el capítulo III, en las plantas piloto de gasificación de lecho fluidizado, así como la caracterización del material de lecho empleado en ambas plantas piloto.

\subsection{MATERIALES A ESTUDIO}

En este estudio se han empleado residuos de procedencia doméstica e industrial. Los residuos domésticos son residuos sólidos urbanos y rechazos de la clasificación y selección de envases, provenientes de una planta de tratamiento de residuos sólidos; mientras que los residuos industriales son rechazos del proceso de clasificación de papel recuperado, papelote, y del proceso de pulpado, los cuales se observan en la Figura 2.1, y lodos, generados ambos residuos en una fábrica de papel prensa reciclado a partir de papel recuperado.

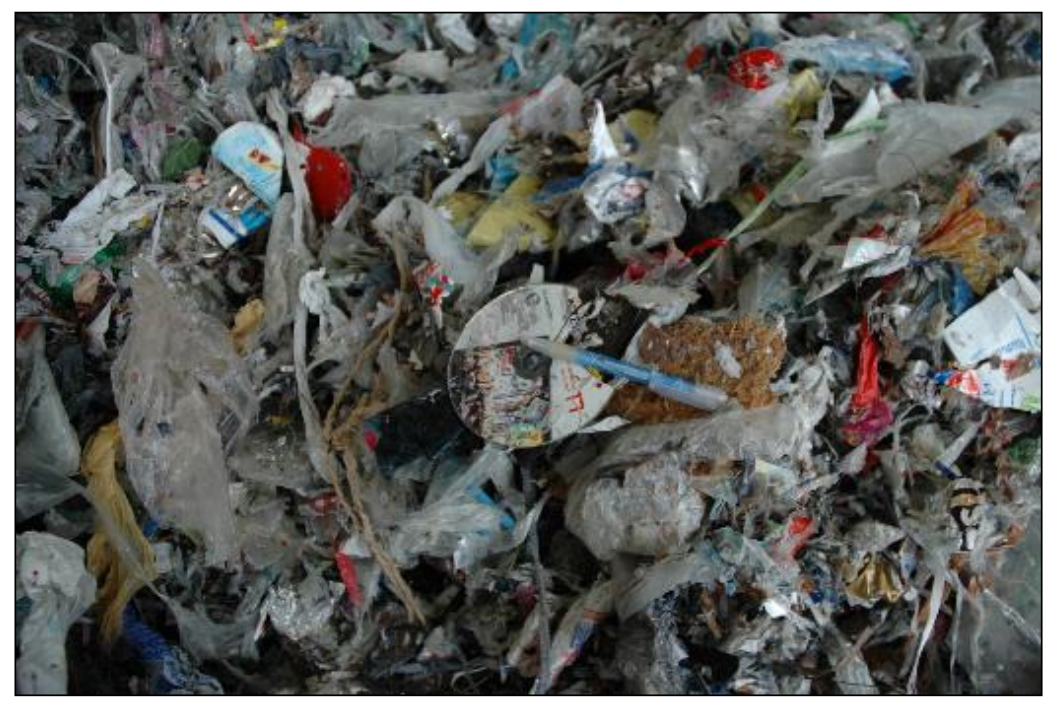

Figura 2.1. Rechazo de la clasificación de papelote y del proceso de pulpado. 


\subsubsection{DOMÉSTICOS}

La Comunidad Foral de Navarra, dispone de centros de gestión y tratamiento de residuos sólidos urbanos repartidos en las diferentes Mancomunidades en las que se divide su territorio. El área de estudio corresponde a la Mancomunidad de RSU de la Ribera Baja, que engloba un total de diecinueve municipios, con una población aproximada de 90.000 habitantes. Además, la planta recibe residuos de otras zonas (Ribera Alta, Mairaga, Valdizarbe, Sangüesa, Sakana, Irati, Bidausi, Eca-Salazar, Mendialdea y Alto Araxes) con una población de 116.248 habitantes.

El complejo de tratamiento de residuos, que opera para la Mancomunidad de residuos sólidos de la Ribera Baja de Navarra, es el suministrador del material de partida, objeto del estudio. Este complejo consta de una planta de selección de residuos de envases (plástico, papel y cartón, metales, bricks, etc.), un vertedero controlado de residuos y una planta de tratamiento de materia orgánica (biometanización). La planta de tratamiento de residuos genera cuatro corrientes residuales de manera independiente:

- Corriente de rechazo de la selección de la fracción orgánica y resto, denominada comúnmente como rechazo de la fracción orgánica.

- Corriente de rechazo de la selección y clasificación de envases, denominada rechazo de envases.

- Corriente de plástico mixto de la selección y clasificación de envases, denominada rechazo mixto de envases.

- Film recuperado en la selección y clasificación de envases, compuesto principalmente de polietileno (PE).

La generación media de residuos sólidos urbanos en la Mancomunidad de la Ribera Baja es de 36.000 T/año. La cantidad total anual de rechazos durante el procesamiento de los residuos sólidos urbanos y de la selección y clasificación de envases que se genera en la Mancomunidad es de 18.000 T/año, por tanto la evaluación de las posibilidades energéticas de los residuos generados anualmente cobra un gran interés.

El aprovechamiento de fracciones resto de procesos de selección y clasificación, que tienen elevados valores de poder calorífico, es una opción a considerar para la producción de combustibles derivados de residuos. Las cantidades de residuos generados durante la anualidad 2011, correspondientes a cada una de las corrientes residuales que se han nombrado anteriormente, se muestran en la Tabla 2.1.

\begin{tabular}{|l|c|c|}
\hline \multicolumn{1}{|c|}{ Fracción } & Cantidad (T) & Composición (\%) \\
\hline $\begin{array}{l}\text { Rechazo de la selección de inertes de la } \\
\text { fracción orgánica y resto }\end{array}$ & 15.540 & 84,8 \\
\hline $\begin{array}{l}\text { Rechazo de la selección y clasificación } \\
\text { de envases }\end{array}$ & 1.350 & 7,4 \\
\hline $\begin{array}{l}\text { Plástico mixto de la selección y } \\
\text { clasificación de envases }\end{array}$ & 855 & 4,7 \\
\hline $\begin{array}{l}\text { Film recuperado en la selección y } \\
\text { clasificación de envases }\end{array}$ & 585 & 3,2 \\
\hline
\end{tabular}

Tabla 2.1. Corrientes residuales obtenidas en el complejo de tratamiento de residuos de la Mancomunidad de la Ribera Baja (Navarra). 
La corriente de rechazo de la fracción orgánica se genera en la planta de tratamiento de materia orgánica, que es una planta de tratamiento mecánico-biológico (TMB) con digestión anaerobia. El rechazo o material residual de entrada a la planta de tratamiento de residuo sólido consta fundamentalmente de materia orgánica y del resto recogidos en contenedor de RSU. En la fase previa, tratamiento mecánico, se separan de la materia orgánica, que se estabiliza mediante tratamiento biológico, dos fracciones.

La primera de las fracciones está formada por material inerte reciclable y la segunda compuesta por el material de rechazo de la selección de la materia orgánica, ver Figura 2.2, que consta principalmente de plásticos, textiles, papel y cartón, madera, resto de materia orgánica, etc.

La segunda fracción consta a su vez de dos fracciones con diferentes tamaños, una fracción con tamaños superiores a $80 \mathrm{~mm}$ y una fracción menor que se corresponde al film aspirado en el pretratamiento seco de la materia orgánica. Actualmente, ambas fracciones son prensadas en forma de balas y depositadas en vertedero.

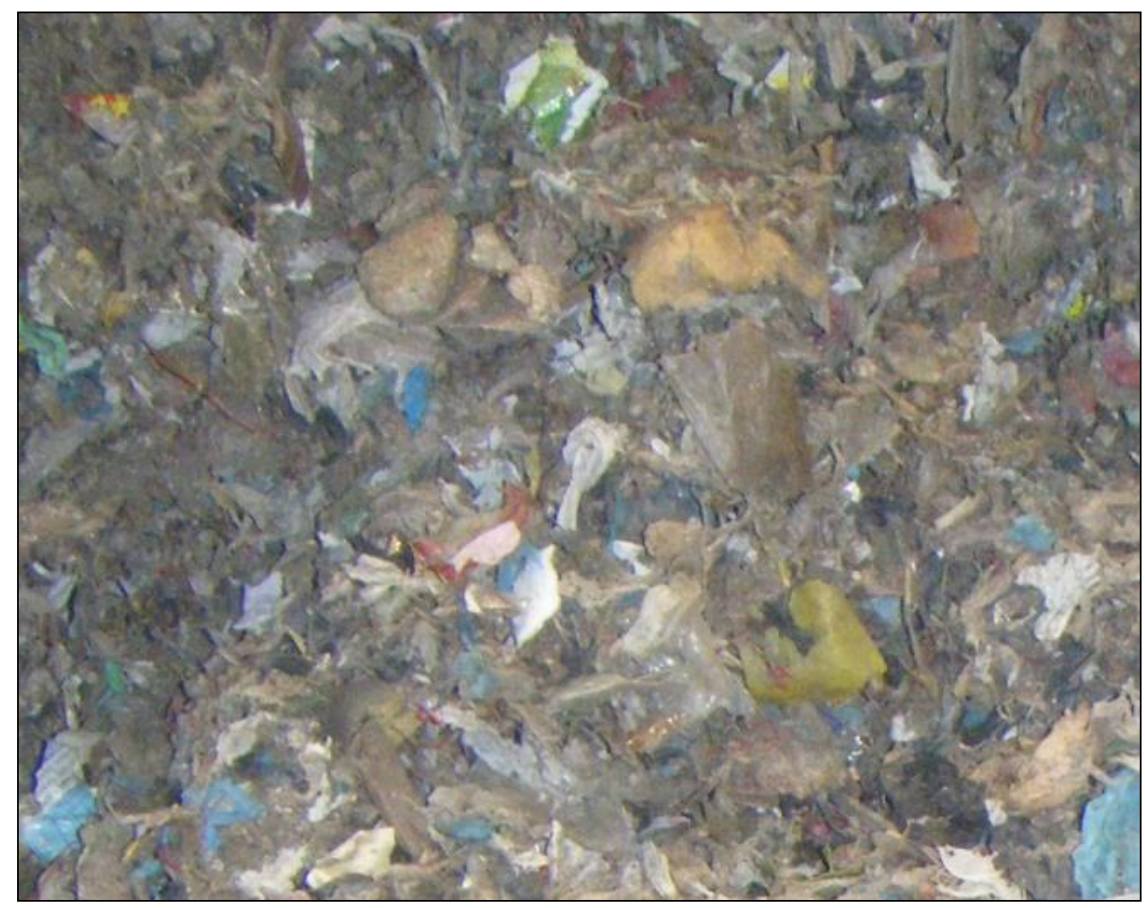

Figura 2.2. Corriente de rechazo de la selección de la materia orgánica en la planta de TMB.

Las corrientes de rechazo de la selección y clasificación de envases, de plástico mixto y el film recuperado se obtienen en la planta de selección y clasificación de envases. En esta planta se separan los materiales susceptibles de reciclaje, es decir: bricks, envases y latas. Estas fracciones residuales se gestionan mediante depósito en vertedero, ya que tanto la fracción rechazo y el film recuperado, no son reciclables, al igual que ocurre con la fracción de plástico mixto, compuesta principalmente por polipropileno (PP), poliestireno (PS) y poliestireno expandido (PSE), que tampoco es reciclable. Un esquema de la planta de TMB se muestra en la Figura 2.3. 


\section{ESQUEMA GENERAL DE FUNCIONAMIENTO PLANTA BIOMETANIZACION}

50.000 TON./AÑO RSU AL 60\% DE M.ORGANICA APROX.

PRETRATAMIENTO SECO

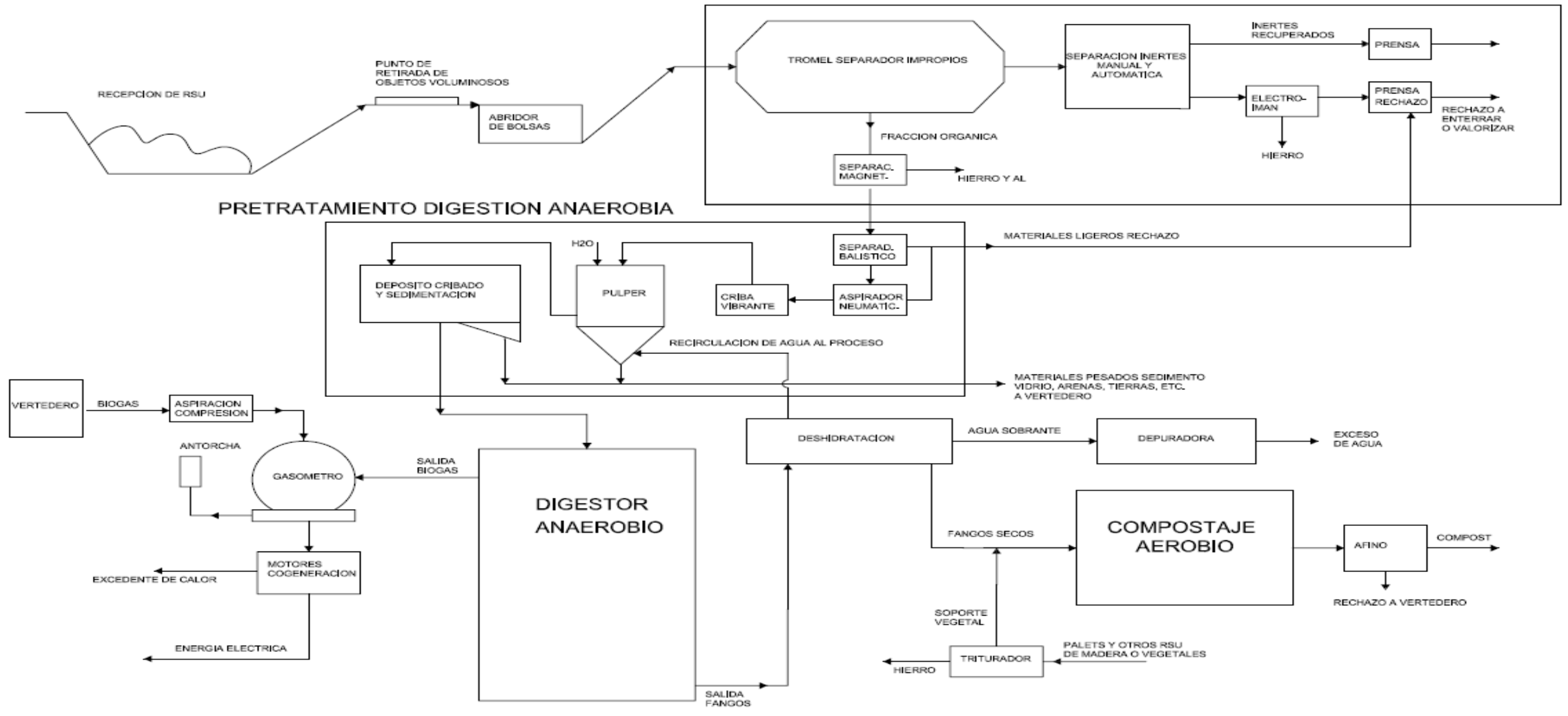

Figura 2.3. Planta de biometanización. 
La caracterización cuantitativa de la composición de los rechazos de la planta de tratamiento de residuos sólidos procedentes de la mancomunidad se realiza dividiendo las diferentes fracciones de las muestras en nueve categorías, ver figuras 2.2 y 2.3 :

- Material orgánico: compuesto de residuos orgánicos

- Madera

- Papel/Cartón: compuesto de papeles de periódico, revistas, papel de oficina, etc.

- Plástico: compuesto de envases y plásticos. Por ejemplo: Film, HDP, PVC, PP, PS, PET, etc.

- Vidrio: compuesto de vidrio incoloro y coloreado

- Metales: compuesto de metales ferrosos y no-ferrosos

- Textiles

- Briks

- Otros: compuestos por residuos finos de difícil catalogación, siendo una mezcla de las categorías mencionadas anteriormente.

\begin{tabular}{|l|c|c|}
\hline \multirow{2}{*}{ Material } & \multicolumn{2}{c|}{ Rechazo de la fracción orgánica } \\
\cline { 2 - 3 } & Cantidad (T) & Composición (\%) \\
\hline Materia orgánica & 2.374 & 15,3 \\
\hline Papel/Cartón & 7.533 & 48,5 \\
\hline Vidrio & 518 & 3,3 \\
\hline Film & 401 & 2,6 \\
\hline Metales & 118 & 0,8 \\
\hline PEAD & 478 & 3,1 \\
\hline PET & 536 & 3,5 \\
\hline Mezcla de plásticos & 1.158 & 7,5 \\
\hline Brik & 95 & 0,6 \\
\hline Otros (madera, textiles,...) & 2.327 & 15,0 \\
\hline
\end{tabular}

Tabla 2.2. Composición de la corriente de rechazo de la selección de inertes de la fracción orgánica y resto.

Los materiales reciclables de residuos de envases son separados mediante diversas técnicas. Inicialmente, un sistema de apertura de bolsas retira el film. Luego, un separador balístico divide los residuos en tres fracciones: componentes ligeros, componentes pesados y fracción fina, que se consideran rechazos.

Posteriormente, la fracción ligera es enviada a un triaje manual a través de seis contenedores para cartón, aluminio, PET, mezcla de plásticos, PE alta densidad coloreado y sin colorear.

Por otro lado, la fracción pesada se envía hacia un separador magnético donde se separan los materiales ferrosos. Los materiales no ferrosos son enviados a un sistema de separadores ópticos para obtener PET. De esta manera, se obtienen dos nuevas fracciones: mezcla de plástico y materiales no plásticos.

Los materiales no plásticos son separados mediante separadores de material no magnético y por triaje inverso. Respecto a la mezcla de plásticos, un separador óptico permite la selección de PE de alta densidad, coloreado y sin colorear. 
La tabla 2.3 muestra la composición de los rechazos de la planta de clasificación y selección de envases, siendo mayoritario el PE en forma de bolsas, film, y la mezcla de plásticos [127].

\begin{tabular}{|l|c|c|c|c|}
\hline \multirow{2}{*}{ Material } & \multicolumn{2}{|c|}{ Rechazo de envases } & $\begin{array}{c}\text { Plástico } \\
\text { mixto }\end{array}$ & Film \\
\cline { 2 - 5 } & $\begin{array}{c}\text { Cantidad } \\
\text { (T) }\end{array}$ & $\begin{array}{c}\text { Composición } \\
(\%)\end{array}$ & $\begin{array}{c}\text { Cantidad } \\
\text { (T) }\end{array}$ & $\begin{array}{c}\text { Cantidad } \\
\text { (T) }\end{array}$ \\
\hline $\begin{array}{l}\text { Materia } \\
\text { Orgánica }\end{array}$ & 68 & 5,0 & & \\
\hline Papel/Cartón & 211 & 15,6 & & \\
\hline Vidrio & 2 & 0,1 & & 585 \\
\hline Film & 257 & 19,0 & & \\
\hline Metales & 74 & 5,5 & & \\
\hline PEAD & 61 & 4,5 & & \\
\hline PET & 74 & 5,5 & & \\
\hline $\begin{array}{l}\text { Mezcla de } \\
\text { plásticos }\end{array}$ & 317 & 23,5 & 855 & \\
\hline Brik & 203 & 15,0 & & \\
\hline Madera & 6 & 0,5 & & \\
\hline Textiles & 49 & 3,6 & & \\
\hline Otros & 30 & 2,2 & & \\
\hline Madera & 85 & 6,3 & & \\
\hline
\end{tabular}

Tabla 2.3. Composición de los rechazos de la planta de selección y clasificación de envases.

\subsubsection{COMERCIALES E INDUSTRIALES}

En el término municipal de Fuenlabrada, en la Comunidad de Madrid, se encuentra una empresa de fabricación de papel reciclado a partir de papel recuperado, que pertenece al grupo Holmen Paper.

Los principales residuos industriales que se generan en esta empresa provienen, por un lado del rechazo de la clasificación del papelote de entrada a la fábrica y del rechazo generado durante el proceso de pulpado, que se mezclan en una sola corriente para su tratamiento y gestión; y por otro lado, se encuentran los lodos producidos en el proceso de fabricación de papel reciclado, es decir: lodo proveniente de las unidades de destintado, lodo primario generado en la clarificación de efluentes líquidos y lodo secundario producido en las operaciones de tratamiento de aguas residuales mediante un sistema de fangos activos, siendo mezcladas estas tres corrientes residuales en una sola, que comúnmente denominaremos lodos.

La crisis en que se encuentra sumido el sector de la construcción hace que su salida natural, como cargas en la fabricación de cemento, se haya visto reducida, por tanto se va a evaluar su utilización como carga en la producción de combustible derivado de residuos. 
La industria papelera genera aproximadamente 300.000 T/año, con una producción de lodos de 100.000 T/año en base húmeda. Las corrientes residuales se corresponden con un 5-6\% para los rechazos de clasificación de papelote y pulpado, es decir: 15.000 T/año. En el caso de la producción de lodos, se corresponde con un 20-22\% en base seca. El rendimiento de esta planta se sitúa en $100 \mathrm{~kg}$ de papel por cada $120 \mathrm{~kg}$ de papel recuperado.

No obstante, el rendimiento en este tipo de industrias se ve influenciado por el aporte de fibra virgen, el contenido en finos y la calidad del papel recuperado empleado. Un elevado contenido en finos, un bajo aporte de fibra virgen y una disminución en la calidad del papel recuperado provocan una disminución en el rendimiento global del proceso.

Las características de las corrientes residuales generadas en este tipo de industria papelera [37] son las siguientes:

- Rechazo de la clasificación de papel recuperado: consta mayoritariamente de envases, plásticos, metales, vidrios, etc. Tienen un contenido en humedad bajo y un poder calorífico significativo.

- Rechazo del proceso de pulpado: consta principalmente de plásticos, grapas, arenas, metales, etc. Tienen un contenido en humedad alto y un poder calorífico significativo.

- Lodos de destintado: constan de cargas minerales, tintas, aditivos, finos, etc. Tienen un contenido en humedad elevado y un poder calorífico bajo.

- Lodos de recuperación de fibras: constan de finos y cargas minerales. Tienen poder calorífico bajo.

- Lodos de tratamiento de efluentes: tienen un alto contenido en biomasa y nutrientes, y además, una elevada humedad.

\subsubsection{Rechazos}

Rechazos es el término que se emplea para referirse a las fracciones residuales que se rechazan en la clasificación del papel recuperado de la recogida selectiva usado como materia prima en la industria papelera, y del cribado a la entrada del pulpado [21]. Los rechazos son bastante heterogéneos y variables, y consisten principalmente en agrupaciones de fibras, grapas, aros, pegamentos, arenas, vidrio y material plástico.

La composición de los rechazos depende del proceso de manufactura del papel. Sin embargo, los rechazos tienen una elevada humedad, pudiendo ser fácilmente secados, un significante poder calorífico debido a su contenido en material plástico y algunas impurezas a eliminar como: arenas, vidrio y metales.

\subsubsection{Lodo de destintado}

El lodo de destintado se refiere a la fracción residual generada durante el proceso de destintado. El lodo de destintado contiene principalmente pequeñas fibras, revestimientos, material de relleno como caolín $\left(\mathrm{Al}_{2} \mathrm{O}_{3}, \mathrm{SiO}_{2}, \mathrm{H}_{2} \mathrm{O}\right)$, talco $\left(\mathrm{Mg}_{3} \mathrm{Si}_{4} \mathrm{O}_{10}\right.$ $\left.(\mathrm{OH})_{2}\right)$, carbonato de calcio $\left(\mathrm{CaCO}_{3}\right)$ y arcillas que se añaden para mejorar las propiedades finales del papel, adicionalmente hay partículas de tinta, substancias extractivas y aditivos de destintado. 
El lodo de destintado tiene una elevada humedad que es reducida entre un $30-40 \mathrm{~m} / \mathrm{m} \%$, un bajo poder calorífico (4-7 MJ/kg), y un elevado contenido en cenizas, siendo aproximadamente un 60-70 m/m\%, Además, se generan otras dos corrientes de lodos durante el proceso de manufactura de papel, que se corresponden con lodo primario, que contiene fibras largas y sólidos inorgánicos eliminados en el primer clarificador, y con el lodo secundario, que proviene del tratamiento de aguas residuales.

\subsection{CARACTERIZACIÓN DE LOS MATERIALES}

\subsubsection{MÉTODOS DE ANÁLISIS GENERALES}

La caracterización físico-química de los materiales a estudio se basa en el análisis de las muestras recogidas. No obstante, se toman varias muestras con el objeto de llevar a cabo una caracterización más fiable. Los datos obtenidos reciben un tratamiento estadístico que contempla la determinación de la media, medida de centralización, y la desviación típica, medida de la dispersión de los datos obtenidos.

Los análisis que se realizan de manera general se basan en la determinación de parámetros químicos y físicos, así como la fracción de contenido de biomasa de los residuos. Por un lado, los parámetros físicos que se determinan son: forma de partícula, tamaño de partícula, contenido en ceniza, contenido en humedad, poder calorífico neto, densidad a granel, contenido en materia volátil y comportamiento de fusión de ceniza. Por otro lado, los parámetros químicos que se determinan son: metales pesados según la Directiva 2000/76/CE de Incineración de residuos, que son de obligatoria especificación para los CSR, y elementos mayoritarios y elementos traza que se consideran no obligatorios de especificar según la normativa europea de CSR.

\subsubsection{Humedad}

La determinación de la humedad se basa en la determinación del contenido en humedad por el método de secado en estufa desarrollado para CSR según la norma UNE-EN 15414-3:2011, basada en la pérdida de masa de la muestra hasta alcanzar un valor constante cuando se calienta a $105^{\circ} \mathrm{C}$.

\subsubsection{Distribución de tamaño de partícula}

La determinación de la distribución del tamaño de partícula se basa en el método del tamiz para partículas pequeñas para CSR según la norma UNE-EN 15415-1:2012, que se basa en la determinación de la masa en las diferentes fracciones retenidas en un juego de tamices.

\subsubsection{Densidad a granel}

La determinación de la densidad a granel se basa en la norma UNE-EN 15401:2010 desarrollada para CSR, basada en la determinación de la masa en un volumen conocido. 


\subsubsection{Análisis inmediato}

El análisis inmediato del material se basa en las normas para CSR: UNE-EN 15403:2011 para la determinación del contenido en ceniza, que se basa en la combustión de la muestra mediante rampas de calentamiento establecidas hasta $550{ }^{\circ} \mathrm{C}$, y UNE-EN 15402:2011 para la determinación del contenido de materia volátil, que se basa en el calentamiento dela muestra bajo condiciones establecidas hasta $900{ }^{\circ} \mathrm{C}$ y en ausencia de aire. El carbono fijo se obtiene como diferencia de ambos.

\subsubsection{Análisis elemental}

El análisis elemental del material se basa en las normas para CSR: UNE-EN 15407:2011 para la determinación del contenido en carbono $(\mathrm{C})$, hidrógeno $(\mathrm{H})$ y nitrógeno (N), usando un analizador elemental TruSpec (Leco), y UNE-EN 15408:2011 para la determinación del contenido en azufre $(\mathrm{S})$, cloro $(\mathrm{Cl})$, flúor $(\mathrm{F})$ y bromo $(\mathrm{Br})$, que se realiza por cromatografía iónica previa recuperación en disolución acuosa de los compuestos de cloro y azufre que provienen de la bomba calorimétrica. Además, el cloro se determina mediante la calcinación a $775^{\circ} \mathrm{C}$ de la materia orgánica presente en las muestras en presencia de la mezcla Eschka que disgrega a las cenizas resultantes.

\subsubsection{Poder calorífico}

La determinación del poder calorífico se basa en la norma UNE-EN 15400:2011 para CSR:

- Poder calorífico superior a volumen constante (base seca): se determina utilizando calorímetros automáticos, marca LECO AC-300 o IKA C-5000, realizando la combustión de la biomasa con exceso de oxígeno bajo condiciones controladas. El poder calorífico superior a volumen constante se calcula a partir de las mediciones de temperatura realizadas antes y después de la combustión.

Para calcular el poder calorífico anterior en base húmeda se aplica la siguiente fórmula:

$\mathrm{PCSv}, \mathrm{x}=\mathrm{PCSv}, \mathrm{o}(1-0.01 \cdot \mathrm{X})$

Ecuación 2.1

Dónde:

PCSv,x: poder calorífico superior a volumen constante en $\mathrm{kJ} / \mathrm{kg}$ con humedad X. PCSv,o: poder calorífico superior a volumen constante (determinado por el calorímetro) en $\mathrm{kJ} / \mathrm{kg}$ con humedad cero.

$\mathrm{X}$ : humedad de la biomasa en \% base húmeda.

- Poder calorífico inferior a presión constante (base seca): Se calcula restando al poder calorífico superior en base seca el calor de vaporización del agua formada, a partir del contenido en hidrógeno de las cadenas hidrocarbonadas del combustible. Se aplica la siguiente expresión para su cálculo:

PCIp,o = PCSv, o $-206,0 \cdot \mathrm{H}$

Ecuación 2.2

Dónde:

PCIp,o: poder calorífico inferior a presión constante en $\mathrm{kJ} / \mathrm{kg}$ con humedad cero. 
PCSv,o: poder calorífico superior a volumen constante en $\mathrm{kJ} / \mathrm{kg}$ con humedad cero.

$\mathrm{H}$ : contenido en hidrógeno en base seca.

Para calcular el poder calorífico inferior en base húmeda se tiene en cuenta que el agua presente al final de la combustión tiene un doble origen: el agua presente en el combustible húmedo y el agua formada a partir del hidrógeno de las cadenas hidrocarbonadas. La expresión de cálculo es la que sigue:

PCIp, $\mathrm{x}=\mathrm{PCSv}, \mathrm{x}-23,05 \cdot(\mathrm{X}+8,9364 \cdot \mathrm{H} \cdot(1-0.01 \cdot \mathrm{X}))$

Ecuación 2.3

Dónde:

PCIp, $\mathrm{x}=$ poder calorífico inferior a presión constante en $\mathrm{kJ} / \mathrm{kg}$ con humedad X.

\subsubsection{Análisis de metales}

La determinación de metales en CSR se realiza a partir de dos normas: UNE-EN 15410:2012 para la determinación del contenido en elementos principales ( $\mathrm{Al}, \mathrm{Ca}, \mathrm{Fe}$, $\mathrm{K}, \mathrm{Mg}, \mathrm{Na}, \mathrm{P}, \mathrm{Si}, \mathrm{Ti})$ y UNE-EN 15411:2012 para la determinación del contenido en oligoelementos (As, Ba, Be, Cd, Co, Cr, Cu, Hg, Mo, Mn, Ni, Pb, Sb, Se, Tl, V y Zn), que se basan en la digestión de la muestra en un horno microondas. Las muestras digeridas se analizan mediante espectrometría de masas por plasma acoplado inductivamente y espectrometría de emisión atómica por plasma de argón acoplado inductivamente, mediante un espectrómetro simultáneo de la marca THERMO JARRELL ASH, modelo IRIS AP.

El cálculo para convertir los resultados analizados sobre la ceniza a biomasa, o viceversa, se realiza según la fórmula:

$\%$ Elemento $_{\text {residuo }}=\%$ Elemento $_{\text {ceniza }} \cdot 0,01 \cdot \%$ cenizas $\quad$ Ecuación 2.4

Esta fórmula generalmente no es válida para el azufre, pues éste suele perderse parcialmente durante la calcinación.

\subsubsection{Determinación del contenido en biomasa}

La determinación del contenido en biomasa se basa en la norma UNE-EN 15440:2012 para la determinación del contenido e biomasa de CSR. Esta determinación se expresa como contenido en carbono y se realiza mediante el método de disolución selectiva y el método de separación manual.

\subsubsection{Comportamiento de fusión de ceniza}

La determinación de la fusibilidad se basa en la norma UNE-EN 15403:2011. Este ensayo se realiza sobre ceniza calcinada a $550{ }^{\circ} \mathrm{C}$ y molida a menos de $0,25 \mathrm{~mm}$. La preparación consiste en producir una muestra cilíndrica de $3 \mathrm{~mm}$ de diámetro por 3 mm de altura. 
La muestra se introduce en el hormo de un microscopio de calefacción óptica, marca LEICA, donde un haz de luz incide sobre la pastilla reflejando su silueta. El horno usa las siguientes rampas de temperatura:

-Rampa $60^{\circ} \mathrm{C} / \mathrm{min}$ de temperatura ambiente hasta $550{ }^{\circ} \mathrm{C}$

-Rampa $10^{\circ} \mathrm{C} / \mathrm{min}$ de $550{ }^{\circ} \mathrm{C}$ hasta $1400^{\circ} \mathrm{C}$

Imágenes de la silueta que refleja la pastilla se graban mediante una cámara digital con el aumento de la temperatura del horno. El equipo registra automáticamente diferentes parámetros (factor de forma, ángulos de esquinas, etc.), que se utilizan para la determinación de las temperaturas características.

\subsubsection{Análisis para material bruto}

Los materiales residuales de partida se someten a una caracterización química completa para determinar su utilidad como combustibles en lechos fluidizados. El total de las fracciones se analizó en el laboratorio de caracterización química del CEDERCIEMAT. Se realizaron distintos análisis con objeto de lograr una caracterización completa del material de rechazo, es decir: análisis inmediato, análisis elemental, humedad y poder calorífico.

Tanto las fracciones procedentes de la planta de tratamientos de residuos sólidos, como los residuos procedentes de la industria papelera fueron preparados para su análisis en laboratorio y caracterizados químicamente mediante análisis de humedad, inmediato, elemental, poder calorífico y análisis de las cenizas. Para poder evaluar la variabilidad estacional y geográfica de los residuos sólidos urbanos generados, se han realizado análisis del material durante diferentes periodos anuales, ya que la zona geográfica permanece inalterable en todo el estudio, centrándose en la Ribera Baja. Con respecto a los residuos de la industria papelera se realizó un estudio de caracterización por turnos de trabajo, que facilitó una caracterización más precisa de los residuos generados.

\subsubsection{Análisis para combustibles de residuos}

El objetivo de este estudio ha sido la obtención de un combustible a partir de residuos de tipo doméstico, RSU, y residuos de tipo industrial, industria papelera. Una vez estudiados los residuos brutos de manera separada, así como las fracciones que los componen, se ha conseguido un combustible derivado de residuos en forma de pélets, que es adecuado para su utilización en plantas de gasificación mediante tecnología de lecho fluidizado.

A raíz de las nuevas normativas europeas con respecto a los combustibles derivados de residuos, se ha establecido una normativa para combustibles sólidos recuperados, que son combustibles sólidos preparados a partir de residuos no peligrosos de acuerdo a la norma UNE-EN 15357: 2012, y que cumplen con los requisitos de clasificación y de especificación establecidos en la norma UNE- EN 15359:2012 del Comité Europeo de Normalización (CEN).

A continuación, se muestran en la Tabla 2.4 la normativa necesaria para la especificación de sus propiedades en los formularios correspondientes según la norma UNE-EN 15359: 2012. 


\begin{tabular}{|c|c|}
\hline Norma & Título \\
\hline $\begin{array}{l}\text { UNE-EN } \\
15415-1: 2012\end{array}$ & $\begin{array}{l}\text { CSR. Determinación de la distribución de tamaño de partícula. } \\
\text { Parte 1: Método del tamiz para partículas pequeñas. }\end{array}$ \\
\hline $\begin{array}{l}\text { UNE-EN } \\
15415-2: 2012\end{array}$ & $\begin{array}{l}\text { CSR. Determinación de la distribución de tamaño de partícula. } \\
\text { Parte 2: Método (manual) de la longitud máxima proyectada para } \\
\text { partículas de grandes dimensiones. }\end{array}$ \\
\hline $\begin{array}{l}\text { UNE-EN } \\
15415-3: 2012\end{array}$ & $\begin{array}{l}\text { CSR. Determinación de la distribución de tamaño de partícula. } \\
\text { Parte 3: Método por análisis de imagen para partículas de grandes } \\
\text { dimensiones. }\end{array}$ \\
\hline $\begin{array}{l}\text { UNE-EN } \\
15590: 2012\end{array}$ & $\begin{array}{l}\text { CSR. Determinación de la tasa de calentamiento potencial por } \\
\text { actividad microbiana usando el índice de respiración dinámica. }\end{array}$ \\
\hline $\begin{array}{l}\text { UNE-EN } \\
15403: 2011\end{array}$ & CSR. Determinación del contenido de ceniza. \\
\hline $\begin{array}{l}\text { UNE-EN } \\
15402: 2011\end{array}$ & CSR. Determinación del contenido de materia volátil. \\
\hline $\begin{array}{l}\text { UNE-EN } \\
15414-3: 2011\end{array}$ & $\begin{array}{l}\text { CSR. Determinación del contenido en humedad por el método de } \\
\text { secado en estufa. Parte 3: Humedad de la muestra para análisis } \\
\text { general. }\end{array}$ \\
\hline $\begin{array}{l}\text { UNE-EN } \\
15400: 2011\end{array}$ & CSR. Determinación del poder calorífico. \\
\hline $\begin{array}{l}\text { UNE-CEN/TR } \\
\text { 15441:2009 IN }\end{array}$ & $\begin{array}{l}\text { Combustibles sólidos recuperados. Directrices sobre aspectos de } \\
\text { salud laboral. }\end{array}$ \\
\hline $\begin{array}{l}\text { UNE-CEN/TR } \\
\text { 14980:2009 IN }\end{array}$ & $\begin{array}{l}\text { CSR. Informe sobre las diferencias relativas entre las fracciones } \\
\text { biodegradables y biogénicas de los combustibles sólidos } \\
\text { recuperados. }\end{array}$ \\
\hline $\begin{array}{l}\text { UNE-EN } \\
\text { 15410:2012 }\end{array}$ & $\begin{array}{l}\text { CSR. Método para la determinación del contenido en elementos } \\
\text { principales ( } \mathrm{Al}, \mathrm{Ca}, \mathrm{Fe}, \mathrm{K}, \mathrm{Mg}, \mathrm{Na}, \mathrm{P}, \mathrm{Si}, \mathrm{Ti} \text { ). }\end{array}$ \\
\hline $\begin{array}{l}\text { UNE-EN } \\
15411: 2012\end{array}$ & $\begin{array}{l}\text { CSR. Método para la determinación del contenido en } \\
\text { oligoelementos (As, } \mathrm{Ba}, \mathrm{Be}, \mathrm{Cd}, \mathrm{Co}, \mathrm{Cr}, \mathrm{Cu}, \mathrm{Hg}, \mathrm{Mo}, \mathrm{Mn}, \mathrm{Ni}, \mathrm{Pb} \text {, } \\
\mathrm{Sb}, \mathrm{Se}, \mathrm{Tl}, \mathrm{V} \text { y Zn). }\end{array}$ \\
\hline $\begin{array}{l}\text { UNE-EN } \\
\text { 15442:2012 }\end{array}$ & CSR. Métodos de muestreo. \\
\hline $\begin{array}{l}\text { UNE-EN } \\
15408: 2011\end{array}$ & $\begin{array}{l}\text { CSR. Métodos para la determinación del contenido en azufre }(\mathrm{S}) \text {, } \\
\text { cloro }(\mathrm{Cl}) \text {, flúor }(\mathrm{F}) \text { y bromo }(\mathrm{Br})\end{array}$ \\
\hline $\begin{array}{l}\text { UNE-EN } \\
15440: 2012\end{array}$ & CSR. Métodos para la determinación del contenido en biomasa. \\
\hline $\begin{array}{l}\text { UNE-EN } \\
15407: 2011\end{array}$ & $\begin{array}{l}\text { CSR. Métodos para la determinación del contenido en carbono } \\
(\mathrm{C}) \text {, hidrógeno }(\mathrm{H}) \text { y nitrógeno }(\mathrm{N}) \text {. }\end{array}$ \\
\hline $\begin{array}{l}\text { UNE-EN } \\
15443: 2011\end{array}$ & CSR. Métodos para la preparación de la muestra de laboratorio \\
\hline $\begin{array}{l}\text { UNE-EN } \\
15413: 2012\end{array}$ & $\begin{array}{l}\text { CSR. Métodos para la preparación de las muestras de ensayo a } \\
\text { partir de muestras de laboratorio. }\end{array}$ \\
\hline $\begin{array}{l}\text { UNE-EN } \\
15358: 2011\end{array}$ & $\begin{array}{l}\text { CSR. Sistemas de gestión de la calidad. Requisitos particulares } \\
\text { para su aplicación a la producción de CSR }\end{array}$ \\
\hline $\begin{array}{l}\text { UNE-EN } \\
15357: 2012\end{array}$ & CSR. Terminología, definiciones y descripciones. \\
\hline $\begin{array}{l}\text { UNE-EN } \\
15359: 2012\end{array}$ & Combustibles sólidos recuperados. Especificaciones y clases \\
\hline
\end{tabular}

Tabla 2.4. Normativa empleada para la caracterización de los CSR. 


\subsubsection{Análisis para cenizas}

El estudio de los riesgos de sinterización se basa en los análisis de metales y de temperaturas de fusión de las cenizas. El análisis de metales se realiza mediante espectroscopia de plasma de acoplamiento inductivo de una disolución ácida de la muestra de cenizas [128]. Este análisis se toma como punto de partida para discernir el comportamiento de cada uno de los materiales de rechazo de que se disponen, previamente a su procesamiento y densificación en las proporciones seleccionadas.

Este estudio se completa con un análisis exhaustivo de posibles causas de aglomeración, empleando como muestra de análisis el combustible sólido recuperado ya peletizado. Los indicadores habituales que dan una estimación del riesgo de sinterización son el contenido en potasio, sodio y sílice que contenga la ceniza analizada. Además, el material de lecho que se emplea en los ensayos de conversión térmica mediante procesos de gasificación, puede fomentar la aparición de sinterizados dependiendo de su composición. Sin embargo, el elevado contenido de otros metales como el calcio o el magnesio, reducen la posibilidad de aparición de sinterizados durante el proceso de gasificación.

El comportamiento de las cenizas fue determinado estudiando la temperatura de fusión de cada una de las fracciones rechazo. Las temperaturas características [63] que se analizaron fueron:

- Temperatura de deformación inicial (TDI), temperatura a la cual el encogimiento del material ocurre.

- Temperatura de esfera (TE), temperatura a la cual el material comienza a mostrar formas redondeadas debido a la fusión que experimenta el material.

- Temperatura de hemiesfera (TH), temperatura a la cual el material forma media esfera.

- Temperatura fluida (TF), temperatura a la cual la ceniza difunde formando una capa con el soporte, siendo su altura la mitad que la altura del material cuando alcanza la temperatura de hemiesfera.

El riesgo de sinterización fue estimado mediante varios índices. Un método teórico empleado para biomasa basado en la relación entre óxidos alcalinos y alcalinotérreos fue empleado para el CSR de origen doméstico.

$$
\text { Rake } / a k=\frac{\mathrm{CaO}+\mathrm{MgO}}{\mathrm{K}_{2} \mathrm{O}+\mathrm{Na}_{2} \mathrm{O}}
$$

Ecuación 2.5

El resto de índices, fueron comúnmente empleados en determinar la formación de escorias, sinterizados y ensuciamiento para carbón. No obstante, estos fueron utilizados con excelentes resultados para CSR por Dunnu en sus investigaciones. Las definiciones de estos índices son:

- Suma de porcentajes de componentes básicos:

$$
R_{b}=\mathrm{Fe}_{2} \mathrm{O}_{3}+\mathrm{CaO}+\mathrm{MgO}+\mathrm{K}_{2} \mathrm{O}+\mathrm{Na}_{2} \mathrm{O}
$$

Ecuación 2.6 
- Relación entre componentes básicos y ácidos en las cenizas:

$$
\begin{aligned}
& R_{b / a}=\frac{\mathrm{Fe}_{2} \mathrm{O}_{3}+\mathrm{CaO}+\mathrm{MgO}+\mathrm{K}_{2} \mathrm{O}+\mathrm{Na}_{2} \mathrm{O}}{\mathrm{Al}_{2} \mathrm{O}_{3}+\mathrm{SiO}_{2}+\mathrm{TiO}_{2}} \\
& R_{b / a(+P)}=\frac{\mathrm{Fe}_{2} \mathrm{O}_{3}+\mathrm{CaO}+\mathrm{MgO}+\mathrm{K}_{2} \mathrm{O}+\mathrm{Na}_{2} \mathrm{O}+\mathrm{P}_{2} \mathrm{O}_{5}}{\mathrm{Al}_{2} \mathrm{O}_{3}+\mathrm{SiO}_{2}+\mathrm{TiO}_{2}} \\
& R_{b / a} \times \mathrm{Na}=\frac{\mathrm{Fe}_{2} \mathrm{O}_{3}+\mathrm{CaO}+\mathrm{MgO}+\mathrm{K}_{2} \mathrm{O}+\mathrm{Na}_{2} \mathrm{O}}{\mathrm{Al}_{2} \mathrm{O}_{3}+\mathrm{SiO}_{2}+\mathrm{TiO}_{2}} \times \mathrm{Na}_{2} \mathrm{O}
\end{aligned}
$$

- Índice de la viscosidad de escorias:

$$
S_{R}=\frac{\mathrm{SiO}_{2}}{\mathrm{Fe}_{2} \mathrm{O}_{3}+\mathrm{SiO}_{2}+\mathrm{CaO}+\mathrm{MgO}} \times 100
$$

Ecuación 2.10

- Índice de escorias en función de las temperaturas características:

$$
F_{S}=\frac{4 \cdot T E+H T}{5}
$$

Ecuación 2.11

\subsubsection{Análisis termogravimétrico}

El equipo utilizado en este estudio fue una termobalanza Mettler TGA/SDTA $851^{\mathrm{e}}$ (Mettler Toledo Corporation, Switzerland). El análisis fue llevado a cabo en un rango de temperaturas de $20^{\circ} \mathrm{C}-1000^{\circ} \mathrm{C}$ y con velocidades de calentamiento de $5^{\circ} \mathrm{C} / \mathrm{min}$ a $20^{\circ} \mathrm{C} /$ min (rampa horizontal), empleando nitrógeno para simular una atmósfera inerte. Sin embargo, las fracciones originales fueron analizadas solamente con una velocidad de calentamiento de $20^{\circ} \mathrm{C} / \mathrm{min}$.

El estudio termogravimétrico se llevó a cabo con el objetivo de conseguir información adicional a la suministrada mediante los análisis elemental e inmediato. Este análisis fue realizado en condiciones simuladas de pirólisis para predecir, por un lado, la estabilidad térmica, y por otro lado, el comportamiento del sólido bajo una atmósfera inerte.

La degradación térmica de las fracciones que conforman las mezclas combustibles fue analizada para determinar, de manera cualitativa, los componentes mayoritarios y los rangos de temperatura donde cada una de ellas experimentó la mayor pérdida de masa. Además, los parámetros cinéticos, energía de activación y factor pre-exponencial, fueron estimados en base a métodos no-isotérmicos.

El estudio cinético de la pérdida de masa de material carbonoso bajo atmósfera inerte, simulando un proceso de pirólisis, es muy complejo debido al gran número de reacciones que intervienen. La estimación de los parámetros cinéticos, se puede realizar en base a dos metodologías, métodos isotérmicos y métodos no-isotérmicos. 
La ventaja del empleo de métodos no-isotérmicos respecto a métodos isotérmicos radica en la posibilidad de obtener resultados en un amplio rango de temperaturas y estimar la influencia de diferentes velocidades de calentamiento en el proceso de descomposición térmica del sólido. Sin embargo, existen discrepancias en la determinación de los parámetros cinéticos empleando experimentos dinámicos, debido al efecto de compensación cinética que se produce, siendo por tanto de obligado estudio, el efecto de la influencia de las velocidades de calentamiento [129].

Generalmente, los métodos no-isotérmicos se dividen en: métodos de modelos de ajuste y métodos de modelos libres, que comúnmente se denominan métodos isoconversionales [132]. Los modelos de ajuste requieren de una selección adecuada del modelo que mejor ajuste los datos experimentales disponibles, mientras que los modelos libres requieren de curvas termogravimétricas a diferentes temperaturas de calentamiento para obtener las curvas cinéticas que permitan obtener la energía de activación para cada punto de conversión.

Los métodos no-isotérmicos mediante modelos de ajuste de datos más utilizados son:

- Differential (Direct Arrhenius method)

- Coats-Redfern

Y los métodos no isotérmicos mediante modelos libres más empleados son:

- Kissinger

- Flynn-Wall-Ozawa (FWO)

- Kissinger-Akhira-Sonuse (KAS)

El proceso de pirólisis se puede describir a partir de una reacción sencilla, donde una partícula sólida es convertida en materia volátil y un residuo sólido:

Combustible $\rightarrow$ Materia volátil + Residuo sólido

La materia volátil está formada por productos gaseosos y alquitrán, y el residuo consiste en un residuo sólido carbonoso, comúnmente denominado char, material inquemado y ceniza. La velocidad de reacción del proceso de pirólisis, que transforma una partícula sólida a su estado gaseoso, puede ser descrita a través de la siguiente expresión:

$\frac{d \alpha}{d t}=K(T) \cdot f(\alpha)$

Ecuación 2.12

Dónde $\mathrm{t}, \mathrm{K}(\mathrm{T})$, $\alpha$ y $\mathrm{f}(\alpha)$ son el tiempo, la constante de la velocidad de reacción dependiente de la temperatura, el grado de conversión y una función que depende de la conversión, respectivamente. El grado de conversión puede ser presentado como sigue:

$\alpha=\frac{m_{0}-m}{m_{0}-m_{f}}$

Ecuación 2.13

Dónde $\mathrm{m}$ es la masa de la muestra a un tiempo $t, \mathrm{~m}_{\mathrm{o}} \mathrm{y} \mathrm{m}_{\mathrm{f}}$ se refieren a los valores de las muestras al comienzo del experimento y al residuo final. Además, la constante de la velocidad de reacción dependiente de la temperatura puede describirse mediante la ecuación de Arrhenius: 


$$
K(T)=A \cdot \exp \left(\frac{-E_{a}}{R T}\right)
$$

Dónde $\mathrm{A}$ es el factor pre-exponencial, $\mathrm{E}_{\mathrm{a}}$ es la energía de activación aparente, $\mathrm{T}$ es la temperatura absoluta y $\mathrm{R}$ es la constante universal de los gases. Para condiciones noisotérmicas, cuando la temperatura varía a una velocidad de calentamiento constante, la ecuación se modifica de la siguiente forma:

$\beta \cdot \frac{d \alpha}{d T}=A \cdot \exp \left(\frac{-E_{a}}{R T}\right) \cdot f(\alpha)$

Ecuación 2.15

Dónde $\beta$ es la velocidad de calentamiento, que se define como $\beta=d T / d t$. La función $\mathrm{f}(\alpha)$ que se usa para describir cualquier evento acaecido durante el proceso de pirólisis, es descrita como:

$f(\alpha)=(1-\alpha)^{n}$

Ecuación 2.16

Dónde $n$ es el orden de reacción. Sustituyendo esta expresión en la ecuación (4) y reordenándola, la expresión de la velocidad de reacción queda de la siguiente forma:

$\frac{d \alpha}{d T}=\frac{A}{\beta} \cdot(1-\alpha)^{n} \exp \left(\frac{-E_{a}}{R T}\right)$

Ecuación 2.17

Tras la integración de la expresión (6), se obtiene:

$$
\int_{x_{0}}^{x} \frac{d x}{(1-\alpha)^{n}}=\frac{A}{\beta} \cdot \int_{T_{0}}^{T} \exp \left(\frac{-E_{a}}{R T}\right) d T
$$

Dónde $\mathrm{T}_{0}$ es la temperatura inicial. La primera parte de la ecuación 2.18 es la forma integral del modelo de reacción, conocido como $\mathrm{g}(\mathrm{x})$, y la segunda parte, que no tiene solución analítica, corresponde con la temperatura integral. Por tanto, la estimación del valor de la temperatura integral se basa en la aplicación de diferentes métodos que permitirán obtener los parámetros de Arrhenius. La única diferencia entre ambos métodos es la necesidad de conocer el mecanismo de la reacción para los métodos noisotérmicos mediante modelos de ajuste, mientras que esto no es necesario para los métodos no-isotérmicos mediante modelos libres.

\section{Métodos no-isotérmicos basados en modelos libres}

\section{Método de Kissinger}

Kissinger [132] desarrolló un método de modelo libre no-isotérmico, donde la determinación de la energía de activación específica fuera independiente de cada valor de conversión. La expresión obtenida fue la siguiente:

$$
\ln \left(\frac{\beta}{T_{m}^{2}}\right)=\ln \left(\frac{A R}{E_{a}}\right)-\left(\frac{E_{a}}{R T_{m}}\right)
$$


Dónde $\mathrm{T}_{\mathrm{m}}$ corresponde al punto de inflexión de las curvas de degradación térmica. El cálculo requiere representar $\ln \left(\beta / T_{m}^{2}\right)$ frente a $1 / T_{m}$ para los experimentos llevados a cabo a diferentes velocidades de calentamiento, donde la energía de activación se obtiene de la pendiente de la gráfica.

\section{Método Flynn-Wall-Ozawa}

El método de Flynn-Wall-Ozawa (FOW) es un método integral isoconversional. Este método usa la aproximación de Doyle [131], siendo la ecuación representativa del método la siguiente:

$$
\log (\beta)=\ln \left(\frac{A E_{a}}{R g(\alpha)}\right)-5.331-1.052 \cdot\left(\frac{E_{a}}{R T}\right)
$$

Ecuación 2.20

El cálculo requiere la representación de $\log (\beta)$ frente a $1 / T$ para un valor dado de conversión a diferentes velocidades de calentamiento, usadas en cada desarrollo experimental, donde la energía de activación se determina mediante la pendiente de la representación gráfica.

\section{Método Kissinger-Akahira-Sunose}

El método de Kissinger-Akahira-Sunose (KAS) es otro método integral isoconversional. Este método se basa en la siguiente expresión:

$$
\ln \left(\frac{\beta}{T^{2}}\right)=\ln \left(\frac{A R}{g(\alpha) E_{a}}\right)-\left(\frac{E_{a}}{R T}\right)
$$

El cálculo requiere representar $\ln \left(\beta / T^{2}\right)$ frente a $1 / T$ para cada valor de conversión a las diferentes velocidades de calentamiento usadas en el desarrollo experimental, de modo que se determine la energía de activación para cada etapa de degradación.

\section{Métodos no-isotérmicos basados en modelos de ajuste}

\section{Método Coats-Redfern}

El método Coats-Redfern es un método no-isotérmico de modelo de ajuste integral que elimina la constante de reacción y permite obtener los parámetros de Arrrhenius directamente. [130].

$$
\ln \left(\frac{1-(1-\alpha)^{(1-n)}}{T^{2}(1-n)}\right)=\ln \left(\left(\frac{A R}{\beta E_{a}}\right) \cdot\left(1-\frac{2 R T}{E_{a}}\right)\right)-\frac{E_{a}}{R T}
$$

Dónde $\mathrm{n}$ es el orden de reacción y $\beta$ es la velocidad de calentamiento. El valor de la energía de activación puede ser determinado a través de la ecuación 2.22, de modo que es posible estimar un valor de energía de activación para cada velocidad de calentamiento usado en el desarrollo experimental. Sin embargo, se asume la siguiente simplificación $2 R T<<E_{a}$ : 
$\ln \left(\frac{1-(1-\alpha)^{(1-n)}}{T^{2}(1-n)}\right)=\ln \left(\frac{A R}{\beta E_{a}}\right)-\frac{E_{a}}{R T}$

La representación de $\ln \left(\left(\left(1-(1-\alpha)^{(1-\alpha)}\right)\right) /\left(T^{2}(1-n)\right)\right)$ frente a $1 / T$ permite obtener una línea recta a través de cuya pendiente se determina la energía de activación.

\section{Método Diferencial}

El método diferencial o método directo de Arrhenius puede ser expresado como sigue:

$$
\ln \left(\frac{1}{1-\alpha}\right)=\ln \left(\frac{A}{\beta}\right)-\left(\frac{E_{a}}{R T}\right)
$$

Ecuación 2.24

La representación de $\ln (1 /(1-\alpha))$ frente a $1 / \mathrm{T}$ da una línea recta, cuya pendiente determina el valor de la energía de activación.

\subsection{INSTALACIONES DE PRETRATAMIENTO}

Las instalaciones de pretratamiento utilizadas en el acondicionamiento y la preparación del combustible derivado de residuos (CDR) constan de diferentes equipos: equipos de trituración, un secadero híbrido solar y una planta piloto de peletización.

\subsubsection{SECADO}

En la Figura 2.4 se muestra un secadero híbrido solar con capacidad para 400 $\mathrm{kg} / \mathrm{h}$, que se emplea para el secado del material según se recibe, para reducir la humedad de partida con anterioridad al proceso de molienda. El funcionamiento se basa en el calentamiento del combustible con aporte mixto de calor mediante radiación solar, a través de un recinto estilo invernadero, y otras fuentes de aporte de calor externo a baja temperatura.

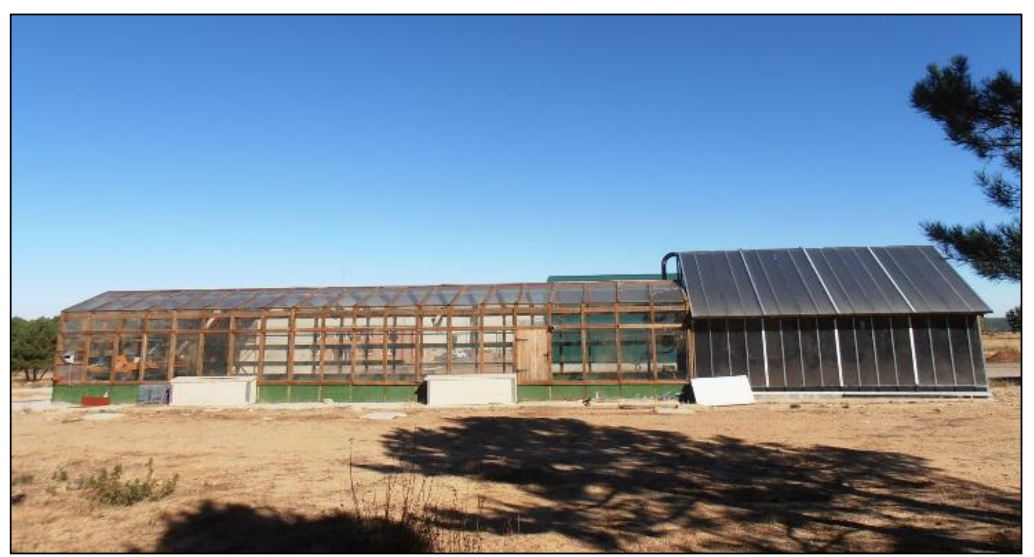

Figura 2.4. Vista general del secadero solar. 


\subsubsection{ELIMINACIÓN DE IMPROPIOS}

La eliminación de impropios, materiales ferromagnéticos y piedras, se lleva a cabo mediante un separador magnético colocado en una cinta transportadora y mediante decantación, respectivamente.

\subsubsection{TRITURACIÓN Y MOLIENDA}

Tras una primera etapa de secado del material de partida, se procede al acondicionamiento del material a través de una segunda etapa de trituración. En la Figura 2.5, se muestra una vista general de los diferentes equipos de trituración disponibles en el CEDER.

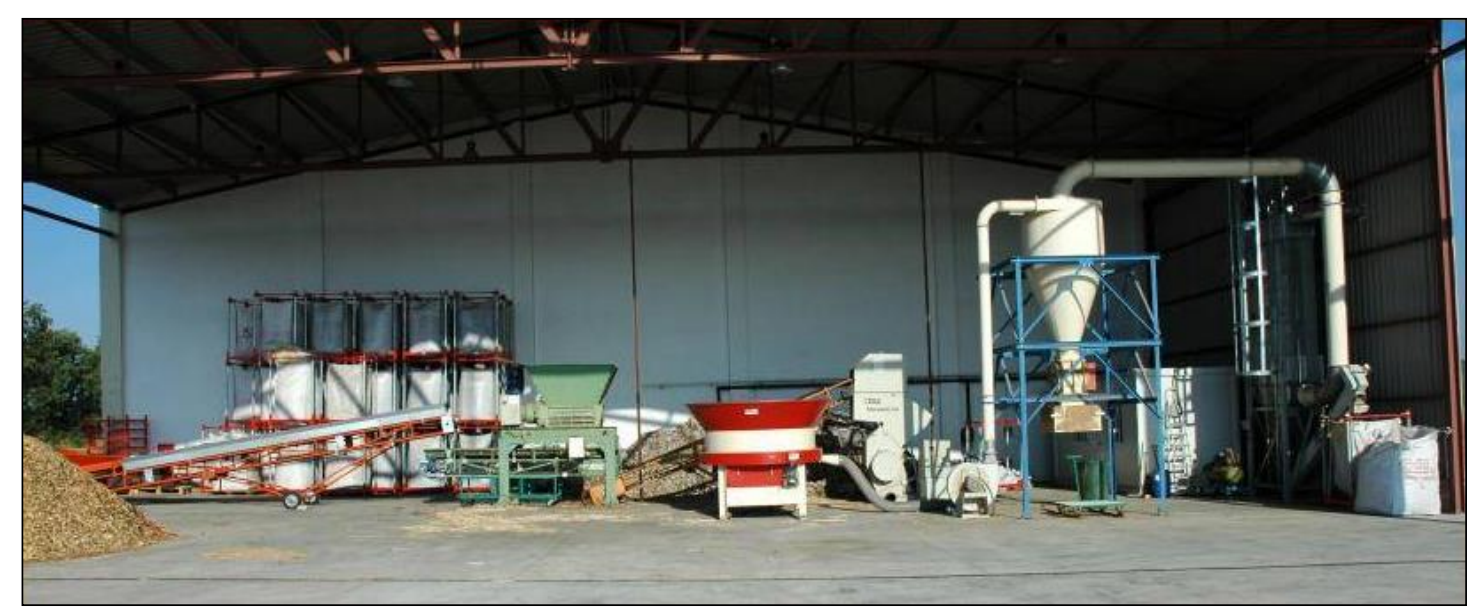

Figura 2.5. Vista general de los equipos de trituración.

La instalación utilizada para el acondicionamiento del combustible previo al proceso de densificación consta de los siguientes elementos: triturador primario, triturador secundario y equipos auxiliares:

- Triturador primario, es un equipo de trituración convencional previo paso al molino de cuchillas para su molienda a un tamaño concreto.

- Triturador secundario, es un molino de cuchillas de eje horizontal con doble cojinete, con una potencia de $35 \mathrm{~kW}$ y una velocidad de rotación de 640 r.p.m. La pantalla de inserción, intercambiable, tiene una abertura en la parte superior para la alimentación del material a la cámara, perpendicularmente al eje del rotor. El rotor consta de nueve cuchillas y seis contra-cuchillas que alcanzan una velocidad periférica de $20 \mathrm{~ms}^{-1}$. El diámetro interno de la cámara de molienda es de $600 \mathrm{~mm}$. El consumo eléctrico del molino de cuchillas se registra de manera continua durante cada ensayo, a través de un equipo de registro de datos. El molino se emplea para reducir el tamaño del material de partida, inicialmente se reduce a $25 \mathrm{~mm}$, para finalizar con una reducción a $8 \mathrm{~mm}$.

- Equipos auxiliares tales como cintas transportadoras, equipos de separación de metales ferrosos, despedregador y equipos de extracción de finos. 


\subsubsection{PELETIZACIÓN}

En la Figura 2.6 se muestra una vista general de la planta de peletización. Los equipos de los que consta la planta piloto de peletización son: un sistema de mezclado, un sistema de acondicionamiento, una prensa, un enfriador en contracorriente, una criba $\mathrm{y}$ un equipo de ensaque.

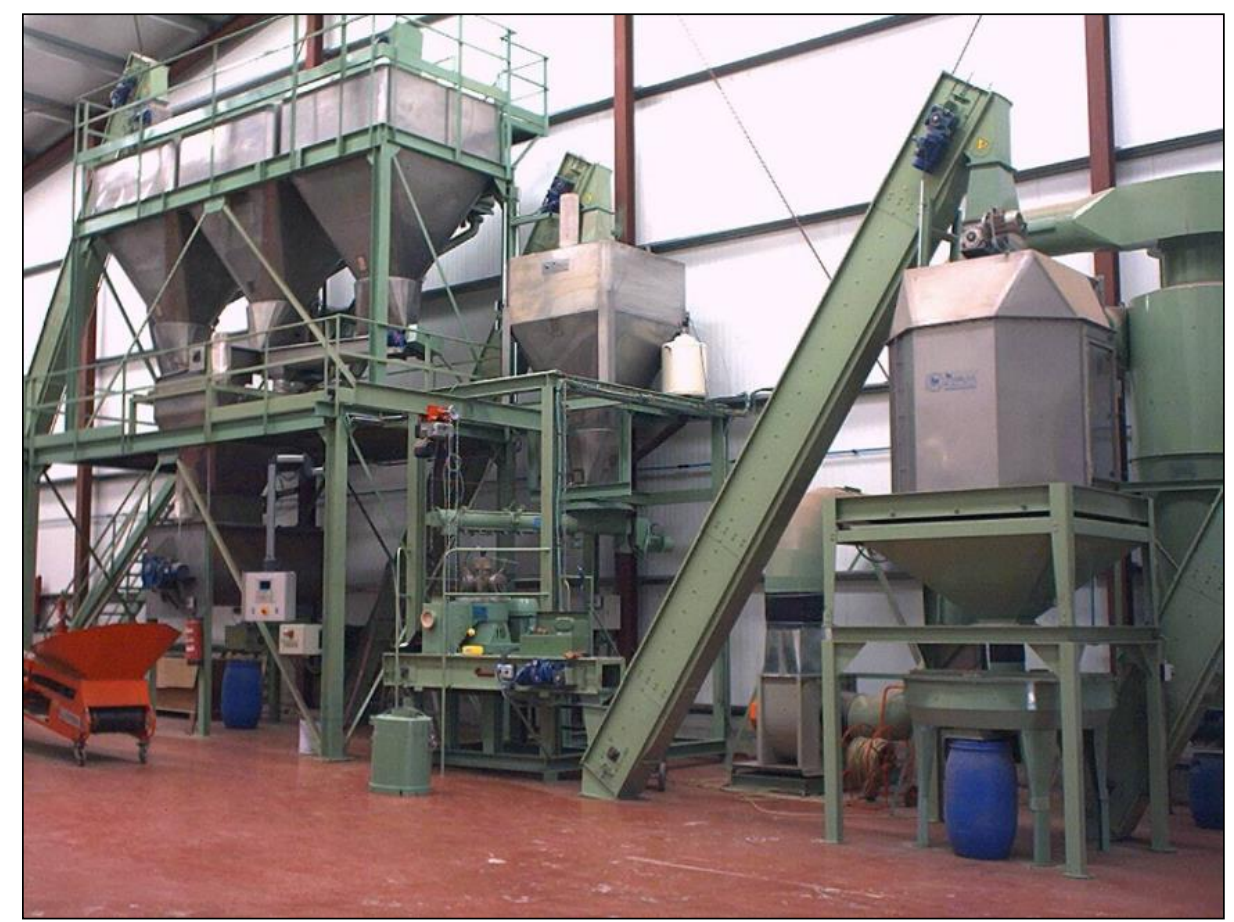

Figura 2.6. Vista general de la planta piloto de densificación.

La Figura 2.7 muestra un esquema de la instalación de peletización, en la que se pueden observar de manera más precisa cada uno de los elementos que la conforman. La numeración de equipos se corresponde con los nombres indicados en la leyenda.

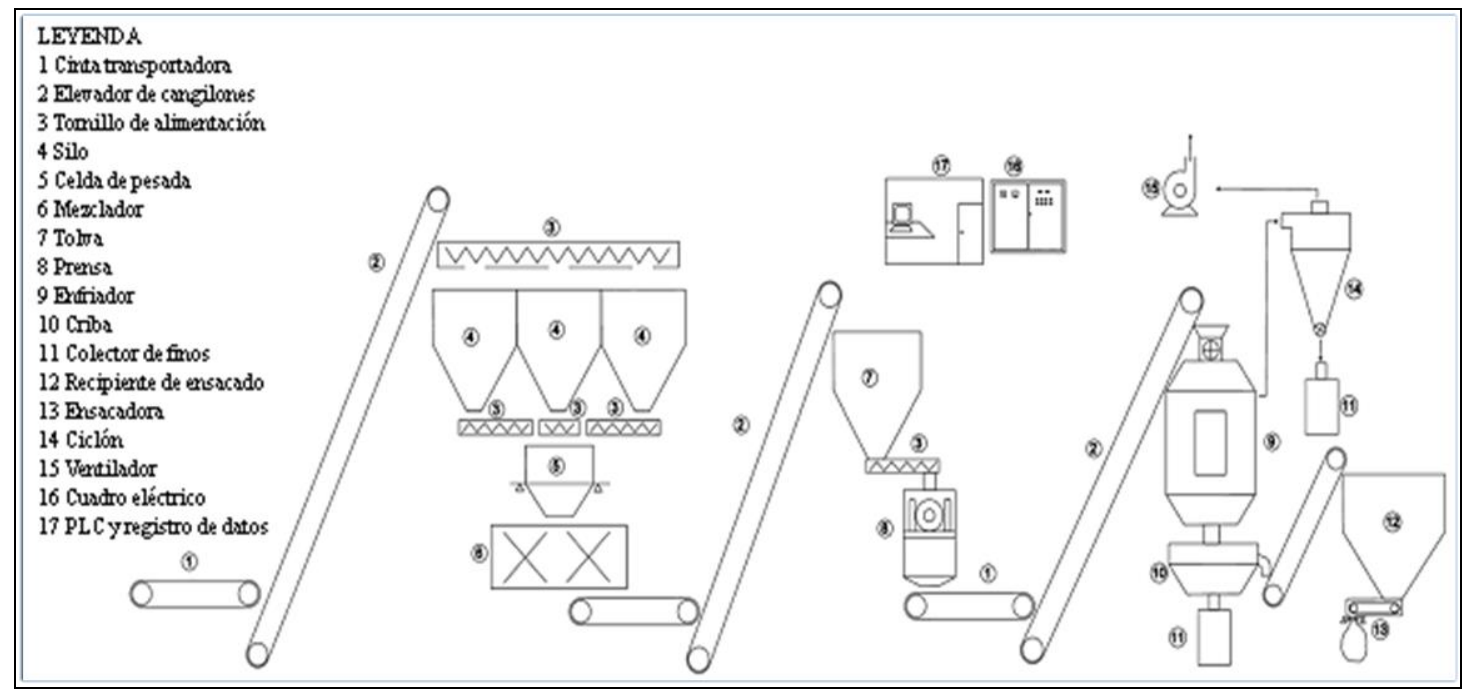

Figura 2.7. Esquema de la planta piloto de densificación. 
La instalación utilizada consta de una planta piloto de peletización, basada en la tecnología de matriz plana, con una capacidad de producción de $300 \mathrm{~kg} / \mathrm{h}$. La Figura 2.8 muestra un esquema de matriz plana, donde la alimentación se realiza de manera perpendicular a dicha matriz. La presión requerida para la producción de pellets se realiza mediante unos rodillos de fricción.

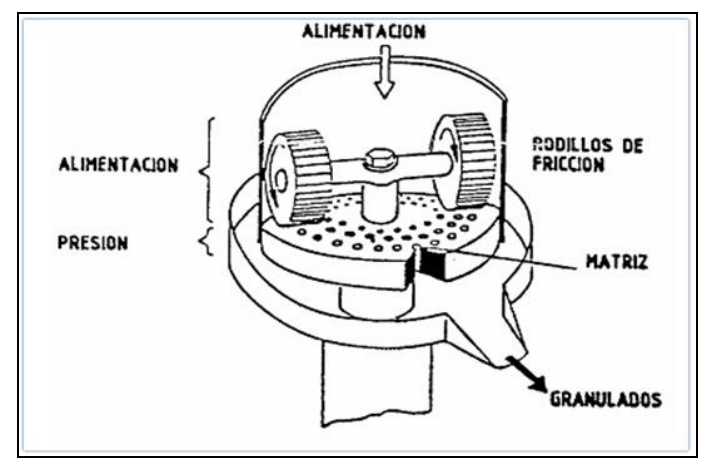

Figura 2.8. Croquis de una prensa de matriz plana.

La prensa es de tipo matriz plana de tecnología Kahl, Amandus Kahl 33-500, con diámetro de la matriz de $500 \mathrm{~mm}$, diámetro del canal de $8 \mathrm{~mm}$ y una potencia de accionamiento de $30 \mathrm{~kW}$. La prensa está equipada con una tuerca hidráulica que genera una presión superior a 110 bar. Las características de la prensa son:

- Diámetro de la matriz (mm): 500

- Diámetro de rodillo/anchura (mm): 230/77

- Número de rodillos: 3

- Motor de accionamiento (kW/r.p.m.): 15-30/1500

- Velocidad de los rodillos $(\mathrm{m} / \mathrm{s}): 2,4$

- Área de la matriz perforada $\left(\mathrm{cm}^{2}\right): 840$

- Masa de la prensa con motor (kg): 1300

Existen diferentes tipos de matrices que pueden utilizarse en la prensa. Sin embargo, las matrices que se emplean durante la experimentación son de acero inoxidable, siendo su codificación 8-5/32/10 y 8-5/35/10, respectivamente. La codificación hace referencia a parámetros tales como diámetro del canal, cono de entrada, canal y cono de salida. La correspondencia de la codificación se muestra en la Figura 2.9. La relación de compresión de las matrices empleadas fue de 37 y 40, que hace referencia a la suma del cono de entrada más el canal de compresión.

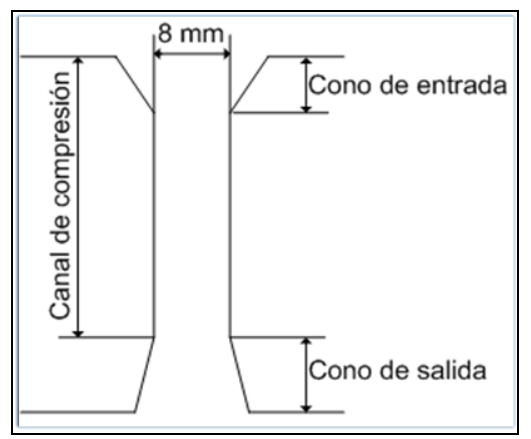

Figura 2.9. Codificación de matrices. 


\subsubsection{MÉTODOS DE PREPARACIÓN}

La realización de cada ensayo de densificación de materiales se realiza siguiendo un protocolo que asegura el correcto desarrollo del proceso. Durante todo el proceso se deben seguir unas rigurosas medidas de seguridad que eviten situaciones de riesgo para los operarios. La pruebas experimentales de densificación requieren de una adecuación previa del material objeto de dicho proceso. Por tanto, el material de partida debe seguir una secuencia de pasos desde su llegada al centro, hasta su tratamiento previo al proceso de densificación.

El primer paso a llevar a cabo es el secado del material de partida, ya que la humedad es un parámetro limitante en la calidad final de pélet producido. El material a secar se extiende en el secadero solar híbrido de forma que se voltea y desplaza secándose en su interior. La necesidad de aporte de calor externo se analiza en función de los análisis de humedad, que se realizan sobre el material durante el tiempo de secado. El tiempo de secado depende de las condiciones de humedad del material necesarias para realizar la experiencia de densificación fijada.

Una vez secado el material a un valor de humedad adecuado, se procede a la reducción de tamaño previa a la densificación. El material es alimentado mediante una cinta transportadora, desde donde se eliminan impurezas como materiales ferromagnéticos y piedras. El material se somete a un primer proceso de trituración, seguido de una trituración más específica. En este caso el material fue triturado inicialmente en un molino de cuchillas con una malla de $25 \mathrm{~mm}$, para finalizar el proceso de trituración con una malla de $8 \mathrm{~mm}$. Tras la homogeneización del tamaño de material, éste es apto para su proceso de densificación.

La alimentación del material a peletizar se realiza mediante una cinta transportadora y un elevador de cangilones, que alimentan una tolva. Existe la posibilidad de alimentación en distintos silos con el objeto de realizar un mezclado de material, aunque éste puede ser realizado previamente. Se realizaron numerosos ensayos con el propósito de seleccionar la matriz plana adecuada para llevar a cabo la experimentación, siendo las matrices elegidas, las siguientes: matriz de acero inoxidable 8-5/32/10 y 8-5/35/10, respectivamente.

Tras la peletización del material, éste se acondiciona previamente a su almacenaje, haciéndose pasar por un equipo de enfriamiento, una criba, donde se retiran los finos producidos, y una tolva de ensaque, que permite la recolección del producto peletizado en sacas.

La figura 2.10, permite observar la transformación del material original proveniente de la planta de tratamiento de residuos sólidos en un combustible adecuado para valorización energética, densificado en forma de pélets. 


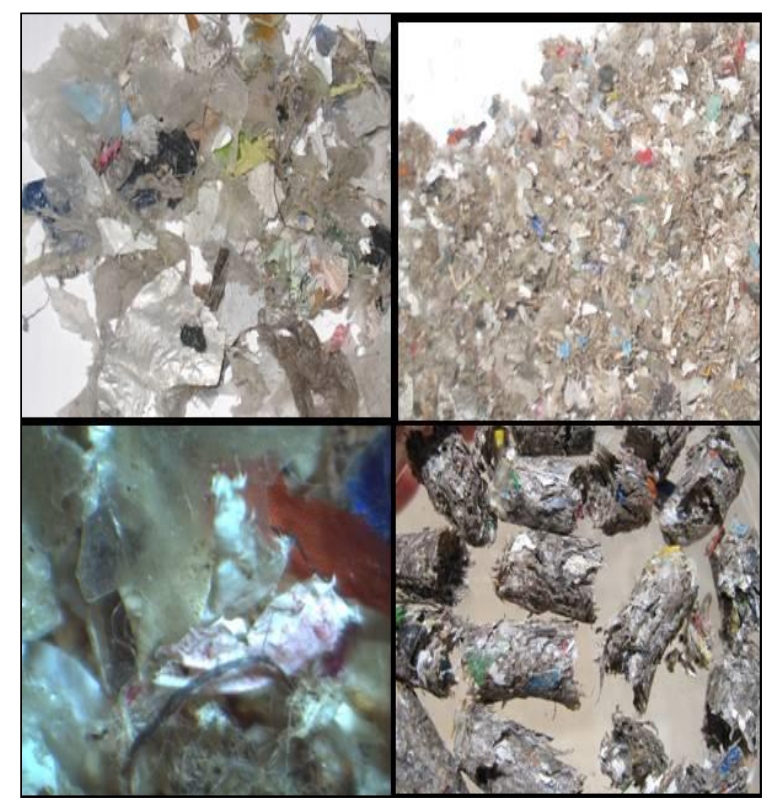

Figura 2.10. Residuo sólido urbano y residuo de la clasificación y selección de envases. Material molido a $25 \mathrm{~mm}$ y $8 \mathrm{~mm}$ en la parte superior. Imagen aumentada de material molido a $25 \mathrm{~mm}$ y pélets en la parte inferior.

Las plantas piloto de trituración y peletizado constan de sistemas de parada de emergencia en caso de riesgo para los operarios o debido a la rotura de algún equipo. Una vez finalizada la experiencia realizada, los equipos son limpiados con el objeto de retirar impurezas que afecten a otros ensayos de preparación.

Además, el registro de las variables de proceso se realiza tanto para los ensayos de trituración, como para los ensayos de peletización. El registro de las variables de proceso se realiza por medio de un computador lógico programable (PLC), que recibe las señales analógicas de los instrumentos de medida de la planta, siendo almacenadas mediante un sistema de adquisición de datos. Tanto en los ensayos de trituración como en los de densificación se determinaron una serie de variables calculadas a partir de las variables de proceso como: flujo de masa ( $\mathrm{kg}$ materia seca/h $\mathrm{kW}$ potencia de accionamiento) y energía ( $\mathrm{kWh} / \mathrm{T}$ materia seca).

\subsection{INSTALACIONES DE GASIFICACIÓN}

\subsubsection{PLANTA PILOTO DE LECHO FLUIDIZADO BURBUJEANTE}

En la Figura 2.11 se muestra la planta piloto de gasificación, que consiste en un lecho fluidizado burbujeante de $0,1 \mathrm{MW}_{\text {th }}$ operado a presión atmosférica. La operación de la unidad burbujeante se realiza de manera autotérmica, es decir sin aporte externo de calor. La instalación se encuentra situada en el interior de una nave industrial, para evitar inclemencias meteorológicas. La caracterización global del proceso de gasificación se realiza en base a la monitorización y registro de parámetros clave durante el desarrollo de la experimentación. La instalación que pretende ser versátil admite diferentes combustibles sólidos, siendo el agente gasificante habitual aire, aunque permite introducir mezclas de aire con oxígeno y/o vapor 


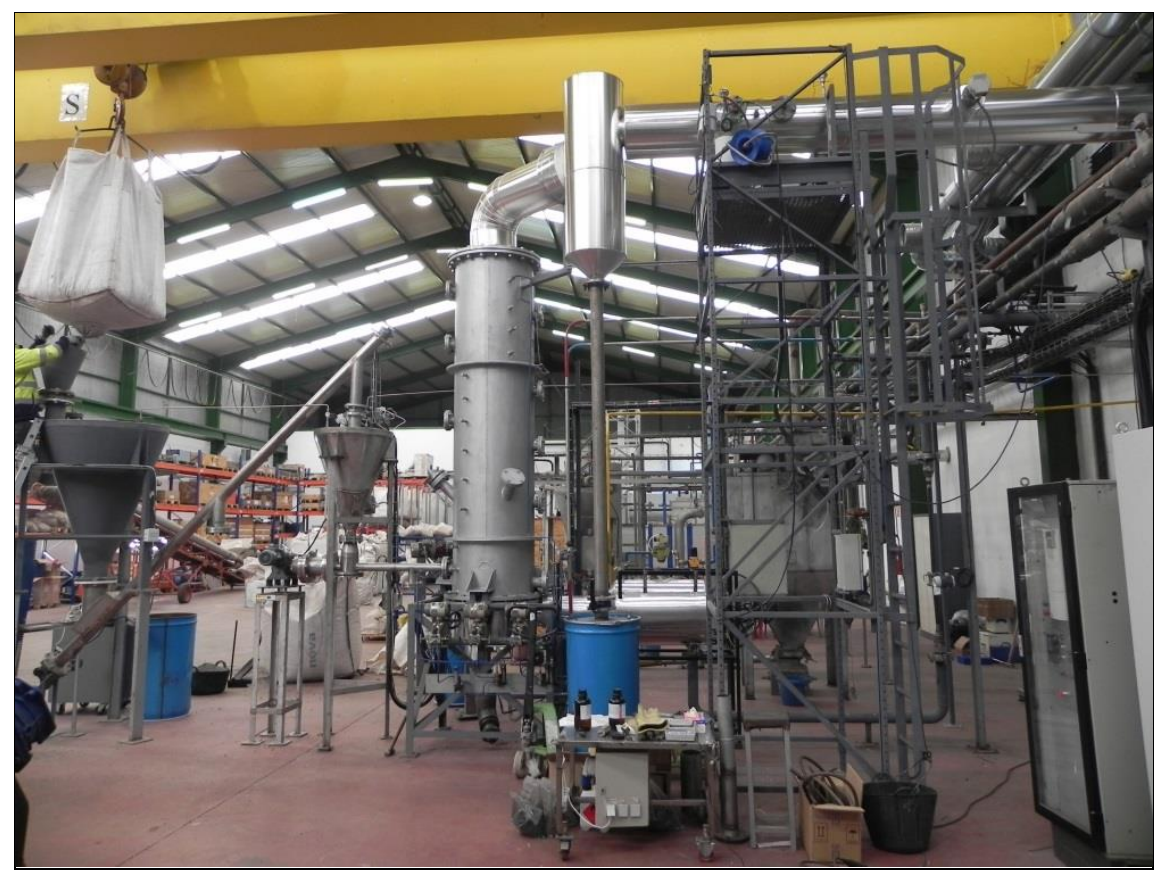

Figura 2.11. Vista general de la planta piloto de gasificación de lecho fluidizado burbujeante.

La instalación está constituida por cinco zonas diferentes, ver Figura 2.12:

- Sistema de alimentación del agente gasificante

- Sistema de alimentación del combustible

- Reactor de gasificación

- Sistema de tratamiento de gas de proceso

- Sistemas auxiliares

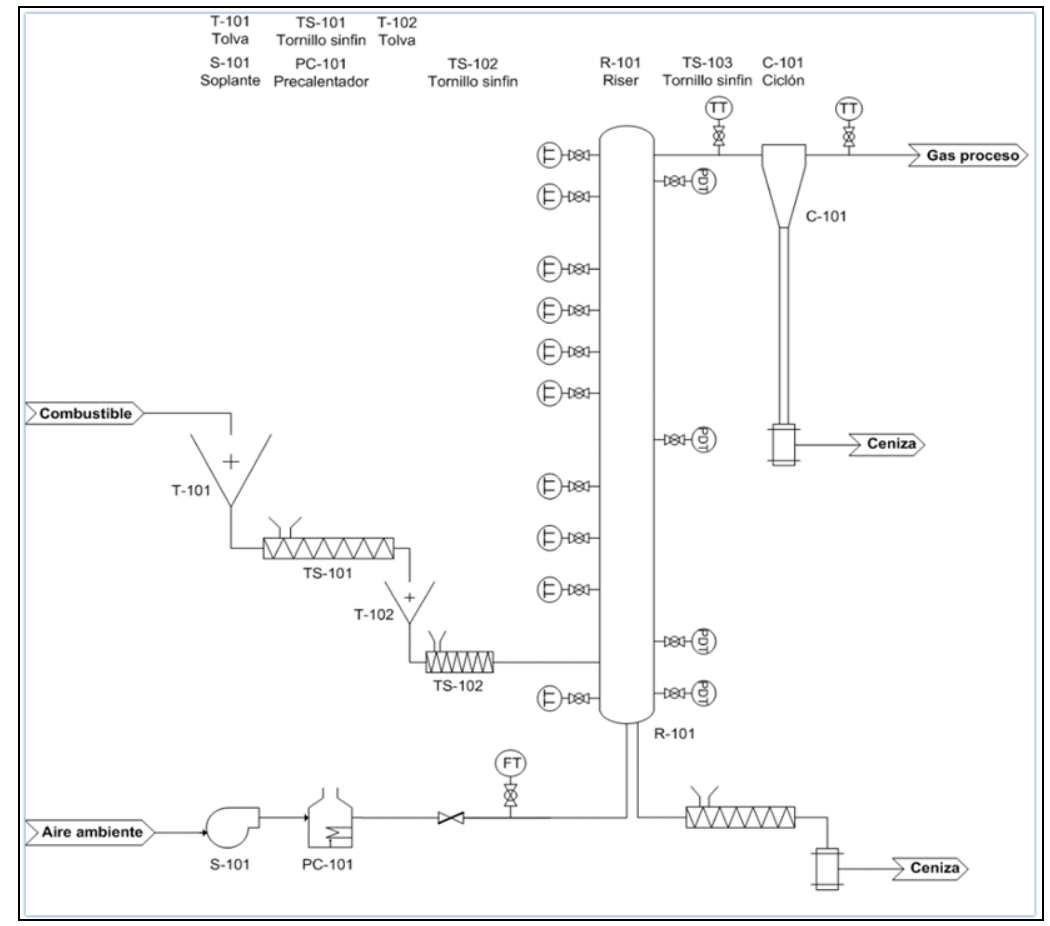

Figura 2.12. Diagrama P\&I de la planta piloto de gasificación de lecho fluidizado burbujeante. 


\subsubsection{Sistema de alimentación del agente gasificante}

Se ha seleccionado aire como agente gasificante de referencia, para conseguir simular el comportamiento de una planta industrial, que opere de manera autotérmica con el menor coste económico posible. El caudal de aire primario se suministra a través de una soplante de émbolos rotativos, que es capaz de aportar un caudal de hasta unos $300 \mathrm{Nm}^{3} / \mathrm{h}$, a los niveles de presión de la instalación, que deben ser ligeramente superiores a la presión atmosférica, aproximadamente 0,5 bar.

La medida y registro del caudal de aire alimentado al gasificador se realiza mediante un caudalímetro de dispersión térmica, modelo ST-50 (FCI). El aire suministrado se alimenta de manera lateral a la caja de vientos, previamente a su paso por un distribuidor de gas, que se aloja en su parte superior. El distribuidor de gas consiste en una placa tipo campana, de $36 \mathrm{~mm}$ de altura, fabricada en acero con un total de 156 campanas cilíndricas como se muestra en la Figura 2.13.

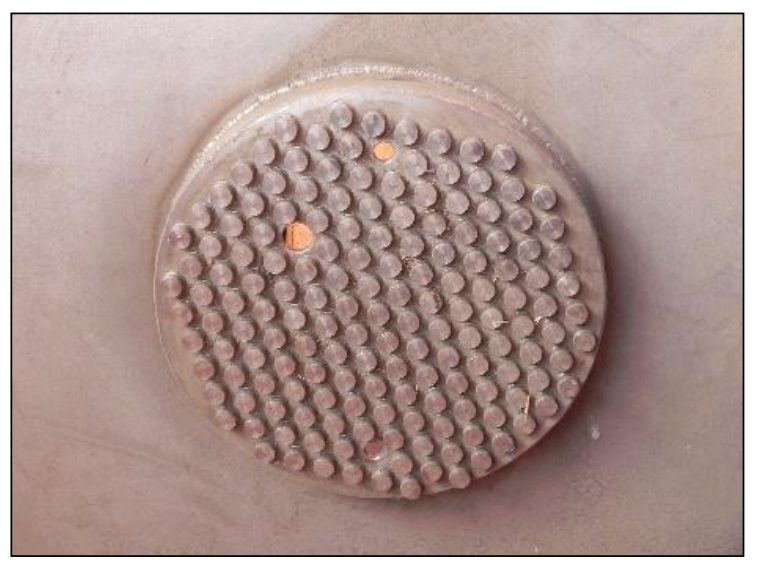

Figura 2.13. Distribuidor de gas utilizado en el gasificador de lecho fluidizado burbujeante.

\subsubsection{Sistema de alimentación del combustible}

El sistema de alimentación de sólidos está formado por cuatro elementos:

- Tolva de almacenamiento con válvula tajadera en la entrada de material

- Tornillo de transporte.

- Tolva de dosificación con válvula tajadera en la entrada de material.

- Tornillo de alimentación rápido.

El sistema de alimentación cuenta con dos tolvas cónicas para almacenar el combustible que se emplea durante el desarrollo experimental. La primera de las tolvas tiene una capacidad de $530 \mathrm{~L}$, siendo su objeto el actuar como reserva de combustible durante la operación, que permite dotar de una mayor autonomía. Esta tolva se alimenta de manera manual. No obstante, la tolva dispone de una válvula de tajadera, situada en la boca de alimentación, de accionamiento neumático, para conseguir lograr un cierre hermético en el sistema de alimentación. Conectada a esta primera tolva se encuentra un tornillo de transporte accionado por un motor, con capacidad máxima de $150 \mathrm{~kg} / \mathrm{h}$, que permite el llenado de la tolva de dosificación, con capacidad para 60 L. 
La tolva de dosificación dispone de dos válvulas de tajadera para realizar el cierre hermético de la misma, una vez haya sido cargada. Esta última tolva ejerce las funciones de dosificación de combustible al reactor. Ambas tolvas llevan incorporadas medidores de nivel mecánico, que avisan sobre el agotamiento de combustible. El sistema de alimentación dispone de una secuencia de carga de combustible que evita el retroceso de gas desde el reactor, es decir: una secuencia neumática para el llenado de la tolva de dosificación. Esta tolva dispone de una válvula de presurización y de otra válvula de by-pass, que actúan en función de la presión medida en su interior. Se emplea nitrógeno para suministrar la sobrepresión necesaria a las tolvas, evitando el retroceso de gas de proceso.

La tolva de dosificación se encuentra directamente conectada a un tornillo sinfín, con capacidad máxima de $42 \mathrm{~kg} / \mathrm{h}$, que hace las veces de dosificador de sólido. El dosificador de sólido es de tipo volumétrico, basado en un tornillo sinfín acoplado a un variador. La variación de la velocidad de giro del tornillo se selecciona mediante un variador de frecuencia que está acoplado al motor del sistema. El caudal alimentado de combustible se relaciona con la velocidad de giro del tornillo dosificador a través de la calibración en frío del tornillo dosificador para cada uno de los combustibles ensayados.

\subsubsection{Reactor de gasificación}

La planta piloto de gasificación de lecho fluidizado burbujeante consiste en un reactor construido en acero refractario con un diámetro interior de $300 \mathrm{~mm}$, una capa de acero refractario de $150 \mathrm{~mm}$ y $5 \mathrm{~mm}$ de espesor de acero, y una altura de $3000 \mathrm{~mm}$. La distribución de aire primario se realiza mediante un distribuidor de aire de tipo campana. Este distribuidor tiene un orificio central de $40 \mathrm{~mm}$, que sirve para la extracción del material de lecho y las cenizas. La instalación está equipada con un sistema de extracción de cenizas en caso de que fuera necesario.

El reactor de gasificación presenta una entrada lateral, que se corresponden con la alimentación de combustible, situada a una altura de $300 \mathrm{~mm}$. Además, dispone de dos entradas de aire secundario, que están situadas a unas alturas de $760 \mathrm{~mm}$ y $1050 \mathrm{~mm}$ respecto de la placa distribuidora, respectivamente. La planta piloto de gasificación dispone de múltiples sondas para la medida de temperatura y transmisores de presión. El reactor dispone de 10 sondas de temperatura situadas a diferentes alturas y 4 transmisores de presión.

\subsubsection{Sistemas de monitorización y control}

El registro de variables del proceso se realiza por medio de un computador lógico programable (PLC), que recibe las señales analógicas de los instrumentos de medida de la planta. El ordenador de control tiene instalado un programa de control supervisor y de adquisición de datos (SCADA), como se muestra en la Figura 2.14, que se comunica con el PLC. Las condiciones de operación del proceso se modifican por el operario a través del SCADA. 


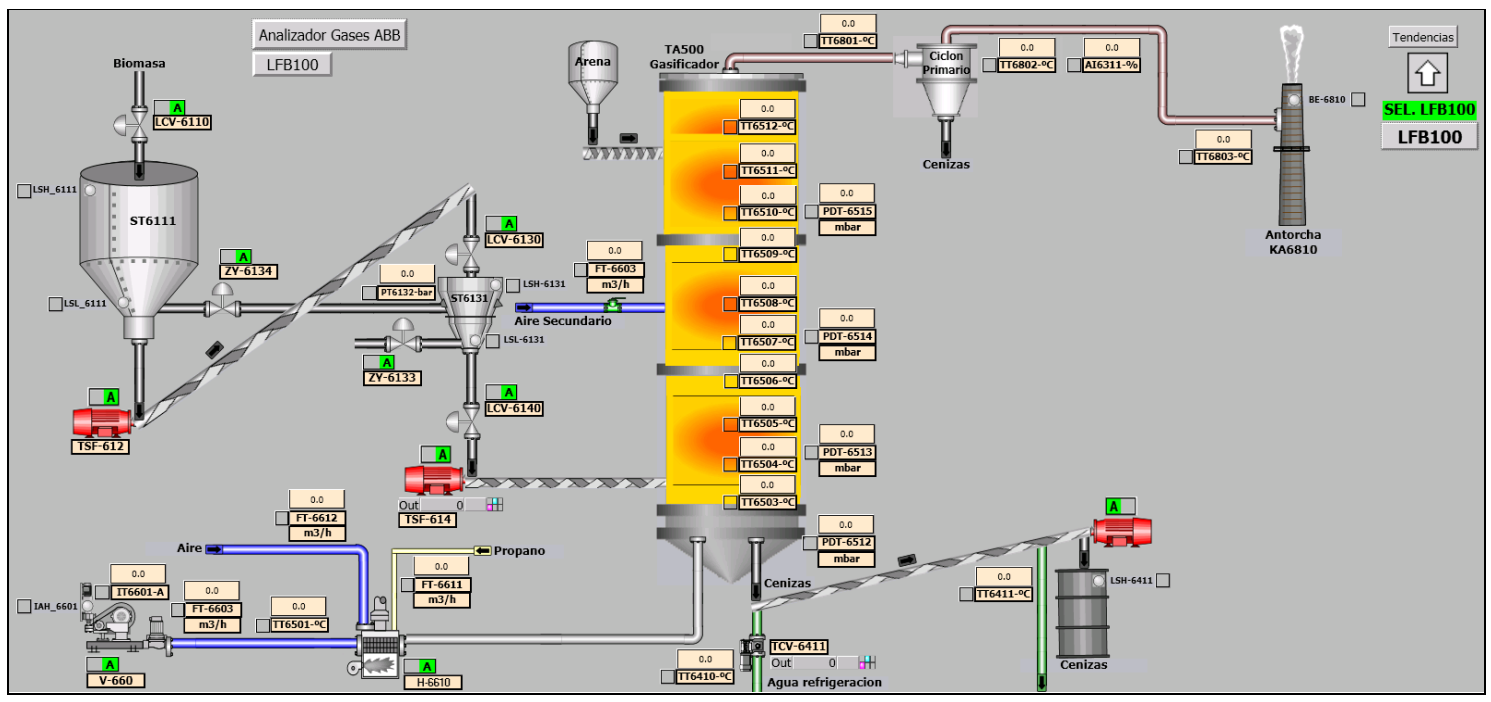

Figura 2.14. Pantalla principal del SCADA usado en la planta piloto de gasificación de lecho fluidizado burbujeante.

\subsubsection{Material de lecho y aditivos}

El material de lecho empleado ha sido arena de sílice, con un diámetro medio de partícula de $428 \mu \mathrm{m}$. La selección de arena de sílice se ha producido debido a su elevada disponibilidad, buena resistencia y bajo coste.

\subsubsection{Desarrollo experimental}

Este apartado muestra la descripción de una prueba de gasificación tipo, desde la preparación del ensayo hasta la parada de la instalación. Cada experiencia de gasificación se realiza siguiendo un protocolo normalizado que permite llevar a cabo cada experimento con las máximas garantías de seguridad.

\subsubsection{Puesta en marcha de la instalación}

El desarrollo de cada prueba experimental requiere de un tiempo de preparación. Esta planificación alberga puesta a punto, operación y limpieza de la planta piloto. En la preparación del ensayo se corrigen los fallos detectados durante la probatura de los instrumentos de medida, se selecciona el combustible a ensayar, y se marcan las condiciones iniciales que serán seleccionadas en la operación de la planta piloto.

Tras la selección del combustible a gasificar, se realiza el calibrado del tornillo de alimentación antes del día de celebración del ensayo. La carga del inerte se reserva para el mismo día del ensayo a fin de evitar problemas derivados del empaquetamiento del material de lecho seleccionado. La carga se realiza a través de una boca embridada, colocada a tal efecto. La comprobación de los rangos de medida de la instrumentación de la planta se lleva a cabo durante la preparación del ensayo. La limpieza y encendido de la antorcha se realiza antes de que se produzca el arranque de la planta de manera que esté operativa. Además, el encendido del analizador de gases se realiza de manera simultánea a las actuaciones necesarias para el arranque de la planta. 
El arranque comienza con el encendido del tornillo de alimentación, para evitar que se bloquee con los inertes arrastrados por el aire primario. Seguidamente, se inicia el calentamiento con el aporte de aire caliente, precalentado con propano, hasta alcanzar un nivel de temperatura suficiente, temperatura de ignición del combustible a alimentar. La temperatura que se pretende alcanzar de esta forma es próxima a los $400^{\circ} \mathrm{C}$, cuando se puede comenzar la alimentación del combustible a gasificar. El aire precalentado se mantiene hasta que se alcance una temperatura que permita el funcionamiento de la instalación sin necesidad de aporte externo de calor, como operaría una planta industrial, para posteriormente operar de manera autotérmica.

\subsubsection{Operación en planta}

Tras haberse alcanzado la temperatura de ignición del combustible, se establecen condiciones de combustión en el reactor mediante el aporte de una cantidad reducida de combustible con exceso de aire primario, que permita quemar todo el combustible alimentado. Este aporte de combustible consigue un aumento rápido de la temperatura en el interior del reactor. Posteriormente, se incrementa la alimentación de manera escalonada, asegurando el consumo del combustible aportado. El caudal de combustible alimentado se aumenta progresivamente hasta que se alcanza una temperatura estable, con las condiciones de gasificación fijadas inicialmente durante la fase de preparación.

La composición de gas se analiza de manera continua hasta que se alcanzan las condiciones de operación programadas. El muestreo de alquitranes se lleva a cabo una vez que se han conseguido las condiciones establecidas para el ensayo en cuestión. Tras la finalización del ensayo, se recogen muestras de la ceniza recogida en el ciclón secundario y del material de lecho.

\subsubsection{Parada de la instalación}

Una vez concluido el ensayo se realiza la parada de la instalación. Ésta se inicia con la parada de la alimentación de combustible, mediante el cierre de una válvula de tajadera, que separa el tornillo de alimentación de la tolva de dosificación. Se continúa introduciendo aire primario durante un tiempo adecuado, hasta agotar completamente el combustible y los inquemados residuales. La parada completa de la planta se realiza cuando se observa una caída de las temperaturas en el interior del reactor, pudiendo llegar a extenderse un tiempo significativo esta acción. No obstante, existen protocolos de apagado en caso de parada obligatoria, debido a incidencias durante el periodo de operación, que permiten apagar la instalación mediante el corte de los aportes de combustible y suministro de aire primario, realizándose una purga con nitrógeno que inertice el reactor.

\subsubsection{PLANTA PILOTO DE LECHO FLUIDIZADO CIRCULANTE}

La planta piloto de gasificación consiste en un lecho fluidizado circulante de 0,5 $\mathrm{MW}_{\text {th }}$ operado a presión atmosférica, ver Figura 2.15. Esta planta está diseñada de manera que se puedan reproducir las condiciones de operación reales de una planta industrial a escala de planta piloto. La instalación se encuentra situada sobre una estructura metálica, que cuenta con cinco pisos. Esta estructura metálica se encuentra confinada en el interior de una nave, evitando inclemencias meteorológicas. 
La caracterización global del proceso se realiza en base a la monitorización y registro de parámetros clave durante la experimentación. Esta instalación está diseñada para su operación con aire como agente gasificante y para la posibilidad de utilización de gran variedad de combustibles.

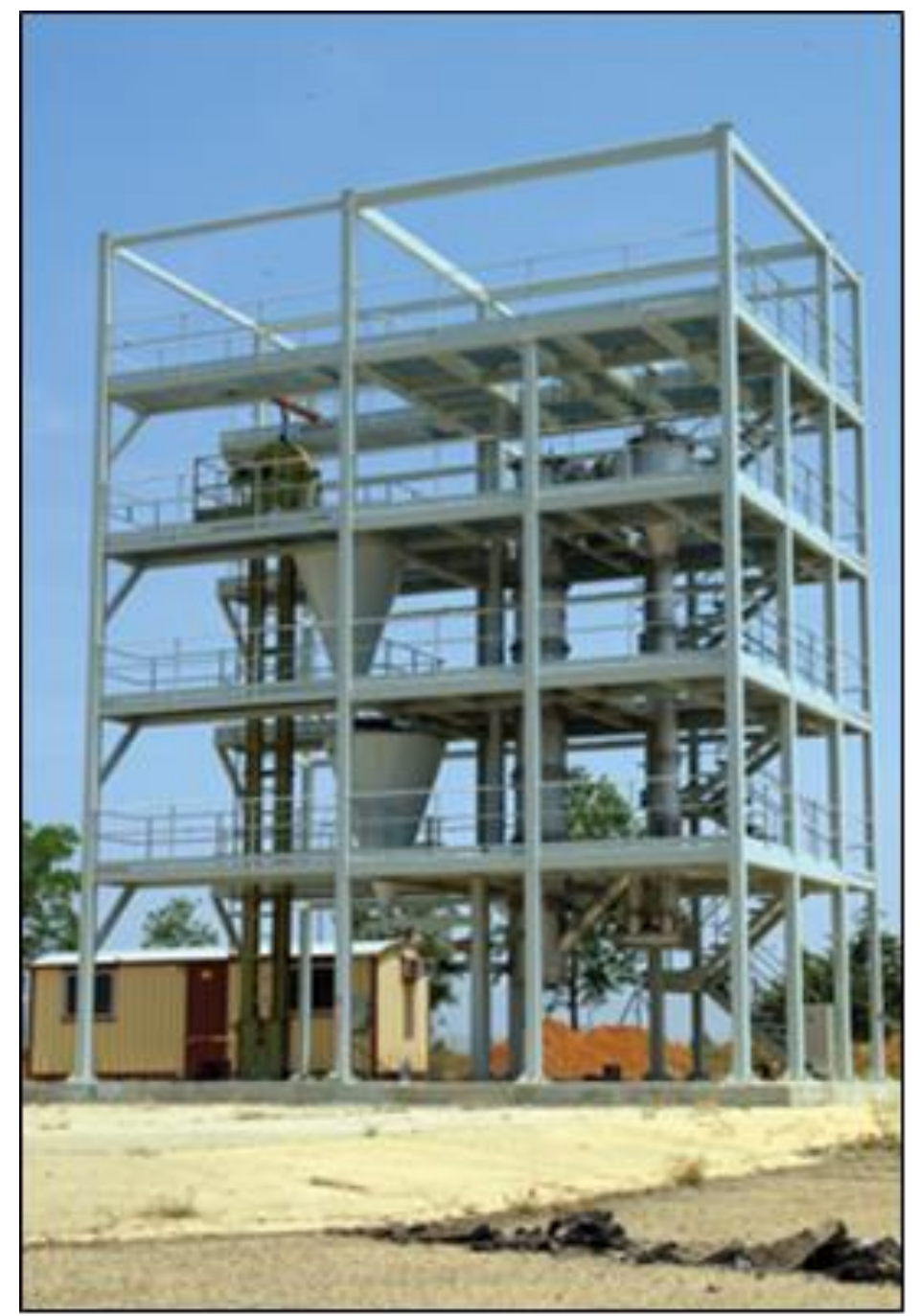

Figura 2.15. Vista general de la planta piloto de gasificación de lecho fluidizado circulante.

La instalación está constituida por cinco zonas diferentes, ver Figura 2.16:

- Sistema de alimentación del agente gasificante

- Sistema de alimentación del combustible

- Reactor de gasificación y sistema de recirculación

- Sistema de tratamiento de gas de proceso

- Sistemas auxiliares 


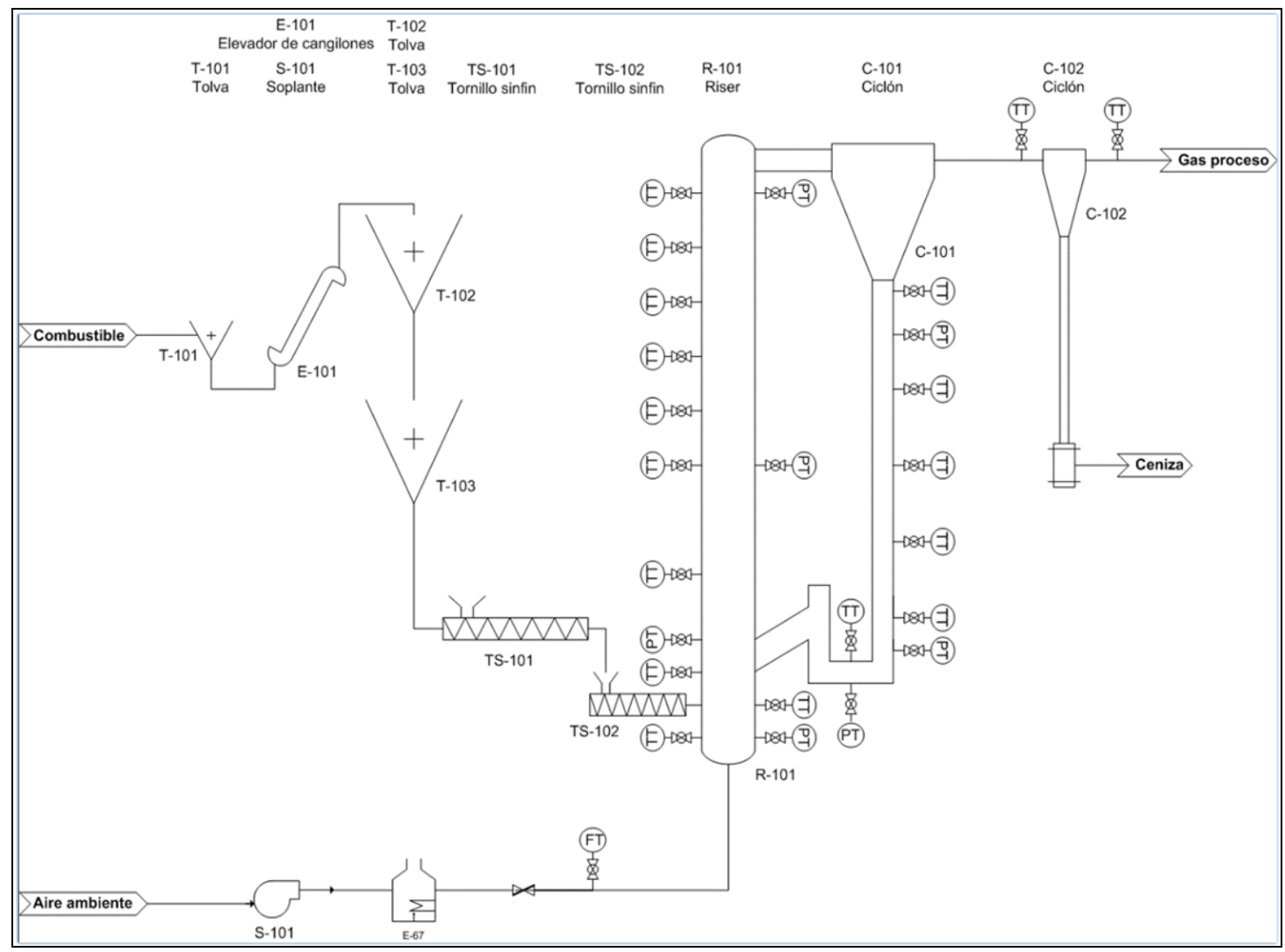

Figura 2.16. Diagrama P\&I de la planta piloto de gasificación de lecho fluidizado circulante.

\subsubsection{Sistema de alimentación de agente gasificante}

La planta piloto está diseñada para operar con aire como agente gasificante, de manera que se obtiene un gas de proceso con un poder calorífico bajo, debido a la dilución que experimenta con el nitrógeno. La selección de este agente gasificante se realizó para la simulación de una planta industrial a escala piloto, que opere de manera autotérmica con el menor coste económico posible.

El aire se suministra a través de una soplante de émbolos rotativos, que es capaz de aportar un caudal de hasta unos $300 \mathrm{Nm}^{3} / \mathrm{h}$. La instalación opera a una presión ligeramente superior a la presión atmosférica, aproximadamente 200 mbar. La medida y registro del caudal de aire alimentado al gasificador se realiza mediante un caudalímetro de dispersión térmica, modelo ST50 (FCI).

El aire primario se suministra, previamente calentado, por la parte inferior del reactor a través de un distribuidor de gas. La caja de vientos del reactor (plenum) está conectada a la tubería de alimentación de aire que suministra la soplante. El aire introducido a la caja de vientos entra de forma lateral al reactor, previamente a su paso por un distribuidor de gas, que se aloja en la parte superior del plenum.

El distribuidor de gas consiste en una placa tipo campana, de $60 \mathrm{~mm}$ de altura, fabricada en acero inoxidable AISI-310 con un total de 40 campanas como se muestra en la Figura 2.17. Además, se muestran los dos modelos de distribuidor de gas que han sido empleados en la instalación, ya que se produjo el cambio del distribuidor que aparece en la primera fotografía por el que aparece en la segunda fotografía debido a su deterioro. 
El objetivo del distribuidor de gas es asegurar la pérdida de carga necesaria para evitar la aparición de caminos preferentes y facilitar la adecuada fluidización del lecho de partículas sólidas que contiene.
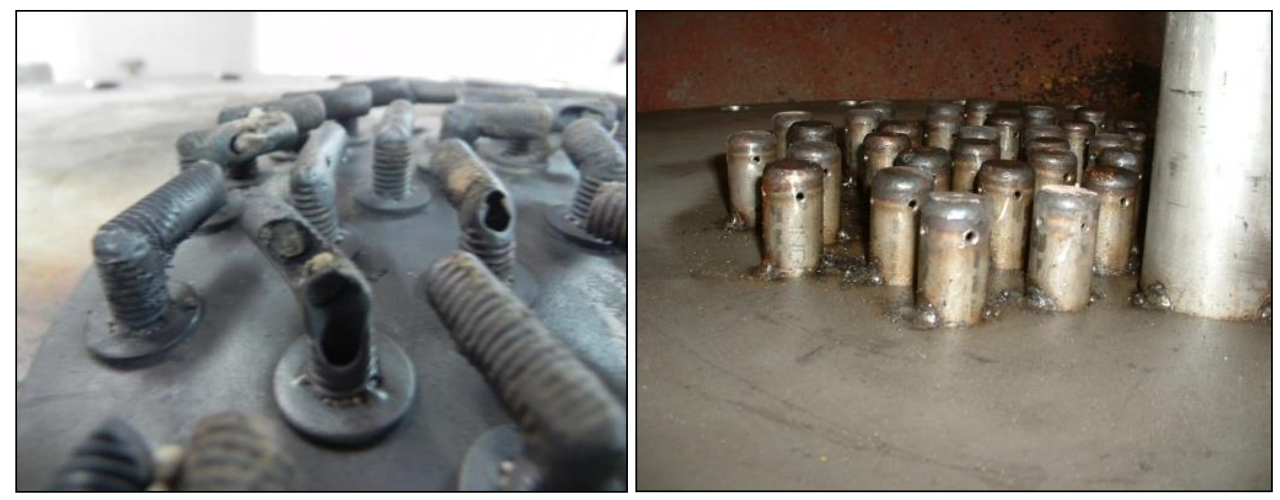

Figura 2.17. Distribuidores de gas utilizados en el gasificador de lecho fluidizado circulante.

El aire primario se precalienta previamente a la entrada en la caja de vientos mediante un precalentador. La temperatura máxima a la que este equipo permite elevar la temperatura del aire es $500^{\circ} \mathrm{C}$. Además, la instalación cuenta con un sistema de seguridad ante emergencias de forma que se puede alimentar nitrógeno industrial por medio de botellas tipo B50, pureza superior al 99,5\% (v/v), para inertizar la instalación si fuera necesario.

\subsubsection{Sistema de alimentación de combustible}

Elementos de que se compone el sistema de alimentación:

- Elevador de cangilones

- Sistema de tolvas y tornillo de dosificación

- Variador de frecuencia para el tornillo dosificador

- Válvula rotativa

- Tornillo de alimentación rápido

El sistema de almacenamiento de sólidos cuenta con un elevador de cangilones, que permite el ascenso del combustible hasta las tolvas de almacenamiento. Además, este sistema cuenta con dos tolvas cónicas para almacenar el combustible que se emplea durante el desarrollo experimental. La primera de las tolvas tiene una capacidad de 3 $\mathrm{m}^{3}$, siendo su objeto el actuar como reserva de combustible durante la operación, para dotar de autonomía a la planta. Esta tolva se alimenta a través de un elevador de cangilones a cuya salida se dispone de una válvula tajadera de tipo neumático.

Conectada a esta primera tolva, se encuentra otra tolva cónica, con capacidad para $3 \mathrm{~m}^{3}$, situándose una válvula de tajadera de tipo neumático como elemento de seguridad intermedio entre las mismas. Esta última tolva ejerce las funciones de dosificación de combustible al reactor. Ambas tolvas llevan incorporadas medidores de nivel de tipo mecánico que avisan al operario sobre el agotamiento de combustible.

La tolva de dosificación se encuentra directamente conectada a un tornillo sinfín, que hace las veces de dosificador de sólido. El dosificador de sólido es de tipo volumétrico, 
basado en un tornillo sinfín acoplado a un variador. La velocidad de giro del tornillo se fija de forma aproximada a través de un reductor. La variación de la velocidad de giro del tornillo se realiza de manera precisa, mediante un variador de frecuencia que está acoplado al motor del sistema. El caudal alimentado de combustible se relaciona con la velocidad de giro del tornillo dosificador a través de la calibración en frío del tornillo dosificador para cada uno de los combustibles experimentados. Como medida de seguridad, se dispone de una válvula de tajadera de accionamiento pneumático en planta, para evitar retroceso de gas de proceso hacia la tolva de dosificación.

El sistema de alimentación, formado por las dos tolvas anteriormente citadas, se encuentra desacoplado del tornillo dosificador a través de un flexible, con el objeto de evitar que las dilataciones que se produzcan en el reactor, debido a las altas temperaturas a las que está sometido durante la operación, afecten a la medida de las células de carga usadas para el pesaje. El flexible está realizado en teflón, que es capaz de soportar temperaturas de hasta $200^{\circ} \mathrm{C}$.

La tolva de dosificación reposa sobre tres células de carga de forma que permiten registrar el peso de combustible a cada instante de tiempo. Por tanto, se determina el valor exacto del flujo de sólido alimentado que permite corregir las pequeñas diferencias con respecto a la calibración en frío. El conjunto cuenta en su parte final con un tornillo de alimentación rápido, que posibilita el paso del combustible alimentado de forma rápida al reactor. El tornillo tiene una contrapresión de aire con el objeto de evitar que se produzca el proceso de pirólisis del combustible antes de que éste llegue al reactor.

\subsubsection{Reactor de gasificación y sistema de recirculación}

La planta piloto de gasificación de lecho fluidizado circulante consiste en un reactor construido en acero refractario tipo AISI-310 con un diámetro interior de 300 $\mathrm{mm}$, dos capas de refractario diferentes: 100 y $150 \mathrm{~mm}, 4 \mathrm{~mm}$ de espesor de acero, 50 $\mathrm{mm}$ de espesor de aislamiento exterior y $0,8 \mathrm{~mm}$ de espesor de chapa de acero inoxidable. La altura del reactor es de $8764 \mathrm{~mm}$ y $9060 \mathrm{~mm}$ a la salida del ciclón. El gasificador se puede dividir en cuatro partes diferenciadas: caja de vientos, reactor de gasificación, ciclón primario y sistema de recirculación.

La distribución de aire primario suministrado por la soplante se realiza a través de un distribuidor tipo campana situado en la parte superior de la caja de vientos. Este distribuidor tiene un orificio central de $40 \mathrm{~mm}$. El orificio sirve para la descarga del material de lecho y para la extracción de cenizas de manera continua, en caso de que fuera requerida por el tipo de combustible empleado. El sistema de extracción de cenizas consta de un tornillo sinfín refrigerado que esta acoplado a un tambor de descarga de cenizas.

El reactor de gasificación es un tubo de $300 \mathrm{~mm}$ de diámetro y $8764 \mathrm{~mm}$ de altura, que presenta dos entradas laterales, que se corresponden con la alimentación de combustible y material de lecho, y con la entrada de material de lecho e inquemados recirculados al reactor de gasificación. Las entradas están situadas a unas alturas de $340 \mathrm{~mm}$ y $700 \mathrm{~mm}$ con respecto a la placa distribuidora. La conexión del reactor con el sistema de recirculación se lleva a cabo a través de una salida abrupta, que provoca la caída al riser de multitud de partículas sólidas arrastradas por el gas de proceso. 
El sistema de recirculación consta de un ciclón primario, que separa las partículas sólidas arrastradas por el gas de proceso, material de lecho e inquemados de manera que son recirculados mediante una válvula no-mecánica clásica denominada "loop-seal" al reactor, como se muestra en la Figura 2.18. La tubería de salida de salida del ciclón primario es un tubo de $127 \mathrm{~mm}$ de diámetro interno.

La recirculación de sólidos hacia el reactor se realiza mediante dos entradas de aire comprimido, cuyos caudales son controlados mediante dos controladores másicos de 0$12 \mathrm{Nm}^{3} / \mathrm{h}$ y $0-60 \mathrm{Nm}^{3} / \mathrm{h}$, respectivamente. La primera de las entradas está ubicada lateralmente en la rama de recirculación justo por encima del tramo horizontal que la sigue, a una altura de $12 \mathrm{~mm}$.

La segunda entrada de aire está situada en la parte final del tramo horizontal, de manera que se dispone de una especie de unidad burbujeante, que hace las veces de suministrador de sólidos al reactor a través de un tramo recto e inclinado de tubería, provocando la caída de los sólidos por gravedad, una vez superado el rebose de dicha unidad.

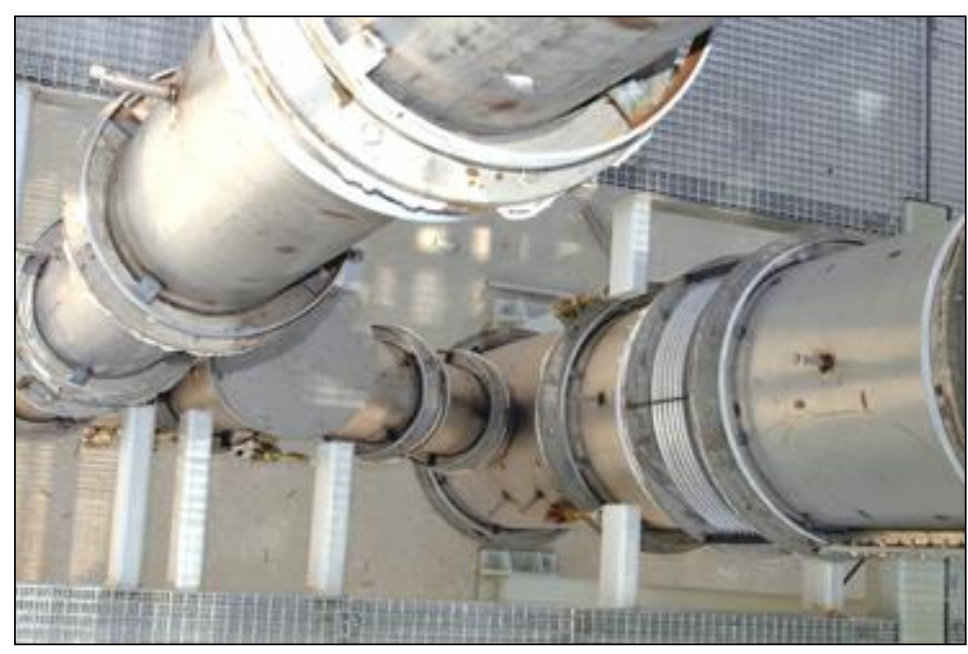

Figura 2.18. Válvula no-mecánica tipo "loop-seal”. 
En la Figura 2.19, se muestra un esquema del gasificador de lecho fluidizado circulante, donde se muestran los elementos que lo componen.

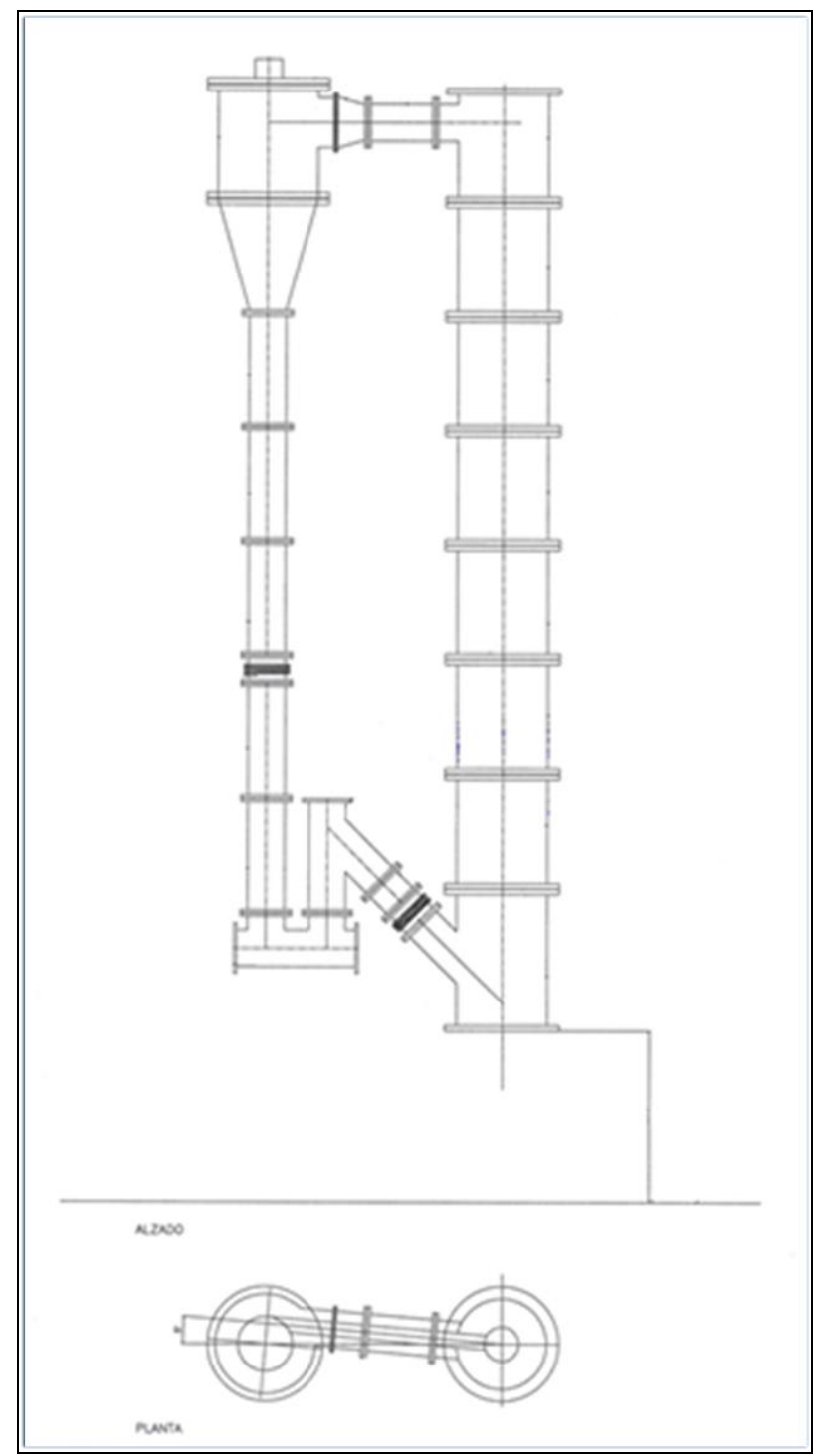

Figura 2.19. Esquema del gasificador de lecho fluidizado circulante.

\subsubsection{Sistemas de monitorización y control}

El registro de las variables del proceso monitorizadas se realiza por medio de un computador lógico programable (PLC), que recibe las señales analógicas de los instrumentos de medida de la planta. La planta piloto de gasificación dispone de múltiples sondas para la medida de temperatura y transmisores de presión.

El reactor dispone de 11 sondas de temperatura situadas a diferentes alturas y 4 transmisores de presión, el sistema de recirculación consta de 3 transmisores de presión y 6 sondas de temperatura. La monitorización de variables de proceso se realiza por medio de un computador lógico programable (PLC), que recibe las señales analógicas de los instrumentos de medida de la planta. El ordenador de control tiene instalado un programa de control supervisor y de adquisición de datos (SCADA), como se muestra en la Figura 2.20, que se comunica con el PLC. 


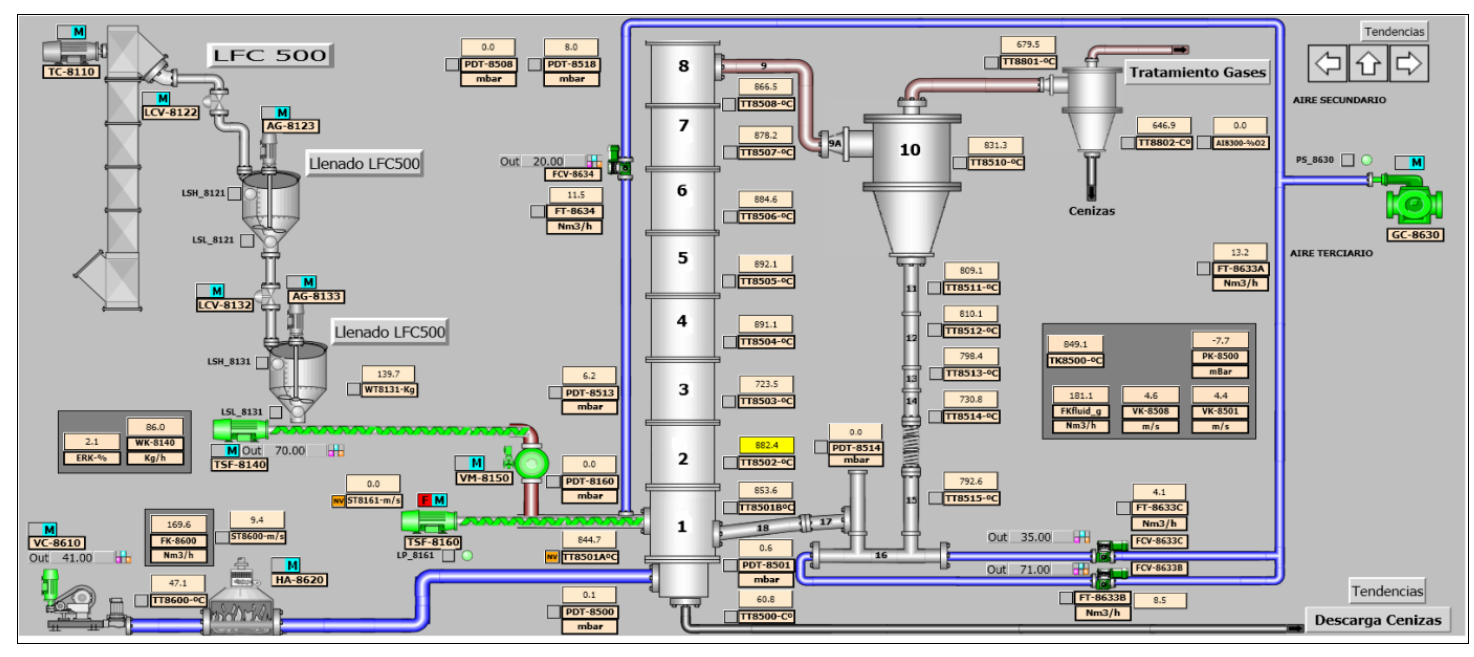

Figura 2.20. Pantalla principal del SCADA usado en la planta piloto de gasificación de lecho fluidizado circulante.

La instalación consta de sistemas auxiliares periféricos que cumplimentan la operación y dotan de medidas de seguridad adicionales a los operarios. Entre estos sistemas auxiliares se encuentran una red de agua, un sistema de saneamiento, una línea de aire comprimido para instrumentos y una central acústica de alarmas que dispone de detectores de $\mathrm{CO}$ en las tres primeras plantas y detectores de $\mathrm{H}_{2}$ en la segunda y tercera. Además, se dispone de equipos de protección individual como máscaras de gas o detectores de $\mathrm{CO}$ y equipos de respiración autónoma.

\subsubsection{Material de lecho y aditivos}

El material de lecho que se ha empleado en la realización de los ensayos en esta planta piloto ha sido arena de sílice. El criterio de selección de este inerte ha sido su alta disponibilidad, buena resistencia mecánica y bajo coste, aspectos de gran relevancia en aplicaciones de tipo de industrial.

\subsubsection{Desarrollo experimental}

La realización de cada experiencia de gasificación se realiza ateniendo a un protocolo normalizado de actuación, que garantiza el correcto desarrollo de la experiencia con las máximas garantías de seguridad a los operarios de la planta piloto. En este apartado se describe una prueba de gasificación genérica desde la preparación del ensayo y operación, hasta la parada de la instalación.

\subsection{Puesta en marcha de la instalación}

La preparación de una prueba experimental requiere de una semana de planificación, que se dividen en preparación, operación y limpieza de la planta piloto. La preparación del ensayo es de gran importancia porque se van a determinar las actuaciones necesarias para corregir los posibles fallos que se detecten, la logística de carga de inertes, el suministro de combustible, y el establecimiento de las condiciones iniciales que se serán seleccionadas en la operación de la planta piloto. Inicialmente se realiza la planificación del ensayo, donde se selecciona el material de lecho, el combustible a gasificar y las condiciones de operación a fijar. 
Una vez seleccionado el combustible a gasificar, se realiza el calibrado del tornillo de alimentación. La carga del inerte se realiza el mismo día del ensayo para evitar problemas derivados del empaquetamiento del material de lecho seleccionado. Esta carga se realiza a través de una de las tapas de que dispone la válvula no-mecánica.

Las siguientes actuaciones corresponden a la comprobación de las variables monitorizadas mediante el SCADA, es decir: la comprobación de la exactitud de los rangos de medida de la instrumentación de la planta. Finalmente, se procede a la limpieza y encendido de la antorcha de manera que esté operativa antes de que se produzca el arranque de la planta. El encendido del analizador de gases se realiza simultáneamente al arranque de la instalación.

El arranque comienza con el encendido del tornillo de alimentación, de manera que se evita que el aire primario suministrado por la soplante pueda arrastrar los inertes, llenando por completo y bloqueando el tornillo. El protocolo de calentamiento se inicia con el suministro de aire caliente precalentado hasta que se alcanza la temperatura de ignición del combustible, se sigue con un pequeño aporte de combustible junto con el aire precalentado hasta alcanzar una temperatura constante que permita el apagado del precalentador. Durante la fase de precalentamiento se procede a la alimentación de combustible en las tolvas de alimentación para garantizar el suministro una vez finalizada la etapa de precalentamiento.

\subsection{Operación en planta}

Una vez alcanzada la temperatura de ignición del combustible a alimentar, se establecen condiciones de combustión en el reactor mediante el aporte de una reducida cantidad de combustible con exceso de aire primario, que permita quemar todo el combustible alimentado. Esta acción provoca un aumento rápido de la temperatura en el interior del reactor. La alimentación se realiza escalonadamente, por cargas, de manera que se asegura que se consume el combustible aportado, evitando problemas de defluidización. Un ejemplo de la evolución transitoria de las temperaturas en el reactor se muestra en la Figura 2.21, que permite observar las curvas oscilatorias en el interior del reactor hasta alcanzar una temperatura constante.

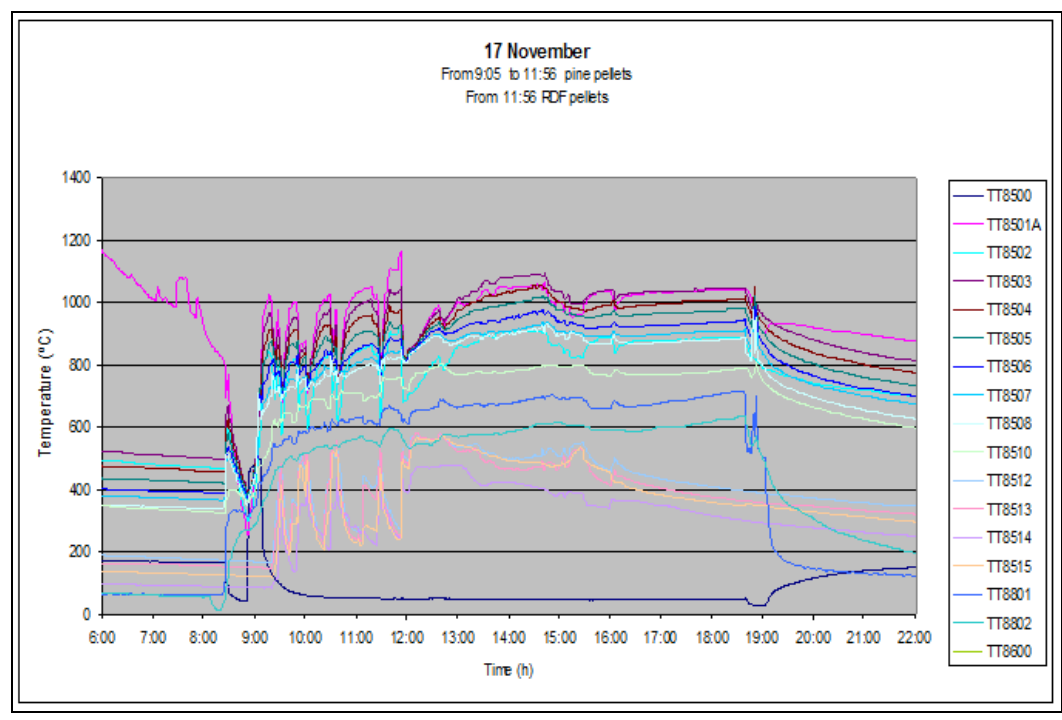

Figura 2.21. Evolución de las temperaturas en el interior del reactor durante el ensayo de gasificación en lecho fluidizado circulante. 
El caudal de combustible alimentado se aumenta de manera progresiva hasta que se alcanza una temperatura estable y por consiguiente, condiciones de gasificación. El caudal de combustible se aumenta hasta alcanzar las condiciones de operación fijadas, fijadas, es decir la proporción buscada entre el caudal de aire primario y de combustible.

El muestreo de composición de gas se realiza de manera continua cuando se han alcanzado las condiciones de operación programadas. Después de observarse que tanto la composición, como la temperatura permanecen estables se procede al muestreo de alquitranes. Tras la finalización del ensayo se recogen muestras de la ceniza recogida en el ciclón secundario y del material de lecho.

\subsection{Parada de la instalación}

La parada de la instalación se realiza siguiendo un protocolo de actuación. Esta secuencia se inicia con la parada de alimentación de combustible, mediante el cierre de una válvula de tajadera, donde quedan separados los tornillos de alimentación de las tolvas, continuando con el funcionamiento de los tornillos de alimentación durante un tiempo hasta agotar el combustible contenido en ellos. Se apagan progresivamente el tornillo de alimentación, la válvula rotativa y el tornillo de alimentación rápido.

Posteriormente, se continúa alimentando aire primario durante un tiempo adecuado, para agotar completamente el combustible y los inquemados residuales. El enfriamiento del gasificador dura hasta que se observe una caída de las temperaturas en el interior del reactor de forma que se pueda realizar una parada completa de la planta a una temperatura adecuada. Además, existen protocolos de apagado en caso de parada obligatoria, debido a incidencias en la operación del gasificador, que impidan continuar con el ensayo. En este caso se detendrían los aportes de combustible y suministro de aire primario, realizándose una purga con nitrógeno que inertice el reactor.

\subsubsection{TRATAMIENTO DE LOS DATOS EXPERIMENTALES}

El tratamiento de los datos experimentales es idéntico en ambas instalaciones. El proceso de gasificación se controla mediante la medición de variables como: presiones y temperaturas a lo largo del cuerpo del gasificador, siendo las presiones de gran importancia en la rama de retorno en un gasificador de lecho fluidizado. Además de la cantidad de aire suministrado al proceso, medido a través de la relación de equivalencia (ER).

$$
E R=\frac{Q_{\text {aire }} / Q_{C S R}}{\left(Q_{\text {aire }} / Q_{C S R}\right)_{\text {estequiomárico }}}
$$

Ecuación 2.25

Dónde:

Q ${ }_{\text {CSR }}$ es el caudal másico del CSR tal como se recibe, en $\mathrm{kg} / \mathrm{h}$

$Q_{\text {aire }}$ es el caudal volumétrico de aire introducido, en $\mathrm{Nm}^{3} / \mathrm{h}$

$\left(\mathrm{Q}_{\text {aire }} / \mathrm{Q}_{\mathrm{CSR}}\right)_{\text {estequiométrico }}$ es el cociente entre el caudal de aire y el del CSR

Otros parámetros de gran interés son la composición de gas, el contenido en alquitranes, la producción del gas y el poder calorífico inferior del mismo: 
- Producción de gas, $\mathrm{Y}_{\text {gas }}$, en $\mathrm{Nm}^{3} / \mathrm{kg}$ de CSR b.s., sin cenizas

$$
Y_{\text {gas }}=\frac{Q_{\text {gas }}}{Q_{C S R, b . s . \text { sincenizas }}} \cdot 100
$$

Dónde,

QCSR, b.s., sin cenizas es el caudal de CSR en base seca y sin cenizas, en $\mathrm{kg} / \mathrm{h}$

- Poder calorífico inferior del gas de proceso, $\mathrm{PCI} \mathrm{gas}_{\mathrm{gas}}$, en $\mathrm{MJ} / \mathrm{Nm}^{3}$

$$
P C I_{\text {gas }}=\sum_{i=1}^{N} P C I_{i} \cdot X_{i} \cdot \rho_{\text {gas }}
$$

Dónde,

$\mathrm{PCI}_{\mathrm{i}}$ es el poder calorífico inferior de cada uno de los compuestos, en $\mathrm{MJ} / \mathrm{kg}$ $\mathrm{X}_{\mathrm{i}}$ es el caudal másico de cada uno de los compuestos del gas de proceso $\rho_{\text {gas }}$ es la densidad del gas en $\mathrm{kg} / \mathrm{m}^{3}$

\begin{tabular}{|l|l|l|l|l|l|l|}
\hline \multirow{2}{*}{$\mathrm{PCI}(\mathrm{MJ} / \mathrm{kg})$} & $\mathrm{H}_{2}$ & $\mathrm{CO}$ & $\mathrm{CH}_{4}$ & $\mathrm{C}_{2} \mathrm{H}_{6}$ & $\mathrm{C}_{2} \mathrm{H}_{4}$ & $\mathrm{C}_{2} \mathrm{H}_{2}$ \\
\cline { 2 - 7 } & 120,97 & 10,11 & 50,01 & 47,55 & 46,89 & 48,26 \\
\hline
\end{tabular}

Tabla 2.5. Poder calorífico inferior de compuestos del gas de proceso.

El rendimiento de un proceso de gasificación se estima a través de una serie de parámetros. A continuación se define la eficiencia del proceso: eficiencia de gas frío, eficiencia de gas caliente y eficiencia de la conversión de carbono:

- Eficiencia en frío: Este parámetro no tiene en cuenta el calor sensible del gas de proceso que se genera durante el proceso de gasificación. Por tanto, la eficiencia de gas frío se define como la proporción entre la energía química del gas de proceso y la del combustible alimentado.

$$
E F G=\frac{Q_{\text {gas }} \cdot P C I_{\text {gas }}}{Q_{C S R} \cdot P C I_{C S R}} \cdot 100
$$

Dónde:

$Q_{\text {gas }}$ es el caudal volumétrico de gas producido, en $\mathrm{Nm}^{3} / \mathrm{h}$

$\mathrm{PCI}_{\mathrm{gas}}$ es el poder calorífico inferior del gas, en $\mathrm{MJ} / \mathrm{Nm}^{3}$

$\mathrm{PCI}_{\mathrm{CSR}}$ es el poder calorífico inferior del CSR húmedo, $\mathrm{MJ} / \mathrm{kg}$

- Eficiencia en caliente: En este parámetro se tiene en cuenta el calor sensible y la energía química contenidos en el gas de proceso. Se define como la proporción entre la suma de la energía química y calor sensible del gas de proceso y entre la suma de la energía química y calor sensible del combustible alimentado.

- Eficiencia de la conversión de carbono: Es la proporción entre la fracción de carbono en el gas de proceso, excluyendo el carbono en los alquitranes y en el residuo carbonoso y la fracción de carbono en el combustible alimentado. Este parámetro da una estimación de la materia no convertida durante el proceso. 
$X_{C}=\frac{Q_{\text {gas }} \cdot X_{C, g a s}}{Q_{C S R} \cdot X_{C, C S R}} 100$

Ecuación 2.29

Dónde:

$\mathrm{X}_{\mathrm{C} \text {, gas }}$ se refiere a la concentración de carbono en el gas de proceso, es decir: masa de carbono asociada a $\mathrm{CO}, \mathrm{CO}_{2}$ y $\mathrm{CH}_{4}$

$\mathrm{X}_{\mathrm{C} \text {, gas }}$ se refiere a la concentración de carbono en el CSR

- Tasa de alimentación (TA): Cociente entre el caudal de CSR y el área del gasificador. Se expresa en $\mathrm{kg} / \mathrm{hm}^{2}$.

$T A=\frac{Q_{C S R}}{S_{\text {gasificado }}}$

Ecuación 2.30

\subsubsection{ANÁLISIS DEL GAS DE GASIFICACIÓN}

El gas de proceso generado en las plantas piloto de gasificación atraviesa un ciclón de alta eficiencia, donde se recogen las partículas sólidas, que han experimentado atrición y son arrastradas por el gas, y las cenizas volantes con un tamaño muy fino. Las partículas sólidas recogidas por el ciclón secundario se depositan en un tambor de cenizas de manera que permite su recolección y análisis tras la finalización del experimento. La medida de la composición del gas de proceso se realiza tomando una pequeña alícuota de gas, que es enviada al equipo de análisis, acondicionándose la muestra para retener sustancias que puedan afectar a la medida, antes de su entrada en los distintos módulos de análisis de que consta el equipo. Además, la toma de muestras de alquitranes se realiza mediante un tren de muestreo específico [119], que permite la recogida de alquitranes para su posterior análisis.

El gas de proceso, ya limpio de partículas sólidas se dirige hacia una antorcha, donde se quema. Las tuberías que comunican la salida del gasificador con la antorcha se encuentran calorifugadas, para evitar la condensación de los alquitranes formados durante el proceso de gasificación, ya que podrían producir ensuciamiento, taponamientos y corrosión en la instalación.

\subsubsection{Análisis de gas en continuo}

El análisis del gas de proceso se realiza de manera continua a través de los equipos de análisis implementados a tal efecto. Se dispone de dos sistemas de análisis, que posibilitan la medida de composición de gas de manera continua, es decir: un analizador de infrarrojos por transformada de Fourier (FTIR) analizador de espectroscopia (Gasmet ${ }^{\mathrm{TM}}$ CX-Series FT_IR Gas Analyzer) para determinar la composición de gases $\left(\mathrm{CO}, \mathrm{CO}_{2}, \mathrm{CH}_{4}\right)$, seguido de un detector de ionización de llama (Heated FID-Analyzer 3-300 A) para el análisis de hidrocarburos, y un analizador de infrarrojo no dispersivo (NDIR) para determinar la composición de gases $\left(\mathrm{CO}, \mathrm{CO}_{2}\right.$, $\left.\mathrm{CH}_{4}\right)$. 
Además, el sistema de análisis de gases en continuo dispone de un analizador paramagnético (Sick-MAIHAK S710), para determinar la composición de $\mathrm{H}_{2}$, un analizador láser para $\mathrm{H}_{2} \mathrm{~S}$ (LaserGas ${ }^{\mathrm{TM}}$ neo monitors as) y un analizador de conductividad para $\mathrm{O}_{2}$. No obstante, existe una celda de circonio a la salida del gas de proceso de gasificación que permite medir la composición de $\mathrm{O}_{2}$, para conocer si se han alcanzado condiciones de gasificación en el proceso. En cuanto al FTIR en la Tabla 2.6 se recogen los gases que podrían medirse por poseer espectros correspondientes en el rango que se especifica. No obstante, los gases condensables dejan de medirse al colocarse trampas de humedad y recogida de isopropanol en la toma de muestras.

\begin{tabular}{|l|l|l|l|}
\hline COMPONENTE & FORMULA & RANGO & UNIDAD \\
\hline Agua & $\mathrm{H}_{2} \mathrm{O}$ & $0-30$ & $\%$ vol. \\
\hline Dióxido de carbono & $\mathrm{CO}_{2}$ & $0-20$ & $\%$ vol. \\
\hline Monóxido de carbono & $\mathrm{CO}$ & $0-20$ & $\%$ vol. \\
\hline Metano & $\mathrm{CH}_{4}$ & $0-5$ & $\%$ vol. \\
\hline Acetileno & $\mathrm{C}_{2} \mathrm{H}_{2}$ & $0-200$ & $\mathrm{ppm}$ \\
\hline Etileno & $\mathrm{C}_{2} \mathrm{H}_{4}$ & $0-200$ & $\mathrm{ppm}$ \\
\hline Etano & $\mathrm{C}_{2} \mathrm{H}_{6}$ & $0-200$ & $\mathrm{ppm}$ \\
\hline Amoníaco & $\mathrm{NH}_{3}$ & $0-5000$ & $\mathrm{ppm}$ \\
\hline Cloruro de hidrógeno & $\mathrm{HCl}$ & $0-10 / 10-100$ & $\mathrm{ppm}$ \\
\hline Fluoruro de hidrógeno & $\mathrm{HF}_{2}$ & $0-20$ & $\mathrm{ppm}$ \\
\hline Sulfuro de hidrógeno & $\mathrm{H}_{2} \mathrm{~S}$ & $0-20$ & $\mathrm{ppm}$ \\
\hline Benceno & $\mathrm{C}_{6} \mathrm{H}_{6}$ & $0-21$ & $\mathrm{ppm}$ \\
\hline Tolueno & & $0-200$ & $\mathrm{ppm}$ \\
\hline Etilbenceno & & $0-500$ & $\mathrm{ppm}$ \\
\hline o-Xileno & & $0-200$ & $\mathrm{ppm}$ \\
\hline m-Xileno & & $0-200$ & $\mathrm{ppm}$ \\
\hline p-Xileno & & $0-200$ & $\mathrm{ppm}$ \\
\hline
\end{tabular}

Tabla 2.6. Rangos de análisis del FTIR para los distintos gases de gasificación.

\subsubsection{Análisis de alquitranes producidos}

El alquitrán está compuesto por una gran cantidad de compuestos, por tanto su cuantificación individual es muy compleja. Este hecho provoca que sea necesario disponer de un patrón puro para cada compuesto. Para reducir la complejidad de este proceso se decidió seleccionar ciertos compuestos para su cuantificación en base a su abundancia en las muestras, su importancia como indicadores del proceso de gasificación y su importancia medioambiental. Los compuestos cuantificados fueron:

PAH's: naftaleno, acenaftileno, acenafteno, fluoreno, fenantreno, antraceno, antraceno, fluoranteno, pireno, benzo(a)antraceno, criseno, benzo(b)fluoranteno, benzo(k)fluoranteno, benzo(a)pireno, indeno(1,2,3-cd)pireno, dibenzo(ah)antraceno y benzo(ghi)perileno.

Polares: piridina, anilina, fenol y benzonitrilo.

BTX: benceno, tolueno, $\mathrm{m}+\mathrm{p}$-xileno y o-xileno.

Para realizar el muestreo con borboteadores se utilizó como base la especificación técnica CEN/TS 15439: 2006. El sistema de muestreo utilizado, ver Figura 2.22, ha consistido en un filtro de fibra de vidrio, cuya temperatura se ha mantenido en torno a $150{ }^{\circ} \mathrm{C}$ a través de una resistencia. La alícuota fue llevada mediante una manguera 
calefactada desde el punto de muestreo hasta una serie de borboteadores. La serie de borboteadores consiste en un borboteador vacío a temperatura ambiente en el que condensan el agua y algunos alquitranes, un borboteador con $100 \mathrm{~g}$ de bolas de vidrio y $130 \mathrm{~mL}$ de isopropanol sumergido en un baño $35^{\circ} \mathrm{C}$, seguido de tres borboteadores con $100 \mathrm{~mL}$ de isoprapanol sumergidos en un baño a $35^{\circ} \mathrm{C}$, un borboteador con $100 \mathrm{~g} \mathrm{de}$ bolas de vidrio y $70 \mathrm{~mL}$ de ispropanol sumergido en un baño a $-20^{\circ} \mathrm{C}$ y un borboteador vacío con $100 \mathrm{~g}$ de bolas de vidrio sumergido también en un baño a $-20{ }^{\circ} \mathrm{C}$. Para el muestreo de alquitranes se hacen pasar $100 \mathrm{~L}$ de gas en aproximadamente una hora de muestreo.

De este sistema de muestreo se obtienen tres tipos de muestras: filtros de fibra de vidrio, condensados acuosos y disoluciones en isopropanol. Los alquitranes retenidos en isopropanol se analizaron por cromatografía de gases (Agilent 6890) acoplado a un detector de espectrometría de masas (Agilent 5975) con inyector automático (Agilent 7683) para evaluar su concentración en PAH's utilizando como patrón interno fenantreno deuterado $(10 \mathrm{ng} / \mu \mathrm{L})$. Además, la concentración de los compuestos polares se determina mediante cromatografía de gases (Hewlett Packard 5890 series II) acoplado a un detector de espectrometría de masas (Hewlett Packard 5971A) utilizando como patrón interno 4-bromofluorobenceno $(50 \mu \mathrm{g} / \mathrm{mL})$.

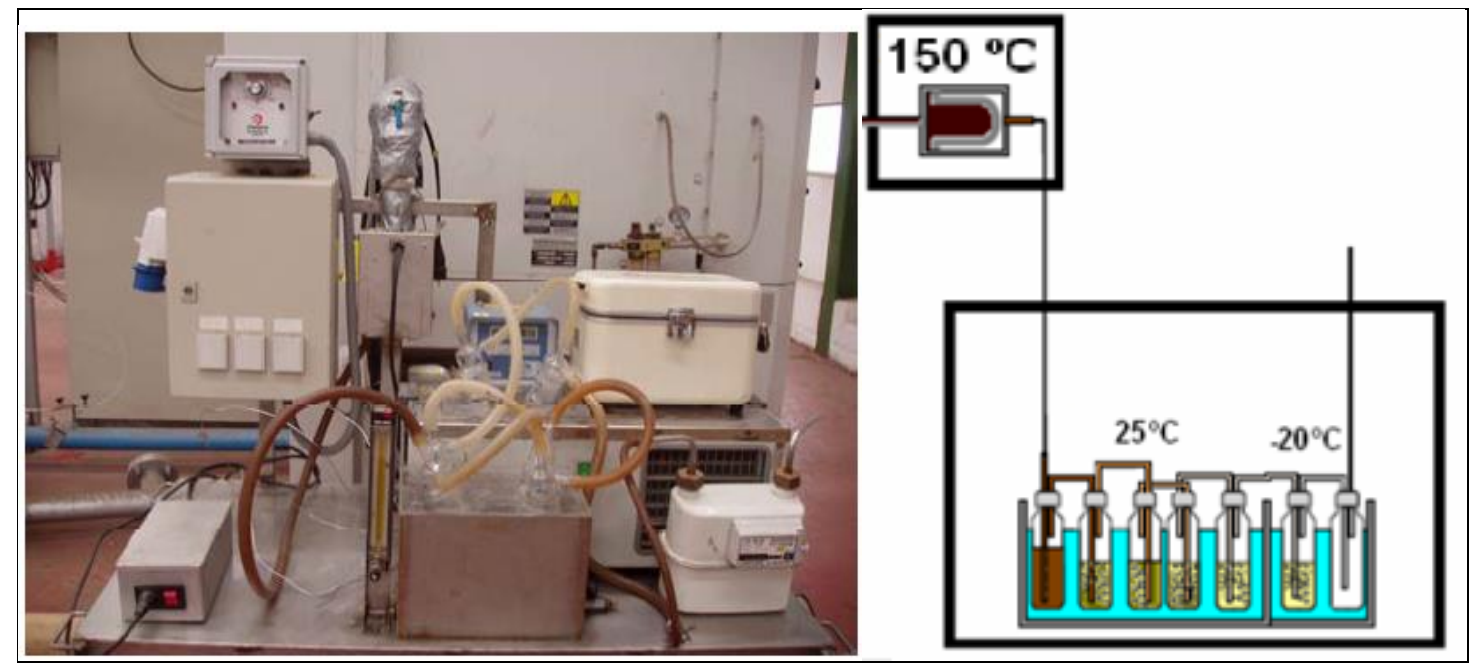

Figura 2.22. Tren de muestreo de alquitranes.

\subsubsection{Análisis de cloro en gases}

La determinación de cloro en el gas de proceso se basó en la medida de $\mathrm{HCl}$ y $\mathrm{Cl}_{2}$ en gases mediante cromatografía iónica.

En el agua acidificada, el $\mathrm{HCl}$ se solubiliza formando iones cloruro $\left(\mathrm{Cl}^{-}\right)$:

$$
\mathrm{HCl}+\mathrm{H}_{2} \mathrm{O} \rightarrow \mathrm{H}_{3} \mathrm{O}^{+}+\mathrm{Cl}^{-}
$$

El gas cloro $\left(\mathrm{Cl}_{2}\right)$ tiene muy baja solubilidad en agua acidificada y pasa hasta la solución alcalina donde se hidroliza:

$$
\mathrm{H}_{2} \mathrm{O}+\mathrm{Cl}_{2} \rightarrow \mathrm{H}^{+}+\mathrm{Cl}^{-}+\mathrm{HClO}
$$


Para estabilizar los iones cloruro se añade tiosulfato sódico, pudiéndose determinar mediante cromatografía iónica.

$$
\mathrm{S}_{2} \mathrm{O}_{3}^{2-}+4 \mathrm{OCl}^{-}+2 \mathrm{OH}^{-} \rightarrow 2 \mathrm{SO}_{4}^{2-}+4 \mathrm{Cl}^{-}+\mathrm{H}_{2} \mathrm{O}
$$

La determinación de cloro se basó en un tren de muestreo, ver Figura 2.23, que es válido para la determinación de $\mathrm{HCl}, \mathrm{HBr}, \mathrm{HF}, \mathrm{Cl}_{2}$ y $\mathrm{Br}_{2}$, seguido de análisis por cromatografía iónica usando un cromatógrafo iónico Dionex ICS-2000 [133, 134].

El sistema de muestreo empleado consiste en un filtro calorifugado a más de $120^{\circ} \mathrm{C}$, un borboteador de tallo corto a modo de condensador con $50 \mathrm{~mL}$ de $\mathrm{H}_{2} \mathrm{SO}_{4} 0,05 \mathrm{M}$ (para gases muy húmedos) o vacío, dos borboteadores con $100 \mathrm{~mL}$ de $\mathrm{H}_{2} \mathrm{SO}_{4} 0,05 \mathrm{M}$, dos borboteadores de $\mathrm{NaOH} 0,1 \mathrm{M}$ y un último borboteador con silicagel. Tras finalizar el muestreo y recoger los borboteadores con $\mathrm{H}_{2} \mathrm{SO}_{4}$ por un lado, y los borboteadores con $\mathrm{NaOH}$ por otro, se añade en estos últimos $2 \mathrm{~mL}$ de $\mathrm{Na}_{2} \mathrm{~S}_{2} \mathrm{O}_{3} 0,5 \mathrm{M}$.

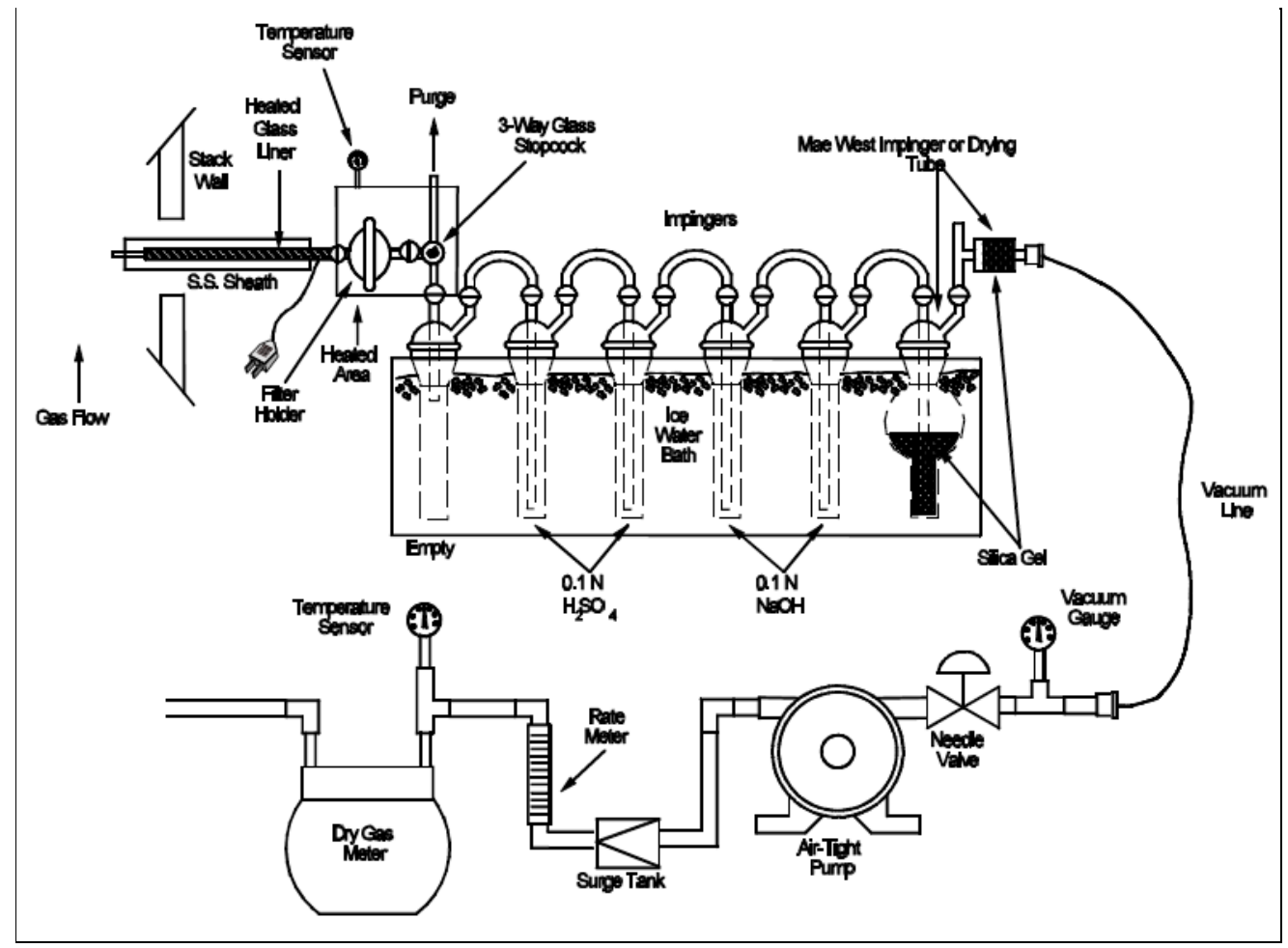

Figura 2.23. Tren de muestreo de cloro para cromatografía iónica.

\subsection{INSTALACIONES PARA ESTUDIO DE LA FLUIDIZACIÓN}

\subsubsection{MODELO UNIDAD CIRCULANTE A TEMPERATURA AMBIENTE}

La planta piloto consiste en una unidad de lecho fluidizado circulante a temperatura ambiente, como se muestra en la Figura 2.24. La unidad circulante consta de un lecho fluidizado rápido (riser), un separador gas/sólido (ciclón), y una rama de retorno (standpipe), conectada a un sistema que posibilita la recirculación de sólidos a través de una válvula no mecánica. 


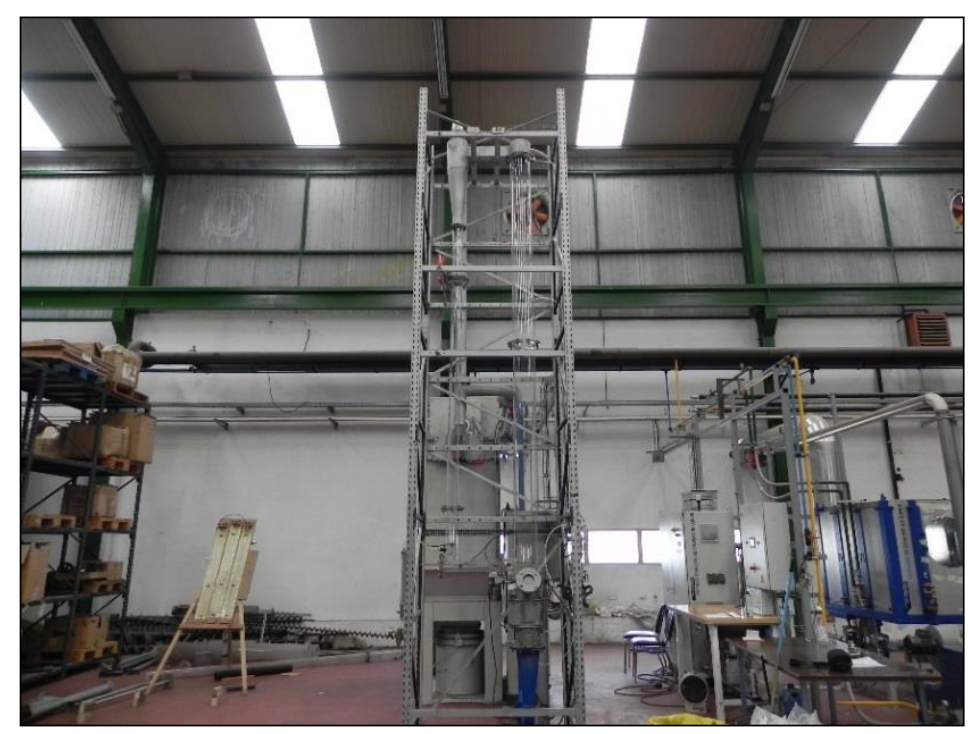

Figura 2.24. Vista general de la planta piloto modelo de unidad circulante a temperatura ambiente.

La instalación emplea aire como agente fluidizante y simula el comportamiento fluidodinámico de un gasificador de lecho fluidizado a presión atmosférica. La instalación se encuentra encajada sobre una estructura metálica que la sustenta. El estudio del comportamiento fluidodinámico se realiza en torno a la monitorización y registro de las presiones durante el desarrollo de la experimentación y la medida in situ de otros parámetros, ver Figura 2.25.

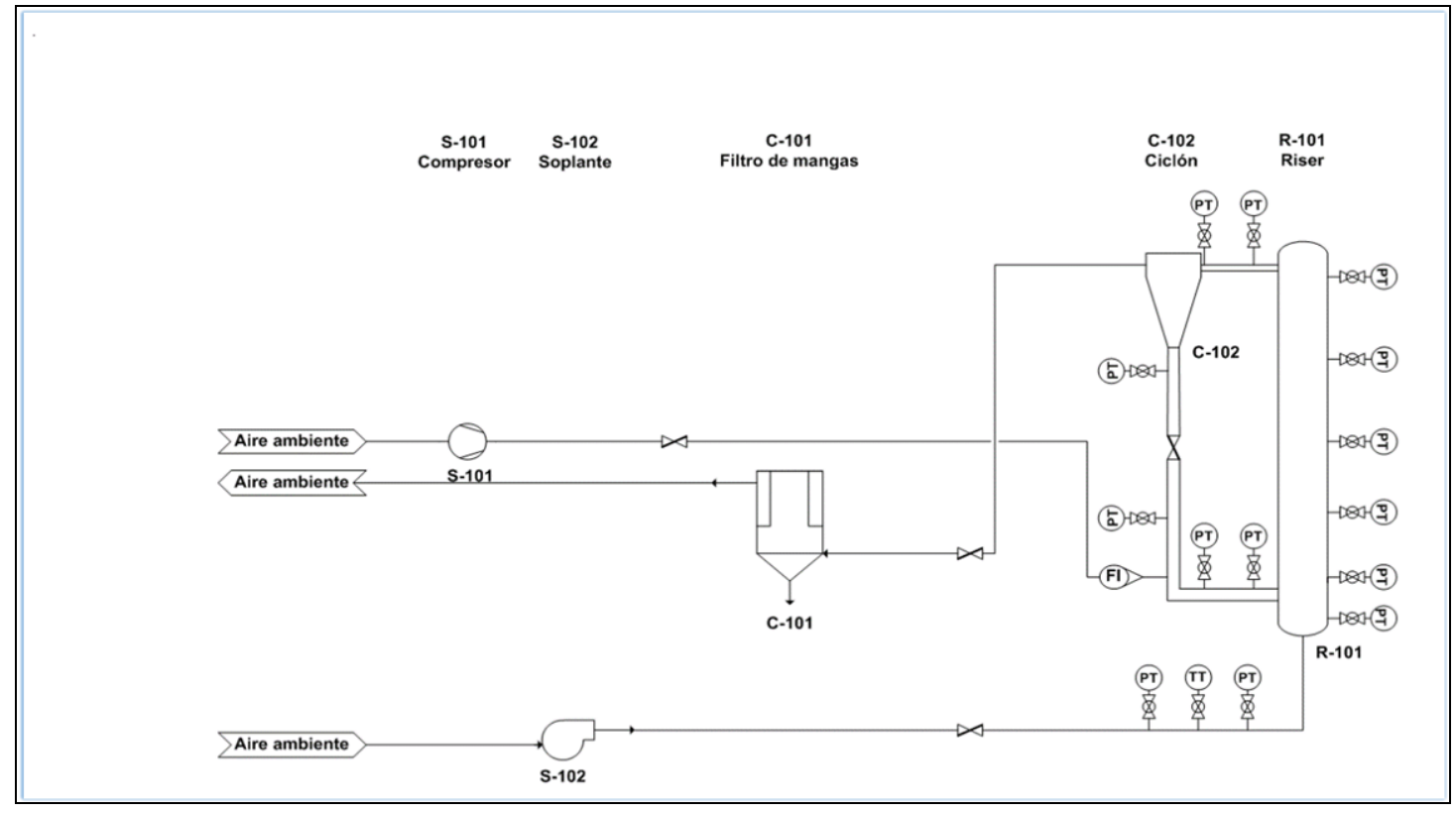

Figura 2.25. Diagrama de flujo del modelo de unidad circulante a temperatura ambiente.

\subsubsection{Sistemas de alimentación de agente gasificante}

El aire se suministra a través de una soplante de émbolos rotativos, que es capaz de aportar un caudal de hasta unos $600 \mathrm{Nm}^{3} / \mathrm{h}$ a los niveles de presión de la instalación, ligeramente superior a 200 mbar. La medida y registro del caudal de aire alimentado al gasificador se realiza mediante un caudalímetro tipo vortex. 
El aire primario se suministra de manera perpendicular, por la parte inferior del reactor a través de un distribuidor de gas. El distribuidor de gas consiste en una placa perforada, de $1 \mathrm{~mm}$ de espesor, fabricada en acero y con una disposición al tresbolillo.

\subsubsection{Reactor de gasificación y sistema de recirculación}

El modelo de flujo a temperatura ambiente consta de un reactor construido en plexiglás con un diámetro interno de $192 \mathrm{~mm}$ y una altura de $4550 \mathrm{~mm}$, aunque dispone de varios tramos construidos en acero que se corresponden con la boca de alimentación de material de lecho, la salida de partículas sólidas hacia la rama de retorno y el tramo donde se aloja la placa distribuidora.

La distribución de aire primario, que suministra la soplante, se realiza a través de un distribuidor de aire de tipo placa perforada, ubicado en la parte superior de la caja de vientos, que posee una forma cónica que permite una mejor distribución del aire primario en la instalación. La placa perforada se encuentra colocada encima de una malla metálica que evita la caída de partículas sólidas a la caja de vientos, y ayuda en la fluidización del material de lecho.

El sistema de recirculación consta de una rama de retorno con un diámetro interno de 92 mm y una altura de $2700 \mathrm{~mm}$, y una válvula no mecánica tipo-L, con un diámetro interno $92 \mathrm{~mm}$ y un tramo horizontal de $480 \mathrm{~mm}$. La recirculación de sólidos hacia el reactor se realiza mediante una entrada de aire comprimido, controlada por un rotámetro. La entrada está ubicada lateralmente en la rama de retorno, justo por encima del tramo horizontal que la sigue, a una altura de $13 \mathrm{~mm}$. La rama de retorno lleva acoplada un válvula de mariposa y un tramo de tubería graduado, que se emplea para medir el flujo externo de circulación, $\mathrm{G}_{\mathrm{s}}$.

La salida abrupta del reactor está unida con el sistema de recirculación mediante una tubería de conexión que se acopla con el ciclón de manera tangencial. Sin embargo, el tipo de salida abrupta provoca la caída de multitud de partículas sólidas que caen nuevamente al reactor, evitando ser arrastradas con el gas de proceso. La recogida de las partículas arrastradas por el gas se lleva a cabo mediante un ciclón.

\subsubsection{Sistemas de monitorización y control}

Las señales analizadas se monitorizan y registran mediante un sistema de adquisición de datos, Novus Field Logger. Las variables registradas son: caudal de aire primario, temperatura de entrada y presiones a lo largo de la instalación. La unidad circulante está equipada con trece transmisores de presión de cuerpo en acero inoxidable con junta viton y sensor cerámico como se muestra la Figura 2.26, un medidor de temperatura (Pt-100), y dos medidores de flujo, un rotámetro para establecer la velocidad de aireación requerida en la válvula-L y un caudalímetro tipo vortex para el caudal primario. 


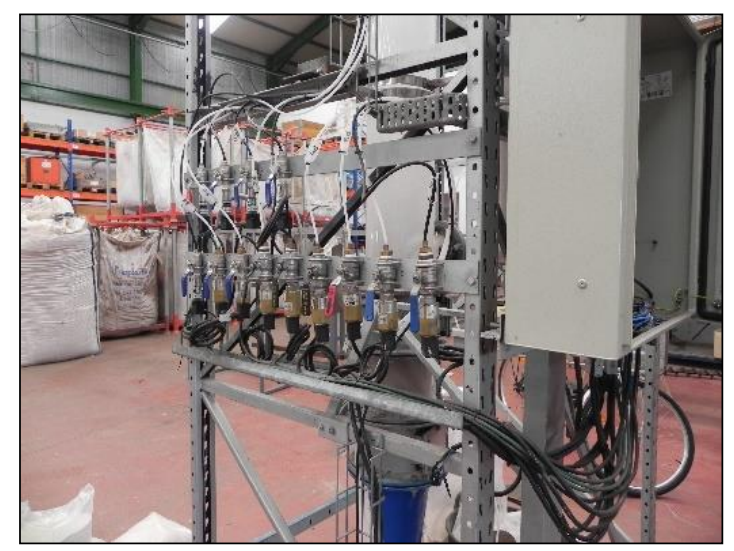

Figura 2.26. Transmisores de presión.

\subsubsection{Material de lecho}

La Tabla 2.7 muestra las propiedades físicas de las arenas de sílice empleadas como material de lecho en los experimentos conducidos en la unidad circulante. La arena fue suministrada por Sílices Gil Arranz S.A, que dispone de una cantera de sílices en Prádena (Segovia). Se determinó la distribución de tamaño de partícula para ambas arenas de sílice, siendo los diámetros de partícula medios obtenidos $428 \mu \mathrm{m}$ para la arena de sílice I y $204 \mu \mathrm{m}$ para la arena de sílice II. La densidad aparente de ambas arenas de sílice es del orden de 1520 y $1560 \mathrm{~kg} / \mathrm{m}^{3}$, respectivamente. Para este trabajo el diámetro medio de partícula se determinó mediante el método convencional:

$\bar{d}_{p}=\frac{1}{\sum\left(x_{i} / d_{p i}\right)}$

Ecuación 2.31

\begin{tabular}{|c|c|c|}
\hline Rango (mm) & Arena de sílice I & Arena de sílice II \\
\hline & \multicolumn{2}{|c|}{ Fracción parcial en peso (\%) } \\
\hline 3 & 0,00 & 0,00 \\
\hline 1,4 & 0,80 & 0,00 \\
\hline 1 & 5,62 & 0,00 \\
\hline 0,5 & 76,66 & 8,04 \\
\hline 0,25 & 16,91 & 70,58 \\
\hline 0,125 & 0,55 & 18,34 \\
\hline 0,063 & 0,12 & 2,84 \\
\hline $\mathrm{d}_{\mathrm{p}}(\mathrm{mm})$ & 0.428 & 0.204 \\
\hline$\rho_{\text {aparente }}$ & 1500 & 1520 \\
\hline$\rho_{\text {partícula }}$ & 2500 & 2500 \\
\hline
\end{tabular}

Tabla 2.7. Propiedades físicas de las partículas sólidas empleadas en los experimentos: distribución de tamaño de partícula, densidad aparente y densidad de partícula.

\subsubsection{Desarrollo experimental}

En este apartado se describe una prueba de circulación de sólidos en una unidad circulante a temperatura ambiente de manera genérica. 


\subsection{Puesta en marcha de la instalación}

La planificación incluye desde la selección del material de lecho a ensayar hasta los parámetros fluidodinámicos que se pretenden estudiar.

\subsection{Operación en planta}

Se introduce el inventario de sólidos fijado antes del experimento en la unidad circulante. El caudal de aire primario se aumenta progresivamente hasta alcanzar el valor requerido para cada prueba experimental. La instalación consta de un transmisor de presión, un medidor de temperatura y un medidor de caudal para fijar las condiciones iniciales del aire primario. El flujo de aireación a través de la válvula tipo L se fija para mantener una recirculación constante y suficiente de partículas sólidas al riser. La instalación consta de un rotámetro y una unidad de mantenimiento, que permiten controlar el caudal de aireación requerido.

Una vez alcanzadas las condiciones de operación planificadas, se deja la instalación en funcionamiento durante diez minutos para que se produzca el registro de presiones a lo largo de la unidad circulante y la medida de la altura que se alcanza en la rama de retorno. La distribución de presiones a lo largo de la unidad circulante se mide en intervalos de diez segundos y se monitoriza constantemente a través del sistema de adquisición de datos.

El muestreo del flujo de circulación de partículas sólidas se realiza de dos maneras distintas. La primera forma consiste en la determinación del flujo externo de sólidos, que se realiza a través del cierre de una válvula de mariposa situada en la parte superior de la rama de retorno y la medida del tiempo requerido para llenar un volumen conocido.

La segunda forma consiste en la determinación de la concentración de partículas sólidas a diferentes alturas y posiciones axiales a lo largo del riser, que fue medida mediante una sonda no isocinética, que se emplea en la medición de partículas sólidas en chimeneas de instalaciones de combustión.

El material de lecho se pesa tras finalizar los ensayos para comprobar la reducción en el inventario de sólidos debido al arrastre de arena debido a fenómenos de atrición, con el objeto de renovarla si fuera necesario. No obstante, se realiza el cambio del material de lecho cada dos días de operación para evitar el cambio de granulometría.

\subsection{Parada de la instalación}

El caudal de aire primario suministrado por la soplante se reduce progresivamente hasta que se para la soplante y el caudal de aire de aireación suministrado por el compresor se corta de manera directa para evitar la pérdida de la columna en la rama de retorno. 


\subsubsection{MODELO VÁLVULA NO-MECÁNICA CLÁSICA TIPO "LOOP-SEAL"}

Modelo de válvula no mecánica semejante a la empleada en el gasificador de lecho fluidizado circulante. La válvula no mecánica tipo "loop-seal" consiste en un modelo construido en plexiglás a temperatura ambiente, que se opera a presión atmosférica, ver Figura 2.27.

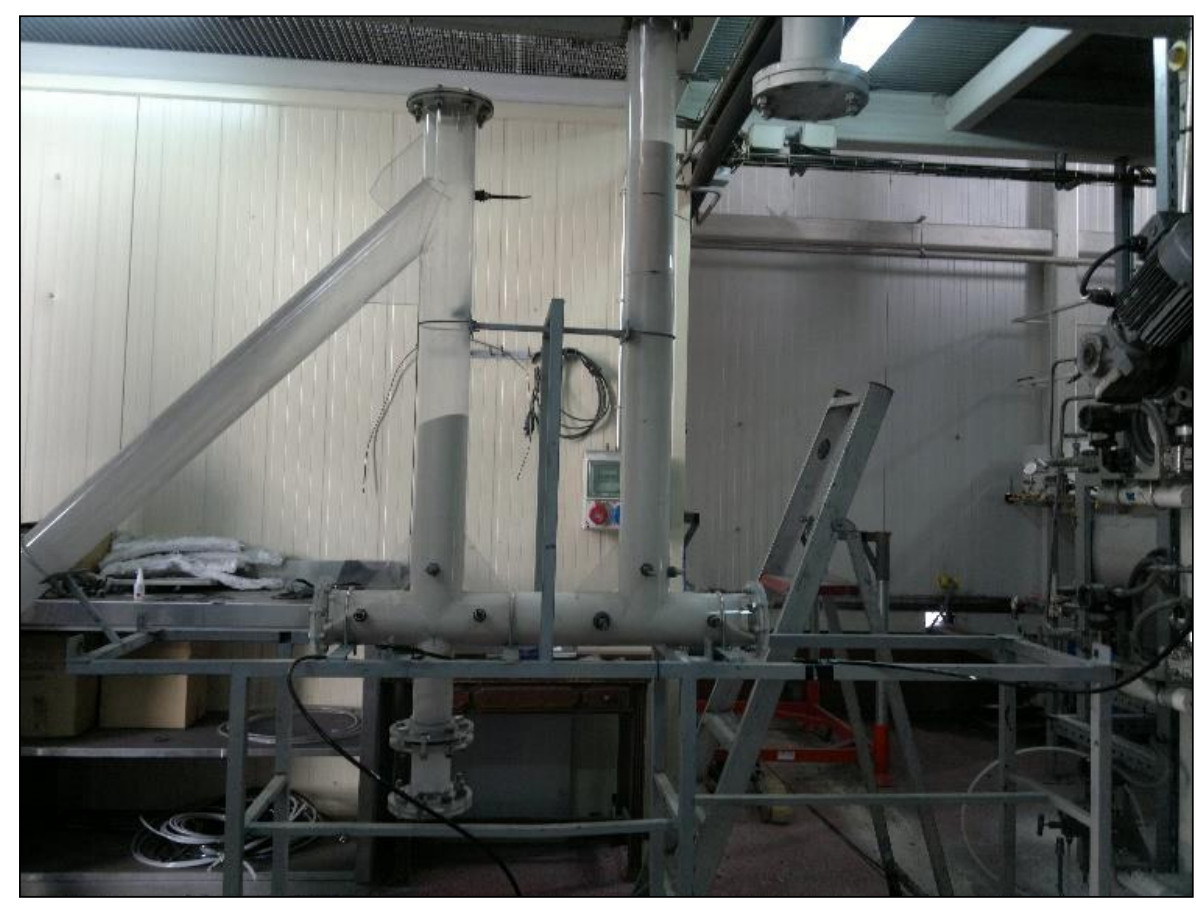

Figura 2.27. Vista general del modelo de válvula no-mecánica tipo "loop-seal”.

\subsubsection{Sistema de alimentación del caudal de aireación}

La simulación del sistema de recirculación de sólidos se realiza a semejanza de la planta piloto de gasificación de lecho fluidizado circulante que se dispone en el CEDER. La recirculación de sólidos se realiza de la misma manera, mediante dos entradas de aire comprimido, cuyos caudales son controlados mediante dos controladores másicos de $0-12 \mathrm{Nm}^{3} / \mathrm{h}$ y $0-60 \mathrm{Nm}^{3} / \mathrm{h}$.

En la Figura 2.28 se muestran las entradas de aireación, estando la primera de ellas ubicada lateralmente en la rama de recirculación justo por encima del tramo horizontal a $12 \mathrm{~mm}$ y la segunda está situada al final del tramo horizontal. La segunda entrada está situada en una especie de unidad burbujeante de reducido tamaño, que hace las veces de cámara de recirculación de partículas sólidas. La distribución del caudal de aireación en las pruebas experimentales a través de la segunda entrada se realiza con distintos tipos de distribuidores: placa perforada, placa porosa y tubos agujereados en forma de flauta. 


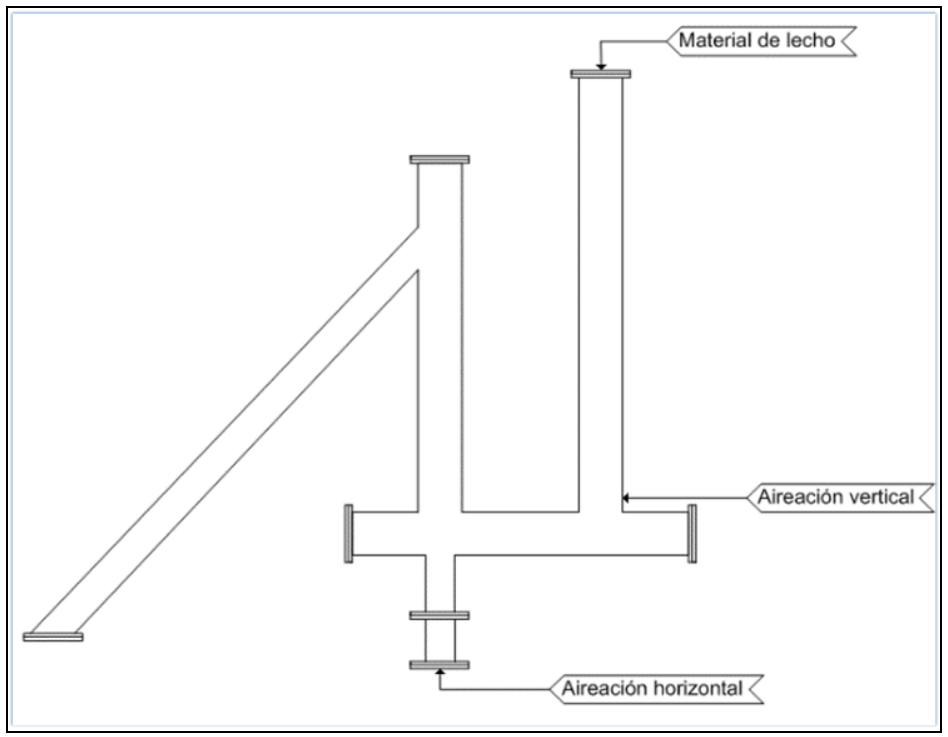

Figura 2.28. Esquema modelo válvula no-mecánica tipo "loop-seal”

\subsubsection{Sistema de monitorización y control}

El registro de las variables monitorizadas se lleva a cabo a través de la instrumentación de la planta piloto de gasificación de lecho fluidizado circulante.

\subsubsection{Material de lecho}

El material de lecho empleado fue arena de sílice de $428 \mu \mathrm{m}$.

\subsubsection{Desarrollo experimental}

\subsection{Puesta en marcha de la instalación}

La planificación de una prueba experimental necesita fijar los valores de caudal de aireación que se quieren ensayar y el distribuidor de aire que se pretende emplear. Con anterioridad al día del ensayo, se debe comprobar el correcto funcionamiento de la instrumentación de la planta. El llenado de la rama de retorno con el material de lecho se realiza antes de que comience la prueba experimental a realizar.

\subsection{Operación en planta}

Se introduce el inventario de sólido necesario para llenar la rama de retorno, de manera que la simulación de la operación de la válvula no mecánica sea lo más cercana a la realidad. Los caudales de aireación se ajustan al valor que se quiere ensayar, previamente a la introducción de aire en la válvula. La instalación consta de dos controladores de caudal que suministran el caudal requerido para cada experiencia. El muestreo del flujo de circulación de partículas sólidas se realiza midiendo el tiempo que tarda en vaciarse una altura conocida de la rama de retorno. 


\subsection{Parada de la instalación}

La parada de la instalación se realiza de manera sistemática, es decir: se produce al apagado de la soplante y del caudal de aireación. Más tarde, se procede a la toma de muestra de arena para analizar la granulometría de la misma.

\subsubsection{TRATAMIENTO DE LOS DATOS EXPERIMENTALES}

En el modelo de unidad circulante a temperatura ambiente se registraron de manera continua datos relativos a presiones a lo largo del sistema con el objeto de establecer un perfil de presiones en la instalación. Estas medidas se realizaron empleando medidores de presión DDS331H12160 SIKA y ST-18 NUOVAFIMA, con rango de medida de 0-0.6 y 0-1 bar, respectivamente. La obtención del flujo externo de sólidos se realiza a través del cierre de una válvula de mariposa, un cronómetro y un tramo graduado que sirve de instrumento de medición de volúmenes. Además, se midió el flujo interno de sólidos se mide a través de una sonda no-isocinética.

Respecto al modelo de válvula no mecánica clásica tipo "loop-seal”, el flujo externo de sólidos se mide a través de la descarga de material de lecho mediante un cronómetro y un tubo graduado, ya que se simularon condiciones de operación reales al encontrarse presurizada la válvula. 


\section{CAPÍTULO III. COMBUSTIBLES SÓLIDOS RECUPERADOS}

\subsection{INTRODUCCIÓN}

El suministro de fracciones residuales provenientes del complejo de tratamiento de residuos sólidos de la Ribera Baja (Navarra) correspondió al vertedero "El Culebrete", sito en Tudela (Navarra). La disponibilidad del material, así como datos relevantes para su estudio y posterior caracterización fueron obtenidos a partir de la colaboración con la Mancomunidad de la Ribera, , Gestión Ambiental de Navarra S.A. (GANASA) y la Fundación de Investigación, Desarrollo e Innovación en Medio Ambiente (FIDIMA), que fueron empresas participantes en el proyecto denominado GASREUR. En cuanto a las fracciones residuales de la industria papelera, ambas fueron suministradas por Holmen Paper, empresa situada en la localidad de Fuenlabrada (Madrid).

Las caracterizaciones llevadas a cabo fueron realizadas por el laboratorio de caracterización de biomasa del Centro de Desarrollo de Energías Renovables (CEDER.), la parte correspondiente a análisis termogravimétricos de esta caracterización ha sido llevada a cabo en las instalaciones del CIEMAT en Madrid.

El acondicionamiento y pretratamiento de los residuos provenientes de la planta de tratamiento de residuos sólidos de Tudela (Navarra) tuvo lugar en dos empresas: Chazar S.L. (Zaragoza) y Mediterranean Wastes S.A. (Castellón). Sin embargo, el acondicionamiento previo a la peletización del residuo, así como la peletización propiamente dicha tuvo lugar en las instalaciones de pretratamiento del CEDER. Con respecto al residuo proveniente de la industria papelera, este fue en su totalidad acondicionado y peletizado en las instalaciones del CEDER.

\subsection{RESIDUOS SÓLIDOS URBANOS (RSU)}

La Tabla 3.1 muestra la caracterización cuantitativa del RSU recibido por la Mancomunidad de la Ribera Baja en su planta de tratamiento en el año 2012.

En comparación con los RSU recibidos en otras plantas geográficamente próximas, como la sita en la provincia de Zaragoza, se observa una similitud en los porcentajes de materiales que componen el RSU, en torno a un 50\% de materia orgánica, $15 \%$ de papel/cartón y $10 \%$ de material plástico.

Respecto a la media nacional, los rasgos más significativos de esta comparativa, se observan en el porcentaje de papel y cartón generado, siendo alrededor de un 5\% menor. Además, los textiles y la madera se incluyen en un apartado sin especificar, "otros", que hacen difícil su estimación respecto a los valores a nivel nacional. 


\begin{tabular}{|l|c|c|c|}
\hline \multicolumn{1}{|c|}{$\begin{array}{c}\text { Composición } \\
\text { RSU }\end{array}$} & $\begin{array}{c}\text { Composición } \\
\text { media en España } \\
(\%)\end{array}$ & $\begin{array}{c}\text { Composición de } \\
\text { RSU en área de 62 } \\
\text { municipios en } \\
\text { Zaragoza }\end{array}$ & $\begin{array}{c}\text { Composición de } \\
\text { RSU en la } \\
\text { Mancomunidad } \\
\text { Ribera Baja, } \\
\text { Navarra }\end{array}$ \\
\hline Materia orgánica & 48,9 & 52,96 & 49,0 \\
\hline Papel/cartón & 20,5 & 16,31 & 15,3 \\
\hline Madera & 0,6 & - & - \\
\hline Textiles & 3,7 & 3,78 & - \\
\hline Plástico & 11,7 & 10,47 & 9,2 \\
\hline Vidrio & 7,6 & 6,28 & 4,0 \\
\hline Metales & 4,1 & 3,70 & 1,5 \\
\hline Bricks & - & - & 13,1 \\
\hline Otros & 2,9 & 6,50 & \\
\hline
\end{tabular}

Tabla 3.1. Comparación de la composición de RSU en distintas áreas de estudio dentro del territorio español [135].

\subsubsection{CARACTERIZACIÓN DE RECHAZOS DE PLANTA DE TRATAMIENTO DE RESIDUOS SÓLIDOS}

Las fracciones residuales de partida se sometieron a una caracterización completa para determinar su utilidad como combustibles en lechos fluidizados en base a sus propiedades químicas y físicas. Se realizaron distintos análisis con objeto de lograr una caracterización completa de los rechazos, es decir: análisis inmediato, análisis elemental, humedad, poder calorífico, densidad a granel, comportamiento de fusión de la ceniza, análisis de elementos mayoritarios y elementos traza.

Los resultados de la caracterización se muestran en la Tabla 3.2, a excepción de la cuarta fracción residual, plástico film, que se decidió no utilizar para la producción del combustible debido a su baja generación (13\% del total de envases tratados). No obstante, al estar compuesta por films de PE, sus características se corresponden a las propias de un plástico de $\mathrm{PE}$, siendo su poder calorífico inferior muy elevado, $44 \mathrm{MJ} / \mathrm{kg}$.

De las fracciones analizadas en el laboratorio de caracterización, se pueden extraer datos muy relevantes sobre sus deficiencias y problemas a solventar en la producción del combustible. Se observó una elevada cantidad de materia volátil para las fracciones de rechazo de la fracción orgánica y de plástico mixto, alrededor del $70 \%$, lo que sugiere una elevada reactividad.

El alto contenido en cenizas de estas tres fracciones de rechazo sugiere que puedan producirse problemas relacionados con la sinterización del material de lecho y las cenizas del combustible, pese a presentar temperaturas de fusibilidad elevadas. La cantidad de cenizas observadas resulta elevada tanto para el rechazo de la fracción orgánica y de plástico mixto, del orden de $21 \%$ y $26 \%$, respectivamente, como para el rechazo de envases, que muestra un valor mucho más alto, $42 \%$. 
Además, el material de lecho que se emplea en los ensayos de conversión térmica mediante procesos de gasificación, puede fomentar la aparición de sinterizados dependiendo de su composición. Sin embargo, el elevado contenido de otros metales como el calcio o el magnesio, reducen la posibilidad de aparición de sinterizados durante el proceso de gasificación. Con respecto a los materiales residuales originales, se observa que presentaron elevados contenidos en óxidos de calcio, 18-30\%, y moderados contenidos en potasio y sodio, por tanto, se puede afirmar que tal vez no se produzcan problemas de aglomeración.

El poder calorífico mostrado en la tabla es elevado, por tanto, es una opción razonable el aprovechamiento de este tipo de fracciones para su empleo como combustible, ya que muestran valores en un rango de $14 \mathrm{MJ} / \mathrm{kg}$ a $20 \mathrm{MJ} / \mathrm{kg}$.

El contenido en cloro que se indica a través del análisis elemental, aunque no fue muy elevado en las fracciones analizadas, indica la necesidad de un pretratamiento que elimine la mayor cantidad posible, con el fin de reducir problemas operacionales futuros. En función de la proporción de rechazos que conformen la mezcla a densificar, la necesidad de eliminación de trazas de PVC, ya que es el componente clorado con mayor contenido en los RSU, fijándose en el rango del 38\% al 66\% [136], que aumentan el contenido en cloro de los rechazos, se hará más necesaria.

En cuanto al rechazo de la fracción orgánica, éste presentó un contenido en cloro a tener en cuenta, siendo del orden de $1,2 \%$, mientras que en el caso de rechazo de envases y plástico mixto, el contenido en cloro se situó en $0,8 \%$ y $0,5 \%$, respectivamente. A pesar de que el contenido de azufre no fue muy elevado, podría requerirse de algún tratamiento posterior de abatimiento del gas de proceso, ya que se generará $\mathrm{H}_{2} \mathrm{~S}$.

El análisis de los rechazos mostró una humedad inicial superior al 20\% en la fracción orgánica y en el rechazo de envases, y en torno al $40 \%$ en la fracción de plástico mixto. Esta última corriente residual requerirá un gasto adicional de secado del material. Este hecho unido a que su generación es también baja (19\% del total de envases tratados), produjo su no utilización como material de partida para el procesamiento del combustible.

Finalmente, el material de partida, apto para su transformación en combustible, se obtuvo a partir de una mezcla de dos fracciones de rechazo solamente, $90 \%$ de rechazo de fracción orgánica y $10 \%$ de rechazo de envases. Como consecuencia de la baja densidad a granel de los rechazos: rechazo de biometanización $\left(120 \mathrm{~kg} / \mathrm{m}^{3}\right)$, rechazo de envases $\left(42 \mathrm{~kg} / \mathrm{m}^{3}\right)$ y rechazo de plástico mixto $\left(5.3 \mathrm{~kg} / \mathrm{m}^{3}\right)$, se hace necesario un proceso de compresión, bien sea por peletizado, briquetado o embalado. En el estudio que nos ocupa esta compactación se realizó a través de un peletizado. 


\begin{tabular}{|c|c|c|c|}
\hline & $\begin{array}{c}\text { Rechazo fracción } \\
\text { orgánica }\end{array}$ & Rechazo envases & Plástico mixto \\
\hline \multicolumn{4}{|c|}{ Análisis inmediato (\% en peso; b.s.) } \\
\hline Humedad (\% b.h.) & 21,2 & 22,2 & 40,0 \\
\hline Materia volátil & 73,7 & 49,0 & 72,1 \\
\hline Cenizas & 25,7 & 42,0 & 21,3 \\
\hline Carbono fijo $^{\mathrm{a}}$ & 0,6 & 9,0 & 6,6 \\
\hline \multicolumn{4}{|c|}{ Análisis elemental (\% en peso; b.s.) } \\
\hline Carbono & 46,6 & 30,5 & 42,5 \\
\hline Hidrógeno & 6,6 & 4,3 & 6,2 \\
\hline Nitrógeno & 0,86 & 0,98 & 1,05 \\
\hline Azufre & 0,46 & 0,35 & 0,70 \\
\hline Cloro & 1,21 & 0,78 & 0,54 \\
\hline Oxígeno $^{\mathrm{a}}$ & 18,56 & 21,09 & 27,71 \\
\hline \multicolumn{4}{|c|}{ Poder calorífico $(\mathrm{MJ} / \mathrm{kg})$} \\
\hline PCI & 17,70 & 13,57 & 18,43 \\
\hline PCS & 19,06 & 14,45 & 19,70 \\
\hline \multicolumn{4}{|c|}{ Elementos mayoritarios en forma de óxidos (\%) } \\
\hline $\mathrm{Al}_{2} \mathrm{O}_{3}$ & 7,9 & 7,9 & 7,5 \\
\hline $\mathrm{BaO}$ & 0,085 & 0,052 & 0,067 \\
\hline $\mathrm{CaO}$ & 23 & 18 & 32 \\
\hline $\mathrm{Fe}_{2} \mathrm{O}_{3}$ & 4,8 & 5,8 & 3,2 \\
\hline $\mathrm{K}_{2} \mathrm{O}$ & 2,5 & 3,4 & 3,0 \\
\hline $\mathrm{MgO}$ & 2,4 & 2,3 & 3,0 \\
\hline $\mathrm{Mn}_{2} \mathrm{O}_{3}$ & 0,09 & 0,10 & 0,078 \\
\hline $\mathrm{Na}_{2} \mathrm{O}$ & 3,1 & 2,1 & 4,9 \\
\hline $\mathrm{P}_{2} \mathrm{O}_{5}$ & 1,1 & 0,84 & 1,5 \\
\hline $\mathrm{SO}_{3}$ & 4,6 & 2,1 & 8,3 \\
\hline $\mathrm{SiO}_{2}$ & 38 & 41 & 25 \\
\hline $\mathrm{SrO}$ & 0,097 & 0,083 & 0,10 \\
\hline $\mathrm{TiO}_{2}$ & 1,1 & 1,0 & 1,4 \\
\hline $\mathrm{ZnO}$ & 0,090 & 0,056 & 0,11 \\
\hline \multicolumn{4}{|c|}{ Temperaturas de fusibilidad $\left({ }^{\circ} \mathrm{C}\right)$} \\
\hline TDI & 1.170 & 1.150 & 1.200 \\
\hline TE & n.d. & n.d. & 1.240 \\
\hline TH & 1.190 & 1.210 & 1.240 \\
\hline TF & 1.200 & 1.240 & 1.250 \\
\hline
\end{tabular}

apor diferencia

Tabla 3.2. Caracterización de las fracciones de rechazo de la planta de tratamiento de residuos.

\subsubsection{PREPARACIÓN DEL COMBUSTIBLE}

Los rechazos obtenidos de la planta de TMB y de la clasificación y selección de envases fueron muy heterogéneos, y con gran cantidad de impurezas, por tanto, es necesario que se sometan a un proceso de separación mecánica con múltiples etapas [137, 138]. Estas plantas de clasificación y separación mecánica llevan a cabo diferentes 
etapas de separación: etapas de cribado, trituración, etapas de separación: magnéticas y pneumáticas, etc. [139].

El residuo fue tratado en dos tandas, siendo la primera efectuada en Chazar S.L., La Puebla de Alfidén (Zaragoza), mientras que la segunda tanda se llevó a cabo en MediterraneanWastes S.L., Almenara (Castellón), ya que la primera planta de pretratamiento tuvo problemas operacionales que impidieron seguir tratando el resto del residuo. Las etapas de tratamiento seguidas en ambos centros de procesamiento fueron: eliminación de impurezas, homogeneización del material y secado. La proporción de impurezas en las corrientes de rechazo, correspondieron con un 12,4\% en el rechazo de la fracción orgánica y un $5,5 \%$ en el rechazo de envases, sin tener en cuenta el contenido de arenas.

Las impurezas que más habitualmente se encuentran en las fracciones resto de RSU son: arenas, piedras, metales, vidrio y PVC. Éstas pueden provocar problemas operacionales durante el acondicionamiento, la producción del combustible y la valorización energética del mismo. Con respecto al acondicionamiento del residuo, la existencia de arenas y piedras puede producir desgaste, atascos y roturas de los elementos en los equipos de trituración. Además, el combustible producido puede presentar heterogeneidades debido a la presencia de metales y vidrio.

La aplicación del combustible producido para valorización energética tendrá problemas asociados a la corrosión por la presencia de cloro, por lo que se valora la eliminación de trazas de PVC. La primera etapa fue un cribado, donde se recogieron arenas y finos, previo a los procesos de separación. La captura de los materiales férricos se realizó mediante un separador magnético, la separación de piedras y vidrios se llevó a cabo mediante un separador pneumático, los metales no ferrosos se capturaron mediante un separador inductivo y finalmente, el PVC se eliminó mediante un separador óptico.

La etapa de homogenización conllevó la trituración del residuo previo al proceso de densificación, de manera que se dispusiera de un material homogéneo en cuanto a tamaño de partícula, reduciéndose el volumen de los rechazos de la fracción orgánica y de envases. El tamaño óptimo de partícula que se obtuvo tras este tratamiento se situó entre 10-30 mm. No obstante, se realizó una molienda fina en las instalaciones del CEDER como paso previo a la densificación en forma de pélets.

Los residuos procesados fueron sometidos a sendos análisis de humedad, mostrando valores próximos al 40\%. Éstos fueron extendidos y aireados hasta que su humedad se redujo en torno al 20\%, como paso previo para el acondicionamiento mediante molienda fina, anterior a la densificación. La humedad de recepción fue más elevada que la humedad que mostraron los análisis de caracterización de cada una de las fracciones residuales analizadas. Esto pudo deberse a un almacenaje incorrecto del material a la intemperie.

\subsubsection{Consumo de energía durante la trituración y el peletizado}

El residuo procesado en las plantas de pretratamiento fue recibido en las instalaciones del CEDER-CIEMAT, donde se densificó en forma de pélets de $8 \mathrm{~mm}$ de diámetro. 
Se realizaron dos moliendas finas, una molienda inicial a $25 \mathrm{~mm}$ y una molienda final a $8 \mathrm{~mm}$. La densificación fue realizada empleando dos matrices planas de acero inoxidable, con relaciones de compresión de $37 \mathrm{~mm}$ y $40 \mathrm{~mm}$, respectivamente. El consumo energético del proceso de molienda fina y de densificación se muestra en la Tabla 3.3. El consumo energético correspondiente a la molienda fina para acondicionar el residuo arrojó valores idénticos.

Inicialmente, se seleccionó una matriz plana con una relación de compresión de $37 \mathrm{~mm}$, siendo la temperatura de salida del material con esta relación de compresión cercana a $50{ }^{\circ} \mathrm{C}$, lo que evitó la aparición de fundidos. Posteriormente, se cambió la matriz, ampliando la relación de compresión hasta $40 \mathrm{~mm}$, lo que se tradujo en un incremento de la temperatura de salida, $76^{\circ} \mathrm{C}$. El aumento de la temperatura de salida de $52{ }^{\circ} \mathrm{C}$ a 76 ${ }^{\circ} \mathrm{C}$, produjo un ligero fundido del material plástico a temperaturas próximas a $60{ }^{\circ} \mathrm{C}$, que resultó en un mayor consumo energético y un menor índice de durabilidad, pasando de $97 \%$ a $93 \%$.

Por tanto, la matriz plana que optimiza el proceso de peletizado para residuos sólidos urbanos, debe tener una relación de compresión de $37 \mathrm{~mm}$, ya que la utilización de matrices con una relación de compresión mayor, produce una reducción de la durabilidad, y para relaciones de compresión menores, aunque no se den datos en este estudio, el producto peletizado obtenido se deshacía con facilidad al tacto.

\begin{tabular}{|c|c|c|c|c|c|}
\hline Matriz & \multicolumn{2}{|c|}{ Molienda $\mathbf{( 8 ~ m m )}$} & \multicolumn{3}{c|}{ Proceso de peletizado } \\
\hline $\begin{array}{c}\text { Relación de } \\
\text { compresión } \\
(\mathrm{mm})\end{array}$ & $\begin{array}{c}\text { Flujo másico } \\
\text { específico } \\
(\mathrm{kg} / \mathrm{h} \mathrm{kW})\end{array}$ & $\begin{array}{c}\text { Energía } \\
\text { específica } \\
\text { consumida } \\
(\mathrm{kWh} / \mathrm{T})\end{array}$ & $\begin{array}{c}\text { Flujo másico } \\
\text { específico } \\
(\mathrm{kg} / \mathrm{h} \mathrm{kW})\end{array}$ & $\begin{array}{c}\text { Energía } \\
\text { específica } \\
\text { consumida } \\
(\mathrm{kWh} / \mathrm{T})\end{array}$ & $\begin{array}{c}\mathrm{T}_{\text {salida }} \\
\left({ }^{\circ} \mathrm{C}\right)\end{array}$ \\
\hline 37 & 4,41 & 193,45 & 10,2 & 53 & 52 \\
\hline 40 & 4,46 & 194,71 & 7,3 & 83 & 76 \\
\hline
\end{tabular}

Tabla 3.3. Consumo energético durante el proceso de molienda y peletizado del RSU procesado.

\subsubsection{Calidad del pélet}

Las propiedades físicas del residuo sólido urbano procesado y peletizado son de gran importancia en los procesos de conversión térmica como: combustión y gasificación. El tamaño de los pélets se ajustó a un diámetro de $8 \mathrm{~mm}$, que es adecuado para su manejo y alimentación en sistemas industriales. Estas pruebas se realizaron, ya que cuanto más fino y corto sea el pélet producido, el proceso de conversión térmica seleccionado y la posibilidad de alimentación en continuo, mejoran.

La decisión de densificar el material procesado de partida hasta un valor de densidad a granel adecuado, se llevó a cabo con objeto de mejorar la eficiencia en el transporte y reducir problemas de alimentación como: la formación de bóvedas en las tolvas de alimentación, agujeros de rata y canales preferentes.

El residuo fue peletizado en dos tandas, la primera tanda correspondió a la anualidad de 2011, mientras que la segunda correspondió a la anualidad de 2012, mostrando valores semejantes en los índices de durabilidad, alrededor de un $97 \%$, y de la densidad a granel, alrededor de $550 \mathrm{~kg} / \mathrm{m}^{3}$. La densidad a granel fue de $130 \mathrm{~kg} / \mathrm{m}^{3}$, por tanto una adecuada compresión fue necesaria para conseguir pélets con calidades similares a los 
comerciales. El valor de densidad a granel obtenida fue $540 \mathrm{~kg} / \mathrm{m}^{3}$, que se aproxima a valores de pélets comerciales, próximos a $600 \mathrm{~kg} / \mathrm{m}^{3}$, resultando superiores a otro tipo de pélets, formados a partir de residuos, residuos de la industria de procesado de tomate [140], aunque de menor densidad a granel que los fabricados a partir de otro tipo de residuos, como pulpa de patata [141].

Las propiedades de resistencia del peletizado se pueden medir mediante dos parámetros, dureza y durabilidad. La dureza es un parámetro que indica la máxima carga admisible, previa a la ruptura de un material determinado, y la durabilidad, influenciada por el tamaño de partícula, simula condiciones de transporte y manejo pneumático y mecánico, produciendo la generación de finos.

En este estudio se usó la durabilidad como uno de los parámetros clave que atesoran la calidad del pélet producido. La durabilidad se considera alta para valores superiores a un $80 \%$, media en torno a 70-80\% y baja para valores inferiores a 70\% [142]. Los pélets producidos, que no requirieron ningún aditivo aglutinante, mostraron durabilidades superiores al 90\% como se observa en la Tabla 3.4, siendo del 96,8\%. Además, el valor de humedad obtenido resultó adecuado para su empleo como combustible en instalaciones de gasificación de lecho fluidizado [74].

\begin{tabular}{|l|c|}
\hline Parámetros & Propiedades físicas \\
\hline Humedad $(\%)$ & 8,8 \\
\hline Durabilidad $(\%)$ & 96,8 \\
\hline Densidad a granel $\left(\mathrm{kg} / \mathrm{m}^{3}\right)$ & 540 \\
\hline Densidad de partícula $\left(\mathrm{kg} / \mathrm{m}^{3}\right)$ & 1.050 \\
\hline Finos $(\%)$ & n.d. \\
\hline
\end{tabular}

Tabla 3.4. Propiedades físicas del pélet.

En la figura 3.1 se muestra una fotografía del combustible producido en forma de pélets, que es semejante en su aspecto exterior para ambas tandas.

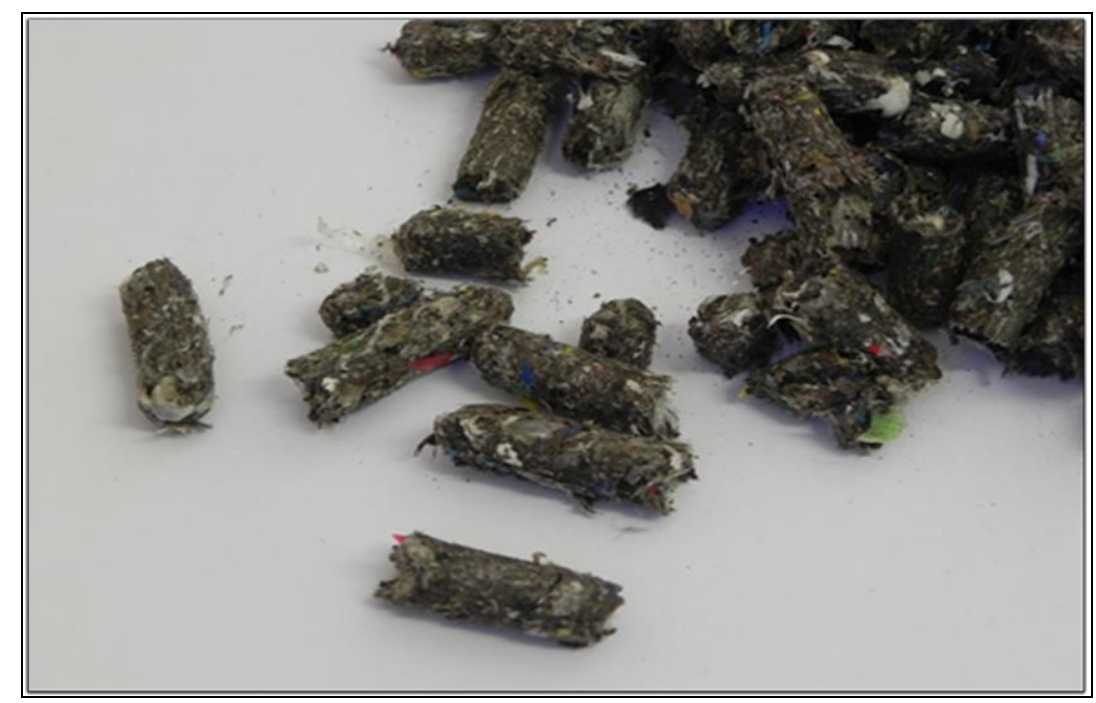

Figura 3.1 Pélets de RSU procesado. 
La humedad jugó un papel clave a la hora del procesamiento de los residuos para la compactación por peletizado, ya que no puede encontrarse totalmente seco el residuo al iniciar la densificación. Tras haber realizado las pruebas de peletización, se observó que el combustible peletizado cumplió con las características perseguidas, ver Tabla 3.4. No obstante, durante las pruebas de peletizado se observó que los pélets una vez almacenados reducían su humedad. Se recogieron diversas muestras en el lote preparado de combustible, y se puede ver en la figura la homogeneidad conseguida en humedad y cenizas del material. La humedad se ve como se perdió por igual en las diferentes muestras del lote, ver figura 3.2. Esta reducción de humedad pudo deberse al alto contenido en material plástico de los pélets correspondiendo a humedad superficial y no estructural como pueda ocurrir en otros materiales.

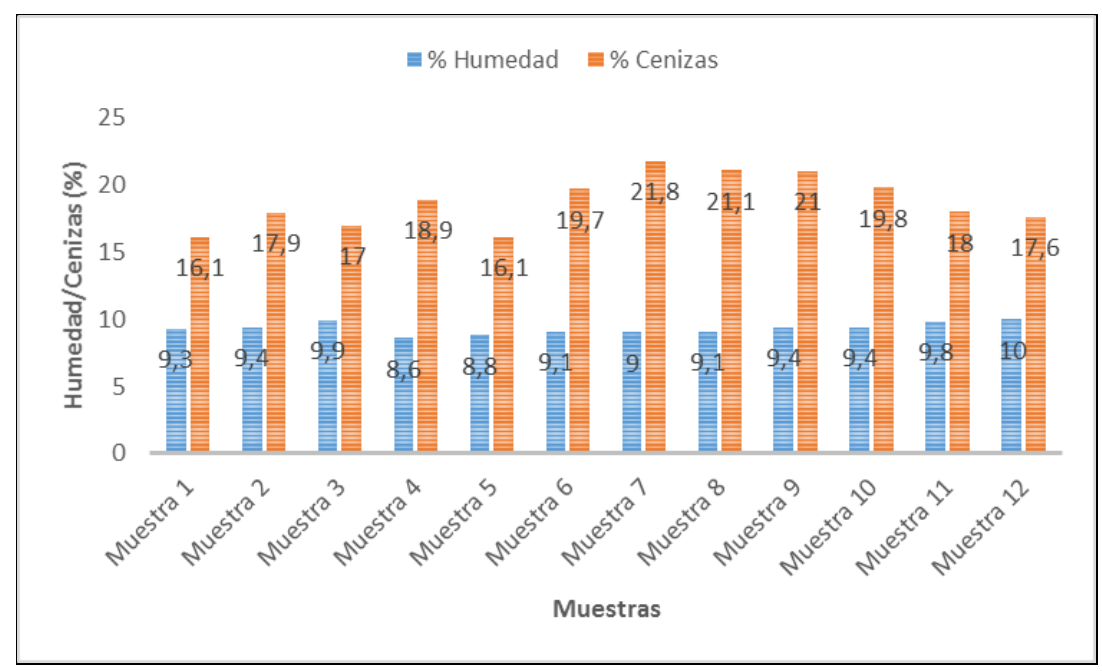

Figura 3.2 Análisis de la humedad y el contenido en cenizas de distintas muestras.

\subsubsection{CARACTERIZACIÓN DEL COMBUSTIBLE DERIVADO DE RESIDUOS}

La caracterización del combustible basada en un análisis inmediato, un análisis elemental y la determinación del poder calorífico se muestra en la Tabla 3.5. El producto peletizado mostró un alto contenido en materia volátil, alrededor del $75 \%$, lo que implica una elevada reactividad. El contenido en cenizas mostró un valor en torno al 20\%, lo que hace necesario la consideración de evacuación del sistema de reacción. Además, el contenido en carbono fijo mostró un valor bajo, muy común en este tipo de CSR de origen doméstico [107]. Respecto a la humedad del combustible, ésta resultó ser suficiente para su empleo en procesos de conversión térmica a tenor de su valor, inferior al $10 \%$ una vez peletizado y estabilizado [74]. Por otro lado, el contenido en cloro es próximo al mostrado en combustibles derivados de residuos comerciales, que son del $0,1 \%$ al $1 \%$ [143].

El análisis elemental mostró que el contenido en cloro del combustible peletizado se redujo con respecto a los materiales de partida, ya que las técnicas de selección usadas para reducir la cantidad de cloro fueron exitosas, lo que reducirá problemas de operación debido a la corrosión asociada durante la utilización del combustible [144]. Además, el poder calorífico que se obtuvo al analizar el combustible indica que puede ser considerado un combustible prometedor para procesos de conversión térmica, ya que 
se encuentra en el rango de 18-20 MJ/kg, que es similar al de otros residuos sólidos urbanos procesados para obtener combustibles sólidos recuperados [63, 109].

\begin{tabular}{|c|c|}
\hline & CSR \\
\hline \multicolumn{2}{|c|}{ Análisis inmediato (\% en peso; b.s.) } \\
\hline Humedad (\% b.h.) & 8,8 \\
\hline Materia volátil & 75,5 \\
\hline Cenizas & 21,1 \\
\hline Carbono fijo $^{\mathrm{a}}$ & 3,4 \\
\hline \multicolumn{2}{|c|}{ Análisis elemental (\% en peso; b.s.) } \\
\hline Carbono & 51,7 \\
\hline Hidrógeno & 7,0 \\
\hline Nitrógeno & 1,20 \\
\hline Azufre & 0,30 \\
\hline Cloro & 0,76 \\
\hline Oxígeno $^{\mathrm{a}}$ & 17,94 \\
\hline \multicolumn{2}{|c|}{ Poder calorífico $(\mathrm{MJ} / \mathrm{kg})$} \\
\hline PCS & 21,92 \\
\hline PCI & 20,34 \\
\hline
\end{tabular}

${ }^{a}$ por diferencia

Tabla 3.5. Caracterización del CSR de origen doméstico.

Los elementos constituyentes más abundantes, aparte del oxígeno y el azufre: $\mathrm{Si}, \mathrm{Fe}, \mathrm{Al}$, $\mathrm{Ca}, \mathrm{P}, \mathrm{K}, \mathrm{Mg}, \mathrm{Na}$, Ti fueron analizados en la ceniza y expresados como óxidos. La Tabla 3.6 muestra los elementos mayoritarios y algunos elementos traza de la ceniza del combustible peletizado. El análisis de metales mostró un alto contenido en óxido de calcio, próximo al 30\%, típico de los rechazos con un contenido apreciable en materiales de origen celulósicos [109] y el contenido en óxido de magnesio fue cercano al $2 \%$. Por tanto, existe un elevado contenido en magnesio y calcio que reducen un posible riesgo de sinterización, ya que el contenido en óxido de sodio cercano al $5 \%$ y el contenido en óxido de potasio próximo al $4 \%$, mostraron valores significativos.

\begin{tabular}{|l|c|}
\hline Composición (\%) & CSR \\
\hline $\mathrm{Al}_{2} \mathrm{O}_{3}$ & 14 \\
\hline $\mathrm{BaO}$ & 0,11 \\
\hline $\mathrm{CaO}$ & 28 \\
\hline $\mathrm{Fe}_{2} \mathrm{O}_{3}$ & 4,9 \\
\hline $\mathrm{K}_{2} \mathrm{O}$ & 4,1 \\
\hline $\mathrm{MgO}$ & 1,9 \\
\hline $\mathrm{Mn}_{2} \mathrm{O}_{3}$ & 0,083 \\
\hline $\mathrm{Na}_{2} \mathrm{O}$ & 4,6 \\
\hline $\mathrm{P}_{2} \mathrm{O}_{5}$ & 2,4 \\
\hline $\mathrm{SO}_{3}$ & 4,4 \\
\hline $\mathrm{SiO}_{2}$ & 21 \\
\hline $\mathrm{SrO}_{\mathrm{TiO}}$ & 0,066 \\
\hline $\mathrm{TiO}_{2}$ & 2,5 \\
\hline $\mathrm{ZnO}$ & 0,31 \\
\hline
\end{tabular}

Tabla 3.6. Metales en las cenizas en forma de óxidos. 
Teniendo en cuenta los citados valores, se puede estimar el riesgo de sinterizado empleando diferentes índices. La tendencia a sinterización de cada muestra puede estimarse mediante la relación entre los óxidos alcalinos y alcalinotérreos, método empleado comúnmente para biomasa [146]. La relación arrojó un valor elevado, 3.2, lo que implica poco riesgo de sinterizado, al ser superior a 2, límite establecido por este método. Por tanto, un mayor contenido en óxidos alcalinotérreos respecto a óxidos alcalinos implica una reducción del riesgo de sinterizado. Además, el contenido en constituyentes inorgánicos, por ejemplo calcio, juega un rol importante en la mejora o reducción de la volatilización de elementos traza (TEs), a través de la formación de compuestos térmicamente estables [147].

No obstante, existen numerosos índices que podrían dar una estimación del riesgo de sinterizado y la aglomeración que podría ocurrir entre el CSR y el material de lecho empleado. Existen varios índices para analizar la inclinación al ensuciamiento y la formación de escorias en las cenizas de carbón que han sido aplicados al estudio de la fusibilidad de las cenizas en CSR [145].

En la Tabla 3.7, se muestran los valores que arrojaron estos índices y su comparativa con el CSR de origen doméstico analizado en el estudio citado. El índice de formación de escorias, $F_{\mathrm{s}}$, que tienen en cuenta las temperaturas características observadas durante los ensayos de fusibilidad de las cenizas, no mostró una inclinación severa, ya que correspondería con temperaturas menores a $1052{ }^{\circ} \mathrm{C}$, como fue estudiado para carbón sub-bituminoso [148].

El resto de índices que aparecen en la Tabla 3.9, fueron estudiados en relación a las temperaturas características, ya que a medida que se observó un cambio al variar las temperaturas de deformación. Por tanto, estos índices pueden ser utilizados como complemento al análisis de las cenizas. Aunque el CSR estudiado en la presente tesis mostrara valores superiores a los obtenidos por Dunnu, su riesgo de sinterización es bajo [145].

\begin{tabular}{|l|c|c|}
\hline Índices & CSR & MSW \\
\hline $\mathrm{R}_{\mathrm{b}}$ & 36,9 & 38,48 \\
\hline $\mathrm{R}_{\mathrm{b} / \mathrm{a}}$ & 1,01 & 0,75 \\
\hline $\mathrm{R}_{\mathrm{b} / \mathrm{a}(+\mathrm{P})}$ & 1,08 & 0,77 \\
\hline $\mathrm{R}_{\mathrm{b} / \mathrm{a}} \times \mathrm{Na}$ & 4,22 & 3,11 \\
\hline $\mathrm{S}_{\mathrm{R}}$ & 41,83 & 54,38 \\
\hline $\mathrm{F}_{\mathrm{S}}\left({ }^{\circ} \mathrm{C}\right)$ & 1.182 & 1.142 \\
\hline
\end{tabular}

Tabla 3.7. Índices de ensuciamiento y formación de escorias [145].

Las temperaturas características fueron muy elevadas en comparación con las que se alcanzan en un gasificador de lecho fluidizado, ver Tabla 3.8, por tanto muestran también un riesgo de sinterización bajo. La temperatura de deformación inicial fue de $1180^{\circ} \mathrm{C}$. La temperatura de esfera no pudo determinarse, ya que se produjo un cambio muy rápido en la forma de la muestra y no se pudo registrar valor alguno. Las temperaturas de hemiesfera y temperatura fluida fueron de $1190^{\circ} \mathrm{C}$. 


\begin{tabular}{|l|c|}
\hline Parámetro & Temperatura $\left({ }^{\circ} \mathbf{C}\right)$ \\
\hline TDI $\left({ }^{\circ} \mathrm{C}\right)$ & 1.180 \\
\hline TE $\left({ }^{\circ} \mathrm{C}\right)$ & n.d. \\
\hline TH $\left({ }^{\circ} \mathrm{C}\right)$ & 1.190 \\
\hline TF $\left({ }^{\circ} \mathrm{C}\right)$ & 1.190 \\
\hline
\end{tabular}

Tabla 3.8. Fusibilidad de las cenizas del CSR de origen doméstico.

La estimación de la fracción biodegradable se realizó a partir de la determinación del contenido de biomasa sobre el material procesado en la proporción fijada. El método de determinación empleado fue disolución selectiva, ya que el método de separación manual no pudo aplicarse al producto ya molido y peletizado. No obstante, en este caso no se consideró necesaria llevar a cabo la determinación del contenido de biomasa al material residual de partida, recibido en las plantas de pretratamiento, debido a que un análisis cuantitativo, composición de cada una de las fracciones de rechazo, fue realizado de manera exhaustiva y permitió disponer de datos relevantes sobre su composición.

El contenido en biomasa fue del $45 \%$, ver Tabla 3.9, siendo similar al obtenido en otros estudios que evaluaron el potencial de RSU como fuente de energía renovable en España [60]. El contenido en biomasa del peletizado se podría incrementar añadiendo al proceso de peletizado materia orgánica biodegradable parcialmente estabilizada, aunque actualmente para esta materia biodegradable estabilizada se contemplen otros usos [128].

\begin{tabular}{|c|c|c|c|}
\hline \multicolumn{4}{|c|}{ Determinación del contenido en biomasa (\% b.s.) } \\
\hline Disolución Selectiva & Biomasa & No biomasa & Inerte \\
\cline { 2 - 4 } & 45 & 40 & 15 \\
\hline
\end{tabular}

Tabla 3.9. Determinación del contenido en biomasa para el CSR doméstico.

\subsubsection{ANÁLISIS TERMOGRAVIMÉTRICO DEL COMBUSTIBLE}

La caracterización del combustible peletizado se completó con un análisis termogravimétrico mediante curvas TG/DTG. El análisis fue realizado empleando dos atmósferas distintas, es decir: atmósfera inerte, simulando un proceso de pirólisis, y atmósfera oxidante, simulando un proceso de combustión. La decisión de elegir una atmósfera inerte que simule condiciones de devolatilización en lugar de una atmósfera que simule condiciones de reducción, simulando un proceso de gasificación, se debe al elevado contenido en volátiles que arrojó el análisis inmediato del residuo, por ende, la conversión del combustible desde fase sólida a gaseosa será prácticamente inmediata y al tener un contenido en carbono fijo tan bajo, ambas curvas termogravimétricas tendrán un comportamiento semejante.

El estudio a nivel laboratorio del comportamiento del combustible en condiciones de pirólisis y combustión, a partir de un análisis termogravimétrico, permite predecir el comportamiento y la estabilidad térmica del sólido. El análisis fue llevado a cabo desde temperatura ambiente hasta $900{ }^{\circ} \mathrm{C}$ con una velocidad de calentamiento de $20{ }^{\circ} \mathrm{C} / \mathrm{min}$ (rampa horizontal), empleando nitrógeno para simular una atmósfera inerte, y aire para simular una atmósfera oxidante. 
La pérdida de masa que experimenta el sólido durante el ensayo termogravimétrico se observa mediante la curva TG. En el proceso simulado de pirólisis, la materia volátil se transforma en productos gaseosos de suma importancia en el proceso de gasificación $\left(\mathrm{CO}, \mathrm{H}_{2}, \ldots\right)$. De este ensayo se pueden extraer datos relativos al porcentaje de residuo generado durante el proceso, el rango de temperaturas donde ocurren las etapas de degradación principales y las temperaturas máximas de degradación para cada etapa.

A partir de este ensayo se infirió la existencia de tres etapas durante el proceso: una etapa de secado, una etapa que se corresponde a la degradación de dos sustancias diferentes y una etapa de degradación lenta, ver Figuras 3.3. No obstante, las mismas etapas se observaron en el proceso simulado de combustión, ver Figura 3.4. Este último ensayo, proceso simulado de combustión, se realizó debido a que el CSR de origen doméstico fue testado en un caldera de lecho fluidizado burbujeante [149].

A continuación se muestran las curvas TG/DTG bajo condiciones de atmósfera oxidante y reductora. Simplemente se ha obtenido la curva DTG de los datos que fueron registrados en ambos procesos. En esta curva se observa más claramente las dos etapas de degradación que se indican en el anterior párrafo.

El inicio de la degradación de los materiales celulósicos apareció a $220^{\circ} \mathrm{C}$ y finalizó a $380{ }^{\circ} \mathrm{C}$, mostrando un pico a $320^{\circ} \mathrm{C}$ y $330^{\circ} \mathrm{C}$ para condiciones oxidantes y reductoras, respectivamente. $\mathrm{Y}$ para los materiales plásticos, la degradación comenzó a $380{ }^{\circ} \mathrm{C}$ y acabó a $540{ }^{\circ} \mathrm{C}$, mostrando un pico a $450{ }^{\circ} \mathrm{C}$ para condiciones oxidantes y a $470{ }^{\circ} \mathrm{C}$ para reductoras.

Al igual que se observó con la curva SDTA, apareció un residuo al final del ensayo, cuando no se detectó una pérdida significativa de masa, alrededor del $28 \%$ para el proceso simulado de pirolisis, y en torno al $13 \%$ para el proceso simulado de combustión. No obstante, la muestra a ensayo es tan pequeña que provoca que los resultados obtenidos sean meramente cualitativos, siendo necesaria la determinación de parámetros químicos a través de análisis de caracterización en laboratorio.

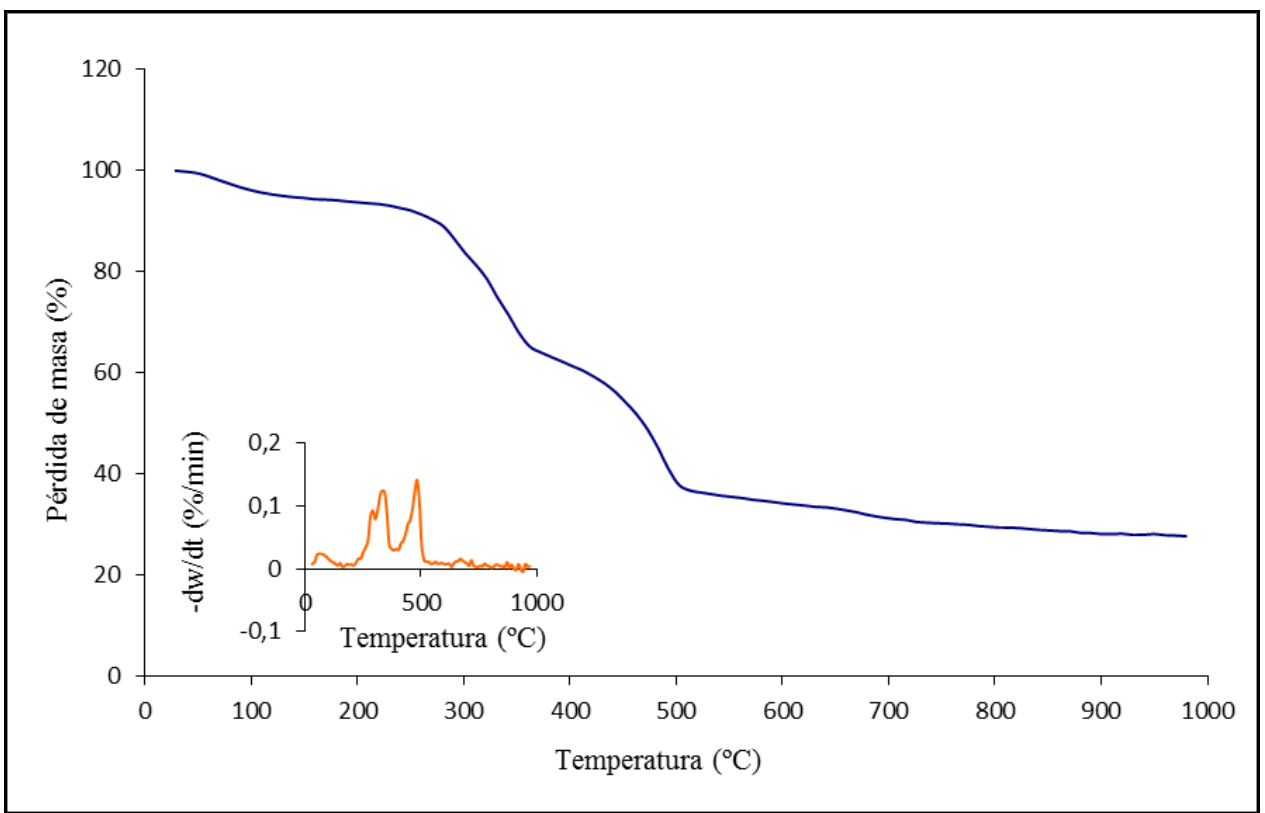

Figura 3.3 Curva TG suministrada tras el ensayo en la termobalanza en atmósfera inerte. Interior: curva DTG. 


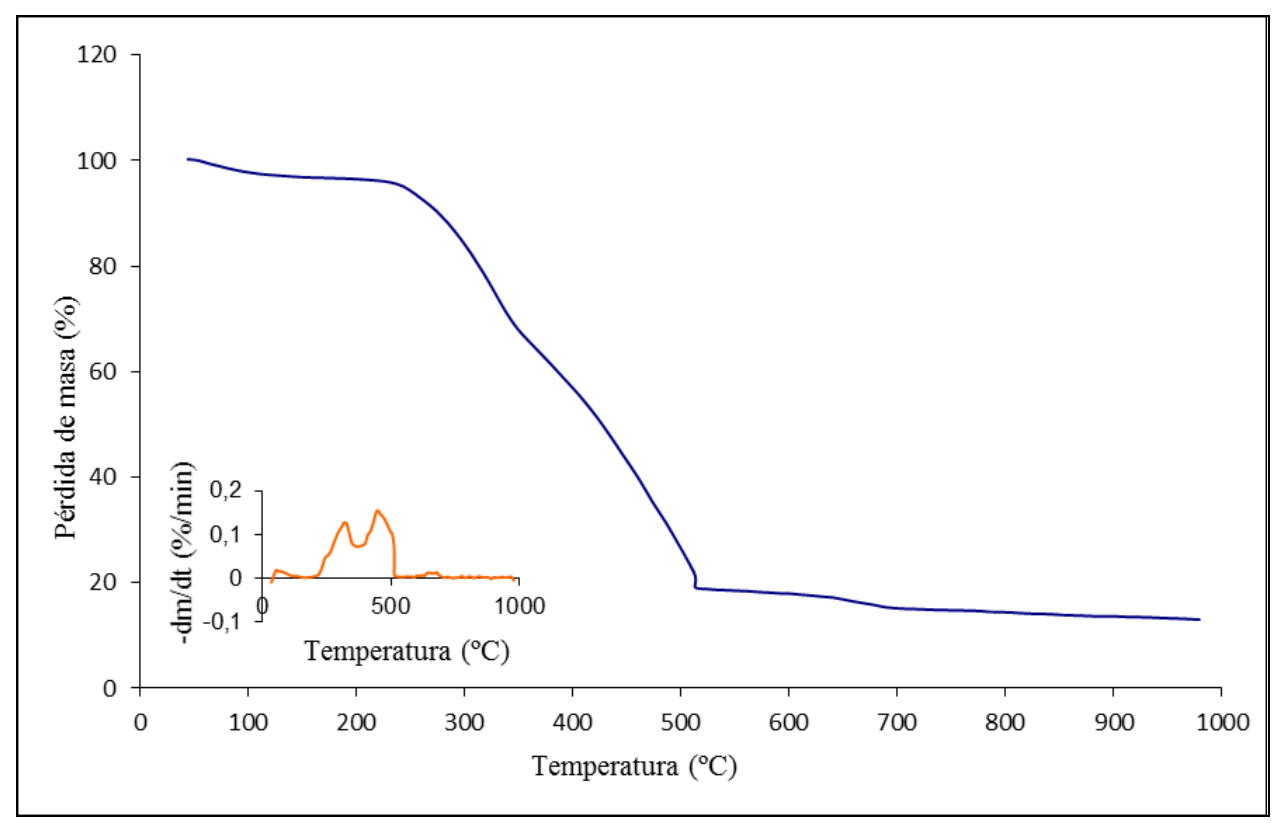

Figura 3.4 Curva TG suministrada tras el ensayo en la termobalanza en atmósfera oxidante. Interior: curva DTG.

La Tabla 3.10 muestra los valores más representativos, que pueden ser determinados a través de las curvas TG/DTG, Figuras 3.3 y 3.4, obtenidos durante el ensayo. Se observaron dos etapas de degradación diferentes, figura 3.3, que corresponden con la degradación del material celulósico y el material plástico [150, 151]. Además, el residuo final para la etapa de pirólisis se corresponde con la suma del contenido en cenizas y el carbono fijo de la muestra ensayada.

\begin{tabular}{|l|c|c|c|c|c|}
\hline Proceso & Etapa I $\left({ }^{\mathbf{}} \mathbf{C}\right)$ & $\mathbf{T}_{\text {pico }}\left({ }^{\mathbf{0}} \mathbf{C}\right)$ & $\begin{array}{c}\text { Etapa II } \\
\left({ }^{\circ} \mathbf{C}\right)\end{array}$ & $\begin{array}{c}\mathbf{T}_{\text {pico }} \\
\left({ }^{\circ} \mathbf{C}\right)\end{array}$ & $\begin{array}{c}\text { Residuo final } \\
(\mathbf{\%})\end{array}$ \\
\hline Pirólisis & $220-370$ & 328 & $390-510$ & 473 & 28 \\
\hline Combustión & $220-380$ & 317 & $380-540$ & 446 & 13 \\
\hline
\end{tabular}

Tabla 3.10. Datos de los análisis termogravimétricos correspondientes a las etapas de degradación del sólido.

\subsubsection{Estudio cinético del combustible}

La determinación de los parámetros cinéticos para la mezcla del rechazo de biometanización y el rechazo de la planta de clasificación y selección de nevases no pudo hacerse por separado, ya que ambos rechazos fueron mezclados y pretratados. No obstante, se hizo un estudio cinético al combustible producido mediante el método de Coats-Redfern, ver Figura 3.5.

El rango de temperatura durante la degradación de la muestra fue usado para la obtención de las principales etapas de degradación, cuyos picos fueron observados a $328^{\circ} \mathrm{C}$ y $473{ }^{\circ} \mathrm{C}$. Los valores de energía de activación, factor pre-exponencial y orden de reacción para la degradación de los materiales celulósicos fueron $31,2 \mathrm{~kJ} / \mathrm{mol}$, $2,5 \times 10^{6} \mathrm{~min}^{-1}$ and 4. La segunda etapa de degradación fue la correspondiente al material plástico, siendo los parámetros cinéticos 55,9 $\mathrm{kJ} / \mathrm{mol}, 2,7 \times 10^{12} \mathrm{~min}^{-1}$ and 1,5 , respectivamente. 


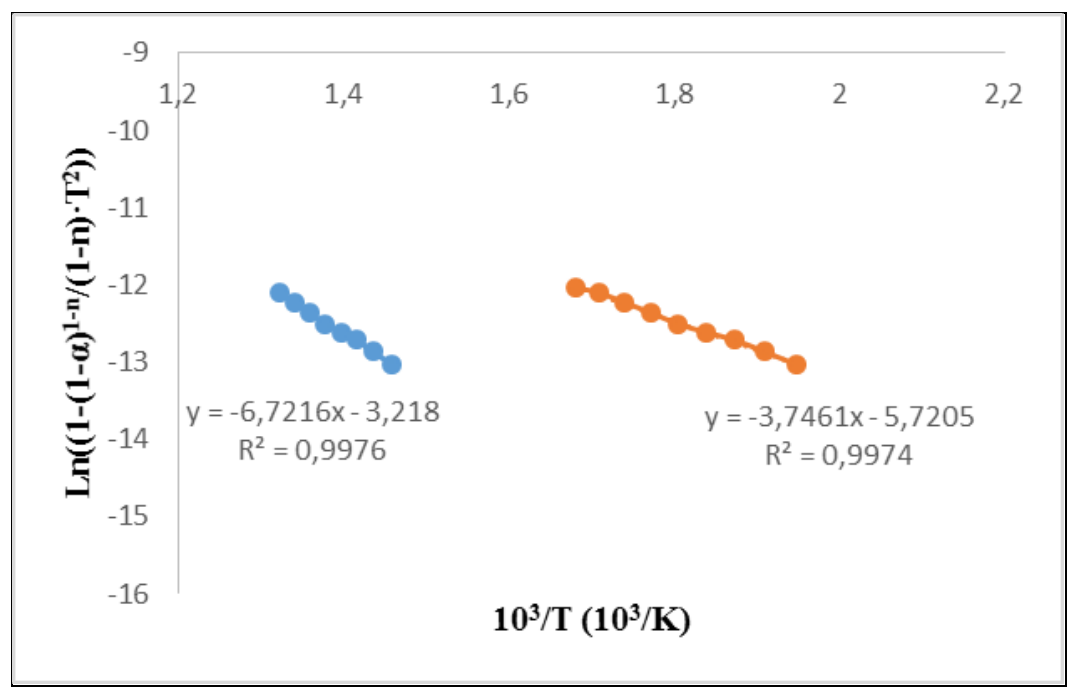

Figura 3.5 Método Coats-Redfern CSR doméstico.

\subsubsection{CLASIFICACIÓN DEL COMBUSTIBLE SÓLIDO RECUPERADO}

En los epígrafes anteriores se ha mostrado una caracterización del RSU ya procesado y transformado en pélets. En esta caracterización se han determinado las propiedades físicas y químicas con el objeto de demostrar la viabilidad de los residuos. No obstante, la nueva normativa europea sobre CSR indica que la presentación de parámetros físicos y químicos debe realizarse a través de una serie de formularios, que indican la obligatoriedad o no de su especificación. Por tanto, a continuación se muestran los formularios completos para cada uno de los combustibles producidos, donde se recoge el código de clase de cada uno de ellos.

\subsubsection{Formulario para la especificación de CSR}

Este formulario corresponde a la parte 1 incluida en el Anexo A (normativo) de la norma UNE-EN 15359:2011, ver Figuras 3.6 y 3.7. Este formulario fue rellanado con los datos obtenidos en la caracterización del CSR de origen doméstico. Se divide en dos partes, A y B, que corresponden con datos obligatorios de especificar y con datos no obligatorios de especificar, respectivamente. En la parte A se indica el código de clase y el origen del CSR, así como los parámetros físicos y químicos más relevantes, mientras que en la parte $\mathrm{B}$, se incluyen datos referidos a preparación, contenido en biomasa, composición, y algunos otros parámetros físicos y químicos no obligatorios de especificar.

La columna "métodos de ensayo" no ha sido rellenada, ya que los métodos empleados se corresponden con los que marca la normativa europea sobre CSR, encontrándose citados en el capítulo II de esta tesis, Tabla 2.4. Dentro de la columna "Valor" se dispone de dos apartados: típico y límite, donde el valor típico hace referencia a las propiedades físicas y químicas del CSR, y el valor límite corresponde al acuerdo entre el usuario y el productor, refiriéndose a envíos. Por tanto, el valor límite no se especifica en este formulario, solamente el valor típico que ha sido obtenido mediante los análisis llevados a cabo sobre el CSR. 


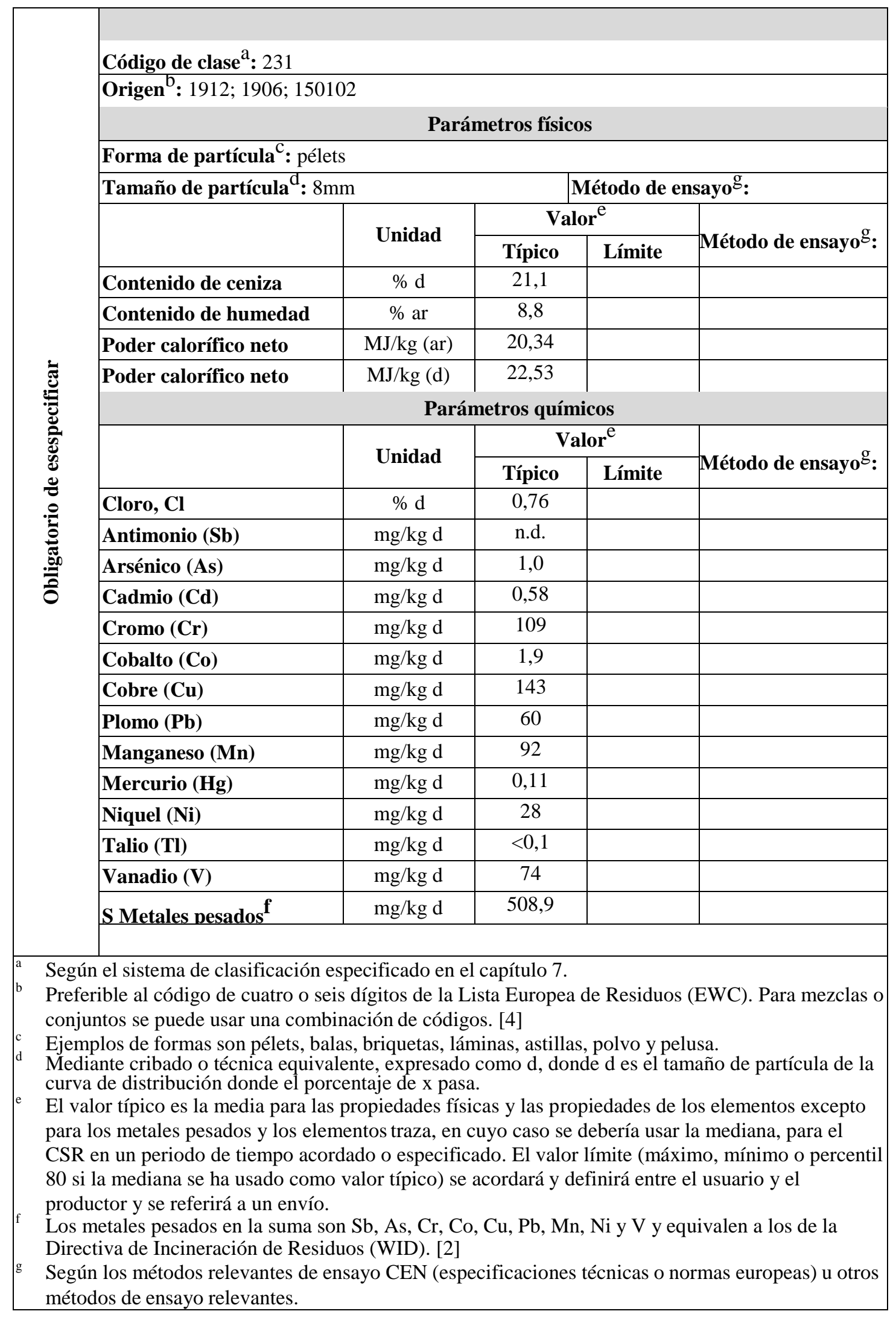

Figura 3.6 Parte 1 Anexo A (normativo)_Obligatorio de especificar. 


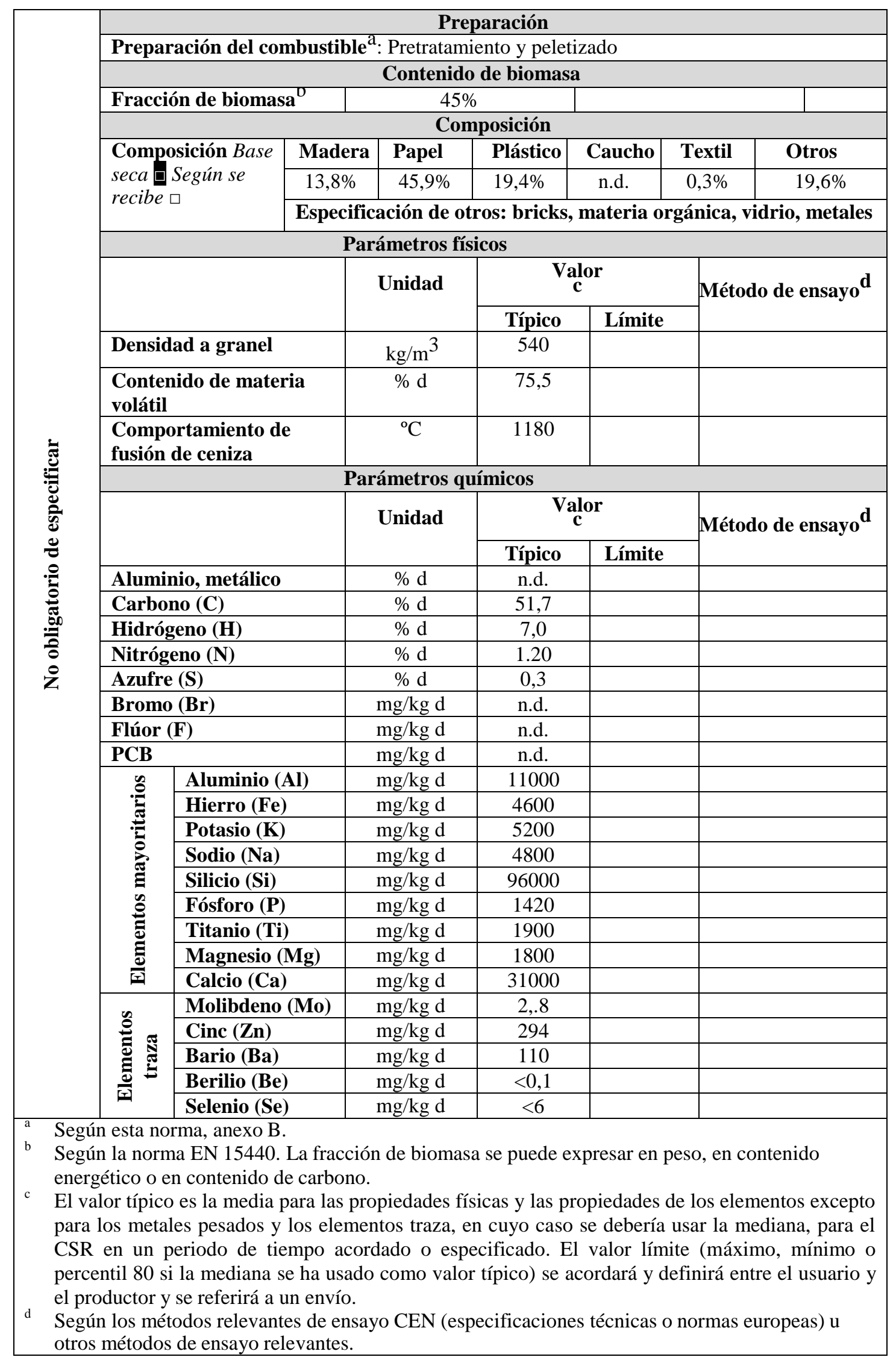

Figura 3.7 Parte 1 Anexo A (normativa)_no obligatorio de especificar. 


\subsubsection{Preparación del combustible}

Este formulario corresponde a la parte 1 incluida en el Anexo A (normativo) de la norma UNE-EN 15359:2011, ver Figura 3.8. Este formulario fue rellanado con los rechazos de la planta de biometanización y de la selección y clasificación de envases.

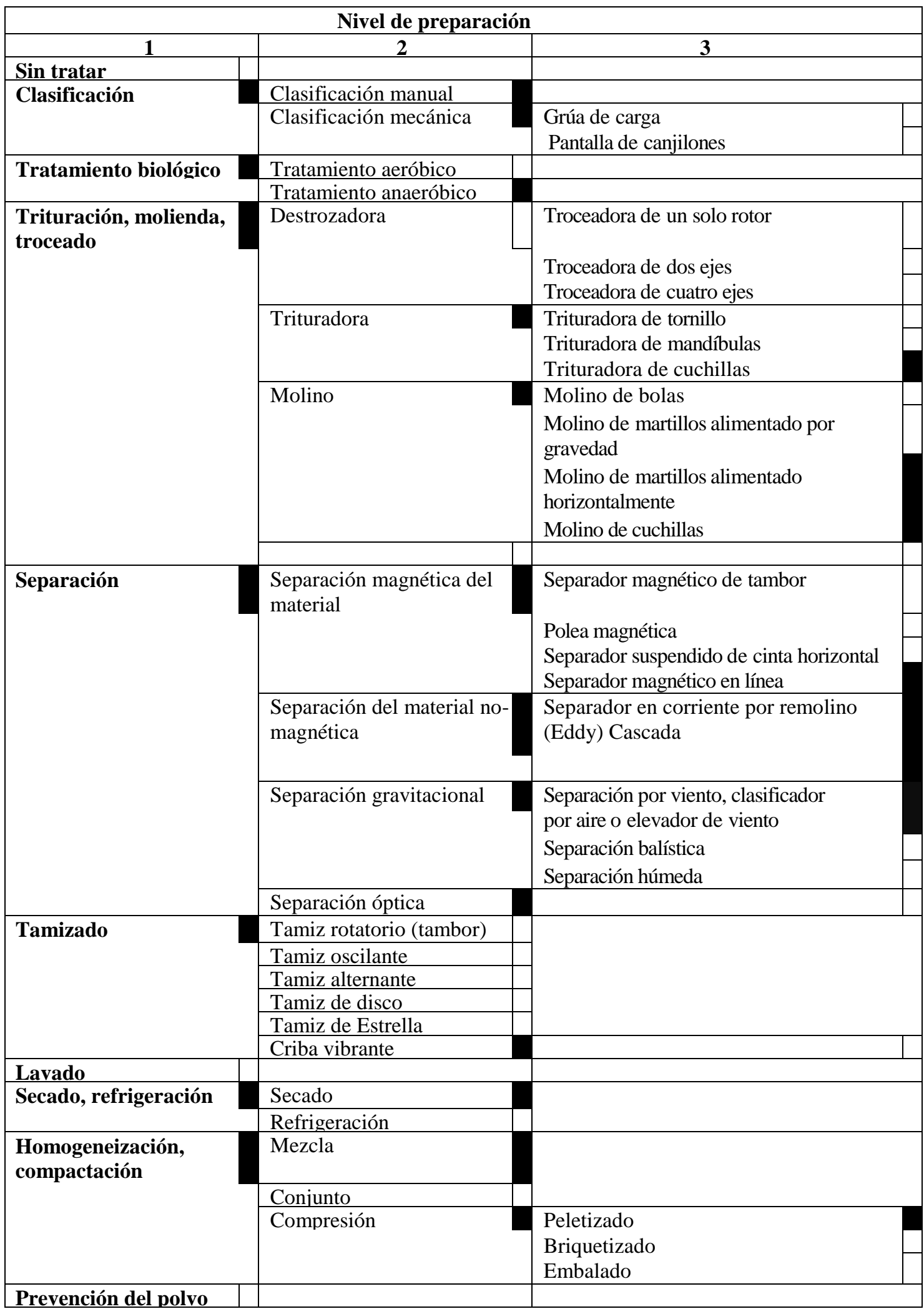

Figura 3.8 Parte 1 Anexo A (normativo)_preparación. 


\subsection{RESIDUOS INDUSTRIALES}

Los residuos industriales provenientes de la industria papelera que fabrica papel reciclado a partir de papel recuperado se generan en puntos diferentes de la misma instalación. En adelante, nos referiremos por rechazo a aquellas fracciones que provienen de la selección y clasificación del papelote, y a la proveniente del proceso de pulpado. Y como lodos de destintado o lodos, nos referiremos tanto a los lodos de destintado, como a lodo primario generado en la clarificación de efluentes líquidos, y lodo secundario generado en las operaciones de tratamiento de aguas residuales.

Ambos residuos industriales, se mezclaron con el objeto de producir cuatro combustibles en función de la cantidad de lodo añadido. Estos se denominarán: M1 (proporción: 95\% rechazo; 5\% lodo); M2 (proporción: 85\% rechazo; 15\% lodo); M3 (proporción: 75\% rechazo; 25\% lodo); M4 (proporción: 65\% rechazo; 35\% lodo).

\subsubsection{CARACTERIZACIÓN DE LOS RESIDUOS INDUSTRIALES}

La caracterización fue hecha mediante análisis inmediato y elemental de los residuos. Además, el poder calorífico fue determinado para investigar el uso potencial de los residuos como combustible en procesos de conversión térmica. Los datos presentados en la Tabla 3.11, fueron recogidos durante los turnos de trabajo completo.

De los resultados de la Tabla 3.11, se observa que los rechazos mostraron un poder calorífico inferior de $26.6 \mathrm{MJ} / \mathrm{kg}$, un alto contenido en materia volátil de $82.5 \%$ y un contenido medio en ceniza, alrededor del 9\%. Esto implica que los rechazos pueden ser aceptables para producir un combustible con ciertas garantías. Además, el contenido en cloro de los rechazos fue significativo, lo cual podría derivar en problemas operacionales debidos a la formación de $\mathrm{HCl} \mathrm{y} \mathrm{Cl}_{2}$, ambos promotores de corrosión, y en la formación de dioxinas y furanos, siendo el $\mathrm{Cl}_{2}$ uno de los mayores contribuyentes $[144,151,152,153,154]$. La dispersión que muestran los datos respecto al contenido en cloro por turnos de trabajo pueden deberse a la existencia de muestras con trazas de PVC [143].

Respecto al lodo de destintado, presentó un poder calorífico inferior de 7,6 MJ/kg y un alto contenido en cenizas. Este hecho podría ocasionar una restricción en la cantidad de lodo a añadir debido a la imperiosa necesidad de instalar sistemas de eliminación de cenizas en los procesos de conversión térmica a los que se destine el combustible. Cabe destacar que el contenido de materia volátil medido, es una medida empírica, que se utiliza para carbón, biomasa y otros combustibles con un bajo contenido en ceniza. Determinándose el contenido en volátiles liberados cuando el combustible se calienta con aire. Cuando el contenido en ceniza es muy elevado, una gran cantidad de componentes inorgánicas en la ceniza, éstos son volatilizados como $\mathrm{CO}_{2}$ de carbonatos y componentes alcalinos ( $\mathrm{KCl}$ funde a $775^{\circ} \mathrm{C}$ ). Por tanto, el contenido en materia volátil, que mostró un valor de $48,4 \%$ es una sobreestimación y no es exacta su medida. 


\begin{tabular}{|l|c|c|}
\hline & $\begin{array}{c}\text { Rechazo de clasificación } \\
\text { y pulpado }\end{array}$ & Lodos \\
\hline Análisis inmediato (\% en peso, b.s.) & $40,4 \pm 15,5$ & $32,5 \pm 6,9$ \\
\hline Humedad (b.h.) & $82,5 \pm 3,2$ & $64,6 \pm 1,9$ \\
\hline Materia volátil & $9,3 \pm 1,5$ & $48,4 \pm 4,2$ \\
\hline Cenizas & $8,2 \pm 2,7$ & n.d. \\
\hline Carbono fijo ${ }^{\text {a }}$ & $25,6 \pm 0,9$ \\
\hline Análisis elemental (\% en peso, b.s.) & $2,7 \pm 0,1$ \\
\hline Carbono & $58,3 \pm 6,4$ & $0,43 \pm 0,03$ \\
\hline Hidrógeno & $8,4 \pm 1,1$ & $0,25 \pm 0,08$ \\
\hline Nitrógeno & $0,29 \pm 0,18$ & $0,01 \pm 0,01$ \\
\hline Azufre & $0,13 \pm 0,09$ & $6,35 \pm 1,38$ \\
\hline Cloro & $1,34 \pm 1,21$ & $7,57 \pm 0,36$ \\
\hline Oxígeno ${ }^{\text {a }}$ & $22,22 \pm 7,32$ & $8,16 \pm 0,38$ \\
\hline Poder calorífico $(\mathbf{M J} / \mathbf{k g})$ & $26,61 \pm 3,88$ & \\
\hline PCI & $28,41 \pm 4,09$ & \\
\hline PCS &
\end{tabular}

${ }^{\text {a }}$ por diferencia

Tabla 3.11. Caracterización de las corrientes residuales procedentes de la industria papelera.

La variabilidad temporal de las corrientes residuales se puede observar de manera gráfica en las Figuras 3.9 y 3.10, para el rechazo de clasificación y pulpado, y para los lodos de destintado, respectivamente. En estas figuras se muestra la variabilidad en función del turno de trabajo. Los datos mostrados corresponden al muestreo durante tres turnos de trabajo en tres días alternos.

El método de muestreo consistió en la toma de muestras manual de cada una de las sacas recibidas, siguiendo el procedimiento normalizado. El lodo mostró poca variabilidad, a excepción del contenido en humedad de las muestras, pero no se ha podido extraer ninguna conclusión sobre el efecto de los turnos de trabajo en el contenido de humedad. Por tanto, se puede afirmar que el lodo es uniforme en su composición, aunque varía ligeramente el contenido de humedad de los mismos.

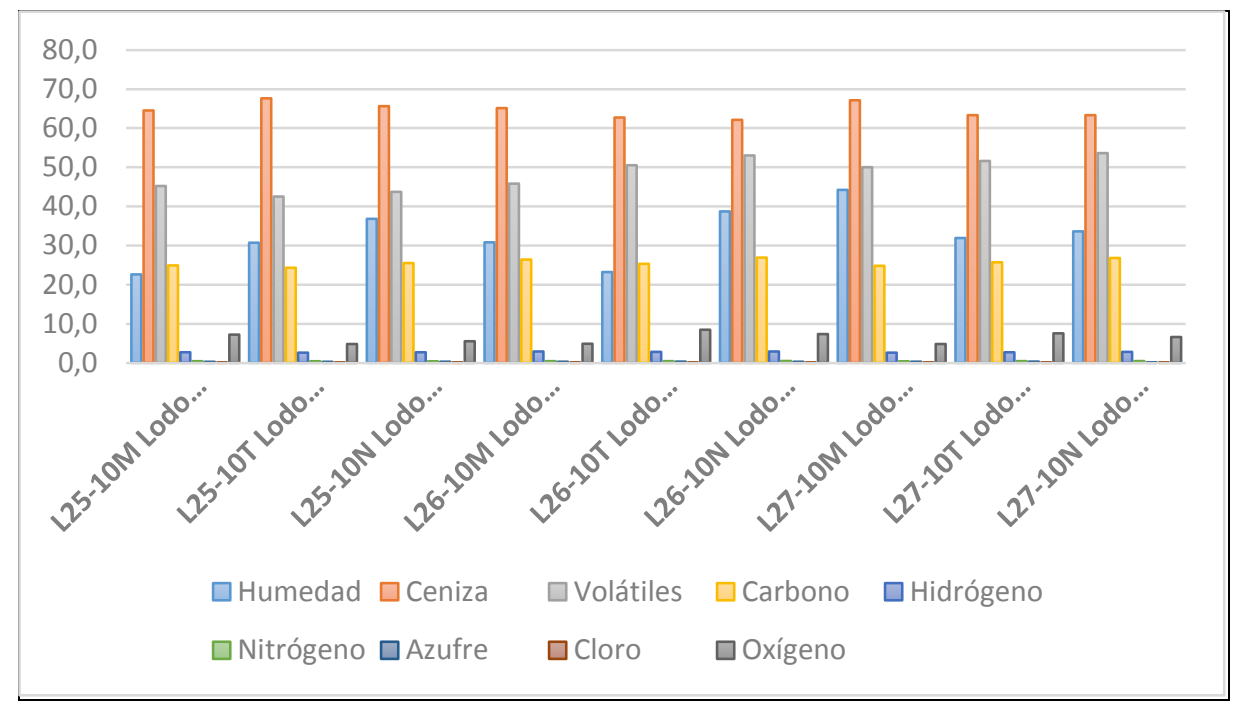

Figura 3.9. Composición química de la corriente residual de lodos. 
Con respecto al rechazo de clasificación de papelote y del proceso de pulpado, se muestra una amplia variabilidad en cuanto a la humedad, aunque en este caso, se observaron elevados valores de contenido en humedad en el turno de noche. Las variaciones en el análisis elemental de los rechazos depende en gran medida del papelote que reciba la fábrica, que influye en el contenido elemental de la muestra y en el poder calorífico final del residuo, ya que está íntimamente ligado a los materiales que conforman este rechazo.

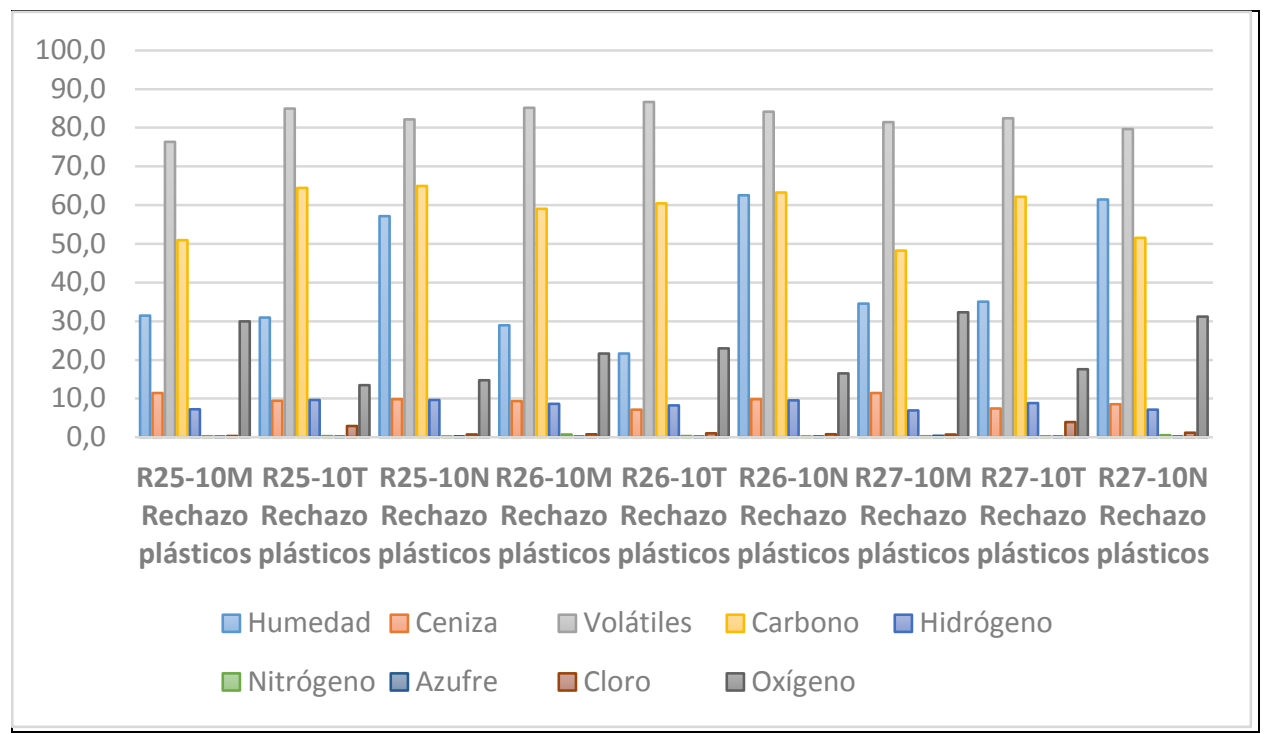

Figura 3.10. Composición química de la fracción rechazo de clasificación de papelote y del proceso de pulpado.

A consecuencia de la elevada proporción de ceniza encontrada en el lodo (64,6\%), la suma de carbono, hidrógeno y oxígeno fue baja, y por tanto, su poder calorífico también. Los elementos mayoritarios encontrados en mayor proporción en la ceniza del lodo fueron calcio ( $28 \%$ en b.s. en base a la ceniza o $20 \%$ b.s. en base al combustible), seguidos de silicio y aluminio. Por otro lado, los rechazos mostraron una elevada proporción de carbono, hidrógeno y oxígeno, lo cual genera un importante poder calorífico superior, alrededor de $28 \mathrm{MJ} / \mathrm{kg}$. Además, el contenido en cloro fue significativo. Este cloro, es principalmente cloro orgánico, y deriva de los materiales plásticos, debido a que los elementos que conforman la ceniza tienen un bajo contenido en potasio y sodio, que combinado con el cloro produce $\mathrm{KCl}$ y $\mathrm{NaCl}$. Los elementos mayoritarios en los rechazos fueron aluminio ( $24 \%$ en b.s. en base a la ceniza o $20 \%$ b.s. en base al combustible), seguidos de calcio y silicio.

Las cenizas de las corrientes residuales de la industria papelera se estudiaron para determinar el riesgo de sinterización de dichos residuos. El elevado contenido en óxido de calcio, alrededor del $45 \%$ en los rechazos y del $17 \%$ en los lodos, reduce la posible formación de sinterizados, como los formados en otros estudios de gasificación, que emplearon residuos de industrias papeleras [117]. Además, el bajo contenido en óxidos de sodio y potasio, evita el descenso en el punto de fusión de las cenizas, como se observa en la Tabla 3.12. La explicación de que el porcentaje de metales totales en forma de óxidos para los lodos no sea del $100 \%$ se debe a que parte del óxido de calcio se encuentra como carbonatos, que se volatilizan a $950{ }^{\circ} \mathrm{C}$. 


\begin{tabular}{|l|c|c|}
\hline Óxidos de metales (\%) & Rechazo & Lodos \\
\hline $\mathrm{Al}_{2} \mathrm{O}_{3}$ & $24,9 \pm 15,2$ & $7,4 \pm 0,9$ \\
\hline $\mathrm{BaO}$ & $0,189 \pm 0,144$ & $0,018 \pm 0,001$ \\
\hline $\mathrm{CaO}$ & $17 \pm 5$ & $46 \pm 3$ \\
\hline $\mathrm{Fe}_{2} \mathrm{O}_{3}$ & $30,82 \pm 22,68$ & $0,54 \pm 0,08$ \\
\hline $\mathrm{K}_{2} \mathrm{O}$ & $0,69 \pm 0,45$ & $0,26 \pm 0,02$ \\
\hline $\mathrm{MgO}$ & $0,9 \pm 0,2$ & $3,0 \pm 0,9$ \\
\hline $\mathrm{Mn}_{2} \mathrm{O}_{3}$ & $0,096 \pm 2,644$ & $0,024 \pm 0,002$ \\
\hline $\mathrm{Na}_{2} \mathrm{O}$ & $2,64 \pm 1,01$ & $0,39 \pm 0,06$ \\
\hline $\mathrm{P}_{2} \mathrm{O}_{5}$ & $1,25 \pm 1,81$ & $0,20 \pm 0,03$ \\
\hline $\mathrm{SO}_{3}$ & $1,26 \pm 0,49$ & $1,11 \pm 0,11$ \\
\hline $\mathrm{SiO}_{2}$ & $12 \pm 6$ & $15 \pm 1$ \\
\hline $\mathrm{SrO}$ & $0,03 \pm 0,01$ & $0,06 \pm 0,00$ \\
\hline $\mathrm{TiO}_{2}$ & $5,47 \pm 3,24$ & $0,25 \pm 0,02$ \\
\hline $\mathrm{ZnO}$ & $0,609 \pm 1,018$ & $0,016 \pm 0,001$ \\
\hline & 97,586 & 73,430 \\
\hline
\end{tabular}

Tabla 3.12. Composición en metales de las cenizas de las corrientes residuales de la industria papelera en forma de óxidos.

De acuerdo con la Directiva 2009/28/CE, la fracción biodegradable de los residuos puede considerarse como una fuente de energía renovable. La determinación del contenido de biomasa es de gran importancia, ya que permite estimar la fracción biodegradable de los residuos [55]. Los métodos empleados para su determinación fueron separación manual y disolución selectiva, ambos recogidos por la norma UNEEN 15440:2012. En la tabla 3.13, se observa que la determinación del contenido en biomasa de los rechazos por ambos métodos resultó en la obtención de valores muy parejos, $17 \%$ y $18 \%$, respectivamente. La incorporación del lodo de destintado tal vez conlleve un aumento en el contenido de biomasa.

\begin{tabular}{|l|c|c|c|}
\hline \multicolumn{4}{|c|}{ Determinación del contenido en biomasa fracción rechazo } \\
\hline & Biomasa & No biomasa & Inerte \\
\hline Separación manual & 18 & 77 & 5 \\
\hline Disolución selectiva & 17 & 76 & 7 \\
\hline
\end{tabular}

Tabla 3.13. Contenido en biomasa de la fracción rechazo de la clasificación de papelote y del rechazo del pulpado.

\subsubsection{ANÁLISIS TERMOGRAVIMÉTRICO DE RECHAZOS DE INDUSTRIA PAPELERA}

La Figura 3.11 muestra las curvas TG/DTG correspondientes a los rechazos de la clasificación del papel recuperado de la recogida selectiva y de los rechazos del proceso de pulpado. Las curvas termogravimétricas fueron obtenidas para una velocidad de calentamiento de $20^{\circ} \mathrm{C} / \mathrm{min}$ desde temperatura ambiente hasta $900{ }^{\circ} \mathrm{C}$.

El análisis muestra que el proceso de degradación térmica tuvo lugar en dos etapas, como se observa a través de los dos picos que muestra la curva DTG. El primer pico, corresponde con material celulósico, cuya degradación comenzó a la temperatura de 270 ${ }^{\circ} \mathrm{C}$ y finalizó a la temperatura de $380^{\circ} \mathrm{C}$, presentando un máximo a $320^{\circ} \mathrm{C}$. El otro pico 
observado, correspondió a la degradación de material plástico, cuya degradación comenzó a $400{ }^{\circ} \mathrm{C}$ y finalizó a $520{ }^{\circ} \mathrm{C}$, mostrando un máximo a $495^{\circ} \mathrm{C}$. En esta etapa, pueden verse dos picos fusionados, que pueden corresponder a materiales plásticos de distinto tipo. Aunque no se haya realizado ningún análisis cuantitativo de la composición del rechazo, un contenido significativo de cloro fue medido, pudiendo corresponder a PVC [143]. Además, el polietileno de baja densidad siempre aparece en grandes cantidades, siendo una fuente de energía viable, ya que se emplea en bolsas de basura y en envoltorios de revistas, cartones, etc [159]. A esta etapa le sigue una pérdida lenta de masa de $520^{\circ} \mathrm{C}$ hasta $900{ }^{\circ} \mathrm{C}$, obteniéndose un residuo del $20 \%$ de la muestra, que puede deberse a restos de material inquemado y ceniza.

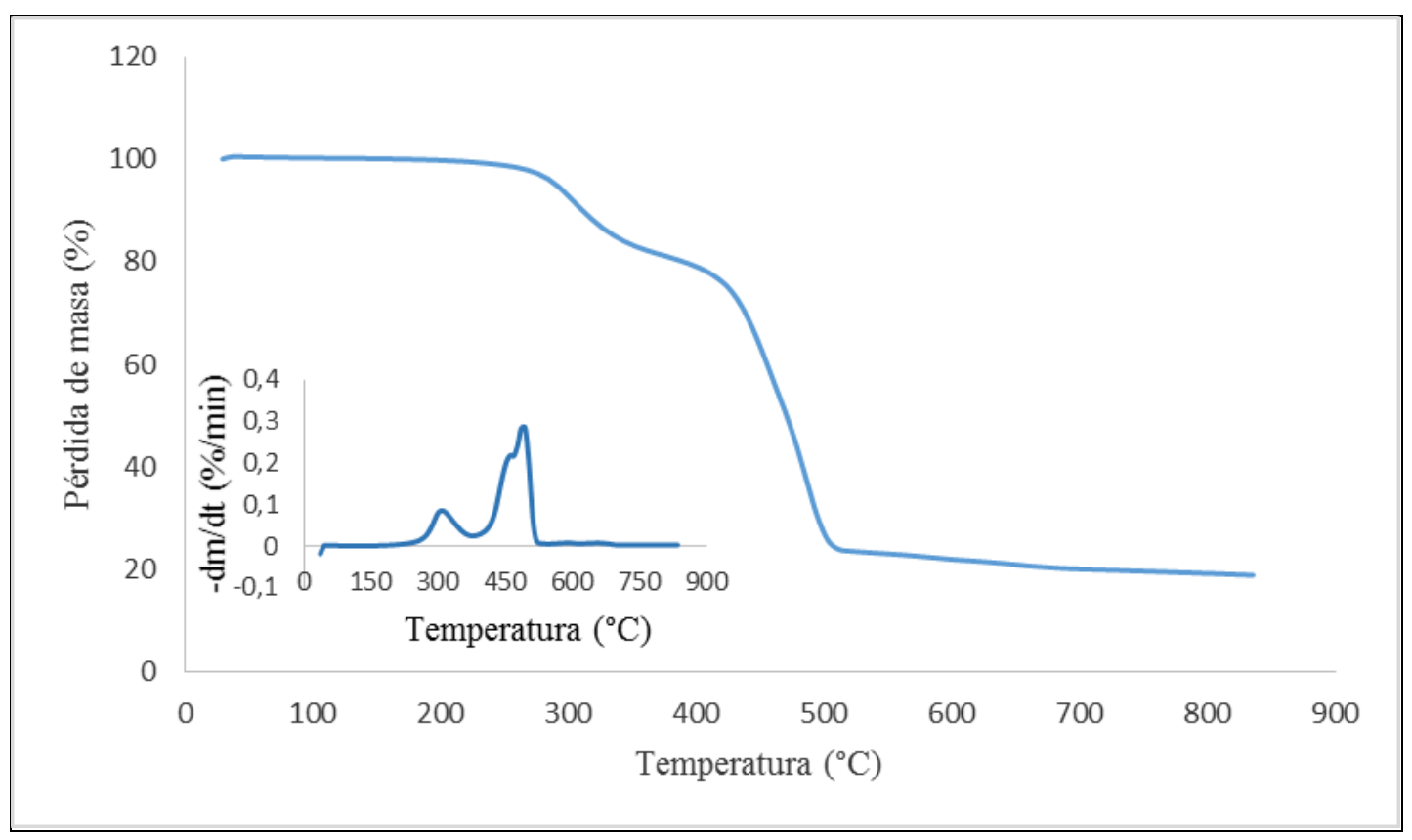

Figura 3.11. Curvas TG para la fracción rechazo a $20^{\circ} \mathrm{C} / \mathrm{min}$. Interior: Curva DTG.

Las mezclas de rechazos y lodo de destintado fueron obtenidos mediante la adición de una pequeña cantidad de lodo al rechazo. Por tanto, la contribución de lodo al comportamiento térmico de cada mezcla se hace más importante según la cantidad añadida. La figura 3.12 muestra las curvas TG/DTG correspondientes al lodo obtenido en la industria papelera, siendo el análisis realizado con una velocidad de calentamiento de $20^{\circ} \mathrm{C} / \mathrm{min}$ desde temperatura ambiente hasta $900{ }^{\circ} \mathrm{C}$.

El análisis muestra que el proceso de degradación térmica tuvo lugar en dos etapas, como se observa en la curva DTG. La primera etapa de degradación comenzó a $250{ }^{\circ} \mathrm{C}$ y finalizó a $430{ }^{\circ} \mathrm{C}$, correspondiendo con la existencia de un pico a $350^{\circ} \mathrm{C}$, que pertenece al material celulósico de la muestra [149]. A esta etapa le sigue una segunda etapa de degradación, cuyo rango de temperaturas varió desde $680{ }^{\circ} \mathrm{C}$ hasta $850{ }^{\circ} \mathrm{C}$, con el proceso de degradación casi finalizado, ya que prácticamente no se detectó pérdida alguna de masa a temperaturas más elevadas. Este segundo pico apareció a $750{ }^{\circ} \mathrm{C}$, que se corresponde con los materiales inorgánicos presentes en forma de aditivos y cargas minerales en la tinta eliminada del papel recuperado. El análisis se mantuvo a $900{ }^{\circ} \mathrm{C}$ durante varios minutos sin encontrarse variación alguna en el peso de la muestra, por tanto el residuo obtenido, corresponde al contenido en ceniza, siendo próximo al $50 \%$. 


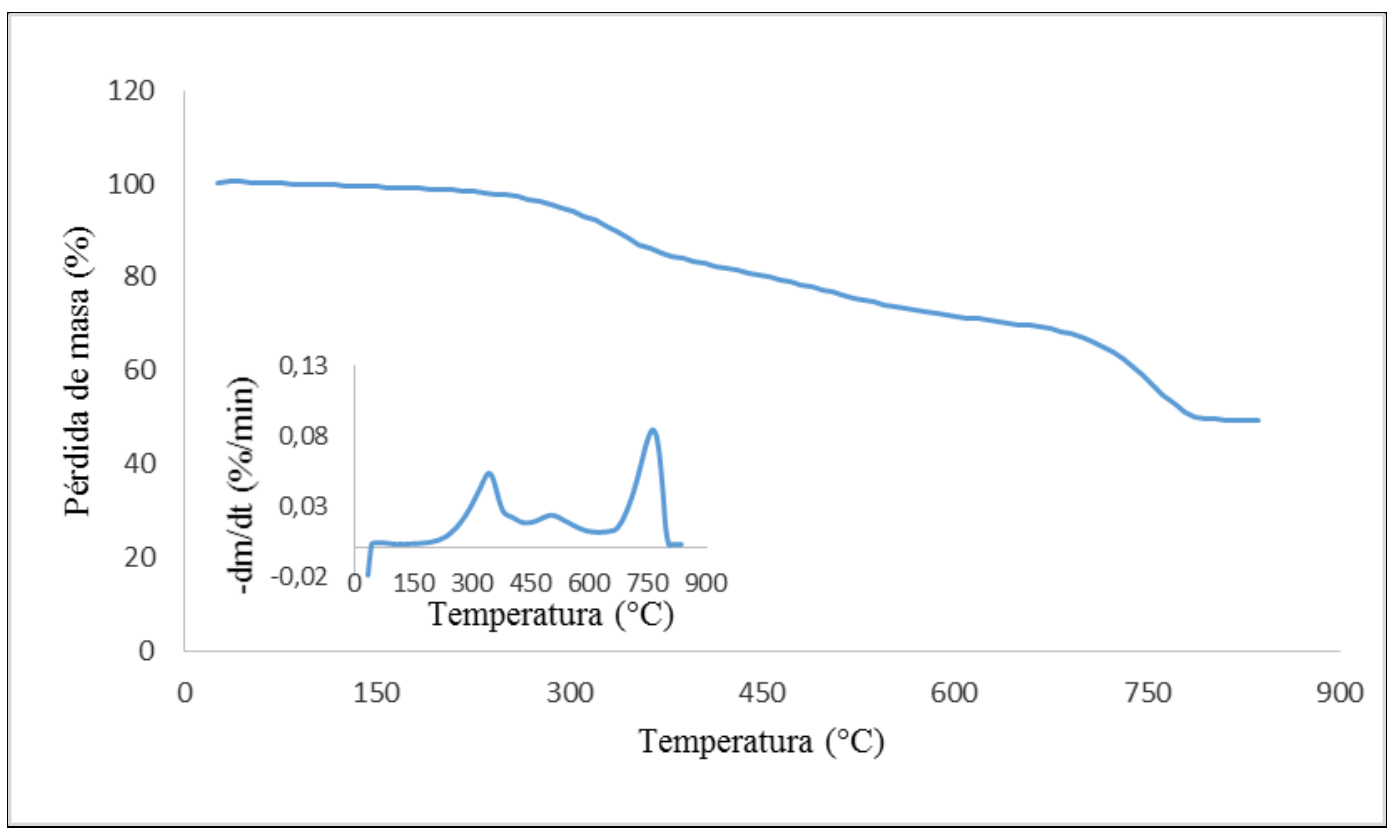

Figura 3.12. Curva TG para lodo a $20^{\circ} \mathrm{C} / \mathrm{min}$. Interior: Curva DTG.

\subsubsection{PREPARACIÓN DEL COMBUSTIBLE}

A la corriente residual no peligrosa, que proviene de la clasificación inicial del papelote y del proceso de pulpado, se la clasifican y separan los elementos susceptibles de ser reciclables, de manera que la corriente residual que se envía al posterior proceso de valorización energética, no contenga elementos reciclables, sino que está compuesta por residuos de difícil reciclabilidad o costosa económicamente. Además, esta corriente residual consta de ciertas impurezas que se deben eliminar previamente a la etapa de trituración.

El combustible se ha producido con diferentes cargas de lodos, de 5 a $35 \%$. El lodo que se emplea mayoritariamente procede del proceso de destintado, habiéndose recuperado la mayor parte de las fibras aprovechables en los lodos que se mezclan para producir el citado combustible.

El material recibido se somete a una serie de etapas de separación y trituración para homogeneizarlo antes de su densificación en forma de pélets. Las etapas de separación a la que se somete son la separación de metales férricos mediante un imán y el cribado manual de material voluminoso indeseable, si este existiera.

\subsubsection{Consumo de energía durante la trituración y el peletizado}

Los consumos energéticos derivados de la producción de las mezclas combustibles, se evaluaron desde el molido y acondicionamiento de las corrientes residuales, hasta la densificación de cada una de las mezclas. El consumo de energía fue registrado durante la trituración y la peletización. En la Tabla 3.13, se puede observar el consumo de energía en términos de flujo de masa específico $(\mathrm{kg} / \mathrm{h} \cdot \mathrm{kW})$ y energía específica $(\mathrm{kW} \cdot \mathrm{h} / \mathrm{T})$. 
Tras el paso por la despedregadora y la separación de los metales ferrosos, se realiza una molienda fina a $8 \mathrm{~mm}$. El consumo energético durante la trituración se refiere únicamente a la energía empleada para alcanzar una reducción de tamaño a $8 \mathrm{~mm}$. Respecto a la peletización, la relación de compresión de la matriz empleada durante el proceso de peletizado fue de 40 , ya que se pudo emplear esta matriz al no detectarse fundidos de material durante la densificación. Esta relación de compresión permitió obtener pellets con unas aceptables características físicas.

En este caso no se puede extraer una conclusión global que indique cuál de las mezclas combustibles ha requerido de un mayor gasto energético, ya que al haberse producido una pequeña cantidad de cada una de las mezclas combustibles, la información obtenida sobre el consumo energético en ambos procesos, molienda y densificado, no es extrapolable al carecer de la fiabilidad necesaria, solamente indica a manera informativa los consumos energéticos en su producción. No obstante, los valores de energía consumida para cada una de las mezclas fueron del mismo orden de magnitud.

Aunque la demanda energética para la reducción de tamaño fue bastante importante, la trituración previa no fue tenida en cuenta para estimar el consumo de energía total en el proceso de molienda. El consumo energético durante la molienda se situó entre 245 y $277 \mathrm{~kW} \cdot \mathrm{h} / \mathrm{T}$. La explicación del elevado consumo energético pudo deberse a que estos materiales están compuestos principalmente por materiales plásticos y celulósicos. El papel y el cartón son materiales ricos en fibras, lo cual podría reducir la velocidad de molienda e incrementar la energía específica [155]. A tenor de los datos arrojados durante la peletización, la cantidad de lodo de destintado añadido no causó un incremento en el consumo energético, siendo este consumo entre 67 y $84 \mathrm{~kW} \cdot \mathrm{h} / \mathrm{T}$. Sin embargo, el flujo de masa específico fue mayor en comparación con el proceso de molienda, siendo alrededor de $5 \mathrm{~kg} / \mathrm{h} \mathrm{kW}$.

\begin{tabular}{|l|c|c|c|c|}
\hline CSR & \multicolumn{2}{|c|}{ Molienda (8 mm) } & \multicolumn{2}{c|}{ Proceso de peletizado } \\
\hline $\begin{array}{c}\text { Flujo másico } \\
\text { específico }(\mathrm{kg} / \mathrm{h} \\
\mathrm{kW})\end{array}$ & $\begin{array}{c}\text { Energía específica } \\
\text { consumida } \\
(\mathrm{kWh} / \mathrm{T})\end{array}$ & $\begin{array}{c}\text { Flujo másico } \\
\text { específico }(\mathrm{kg} / \mathrm{h} \\
\mathrm{kW})\end{array}$ & $\begin{array}{c}\text { Energía específica } \\
\text { consumida } \\
(\mathrm{kWh} / \mathrm{T})\end{array}$ \\
\hline M1 & 2,2 & 277 & 5,0 & 67 \\
\hline M2 & 2,7 & 245 & 4,7 & 84 \\
\hline M3 & 2,3 & 268 & 5,1 & 77 \\
\hline
\end{tabular}

Figura 3.13. Consumo energético durante el proceso de molienda y peletizado de las mezclas fracción rechazo/lodo.

\subsubsection{Calidad de los pélets}

No solamente fue evaluado el consumo energético durante la peletización, ya que fue evaluada también la calidad de los pélets. La calidad del pélet se evalúa en base a la estimación de una serie de parámetros físicos como: humedad, durabilidad, finos y densidad a granel $[144,141]$. Por tanto, la combinación de ambas investigaciones ha llevado a una optimización real del proceso de peletizado. 
La Tabla 3.14 muestra los parámetros físicos más importantes de los combustibles. Los pélets producidos con diferentes cargas de lodo mostraron un índice de durabilidad parejo, en torno al 98\%, y un contenido en finos cercano al 1\%, en general. Además, el valor de la densidad a granel se vio influenciado por la carga de lodo.

\begin{tabular}{|l|c|c|c|c|}
\hline CSR & M1 & M2 & M3 & M4 \\
\hline Humedad (\%) & 3,2 & 2,9 & 3,6 & 3,0 \\
\hline Durabilidad (\%) & 98,6 & 98,2 & 98,2 & 98,2 \\
\hline Densidad a granel $\left(\mathbf{k g} / \mathbf{m}^{\mathbf{3}}\right)$ & 420 & 430 & 460 & 510 \\
\hline Finos (\%) & 0,7 & 0,8 & 0,9 & 1,0 \\
\hline
\end{tabular}

Tabla 3.14. Calidad del pélet de las mezclas lodo/fracción rechazo.

\subsubsection{Efecto del lodo de destintado en la densidad a granel y la durabilidad}

Todos los análisis fueron llevados a cabo intentando mantener el mismo contenido en humedad, evitando discrepancias debido al posible efecto de la humedad en las propiedades físicas. Respecto a los residuos de partida, la densidad a granel del lodo fue $780 \mathrm{~kg} / \mathrm{m}^{3}$ y del rechazo fue $100 \mathrm{~kg} / \mathrm{m}^{3}$, según fueron recibidos de la industria papelera.

La densidad a granel aumentó con la carga de lodo añadida, estando en consonancia con los datos de densidad a granel de los materiales residuales de partida, ya que la densidad del lodo es mayor que la del rechazo. A parte del efecto de la compactación por peletizado, la carga de lodo provocó un aumento de la densidad a granel. El máximo valor de densidad a granel $\left(510 \mathrm{~kg} / \mathrm{m}^{3}\right)$ se obtuvo para la mayor carga de lodo, $35 \%$. El índice de durabilidad permaneció constante, alrededor del 98\%, sin afectar la carga de lodo añadida, aunque se produjo un ligero incremento en el porcentaje de finos generado.

\subsubsection{Efecto del contenido de humedad en la densidad a granel y la durabilidad}

La humedad inicial de los materiales residuales a peletizar es un parámetro clave que afecta notablemente a las características del producto densificado [140]. El efecto de la humedad en las propiedades físicas: durabilidad y densidad a granel fue estudiada a través del M3, 75\% de fracción rechazo de la clasificación del papelote y del proceso de pulpado y $25 \%$ de lodo. Esta elección fue tal debido a que los rechazos pueden perder agua fácilmente, mientras que el lodo es capaz de mantener el contenido en humedad.

En la Figura 3.14, se observa que para valores ligeramente superiores a un $10 \%$ de humedad, se produjo un descenso en ambos propiedades, siendo más acusado el descenso para la durabilidad, repercutiendo negativamente en la calidad del pélet. La densidad a granel experimentó un descenso más ligero a partir del $10 \%$ de humedad, incrementándose notablemente en torno al $15 \%$ de humedad, empeorando las características del pélet, sobre todo afectando a su manipulación: almacenamiento en tolvas y alimentación como combustible. 
Por tanto, se observa que la calidad del pélet permanece inalterada siempre y cuando el contenido en humedad de la mezcla a densificar no supere un cierto umbral de contenido en humedad. No obstante, la optimización del proceso de peletización, que requirió de un intenso secado del material, permitió alcanzar elevados valores de índice de durabilidad, en torno al 98\%, y de densidad a granel, próxima a $470 \mathrm{~kg} / \mathrm{m}^{3}$ para la mezcla ensayada.

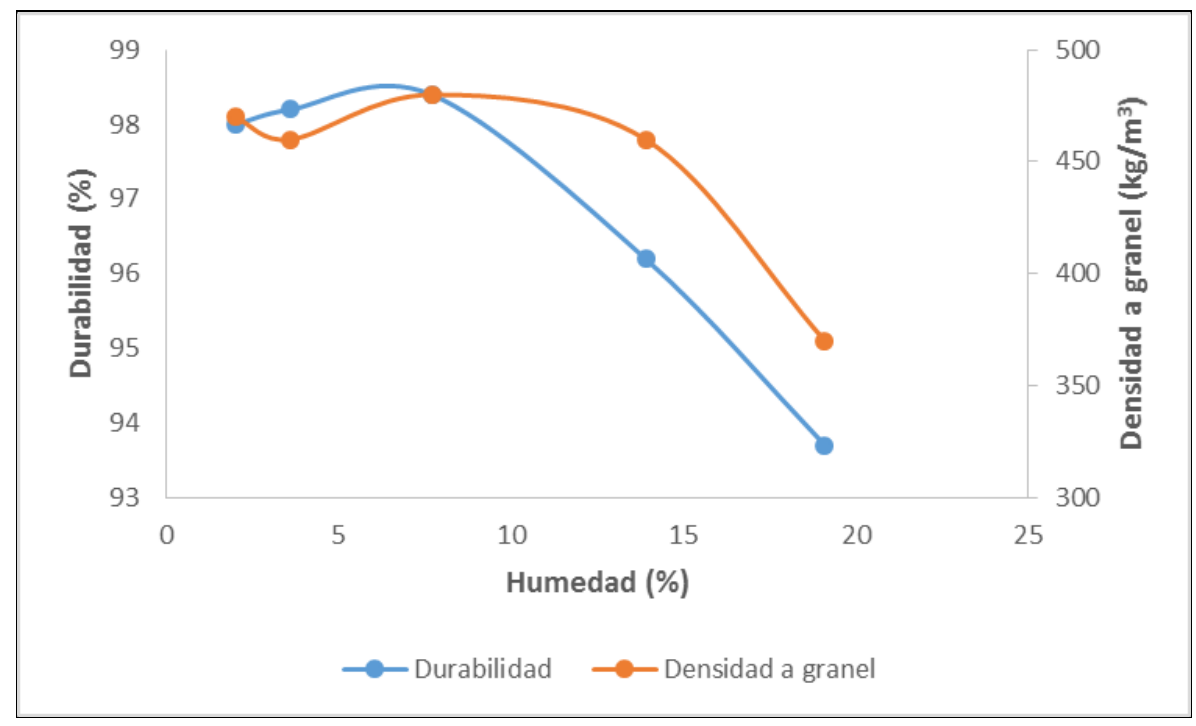

Figura 3.14. Evaluación del efecto de la humedad de la muestra en el índice de durabilidad y la densidad a granel para M3.

\subsubsection{CARACTERIZACIÓN DEL COMBUSTIBLE DERIVADO DE RESIDUOS}

La peletización fue llevada a cabo con el objeto de permitir la obtención de los combustibles adecuados para ser usados en procesos de combustión o gasificación con tecnologías de lecho fluidizado. Las muestras fueron obtenidas de los pélets preparados en el proceso de densificación, de manera que la caracterización fue realizada sobre un combustible apto para ser alimentado en un proceso de conversión térmica. Los resultados de la caracterización de estos materiales están recogidos en la Tabla 3.15, donde se muestra un análisis inmediato y elemental de las mezclas, así como sus poderes caloríficos.

En función de la cantidad de lodo añadido, se muestra una reducción en el contenido de materia volátil del $75.2 \%$ al $66,7 \%$. No obstante, estos valores son adecuados para gasificación, ya que las mezclas mostraron un alto contenido en materia volátil. Esto significa que los combustibles serán convertidos instantáneamente en productos gaseosos. Se produjo un incremento del contenido en ceniza del $17 \%$ al $28.3 \%$ al aumentar la carga de lodo, lo que podría desembocar en la necesidad de instalar un sistema de recogida de cenizas para su empleo como combustible en instalaciones de gasificación. Además, todos los combustibles mostraron un contenido bajo en carbono fijo, que es muy común en combustibles derivados de residuos [107]. 
El análisis elemental mostró una reducción del contenido en carbono e hidrógeno cuando los rechazos, que tienen base carbonosa, fueron mezclados con una cierta cantidad de lodo de destintado. Como una consecuencia del incremento en la cantidad de ceniza debido a la adición de lodo, la suma de carbono, hidrógeno y oxígeno se redujo y, por tanto, disminuyó el poder calorífico. No obstante, cada combustible mostró un elevado poder calorífico inferior, cuyos valores se situaron entre 20,21 y $26,62 \mathrm{MJ} / \mathrm{kg}$. Por ende, las mezclas compuestas principalmente de los rechazos procedentes de la selección y clasificación del papelote y de los rechazos del proceso de pulpado pueden considerarse combustibles muy prometedores.

\begin{tabular}{|c|c|c|c|c|}
\hline CSR & M1 & M2 & M3 & M4 \\
\hline \multicolumn{5}{|c|}{ Análisis inmediato (\% en peso; b.s.) } \\
\hline Humedad (\% b.h.) & 3,2 & 2,9 & 3,6 & 3,0 \\
\hline Materia volátil & 75,2 & 71,4 & 67,5 & 66,7 \\
\hline Cenizas & 17,0 & 18,4 & 26,5 & 28,3 \\
\hline Carbono fijo $^{\mathrm{a}}$ & 11,7 & 10,2 & 6,0 & 5,0 \\
\hline \multicolumn{5}{|c|}{ Análisis elemental (\% en peso; b.s.) } \\
\hline Carbono & 55,6 & 50,9 & 48,7 & 44,9 \\
\hline Hidrógeno & 7,6 & 6,9 & 6,8 & 6,0 \\
\hline Nitrógeno & 0,35 & 0,39 & 0,26 & 0,32 \\
\hline Fluor & 0,006 & 0,006 & 0,004 & 0,004 \\
\hline Azufre & 0,07 & 0,08 & 0,15 & 0,13 \\
\hline Cloro & 1,56 & 1,55 & 1,45 & 1,17 \\
\hline Oxígeno $^{\mathrm{a}}$ & 19,72 & 21,78 & 16,14 & 19,18 \\
\hline \multicolumn{5}{|c|}{ Poder calorífico (MJ/kg) } \\
\hline PCI & 24,99 & 22,64 & 20,00 & 18,92 \\
\hline PCS & 26,62 & 24,12 & 21,46 & 20,21 \\
\hline
\end{tabular}

Tabla 3.15. Caracterización de las mezclas combustibles de la industria papelera.

Con respecto al contenido en cloro, éste se fue reduciendo, diluyéndose con la cantidad de lodo añadido, hasta un $1,17 \%$. No obstante, el contenido en cloro siguió siendo significativo pese a la adición de lodo, lo que podría derivar en la necesidad de eliminar el cloro de los rechazos debido a la corrosión asociada durante la utilización del combustible [144]. Como se indicó anteriormente, el contenido en cloro tal vez sea debido a la presencia de materiales plásticos, siendo fundamentalmente cloro orgánico.

Respecto al lodo de destintado, la gran cantidad de ceniza que tiene podría originar problemas operacionales relacionados con la fusibilidad de las cenizas en presencia del material de lecho. Es por este motivo que un análisis del contenido en metales es muy necesario para determinar las tasas entre el contenido de potasio/sodio y calcio/magnesio. Las cenizas del combustible fueron analizadas en forma de óxidos de los elementos mayoritarios, a parte de oxígeno y azufre. $\mathrm{Si}, \mathrm{Al}, \mathrm{Fe}, \mathrm{Ca}, \mathrm{Mg}, \mathrm{K}, \mathrm{Na}$ y $\mathrm{Ti}$, ver Figura 3.19. Además, se analizaron otros elementos como: Ba, P, Sr y Zn. Los análisis fueron repetidos por triplicado para solventar problemas relacionados con la falta de homogeneidad de los combustibles y el tamaño de las muestras empleadas [157]. 
Los elementos mayoritarios en las cenizas fueron calcio, silicio y aluminio. Sin embargo, la adición de lodo cambió su proporción en cada mezcla. Éstos mostraron un elevado contenido en óxido de calcio, típicamente debido a que los rechazos están compuestos por materiales celulósicos como muestran algunas fracciones resto [109].

Respecto al calcio, se detectó un incremento a medida que aumentó la carga de lodo, del $24 \%$ al $40 \%$ y además, el contenido en magnesio aumentó de un $1,3 \%$ a un $1,9 \%$. Por tanto, hay un elevado contenido en calcio y magnesio que podría minimizar el riesgo de sinterizado. Sin embargo, el contenido en sodio se modificó desde un 3,5\% hasta un $0.54 \%$ y el contenido de potasio cambió desde un $1.8 \%$ hasta un $0,47 \%$, reduciéndose en ambos casos con la cantidad de lodo añadida. Por contra, el aluminio y la sílice experimentaron una fuerte reducción con la adición de lodo. El silicio se redujo de un $25 \%$ a un $13 \%$, mientras que el aluminio se redujo de un $22 \%$ a un $9,9 \%$. En concreto estas variaciones tienen su explicación en que los lodos de destintado llevan las cargas del papel, y algunas de ellas son minerales cálcicos. En cuanto a sílices y aluminios más abundantes en arenas que lleva el rechazo de esta forma se diluyen.

Estos contenidos de lodo y potasio no son significativos para considerar un riesgo de sinterizado real. Además, las temperaturas características obtenidas en el análisis del comportamiento de fusión de las cenizas fueron bastante elevadas lo que reduce el riesgo de sinterizado también, ver Tabla 3.16 [145].

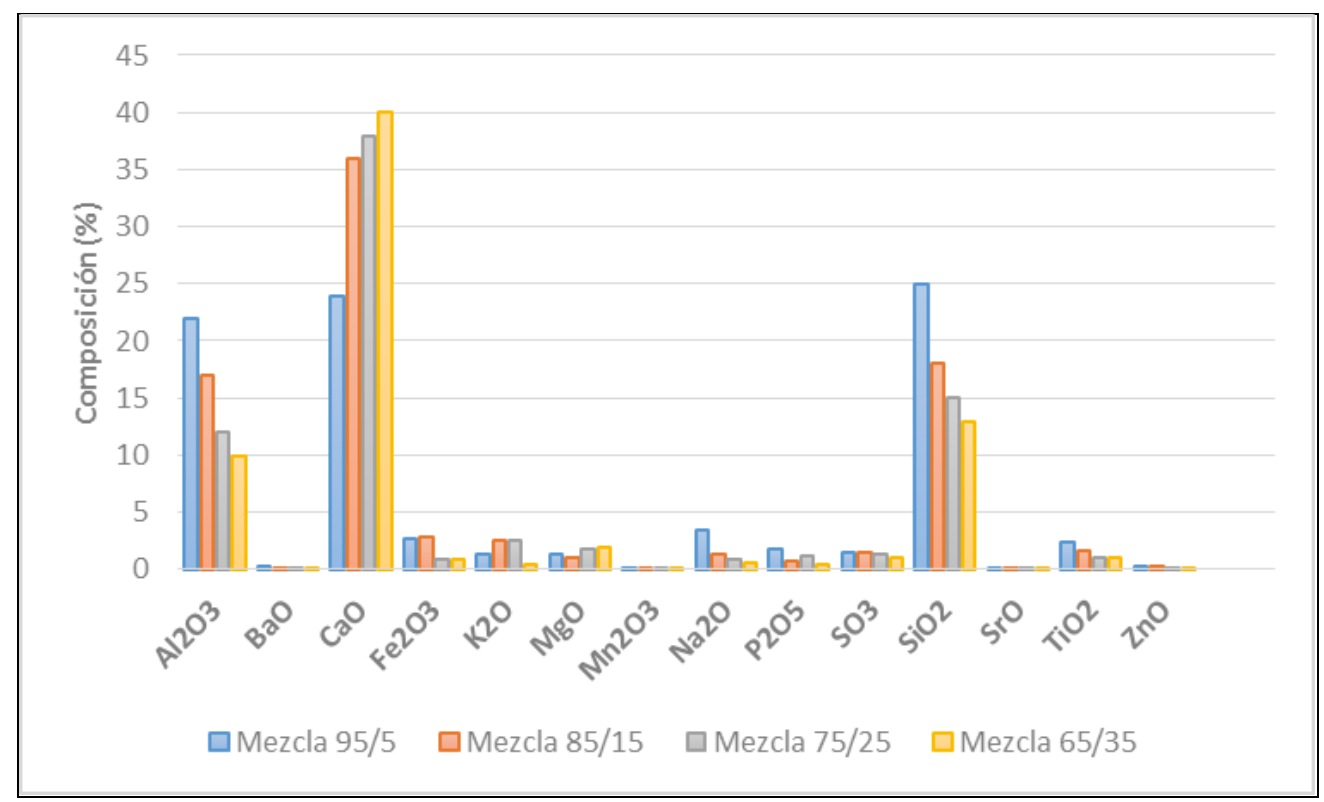

Figura 3.15. Metales en las cenizas en forma de óxidos de las mezclas lodo/fracción rechazo.

En la Tabla 3.16, se muestran los índices usados para estimar el riesgo de sinterización en carbón. Estos índices han sido utilizados con CSR con resultados satisfactorios [145]. Además, se muestra una comparativa con un CSR semejante al CSR de origen industrial bajo estudio. El índice de formación de escorias, $\mathrm{F}_{\mathrm{s}}$, no se pudo determinar debido a que el equipo no fue capaz de registrar las temperaturas de esfera y hemiesfera durante el análisis de fusibilidad de las cenizas. Respecto a los índices $R b, R_{b / a}, R_{b / a}(+P)$ y $R_{b / a} \times \mathrm{Na}$, su comportamiento fue semejante para los CSR tratados por Dunnu, donde un aumento de estos índices significó un descenso en la temperatura característica de esfera. 
En el caso que nos ocupa, no se puede indicar que un aumento o descenso de estos índices se deba a las temperaturas, ya que las mezclas varían en composición. Esta comparativa se ha intentado observar según que CSR se trataba. Además, se puede observar los valores de los distintos índices para una mezcla papel/plástico semejante a los rechazos y lodo seco más similar al lodo de destintado. La primera mezcla M1 tiene un comportamiento en sus índices semejante a la mezcla papel/plástico salvo para $\mathrm{R}_{\mathrm{b} / \mathrm{a}} \mathrm{X}$ $\mathrm{Na}$, mientras que la mezcla M4 tuvo un comportamiento semejante en sus índices al lodo seco solamente en este índice.

\begin{tabular}{|l|c|c|c|c|c|c|}
\hline Índices & M1 & M2 & M3 & M4 & Papel/Plástico $^{\mathrm{a}}$ & Lodo seco $^{\mathrm{a}}$ \\
\hline $\mathrm{R}_{\mathrm{b}}$ & 32,80 & 43,80 & 44,16 & 43,67 & 35,96 & 35,44 \\
\hline $\mathrm{R}_{\mathrm{b} / \mathrm{a}}$ & 0,66 & 1,19 & 1,58 & 1,82 & 0,67 & 0,61 \\
\hline $\mathrm{R}_{\mathrm{b} / \mathrm{a}(+\mathrm{P})}$ & 0,70 & 1,21 & 1,62 & 1,84 & 0,70 & 0,65 \\
\hline $\mathrm{R}_{\mathrm{b} / \mathrm{a}} \times \mathrm{Na}$ & 2,32 & 1,55 & 1,47 & 0,98 & 3,23 & 0,74 \\
\hline $\mathrm{S}_{\mathrm{R}}$ & 47,17 & 31,09 & 26,92 & 23,31 & 56,01 & 54,00 \\
\hline $\mathrm{F}_{\mathrm{S}}\left({ }^{\circ} \mathrm{C}\right)$ & n.d. & n.d. & n.d. & n.d. & 1183 & 1171 \\
\hline
\end{tabular}

${ }^{a}$ Papel/plástico y lodo seco [145]

Tabla 3.16. Índices de ensuciamiento y formación de escorias.

Las temperaturas características, que muestra la Tabla 3.17, muestran elevados valores, que permiten asegurar que no habrá problemas de sinterización del combustible. La temperatura de deformación inicial fue muy elevada, situándose entre 940 y $1340{ }^{\circ} \mathrm{C}$, en comparación con las temperaturas de operación en un gasificador de lecho fluidizado. Por otro lado, las temperaturas de esfera y hemiesfera no pudieron detectarse debido a la rapidez del cambio que experimentó la muestra en su forma. Finalmente, la temperatura fluida fue alcanzada a una temperatura superior a $1400^{\circ} \mathrm{C}$.

\begin{tabular}{|l|c|c|c|c|}
\hline \multicolumn{5}{|c|}{ Fusibilidad de las cenizas $\left({ }^{\mathbf{}} \mathbf{C}\right)$} \\
\hline T $\left({ }^{\circ} \mathbf{C}\right)$ & M1 & M2 & M3 & M4 \\
\hline TDI & 1.260 & 1.340 & 1.210 & 940 \\
\hline TE & n.d. & n.d. & n.d. & n.d. \\
\hline TH & n.d. & n.d. & n.d. & n.d. \\
\hline TF & $>1.400$ & $>1.400$ & $>1.400$ & $>1.400$ \\
\hline
\end{tabular}

Tabla 3.17. Fusibilidad de las cenizas de las diferentes mezclas producidas.

\subsubsection{Efecto de la adición de lodo de destintado}

El contenido en biomasa de las mezclas fue determinado con el objeto de estimar como podría afectar la carga de lodo al incremento de la fracción biodegradable, ya que los combustibles con un alto contenido en biomasa son susceptibles de ser considerados fuentes de energía renovable [145].

En la Tabla 3.18, se muestra el contenido en biomasa de las mezclas a través del método de disolución selectiva. Se observó un incremento de del contenido en biomasa desde un $18 \%$ hasta un $25 \%$ con la adición de lodo. Por otro lado, el contenido en no-biomasa se redujo desde un $73 \%$ hasta un $47 \%$, a medida que aumentó el contenido de inertes. Por tanto, la adición de lodo al rechazo produjo un incremento del contenido en biomasa y una reducción en el contenido de no-biomasa. Sin embargo, el aumento de inertes es notable, lo que deriva en un aumento de ceniza del combustible. 


\begin{tabular}{|l|c|c|c|}
\hline \multicolumn{4}{|c|}{ Determinación del contenido en biomasa (\% b.s.) } \\
\hline Disolución selectiva & Biomasa & No biomasa & Inerte \\
\hline M1 & 18 & 73 & 9 \\
\hline M2 & 20 & 62 & 18 \\
\hline M3 & 22 & 55 & 23 \\
\hline M4 & 25 & 47 & 28 \\
\hline
\end{tabular}

Tabla 3.18. Determinación del contenido de biomasa en las mezclas fracción rechazo/lodo por disolución selectiva.

\subsubsection{ANÁLISIS TERMOGRAVIMÉTRICO DEL COMBUSTIBLE}

La caracterización de los combustibles fue completada con un análisis termogravimétrico con la finalidad de conocer el comportamiento térmico de las mezclas, que a su vez permitió la determinación de los parámetros cinéticos para cada etapa de degradación que experimentó cada una de las mezclas. En la Figura 3.16, se muestran las curvas TG/DTG a $20^{\circ} \mathrm{C} / \mathrm{min}$.

En estas curvas se observan tres etapas diferentes de degradación térmica, viéndose los rangos de temperatura a través de las curvas DTG. Las curvas DTG se obtuvieron para cada velocidad de calentamiento, de $5{ }^{\circ} \mathrm{C} / \mathrm{min}$ a $20{ }^{\circ} \mathrm{C} / \mathrm{min}$. No obstante, la determinación de cada rango se antoja complicada debido a la superposición de picos de cada material de partida. Además, se nota el dominio de la degradación de los rechazos respecto al lodo a tenor del tamaño de cada pico. Por tanto, el rango de temperaturas para las mezclas cambia ligeramente en comparación con los de los componentes de partida. En las mezclas combustibles, los rechazos y el lodo degradan a temperaturas diferentes a los residuos de partida, aunque la variación no es significativa.

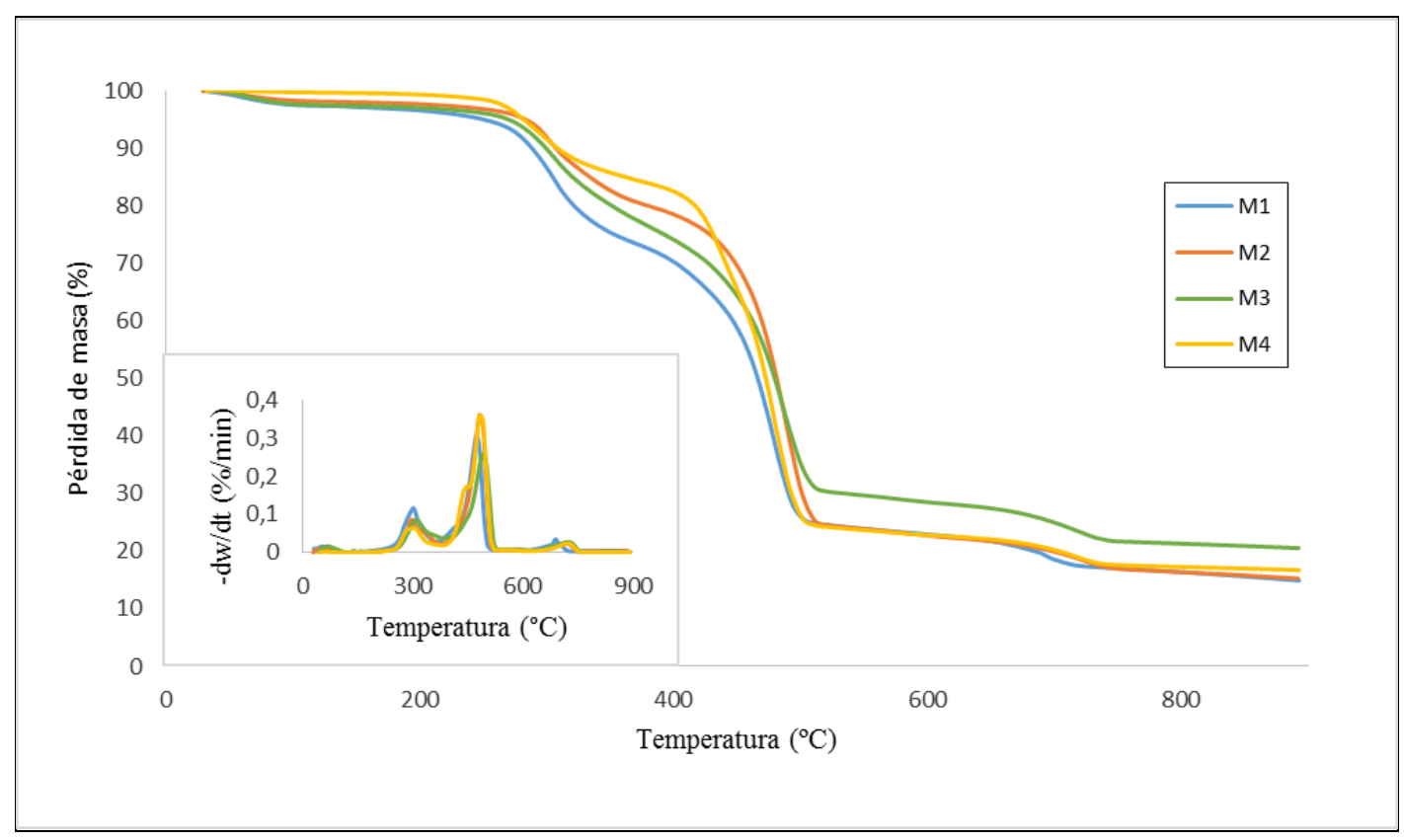

Figura 3.16 Curvas TG para las mezclas combustible rechazo/lodo $20^{\circ} \mathrm{C} / \mathrm{min}$. Interior: Curva DTG. 
En la Figura 3.16, se muestran con claridad las tres etapas de degradación indicadas anteriormente. La primera de las etapas, ocurrió de $230{ }^{\circ} \mathrm{C}$ a $380{ }^{\circ} \mathrm{C}$, mostrando la descomposición de materiales celulósicos, la segunda etapa de degradación, rango de temperaturas de $380{ }^{\circ} \mathrm{C}$ a $550{ }^{\circ} \mathrm{C}$, corresponde con la descomposición de material plástico [150], y por último, la tercera etapa de degradación, de $640{ }^{\circ} \mathrm{C}$ a $780{ }^{\circ} \mathrm{C}$, que corresponde con los aditivos inorgánicos retenidos en el lodo.

Otros estudios en combustibles derivados de residuos mostraron una composición basada principalmente en materiales celulósicos, madera y material plástico como propileno y polietileno [158]. No obstante, en la Tabla 3.19 se muestran las etapas de degradación de todas las mezclas combustibles rechazo/lodo. El pico de temperatura de cada etapa de degradación se movió ligeramente hacia la derecha cuando la velocidad de calentamiento se incrementó. Aunque los valores de las temperaturas pico fueron bastante similares, se detectaron pequeñas variaciones, pudiendo haberse originado debido a la heterogeneidad del material.

\begin{tabular}{|c|c|c|c|}
\hline CSR & $5^{\circ} \mathrm{C} / \mathrm{min}$ & $10^{\circ} \mathrm{C} / \mathrm{min}$ & $20^{\circ} \mathrm{C} / \mathrm{min}$ \\
\hline \multicolumn{4}{|l|}{ M1 } \\
\hline & $207-359^{\circ} \mathrm{C}(284,1)$ & $216-368^{\circ} \mathrm{C}(287,1)$ & $239-376^{\circ} \mathrm{C}(312,2)$ \\
\hline & $386-510^{\circ} \mathrm{C}(461,2)$ & $377-530^{\circ} \mathrm{C}(474,1)$ & $376-539^{\circ} \mathrm{C}(483,9)$ \\
\hline & $598-711^{\circ} \mathrm{C}(667,2)$ & $641-728^{\circ} \mathrm{C}(694,0)$ & $654-751^{\circ} \mathrm{C}(698,1)$ \\
\hline \multicolumn{4}{|l|}{ M2 } \\
\hline & $238-328^{\circ} \mathrm{C}(278,8)$ & $247-377^{\circ} \mathrm{C}(284,3)$ & $257-384^{\circ} \mathrm{C}(311)$ \\
\hline & $402-529^{\circ} \mathrm{C}(468,1)$ & $384-529^{\circ} \mathrm{C}(473,3)$ & $393-548^{\circ} \mathrm{C}(491,6)$ \\
\hline & $661-710^{\circ} \mathrm{C}(693,5)$ & $644-743^{\circ} \mathrm{C}(708,1)$ & $644-777^{\circ} \mathrm{C}(732,9)$ \\
\hline \multicolumn{4}{|l|}{ M3 } \\
\hline & $222-354^{\circ} \mathrm{C}(327,7)$ & $248-385^{\circ} \mathrm{C}(349,4)$ & $248-384^{\circ} \mathrm{C}(311,3)$ \\
\hline & $376-494^{\circ} \mathrm{C}(459,0)$ & $385-526^{\circ} \mathrm{C}(472,6)$ & $384-538^{\circ} \mathrm{C}(492,3)$ \\
\hline & $607-719^{\circ} \mathrm{C}(684,6)$ & $630-759^{\circ} \mathrm{C}(684,6)$ & $645-787^{\circ} \mathrm{C}(684,6)$ \\
\hline \multicolumn{4}{|l|}{ M4 } \\
\hline & $152-372^{\circ} \mathrm{C}(328,1)$ & $170-376^{\circ} \mathrm{C}(331,4)$ & $211-385^{\circ} \mathrm{C}(348,5)$ \\
\hline & $354-501{ }^{\circ} \mathrm{C}(451,5)$ & $367-510^{\circ} \mathrm{C}(465,1)$ & $385-538^{\circ} \mathrm{C}(482,8)$ \\
\hline & $584-714^{\circ} \mathrm{C}(688,3)$ & $599-759^{\circ} \mathrm{C}(714,5)$ & $627-778^{\circ} \mathrm{C}(741,0)$ \\
\hline
\end{tabular}

Tabla 3.19 Etapas de degradación de las mezclas combustible rechazo/lodo.

\subsubsection{ESTUDIO CINÉTICO}

\subsubsection{Estudio cinético del material de partida}

La determinación de los parámetros cinéticos para los rechazos fue llevada a cabo mediante el método de Coats-Redfern, ver Figura 3.17. El rango de temperatura durante la degradación de la muestra fue usado para la obtención de las principales etapas de degradación, cuyos picos fueron observados a $320{ }^{\circ} \mathrm{C}$ y $495{ }^{\circ} \mathrm{C}$. Los valores de energía de activación, factor pre-exponencial y orden de reacción para la degradación de los materiales celulósicos fueron $88,4 \mathrm{~kJ} / \mathrm{mol}, 7,2 \times 10^{6} \mathrm{~min}^{-1}$ and 4 . La segunda etapa de degradación fue la correspondiente al material plástico, siendo los parámetros cinéticos $184,7 \mathrm{~kJ} / \mathrm{mol}, 9 \times 10^{12} \mathrm{~min}^{-1}$ and 1,5 , respectivamente. 


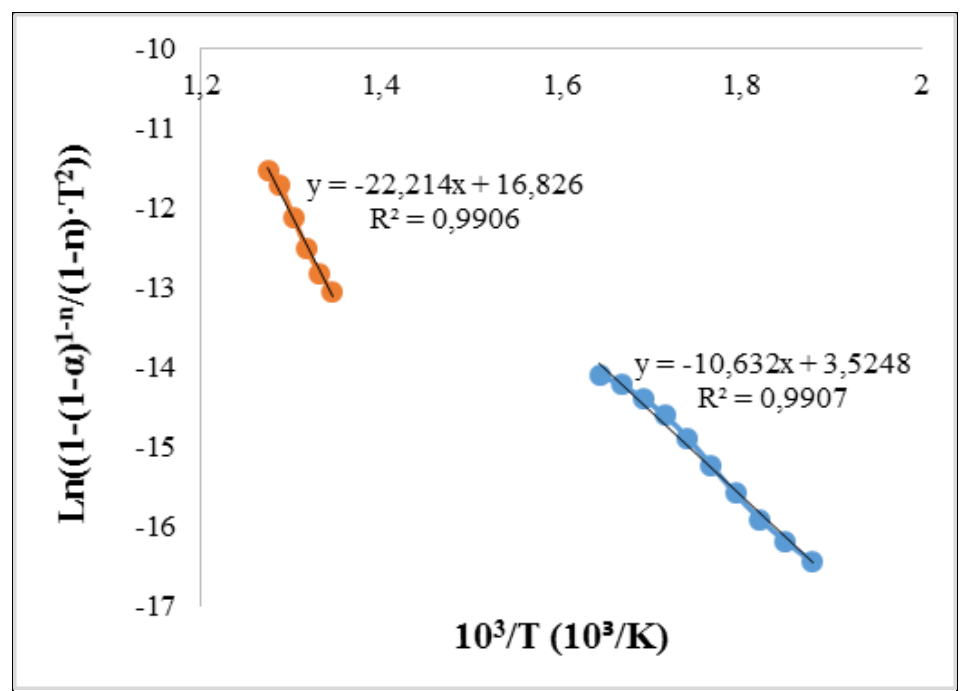

Figura 3.17. Método Coats-Redfern para la fracción rechazo.

La determinación de los parámetros cinéticos del lodo de destintado se realizó empleando el mismo método usado para la obtención de los parámetros cinéticos de los rechazos, ver Figura 3.18. La primera etapa de degradación mostró un pico de temperatura perteneciente a algún tipo de material celulósico de fibras retenidas durante el proceso de destintado. Los valores de energía de activación, factor pre-exponencial y orden de reacción para la degradación de los materiales celulósicos fueron 45,4 kJ/mol, $6 \times 10^{2} \min ^{-1}$ y 2,5 . La segunda etapa de degradación con un pico a $700{ }^{\circ} \mathrm{C}$, que corresponde a aditivos, arrojó los siguientes valores de los parámetros cinéticos 164,4 $\mathrm{kJ} / \mathrm{mol}, 1,9 \times 10^{8} \mathrm{~min}^{-1}$ y 1,1 , respectivamente.

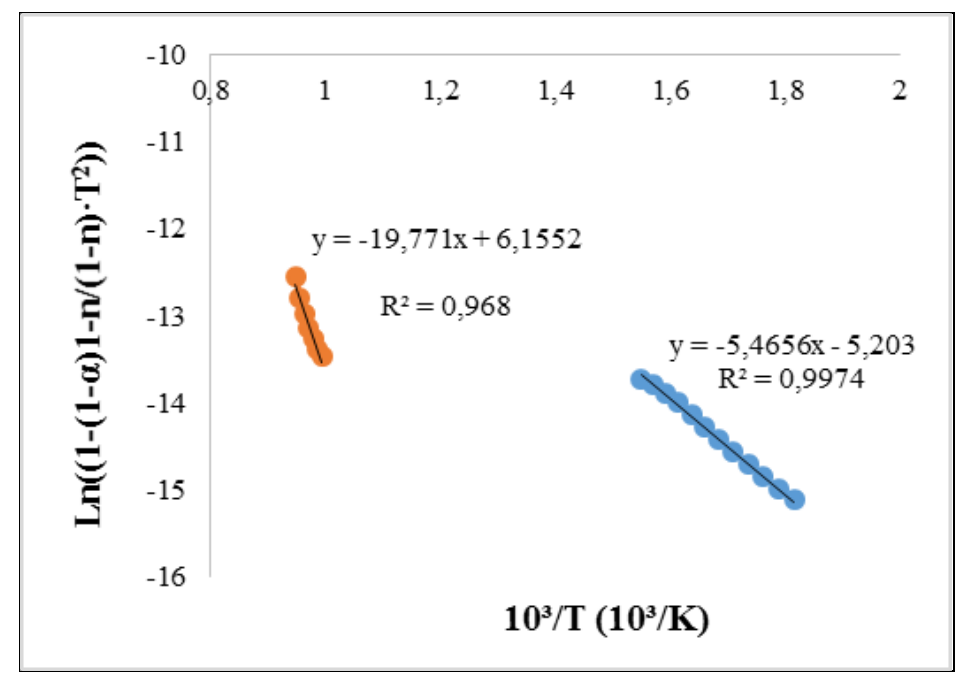

Figura 3.18. Método Coats-Redfern para lodo.

\subsubsection{Estudio cinético de las mezclas combustibles}

La estimación de los parámetros cinéticos de las mezclas combustibles rechazo/lodo fue llevada a cabo usando tres métodos no isotérmicos diferentes. Mostraron una importante contribución de los materiales plásticos, considerando el tamaño de los picos obtenidos en las curvas TG/DTG. El método Coats-Redfern fue empleado para comparar la energía de activación y el factor pre-exponencial respecto al material de partida. 
Las mezclas combustibles mostraron tres etapas de degradación, por tanto se determinó la energía de activación para cada una de ellas. Los valores obtenidos de energía de activación son próximos a los determinados para el material original, excepto para la última etapa de degradación, relativa a los aditivos encontrados en el lodo. Se determinó un primer pico con energías de activación alrededor de $60-80 \mathrm{~kJ} / \mathrm{mol}$, que corresponde con el material celulósico, y un segundo pico con energías de activación entre 120 y 160 $\mathrm{kJ} / \mathrm{mol}$, que corresponde con el pico detectado para material plástico en el rechazo original, ver Tabla 3.20.

\begin{tabular}{|l|c|c|c|c|}
\hline CSR & Ea $(\mathbf{k J} / \mathbf{m o l})$ & $\mathbf{A}\left(\mathbf{m i n}^{-\mathbf{1}}\right)$ & $\mathbf{n}$ & $\mathbf{R}^{\mathbf{2}}$ \\
\hline $\mathbf{M 1}$ & & & & \\
\hline & 73,6 & $4,8 \times 10^{5}$ & 2,5 & 0,994 \\
\hline & 141,4 & $7 \times 10^{9}$ & 2 & 0,989 \\
\hline & 47,0 & $1,5 \times 10^{2}$ & 1,1 & 0,987 \\
\hline $\mathbf{M 2}$ & & & & \\
\hline & 78,9 & $1 \times 10^{6}$ & 2,5 & 0,982 \\
\hline & 161,9 & $1,4 \times 10^{11}$ & 2 & 0,981 \\
\hline & 41,6 & $6 \times 10^{1}$ & 1,1 & 0,946 \\
\hline M3 & & & & \\
\hline & 77,4 & $1,4 \times 10^{6}$ & 2,5 & 0,995 \\
\hline & 118,7 & $1,2 \times 10^{8}$ & 2 & 0,986 \\
\hline & 50,1 & $1,7 \times 10^{2}$ & 1,1 & 0,948 \\
\hline M4 & & & & \\
\hline & 62,1 & $1,3 \times 10^{4}$ & 2,5 & 0,997 \\
\hline & 152,4 & $2,3 \times 10^{10}$ & 1,5 & 0,991 \\
\hline & 55,9 & $3,1 \times 10^{2}$ & 1,1 & 0,943 \\
\hline
\end{tabular}

Tabla 3.20 Parámetros cinéticos de las mezclas combustibles rechazo/lodo mediante el método CoatsRedfern.

Los otros dos métodos no-isotérmicos usados fueron Flynn-Wall-Ozawa (FOW) y Kissinger-Akahira-Sunose (KAS). Ambos son métodos integrales isoconversionales, por tanto la energía de activación se estimó para cada valor de conversión, es decir como función de la conversión, en lugar de asumir un modelo de reacción como ocurre con el método Coats-Redfern. En la Figura 3.19 se muestra un ejemplo de representación gráfica de las curvas isoconversionales derivadas de los métodos FOW y KAS. Estos dos métodos fueron usados para comparar los valores de energía de activación obtenidos en las etapas de degradación térmica de las mezclas combustibles.

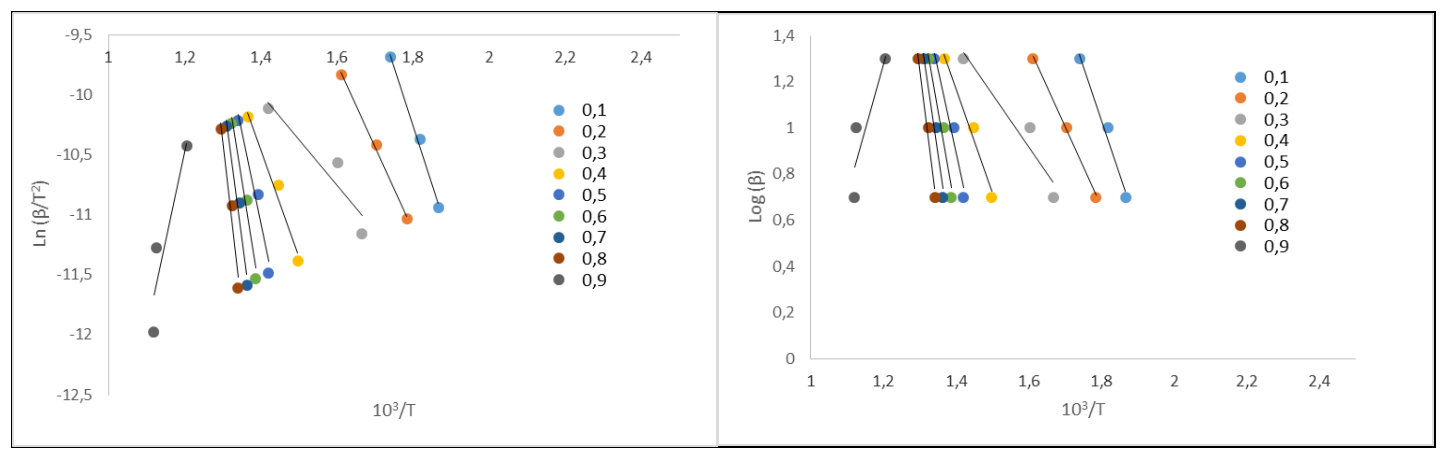

Figura 3.19 Ejemplo de la representación gráfica usando los métodos FWO and KAS, respectivamente, para la mezcla combustible 85/15 para diferentes valores de conversión. 
A través de las curvas TG/DTG se observa la existencia de tres etapas de degradación diferenciadas, que corresponden a tres constituyentes distintos: materiales celulósicos, materiales plásticos y materiales inorgánicos. Sin embargo, los modelos isoconversionales permiten determinar la energía de activación para diferentes valores de conversión, relacionados con las diferentes etapas de degradación.

La energía de activación fue calculada de $0,1<\alpha<0,9$ para cubrir el rango de degradación térmica de las muestras, ver Tabla 3.25. Los valores de energía de activación para los materiales plásticos, fueron obtenidos en el rango de conversión $0,4<\alpha<0,8$, mostrando resultados similares en comparación a otros estudios donde los componentes principales de combustibles derivados de residuos fueron analizados [156]. En comparación con el método de modelo de ajuste empleado anteriormente, la variación de los resultados no fue significativa. Respecto a los materiales celulósicos, claramente identificados de $0,1<\alpha<0,2$, sus resultados mostraron una variación significativa, tal vez debida a la heterogeneidad de las muestras.

\begin{tabular}{|l|c|c|c|c|}
\hline $\mathbf{E}_{\mathbf{a}}(\mathbf{k J} / \mathbf{m o l})$ & M1 & M2 & M3 & M4 \\
\hline FOW & 73,1 & 74,2 & 62,0 & 56,4 \\
\hline KAS & 66,0 & 69,7 & 55,0 & 49,7 \\
\hline \multicolumn{5}{|c|}{ Materiales plásticos } \\
\hline FOW & 169,5 & 162,9 & 160,4 & 161,0 \\
\hline KAS & 164,4 & 160,0 & 154,7 & 157,3 \\
\hline
\end{tabular}

Tabla 3.21 Parámetros cinéticos de las mezclas combustible rechazo/lodo para la degradación del material plástico mediante los métodos FOW y KAS.

\subsubsection{CLASIFICACIÓN DEL COMBUSTIBLE SÓLIDO RECUPERADO}

En los epígrafes anteriores se ha mostrado una caracterización de cada una de las mezclas preparadas para ser usadas como combustibles en procesos de conversión térmica. Esta caracterización ha servido para mostrar datos relevantes de cara a su uso potencial como combustibles. Se han determinado propiedades físicas y químicas de cada una de las mezclas.

Estas caracterizaciones se han realizado en función de la necesidad de demostrar la viabilidad de los residuos, es decir: se han determinado ciertas parámetros físicos como densidad a granel, comportamiento de fusión de ceniza, contenido en materia volátil, contenido en ceniza, contenido en humedad, durabilidad, porcentaje de finos o poder calorífico, y otros ciertos parámetros químicos como contenido en carbono, hidrógeno y oxígeno, elementos mayoritarios en forma de óxido en las ceniza, contenido en cloro, etc.

La presentación de los datos se ha realizado basándose en la documentación existente en la bibliografía en el campo de actuación en el que se centra esta tesis [109, 117, 145]. Sin embargo, la nueva normativa europea sobre CSR indica que la presentación de parámetros físicos y químicos debe realizarse a través de una serie de formularios, que indican la obligatoriedad o no de su especificación. Por tanto, a continuación se muestran los formularios completos para cada uno de los combustibles producidos, donde se recoge el código de clase de cada uno de ellos. 


\subsubsection{Formulario para la especificación de CSR}

Este formulario corresponde a la parte 1 incluida en el Anexo A (normativo) de la norma UNE-EN 15359:2011. Este formulario fue rellanado con cada uno de los CSR de origen industrial: M1, M2, M3 y M4, ver Figuras 3.20 a 3.27. Los datos incluidos en este formulario provienen de la caracterización de los combustibles.

La columna "métodos de ensayo" no ha sido rellenada, ya que los métodos empleados se corresponden con los que marca la normativa europea sobre CSR, encontrándose citados en el capítulo II de esta tesis, Tabla 2.4. Dentro de la columna "Valor" se dispone de dos apartados: típico y límite, donde el valor típico hace referencia a las propiedades físicas y químicas del CSR, y el valor límite corresponde al acuerdo entre el usuario y el productor, refiriéndose a envíos. Por tanto, el valor límite no se especifica en este formulario, solamente el valor típico que ha sido obtenido mediante los análisis llevados a cabo sobre el CSR. 
- M1 (95\% rechazos; $5 \%$ lodo de destintado Parte 1

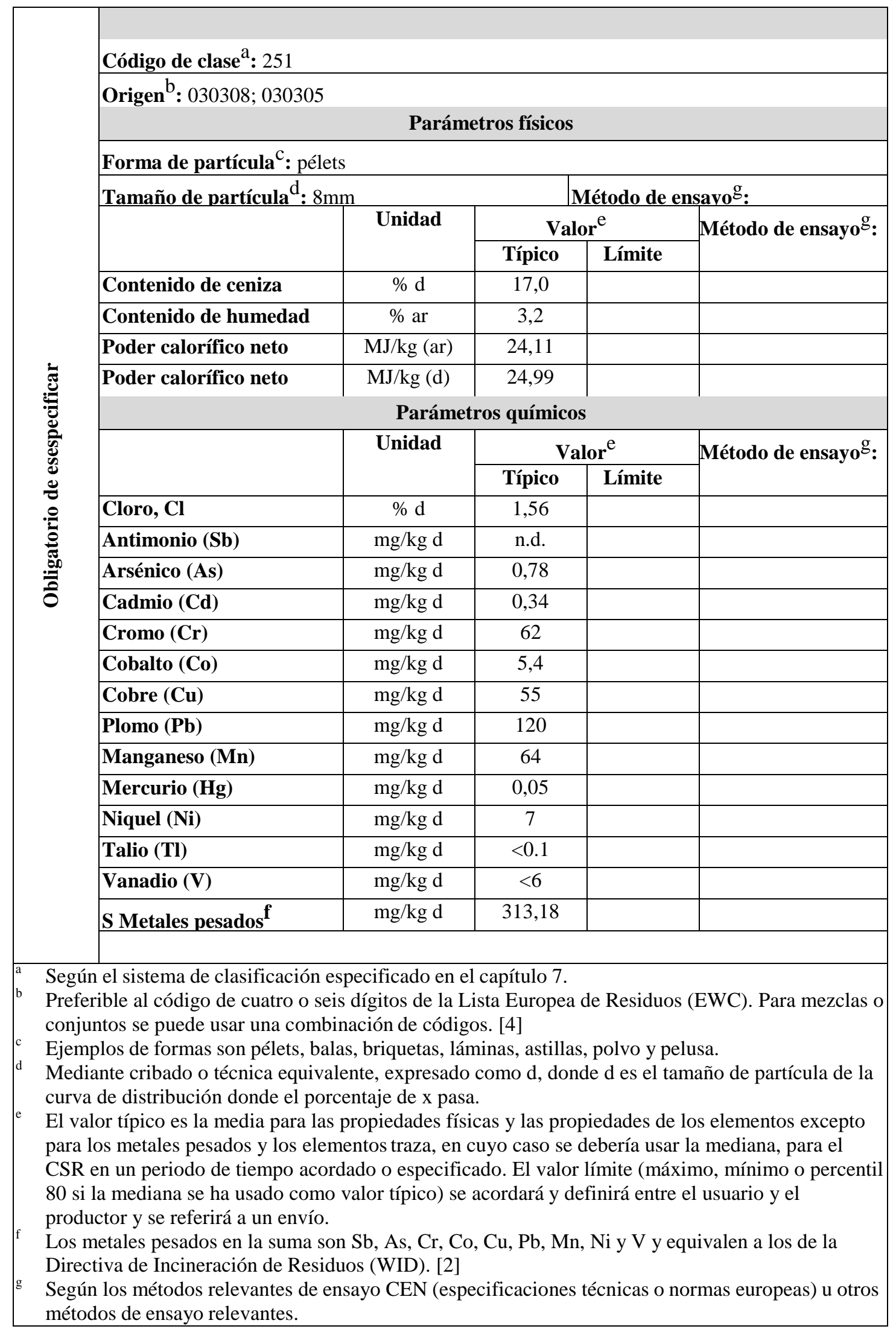

Figura 3.20. M1: Parte 1 Anexo A (normativo)_Obligatorio de especificar. 


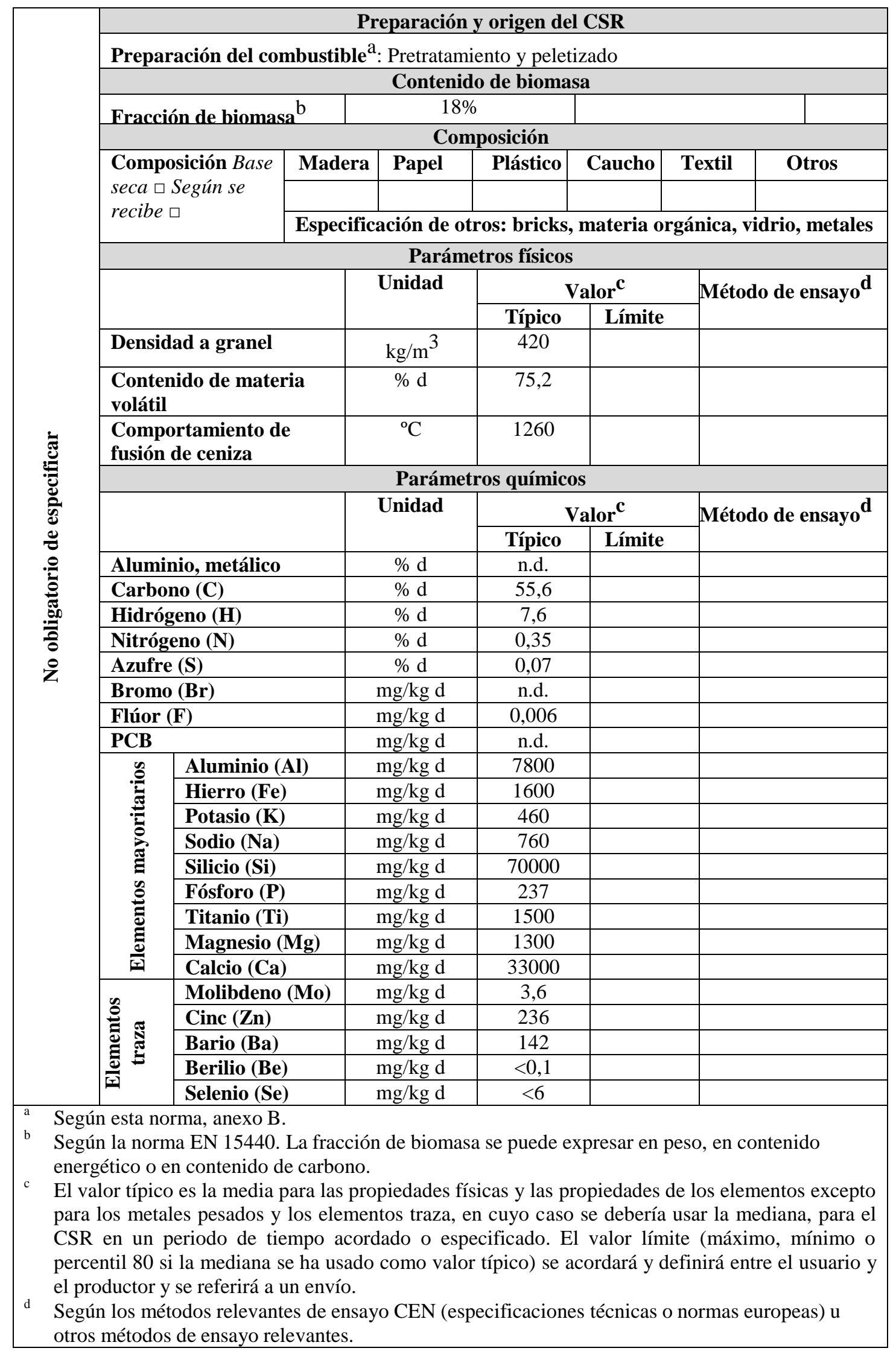

Figura 3.21. M1: Parte 1 Anexo A (normativo)_No obligatorio de especificar. 
- $\quad$ M2 (85\% rechazos; $15 \%$ lodo de destintado)

Parte 1

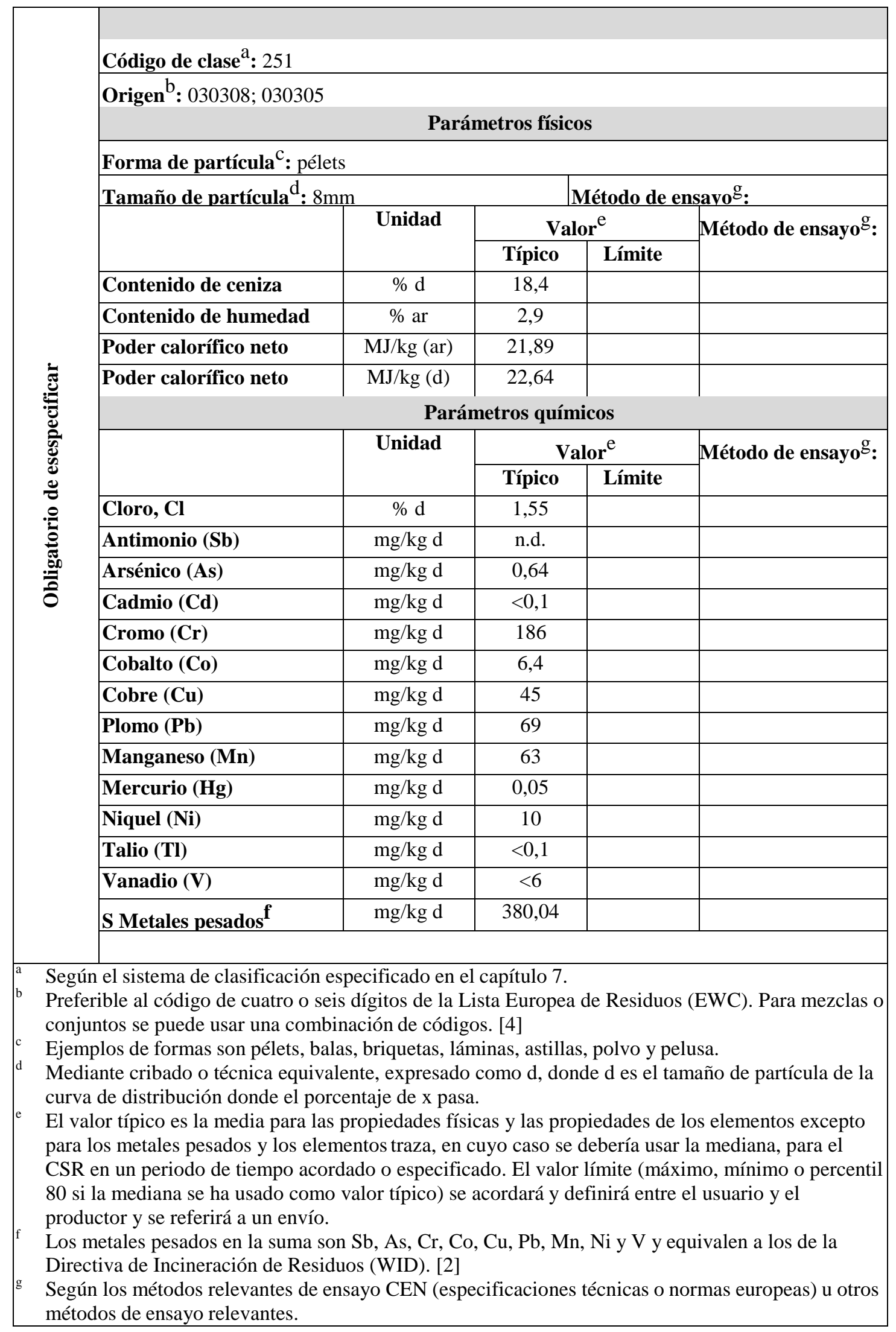

Figura 3.22. M2: Parte 1 Anexo A (normativo)_Obligatorio de especificar. 


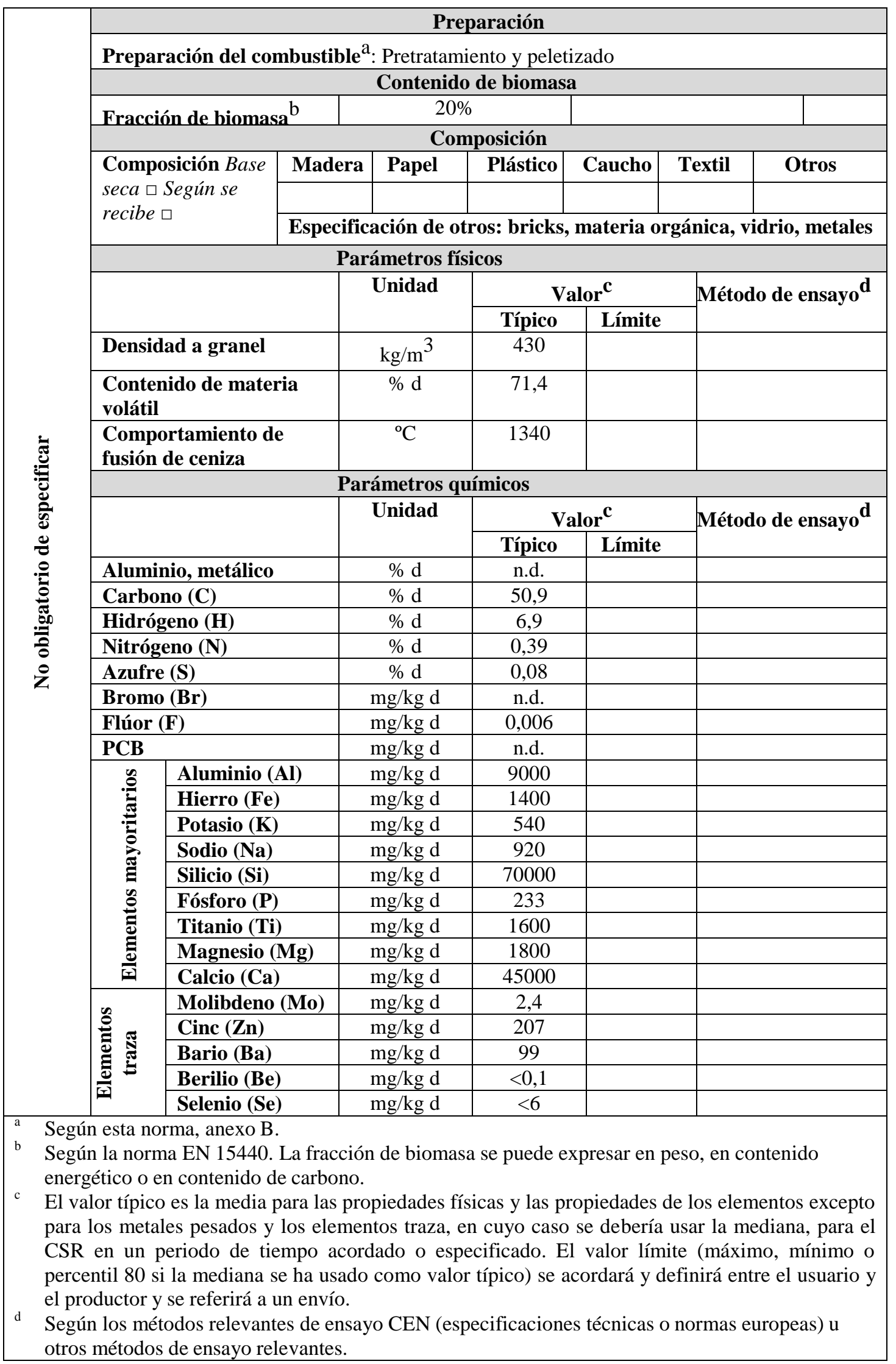

Figura 3.23. M2: Parte 1 Anexo A (normativo)_No obligatorio de especificar. 
- $\quad$ M3 (75\% rechazos; 25\% lodo de destintado)

Parte 1

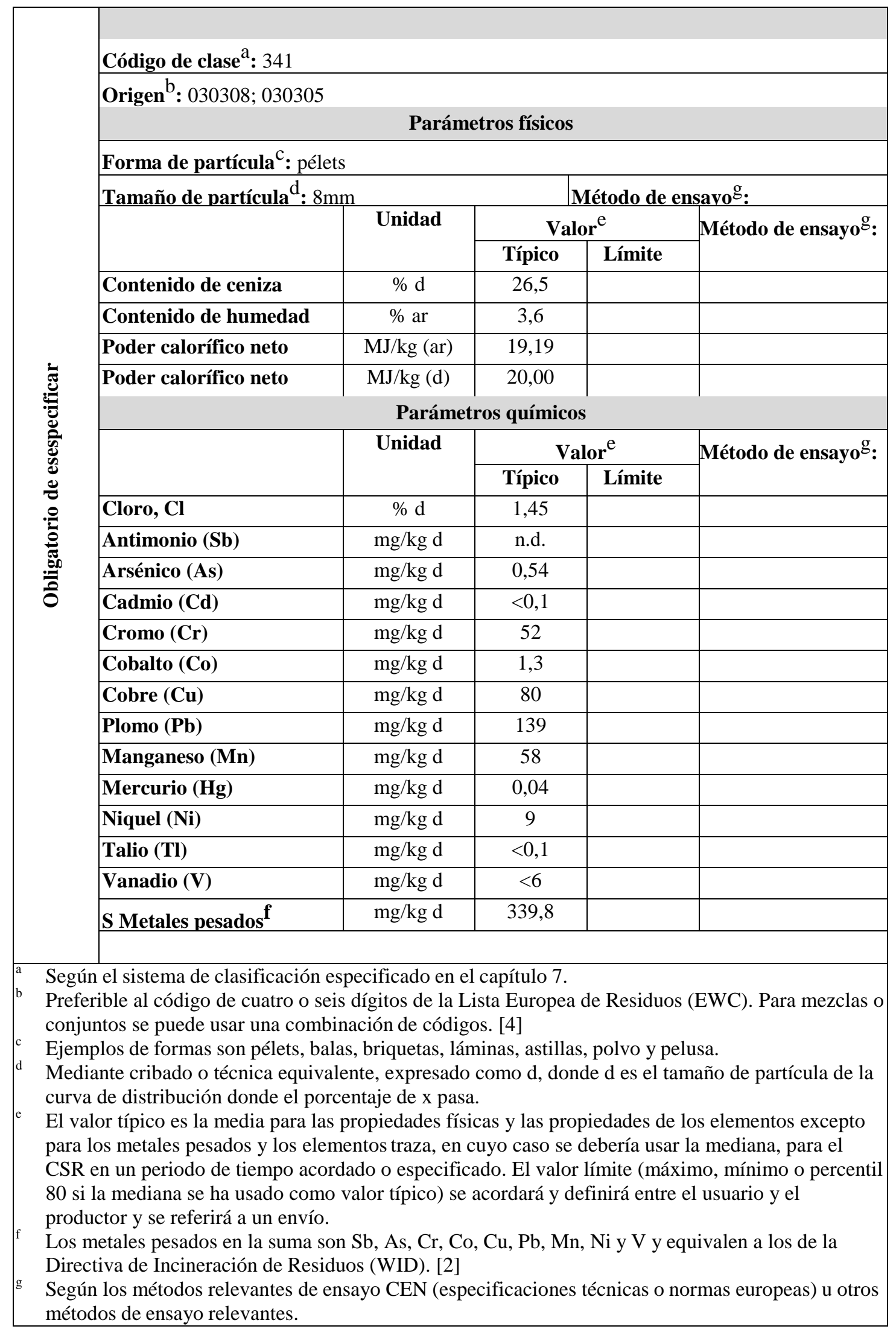

Figura 3.24. M3: Parte 1 Anexo A (normativo)_Obligatorio de especificar. 


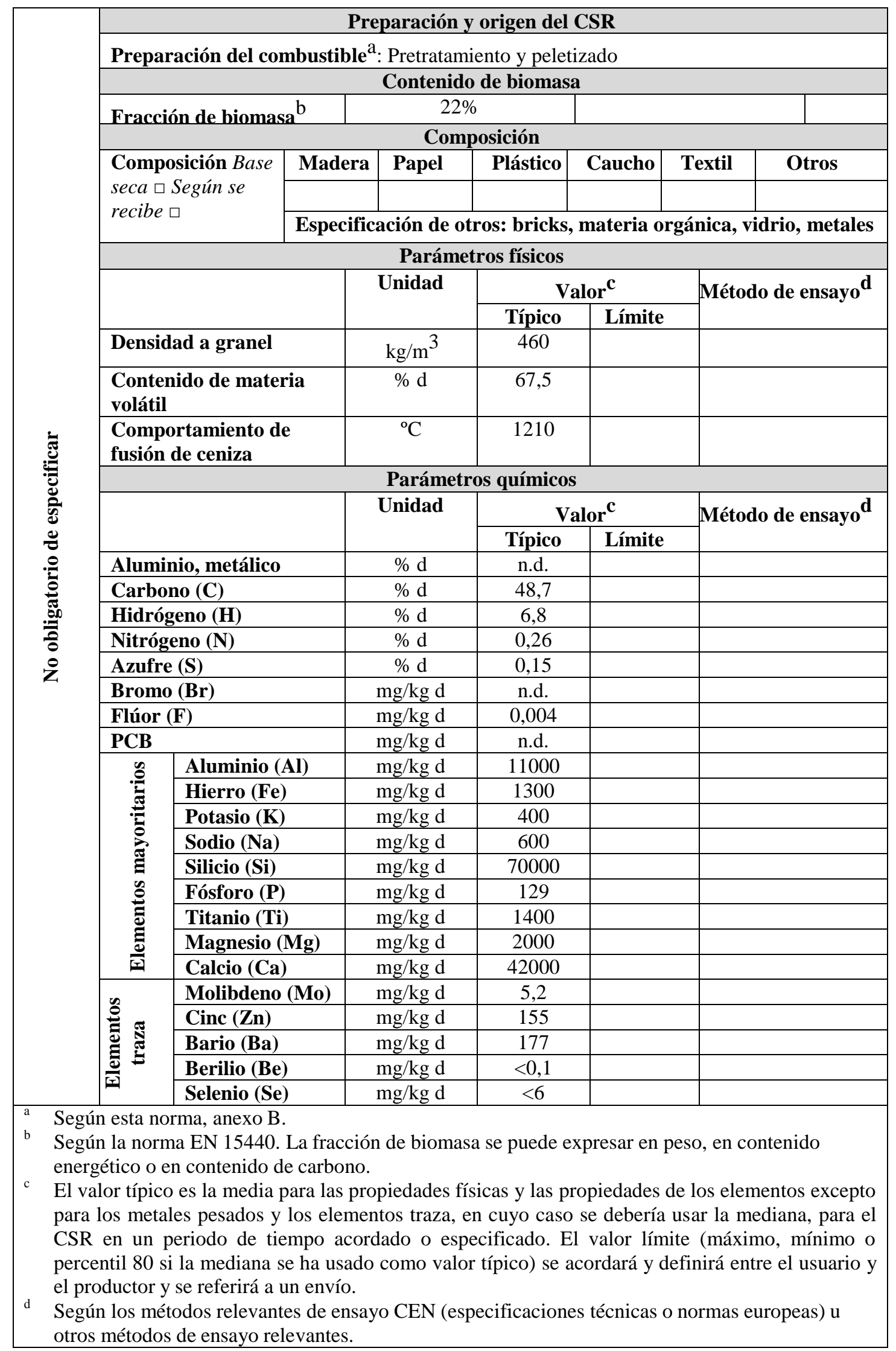

Figura 3.25. M3: Parte 1 Anexo A (normativo)_No obligatorio de especificar. 
- M4 (65\% rechazos; 35\% lodo de destintado)

Parte 1

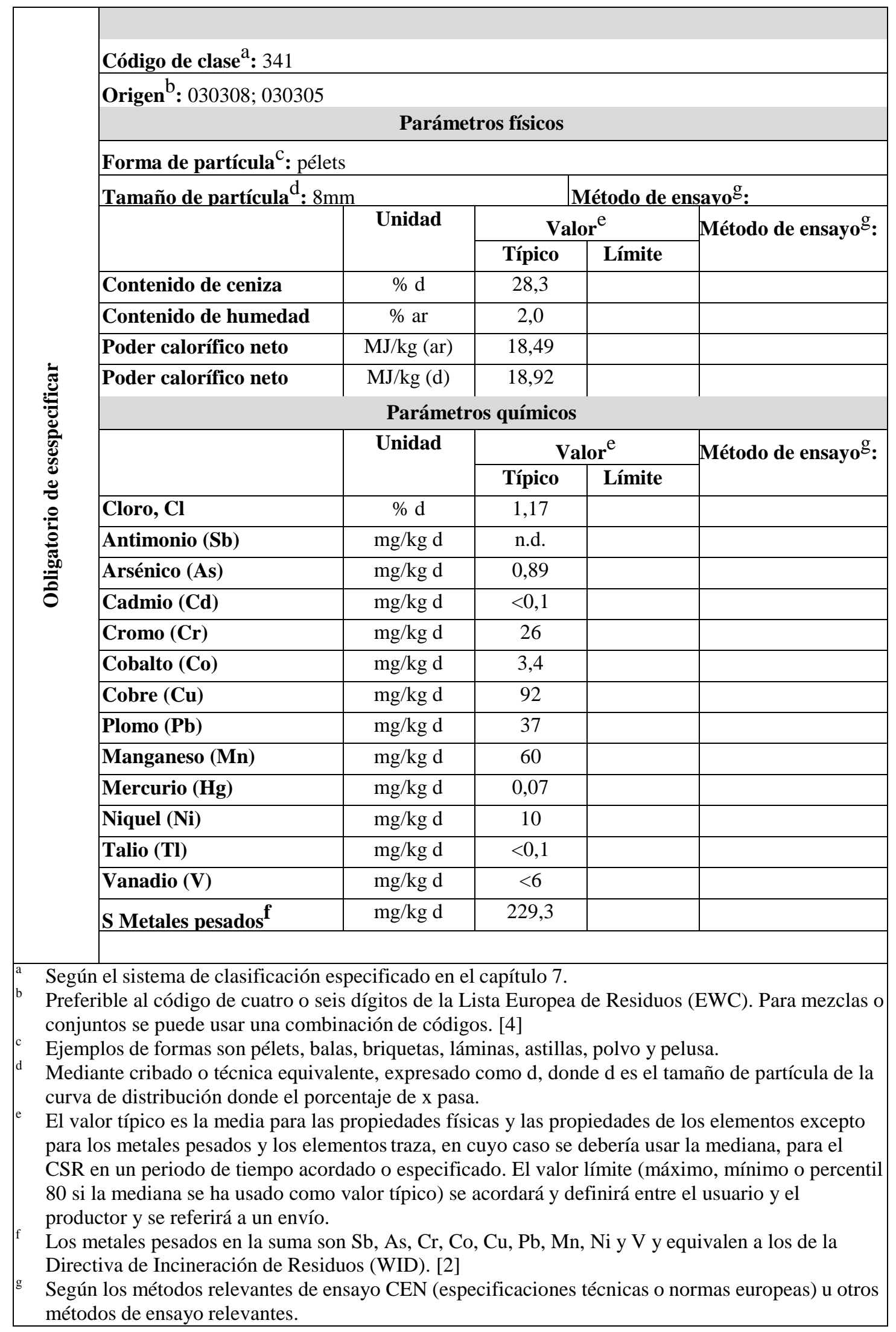

Figura 3.26. M4: Parte 1 Anexo A (normativo)_Obligatorio de especificar. 


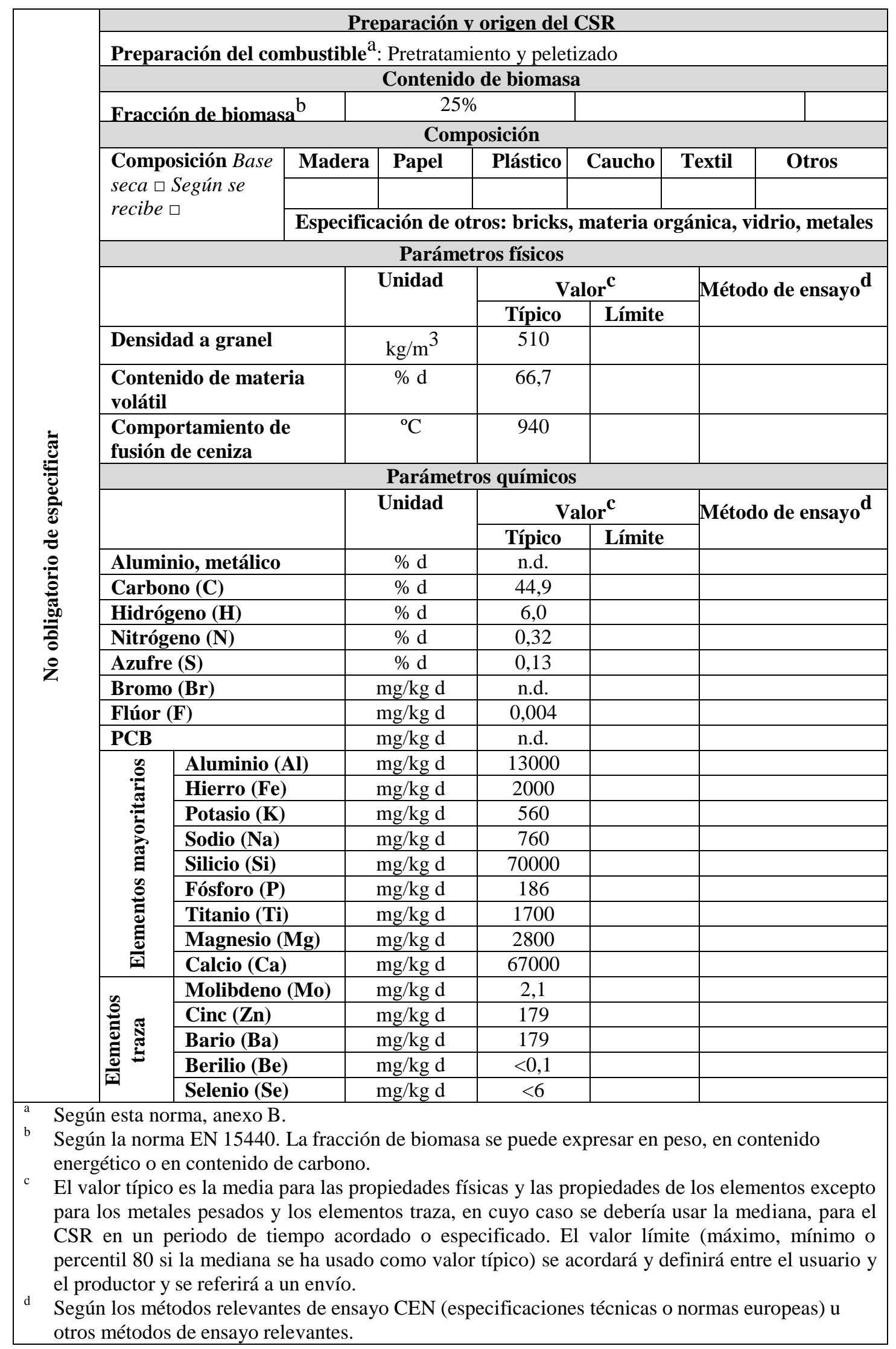

Figura 3.27. M4: Parte 1 Anexo A (normativo)_No obligatorio de especificar. 


\subsubsection{Formulario para la preparación del combustible}

Este formulario corresponde a la parte 1 incluida en el Anexo A (normativo) de la norma UNE-EN 15359:2011. Solamente se ha rellenado un formulario de preparación del combustible, ya que los cuatro combustibles gozaron de la misma preparación, es decir: pretratamiento y compactación por peletizado. No se especifica ninguna mezcla en concreto, siendo igualmente válido para cualquiera de ellas: M1, M2, M3 y M4.

\begin{tabular}{|c|c|c|}
\hline \multicolumn{3}{|c|}{ Nivel de preparación } \\
\hline 1 & 2 & 3 \\
\hline \multicolumn{3}{|l|}{ Sin tratar } \\
\hline \multirow{2}{*}{ Clasificación } & Clasificación manual & \\
\hline & Clasificación mecánica & $\begin{array}{l}\text { Grúa de carga } \\
\text { Pantalla de canjilones }\end{array}$ \\
\hline \multirow[t]{2}{*}{ Tratamiento biológico } & Tratamiento aeróbico & \\
\hline & Tratamiento anaeróbico & \\
\hline \multirow{4}{*}{$\begin{array}{l}\text { Trituración, molienda, } \\
\text { troceado }\end{array}$} & Destrozadora & Troceadora de un solo rotor \\
\hline & & $\begin{array}{l}\text { Troceadora de dos ejes } \\
\text { Troceadora de cuatro ejes }\end{array}$ \\
\hline & Trituradora & $\begin{array}{l}\text { Trituradora de tornillo } \\
\text { Trituradora de mandíbulas } \\
\text { Trituradora de cuchillas }\end{array}$ \\
\hline & Molino & $\begin{array}{l}\text { Molino de bolas } \\
\text { Molino de martillos alimentado por } \\
\text { gravedad } \\
\text { Molino de martillos alimentado } \\
\text { horizontalmente } \\
\text { Molino de cuchillas }\end{array}$ \\
\hline \multirow[t]{5}{*}{ Separación } & $\begin{array}{l}\text { Separación magnética del } \\
\text { material }\end{array}$ & Separador magnético de tambor \\
\hline & & $\begin{array}{l}\text { Polea magnética } \\
\text { Separador suspendido de cinta horizontal } \\
\text { Separador magnético en línea }\end{array}$ \\
\hline & $\begin{array}{l}\text { Separación del material no- } \\
\text { maonética }\end{array}$ & $\begin{array}{l}\text { Separador en corriente por remolino } \\
\text { (Eddy) Cascada }\end{array}$ \\
\hline & Separación gravitacional & $\begin{array}{l}\text { Separación por viento, clasificador } \\
\text { por aire o elevador de viento } \\
\text { Separación balística } \\
\text { Separación húmeda }\end{array}$ \\
\hline & Separación óptica & \\
\hline \multirow[t]{6}{*}{ Tamizado } & Tamiz rotatorio (tambor) & \\
\hline & Tamiz oscilante & \\
\hline & Tamiz alternante & \\
\hline & Tamiz de disco & \\
\hline & Tamiz de Estrella & \\
\hline & Criba vibrante & \\
\hline \multicolumn{3}{|l|}{ Lavado } \\
\hline \multirow[t]{2}{*}{ Secado, refrigeración } & Secado & \\
\hline & Refrigeración & \\
\hline \multirow{3}{*}{$\begin{array}{l}\text { Homogeneización, } \\
\text { compactación }\end{array}$} & Mezcla & \\
\hline & Conjunto & \\
\hline & Compresión & $\begin{array}{l}\text { Peletizado } \\
\text { Briquetizado } \\
\text { Embalado } \\
\end{array}$ \\
\hline Prevención del polvo & & \\
\hline
\end{tabular}

Figura 3.28. Mezclas (M1, M2, M3, M4): Parte 1 Anexo A (normativo)_preparación. 


\section{CAPÍTUlo iv. TECNOLOGía DE LECHO FLUIDIZADO}

\subsection{INTRODUCCIÓN}

El proceso de gasificación puede ser clasificado en función de la tipología del gasificador: lecho fijo/móvil, lecho fluidizado, lecho de arrastre, etc. [160] o en función del agente gasificante empleado: aire, vapor, aire/vapor, oxígeno/vapor o exceso de oxígeno.

Los gasificadores de lecho móvil de flujo en contracorriente, que producen elevadas tasas de alquitranes en el gas de proceso, y los de lecho móvil en corrientes paralelas, tienen la dificultad de mantener perfiles uniformes de temperatura en la dirección radial y evitar problemas de canales preferentes, siendo poco adecuado su empleo en grandes instalaciones [161]. Por contra, los gasificadores de lecho fluidizado ofrecen ventajas en comparación a los lechos fijos, ya que dotan de un elevado grado de mezcla de partículas sólidas y un mayor contacto entre la fase gaseosa y sólida que mejora la velocidad de reacción y la eficiencia en la conversión. Los gasificadores de lecho fluidizado se clasifican en unidades de tipo burbujeante y de tipo circulante.

El interés comercial en la tecnología de lechos fluidizados data del 1940 cuando comienza a desarrollarse el proceso de craqueo catalítico en lecho fluidizado, pero su abandono se produjo debido a dificultades técnicas y a la baja actividad catalítica en estos procesos. Sin embargo, a partir del año 1970, la tecnología de lecho fluidizado es relanzada con un notable interés [162]. Las unidades circulantes alcanzan un grado de conversión de carbono mayor que no se podría lograr en una unidad sencilla de lecho fluidizado, lo que hace que sean más eficientes, aunque su operación sea más compleja.

Los reactores de lecho fluidizado circulante gozan de grandes ventajas respecto a los reactores de lecho fluidizado burbujeante como una eficiencia del contacto gas-sólido más elevada, una reducción de la dispersión axial en fase sólida y gaseosa, así como mayores tiempos de residencia del combustible debido a la recirculación de residuos carbonosos e inquemados recogidos mediante un separador gas-sólido. La recirculación se lleva a cabo mediante válvulas no mecánicas, más robustas y que aguantan altas temperaturas en comparación con las válvulas mecánicas. El establecimiento de un adecuado flujo de partículas sólidas en el sistema es clave en el funcionamiento del equipo, existiendo varias configuraciones de válvulas no mecánicas que pueden emplearse en el sistema de recirculación, como son: válvula-L, válvula-J, loop-seal, etc.

El empleo de un material de lecho adecuado que no tenga elevada atrición y el diseño de un sistema de recirculación adaptado al proceso son claves tanto en la operación como en la reducción de los alquitranes generados [163]. Además, este tipo de reactores adolecen de retromezcla de partículas sólidas, segregaciones de gas y partículas sólidas debido a estructuras no uniformes en las direcciones radial y axial y segregaciones causadas por agrupamientos de partículas (clusters). 
No obstante, se están experimentando diferentes configuraciones, lechos fluidizados duales, que permiten una mejora en la eficiencia del proceso, al aprovechar los inquemados como aporte de calor al material de lecho, reduciendo la cantidad de inquemados y residuos carbonosos generados.

Por otro lado, otras tecnologías de gasificación como la gasificación por plasma o la gasificación en reactor de lecho de arrastre se encuentran, actualmente, en pleno desarrollo. Estas tecnologías permiten una reducción de los alquitranes formados, así como un aumento de la conversión de carbono, debido a las altas temperaturas que se alcanzan, produciendo un gas de proceso más limpio. La reducción del contenido de alquitranes en el gas de proceso se observa también en otras tecnologías en desarrollo como son la gasificación con agua supercrítica y la gasificación el lecho de chorro.

\subsection{ASPECTOS FLUIDO-DINÁMICOS}

\subsubsection{FLUDIZACIÓN}

La fluidización es el fenómeno por el cual partículas sólidas, inicialmente en reposo, experimentan un comportamiento fluido a través de una suspensión en gas o líquido. Este fenómeno se produce cuando un fluido se mueve de manera ascendente por un lecho de partículas sólidas.

El fluido asciende entre los espacios que dejan las partículas sólidas estacionarias, lecho fijo, sin embargo, un aumento del flujo provoca que éstas comiencen a separarse y a vibrar, lecho expandido. A medida que aumenta el flujo que asciende a través del lecho de partículas, éstas comienzan a separarse hasta que quedan completamente suspendidas. Una vez alcanzado ese estado, donde las partículas sólidas se encuentran completamente suspendidas, se dice que el lecho se encuentra fluidizado o a mínima fluidización. Esto ocurre cuando las fuerzas de fricción entre las partículas sólidas y el fluido ascendente igualan al peso de las partículas.

Un incremento en el flujo ascendente significa una expansión progresiva del lecho, fluidización homogénea, hasta que comienzan a aparecer las primeras burbujas de fluido. Sin embargo, cuando se tienen elevados flujos, los sistemas de contacto gassólido se comportan de manera distinta. Un incremento del flujo superior al mínimo de fluidización resulta en un aumento de la agitación, favoreciendo el contacto, y que el movimiento de las partículas sólidas se hace más intenso. Esta etapa marcada por la aparición de burbujas, se denomina fluidización burbujeante. En esta etapa se observa un lecho fluidizado denso con una capa superficial definida.

Sin embargo, con el aumento del flujo se observa como las burbujas de gas crecen y se unen a medida que ascienden en a través del lecho, arrastrando partículas sólidas finas en su interior. La ruptura de estas burbujas, que se produce en la superficie del lecho, dando lugar a la zona denominada de chapoteo (splash), provoca el retorno de las partículas nuevamente al lecho. 
Cuando el aumento de flujo es de tal forma que las partículas sólidas más finas son arrastradas fuera del lecho, fluidización turbulenta, se observan agrupamientos de partículas y espacios vacíos de partículas de diferentes tamaños en lugar de burbujas, provocando la desaparición de la capa superficial del lecho. Un posterior aumento en el flujo ascendente produce un transporte de sólidos con el fluido, fluidización en fase dispersa con transporte pneumático.

En la Figura 4.1 se observa el comportamiento de un lecho fluidizado a medida que aumenta el flujo ascendente a través del lecho de partículas. En esta figura podemos observar los estados correspondientes a un lecho fluidizado burbujeante y a un lecho fluidizado circulante. En el lecho burbujeante se produce la formación de burbujas y su ruptura en la capa superficial del lecho. Este lecho es denso y no existe arrastre de partículas sólidas con el fluido. Por contra, en el lecho circulante se produce un arrastre de partículas sólidas finas y se diferencian claramente dos zonas, una fase densa y otra dispersa.

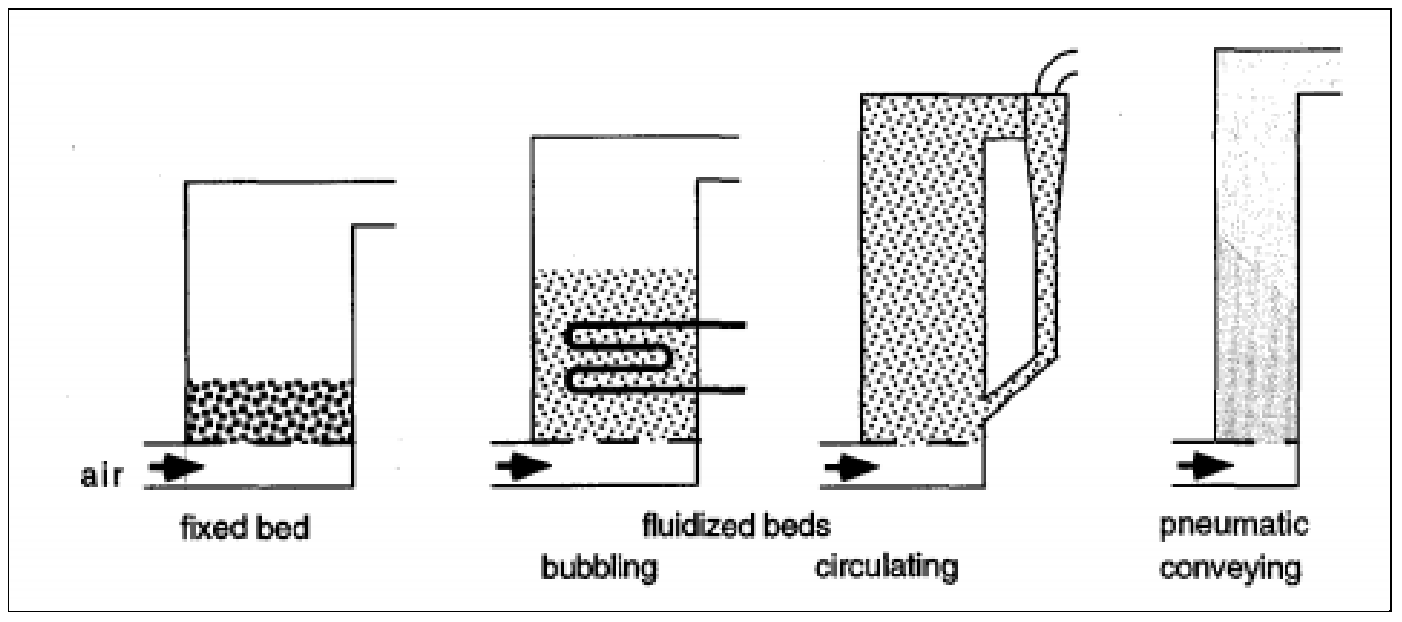

Figura 4.1. Variaciones de un lecho de partículas sólidas en un reactor por contacto con un fluido ascendente [166].

\subsubsection{MATERIAL DE LECHO}

La clasificación de partículas sólidas establecidas por Geldart (1973) divide a éstas en cuatro grupos, como se observa en la Figura 4.2: A (aireables), B (comportamiento semejante a arena), C (cohesivas) y D (arrastrables).

Grupo A $\left(\mathrm{u}_{\mathrm{mb}}>\mathrm{u}_{\mathrm{mf}}\right)$ : Está compuesto por partículas sólidas de pequeño diámetro y bajas densidades. Estas partículas fluidizan adecuadamente para bajas velocidades de gas y para altas velocidades de gas en lechos rápidos burbujeantes controlados, pero expanden considerablemente una vez superada la velocidad mínima de fluidización y antes de la aparición de las burbujas.

Grupo B $\left(\mathrm{u}_{\mathrm{mb}}>\mathrm{u}_{\mathrm{mf}}\right)$ : Estas partículas fluidizan adecuadamente y una vez sobrepasada la velocidad de fluidización comienza la aparición de burbujas. Las burbujas ascienden más lentamente que las formadas para el caso de partículas sólidas del grupo A. 
Grupo C: Este tipo de partículas son muy finas y son muy difíciles de fluidizar, generándose canales preferentes al aumentar la velocidad de fluidización, como se observa en la Figura 4.3. Se requieren técnicas especiales para su fluidización, ya que las fuerzas inter-partícula son superiores a las fuerzas de arrastre generadas por el fluido.

Grupo D: Está compuesto por partículas sólidas de gran tamaño y elevadas densidades. Estas partículas requieren una mayor velocidad para fluidizar, pero tienden a ser lanzadas a chorro durante la fluidización. Se produce la coalescencia y el crecimiento de las burbujas de manera lenta, debido a que ascienden más lentamente que el fluido de la fase de emulsión a su alrededor.

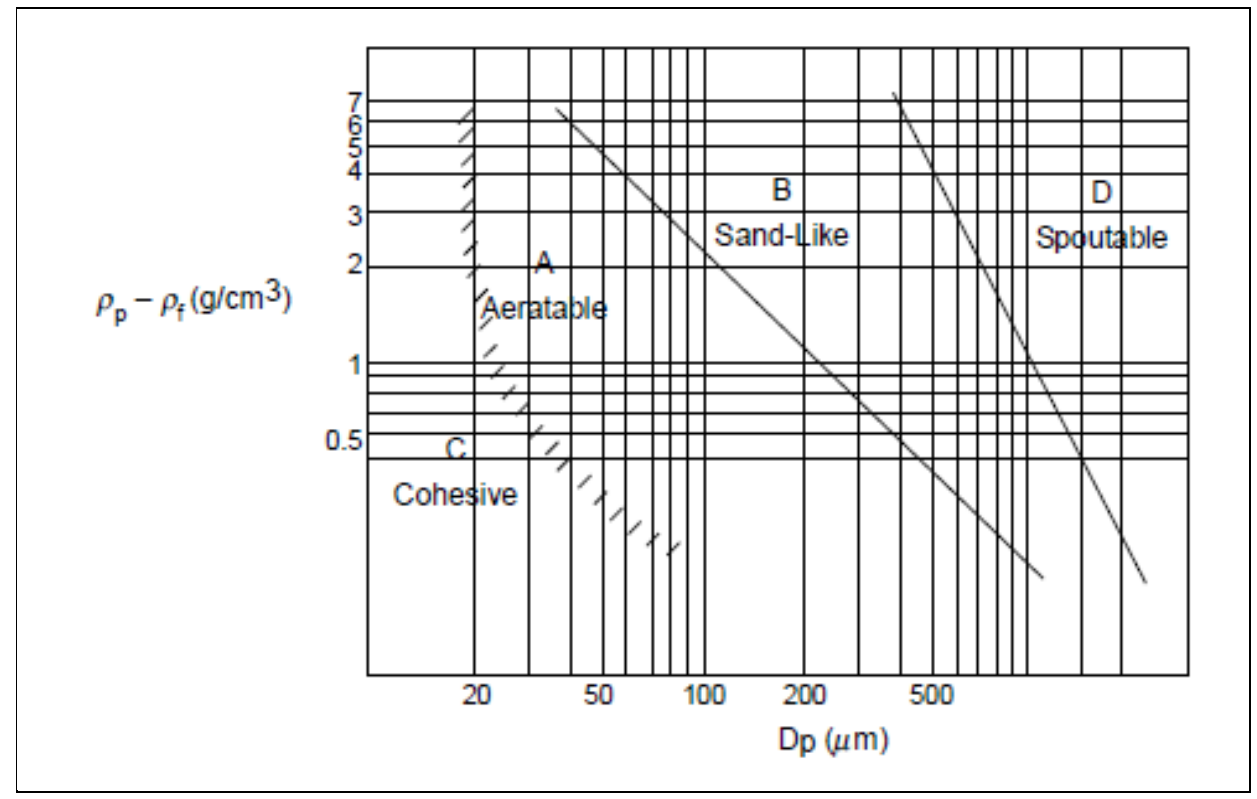

Figura 4.2. Clasificación de partículas sólidas desarrolladas por Geldart [74].

La distribución de tamaño de partículas es de gran importancia en lechos fluidizados, ya que operan con una cantidad constante de partículas sólidas, inventario de sólidos. La distribución de tamaño del material de lecho que se emplea puede sufrir variaciones a consecuencia de distintos efectos:

- Fragmentación: rotura de partículas sólidas en otras de menor tamaño.

- Secado y devolatilización, las partículas sólidas pierden masa debido a la formación de especies gaseosas.

- Atrición: las partículas generan finos debido a la abrasión.

- Elutriación: las partículas más finas son arrastradas por el gas de proceso.

- Segregación: las partículas sólidas más gruesas se acumulan en la parte baja del lecho, donde se extraen para mantener el inventario de sólidos constante.

Por tanto, la elección de un inventario de sólidos adecuado cobra gran importancia para evitar problemas operacionales en lechos fluidizados, ver Figura 4.3. 


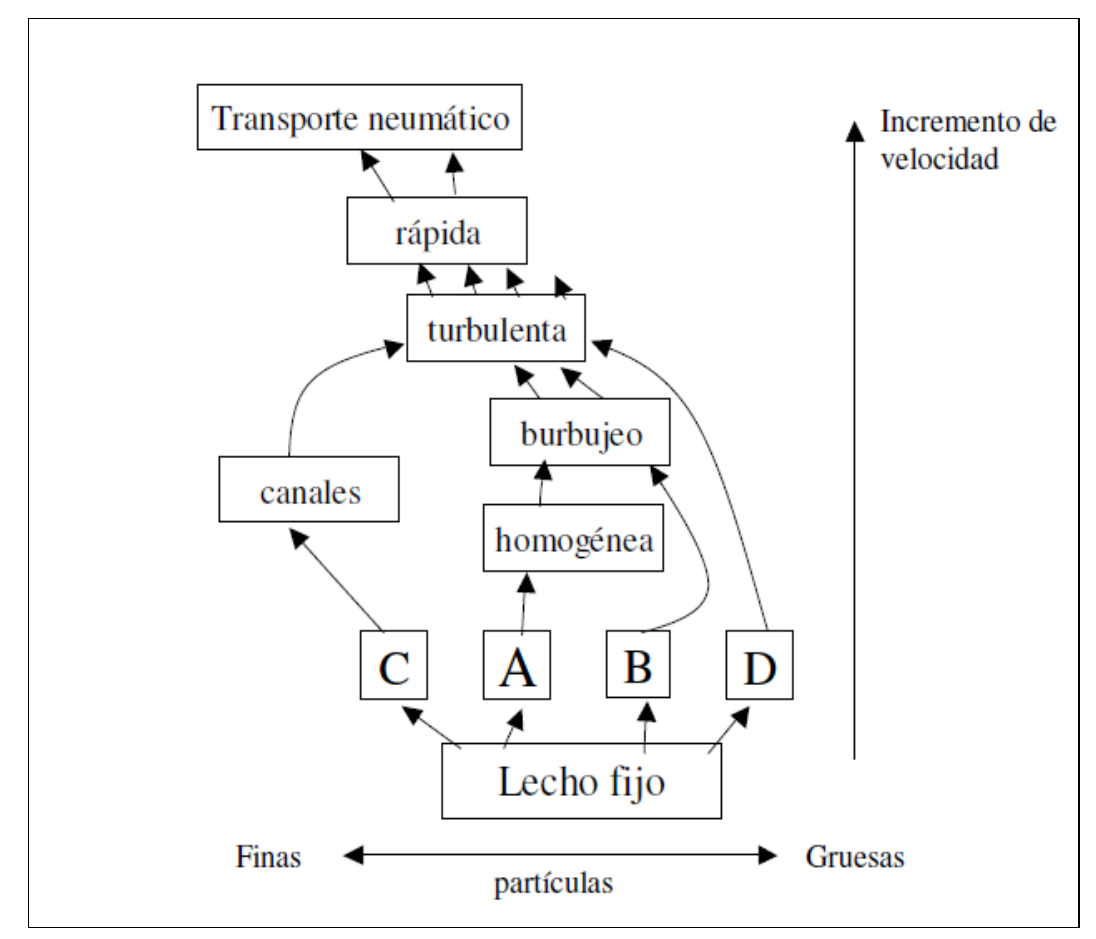

Figura 4.3. Relación entre la clasificación de partículas sólidas propuesta por Geldart y la velocidad de fluidización [74].

El material de lecho que se decidió emplear en las instalaciones de fluidización disponibles, lecho burbujeante y circulante, fue arena de sílice debido a su menor coste y disponibilidad. La empresa suministradora fue Sílices Gil Arranz S.A, que dispone de una cantera de sílices en Prádena (Segovia). Esta empresa dispone de arena de sílice de diferente granulometría. Ambas arenas fueron estudias para su uso como material de lecho. Se determinó la distribución de tamaño de partícula para ambas arenas, siendo los diámetros de partícula medios obtenidos $0,428 \mathrm{~mm}$ para la arena de sílice I y 0,204 $\mathrm{mm}$ para la arena de sílice II. La densidad aparente de ambas arenas de sílice es del orden de 1520 y $1560 \mathrm{~kg} / \mathrm{m}^{3}$, respectivamente. El diámetro medio de partícula se determinó mediante el método convencional [168]:

$\bar{d}_{p}=\frac{1}{\sum\left(x_{i} / d_{p i}\right)}$

Ecuación 4.1

Ambas arenas pertenecen al grupo B según reza la clasificación de Geldart. Por tanto, son adecuadas para su utilización con tecnologías de fluidización.

\subsubsection{MÍNIMA FLUIDIZACIÓN}

La fluidización del material empleado como lecho se produce cuando la velocidad del fluido excede la velocidad de mínima fluidización de las partículas sólidas, que provoca que se encuentren suspendidas en una corriente de flujo ascendente a través del lecho [164]. La ecuación de Ergun (1952), establece una relación adecuada para la caída de presión en lechos fijos de partículas esféricas del mismo tamaño, que permite describir el comportamiento de un lecho fluidizado a la velocidad de mínima fluidización [165]. 
Al inicio de la fluidización, la caída de presión debida a fricción se equilibra con la caída de presión debida al peso de las partículas sólidas [166], combinando ambos términos se obtiene la siguiente ecuación:

$$
\frac{1.75}{\varepsilon_{m f}^{3} \cdot \phi_{s}} \cdot \operatorname{Re}_{p, m f}^{2}+150 \cdot \frac{\left(1-\varepsilon_{m f}\right)}{\varepsilon_{m f}^{3} \cdot \phi_{s}} \cdot \operatorname{Re}_{p, m f}=\mathrm{Ar}
$$

Donde el número adimensional de Arquímedes recoge las propiedades de las partículas sólidas y del fluido:

$$
\mathrm{Ar}=\frac{d_{p}^{3} \cdot \rho_{g} \cdot\left(\rho_{p}-\rho_{g}\right) \cdot g}{\mu^{2}}
$$

Además, el número adimensional de Reynolds permite la obtención de la velocidad de mínima fluidización:

$$
\operatorname{Re}_{m f}=\frac{u_{m f} \cdot d_{p} \cdot \rho_{g}}{\mu_{g}}
$$

Ecuación 4.4

La aplicabilidad de correlaciones que permiten la determinación de la velocidad de mínima fluidización depende de la naturaleza de las superficies de las partículas sólidas, es decir de sus propiedades físicas y químicas, siendo aplicables en casos particulares. La predicción de la velocidad de mínima fluidización se realiza mediante distintas correlaciones que se basan en propiedades del fluido y de las partículas sólidas como: esfericidad, diámetro de partícula y porosidad de mínima fluidización.

Generalmente, la predicción de la velocidad de mínima fluidización se realiza teóricamente a partir de ecuaciones tipo Ergun. El empleo de correlaciones para predecir la velocidad de mínima de fluidización es adecuado, ya que evita el tener que medir la velocidad de mínima fluidización para cada sistema nuevo de que dispongamos.

Las expresiones tipo Ergun permiten obtener el mejor ajuste estadístico de los datos experimentales. Sin embargo, es necesario el conocimiento de la esfericidad y la porosidad de las partículas sólidas empleadas, ya que se hacen necesarias para describir adecuadamente el comportamiento de lechos fluidizados bajo condiciones de mínima fluidización.

El ajuste de datos experimentales se puede ser llevar a cabo mediante un ajuste lineal que depende del valor del número de Reynolds, ya que en función del valor de éste, el ajuste lineal no se cumplirá en función de la esfericidad y la porosidad [167]. Pueden ocurrir variaciones en los valores de porosidad, incluso para un mismo material en las mismas condiciones de operación (presión, temperatura y agente fluidizante). El procedimiento de obtener una correlación tras ajuste de datos experimentales a una ecuación tipo Ergun, se cumple siempre y cuando los sistemas muestren valores de porosidad y esfericidad invariantes. 
Las expresiones empleadas para la determinación de $\operatorname{Re}_{\mathrm{mf}} \mathrm{y} \mathrm{u}_{\mathrm{mf}}$ incluyen propiedades físicas del agente fluidizante como viscosidad y densidad. Ambas se incorporan en el número adimensional de Arquímedes. Generalmente, la viscosidad se considera independiente de la presión, aunque debe ser corregida en función de las condiciones de operación, mientras que la densidad experimenta una importante variación, en función de la presión y la temperatura, que debe tenerse en cuenta.

Por tanto, la estimación de la velocidad de mínima fluidización, sin considerar las condiciones de operación, tanto presión como temperatura, resulta en una predicción errónea [168, 169]. Fletcher et al. (1992), descubrieron una expresión para correlacionar la temperatura con la velocidad de mínima fluidización:

$u_{m f} \cdot T^{0.27}=k_{f}$

Ecuación 4.5

Donde $\mathrm{k}_{\mathrm{f}}$ es una constante de fluidización que permite estimar la velocidad de mínima fluidización a una temperatura dada.

Existen infinidad de expresiones para predecir la velocidad de mínima fluidización. Multitud de estas correlaciones propuestas se basan en la ecuación de Ergun para la caída de presión en un lecho. Las correlaciones tipo Ergun se basan en la modificación de la ecuación de Ergun tras análisis experimental de diferentes sistemas de fluidización, es decir para un material específico de lecho, centrándose en unos parámetros determinados, siendo a veces las correlaciones puramente empíricas. En la literatura se han encontrado cuatro tipos de expresiones [165], formuladas en forma adimensional como $\operatorname{Re}_{m f}=f(A r)$ y $A r=f\left(\operatorname{Re}_{m f}\right)$ :
a) $\operatorname{Re}_{m f}=C \cdot A r^{m}$ Ecuación 4.6
donde $C=f\left(\varepsilon_{m f}, \Phi_{s}, \mu, d_{p}, \rho_{s}, \rho_{g}\right) ; 0.5<\mathrm{m}<1$
b) $\frac{A r}{\operatorname{Re}_{m f}}=\left(C_{1} \cdot A r^{0.15}+C_{2} \cdot A r\right)^{1 / 2}$
Ecuación 4.7
donde $C_{1,2}=f\left(\rho_{s}, \rho_{g}\right)$

En este caso se muestra el significado físico, primer término correspondiente a la velocidad de mínima fluidización, segundo término correspondiente a las propiedades del material y el tercer término correspondiente a las propiedades de flujo.
c) $\operatorname{Re}_{m f}=\frac{A r}{C_{1}+C_{2} \cdot A r^{1 / 2}}$
Ecuación 4.8
donde $C_{1,2}=f\left(\varepsilon_{m f}\right)$
d) $A r=C_{1} \cdot \operatorname{Re}_{m f}+C_{2} \cdot \operatorname{Re}_{m f}{ }^{n}$
Ecuación 4.9 donde $C_{1,2}=f\left(\varepsilon_{m f}, \Phi_{s}\right) ; 1.5<\mathrm{n}<2$

Se ha encontrado otra reformulación en la literatura para el tipo de ecuaciones 4.9 [170], que se basan en la existencia de los parámetros que son prácticamente constantes, lo que implica que independientemente del material empleado, existe un valor medio de $\Phi_{\mathrm{s}} \mathrm{y}$ de $\varepsilon_{\mathrm{mf}}$ :

$$
\operatorname{Re}_{m f}=\left(a_{1}^{2}+a_{2} \cdot A r\right)^{1 / 2}-a_{1}
$$

Donde los parámetros $\mathrm{a}_{1}, \mathrm{a}_{2}$ son funciones de $\Phi_{\mathrm{s}} \mathrm{y} \varepsilon_{\mathrm{mf}}$. 
En la Tabla 4.1, se muestran las estimaciones de velocidad y porosidad de mínima fluidización obtenidas con distintas correlaciones para partículas sólidas para los dos tipos de arena de sílice, que se emplean en el este estudio:

\begin{tabular}{|c|c|c|c|}
\hline Investigador & Correlación & $\begin{array}{l}204 \\
\mu \mathrm{m}\end{array}$ & $\begin{array}{l}428 \\
\mu \mathrm{m}\end{array}$ \\
\hline Grace & $\operatorname{Re}_{m f}=\sqrt{27.2^{2}+0.0408 \cdot A r}-27.2$ & $\begin{array}{c}0,04 \\
(0,43)\end{array}$ & $\begin{array}{c}0,18 \\
(0,43)\end{array}$ \\
\hline Wen and You & $\operatorname{Re}_{m f}=\sqrt{33.7^{2}+0.0408 \cdot A r}-33.7$ & $\begin{array}{c}0,04 \\
(0,41)\end{array}$ & $\begin{array}{c}0,15 \\
(0,41)\end{array}$ \\
\hline Borgeois et Grenier & $\operatorname{Re}_{m f}=\sqrt{25.46^{2}+0.03824 \cdot A r}-25.46$ & $\begin{array}{c}0,04 \\
(0,43)\end{array}$ & $\begin{array}{c}0,18 \\
(0,43)\end{array}$ \\
\hline $\begin{array}{l}\text { Richardson and St. } \\
\text { Jeronimo }\end{array}$ & $\operatorname{Re}_{m f}=\sqrt{25.7^{2}+0.0365 \cdot A r}-25.7$ & $\begin{array}{c}0,04 \\
(0,42)\end{array}$ & $\begin{array}{c}0,17 \\
(0,42)\end{array}$ \\
\hline Babu et al. & $\operatorname{Re}_{m f}=\sqrt{25.25^{2}+0.0651 \cdot A r}-25.25$ & $\begin{array}{c}0.08 \\
(0,49)\end{array}$ & $\begin{array}{c}0,29 \\
(0,50)\end{array}$ \\
\hline Saxena et Vogel & $\operatorname{Re}_{m f}=\sqrt{25.28^{2}+0.0571 \cdot A r}-25.28$ & $\begin{array}{c}0,07 \\
(0,48)\end{array}$ & $\begin{array}{c}0,26 \\
(0,48) \\
\end{array}$ \\
\hline J. Reina et al. & $\operatorname{Re}_{m f}=\sqrt{48^{2}+0.045 \cdot A r}-48$ & $\begin{array}{c}0,03 \\
(0,38)\end{array}$ & $\begin{array}{c}0,12 \\
(0,38)\end{array}$ \\
\hline Frantz & $\mathrm{Re}_{m f}=1.065 \cdot 10^{-3} \cdot A r$ & $\begin{array}{c}0,06 \\
(0,47)\end{array}$ & $\begin{array}{c}0,28 \\
(0,49)\end{array}$ \\
\hline Davies and Richardson & $\operatorname{Re}_{m f}=7.8 \cdot 10^{-4} \cdot A r$ & $\begin{array}{c}0,05 \\
(0,44)\end{array}$ & $\begin{array}{c}0,21 \\
(0,45)\end{array}$ \\
\hline Doichev et Akhamov & $\operatorname{Re}_{m f}=1.08 \cdot 10^{-3} \cdot A r^{0.947}$ & $\begin{array}{c}0,05 \\
(0,43)\end{array}$ & $\begin{array}{c}0,18 \\
(0,43)\end{array}$ \\
\hline Miller et Logwinuk & $u_{m f}=\frac{0.00125 \cdot\left(\rho_{p}-\rho_{g}\right)^{0.9} \cdot \rho_{g}^{0.1} \cdot g \cdot d_{p}^{2}}{\mu}$ & $\begin{array}{c}0,04 \\
(0,40)\end{array}$ & $\begin{array}{l}0,15 \\
(0,41)\end{array}$ \\
\hline Bin & $\frac{A r}{\operatorname{Re}_{m f}}=1416+25.926 \cdot \operatorname{Re}_{m f}$ & $\begin{array}{c}0,04 \\
(0,42)\end{array}$ & $\begin{array}{c}0,17 \\
(0,42)\end{array}$ \\
\hline Leva & $u_{m f}=\frac{7.169 \cdot 10^{-4} \cdot\left(\rho_{p}-\rho_{g}\right)^{0.94} \cdot g \cdot d_{p}^{1.82}}{\mu^{0.88} \cdot \rho_{g}^{0.06}}$ & $\begin{array}{c}0,03 \\
(0,40)\end{array}$ & $\begin{array}{c}0,13 \\
(0,39)\end{array}$ \\
\hline Pillai et Raja Rao & $u_{m f}=7.01 \cdot 10^{-4} \cdot d_{p}^{2} \cdot\left(\rho_{p}-\rho_{g}\right) g / \mu$ & $\begin{array}{c}0,04 \\
(0,42)\end{array}$ & $\begin{array}{c}0,28 \\
(0,49)\end{array}$ \\
\hline Broadhurst et Becker & $\operatorname{Re}_{m f}=\operatorname{Ar} /\left(2.425 \cdot 10^{5} \cdot A r^{-0.85}+\left(\frac{\rho_{p}}{\rho_{g}}\right)^{0.13}+37.7\right)^{0.5}$ & $\begin{array}{c}0,04 \\
(0,43)\end{array}$ & $\begin{array}{c}0,16 \\
(0,41)\end{array}$ \\
\hline Goroshko et al. & $\operatorname{Re}_{m f}=A r /\left(1400+5.2 \cdot\left(A r^{0.5}\right)\right)$ & $\begin{array}{c}0,04 \\
(0,41)\end{array}$ & $\begin{array}{c}0,14 \\
(0,40)\end{array}$ \\
\hline Bena & $\operatorname{Re}_{m f}=1.38 \cdot 10^{-3} \cdot A r /(A r+19)^{0.11}$ & $\begin{array}{c}0,04 \\
(0,41)\end{array}$ & $\begin{array}{c}0,14 \\
(0,39)\end{array}$ \\
\hline Coltters & $u_{m f}=K \cdot\left[\frac{D_{p}^{2} \cdot\left(\rho_{s}-\rho_{g}\right) g}{\mu} \cdot\left(\frac{\rho_{s}}{\rho_{g}}\right)^{1.23}\right]^{\alpha}$ & $\begin{array}{c}0,08 \\
(0,50)\end{array}$ & $\begin{array}{c}0,28 \\
(0,49)\end{array}$ \\
\hline
\end{tabular}

Tabla 4.1. Correlaciones para estimar la velocidad de mínima fluidización. 
Coltters and Rivas (2004), propusieron una correlación para estimar la velocidad de mínima fluidización sin la necesidad de la determinación experimental de la porosidad y de la esfericidad de las partículas sólidas [171].

$u_{m f}=K \cdot\left[\frac{D_{p}^{2} \cdot\left(\rho_{s}-\rho_{g}\right) g}{\mu} \cdot\left(\frac{\rho_{s}}{\rho_{g}}\right)^{1.23}\right]^{\alpha}$

Ecuación 4.11

Donde $\mathrm{K}$ y $\alpha$ son constantes y funciones del sistema de fluidización empleado. Los valores de $\mathrm{K}$ y $\alpha$ para la ecuación anteriormente mencionada han sido obtenidos para diferentes sistemas de fluidización.

Los valores para el sistema de fluidización empleando arena de sílice como material de lecho son:

$95 \mu \mathrm{m}<\mathrm{D}_{\mathrm{p}}<800 \mu \mathrm{m} \quad \mathrm{K}=9.7 \cdot 10^{-7} \alpha=0,84$

$800 \mu \mathrm{m}<\mathrm{D}_{\mathrm{p}}<2800 \mu \mathrm{m} \quad \mathrm{K}=6.4 \cdot 10^{-3} \alpha=0,43$

No obstante, la porosidad de mínima fluidización se debe determinar a partir de la ecuación de Ergun (1952).

\subsubsection{VELOCIDAD TERMINAL}

La velocidad terminal de caída de una partícula aislada en un gas puede obtenerse mediante un balance de fuerzas a la partícula, considerando las fuerzas de gravedad, rozamiento y flotación:

$\left(\rho_{p}-\rho_{g}\right) \frac{\pi}{6} \cdot d_{p}^{3} \cdot g=C_{D} \cdot \frac{\pi \cdot d_{p}^{2}}{4} \cdot \frac{1}{2} \cdot \rho_{g} \cdot u_{t}^{2}$

Ecuación 4.12

Adimensionalizando la anterior expresión:

$$
A r=\frac{3}{4} \cdot C_{D} \cdot \operatorname{Re}_{t}^{2}
$$

A partir de la modificación del cálculo del coeficiente de arrastre para flujo laminar en régimen de Stokes, se obtiene un coeficiente de arrastre en el que se consideran los términos correspondientes a flujo laminar en régimen de Stokes, régimen de transición y turbulento en régimen de Newton [172].

El coeficiente de arrastre modificado presenta la siguiente forma:

$$
C_{D}=C_{D, \text { Stokes }} \cdot f=\frac{24}{\operatorname{Re}_{p}} \cdot f
$$


Distintas ecuaciones para el cálculo del coeficiente de arrastre modificado, obtenido a partir del coeficiente de arrastre de Stokes, se pueden obtener en la literatura [173] como el de Schiller and Naumann (1933):

$f=1+0.15 \cdot \operatorname{Re}_{p}^{0.6875}, \operatorname{Re}_{\mathrm{p}}<800$

Ecuación 4.15

La ecuación de Clift y Gauvin (1970),

$f=\left(1+0.15 \cdot \operatorname{Re}_{p}^{0.687}\right)+0.0175 \cdot\left(1+4.25 \cdot 10^{4} \cdot \operatorname{Re}_{p}^{-1.16}\right)^{-1}, \operatorname{Re}_{\mathrm{p}}<3,5 \cdot 10^{5} \quad$ Ecuación 4.16

O la ecuación de Brauer (1971),

$f=1+0.167 \cdot \operatorname{Re}_{p}^{0.5}+0.0167 \cdot \operatorname{Re}_{p}, \operatorname{Re}_{\mathrm{p}}<3,5 \cdot 10^{5}$

Ecuación 4.17

Muschelknautz (1988) estudió la esfericidad de las partículas, adaptando las constantes de la ecuación de Brauer de acuerdo a la forma de las partículas, ver Tabla 4.2.

\begin{tabular}{|c|c|c|c|c|}
\hline Forma & $\begin{array}{c}\text { Diámetro } \\
\text { equivalente }\end{array}$ & $\begin{array}{c}\text { Régimen } \\
\text { Stokes }\left(\mathrm{K}_{1}\right)\end{array}$ & Transición $\left(\mathrm{K}_{2}\right)$ & $\begin{array}{c}\text { Régimen } \\
\text { turbulento }\left(\mathrm{K}_{3}\right)\end{array}$ \\
\hline Esfera & 1 & 21,5 & 6,5 & 0,23 \\
\hline Poliedro & 1,1 & 24 & 6 & 0,35 \\
\hline Cilindro & 1,14 & 23 & 6 & 0,5 \\
\hline Cubo & 1,24 & 27 & 4,5 & 0,65 \\
\hline $\begin{array}{c}\text { Grano } \\
\text { elíptico }\end{array}$ & 1,26 & 25 & 6 & 0,4 \\
\hline $\begin{array}{c}\text { Lente } \\
\text { elíptica }\end{array}$ & 0,79 & 28 & 6,5 & 0,7 \\
\hline
\end{tabular}

Tabla 4.2. Factores de forma para la ecuación de Brauer modificada por Muschelknautz.

El coeficiente de arrastre, $\mathrm{C}_{\mathrm{D}}$, depende del número de Reynolds y de la esfericidad de partícula. Existen diferentes ecuaciones para el cálculo del coeficiente de rozamiento como la sugerida por Haider and Levenspiel (1989). Esta ecuación es aplicable a partículas de cualquier forma [174]:

$C_{D}=\frac{24}{\operatorname{Re}}\left[1+\left(8.1716 e^{-4.0655 \Phi} \cdot \operatorname{Re}^{0.0964+0.5565 \Phi}\right)\right]+\frac{73.69 \cdot\left(e^{-5.0784 \Phi}\right) \cdot \operatorname{Re}}{\operatorname{Re}+5.378 \cdot e^{6.2122 \Phi}}$

Ecuación 4.18

Al igual que ocurre con la ecuación de Turton and Clark (1987),

$$
C_{D}=\frac{A r^{1 / 3}}{\frac{18}{A r^{2 / 3}}+\frac{2.335-1.744 \cdot \Phi}{A r^{1 / 6}}}
$$

El coeficiente de arrastre se ve afectado por diversidad de factores, desde la turbulencia, y la rotación de las partículas sólidas hasta la no esfericidad de las partículas sólidas, como se observa en la Figura 4.4: 


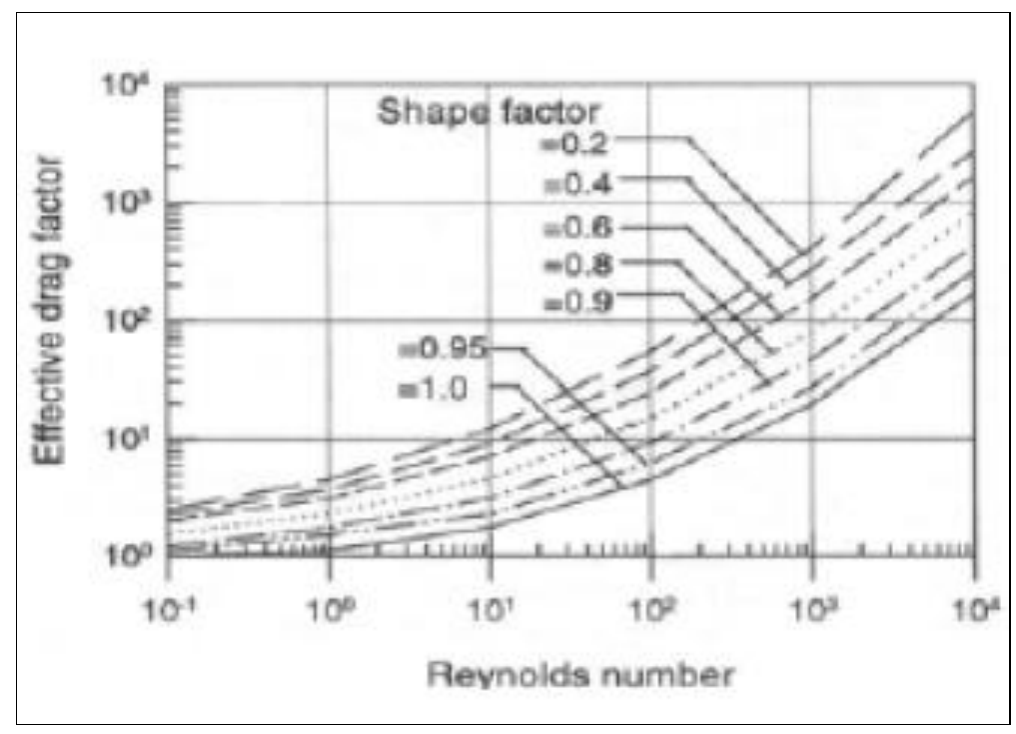

Figura 4.4. Coeficiente de rozamiento frente al número de Reynolds [174].

La evaluación de las distintas expresiones citadas anteriormente se muestra en la Figura 4.5, donde se representa la velocidad terminal adimensional frente al diámetro de partícula adimensional.

A continuación se exponen las velocidades terminales adimensionales para las ecuaciones de Haider and Levenspiel y Turton and Clark, respectivamente:

$$
\begin{aligned}
& u_{t, 1}=\left[\frac{18}{d_{p, 1}^{2}}+\frac{2.335-1.744 \cdot 0.95}{d_{p, 1}^{0.5}}\right]^{-1} \\
& u_{t, 1}=\left[\frac{18}{d_{p, 1}^{2}}+\frac{0.321^{0.412}}{d_{p, 1}}\right]^{-.1 .214}
\end{aligned}
$$

Donde las variables adimensionales definidas en función del diámetro de partícula y la velocidad terminal son:

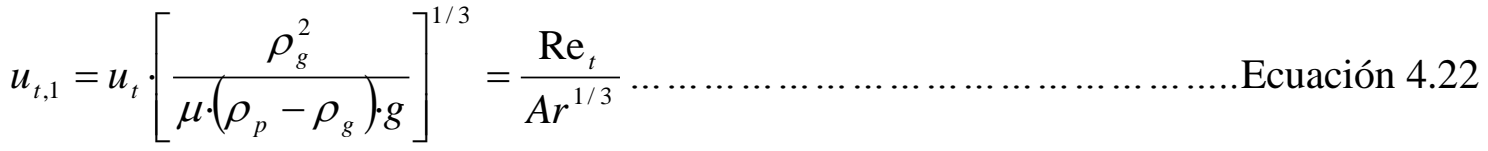

$$
\begin{aligned}
& d_{p, 1}=d_{p} \cdot\left[\frac{\rho_{g} \cdot\left(\rho_{p}-\rho_{g}\right) \cdot g}{\mu^{2}}\right]^{1 / 3}=\operatorname{Ar}^{1 / 3}
\end{aligned}
$$

La Figura 4.5 muestra el efecto de la esfericidad de las partículas sólidas en el coeficiente de rozamiento. El aumento de la esfericidad del de las partículas sólidas produce una reducción del factor de rozamiento. 


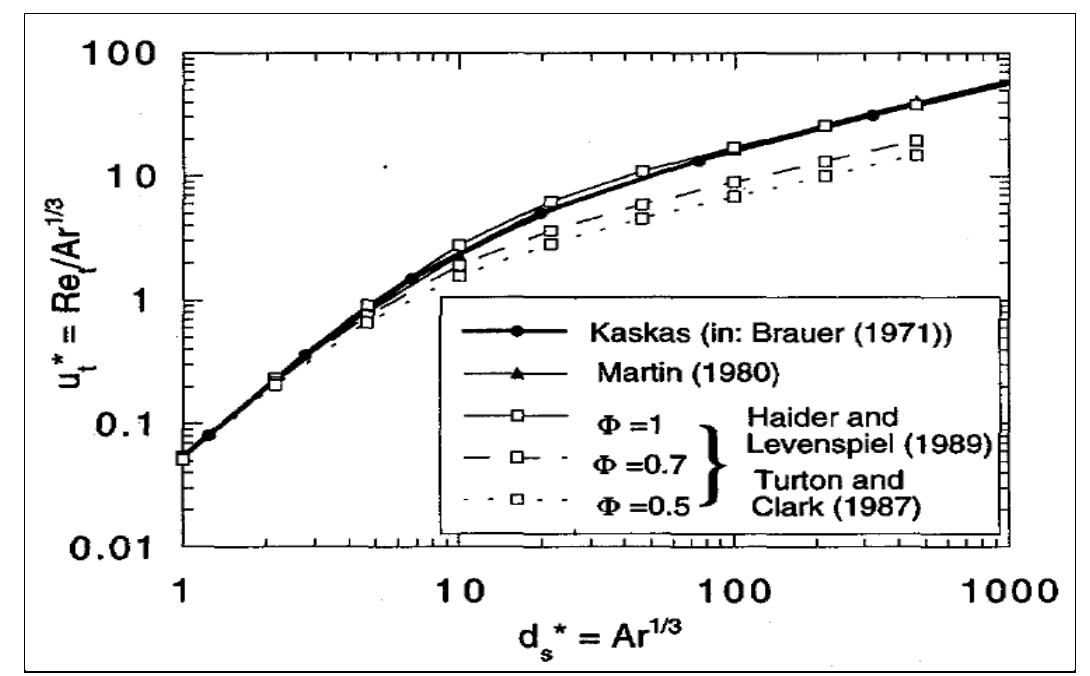

Figura 4.5. Comparación de correlaciones para el cálculo de la velocidad terminal de partículas sólidas aisladas [168].

En la Tabla 4.3 se muestran diferentes correlaciones empleadas para la determinación de la velocidad terminal a partir del diámetro de partícula adimensional y de la velocidad terminal adimensional. Se han determinado las velocidades terminales empleando cada una de ellas con el objeto de comparar sus desviaciones.

\begin{tabular}{|c|c|c|c|}
\hline Investigador & Velocidad terminal adimensional & $\begin{array}{l}204 \\
\mu \mathrm{m}\end{array}$ & $\begin{array}{l}428 \\
\mu \mathrm{m}\end{array}$ \\
\hline $\begin{array}{l}\text { Haider and } \\
\text { Levenspiel }\end{array}$ & $u_{t, 1}=\left[\frac{18}{d_{p, 1}^{2}}+\frac{2.335-1.744 \cdot 0.95}{d_{p, 1}^{0.5}}\right]^{-1}$ & 1,57 & 3,32 \\
\hline $\begin{array}{l}\text { Brown and } \\
\text { Lawler }\end{array}$ & $u_{t, 1}=\left[\left(\frac{18}{d_{p, 1}^{2}}\right)^{0.898\left(\frac{0.936 d_{p, 1}+1}{d_{p, 1}+1}\right)}+\left(\frac{0.317}{d_{p, 1}}\right)^{0.449}\right]^{-1.114}$ & 1,65 & 3,65 \\
\hline $\begin{array}{l}\text { Kan and } \\
\text { Richardson }\end{array}$ & $u_{t, 1}=\frac{\left(2.33 \cdot d_{p, 1}^{0.054}-1.53 \cdot d_{p, 1}^{-0.048}\right)^{13.3}}{d_{p, 1}}$ & 1,46 & 3,27 \\
\hline $\begin{array}{l}\text { Turton and } \\
\text { Clark }\end{array}$ & $u_{t, 1}=\left[\frac{18}{d_{p, 1}^{2}}+\frac{0.321^{0.412}}{d_{p, 1}}\right]^{-.1 .214}$ & 1,48 & 3,35 \\
\hline $\begin{array}{l}\text { Zigrang and } \\
\text { Silvestre }\end{array}$ & $u_{t, 1}=\left[\frac{\left(\sqrt{14.51+1.83 * d_{p, 1}^{3 / 2}-3.81}\right)}{d_{p, 1}}\right]$ & 1,68 & 2,66 \\
\hline Turian et al. & $\begin{array}{l}u_{t, 1}=10^{\lambda} / d_{p, 1} \\
\text { donde } \\
\lambda=-1.38+1.94 \cdot Z-0.086 \cdot Z^{2}-0.0252 \cdot Z^{3}+9.19 \cdot 10^{-4} \cdot Z^{4}+5.35 \cdot Z^{5} \\
Z=\log \sqrt{4 \cdot d_{p, 1}^{3} / 3}\end{array}$ & 1,40 & 3,31 \\
\hline
\end{tabular}

Tabla 4.3. Correlaciones para la determinación de la velocidad terminal. 
El comportamiento de las partículas sólidas en una suspensión concentrada es diferente al comportamiento de una partícula aislada, ya que no se tienen en cuenta distintos efectos que ocurren cuando se encuentran en una suspensión concentrada. Estos efectos son: los efectos de colisión que causan aceleraciones, las altas velocidades locales del fluido al producir las partículas desplazamientos del mismo y la formación de agregados que permite que las partículas estén protegidas de la fuerza de arrastre del fluido. La ecuación de Richardson y Zaki (1954), permite describir las características de sedimentación en suspensiones concentradas [175], siendo una correlación para el cálculo de la velocidad terminal dependiente de la porosidad a granel:

$u=u_{i} \cdot \varepsilon^{n}$

Ecuación 4.24

Según la ecuación de Richardson and Zaki, el factor $n$ es una función del régimen de flujo, expresado en términos del número de $\mathrm{Re}_{\mathrm{t}}$, y de la relación entre el diámetro de la partícula y la columna como se muestra en la Tabla 4.4. El factor $\mathrm{u}_{\mathrm{i}}$ representa la extrapolación de la velocidad a una porosidad equivalente a la unidad.

\begin{tabular}{|l|l|}
\hline$R e_{t}<0.2$ & $n=4.65+19.5 d D$ \\
\hline $0.2<\operatorname{Re}_{t}<1$ & $n=(4.35+17.5 d D) R e_{t}^{-0.09}$ \\
\hline $1<R e_{t}<00$ & $n=(4.45+18 d / D) R e_{t}^{-01}$ \\
\hline $200<R e_{t}<500$ & $n=4.45 \operatorname{Re}_{t}^{-01}$ \\
\hline$R e_{l}>500$ & $n=2.39$ \\
\hline
\end{tabular}

Tabla 4.4. Valores recomendados para n por Richardson y Zaki.

El parámetro n es una función del número de Reynolds, pero no una función de la relación entre el diámetro de partícula y de columna como sugiere la relación de Rowe:

$$
\frac{4.7-n}{n-2.35}=0.175 \cdot \mathrm{Re}_{t}^{0.75}
$$

Ecuación 4.25

O en la relación propuesta por Khan and Richardson, que lo relaciona con el número de Arquímedes:

$$
\frac{4.8-n}{n-2.4}=0.043 \cdot A r^{0.57}
$$

Ecuación 4.26

\subsection{LECHO FLUIDIZADO CIRCULANTE}

\subsubsection{INTRODUCCIÓN}

La viabilidad de la gasificación de residuos con alto contenido en material plástico requirió un estudio previo sobre la tecnología a usar, es decir: fluidización. En las instalaciones del CEDER se dispone de un gasificador de lecho fluidizado burbujeante y un lecho fluidizado circulante. 
A través de un estudio bibliográfico extenso se encontraron diferentes correlaciones para estimar la velocidad mínima necesaria para fluidizar un lecho de partículas sólidas, al igual que la velocidad mínima necesaria para que se produzca el arrastre de partículas junto al gas de proceso.

El estudio fluido-dinámico se centró en una unidad circulante a temperatura ambiente y en una válvula no-mecánica tipo loop-seal clásico debido a la existencia de problemas de circulación de sólidos en el gasificador circulante de 0,5 MWth existente en el CEDER. Esta instalación había sido utilizada con anterioridad y había mostrado problemas relacionados con el retorno de partículas sólidas al sistema durante la operación.

Por el contrario, la otra instalación disponible en el CEDER es un gasificador de lecho fluidizado burbujeante. El estudio fluido-dinámico de un equipo semejante, generalmente, se realiza en base a propiedades de fluidización como: caída de presión, velocidad mínima de fluidización, formación de burbujas y arrastre de material de lecho. El estudio fluido-dinámico de una instalación burbujeante tipo no se consideró necesaria, ya que este equipo fue reconvertido a gasificador siendo su anterior uso como combustor de lecho fluidizado burbujeante. Por tanto, este equipo ha sido probado con garantía.

Además, al disponer de datos relativos a velocidad mínima de fluidización y velocidad terminal de los materiales de lecho se optó por elegir aquel cuyo diámetro de partícula es de $428 \mu \mathrm{m}$, para evitar fenómenos de atrición y elutriación, que pudieran reducir el inventario de sólidos.

\subsubsection{FLUJO DE SÓLIDOS AXIAL Y LATERAL EN EL RISER}

La distribución de partículas sólidas en un lecho fluidizado se origina debido al arrastre de partículas sólidas a través de un flujo de fluido ascendente en el riser, pudiéndose establecer perfiles axiales de porosidad y densidad.

El riser se puede dividir en diferentes zonas: zona de entrada, zona densa, zona de chapoteo o splash, zona de transporte o freeboard y zona de salida [176]. Los efectos de entrada y salida afectan a los perfiles axiales, por tanto la forma de la zona de salida, abrupta o suave, y la zona de entrada o de aceleración, que posee una elevada concentración de sólidos y que se sitúa por encima de la placa de distribución de gas, influyen notablemente en el transporte de partículas sólidas. Se produce un transporte de partículas sólidas en forma de flujo estable, desde la zona densa atravesando la zona de transporte hasta llegar de nuevo al lecho denso a través de un sistema de recirculación.

La cuantificación de las partículas sólidas arrastradas durante la operación del sistema permite determinar la distribución vertical de partículas sólidas. En el riser ocurren diferentes fenómenos de retromezcla que producen un declive de la concentración vertical de sólidos. La zona densa se asemeja a un lecho fluidizado burbujeante, que se modifica en función del aumento del caudal de gas de entrada, pudiendo llegar a desaparecer. Las partículas sólidas son expulsadas de la zona densa por arrastre de gas y mediante erupciones de burbujas que forman una zona de elevada retromezcla de partículas sólidas conocida como zona de chapoteo o splash, generalmente a través de la 
estela de burbujas o a través de la unión de burbujas originadas en la superficie de la zona densa.

El mecanismo que rige el fenómeno de retromezcla, es el retorno de una fracción de las partículas sólidas a la zona densa como consecuencia de un aumento de la velocidad terminal de las partículas por agrupamiento, es decir formación de clusters, o porque la velocidad del gas no es suficiente para producir el arrastre de partículas sólidas. El resto de partículas sólidas son arrastradas por encima de la zona de chapoteo por un flujo estable de gas saturado.

En esta zona, denominada zona de transporte, los fenómenos de retromezcla son el transporte de partículas desde el centro del riser hasta las paredes, lo que provoca un flujo descendente de sólidos en las cercanías de la pared, y el retorno de una fracción de partículas sólidas del centro del riser debido al agrupamiento de partículas, siendo este fenómeno de menor contribución a diferencia de lo ocurrido en la zona de chapoteo o splash donde es el fenómeno dominante.

Los perfiles axiales de densidad y porosidad decrecen debido a la transferencia de partículas sólidas desde el núcleo hacia las paredes, hasta que se alcanza la capacidad de transporte a saturación, donde se dispone de un flujo estable de gas y sólidos. Sin embargo, el efecto de salida puede modificar estos perfiles cambiando de perfiles tipo $S$ a perfiles tipo $\mathrm{C}$, con una mayor concentración de partículas sólidas a la salida.

Los perfiles laterales muestran una variación de la densidad de flujo de sólidos y de la densidad en la dirección horizontal. Un incremento de la fracción de sólidos se observa hacia la pared del riser a cualquier altura, ya que el gradiente de presión radial decrece desde el núcleo a la pared como fue medido por Chen and Weinstein (1993). En las regiones densas, el perfil que se observa es aproximadamente parabólico, como ocurre para risers estrechos y alargados, y en las zonas secciones más diluidas, se obtiene un perfil plano con un ratio altura/diámetro menor.
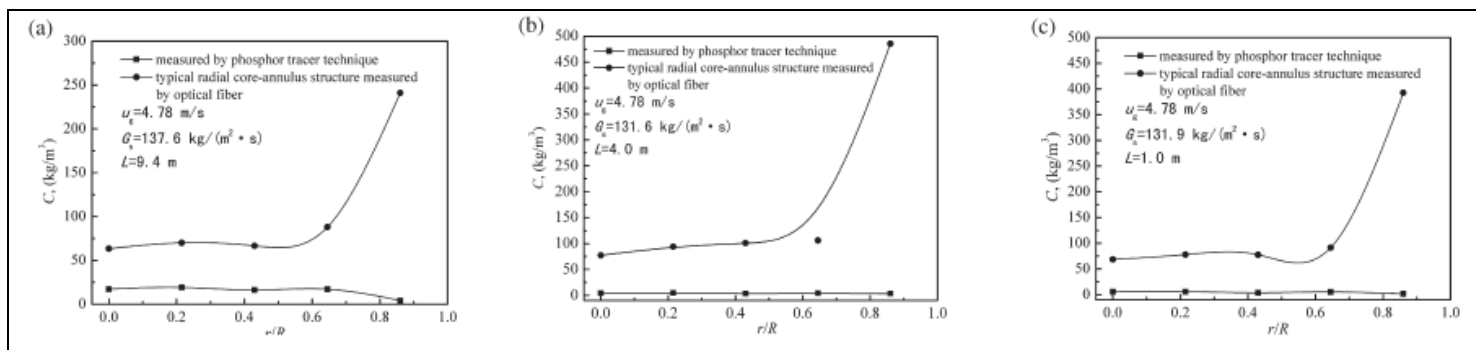

Figura 4.6. Perfiles laterales en el riser [167].

\subsubsection{Zona densa}

Las unidades de lecho fluidizado circulante comparten características comunes a las unidades de lecho burbujeante y a las de transporte pneumático, ya que en la parte inferior de una unidad circulante se forma un lecho fluidizado estacionario, que puede desparecer en función de la velocidad del gas y del inventario de sólido, mientras que en la parte superior, se produce el arrastre del material. La zona densa formada en la parte inferior, se caracteriza por un intenso burbujeo, semejante al que ocurre en un lecho fluidizado burbujeante, y la zona de transporte, conocida como freeboard, presenta arrastre de material semejante al generado debido a transporte pneumático. 
Uno de los primeros modelos para describir los fundamentos fluidodinámicos en un lecho fluidizado burbujeante, denominada teoría de las dos fases simple, fue propuesto por Toomey and Johnstone (1952). Las dos fases constan de una fase densa formada por agregados de partículas y una fase dispersa de elevadas velocidades de gas ascendente. El gas y las partículas sólidas son intercambiados constantemente entre ambas fases debido a la desintegración de los agregados de partículas y a la coalescencia de partículas sólidas de la fase dispersa.

La teoría de las dos fases fue desarrollada incialmente por Toomey and Johnstone (1952) [178], y mejorada por Shen and Johnstone (1955), Pansing (1956) y Lewis et al. (1959). El intercambio de gas entre la fase burbuja y la fase densa se representa a través de un coeficiente de transferencia en el modelo desarrollado. Las consideraciones que se derivan en la teoría de las dos fases implican la no consideración de una posible retromezcla de gas en la fase burbuja y el completo mezclado vertical o nula retromezcla de gas para la fase densa.

Posteriormente, la teoría de las dos fases fue modificada por May (1959) y van Deemter (1961), ya que se introduce el coeficiente de difusión vertical para la fase densa junto al intercambio en ambas fases [179]. Toomey and Johnstone (1952), asumieron que en la fase emulsión solamente entraba la cantidad requerida de gas para mantenerla fluidizada y que el exceso de gas pasaba a través del centro (core) del lecho, en forma de burbujas con velocidades bajas o cercanas a la velocidad de mínima fluidización [180], por tanto el lecho denso consta de una fase emulsión en un estado de mínima fluidización en el que coexisten burbujas libres de sólidos.

El exceso de gas requerido para mínima fluidización pasa al lecho en forma de burbujas o bolsas de gas [181]. Según la teoría de las dos fases, el flujo de gas suministrado a la base del riser se divide en el flujo que circula en la fase emulsión, que se corresponde con el requerido para mantener el material de lecho en mínima fluidización, por tanto $\mathrm{u}_{\mathrm{e}}=\mathrm{u}_{\mathrm{mf}}$, y el exceso de gas atraviesa el lecho en forma de burbujas siendo su velocidad:

$u_{v i s}=u-u_{m f}$

Ecuación 4.27

Como recoge Pallarés et al. (2006), la teoría de las dos fases sobreestima la expansión del lecho, y como consecuencia aparece un tercer término en el balance de flujo, denominado "throughflow", $\mathrm{u}_{\mathrm{tf}}$, que es el gas que fluye principalmente a través de pasos de gas de baja resistencia dentro y entre las burbujas [182]. El incremento del exceso de gas provoca un aumento del término "throughflow", y una reducción del término de flujo de burbuja visible.

$u=u_{m f}+u_{v i s}+u_{t f}$

Ecuación 4.28

Donde el flujo de burbuja visible,

$u_{v i s}=\delta_{b u b} \cdot u_{b u b}$

Ecuación 4.29

La caracterización de la fase dispersa, fase burbuja, se basa en una serie de expresiones como la correlación de Darton et al. (1979) para el crecimiento de burbuja y la velocidad de una sola burbuja de Davidson et al. (1977). Darton et al. (1977) muestran un modelo para determinar el tamaño de burbuja basándose en el crecimiento de la 
burbuja a medida que se incrementa con la altura de lecho. Este crecimiento se produce en base a la coalescencia de las burbujas en el lecho una vez que han recorrido una determinada distancia, por tanto el volumen no cambia por el aumento de la altura sino debido a la coalescencia de las burbujas:

$$
d_{\text {bub }}=0.54 \cdot\left(u_{0}-u_{m f}\right)^{0.4} \cdot\left(h+4 \cdot \sqrt{A_{0}}\right)^{0.8} \cdot g^{-0.2}
$$

Ecuación 4.30

Clift and Grace (1985), determinaron una correlación para el cálculo de la velocidad de una burbuja aislada en un lecho burbujeante libre [183], definiéndose dicha velocidad en un lecho infinito como:

$$
u_{b u b b o}=0.71 \cdot \sqrt{g \cdot d_{b u b}}
$$

La combinación de las anteriores ecuaciones permite la determinación de la velocidad de burbuja aislada:

$$
u_{\text {bubso }}=1.3 \cdot\left(u_{0}-u_{m f}\right)^{0.2} \cdot\left(h+4 \cdot \sqrt{A_{0}}\right)^{0.4}
$$

Ecuación 4.32

La corrección de esta velocidad teniendo en cuenta la presencia de otras burbujas, y el incremento en la velocidad relativa entre la burbuja ascendente y el flujo de sólidos descendente a su alrededor, se determina mediante la expresión siguiente:

$u_{b u b}=u_{v i s i b l e}+u_{b u b s}$

Ecuación 4.33

Aunque esta expresión está en entredicho porque la velocidad ascendente de una burbuja aislada ha llegado a ajustarse más fácilmente con valores experimentales.

La fracción de burbuja o densidad de burbuja se calcula aplicando la teoría de las dos fases modificada como propone Johnson et al. (1991):

$$
\delta_{b}=\frac{1}{1+\frac{u_{b \infty}}{u-u_{m f}-u_{t f}}}
$$

Ecuación 4.34

La expresión del flujo a través y entre las burbujas se obtiene a partir del gradiente de presiones, y la consideración de que la porosidad permanece constante a lo largo del lecho:

$u_{t f}=f_{1} \cdot\left(u-u_{m f}\right)$

Ecuación 4.35

La función $f_{1}$ depende de la altura, de la velocidad de fluidización, del tamaño de partícula etc.

$f_{1}=1-f_{2} \cdot\left(h+4 \cdot \sqrt{A_{0}}\right)^{0.4}$

Ecuación 4.36 
El parámetro $f_{2}$ se ajusta experimentalmente para el lecho estacionario de una unidad burbujeante,

$$
f_{S F B}=\left[0.26+0.70 \cdot \exp \left(-3.3 \cdot d_{p}\right)\right]\left[\left[0.15+\left(u_{0}-u_{m f}\right)\right]^{-1 / 3}\right.
$$

Ecuación 4.37

Los resultados obtenidos para valores de la velocidad de exceso de gas mayores de 2,5 $\mathrm{m} / \mathrm{s}$, por tanto la correlación es inexacta para unidades circulantes [184].

O de una unidad circulante [182],

$$
f_{C F B}=0.3121+0.129 \cdot u_{0}^{-1}-16.6 \cdot d_{p}-2.61 \cdot 10^{-5} \cdot \Delta P_{r e f}
$$

Ecuación 4.38

Donde $\mathrm{d}_{\mathrm{p}}$ es el diámetro de partícula en $\mathrm{mm}$.

La determinación de la fracción de burbuja a partir de los parámetros mencionados arriba permite obtener una expresión independiente de la altura:

$$
\delta_{b}=\frac{1}{1+\frac{1.3}{f_{2}} \cdot\left(U_{1}-U_{m f}\right)^{-0.8}}
$$

Hilligardt and Werther (1990), introdujeron el término adimensional denominado flujo de burbuja visible $(\psi)$, que indicaba la desviación del modelo de las dos fases modificado con respecto a sus datos experimentales:

$$
\begin{aligned}
& u_{v i s}=\psi \cdot\left(u-u_{m f}\right) \\
& u_{t f}=(1-\psi) \cdot\left(u-u_{m f}\right)
\end{aligned}
$$

Ecuación 4.40

Ecuación 4.41

Donde,

$$
\psi=f_{2} \cdot\left(h+4 \cdot \sqrt{A_{0}}\right)^{0.8}
$$

Ecuación 4.42

Basándose en el hecho de que el gradiente de presión es independiente de la posición vertical en el lecho, se pueden obtener los valores correspondientes a la porosidad local. La porosidad local se obtiene a través del gradiente de presiones:

$$
-\frac{d p}{d h}=\rho_{d z} \cdot g=\left(1-\varepsilon_{d z}\right) \rho_{p} \cdot g
$$

En el lecho denso se establece la relación entre la porosidad local media del lecho y la fracción de burbuja como:

$$
\varepsilon_{d z}=\delta_{b}+\varepsilon_{m f} \cdot\left(1-\delta_{b}\right)
$$

Ecuación 4.44

La porosidad de mínima fluidización se obtiene mediante la ecuación de Ergun (1952), una vez determinados los números adimensionales de Arquímedes y Reynolds. En base al estudio de las correlaciones, para el cálculo de la velocidad de mínima fluidización, 
encontradas en la literatura, se ha decidido optar por el cálculo del número de Reynolds mediante la ecuación de Grace (1992).

La determinación de la densidad de la suspensión a partir de la porosidad promedio en la zona densa se obtiene como:

$\rho_{x}=\rho_{d z}=\left(1-\varepsilon_{d z}\right) \cdot \rho_{p}$

Ecuación 4.45

$\rho_{x}$ se refiere a la densidad de la superficie libre del lecho, que se asume igual a la densidad en la zona densa debido a que la porosidad se considera constante en dicha zona.

La caída de presión en la zona densa se obtiene como la caída de presión de una columna vertical con sólidos:

$\Delta P_{d z}=\left(1-\varepsilon_{d z}\right) \rho_{p} \cdot g \cdot h_{d z}$

Ecuación 4.46

La masa de sólidos que se encuentra en la zona densa se calcula como:

$M_{d z}=\left(1-\varepsilon_{d z}\right) \rho_{p} \cdot g \cdot A_{g a s}$

Ecuación 4.47

\subsubsection{Zona de transporte}

El balance de flujo de sólidos en el centro del riser, en la zona de transporte, relaciona el flujo neto de sólidos ascendente, con el flujo neto de sólidos descendente y el flujo neto de sólidos lateral hacia la pared.

$$
F_{c, e n t}=F_{c, s a l}+F_{l a t}
$$

Ecuación 4.48

$$
\frac{m_{c, e n t}}{V} \cdot u_{s} \cdot A=\frac{m_{c, s a l}}{V} \cdot u_{s} \cdot A+\frac{m_{l a t}}{V} \cdot k \cdot \pi \cdot D_{e} \cdot h_{t z}
$$

Ecuación 4.49

Donde $\mathrm{D}_{\mathrm{e}}$ es el diámetro equivalente del centro del riser, $\mathrm{h}_{\mathrm{tz}}$ es la altura de la zona de transporte $\mathrm{y}_{\mathrm{c}, \text { ent }}, \mathrm{m}_{\mathrm{c}, \mathrm{sal}}, \mathrm{m}_{\mathrm{lat}}$ representan la masa de sólidos en cada corriente. El coeficiente de transferencia de sólidos neto se obtiene a partir del balance de flujo de sólidos, asumiendo una velocidad vertical de partículas sólidas constante [185], por tanto el flujo lateral de sólidos se puede escribir como:

$$
d F_{l}=\rho_{c} \cdot k \cdot\left(\pi \cdot D_{e}-8 \cdot \delta\right) \cdot d h
$$

Ecuación 4.50

Se asume que el espesor de la pared es mucho menor que la anchura del reactor de lecho fluidizado $(\delta<<\mathrm{L})$ y tras aplicar el balance de masa sobre un elemento de altura:

$$
d F_{c}+d F_{l}=0
$$

Ecuación 4.51

Se obtiene:

$$
\frac{-d F_{c}}{F_{c}}=\frac{4 \cdot k}{D_{e} \cdot u_{s}} d h
$$


Asumiendo que la velocidad de sólidos en el centro es independiente de la altura y que la variación vertical del área del centro es mínima, integrando la anterior ecuación desde una altura $h$ hasta una altura $h=\mathrm{H}_{\mathrm{t}}$ :

$$
F_{c}=\rho_{0} \cdot A_{c} \cdot u_{s o} \cdot \exp \left(\frac{4 \cdot k\left(H_{t}-h\right)}{u_{s} \cdot D_{e}}\right)
$$

Donde $\rho_{0} \mathrm{y} \mathrm{u}_{\mathrm{s} 0}$ son la densidad y la velocidad en la parte superior del riser. Siendo $K=4 \cdot k / u_{s} \cdot D_{e}$, el coeficiente de decaimiento de la zona de transporte.

La Figura 4.7 muestra el flujo de partículas sólidas en la zona de transporte de un lecho fluidizado. Se observa una distinción entre el flujo ascendente en el centro, $\mathrm{F}_{\mathrm{c}}$, y el flujo descendente en la pared, $\mathrm{F}_{\mathrm{w}}$.

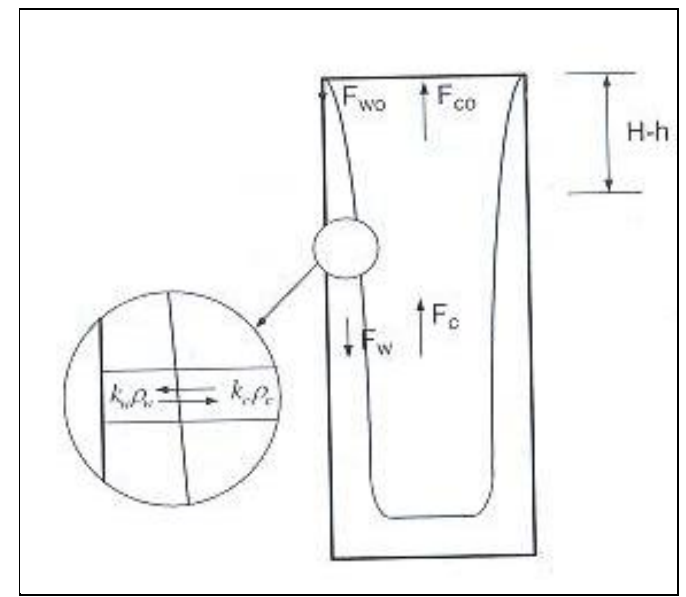

Figura 4.7. Flujo de partículas sólidas en la zona de transporte de un lecho fluidizado.

A cualquier altura se cumple la relación:

$$
F_{w}+F_{c}=F_{c 0}+F_{w 0}
$$

Ecuación 4.54

A partir de la relación entre el flujo ascendente y descendente en el centro, el flujo descendente en la pared es:

$$
F_{w}=F_{w 0}+F_{c 0} \cdot\left(1-\exp \left(K\left(H_{t}-h\right)\right)\right)
$$

Ecuación 4.55

Sin la existencia de efectos de salida a consecuencia de salidas de restricción débil en el riser, $\mathrm{F}_{\mathrm{w} 0}=0$ y $\mathrm{F}_{\mathrm{c} 0}=\mathrm{G}_{\mathrm{s}} \cdot \mathrm{A}$, que se corresponde con el flujo de sólidos neto. Sin embargo, la existencia de salidas abruptas o de elevada restricción al flujo de sólidos, provoca que una fracción de los sólidos retorne al riser [186]. Los flujos de sólidos ascendente y descendente experimentan un cambio como refleja Johnsson et al. (1995) en base a la tasa neta de sólidos:

$$
\begin{aligned}
& F_{w 0}=-k_{b} \cdot G_{s} \cdot A \\
& F_{c 0}=\left(1+k_{b}\right) G_{s} \cdot A
\end{aligned}
$$$$
\text { Ecuación } 4.56
$$ 
Un riser con salida abrupta funciona como un separador inercial con una eficiencia $\eta_{\mathrm{sep}}=\mathrm{k}_{\mathrm{b}} /\left(1+\mathrm{k}_{\mathrm{b}}\right)$. Por tanto, el flujo descendente de sólidos en la pared queda como:

$$
F_{w}=A \cdot G_{s} \cdot\left[1-\left(1+k_{b}\right) \exp (-K(h-H))\right]
$$

Ecuación 4.58

Existen diferentes modelos para describir los fenómenos de retromezcla, que incrementan el tiempo de residencia de las partículas sólidas [187], que ocurren en la zona de transporte de un riser. Kunni and Levenspiel (1991), en su modelo para un lecho fluidizado burbujeante expresaron la distribución vertical de sólidos [188] como:

$$
\rho=\rho_{\text {sal }}+\left(\rho_{x}-\rho_{\text {sal }}\right) \exp \left[-a \cdot h_{f}\right\rfloor
$$

Ecuación 4.59

Lewis et al. (1962), para partículas sólidas finas y agrupamientos, llegaron a la conclusión de que el coeficiente de decaimiento para lechos fluidizados burbujeantes [189] se podía escribir como:

$a \cdot u_{s} \approx c t e$

Ecuación 4.60

Este modelo se ha demostrado válido para emplearlo en lechos fluidizados circulantes. Sin embargo, en condiciones de circulación existe otra contribución adicional al fenómeno de retromezcla, que hace que la determinación de las constantes de decaimiento adquiera un significado físico relacionado con el mecanismo dominante, evitando de esta manera lo que ocurre en otros modelos donde se corta claramente la región de chapoteo o splash de la región de transporte. Johnsson and Leckner (1995), establecieron un modelo que contemplaba ambos mecanismos en cualquier altura, ya que el solape entre regiones se realiza de manera natural y consistente [190], evitando distinciones artificiales para separar ambas regiones.

$$
\rho_{f b}(h)=\left(\rho_{b x}\right) \exp \left(-a \cdot\left(h-H_{x}\right)\right)+\rho_{\text {sal }} \cdot \exp \left(K \cdot\left(H_{g a s}-h\right)\right) \quad \text { Ecuación } 4.61
$$

Donde a y K son los coeficientes de decaimiento que corresponden a los fenómenos de retromezcla para la zona de chapoteo o splash y para el flujo centro/pared de la zona de transporte.

Una correlación basada en medidas experimentales fue sugerida para el coeficiente de decaimiento de la zona de transporte:

$$
K=0.23 /\left(u_{0}-u_{t}\right)
$$

Ecuación 4.62

No obstante, existen distintas correlaciones experimentales para el cálculo de la constante de decaimiento en la zona de transporte [191, 192].

Para la zona de chapoteo (splash) el coeficiente de decaimiento se determina según:

$$
a=c \cdot \frac{u_{t}}{u_{s}}
$$


Johnsson and Leckner (1995) sugirieron un valor de $\mathrm{c}=4 \mathrm{~m}^{-1}$, aunque los resultados experimentales de Löffler et al. (2003) casan mejor casan mejor con un valor de $c=10$ $\mathrm{m}^{-1}$.

$\rho_{\mathrm{bx}}$ se refiere a la densidad de la suspensión en la superficie del lecho si el arrastre de partículas sólidas se debiera a fenómenos de coalescencia de burbujas y formación de aglomerados, sin tener en cuenta el arrastre de material. En las cercanías de la superficie libre de lecho su importancia relativa disminuye de manera que:

$\rho_{b x}=\rho_{x}-\rho_{o x}$

Ecuación 4.64

Por tanto, la contribución de la corriente de arrastres originada por el transporte en fase dispersa, se determina como:

$$
\rho_{\text {trans }}=\rho_{\text {sal }} \cdot \exp \left(K \cdot\left(H_{\text {gas }}-h\right)\right)
$$

Ecuación 4.65

$\rho_{\text {sal }}$ se refiere a la densidad de la suspensión a la salida del freeboard. La determinación de este parámetro no puede realizarse teóricamente, ya que depende de condiciones de operación, geometría, etc. La corriente en la parte superior del freeboard se considera suficientemente diluida para que la velocidad de las partículas se pueda calcular como $\mathrm{u}_{\mathrm{p}}=\mathrm{u}_{\mathrm{s}}-\mathrm{u}_{\mathrm{t}}$ :

$$
\rho_{\text {sal }}=\frac{b \cdot\left(1+k_{b}\right) G_{s}}{\left(u_{s}-u_{t}\right)}
$$

Ecuación 4.66

El parámetro b que expresa la relación entre la densidad media en una sección y la que existe en la zona central o núcleo del riser ha sido estudiada por diferentes autores como Zhang et al. (1993) dándole el valor de $b=2$, y Seiter (1990) que indicó que el annulus es 2.3 superior al valor de la densidad media y el centro o núcleo es 0.8 veces esta densidad media.

La determinación de una cota inferior para estimar el rango de valor de $\rho_{\text {sal }}$ se realiza a partir de $\rho_{\infty}$, que es la densidad de la suspensión que se alcanzaría en una unidad hipotética que sea lo suficientemente alta como para que la densidad de la corriente ascendente dejara de variar con la altura, superior a la denominada TDH. Esta determinación se realiza a partir de la constante de elutriación $\mathrm{K}_{\infty}$.

$$
\rho_{\infty}=\left(1-\varepsilon_{\infty}\right) \rho_{p}=\frac{K_{\infty}}{\left(u_{s}-u_{t}\right)}
$$

Ecuación 4.67

Para la determinación de la $\mathrm{K}_{\infty}$, se emplea la correlación de Colakyan and Levenspiel (1984) [193].

$$
K_{\infty}=0.011 \cdot \rho_{p} \cdot\left(1-\frac{U_{t}}{U_{r i s}}\right)^{2}
$$

Ecuación 4.68

No obstante, la constante de elutriación se puede determinar empleando diversas correlaciones [194, 195]. 


\subsubsection{Zona de salida}

La fluidodinámica de una unidad circulante está influenciada por la conexión de salida empleada en el riser, la configuración interna que disponga dicha conexión, es decir la presencia o no presencia de deflectores que modifiquen el patrón de flujo, y el área de salida de la conexión, ya que modifican la recirculación interna de sólidos. Estas apreciaciones se pueden hacer en las distribuciones de porosidad y de presiones axiales en el riser.

Las conexiones de salida del riser pueden clasificarse en estructuras de salida con restricciones elevadas, abruptas, y estructuras de salida con restricciones débiles. Las salidas con restricción débil, originan tiempos de residencia de partículas sólidas cortos y uniformes, que permiten flujos de operación de partículas sólidas elevados, mientras que las salidas abruptas, que en general son conexiones de $90^{\circ}$ en lugar de conexiones curvadas como las anteriormente mencionadas, aumentan el reflujo interno de partículas sólidas. Además, las salidas abruptas pueden disponer de extensiones que finalizan en tapas o caperuzas encima de la conexión de salida.

En la figura 4.8 se observan las distintas configuraciones, tanto de salidas de restricción débil, como abruptas. La configuración de la conexión de salida, por tanto va a influir notablemente en la distribución de partículas sólidas en la parte superior del riser, como detectó Lim et al. (1995) debido a que una restricción fuerte daba como resultado un perfil axial de concentración de sólidos con forma de C.

De acuerdo con el trabajo de Zheng and Zhang (1994), las salidas abruptas tendrán una influencia relativa en el perfil de presiones en la parte superior del riser, modificándose aún más si dispone de caperuzas en la parte superior de la conexión, que incrementarían la caída de presión, no ocurriendo en el caso de salidas de restricción débil, aunque este comportamiento no ha sido detectado en el trabajo realizado por Johnsson et al. (1999), en el que se probaron distintas configuraciones de conexión abrupta junto con sus correspondientes deflectores, siendo su influencia mínima [196].

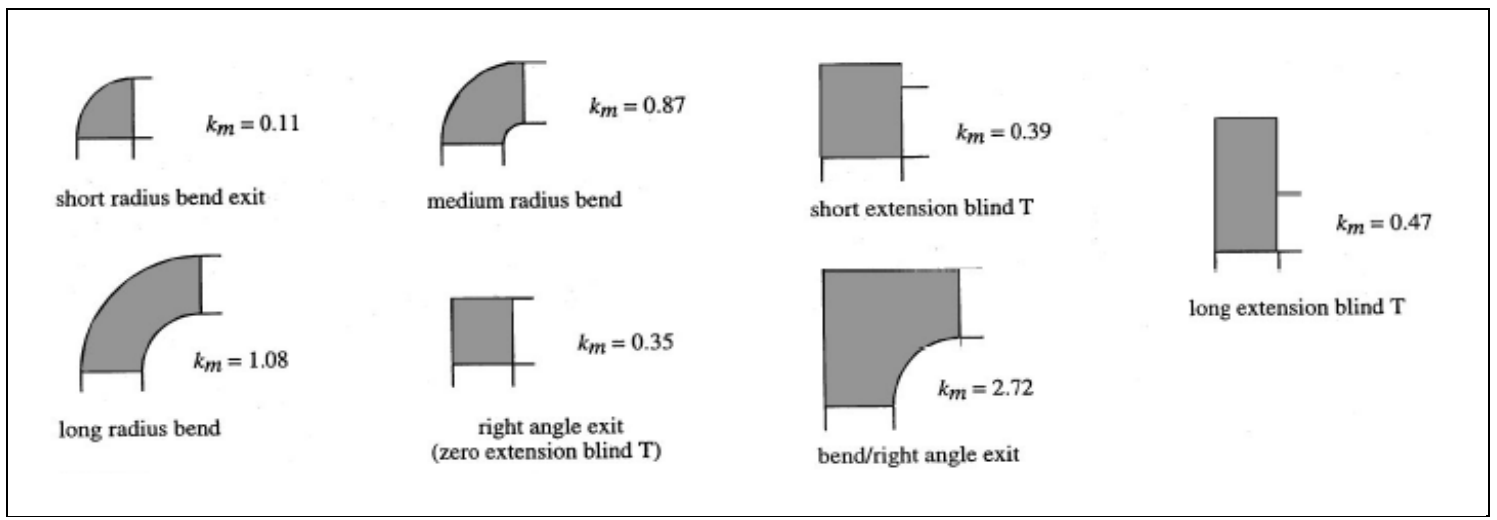

Figura 4.8. Tipos de configuraciones de las conexiones de salida del riser junto con los valores de la tasa de reflujo de cada una de ellas [197].

Existen distintas maneras de contabilizar y clasificar el efecto de la geometría de salida provocado por las diferentes configuraciones de conexiones de salida existentes. Brereton (1987) y Senior (1992), emplearon un coeficiente de reflexión, $\mathrm{R}_{\mathrm{f}}$, que mostraba el ratio del flujo de sólidos descendente frente al flujo de sólidos ascendentes. 
Van der Meer et al. (2000), definió una tasa de reflujo en base a medidas radiales locales de flujo de partículas sólidas [198]:

$k_{m}=\frac{\text { Flujo descendente sólidos recodo de salida }}{\text { Tasa externa circulación sólidos }}$

Ecuación 4.69

Su definición en semejanza a una columna de destilación se expresa como:

$k_{m}=\frac{M_{s a}}{M_{s}}=\frac{M_{s c}-M_{s}}{M_{s}}$

Ecuación 4.70

Donde $\mathrm{M}_{\mathrm{s}}$ corresponde a la tasa externa de circulación de sólidos, $\mathrm{M}_{\mathrm{sa}} \mathrm{y} \mathrm{M}_{\mathrm{sc}}$, son los flujos descendente y ascendente en annulus y core, respectivamente. La tasa de reflujo $\mathrm{k}_{\mathrm{m}}$ se relaciona con el concepto de coeficiente de reflexión mediante la siguiente expresión [199]:

$R_{f}=\frac{k_{m}}{1+k_{m}}$

Ecuación 4.71

El reflujo de sólidos que se origina en las proximidades de salida del riser ha sido explicado por diversos mecanismos físicos. El patrón de flujo del gas a la salida del riser experimenta pequeñas variaciones en función de la geometría de la conexión de salida. La distribución de porosidad axial en el riser permite explicar de manera adecuada la influencia de las conexiones de salida del riser.

Con respecto a la conexión de salida de restricción débil, este tipo de salida prácticamente no influye en dicha distribución, ya que se observa un perfil con forma de $\mathrm{S}$, que se corresponde con baja porosidad en la sección inferior del lecho, y elevada porosidad en la sección superior del lecho.

En cuanto a la conexión de salida con restricción elevada, Bai et al. (1992) explicaron el comportamiento del flujo de sólidos en las proximidades de una salida abrupta con caperuza a través de la existencia de tres regiones diferenciadas. En este caso se observa un perfil de distribución axial de la porosidad media en forma de $\mathrm{C}$, que muestra alta y baja porosidad en las zona media y de salida, respectivamente [180].

Estas regiones se clasifican en:

\section{- Región de retorno de sólidos}

Esta región se encuentra situada a la salida del riser. Se produce el choque de las partículas sólidas con la caperuza de salida del riser debido la inercia, lo que provoca la acumulación de sólidos en esta región. Parte de estos sólidos son arrastrados por el flujo de gas hacia la salida, formándose una corriente de flujo descendente de partículas sólidas con el resto. 
En esta región, el flujo descendente de sólidos proveniente de la caperuza de salida, que interacciona con el flujo ascendente de sólidos, pudiéndose unir a la corriente de sólidos principal.

\section{- Región de fluidización rápida}

En esta región la influencia del flujo de sólidos descendente como consecuencia de la conexión abrupta de salida desaparece, teniéndose una distribución usual de la porosidad media axial.

Van der Meer (1997) explicó el flujo de sólidos en la salida del riser mediante el número de Froude, que representa la relación entre la aceleración centrífuga y la aceleración debida a la gravedad:

$$
F r=\frac{u_{r}^{2}}{g \cdot R}
$$

Ecuación 4.72

Van der Meer (1997) postuló que las partículas sólidas recorrían un camino curvo en su salida del riser, por tanto la aceleración centrífuga actuando hacia el centro de la conexión podría ser igualada con la aceleración de la gravedad. Elevados valores del número de Froude indican un flujo de sólidos hacia el exterior de la conexión, mientras que bajos valores implican un flujo de sólidos hacia el interior de la conexión. El reflujo mínimo de sólidos se produce cuando se encuentran igualadas la fuerza gravitacional y la aceleración centrífuga.

La Figura 4.9, muestra el mecanismo de reflujo de sólidos de acuerdo al concepto de número de Froude, centrándose en el reflujo de sólidos desde el interior de la conexión debido a la acumulación de sólidos en su interior que caerá formado una capa de sólidos a lo largo de la pared en el riser y el retorno de sólidos desde las caperuzas situadas en la parte superior del riser, pudiendo ser extendidas, debido a la separación inercial de las partículas sólidas, y el movimiento hacia el exterior de la conexión.

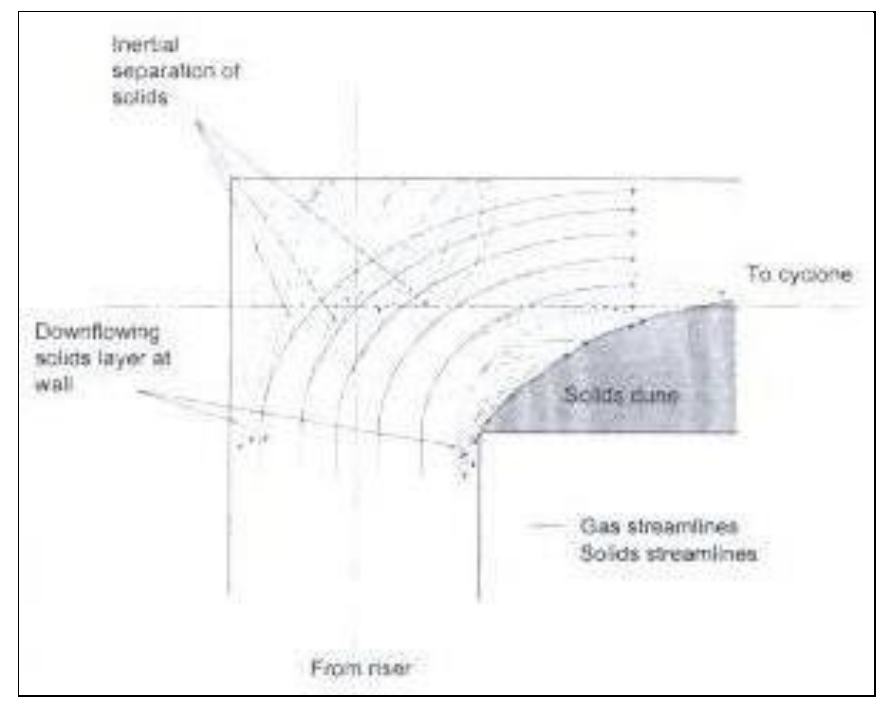

Figura 4.9. Mecanismo físico del reflujo de sólidos debido a la conexión de salida del riser [196]. 


\subsubsection{Separador gas/sólido}

Los ciclones son equipos que permiten separar partículas sólidas en corrientes gaseosas. Su reducido coste y mantenimiento hace que sea extendido su utilización para el control de partículas sólidas en unidades de lecho fluidizado circulante [200].

El ciclón consta de una cámara de separación cilíndrica, donde el gas cargado de partículas sólidas penetra de manera tangencial. Las dimensiones de la entrada de sección transversal se reducen para acelerar el flujo y obtener elevadas velocidades de entrada al ciclón, siendo generalmente de forma rectangular. Tras la sección cilíndrica de entrada se encuentra una sección cónica del cilindro se estrecha hasta su salida. La parte superior de un ciclón consta de una tapa, atravesada por el tubo de salida. Debido a su inercia, las partículas sólidas se desplazan hacia la pared exterior del separador, desde la cual son conducidas a un receptor. La salida de las partículas sólidas se produce a través de una abertura central, que es una ampliación del tubo de salida que se denomina canalizador de vórtice.

La correcta operación de este tipo de equipos de separación se basa en la eficiencia de recogida de partículas sólidas, que está relacionada íntimamente con su diseño, Figura 4.10, y la caída de presión a través del ciclón, relacionada con la operación.

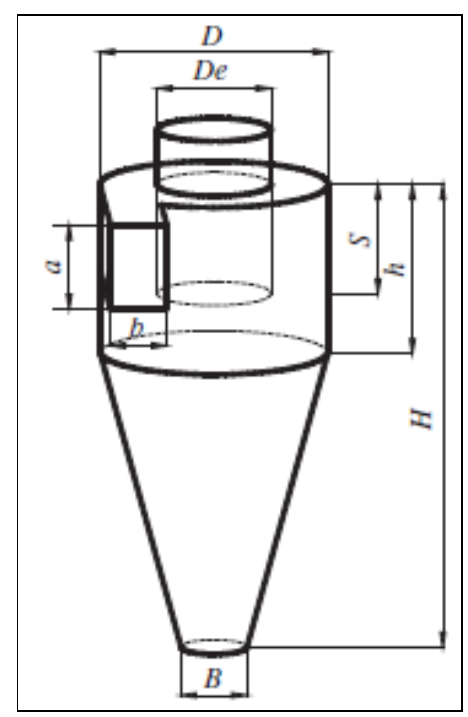

Figura 4.10. Esquema ciclón [200].

La longitud del canalizador de vórtice es de gran importancia en la predicción de la eficiencia de un ciclón, sobre todo en ciclones cortos. La eficiencia de un ciclón se ve incrementada al aumentar su longitud hasta un cierto tamaño, tras el cual comienza a decrecer [201].

La caída de presión en un ciclón es un parámetro que indica la cantidad de trabajo necesario para operar el ciclón en unas determinadas condiciones. Ésta consiste en la caída de presión en la entrada, en la salida y en el interior del ciclón. El 80\% de la caída de presión en un ciclón se genera a consecuencia de disipación de energía debido al flujo turbulento en el interior del ciclón, y el $20 \%$ restante debido a la geometría de salida, la expansión en la entrada y la fricción en su superficie [202]. 
Existen estudios que indican que la caída de presión en un ciclón se ve reducida por un descenso en la velocidad tangencial de gas originada por la presencia de depósitos de partículas sólidas en las paredes del ciclón [203] o debido al aumento del coeficiente de fricción con la pared, la concentración de sólidos o la longitud del ciclón [204].

La determinación de las relaciones existentes entre la caída de presión y las características del ciclón requieren del empleo de modelos matemáticos. Los modelos matemáticos que se emplean se clasifican según el método de investigación en: modelos teóricos o semi-empíricos, modelos estadísticos y modelos CFD. Inicialmente, se desarrollaron modelos teóricos o semi-empíricos que fueron desarrollados por diferentes investigadores como Barth (1956), Shepherd and Lapple (1939), Alexander (1949), Avci and Karagoz (2001) y Zhao (2004), derivados de relaciones físicas y matemáticas.

La predicción de la caída de presión en un ciclón también se ha llevado a cabo a través de diferentes modelos, como los estadísticos, que surgen a partir de datos experimentales de ciclones con distintas configuraciones como los empleados en los 1980s por Casal and Martínez-Benet (1983) y Dirgo (1988). La mayor dificultad radica en la búsqueda de una correlación que sea capaz de ajustar los datos experimentales de que se dispone, a pesar de que este tipo de modelos predigan eficazmente la caída de presión.

Con posterioridad, aparecen modelos CFD a través de Fluent, para predecir los efectos de la temperatura y la velocidad de entrada al ciclón, como el desarrollado por Gimbun et al. (2005).

La caída de presión en un ciclón depende tanto de la geometría del ciclón, como de las condiciones de operación, por tanto se puede definir normalmente la caída de presión como proporcional a la velocidad de entrada al ciclón [205]:

$\Delta P=\frac{1}{2} \cdot \alpha \cdot \rho_{g} \cdot u_{i}^{2}$

Ecuación 4.73

Existen diferentes correlaciones en literatura mediante las que se puede predecir la caída de presión en un ciclón como la correlación de Shepherd and Lapple (1939),

$\alpha=16 \cdot \frac{a \cdot b}{D_{e}^{2}}$

Ecuación 4.74

O la de Coker (1993),

$\alpha=9.47 \cdot \frac{a \cdot b}{D_{e}^{2}}$

Ecuación 4.75

La correlación de Alexander (1949), que fue desarrollada para aire y gases de combustión por encima de $1100^{\circ} \mathrm{C}$ :

$$
\alpha=4.62 \cdot\left(\frac{a \cdot b}{D_{c} \cdot D_{e}^{2}}\right) \cdot\left[\left(\left(\frac{D_{c}}{D_{e}}\right)^{2 \Pi}-1\right) \cdot\left(\frac{1-n}{n}\right)+f_{g} \cdot\left(\frac{D_{c}}{D_{e}}\right)^{2 \Pi}\right]
$$


Las correlaciones de Barth (1956) y de Muschelknautz and Kambrock (1970), que tiene en cuenta la caída de presión en el interior del ciclón y en el canalizador de vórtice:

$$
\begin{aligned}
& \alpha=\left(\frac{a \cdot b}{\Pi \cdot D_{e}^{2} / 4}\right)^{2} \cdot\left(\alpha_{c}+\alpha_{c v}\right) \\
& \alpha=\left(\frac{a \cdot b}{\Pi \cdot D_{e}^{2} / 4}\right) \cdot\left(\alpha_{c}+\alpha_{c v}\right)
\end{aligned}
$$

Ecuación 4.78

Otros modelos empíricos se basan en el análisis estadístico de datos experimentales como el de Casal and Martínez (1983),

$$
\alpha=11.3 \cdot\left(\frac{a \cdot b}{D_{e}^{2}}\right)^{2}+3.3
$$

O el de Dirgo (1988), donde $\alpha$ es función de las dimensiones del ciclón

$$
\alpha=20 \cdot\left(\frac{a \cdot b}{D_{e}^{2}}\right) \cdot\left[\frac{S / D}{((H / D) \cdot(h / D) \cdot(B / D))}\right]
$$

La correlación empírica de Perry (1988) tiene una configuración similar a las correlaciones empíricas anteriormente citadas. Sin embargo, como se muestra en la figura 4.11 estima un valor de la caída de presión superior al resto de las correlaciones estudiadas, pero próxima a los datos experimentales obtenidos en el modelo de unidad circulante a temperatura ambiente.

$$
\Delta P_{c}=K_{c} \cdot \rho_{g} \cdot U_{r}^{2}
$$

Ecuación 4.81

Donde el parámetro $\mathrm{K}_{\mathrm{c}}$ depende principalmente de la geometría del ciclón.

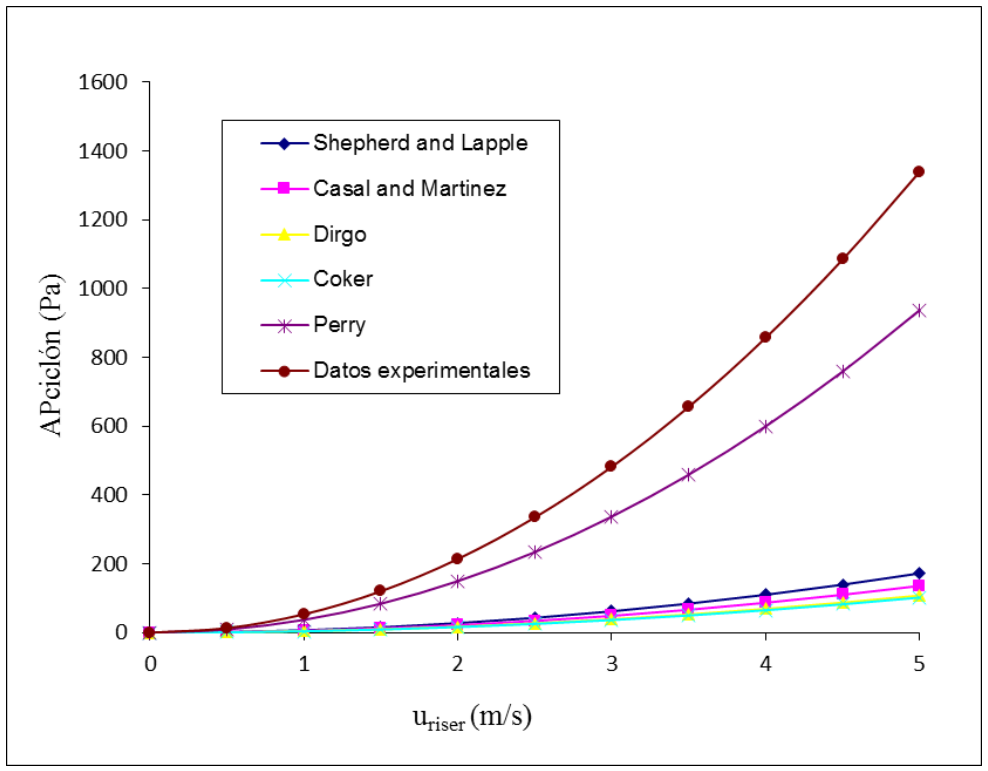

Figura 4.11. Correlaciones para la estimación de la pérdida de carga en un ciclón. 


\subsubsection{Sistemas de retorno válvula no-mecánica}

El movimiento de las partículas sólidas en los reactores de lecho fluidizado circulante se lleva a cabo mediante el empleo de un sistema de recirculación de sólidos, siendo el componente clave en el bucle de circulación. El sistema de recirculación de sólidos mueve las partículas sólidas desde la zona de baja presión, que se corresponde con el sistema de separación gas-sólido, hasta la zona de alta presión, que se corresponde con la parte inferior del riser, evitando el flujo directo de gas desde la parte inferior del riser al ciclón.

El empleo de válvulas no mecánicas en lugar de válvulas mecánicas que posibiliten la operación de la unidad circulante se debe a su robustez, coste, y facilidad de construcción debido a la ausencia de partes móviles. Además, las elevadas tasas de recirculación de sólidos requeridas y elevadas temperaturas de operación reducen la posibilidad de empleo de válvulas mecánicas [206]. La tasa de flujo de sólidos se controla mediante la aireación y la forma geometría de la válvula. Las partículas sólidas fluyen a través de la válvula debido a fuerzas de arrastre en las partículas, originadas por la aireación de gas [207].

Las partículas sólidas fluyen cuando las fuerzas de arrastre originadas por la aireación son mayores que la resistencia que mantiene a los sólidos unidos, debiéndose superar un valor umbral de aireación. Las válvulas no-mecánicas empleadas para control de flujo requieren tamaños de partículas superiores a las $100 \mu \mathrm{m}$ para densidades de partícula de $2500 \mathrm{~kg} / \mathrm{m}^{3}$ [207], es decir partículas sólidas pertenecientes a los grupos B y D. Las partículas sólidas del grupo A no defluidizan instantáneamente tras parar la inyección de aire de fluidización, lo que hace que su comportamiento a través de la válvula no mecánica sea difícilmente controlable, y las partículas sólidas pertenecientes al grupo $\mathrm{C}$ forman canales preferentes al fluidizarlas.

Existen diferentes tipos de válvulas no mecánicas empleadas en las unidades circulantes para la recirculación de partículas sólidas, ver Figura 4.12. Las válvulas no mecánicas empleadas a tal efecto son: válvula tipo L (L-valve), válvula tipo J (J-valve), válvula tipo $\mathrm{N}$ (N-valve), válvula tipo $\mathrm{V}$ (V-valve), y válvulas tipo loop-seal o seal pot, éstas últimas son de mayor tamaño y requieren una mayor cantidad de aireación.

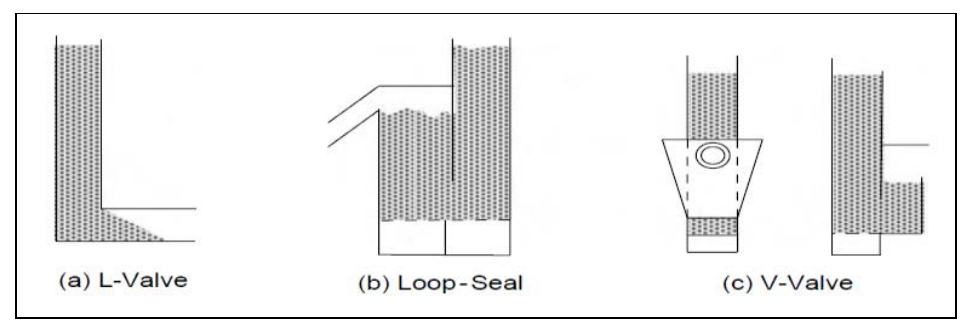

Figura 4.12. Válvulas no mecánicas [74].

\subsection{Válvula no-mecánica}

\subsection{Loop-seal}

Esta válvula no mecánica está formada por dos secciones, una cámara de aprovisionamiento que transfiere las partículas sólidas a una cámara de recirculación que los envía al riser a través de una tubería de recirculación. 
Las partículas sólidas de la cámara de aprovisionamiento se mueven horizontalmente a través de una sección horizontal que separa ambas cámaras hasta llegar a la cámara de recirculación. Existen diferentes configuraciones para este tipo de válvula difiriendo en la existencia o no existencia de un tramo horizontal entre ambas cámaras.

La no existencia de tramo horizontal, muestra la separación entre ambas cámaras a través de un deflector como se observa en la Figura 4.13. En la cámara de recirculación se produce la fluidización de las partículas sólidas para permitir su paso por rebose hacia la tubería de reciclo, mostrando un comportamiento semejante a un líquido.

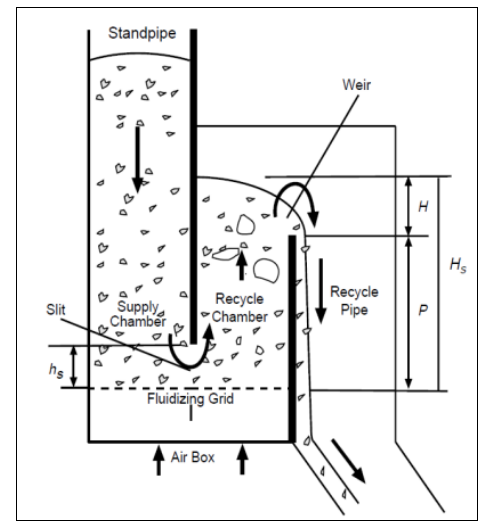

Figura 4.13. Aireación en una válvula tipo-L [74].

\subsection{1 Tramo horizontal}

De acuerdo al trabajo de Basu y Butler (2009), la longitud de la conexión del tramo horizontal entre las cámaras de aprovisionamiento y reciclo del loop-seal afecta considerablemente al flujo de partículas sólidas [208]. La caída de presión por unidad de longitud en la conexión de tramo horizontal se incrementa a medida que se incrementa su longitud, incrementándose el caudal de aireación mínimo para el movimiento de las partículas sólidas.

El ángulo de reposo de las partículas sólidas no se modifica significativamente hasta que se alcanza la velocidad de mínima fluidización, lo que implica que se requiere aumentar la aireación hasta superar este valor, permitiendo vencer las fuerzas de fricción inter-partícula, que se ve reducida al aumentar la esfericidad de las partículas sólidas, para posibilitar el movimiento de sólidos. Un aumento de la longitud de la conexión provoca una mayor restricción al paso de sólidos y por tanto, se transportará una menor cantidad de sólidos para un caudal de aireación determinado. Siempre y cuando el ángulo de reposo sea suficientemente pequeño y el tramo horizontal suficientemente corto, se puede considera la configuración del loop-seal con abertura como el caso de una loop-seal sin tramo horizontal.

La rama de retorno no requiere ser fluidizada. Solamente necesita de una reducida cantidad de aire para operación con partículas de los grupos A y B según la clasificación de Geldart (1973). La recirculación de partículas sólidas se incrementa al disminuir el tamaño de partícula. Para partículas sólidas de amplio rangos de tamaño, se observa que los sólidos finos mejoran las características de fluidización de las partículas gruesas [209]. 


\subsection{2 Reparto en el loop-seal}

El trabajo de Cheng and Basu (1999) para conocer el comportamiento del sistema de recirculación en el movimiento de sólidos, fue realizado variando el flujo en ambas cámaras. Se observa un aumento del flujo de sólidos al aumentar la aireación en la cámara de aprovisionamiento. Este flujo de aire colabora en el movimiento horizontal de sólidos entre ambas cámaras, solamente empleándose un pequeño caudal para la rama de retorno, que fue del orden del 9,5\% del caudal de aireación total a través del loop-seal, de manera que se forma un lecho empaquetado en esta rama. Las partículas sólidas en la rama de retorno no se encuentran fluidizadas para asegurar una operación suave en el loop-seal, consiguiéndose una altura adecuada de sólidos que se mantiene para compensar las caídas de presión existentes en el resto de la unidad circulante.

No obstante, el comportamiento del sistema de recirculación de una unidad circulante provoca que para bajas tasas de flujo de sólidos, la aireación en la cámara de aprovisionamiento sea tal, que la velocidad superficial del aire permanece bajo la requerida para mínima fluidización, siendo empleado el resto del flujo de aire en el transporte de sólidos a través de la conexión de tramo horizontal, mientras que para elevadas tasas de flujo de sólidos, el flujo de aireación de la cámara de aprovisionamiento fluye junto con aire arrastrado por los sólidos en la rama de retorno.

Además, inyectando aire exclusivamente en la cámara de aprovisionamiento se consigue un reducido flujo de sólidos a consecuencia de una distribución no uniforme de aire y el aire adicional en la cámara de aprovisionamiento. El flujo de sólidos se incrementa al aumentar la aireación en la cámara de recirculación, pero para un cierto valor de la aireación se nivela el flujo de sólidos, es decir se hace constante [210, 211].

El reparto del flujo de aire a través del loop-seal se basa en un coeficiente de reparto, $\mathrm{R}_{\mathrm{ls}}$, como el obtenido por Cheng y Basu (199) en sus experimentos:

$$
Q_{l s}=Q_{s p}+Q_{d c}
$$

Ecuación 4.82

$Q_{d c}=R_{l s} \cdot Q_{l s}$

Ecuación 4.83

$Q_{s p}=\left(1-R_{l s}\right) \cdot Q_{l s}$

Ecuación 4.84

$\mathrm{R}_{\mathrm{ls}}$ sería muy cercano a 0.5 si $\mathrm{Adc}=\mathrm{Asp}$, o si el caudal de sólidos fuera demasiado pequeño, haciendo que el arrastre de gas por el movimiento neto de sólidos fuera despreciable. No obstante, el coeficiente de reparto influye muy poco en las pérdidas de carga de la unidad circulante.

\subsection{3 Caída de presión}

El paso de sólidos entre las cámaras de aprovisionamiento de sólidos y la cámara de recirculación se produce a través de una abertura en la separación entre ambas cámaras. La caída de presión a través de la abertura puede determinarse como la caída de presión entre dos lechos fluidizados conectados [209]. Esta caída de presión tiene en cuenta las contribuciones debidas al flujo de gas y al flujo de sólidos:

$$
\Delta P_{l s h o r}=k_{l s} \cdot f\left(G_{s}\right)+\frac{1}{2} \cdot f_{g} \cdot \rho_{g} \cdot u_{h o r}^{2}
$$

Ecuación 4.85 
Donde $\mathrm{k}_{\mathrm{ls}}$ es un parámetro que depende de la geometría del loop-seal, $f_{g}$ es el factor de fricción del gas y $\mathrm{u}_{\text {hor }}$ es la velocidad en el tramo horizontal.

El segundo término correspondiente a la caída de presión por fricción del gas en la abertura, es desdeñable en comparación con el primer término en las condiciones de operación de un loop-seal. La determinación de la caída de presión en este tramo horizontal que separa ambas cámaras se ha llevado a cabo empleando distintas correlaciones como la de Kuramoto (1986) [210], que no tiene en cuenta las propiedades de las partículas para valores bajos de $\mathrm{G}_{\mathrm{s}}$ :

$$
\Delta P_{l s h o r}=0.66 \cdot\left(\frac{A_{a}}{A_{s p}}\right)^{-1.2} \cdot G_{s}
$$

Ecuación 4.86

Kim et al. (2002) propusieron una correlación para determinar la caída de presión en el loop-seal, que está basada en las características de operación, ya que correlacionaron los datos experimentales obtenidos con los grupos adimensionales Reynolds, Froude modificado y el cociente entre la densidad del sólido y el gas [212]:

$$
\Delta P_{\text {lshor }}=1.8 \cdot 10^{-5} \cdot\left[\frac{\left(G_{s} / \rho_{s}\right)^{2}}{d_{p} \cdot g}\right]^{0.4} \cdot\left[\frac{G_{s} \cdot d_{p}}{\mu}\right]^{-0.36} \cdot\left[\frac{\rho_{s}}{\rho_{g}}\right]^{2.88}
$$

Ecuación 4.87

La operación en la cámara de recirculación de un loop-seal se realiza por encima de la velocidad de mínima fluidización de las partículas sólidas que en ella se encuentran. La altura de la columna viene fijada por la altura a la que está situado el rebosadero. La caída de presión en la cámara de recirculación se puede determinar como la caída de presión que hay en una columna vertical de sólidos:

$\Delta P_{d c}=\left(1-\varepsilon_{l s}\right) \cdot \rho_{p} \cdot h_{r} \cdot g$

Ecuación 4.88

Lim et al. (1999) sugirieron una expresión para la determinación de la caída de presión, tanto en el tramo horizontal, como en el lecho fluidizado situado en la cámara de recirculación, downcomer:

$$
\Delta P_{d c}+\Delta P_{l s h o r}=\frac{\left(G_{s} \cdot A_{s p}\right)^{2}}{\left(C_{D o} \cdot A_{l s}\right)^{2} \cdot 2 \cdot \rho_{s} \cdot\left(1-\varepsilon_{m f}\right)}
$$

Ecuación 4.89

Donde $\mathrm{C}_{\mathrm{Do}} \cdot \mathrm{A}_{\mathrm{ls}}=11 \cdot 10^{-6} \mathrm{~m}^{2}$

La pérdida de carga por fricción en el tramo horizontal puede determinarse mediante la caída de presión debida a la fricción del sólido/pared análogo a la caída de presión de un fluido con flujo laminar de un fluido en una tubería:

$$
\Delta P_{l s h o r, f r i c c i o ́ n}=\lambda \cdot \frac{u_{s}^{2}}{2} \cdot \frac{A_{w}}{A_{c}} \cdot \rho_{p} \cdot\left(1-\varepsilon_{l s}\right)
$$

El factor de fricción depende del material empleado, su forma y su tamaño. De acuerdo al trabajo de Venderbosch et al. (1996) [191]: 
$\lambda=\frac{K_{c o n}}{u_{s, c o n}^{2}}$

Ecuación 4.91

Donde $\mathrm{K}_{\mathrm{con}}=3.5$

\subsection{Válvula $L$}

La válvula no mecánica tipo $\mathrm{L}$, consiste en tubería con forma de $\mathrm{L}$ en ángulo recto que conecta los dos recipientes entre los cuales las partículas sólidas van a ser transferidas. Es una válvula de simple construcción, pero la localización de la aireación es un parámetro crítico, ya que debe situarse tan baja como sea posible, pero por encima del codo, de manera que garantice una caída de presión mínima en la válvula y una máxima longitud en la rama de retorno.

En una unidad circulante, la válvula L se encuentra conectada al correspondiente separador de gas-sólido, y la sección horizontal está conectada al riser. El aire de fluidización permite el movimiento de los sólidos desde un lecho empaquetado en movimiento en la rama vertical hasta un lecho menos denso en el riser, donde se alimentan los sólidos. La aireación se produce de manera que el aire se mueva hacia abajo a través de las partículas sólidas, pasando posteriormente a través del codo que une la parte vertical con la horizontal en la válvula debido a fuerzas de arrastre de los sólidos. El comportamiento de una válvula tipo L es semejante al de una válvula mecánica donde la apertura se controla mediante el caudal de aireación.

En la figura 4.14, se observa que para una aireación baja, solamente una pequeña proporción de sólidos parte superior de la rama horizontal se encuentran fluidizados, permaneciendo el resto de sólidos sin movimiento alguno. A medida que se aumenta la aireación externa, el área de sólidos fluidizados aumenta, llegando a estar enteramente fluidizado el área del tramo horizontal [213]. El comportamiento del tramo vertical es semejante al descrito anteriormente para el tramo horizontal, observándose que para bajos caudales de aireación solamente está operativa una pequeña proporción interna del tramo vertical, que se incrementa al aumentar el caudal de aireación.

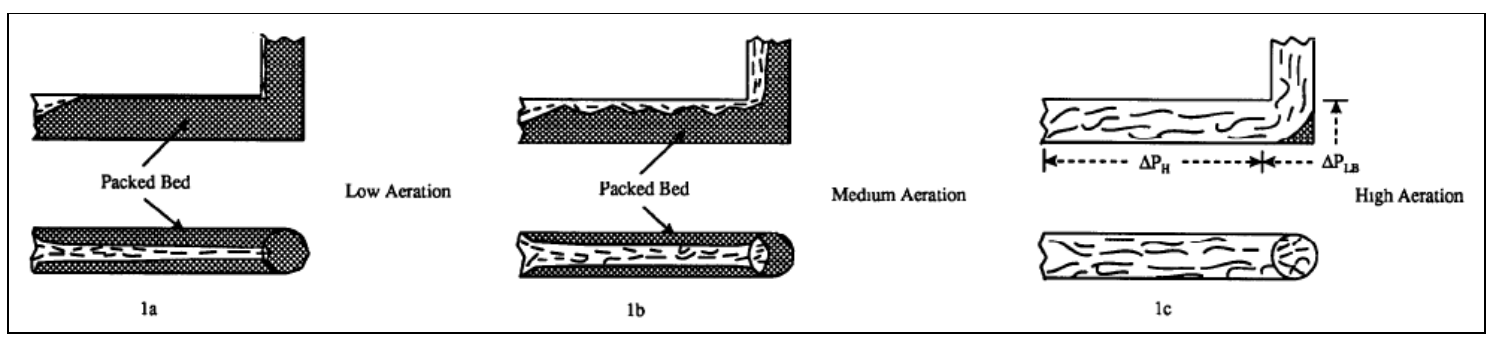

Figura 4.14. Patrones de flujo en una válvula L con diferentes tasas de aireación [74].

Partiendo de la explicación anterior se puede calcular la caída de presión en la válvula tipo L como:

$\Delta P_{V L}=\Delta P_{h o r}+\Delta P_{c o d o}$

Ecuación 4.92

Donde el primer y segundo términos corresponden con la caída de presión en el tramo horizontal y la caída de presión en el codo de unión entre ambas ramas, vertical y horizontal. 
La caída de presión en el codo de unión entre ambos tramos puede ser determinado como la caída de presión en una válvula pseudo-mecánica operada pneumáticamente. La apertura de la válvula se consigue variando el caudal de aireación introducido. Yang and Knowlton (1993) recopilaron correlaciones para la estimación de la caída de presión para una válvula de distribución que puede asemejarse a una válvula L como la de Jones and Davidson (1965):

$$
\Delta P_{v}=\frac{1}{2 \cdot \rho_{s} \cdot\left(1-\varepsilon_{m f}\right)} \cdot\left[\frac{W_{s}}{C_{D} \cdot A_{0}}\right]^{2}
$$

Ecuación 4.93

Donde $C_{D}$ se toma como 0.5 basándose en estudios para Leung et al. (1987) [213].

Sin embargo, la determinación de la caída de presión en el tramo horizontal basándose en ecuaciones de transporte pneumático de la fase densa, no son adecuadas debido al comportamiento del transporte de sólidos. No obstante, la determinación de la apertura de válvula se realiza a través del control de la aireación, que consiste del caudal de entrada en el downcomer y la aireación externa.

$$
Q_{t}=Q_{e x t}+Q_{e n t}
$$

Ecuación 4.94

$$
Q_{t}=0.177 \cdot(\Pi / 4) \cdot D_{h}^{2} \cdot L_{h}+0.710 \cdot u_{t} \cdot A_{0}
$$

Ecuación 4.95

La caída de presión a través de una válvula tipo L se supone proporcional a la longitud del tramo horizontal. Sin embargo, Smolders and Bayens (1995) mostraron que de esta forma se sobreestimaba la contribución del tramo horizontal, y desarrollaron una correlación para estimar la caída de presión en relación al flujo de circulación de sólidos, que se muestra independiente del diámetro de la válvula tipo L y poco dependiente del tamaño de partícula:

$$
\Delta P_{h}=3500 \cdot G_{s}^{0.30} \cdot d_{p}^{-0.1} \cdot L_{h}{ }^{0.3}
$$

Ecuación 4.96

Existen diversas correlaciones para medir la caída de presión entre el punto de aireación y el punto de descarga de sólidos al riser, que permiten estimar la caída de presión en una válvula tipo $L$.

Geldart and Jones (1991) [214],

$$
\Delta P_{h}=216 \cdot G_{s}^{0.17} \cdot D^{-0.63} \cdot d_{p}^{-0.15} \cdot L_{h}
$$

Ecuación 4.97

Umberto Arena (1998) obtuvo una correlación que tenía en cuenta partículas sólidas con diferentes densidades aparentes [215],

$$
\Delta P_{h}=0.0498 \cdot G_{s}^{0.203} \cdot D^{-0.63} \cdot \rho_{a}^{0.961} \cdot d_{p}^{-0.269} \cdot L_{h}
$$

Y una más extendida tomando datos experimentales de la literatura 
$\Delta P_{h}=0.0649 \cdot G_{s}^{0.178} \cdot D^{-0.574} \cdot \rho_{a}^{0.996} \cdot d_{p}^{-0.237} \cdot L_{h}$

Ecuación 4.99

Por otro lado, la determinación del flujo de circulación sólidos se realiza en base a diferentes correlaciones:

Geldart and Jones (1990),

$\frac{G_{s}}{D}=3354 \cdot \frac{u_{e x t}}{u_{m f}}-2965$

Ecuación 4.100

Smolders and Baeyens (1995),

$$
\frac{G_{s}}{D}=780 \cdot\left(\frac{u_{e x t}}{u_{m f}}\right)^{2}
$$

Ecuación 4.101

Y,

$$
\frac{G_{s}}{D}=79600 \cdot\left(\frac{u_{e x t}}{u_{m f}}\right)^{2.2} \cdot d_{p}^{0.6}
$$

Ecuación 4.102

\subsection{MODELO UNIDAD CIRCULANTE A TEMPERATURA AMBIENTE}

\subsubsection{INTRODUCCIÓN}

La unidad circulante fue empleada para el estudio de parámetros clave en la operación de un lecho fluidizado circulante. El caudal primario, aire de fluidización, fue medido mediante un medidor tipo Vortex, y su ajuste se realizó en base a la temperatura y presión del aire de entrada, llevándose a cabo a través de dos medidores colocados antes de la caja de vientos (plenum). Además, el caudal de aireación fue medido con un rotámetro. Por otro lado, se colocaron trece medidores de presión en la unidad circulante.

Las medidas de presión se registraron junto con la medida del caudal, temperatura y presión de entrada para cada nueva condición fijada. Los medidores de presión empleados, cuerpo en acero inoxidable con junta Viton y sensor cerámico, modelo DDS331H12160 SIKA y ST-18 NUOVAFIMA, con rango de medida de 0-0,6 y 0-1 bar, respectivamente. La porosidad se calculó en base a las mediciones de presiones realizadas a lo largo del riser donde el flujo puede considerarse completamente desarrollado. Además, la circulación de sólidos en el sistema fue medida para cada condición fijada.

\subsubsection{UNIDAD CIRCULANTE CON VÁLVULA TIPO L}


En las instalaciones del CEDER se disponía de un modelo de unidad circulante a temperatura ambiente con válvula tipo-L. Este modelo fue reparado para poder acometer los ensayos relativos al estudio de presiones a lo largo del sistema y la determinación del flujo externo e interno de sólidos. Aunque la válvula no-mecánica es más sencilla que un loop-seal, ésta sirvió para conocer el funcionamiento de una válvula no-mecánica en una lecho fluidizado circulante. Además, esta unidad circulante dispone de una salida abrupta, semejante a la salida abrupta del gasificador de lecho circulante de 0,5 MWth, ver Figura 4.15.

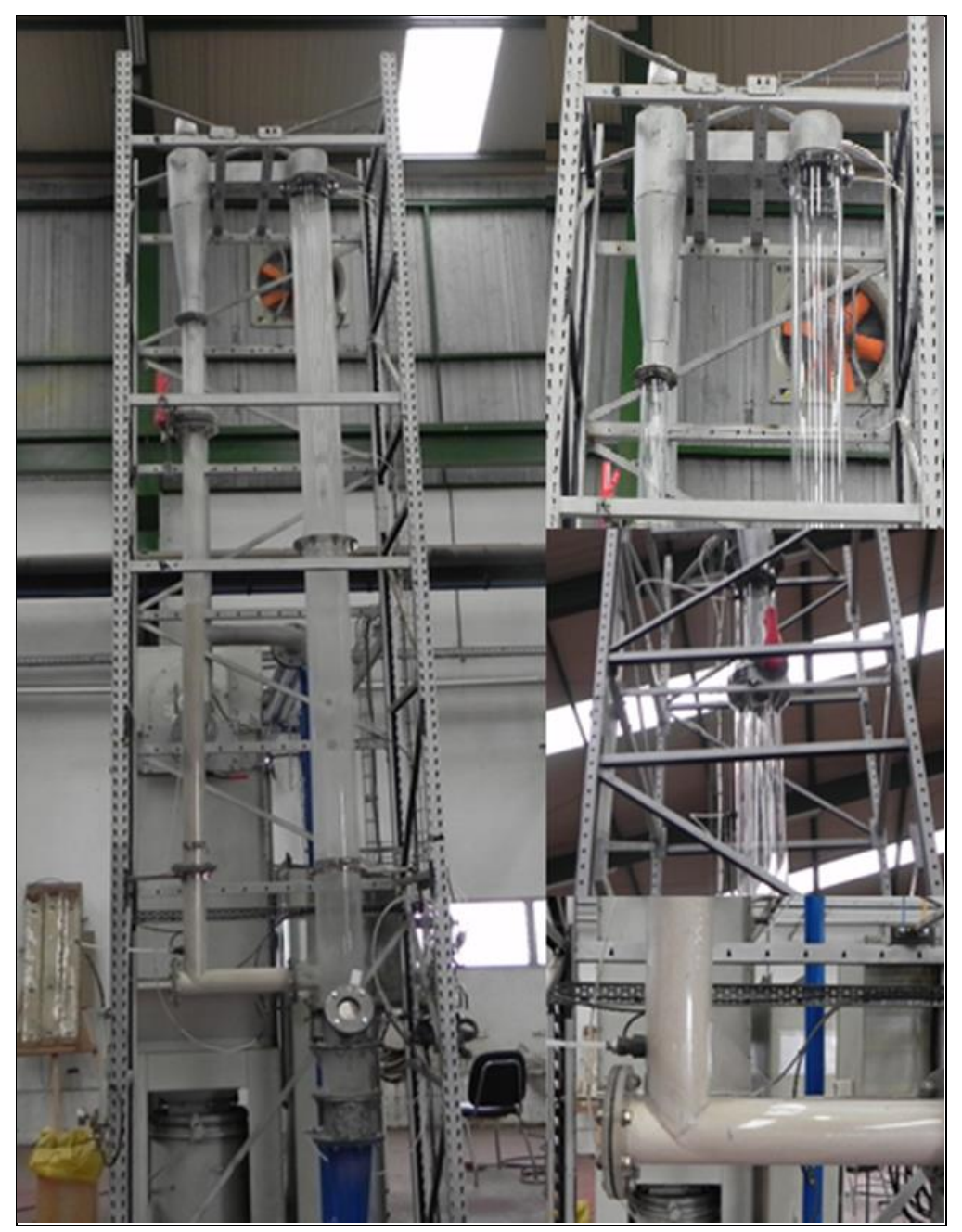

Figura 4.15. Modelo unidad circulante a temperatura ambiente (salida abrupta; válvula de mariposa; válvula tipo-L).

La aireación es un parámetro clave, ya que permite controlar la circulación de sólidos. La elección del punto de aireación a lo largo de la rama de retorno es clave para disponer de la circulación de sólidos óptima, ver Figura 4.16,ya que se deberán mover las partículas sólidas desde una zona de alta presión (válvula L) hacia una zona de baja presión (lecho rápido o riser). El establecimiento de una atura óptima hace que se disponga de una circulación de sólidos adecuada, necesitándose un caudal de aireación mínima para que dicha circulación tenga lugar. La altura óptima se fijó en $13 \mathrm{~mm}$ por encima del tramo horizontal de la válvula tipo-L. 


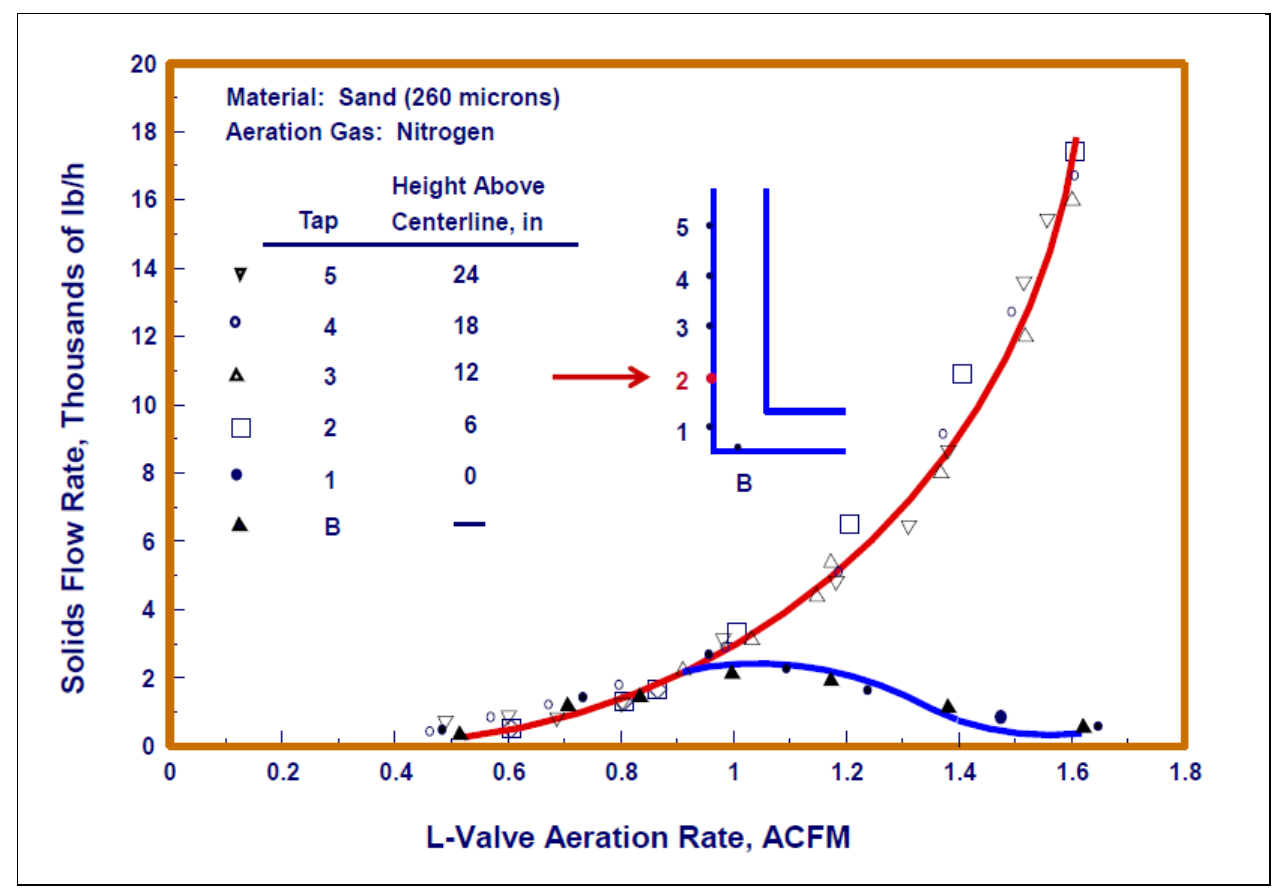

Figura 4.16. Estudios de circulación de sólidos de Knowlton con una válvula tipo-L.

Se realizaron medidas a diferentes condiciones de operación con el objeto de conocer el comportamiento del sistema bajo diferentes condiciones. Las condiciones de fluidización, la distribución axial de presiones y la tasa de circulación se estudiaron variando el inventario de sólidos, el caudal de aire primario y el caudal de aireación. Además, una sonda de medición de partículas fue colocada a modo de comprobación de la tasa de circulación de sólidos, en dos alturas distintas del riser. La velocidad de fluidización y el inventario de sólidos fueron variados con el objeto de estudiar el flujo de partículas sólidas en la unidad circulante y la modificación de los perfiles de presión y porosidad axial medios. La velocidad de fluidización fue variada de 3 a $6 \mathrm{~m} / \mathrm{s}$, como se muestra en la Tabla 4.5.

\begin{tabular}{|c|c|c|c|c|}
\hline Material & $\begin{array}{c}\text { Temperatura } \\
\left({ }^{\circ} \mathrm{C}\right)\end{array}$ & $\begin{array}{c}\text { Velocidad de } \\
\text { fluidización }(\mathrm{m} / \mathrm{s})\end{array}$ & $\begin{array}{c}\text { Inventario de } \\
\text { sólidos }(\mathrm{kg})\end{array}$ & $\begin{array}{c}\mathrm{d}_{\mathrm{p}} \\
(\mathrm{mm})\end{array}$ \\
\hline Arena de sílice I & 25 & $3-6$ & $20-35$ & 0,428 \\
\hline Arena de sílice II & 25 & $3-6$ & $20-35$ & 0,204 \\
\hline
\end{tabular}

Tabla 4.5. Condiciones de operación en los ensayos con la unidad circulante.

\subsubsection{Perfiles de presiones}

El material de lecho que se empleó fue arena de sílice. Se elaboraron perfiles axiales de presiones para cada uno de ellos. Los parámetros que se variaron fueron: inventario de sólidos, velocidad de fluidización y caudal de aireación. Por tanto, se obtuvieron multitud de perfiles de presiones del sistema para cada variable modificada.

Los ensayos nos permitieron ver de manera gráfica, una vez tratados los datos, y visual el comportamiento de una unidad circulante bajo condiciones de fluidización. En un lecho fluidizado se disponen de partes diferenciadas dentro del riser, lecho denso y lecho disperso. Al realizar estos ensayos se observaron los cambios que fueron 
ocurriendo en el riser. La modificación de la velocidad de fluidización, alteró notablemente estos lechos.

Un aumento de la velocidad del riser significó una reducción del lecho denso hasta casi su desaparición a velocidades altas. Este efecto fue más notorio cuando se usó arena de sílice de $204 \mu \mathrm{m}$ como material de lecho. Por tanto, existen unas velocidades óptimas de fluidización para poder operar, ya que como pudo observarse, una velocidad muy elevada provocó la desaparición del lecho denso y un aumento de ruidos y vibraciones en el sistema debido a que la rama de retorno comenzó a llenarse del material de lecho.

Por contra, una velocidad baja propició la desaparición de la columna de lecho en la rama de retorno, lo que significó que el sistema se descontrolara completamente. La rama de retorno es el elemento que proporciona estabilidad al sistema, ya que asume las variaciones de presión que experimenta el sistema en su operación, volviendo siempre al mismo punto de estabilidad, que se refleja con la altura que alcanza el material de lecho en la rama de retorno.

Respecto al inventario de sólidos, los ensayos se realizaron con tres valores de inventario distinto, es decir: $25 \mathrm{~kg}, 30 \mathrm{~kg}$ y $35 \mathrm{~kg}$. Se observó que con un inventario bajo, se produjeron inestabilidades en el sistema en función de las velocidades de fluidización. La desaparición del lecho denso fue uno de los efectos más repetidos, al igual que la inestabilidad del sistema debido a no tener una altura suficiente de material de lecho en la rama de retorno que pudiera asumir las fluctuaciones de presión del sistema. Un inventario alto, en este caso el máximo permitido por la unidad circulante, $35 \mathrm{~kg}$, produjo ruidos y vibraciones cuando se empleó como material de lecho la arena de $428 \mu \mathrm{m}$.

El caudal de aireación también fue variado para permitir la circulación de sólidos en el sistema. Se detectó la existencia de un caudal de aireación mínimo para cada condición fijada. Los parámetros que más afectaron al aumento o disminución del caudal de aireación mínimo fueron el inventario de sólidos y el tipo de arena ensayada. Un inventario de sólidos mayor requirió un caudal de aireación mayor. Este efecto se notó de manera más leve en el cambio de material de lecho ensayado, aunque también fue apreciado.

Finalmente, las arenas ensayadas mostraron un comportamiento claramente distinto. El arrastre de partículas fue muy grande cuando se utilizó la arena de $204 \mu \mathrm{m}$ como material de lecho, lo que podría ocasionar problemas de desaparición del lecho denso en el gasificador, así como ser más propensa a fenómenos de atrición. Por tanto, a tenor de los resultados obtenidos durante los experimentos, se decidió emplear la arena de 428 $\mu \mathrm{m}$ como material de lecho en el gasificador circulante. No obstante, su empleo como complemento de esta última no queda descartado totalmente.

A continuación se muestran dos gráficos, ver Figura 4.17 y 4.18, que recogen los resultados más satisfactorios de los ensayos con ambos materiales de lecho para un inventario de sólidos de $30 \mathrm{~kg}$. La Figura 4.17 muestra el perfil axial de presiones que corresponden a velocidades de fluidización de $3.5 \mathrm{~m} / \mathrm{s}$ a $5 \mathrm{~m} / \mathrm{s}$. La circulación de sólidos aumentó con la velocidad, pero para velocidades muy altas, el sistema fue haciéndose menos estable, debido a ruidos y vibraciones, a consecuencia de la desaparición progresiva del lecho denso y el aumento de material de lecho en la rama de retorno. 


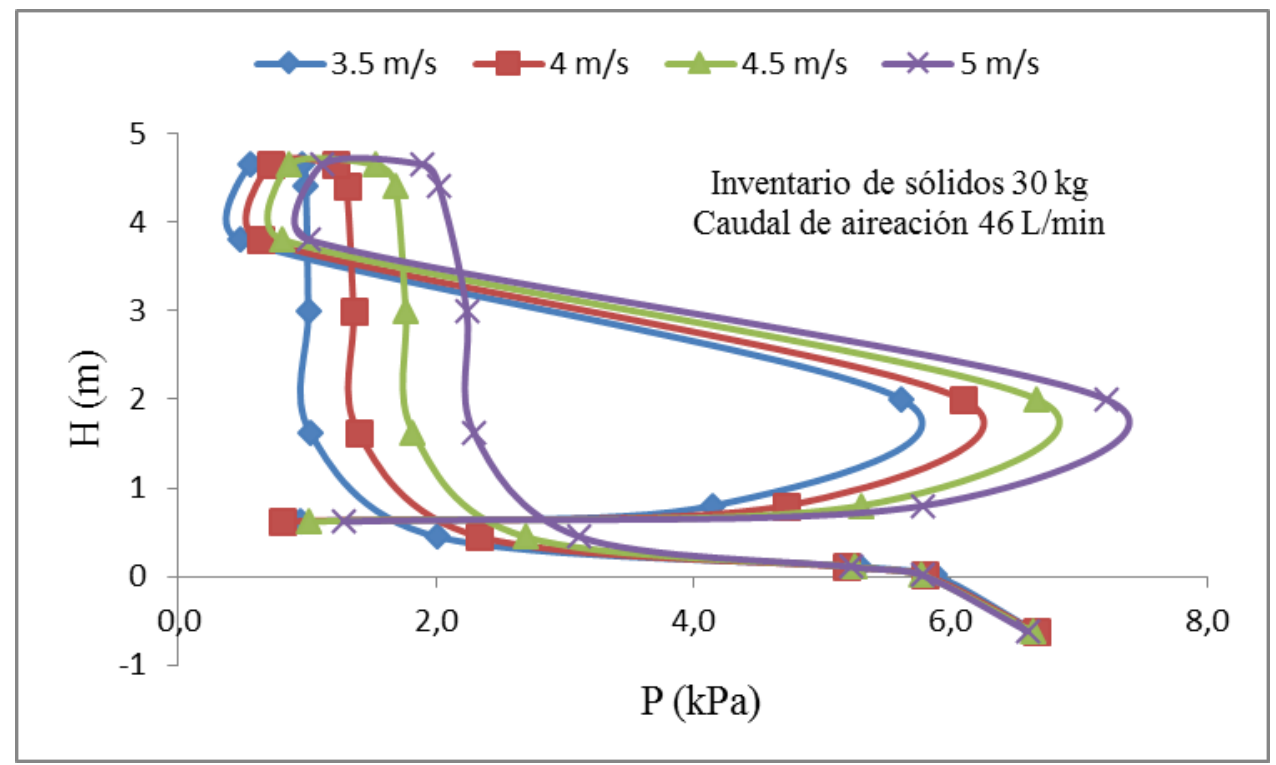

Figura 4.17. Perfil axial de presiones arena de $204 \mu \mathrm{m}$.

En la figura 4.18 se muestra el perfil axial de presiones que corresponden a velocidades de fluidización de $5 \mathrm{~m} / \mathrm{s}$ a $6 \mathrm{~m} / \mathrm{s}$. La circulación de sólidos aumentó con la velocidad de fluidización. Sin embargo, a velocidades más bajas de fluidización la columna en la rama de retorno era prácticamente inexistente. Durante la operación se fueron haciendo cambios en el sistema, aumento y descenso de la velocidad de fluidización, medida de flujos externo e interno de sólidos que afectaron a las presiones. Estas fluctuaciones de presión fueron paulatinamente desapareciendo a medida que el material de lecho recuperó la altura en la rama de retorno. Para una velocidad de $6 \mathrm{~m} / \mathrm{s}$ se observó que el lecho denso prácticamente era inexistente, este dato se extrae del valor menor de presión en la parte inferior del riser en comparación con las otras dos velocidades de fluidización probadas.

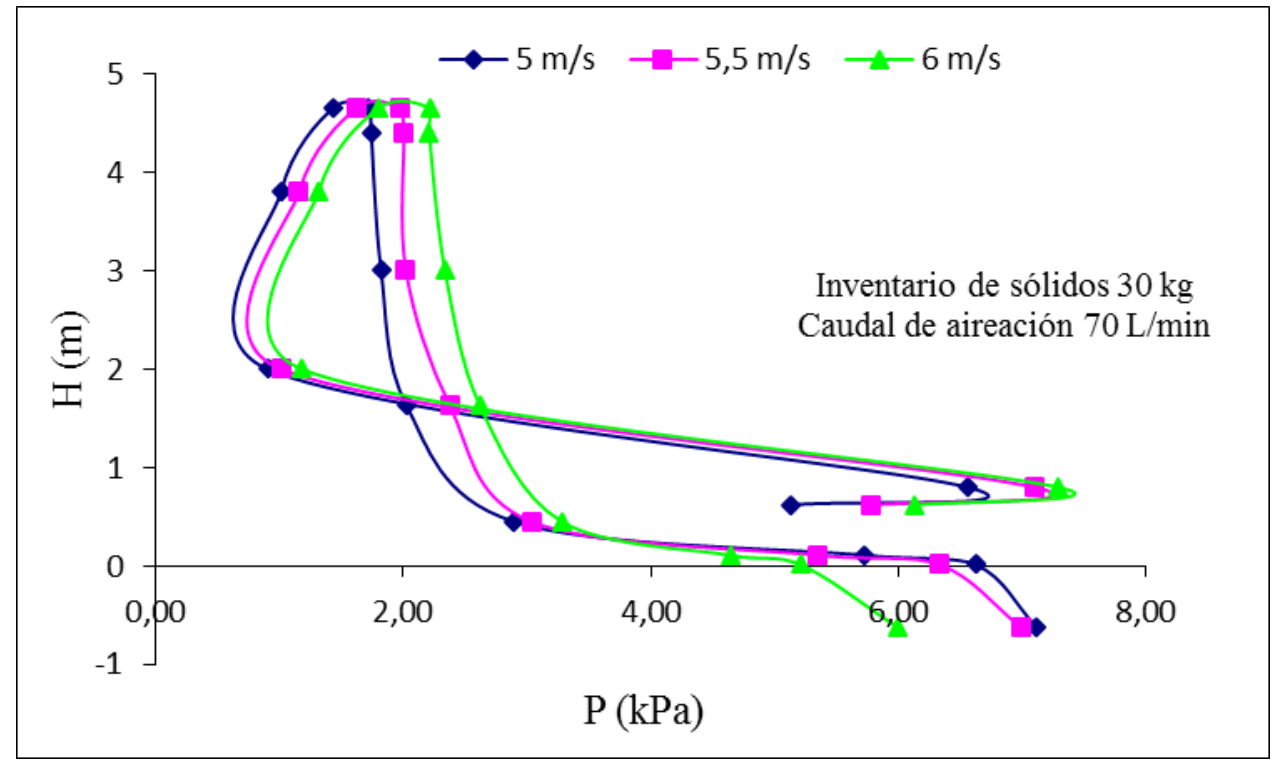

Figura 4.18. Perfil axial de presiones arena de $428 \mu \mathrm{m}$. 


\subsubsection{Medida de flujo externo de sólidos}

La obtención del flujo externo de sólidos se realiza a través del cierre de una válvula de mariposa, un cronómetro y un tramo graduado que nos sirve de instrumento de medición de volúmenes, ver Figura 4.19. Se interrumpe el proceso durante un breve espacio de tiempo, que provoca el llenado del tramo graduado, y a través de la densidad a granel, el volumen y el tiempo se obtiene la tasa de circulación de sólidos. Se repiten varias medidas con el propósito de depurar errores en las medidas, bien sean debido al aparato de medida, como por errores humanos, de manera que se obtiene un valor medio que evita datos erróneos debido a condiciones de operación anómalas debidas a significantes cambios en las condiciones ambientales.

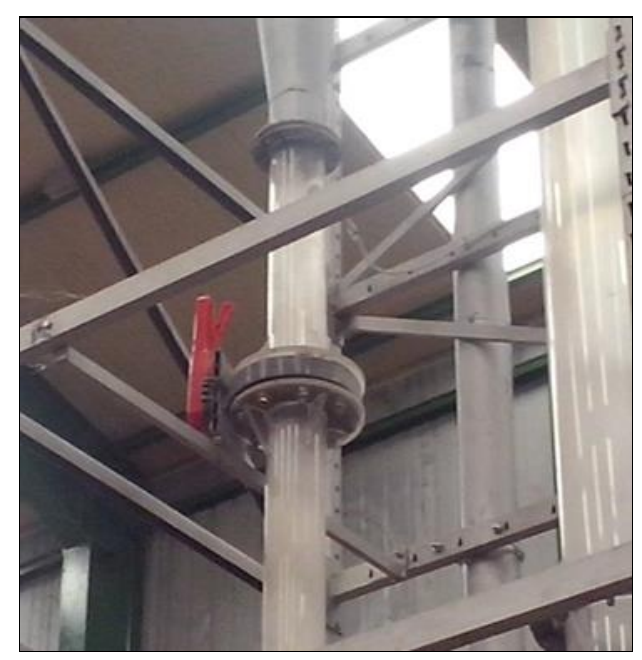

Figura 4.19. Válvula de mariposa.

En las Figuras 4.20 y 4.21 se observan los datos experimentales de medida de flujo externo para un inventario de sólidos de $30 \mathrm{~kg}$ para ambos materiales de lecho. La arena de $428 \mu \mathrm{m}$ fue la que mejores resultados mostró durante los ensayos y, por tanto, puede decirse que es la más apta para ser usada en un lecho fluidizado circulante. Además, cada gráfica muestra datos experimentales para cada caudal de aireación usado. La arena de $204 \mu \mathrm{m}$ mostró un valor máximo de flujo externo de sólidos de $13 \mathrm{~kg} / \mathrm{m}^{2} \mathrm{~s}$ para un inventario de sólidos de $30 \mathrm{~kg}$, ver Figura 4.20, siendo el caudal de aireación usado el máximo permitido por el sistema, $46 \mathrm{~L} / \mathrm{min}$.

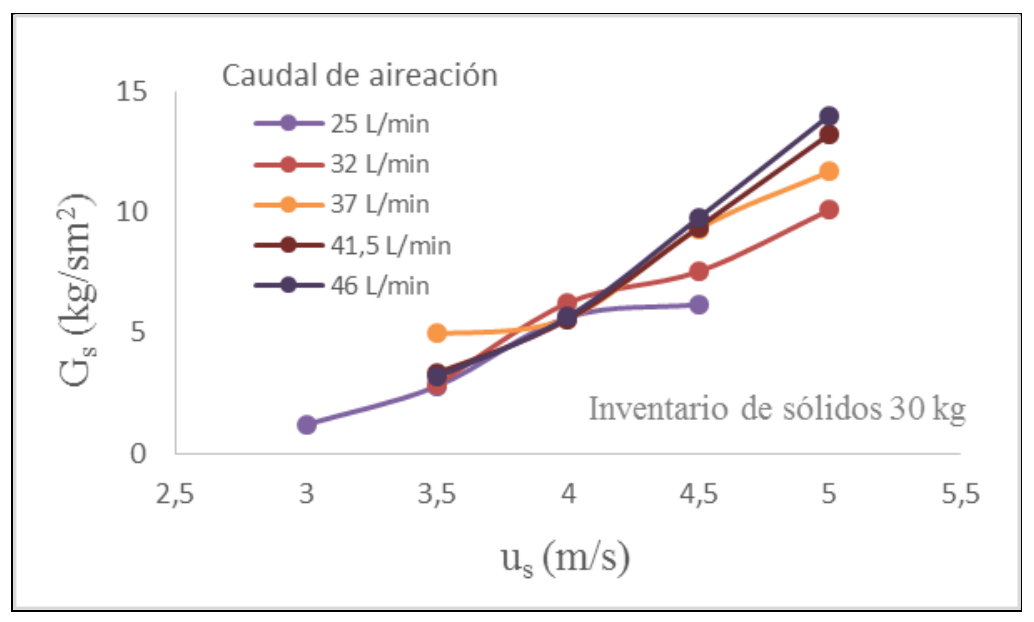

Figura 4.20. Flujo externo de sólidos para la arena de $204 \mu \mathrm{m}$. 
Respecto a la arena de $428 \mu \mathrm{m}$, el valor máximo de flujo externo de sólidos con un inventario de $30 \mathrm{~kg}$ fue de $8 \mathrm{~kg} / \mathrm{m}^{2}$ s con un caudal de aireación de $70 \mathrm{~L} / \mathrm{min}$, ver Figura 4.21. Para lograr un aumento del flujo externo de sólidos se requiere aumentar el caudal de aireación, aunque en este equipo no fue posible su aumento. No obstante, con estas condiciones se alcanzaron las condiciones de fluidización óptimas empleando esta arena como material de lecho.

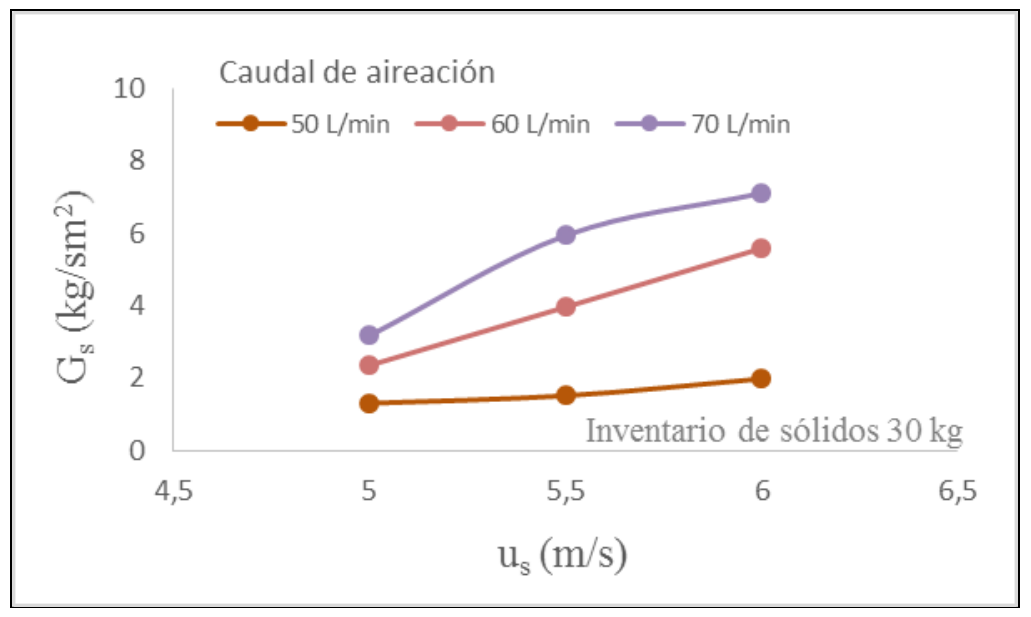

Figura 4.21. Flujo externo de sólidos para la arena de $428 \mu \mathrm{m}$.

\subsubsection{Medida de flujo interno de sólidos}

El flujo interno de sólidos se midió a través de una sonda no-isocinética, ver Figura 4.22, que fijó la velocidad del gas en el riser con una bomba de vacío, permitiendo la comprobación de la tasa de circulación de sólidos obtenida mediante el sistema anteriormente explicado. Se realizaron tres repeticiones para depurar errores en la medición, como se hizo en el caso de la medida de flujo externo.

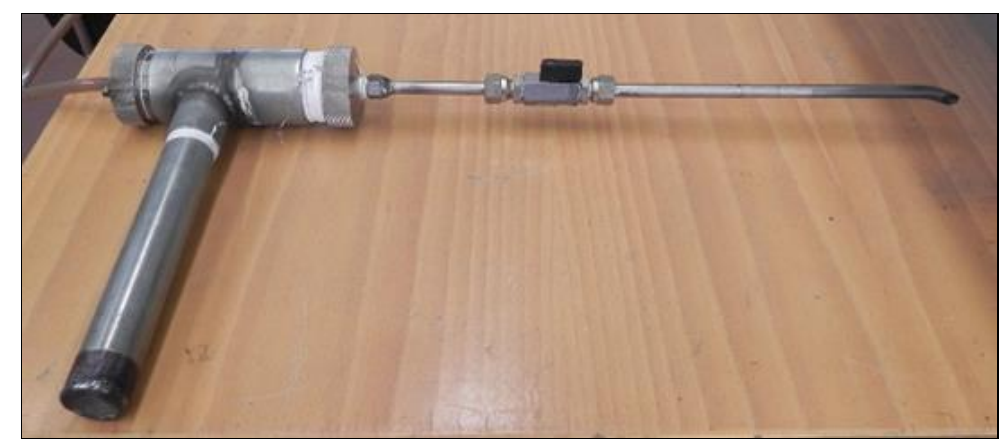

Figura 4.22. Sonda no-isocinética para la medida de flujo interno de sólidos.

En la Tabla 4.6, se observa que el flujo interno de sólidos fue superior al flujo externo de sólidos. Este hecho es debido a la salida de la unidad circulante, forma abrupta, que provoca la caída de multitud de partículas sólidas al riser. El descenso de partículas, se observa en los laterales del riser. La medida de flujo interno se determinó midiendo la caída y subida de partículas sólidas en dos secciones del riser. La medición se realizó en tres puntos: centro, pared y en una zona intermedia. 


\begin{tabular}{|c|c|c|c|c|}
\hline $\mathrm{u}_{\mathrm{s}}$ & \multicolumn{2}{|c|}{ Flujo interno de sólidos $\left(\mathrm{kg} / \mathrm{m}^{2} \mathrm{~s}\right)$} & \multicolumn{2}{c|}{ Flujo externo de sólidos $\left(\mathrm{kg} / \mathrm{m}^{2} \mathrm{~s}\right)$} \\
\hline $\mathrm{m} / \mathrm{s}$ & Arena $204 \mu \mathrm{m}$ & Arena $428 \mu \mathrm{m}$ & Arena $204 \mu \mathrm{m}$ & Arena $428 \mu \mathrm{m}$ \\
\hline 4 & 24,2 & 16,5 & 5,7 & 3,2 \\
\hline 4,5 & 30,3 & 23,3 & 9,8 & 5,9 \\
\hline 5 & 33,1 & 28,6 & 14 & 7,1 \\
\hline
\end{tabular}

Tabla 4.6. Comparativa medida flujo interno de sólidos y externo de sólidos para un inventario de sólidos de $30 \mathrm{~kg}$.

\subsection{MODELO VÁLVULA NO-MECÁNICA TIPO LOOP-SEAL A TEMPERATURA AMBIENTE}

\subsubsection{INTRODUCCIÓN}

Las instalaciones del CEDER disponen de un gasificador circulante de 0.5 MWth. Este gasificador fue diseñado para operar como un gasificador autotérmico. Tras un breve calentamiento del reactor, hasta una temperatura cercana a la temperatura de ignición del combustible, comienza a operar de manera autónoma sin necesidad de ningún aporte externo de calor. El mantenimiento de una temperatura uniforme a lo largo del reactor se logra con la recirculación del material de lecho que es arrastrado por el gas de proceso, pero recogido en un primer ciclón.

Las partículas sólidas recogidas en la rama de retorno tras abandonar el ciclón, son enviadas nuevamente al reactor a través de una válvula no-mecánica. Esta válvula es la encargada de mantener un flujo de sólidos constante, que permita el correcto funcionamiento del gasificador. El tipo de vávula que fue diseñada para el gasificador, fue una válvula no-mecánica loop-seal tipo U. Este tipo de válvula tiene el inconveniente de disponer de un tramo horizontal largo, que conecta las cámaras de recirculación y suministro de sólidos.

\subsubsection{SISTEMA DE RECIRCULACIÓN}

El sistema de recirculación consta de una rama de retorno (standpipe), encargada de recoger las partículas sólidas separadas del gas de proceso mediante el primer ciclón. La altura de esta rama compensa las pérdidas de carga que se producen en el resto de la instalación, es decir: pérdidas de carga en el riser, ciclón, tubería de conexión con el ciclón y loop-seal.

En la parte inferior de esta rama, se encuentra la cámara de suministro. Desde su parte inferior se introduce un caudal de aire, denominado de caudal de aireación, que posibilita el movimiento de partículas sólidas desde esta cámara hacia la cámara de recirculación, atravesando un tramo horizontal. Al llegar a esta cámara, las partículas sólidas experimentan un movimiento ascendente a consecuencia de la entrada de un flujo de aire por la parte inferior de la cámara. 
Esta cámara se comporta como un pequeño lecho burbujeante, ya que las partículas sólidas experimentan un fenómeno de fluidización debido al ascenso del aire. Parte de estas partículas sólidas caen al riser por gravedad a través de una tubería de recirculación al superar la altura que fija un rebosadero situado en este tramo. En la Figura 4.23 se puede observar un esquema de la válvula no-mecánica loop-seal tipo U.

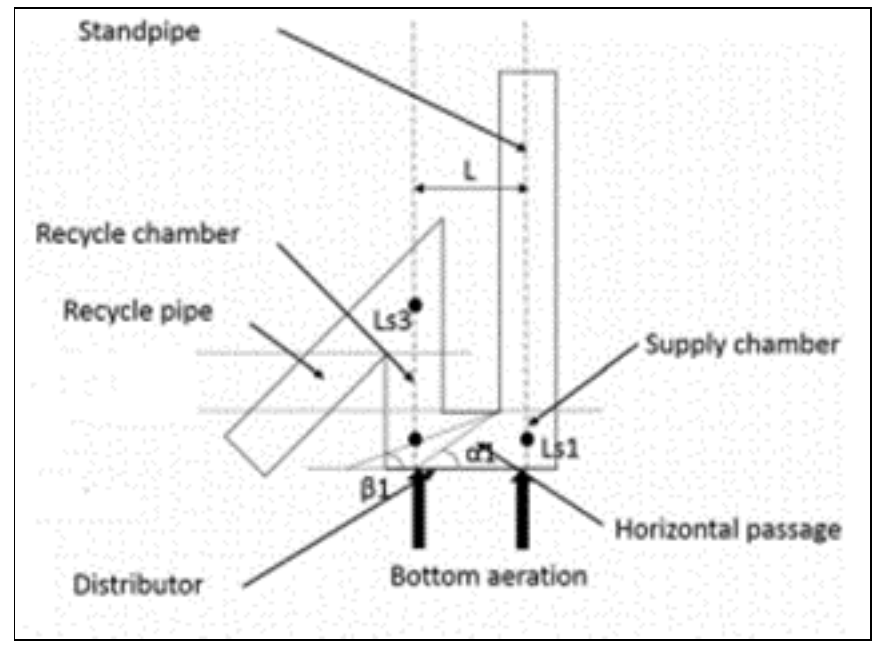

Figura 4.23. Loop-seal clásico con tramo horizontal.

El caudal de aireación requerido, tanto para la cámara de suministro, como para la cámara de recirculación, fue aportado mediante tuberías largas perforadas, ver Figura 4.24. La colocación de estas tuberías fue realizada de manera que el aire saliese perpendicularmente al fondo del loop-seal.

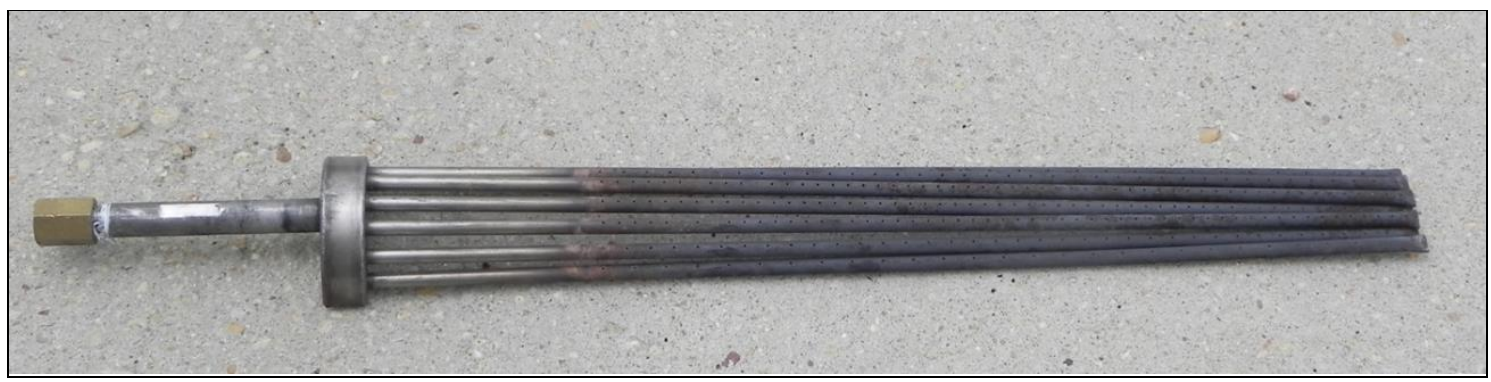

Figura 4.24. Distribuidor de aire mediante tuberías perforadas.

\subsubsection{VÁLVULA NO-MECÁNICA LOOP-SEAL TIPO U}

Tras realizar varias pruebas de gasificación no satisfactorias debido al aumento de temperatura en el interior del reactor, tras 8 horas de trabajo estable, se descubrió que la circulación de sólidos en el sistema no era suficiente para mantener una temperatura constante en su interior. Las causas de una insuficiente circulación de sólidos en una unidad circulante pueden ser: granulometría de la arena utilizada, reducción del tamaño de partícula debido a atrición, insuficiente inventario de sólidos, incorrecto diseño del ciclón que recoge las partículas arrastradas por el gas de proceso o mal funcionamiento del loop-seal. 
Una vez finalizado cada ensayo, se recogieron muestras del material de lecho y se determinó la cantidad de sólidos que permanecen aún en el sistema. De esta forma, se analizó la granulometría y se determinó el porcentaje de partículas sólidas arrastradas por el gas de proceso y recogidas, por tanto, en el segundo ciclón.

La función de este segundo ciclón es la recogida de cenizas volantes que acompañan al gas de proceso. Tras comprobar que la granulometría y la cantidad de inventario de sólidos eran semejantes al inicio del ensayo, se puso el foco en el diseño de la válvula no-mecánica. Por tanto, se decidió construir un modelo en plexiglás sobre el que se pudiera estudiar la circulación de sólidos, ver Figura 4.25.

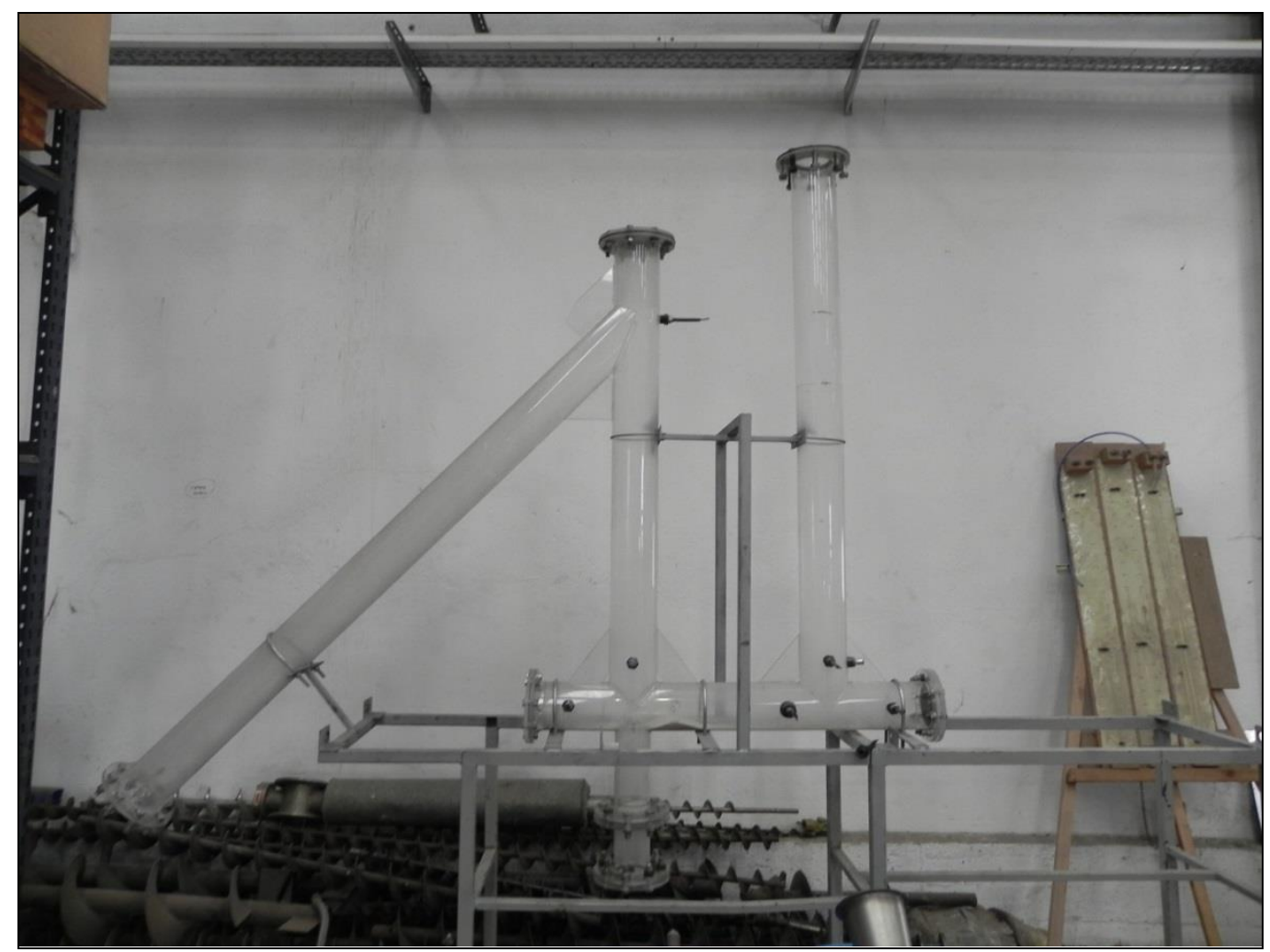

Figura 4.25. Modelo válvula loop-seal tipo U a temperatura ambiente.

La primera actuación que se llevó a cabo fue comprobar las fugas de aire que pudiera tener el sistema. Como se puede observar en la Figura 4.26, se instalaron las mismas tuberías largas perforadas que utilizaba el gasificador circulante de 0,5 MWth, ya que se quería comprobar su anormal funcionamiento.

Tras la realización de los primeros ensayos, la tasa de circulación de sólidos fue nula, ya que no se consiguió mover ninguna partícula sólida en el tramo horizontal. No obstante, se observó que en la cámara de recirculación, rama de salida, si existe ese movimiento de partículas sólidas, ya que asciendían hasta el rebosadero y una vez allí, descendían a través de la tubería de recirculación. Por tanto, solamente se decidió modificar el punto de aireación en la cámara de suministro, rama de retorno. 


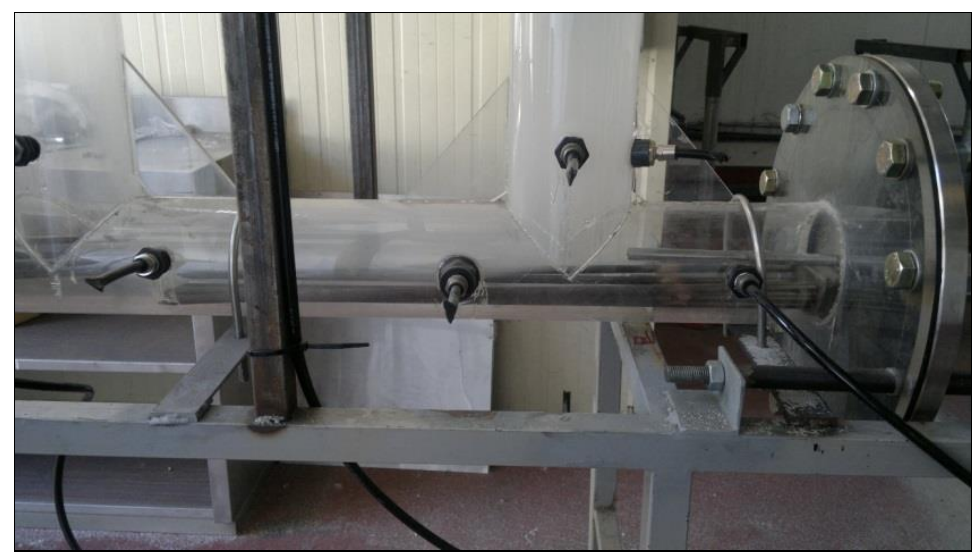

Figura 4.26. Instalación de las tuberías largas perforadas en el modelo.

Estudiando la bibliografía, se descubrió que la configuración del loop-seal era tipo U, con un tramo horizontal bastante largo, que recuerda a una válvula J [216]. En este tipo de válvulas no-mecánicas, al igual que ocurre en una válvula tipo L, la aireación tiene lugar desde la rama de retorno en lugar de desde la cámara de suministro. Con el bagaje obtenido con el modelo de unidad circulante a temperatura ambiente, cuya válvula nomecánica es tipo L, se pensó en modificar el punto de aireación de forma similar a lo que se hizo con la válvula L, es decir: determinar que altura de altura de la rama de retorno era óptima para la circulación de sólidos.

En la Figura 4.27, se observa que se dispone de un racor situado en la rama de retorno justo por encima del tramo horizontal. La altura seleccionada fue a $130 \mathrm{~mm}$ del centro del tramo horizontal. No obstante, se hicieron racores en varias alturas de la rama de retorno como entradas de aireación, aunque todos ellos fueron descartados. Además, se hicieron varias tomas de aire a la altura del centro del tramo horizontal en diferentes puntos, siendo ambas descartadas. La implementación final de esta mejora en el gasificador circulante de 0,5 MWth tuvo una ligera modificación, ya que por razones constructivas, se tuvo que elevar la altura del punto de aireación hasta $230 \mathrm{~mm}$ desde el centro del tramo horizontal, no modificando en exceso el funcionamiento de la rama de retorno.

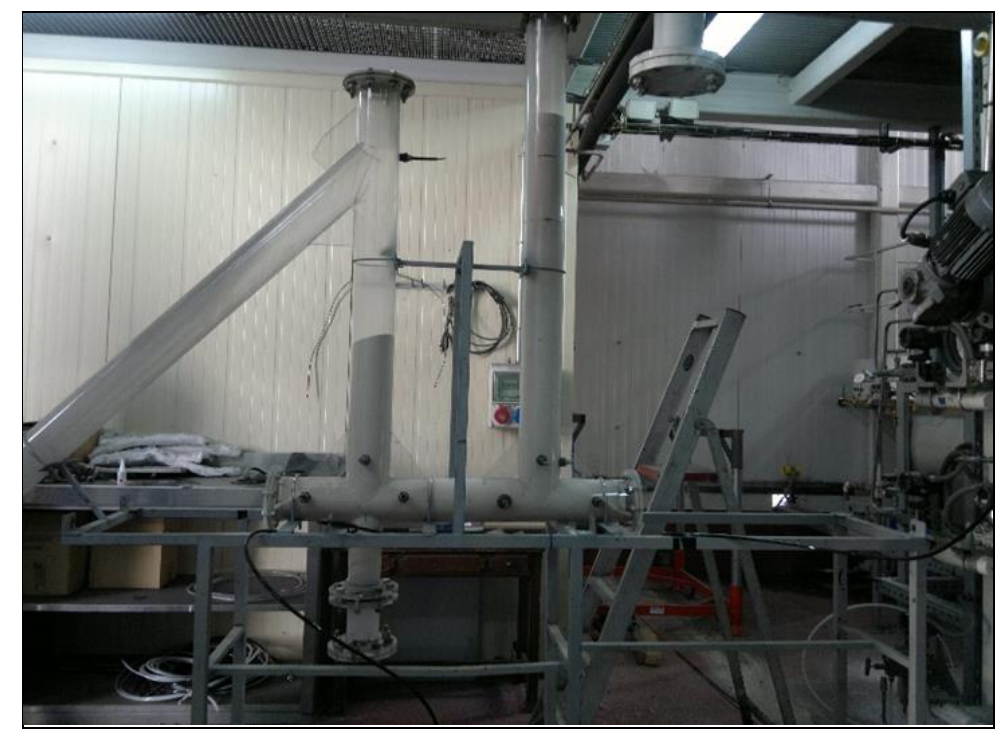

Figura 4.27. Instalación del punto de aireación sobre la rama de retorno en el modelo. 


\subsubsection{Modificaciones en la cámara de recirculación}

Tras la modificación de la aireación en la rama de retorno, se decidió probar dos placas de distribución de aire para la cámara de recirculación en vez de los tubos largos perforados. Las placas que se probaron fueron:

- Placa perforada: distribución al tresbolillo, diámetro de agujeros de $1 \mathrm{~mm}$, paso de $1,29 \mathrm{~mm}$.

- Placa porosa de borosilicato: tamaño de poro de 40-100 $\mu \mathrm{m}$, diámetro $140 \mathrm{~mm}$, y espesor de $10 \mathrm{~mm}$, temperatura de tansformación $525^{\circ} \mathrm{C}$.

Las tasas de circulación externa de sólidos $\left(\mathrm{G}_{\mathrm{s}}\right)$, utilizando la placa perforada, mostraron valores comparables a los obtenidos mediante los tubos largos perforados, ver Figura 4.28. Las mayores tasas de circulación de sólidos se situaron en torno a $13 \mathrm{~kg} / \mathrm{m}^{2} \mathrm{~s}$, siendo los caudales de aire $8-9 \mathrm{Nm}^{3} / \mathrm{h}$ en la rama de retorno y $7-8 \mathrm{Nm}^{3} / \mathrm{h}$ en la rama de salida. Además, se estudiaron caudales mayores de aireación en la rama de salida, mostrando en este caso un cierto aumento de la circulación externa de sólidos, aunque vino acompañada de ciertas inestabilidades, recordando a un transporte pneumático.

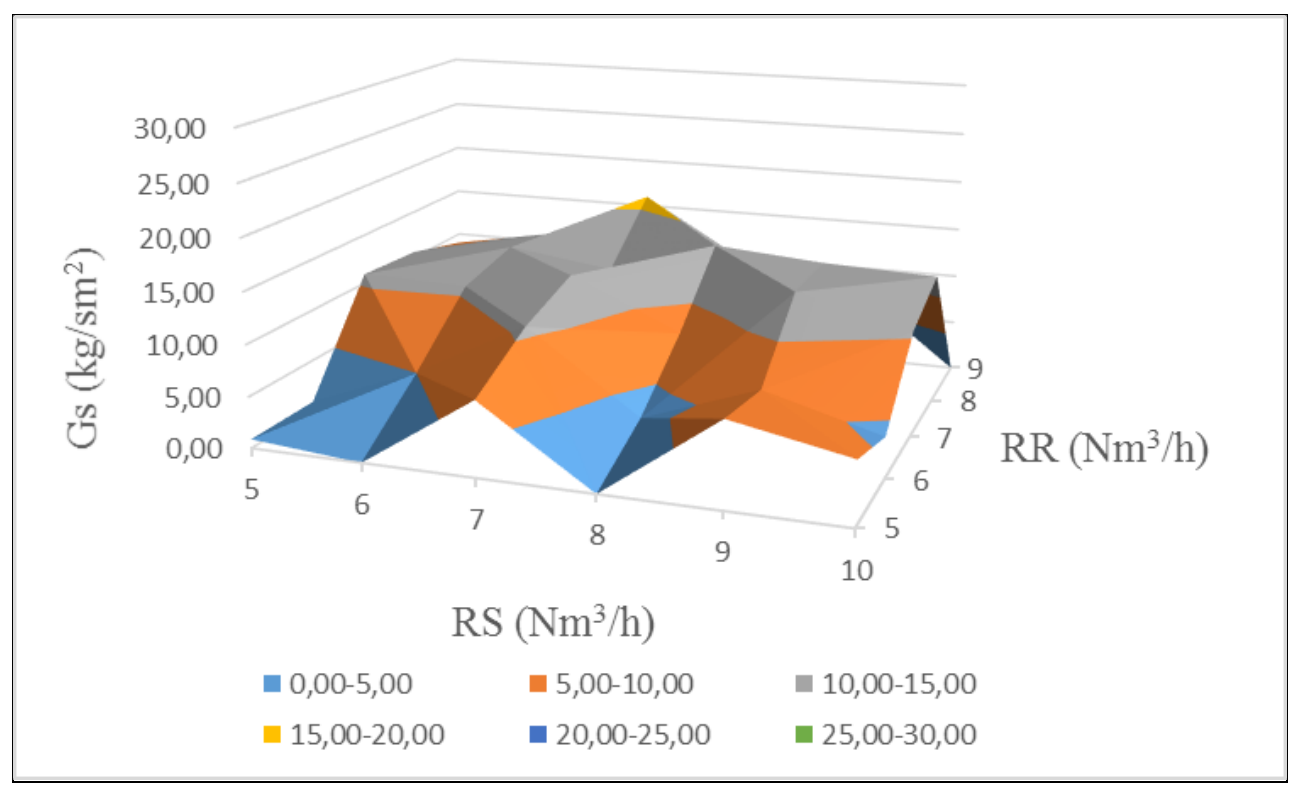

Figura 4.28. Tasas de circulación de placa perforada en función de los caudales de aire de la rama de retorno y salida.

En la Figura 4.29, se tienen los datos experimentales relativos a la tasa de circulación externa de sólidos $\left(\mathrm{G}_{\mathrm{s}}\right)$ para la placa de borosilicato. Las mayores tasas de circulación de sólidos, $15 \mathrm{~kg} / \mathrm{m}^{2} \mathrm{~s}$, se observaron a $9-10 \mathrm{Nm}^{3} / \mathrm{h}$ en la rama de retorno y a $10-11$ $\mathrm{Nm}^{3} / \mathrm{h}$ en la rama de salida. Además, se estudiaron caudales mayores de aireación en la rama de salida, sin embargo, su aumento no significó un aumento de la tasa de circulación de sólidos.

Esta placa porosa de borosilicato no es adecuada para utilizar en un gasificador, ya que se alcanzan temepraturas superiores a $525{ }^{\circ} \mathrm{C}$. No obstante, se realizaron ensayos con este tipo de distribuidor de aire con el fin de comprobar que la distribución de aire tanto con los tubos largos perforados como con la placa perforada es aún mejorable. 


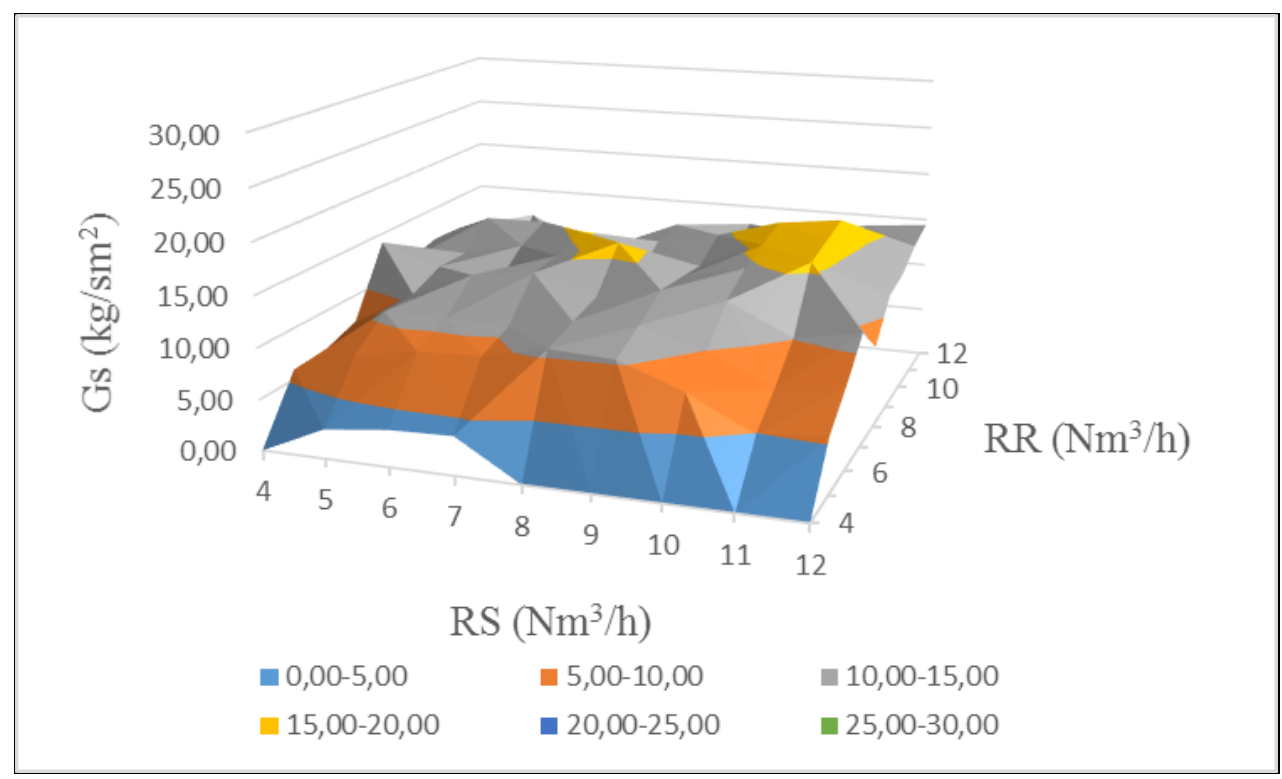

Figura 4.29. Tasas de circulación de placa porosa de borosilicato en función de los caudales de aire de la rama de retorno y salida.

\subsection{SIMULACIÓN GASIFICADOR LECHO FLUIDIZADO CON VÁLVULA NO-MECÁNICA TIPO LOOP-SEAL}

Se ha hecho una sencilla simulación del comportamiento fluidodinámico de una unidad circulante. A continuación se muestra la variación de sólidos en el sistema, ver Tabla 4.7, para un inventario de sólidos de $100 \mathrm{~kg}$, seleccionando una velocidad de fluidización de $4 \mathrm{~m} / \mathrm{s}$ y de $0,2 \mathrm{~m} / \mathrm{s}$ en la válvula no mecánica. La altura alcanzada en la rama de retorno fue de $2,15 \mathrm{~m}$ y la altura del lecho fue de $1,13 \mathrm{~m}$. Además, se obtuvo la tasa de circulación de sólidos en el riser, que fue de $7,67 \mathrm{~kg} / \mathrm{m}^{2} \mathrm{~s}$, y el flujo de sólidos del sistema que fue de $0,54 \mathrm{~kg} / \mathrm{s}$. La densidad del lecho denso fue de $511,71 \mathrm{~kg} / \mathrm{m}^{2} \mathrm{~s}$ y la densidad de la suspensión en la zona de transporte fue de $4,98 \mathrm{~kg} / \mathrm{m}^{2} \mathrm{~s}$.

\begin{tabular}{|c|c|c|c|}
\hline \multicolumn{4}{|c|}{ Inventario de sólidos $100 \mathrm{~kg}$} \\
\hline Gasificador & Sección & $\Delta \mathrm{P}(\mathrm{kPa})$ & $\mathrm{M}(\mathrm{kg})$ \\
\hline \multirow{3}{*}{ Lecho rápido (riser) } & Zona densa & 5,66 & 40,79 \\
\cline { 2 - 4 } & Zona transporte & 4,49 & 34,58 \\
\cline { 2 - 4 } & Conexión & 0,02 & 0 \\
\cline { 2 - 4 } & Total & 10,52 & 75,31 \\
\hline Ciclón & & 0,5 & 0 \\
\hline Válvula no mecánica (loop-seal) & Cámara de reciclo & 16,15 & 18,64 \\
\cline { 2 - 4 } & Cámara de suminsitro & 5,19 & 5,98 \\
\cline { 2 - 4 } & Conexión & n.d. & n.d. \\
\hline
\end{tabular}

Tabla 4.7. Variación de la masa de sólidos en el sistema.

Las presiones por sección del gasificador mostradas en la Tabla 4.7 se recogen en función de la altura en el perfil de presiones de la Figura 4.30. Esta figura muestra el comportamiento de la unidad circulante cuando se dispone de un inventario de sólidos de $100 \mathrm{~kg}$. No obstante, esta simulación, Anexo III, se ha comparado con datos reales de 
operación obtenidos en el gasificador, como los observados a través de un diagrama de presiones de la Figura 4.31.

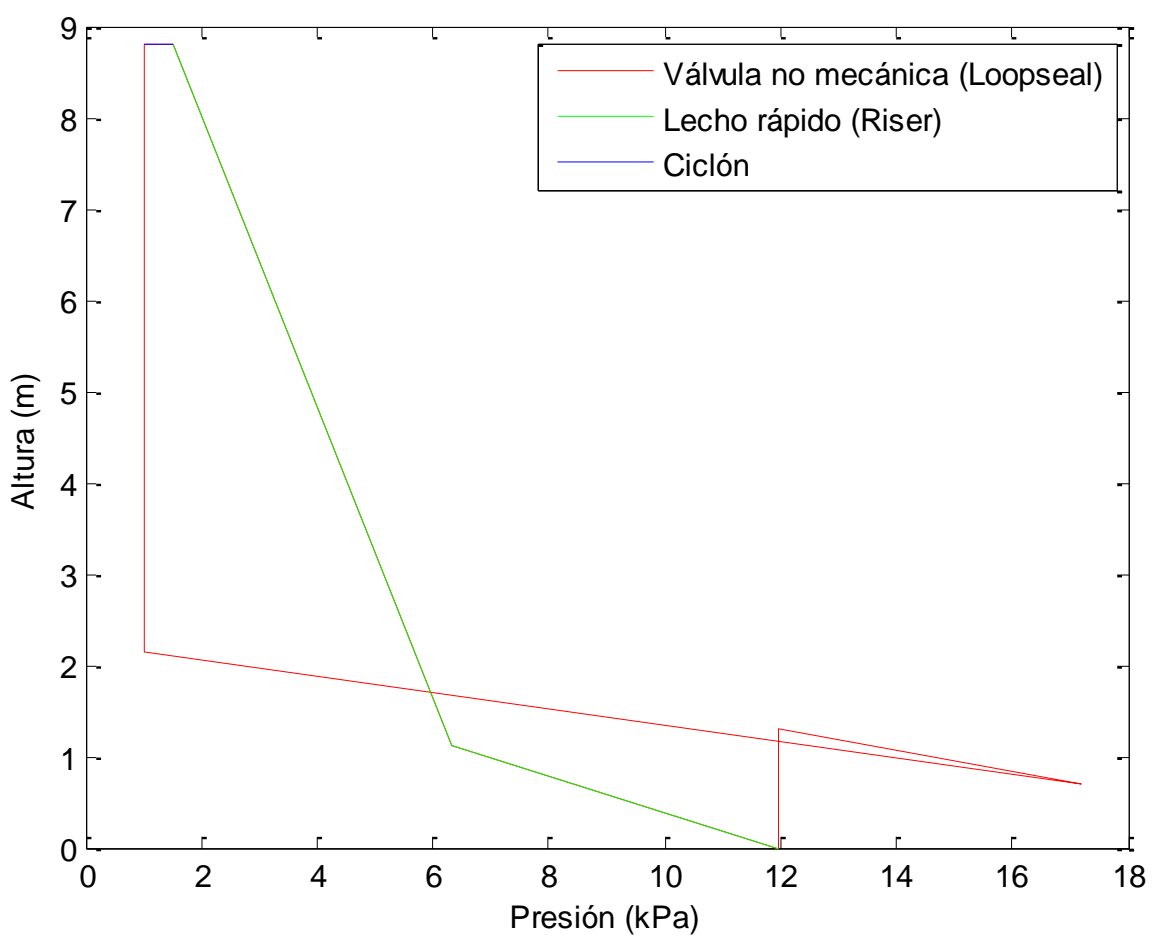

Figura 4.30. Perfil de presiones en el lecho fluidizado circulante_simulación.

Comparando ambas figuras se observa un comportamiento semejante en cuanto a la distribución de presiones en el gasificador, ya que la cámara de recirculación de sólidos se encuentra a una presión de $12 \mathrm{kPa}$, tanto para la simulación, cómo para la operación en planta. En el lecho rápido, Figura 4.31, se observan mayores presiones, siendo estas debidas a la placa de distribución de aire, no siendo contemplado en la simulación.

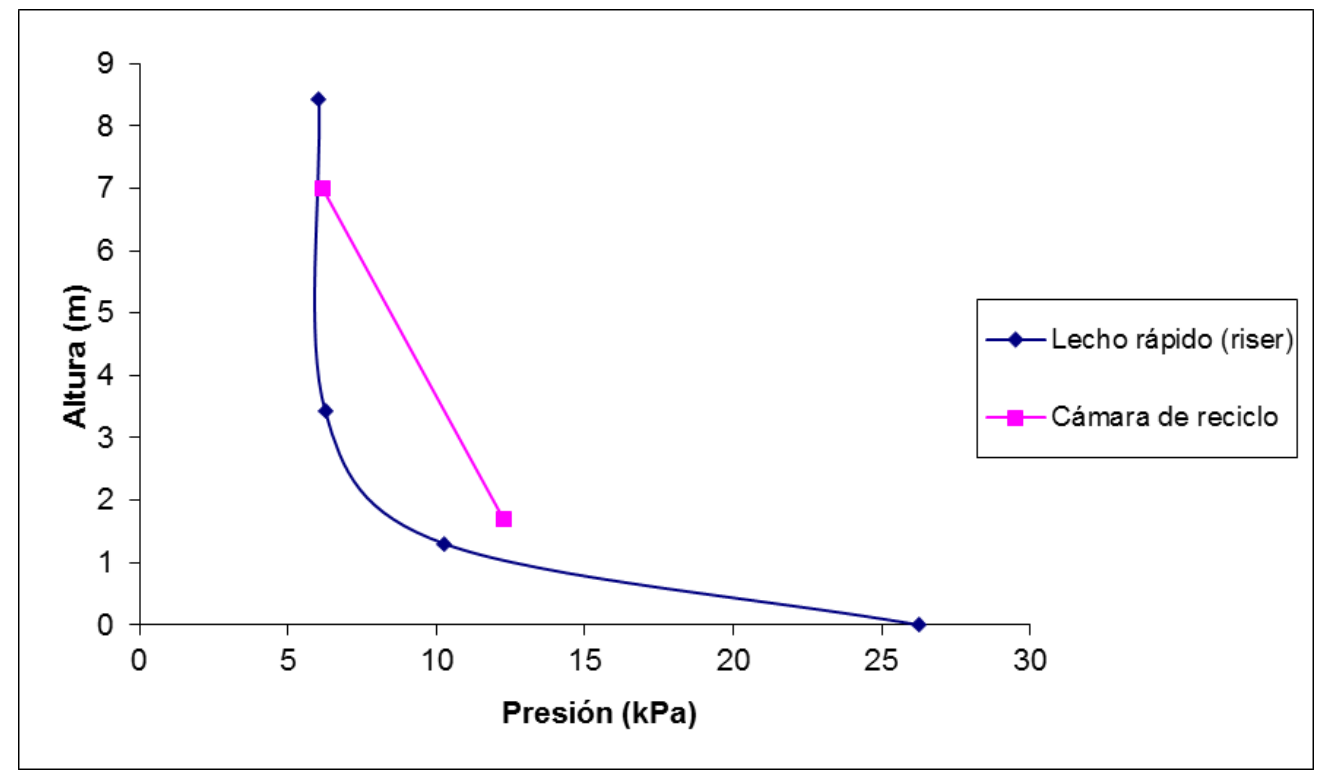

Figura 4.31. Perfil de presiones en el lecho fluidizado circulante 0,5 $\mathrm{MW}_{\mathrm{th}}$. 


\section{CAPÍTULO V. VIABILIDAD DE LA GASIFICACIÓN CON CSR}

Tras la obtención de combustibles adecuados para ser catalogados como CSR, se avanzó hacia la siguiente etapa, su viabilidad en un proceso de gasificación. Tanto el CSR de origen doméstico, como los CSR de origen industrial fueron utilizados como combustibles en procesos de recuperación energética mediante un lecho fluidizado burbujeante. Durante cada proceso de gasificación se analizaron parámetros clave: composición de gas, temperaturas y presiones lo largo del gasificador y generación de alquitranes. Además se recogieron las cenizas generadas durante el proceso para su análisis.

El CSR de origen doméstico fue empleado como combustible para un lecho fluidizado burbujeante mediante el análisis de diversos parámetros (presiones, temperaturas, composición del gas) durante cada uno de los ensayos, donde se modificaron las condiciones de gasificación. Respecto a los CSR de origen industrial, mezclas combustibles, fue probada su idoneidad como combustibles para gasificadores de lecho fluidizado en la unidad burbujeante mediante el análisis de presiones, temperaturas y composición del gas de proceso durante cada ensayo. Además, para cada una de las mezclas se analizó su contenido en alquitranes y componentes minoritario como: amoniaco, sulfuro de hidrógeno y cloro, debido a la elevada concentración detectada en la caracterización de los CSR. Finalmente, el CSR de menor contenido en cenizas se empleó como combustible en un gasificador de lecho fluidizado circulante con el mismo objetivo.

El análisis de los alquitranes se basó en las clasificaciones de la EPA y del ECN. Fueron analizados los 16 PAH'S fijados por la EPA, ver Figura 1.23, y cada uno de los compuestos indicados por el ECN en su clasificación como muestra la Tabla 5.1:

\begin{tabular}{|l|l|}
\hline Clase I & Gravimétricos \\
\hline Clase II & Componentes hetorocíclicos: piridina, fenol, cresol, quinolina. \\
\hline Clase III & Componentes aromáticos: xileno, estireno, tolueno. \\
\hline Clase IV & $\begin{array}{l}\text { Componentes poliaromáticos ligeros: naftaleno, metil-naftaleno, } \\
\text { bifenil, etenilnaftaleno, acenaftileno, acenafteno, fluoreno, fenantreno, } \\
\text { antraceno. }\end{array}$ \\
\hline Clase V & $\begin{array}{l}\text { Hidrocarburos aromáticos pesados: fluoranteno, pireno, benzo- } \\
\text { antraceno, criseno, benzo-fluoranteno, benzo-pireno, perileno, indeno- } \\
\text { pireno, dibenzo-antraceno, benzo-perileno }\end{array}$ \\
\hline
\end{tabular}

Tabla 5.1. Clasificación de los alquitranes según el ECN.

Los resultados obtenidos para todos los ensayos realizados en los gasificadores de lecho fluidizado burbujeante y circulante para el estudio de la viabilidad de los CSR se presentan en la Tabla 5.2 y en la Tabla 5.3. En ambas tablas se presentan cada uno de los ensayos realizados con un número indicativo. En la Tabla 5.2 se recopilan los datos de composición de gas, $\mathrm{PCI}_{\text {gas }}, \mathrm{Y}_{\text {gas }}$, EFG y $\mathrm{X}_{\mathrm{c}}$, mientras que en la Tabla 5.3 se muestra la producción de alquitranes en función de la clasificación ECN o EPA. Además, se presentan otros datos como temperaturas de operación, velocidades de fluidización, etc. 


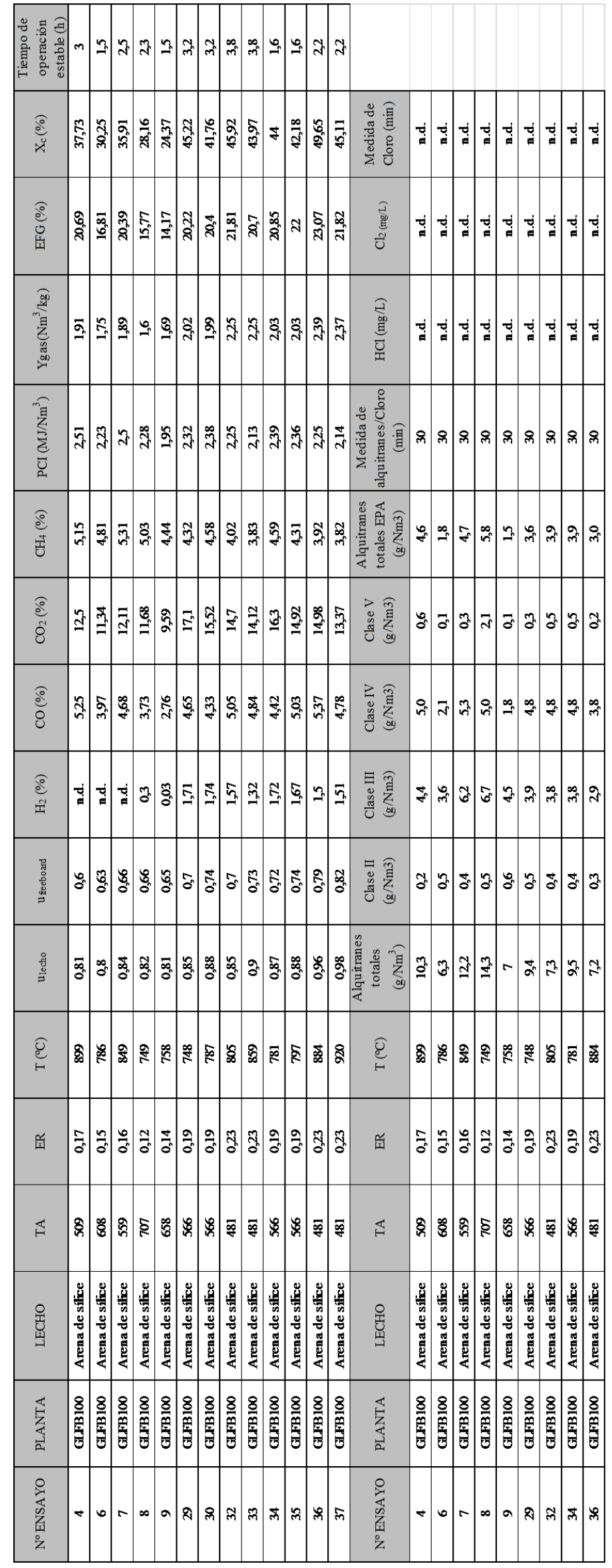

Tabla 5.2. Ensayos CSR de origen doméstico. 


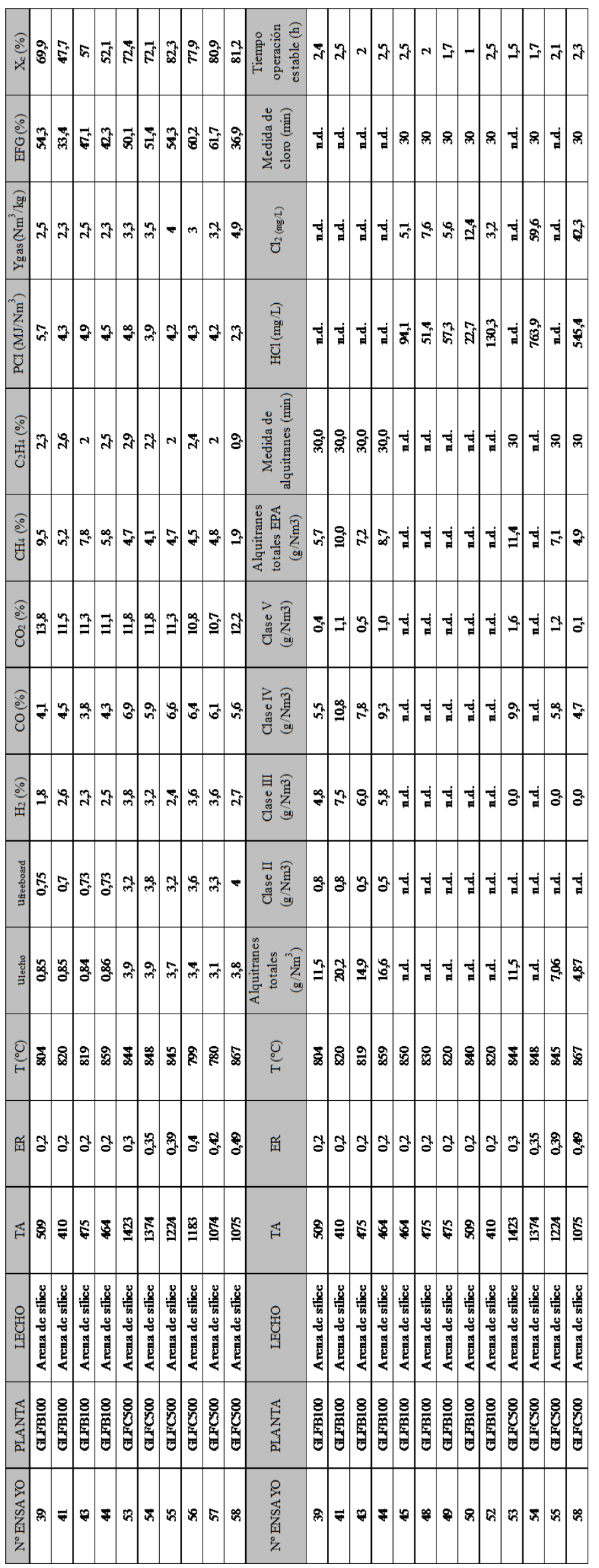

Tabla 5.3. Ensayos CSR de origen industrial. 


\subsection{CSR DE ORIGEN DOMÉSTICO. RSU Y ENVASES}

\subsubsection{INFLUENCIA DEL ER}

La viabilidad de los CSR de origen doméstico para recuperación energética en un proceso térmico convencional de gasificación se estudió a través del lecho fluidizado burbujeante definido en el apartado 2.5.1. El control del proceso de gasificación se llevó a cabo a través del análisis de variables clave como: composición de gas, contenido en alquitranes, producción de gas, poder calorífico, eficiencia de la gasificación en frío y conversión de carbono. El material de lecho empleado durante los ensayos fue arena de sílice, $428 \mu \mathrm{m}$, siendo el inventario de sólidos empleado de $50 \mathrm{~kg}$. La operación se llevó a cabo de manera autotérmica empleando aire como agente gasificante, requiriendo el uso de propano solamente hasta alcanzar la temperatura de ignición del combustible.

Con el objeto de reducir la cantidad de alquitranes generados en el proceso, la operación se realizó modificando las condiciones de gasificación, aumentando la cantidad de aire de proceso. Inicialmente, se realizaron ensayos solamente desde un ER de 0,12 a 0,17, ya que el gasificador de lecho fluidizado burbujeante no permitía un incremento del caudal de aire sin que se descontrolase el proceso. Tras algunas ligeras modificaciones, consistentes básicamente en un incremento del inventario de sólidos hasta $50 \mathrm{~kg}$, se consiguieron alcanzar valores de ER hasta 0,23.

Con esta cantidad de inventario de sólidos, y usando el mismo material de lecho, arena de sílice, se realizaron varios ensayos para dos valores de ER: 0,19-0,23. Para alcanzar las citadas condiciones de operación, se mantuvo constante el caudal de aire primario, variándose el combustible alimentado. Por tanto, se fijaron dos TA: $481 \mathrm{~kg} / \mathrm{m}^{2} \mathrm{~h}$ para un ER de 0,19 y $566 \mathrm{~kg} / \mathrm{m}^{2}$ para un ER de 0,23 , respectivamente. El caudal de aire primario se mantuvo constante, variando el combustible alimentado hasta alcanzar la condición de operación seleccionada. Para la condición de operación de $\mathrm{ER}=0,19$, las velocidad del lecho fueron más constantes, entre 0,84 y $0,88 \mathrm{~m} / \mathrm{s}$, mientras que las velocidades a la salida del gasificador variaron entre 0,69 y $0,81 \mathrm{~m} / \mathrm{s}$. Para la condición de operación de $E R=0,23$, las velocidades alcanzadas en el lecho, variaron entre 0,85 y $1 \mathrm{~m} / \mathrm{s}$, mientras que las velocidades alcanzada a la salida del gasificador fueron de $0,7 \mathrm{a}$ $0,8 \mathrm{~m} / \mathrm{s}$ para los distintos ensayos realizados.

A continuación, se van a mostrar los ensayos realizados con ER: 0,12-0,17 empleando un inventario de sólidos de $25 \mathrm{~kg}$, junto con los realizados a un ER: 0,19-0,23 empleando un inventario de sólidos de $50 \mathrm{~kg}$. Al variar el inventario de sólidos, se observará la variación de parámetros clave para el estudio de un proceso de gasificación como: composición de gas, producción de gas, EFG, conversión de carbono y alquitranes generados. El inventario de sólidos máximo fijado ha sido de $50 \mathrm{~kg}$, ya que debido a las características constructivas de la unidad burbujeante, altura $3 \mathrm{~m}$, esta cantidad de inventario es la máxima que permite una correcta operación de fluidización. Una mayor cantidad de inventario de sólidos, expandiría el lecho más de manera que se reduciría la zona de transporte, pudiendo verse arrastradas partículas del lecho y afectar a la admisión del combustible. Además, se reduciría el tiempo de residencia en la zona de transporte afectando a reacciones propias del proceso de gasificación. 


\subsubsection{Composición del gas}

En la Figura 5.1 se muestra la composición del gas de proceso con respecto al ER. Una vez alcanzadas condiciones estables de operación se procedió al análisis de una alícuota del gas de proceso. La medida del gas de proceso fue realizada mediante el análisis de su composición gaseosa en continuo: $\mathrm{O}_{2}, \mathrm{H}_{2}, \mathrm{CO}_{2}, \mathrm{CO}$ y $\mathrm{CH}_{4}$, mediante diversos analizadores, es decir: analizador de conductividad, analizador paramagnético y NDIR. Para cada ensayo, este análisis se prolongó durante 30 minutos para cada una de las condiciones fijadas.

El contenido en dióxido de carbono experimentó un aumento paulatino con el ER, pasando de un 9,5\% a un 12,5\% para los ensayos de ER: 0,12-0,17, y un descenso desde un $15,9 \pm 0,9 \%$ para un $E R=0,19$ a un $14,3 \pm 0,7 \%$ para un $E R=0,23$. Teniéndose en cuenta los datos correspondientes a los valores de ER: 0,19-0,23 se observa un descenso moderado del contenido de $\mathrm{CO}_{2}$. El monóxido de carbono sufrió un ligero incremento para los ensayos de ER: 0,12-0,17 desde un valor de 2,8\% hasta un valor de 5,2\%. Este mismo comportamiento se observó para los ensayos de ER: 0,19-0,23, ya que el contenido de $\mathrm{CO}$ aumentó desde un valor de $4,6 \pm 0,3 \%$ hasta un valor de $5 \pm 0,3 \%$.

El contenido en metano, se mantuvo prácticamente constante, situándose entre un 4,4$5,2 \%$ para los ensayos de ER: $0,12-0,17$, y variando desde un $4,5 \pm 0,2 \%$ a un $3,9 \pm 0,1 \%$ para los ensayos de $E R=0,19-0,23$, respectivamente, lo que se tradujo en un ligero descenso del contenido de $\mathrm{CH}_{4}$. El hidrógeno mostró una reducción en su contenido al pasar de $1,7 \%$ a $1,5 \pm 0,1 \%$, para los valores de ER: 0,19-0,23, respectivamente.

Los valores mostrados en cuanto al contenido de $\mathrm{CO}, \mathrm{CO}_{2}$ y $\mathrm{CH}_{4}$ son similares a los arrojados por otros estudios sobre CSR [109, 110], sin embargo, el contenido en hidrógeno resultó ser muy bajo.

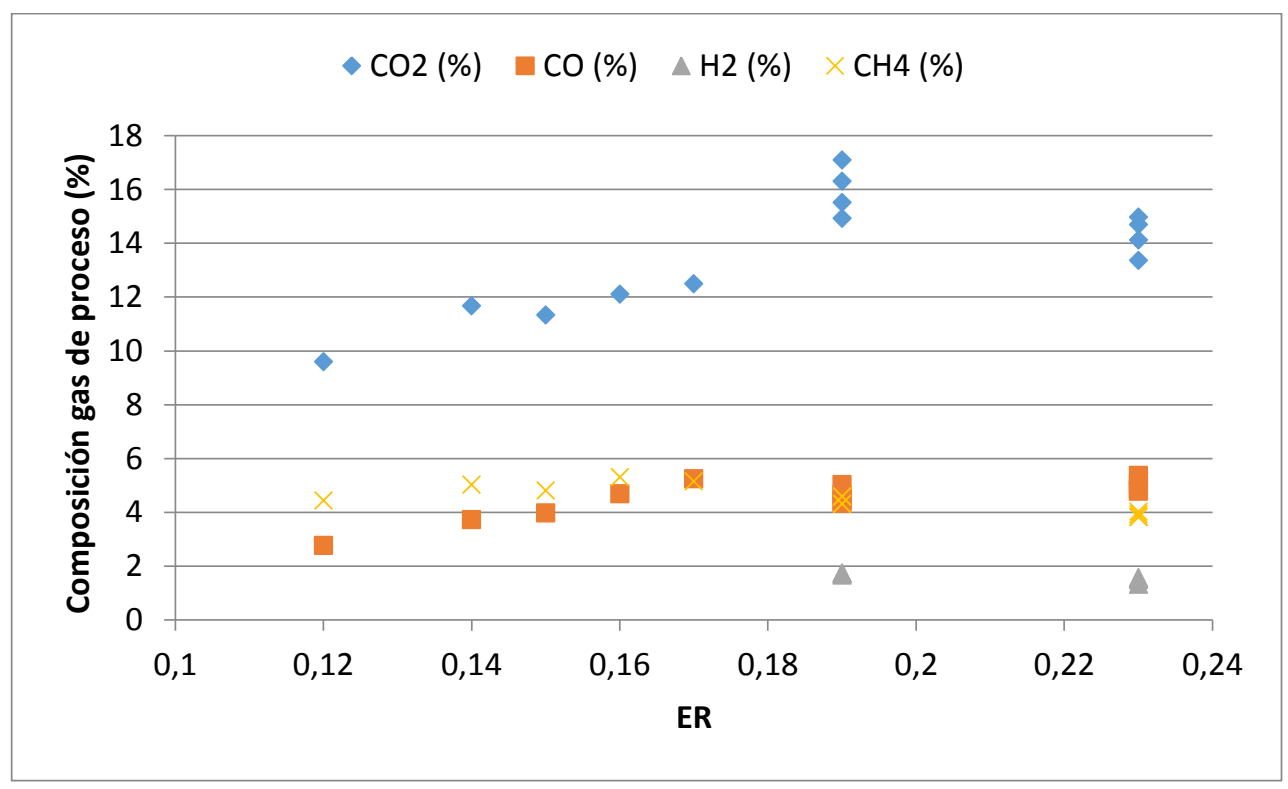

Figura 5.1. Composición del gas de proceso en función del ER en el gasificador de LFB para el CSR de origen doméstico. 


\subsubsection{Producción de gas y poder calorífico inferior}

En la Figura 5.2 se presentan la producción de gas y el poder calorífico inferior del gas de gasificación en función del ER del proceso.

Se observa que la producción de gas de proceso experimentó un incremento a medida que se aumentó el ER, siendo de 1,69 a 2,3 Nm3/kg combustible b.s.s.c. Este hecho, se justifica con que la mayor contribución en la producción de gas corresponde al agente gasificante, con independencia del inventario de sólidos empleado en cada uno de los ensayos, ya que el caudal de aire primario utilizado fue el mismo en todos los ensayos.

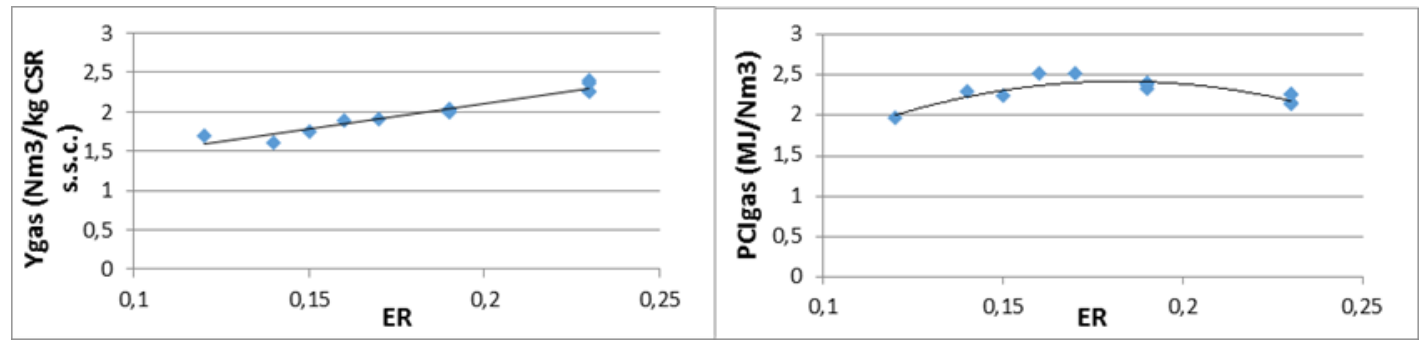

Figura 5.2. Producción de gas y PCI en función del ER para el CSR de origen doméstico en el gasificador de LFB para el CSR de origen doméstico.

El poder calorífico inferior del gas de proceso mostró valores de 1,95 a 2,5 $\mathrm{MJ} / \mathrm{Nm}^{3}$, ver Figura 5.2. Los valores obtenidos de poder calorífico reflejaron un máximo para valores de ER de 0,16-0,17, ya que éste se fue incrementado para los ensayos de ER: 0,12-0,17. Sin embargo, la tendencia que mostró para los ensayos de ER: 0,19-0,23 fue descendente, favoreciéndose las reacciones de oxidación total, generando más $\mathrm{CO}_{2}$ en detrimento de $\mathrm{CO}$ e $\mathrm{H}_{2}$. No obstante, el poder calorífico inferior esta subestimado, ya que el analizador empleado, un NDIR, solamente disponía de cuatro canales de medida, es decir: $\mathrm{CH}_{4}, \mathrm{CO}, \mathrm{CO}_{2}$ e $\mathrm{H}_{2}$. Este hecho hace que la estimación del poder calorífico inferior se vea reducida a tenor de los resultados vistos en estudios de gasificación con CSR, donde la contribución de las especies $\mathrm{C}_{2} \mathrm{H}_{2}, \mathrm{C}_{2} \mathrm{H}_{4}$ y $\mathrm{C}_{2} \mathrm{H}_{6}$ es significativa $[63,109$, 110].

\subsubsection{Eficiencia en frío de la gasificación y conversión de carbono}

En la Figura 5.3 se observa la evolución de la eficiencia en frío y la conversión de carbono durante el proceso de gasificación. La EFG arrojó valores muy bajos en

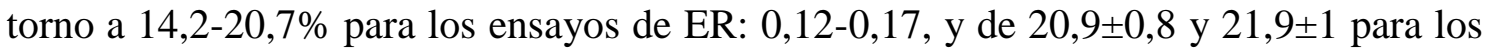
ensayos de ER: 0,19-0,23, respectivamente, no mostrándose afectados estos valores por la variación de ER, ya que el aumento en la producción de gas se compensó con la disminución del poder calorífico. Ambos valores fueron inferiores en comparación con los mostrados por otros CSR [109, 110].

La conversión de carbono, mostró valores de 24,4-37,7\% para los ensayos de ER: 0,120,17 que se incrementaron al aumentar ER. El mismo comportamiento mostraron los ensayos de ER: 0,19-0,23, mostrando los siguientes valores: 43,3 $\pm 1,6$ y 46,2 $\pm 2,5$. Este aumento se debió a que un mayor aporte de aire favoreció la conversión de las partículas sólidos del combustible en un producto gaseoso. Aunque la tendencia que mostró la conversión de carbono es semejante a la mostrada en la gasificación de otros 
CSR, ésta puede estar ligeramente subestimada, ya que solamente se contabilizaron las siguientes especies: $\mathrm{CO}_{2}, \mathrm{CO}, \mathrm{CH}_{4}[109,110]$.

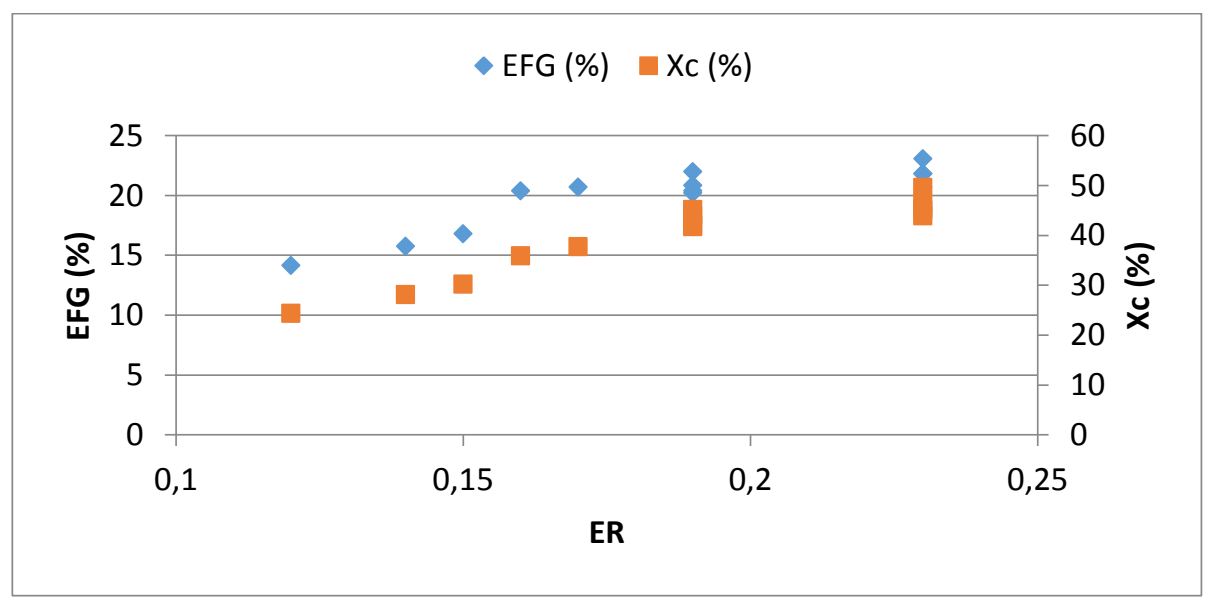

Figura 5.3. EFG y conversión de carbono para el CSR de origen doméstico en el gasificador de LFB para el CSR de origen doméstico.

\subsubsection{Alquitranes}

La toma de muestra para la realización del tren de alquitranes fue afectada, sufriendo taponamientos, debido a la cantidad de cenizas volantes que se formaron durante el proceso de gasificación de este CSR de origen doméstico. En la primera tanda de ensayos, correspondientes a un ER: 0,12-0,17, con un inventario de sólidos de $25 \mathrm{~kg}$, se registraron diversos problemas a la hora de obtener muestras de alquitranes, ver Figura 5.4, para su posterior análisis en laboratorio, resultando en análisis poco útiles, ya que la toma de muestra no fue correcta debido a estos inconvenientes, quedando la práctica totalidad de sus resultados sin ningún valor, a excepción de los resultados para los ER: 0,16-0,17. Al aumentar el ER, estos problemas se minimizaron, ya que para un mismo caudal de aire de gasificación, la cantidad de combustible alimentado fue menor. Estos problemas no se arrastraron en los ensayos posteriores, ya que al incrementar el caudal de aire primario para aumentar el ER, se evitaron en gran medida estos taponamientos.

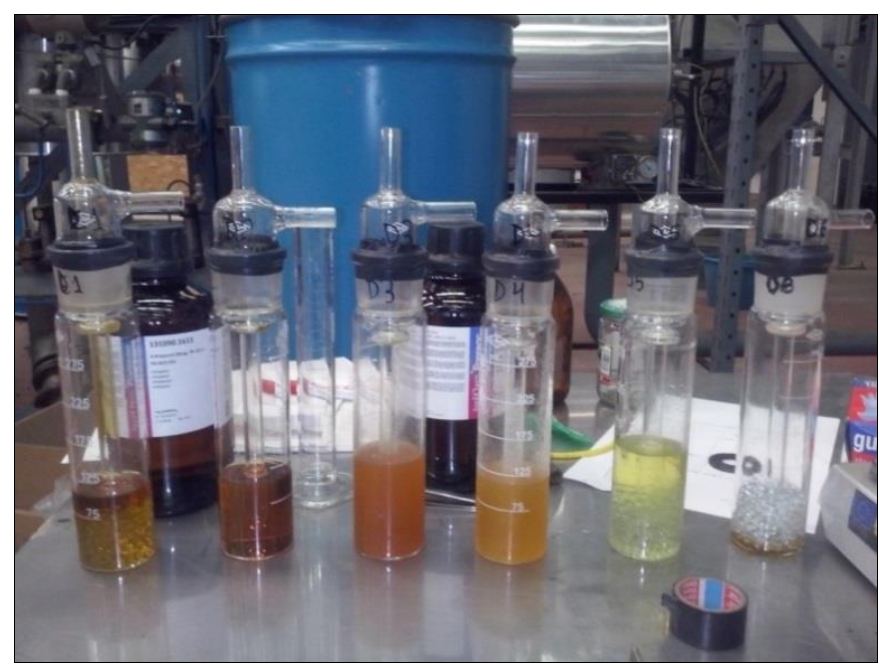

Figura 5.4. Borboteadores tras un tren de alquitranes. 
En las Figuras 5.5 y 5.6 se representan los alquitranes medidos en base a la clasificación propuesta por el ECN, ver Tabla 5.1. Todos los compuestos indicados en la Tabla 5.1 fueron determinados, a excepción de aquellos que no pudieron detectarse por estar por debajo del límite de detección del analizador o que fue imposible su determinación al carecer de los patrones correspondientes.

Los alquitranes que se muestran son los compuestos que se incluyen en las clases II, III, IV y V, a excepción del cresol y la quinolina, clase II, el estireno, clase III, el bifenil, clase IV, y el perileno, clase V, que no fueron analizados al no disponerse de los patrones correspondientes. No obstante, la mayoría de los compuestos incluidos en la clasificación del ECN sí que pudieron medirse.

En la Figura 5.5 se observa la evolución de las clases en las que se dividen los alquitranes para los ensayos de ER: 0,12-0,17. Solamente son confiables los resultados que arrojan los ER: 0,16-0,17, ya que en el resto se realizaron tomas de muestra muy complicadas y poco precisas.

Las clases IV y V, correspondientes a componentes poliaromáticos, experimentaron una reducción con el aumentó el ER de 0,16 a 0,17 , pasando de 5,3 a $5 \mathrm{~g} / \mathrm{Nm}^{3}$ para la clase IV y un aumento de 0,31 a $0,62 \mathrm{~g} / \mathrm{Nm}^{3}$ para la clase $\mathrm{V}$, pudiendo ser debida a los mecanismos de formación de estos alquitranes, es decir: craqueo de los alquitranes de clase I o a las reacciones de los alquitranes del resto de clases. Se observa un mayor contenido en alquitranes corresponde a la clase IV, aquellos que condensan a bajas temperaturas, como ocurre en otros estudios con CSR, siendo menor en contenido la clase $\mathrm{V}$, aquellos que condensan a mayor temperatura [12].

La clase II sufrió una ligera reducción en su contenido, pasando de 0,4 a $0,3 \mathrm{~g} / \mathrm{Nm}^{3}$. Y la clase III mostró una reducción, pasando de 6,2 a $4,5 \mathrm{~g} / \mathrm{Nm}^{3}$. El contenido de los alquitranes de clase II, III y IV disminuyó al aumentar ER, al encontrarse favorecidos por las reacciones de oxidación [224]. Por ende, el contenido total de alquitranes fue de $10,3 \mathrm{~g} / \mathrm{Nm}^{3}$ y de $12,2 \mathrm{~g} / \mathrm{Nm}^{3}$ para un ER de 0,16 y 0,17 , respectivamente. Estos valores son menores que los mostrados por otros CSR con alto contenido en material plástico y textil $[64,108,109,110]$.

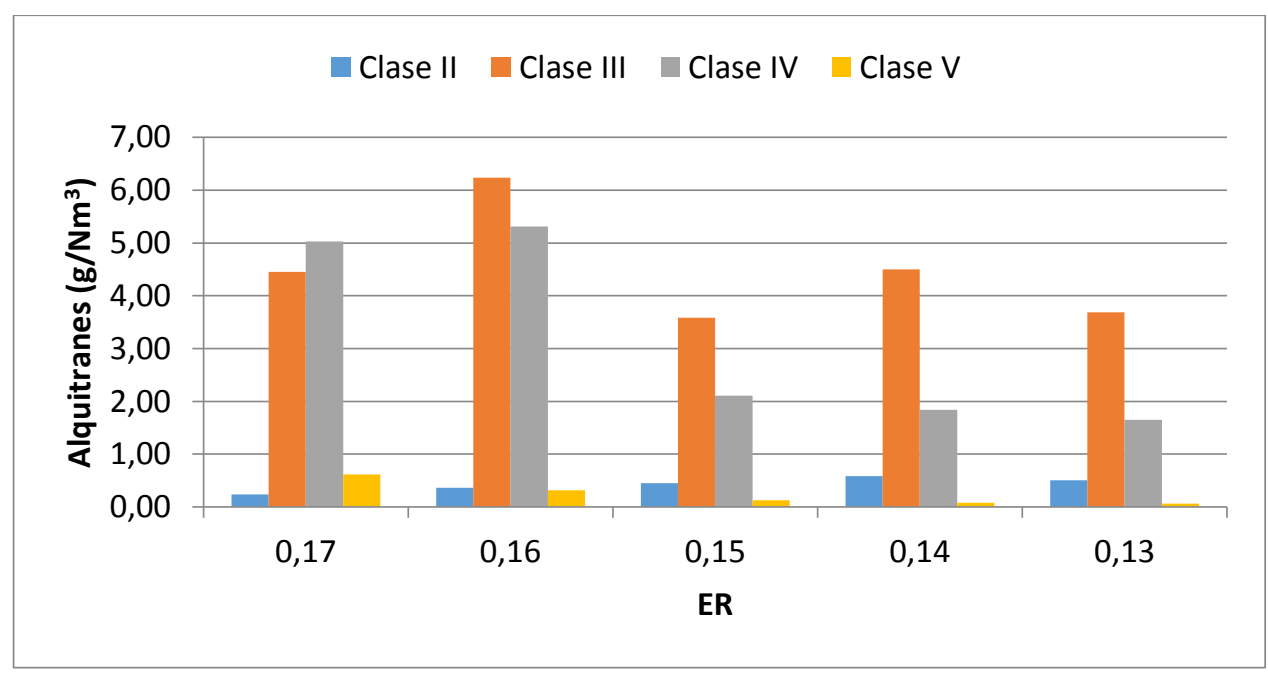

Figura 5.5. Alquitranes según clasificación del ECN en el gasificador de LFB para el CSR de origen doméstico. 
En la Figura 5.6 se observa la evolución de las clases en las que se dividen los alquitranes. Las clases IV y $\mathrm{V}$, correspondientes a componentes poliaromáticos, experimentaron una reducción con el aumentó el ER de 0,19 a 0,23, pasando de 4,8 a $3,8 \mathrm{~g} / \mathrm{Nm}^{3}$ para la clase IV y de 0,4 a $0,3 \mathrm{~g} / \mathrm{Nm}^{3}$ para la clase V. Se observa un mayor contenido en alquitranes corresponde a la clase IV, aquellos que condensan a bajas temperaturas, como ocurre en otros estudios con CSR, siendo menor en contenido la clase $\mathrm{V}$, aquellos que condensan a mayor temperatura [12]. La clase II sufrió una ligera reducción en su contenido, pasando de 0,5 a $0,3 \mathrm{~g} / \mathrm{Nm}^{3}$, mientras que la clase III pasando de 3,9 a $2,9 \mathrm{~g} / \mathrm{Nm}^{3}$. El contenido de los alquitranes de clase II, III y IV disminuyó al aumentar ER, al favorecerse las reacciones de oxidación [224].

Por tanto, el contenido total de alquitranes fijado para un ER de 0,19 fue de $9,5 \mathrm{~g} / \mathrm{Nm}^{3}$ $\left(19,5 \mathrm{~g} / \mathrm{kg}\right.$ b.s.s.c.) y el fijado para un ER de 0,23 fue de $7,3 \mathrm{~g} / \mathrm{Nm}^{3}(16,8 \mathrm{~g} / \mathrm{kg}$ b.s.s.c.). Estos valores son menores que los mostrados por otros CSR con alto contenido en material plástico y textil $[64,108,109,110]$.

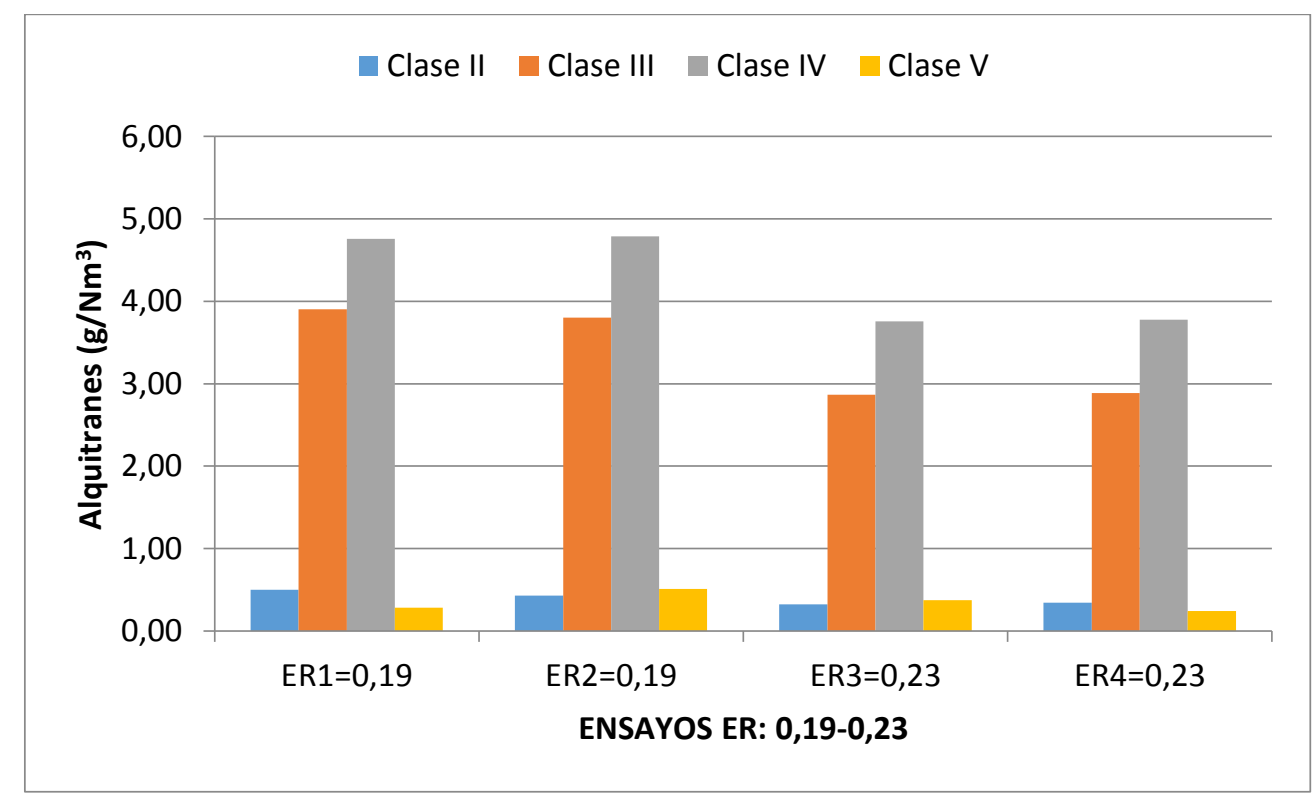

Figura 5.6. Alquitranes según clasificación del ECN en el gasificador de LFB para el CSR de origen doméstico.

Según la clasificación de la EPA se tuvieron los siguientes valores de alquitranes totales: $3,60 \mathrm{~g} / \mathrm{Nm}^{3}\left(7,2 \mathrm{~g} / \mathrm{kg}\right.$ b.s.s.c.) y $3,92 \mathrm{~g} / \mathrm{Nm}^{3}(7,9 \mathrm{~g} / \mathrm{kg}$ b.s.s.c.) para un $\mathrm{ER}=0,19$, y $2,68 \mathrm{~g} / \mathrm{Nm}^{3}(6,0 \mathrm{~g} / \mathrm{kg}$ b.s.s.c. $)$ y $2,96 \mathrm{~g} / \mathrm{Nm}^{3}$ (7,1 g/kg b.s.s.c.) para un $\mathrm{ER}=0,23$. Se observó, por tanto, un descenso de alquitranes con el aumento del ER.

\subsubsection{Cenizas de proceso}

En la Tabla 5.4 se muestran los análisis de las cenizas recogidas en los proceso de gasificación del CSR de origen doméstico para un ER de 0,19 y 0,23. Además, se incluyen los análisis del lecho utilizado durante los ensayos.

El análisis de las cenizas tras los ensayos de gasificación del CSR muestra un contenido significativo de carbono, que se reduce al aumentar el ER de 5,4 a 4,1\%. El contenido en cloro resultó ser semejante para ambas condiciones de gasificación, entre 4,8 y un $5,2 \%$. Respecto a los metales encontrados en las cenizas, estos análisis arrojaron un 
elevado contenido en aluminio, 9-11\%, calcio, 15-16\%, silicio, 13-15\%, hierro, 5,7$7,2 \%$, y magnesio, 1,2\%. Además, se observó un elevado contenido en sodio, 3\%, y potasio, 2,2-2,4\%, lo que se traduce en significativo riesgo de sinterización, sin embargo, el elevado contenido en calcio y magnesio lo compensa. No se detectó ningún sinterizado, ni aglomeración durante los ensayos con el CSR.

Respecto al lecho, se observa un elevado contenido en calcio, 5,8-7,2\%, y hierro, 1,5$2,6 \%$. También se detectó un contenido relativamente alto en cloro, entre 0,79 y 1,9\%, respectivamente.

\begin{tabular}{|l|c|c|c|c|}
\hline $\mathbf{C S R}$ & $\mathbf{E R = 0 , 1 9}$ & $\begin{array}{c}\text { Lecho } \\
\mathbf{E R = 0 , 1 9 )}\end{array}$ & $\mathbf{E R = 0 , 2 3}$ & $\begin{array}{c}\text { Lecho } \\
(\mathbf{E R = 0 , 2 3 )}\end{array}$ \\
\hline $\mathrm{C}$ & 5,4 & $<1$ & 4,1 & $<1$ \\
\hline $\mathrm{H}$ & $<0,4$ & $<0,4$ & $<0,4$ & $<0,4$ \\
\hline $\mathrm{N}$ & 0,24 & $<0,05$ & 0,15 & $<0,05$ \\
\hline $\mathrm{Cl}$ & 4,83 & 1,87 & 5,18 & 0,79 \\
\hline $\mathrm{Al}$ & 11 & 1,2 & 9,0 & 0,96 \\
\hline $\mathrm{Ba}$ & 0,079 & 0,029 & 0,078 & 0,024 \\
\hline $\mathrm{Ca}$ & 16 & 7,2 & 15 & 5,8 \\
\hline $\mathrm{Fe}$ & 5,7 & 2,6 & 7,2 & 1,5 \\
\hline $\mathrm{K}$ & 2,2 & 0,62 & 2,4 & 0,19 \\
\hline $\mathrm{Mg}$ & 1,2 & 0,34 & 1,2 & 0,26 \\
\hline $\mathrm{Mn}$ & 0,065 & 0,019 & 0,065 & 0,013 \\
\hline $\mathrm{Na}$ & 3,1 & 1,1 & 3,2 & 0,53 \\
\hline $\mathrm{P}$ & 1,0 & 0,72 & 1,1 & 0,38 \\
\hline $\mathrm{S}$ & 0,86 & 0,28 & 0,61 & 0,12 \\
\hline $\mathrm{Si}$ & 15 & 33 & 13 & 38 \\
\hline $\mathrm{Sr}$ & 0,048 & 0,015 & 0,045 & 0,012 \\
\hline $\mathrm{Ti}$ & 0,62 & 0,31 & 0,69 & 0,24 \\
\hline $\mathrm{Zn}$ & 0,23 & 0,14 & 0,25 & 0,058 \\
\hline
\end{tabular}

Tabla 5.4. Composición de las cenizas de ciclón y del lecho de los CSR de origen doméstico tras los ensayos de gasificación.

El material de lecho empleado en los ensayos del CSR se cambió tras cada ensayo, aunque no sufriera atrición. Tras finalizar cada ensayo, éste fue extraído para toma de muestra y ser pesado. Al principio del ensayo la tolva fue llenada con $128 \mathrm{~kg}$ de CSR, con un contenido en ceniza de $29,8 \mathrm{~kg}$. En el primer ensayo, ER=0,19, se recogieron $26,5 \mathrm{~kg}$ de ceniza tras 3,2 horas de operación, lo que resultó en una pérdida de $3 \mathrm{~kg}$ en ceniza volante, ya que el material de lecho pesado fue de $50,3 \mathrm{~kg}$. Respecto al segundo ensayo, $\mathrm{ER}=0,23$, se recogieron $24,5 \mathrm{~kg}$ de ceniza provenientes de los $128 \mathrm{~kg}$ de CSR introducidos en la tolva al principio del ensayo. Esto significó un tiempo de operación de 3,8 horas. La pérdida de ceniza como ceniza volante resultó en $3,2 \mathrm{~kg}$, ya que la cantidad de ceniza y partículas sólidas en el lecho fue de $52,1 \mathrm{~kg}$. Se repitieron ambos ensayos con la misma condición de ER, sin embargo, esta vez el material de lecho se mantuvo hasta su finalización.

No obstante, la cantidad de ceniza recogida por el ciclón fue muy similar a los ensayos previos. Por tanto, los porcentajes de pérdida de ceniza por chimenea representaron un 11 y un $13 \%$ para $E R=0,19$ y $E R=0,23$, respectivamente. Estos altos porcentajes de ceniza volante hacen que no sea necesaria la extracción del lecho en continuo. Sin 
embargo, subyace la necesidad de un mejor sistema de retención de partículas sólidas que un ciclón, ya que el diámetro medio de partícula retenida por el ciclón fue de 95,2 a $107,8 \mu \mathrm{m}$, ver Anexo IV.

\subsection{CSR DE ORIGEN INDUSTRIAL. INDUSTRIA PAPELERA}

\subsubsection{INFLUENCIA DEL LODO DE DESTINTADO}

El uso potencial de las mezclas obtenidas a partir de rechazos de papelote y del proceso de pulpado mezclados con lodo de destintado fue estudiado en un proceso térmico convencional, gasificación, a través del lecho fluidizado burbujeante definido en el apartado 2.5.1. La viabilidad del proceso de gasificación de las mezclas se llevó a cabo a través del control de variables clave como composición de gas, contenido en alquitranes, contenido en cloro, producción de gas, poder calorífico, eficiencia de la gasificación en frío y conversión de carbono.

Para establecer una comparativa lo más fiel posible entre las distintas mezclas, las variables citadas anteriormente fueron comparadas para un mismo valor de ER. La selección del valor de ER se realizó en base a una serie de ensayos preliminares que arrojaron una operación estable en el gasificador para un valor de 0,2.

Este valor fue el máximo permitido durante el proceso de gasificación de las mezclas en la unidad burbujeante, ya que su aumento se tradujo en un incremento de la temperatura de lecho, impidiendo una operación estable para las mezclas M1 y M2. El material de lecho empleado durante los ensayos fue arena de sílice, $428 \mu \mathrm{m}$, siendo el inventario de sólidos empleado de $50 \mathrm{~kg}$. La operación se llevó a cabo de manera autotérmica empleando aire como agente gasificante, empleándose propano solamente hasta alcanzar la temperatura de ignición del combustible.

La operación durante el proceso de gasificación se ha realizado manteniendo constante la velocidad en el lecho y en la zona de salida (freeboard). Las velocidades alcanzadas fueron de $0,86 \mathrm{~m} / \mathrm{s}$ y $0,72 \mathrm{~m} / \mathrm{s}$, respectivamente. La selección de una velocidad constante se realizó con el objeto de disponer del mismo tiempo de residencia para cada combustible de manera que el proceso de gasifición fuera lo más semejante posible.

El caudal de aire usado como agente gasificante y de fluidización se mantuvo constante, variando el combustible alimentado. Estas variaciones se deben al distinto comportamiento del material sólido en su alimentación, es decir: la tasa de alimentación (TA) varió en función del combustible alimentado, ya que para alcanzar el mismo ER fue necesario alimentar una mayor cantidad de combustible a medida que la mezcla incluyó un mayor contenido en lodo de destintado. Las TA fueron de $410 \mathrm{~kg} / \mathrm{m}^{2} \mathrm{~h}$ para M1, $464 \mathrm{~kg} / \mathrm{m}^{2} \mathrm{~h}$ para M2, $475 \mathrm{~kg} / \mathrm{m}^{2} \mathrm{~h}$ para M3 y $509 \mathrm{~kg} / \mathrm{m}^{2} \mathrm{~h}$ para M4, respectivamente.

Las temperaturas alcanzadas en el lecho, mostraron valores similares, ya que éstas se encuentran ligadas al ER al ser variables dependientes. Los valores de las temperaturas del lecho variaron de 805 a $859{ }^{\circ} \mathrm{C}$, correspondiendo los valores más bajos con el combustible con mayor proporción de lodo. No obstante, las temperaturas en la zona de salida también fueron del mismo orden de magnitud, variando desde 644 a $666{ }^{\circ} \mathrm{C}$. 


\subsubsection{Composición del gas y poder calorífico}

La Tabla 5.5 muestra la composición del gas de proceso para cada una de las mezclas combustibles ensayadas. El análisis del gas de proceso se llevó a cabo mediante un FTIR y un FID de manera que se analizaron distintos compuestos orgánicos para observar con más precisión la influencia del lodo de destintado.

El gas de proceso obtenido al gasificar mezclas combustibles con mayor contenido en lodo arrojó valores muy significativos en el contenido de metano, pasando de un 5,2\% a un $9,5 \%$ cuando el lodo añadido a los rechazos fue de 5 a $35 \%$. Por el contrario, se produjo una reducción en el contenido de hidrógeno en el gas, pasando de un 2,6\% a un $1,8 \%$. Este hecho muestra una relación inversa en el contenido de hidrógeno y metano en el gas de proceso. Por tanto, un aumento del contenido en metano implica una reducción del contenido en hidrógeno.

El dióxido de carbono no experimentó ningún cambio apreciable, mientras que el monóxido de carbono se redujo ligeramente con el aumento de la cantidad de lodo presente en el combustible. Respecto al resto de hidrocarburos, no siguieron ninguna tendencia, aunque si mostraron valores similares para cada combustible, no apreciándose grandes diferencias. No obstante, el gas de proceso generado con la gasificación de las mezclas mostró un alto contenido en etileno.

La composición del gas de proceso mostró un elevado contenido en metano y un bajo contenido en hidrógeno que le hace diferir de algunos estudios con CSR [108, 109, 110], aunque ese aumento del metano sí que ha sido observado en otros estudios al emplear CSR o CDR con alto contenido en material plástico, o incluso en mezclas de carbón y biomasa con residuos plásticos [64, 110, 217, 218, 219].

\begin{tabular}{|l|c|c|c|c|}
\hline & M1 & M2 & M3 & M4 \\
\hline $\mathrm{CO}_{2}(\%)$ & 11,45 & 11,12 & 11,26 & 13,80 \\
\hline $\mathrm{CO}(\%)$ & 4,54 & 4,33 & 3,83 & 4,07 \\
\hline $\mathrm{H}_{2}(\%)$ & 2,59 & 2,47 & 2,34 & 1,79 \\
\hline $\mathrm{CH}_{4}(\%)$ & 5,15 & 5,80 & 7,84 & 9,52 \\
\hline $\mathrm{C}_{2} \mathrm{H}_{2}(\%)$ & 0,13 & 0,16 & 0,16 & 0,19 \\
\hline $\mathrm{C}_{2} \mathrm{H}_{4}(\%)$ & 2,57 & 2,49 & 2,04 & 2,34 \\
\hline $\mathrm{C}_{2} \mathrm{H}_{6}(\%)$ & 0,11 & 0,16 & 0,14 & 0,16 \\
\hline $\mathrm{PCI}\left(\mathrm{MJ} / \mathrm{Nm}^{3}\right)$ & 4,3 & 4,5 & 4,9 & 5,7 \\
\hline
\end{tabular}

Tabla 5.5. Composición y PCI del gas de proceso para los CSR de origen industrial.

El poder calorífico inferior del gas de proceso mostró valores de 4.3 a $5.7 \mathrm{MJ} / \mathrm{Nm}^{3}$, ver Tabla 5.5, aumentando en función de la cantidad de lodo añadido. Aunque en principio se podría aventurar un mayor poder calorífico del gas de proceso cuanta más proporción de rechazos existiera en las mezclas combustibles en función de la caracterización, la composición obtenida mediante la gasificación de los combustibles reflejó un comportamiento totalmente diferente. Sin embargo, el incremento que experimentó el contenido en metano a medida que aumentó la proporción de lodo en el combustible provocó un aumento considerable en el poder calorífico del gas de proceso. El poder calorífico mostrado es propio de estudios de gasificación empleando aire como agente gasificante [64, 108, 109, 110]. 


\subsubsection{Producción de gas, eficiencia en frio de la gasificación y conversión de carbono}

La producción de gas se mantuvo relativamente constante, variando de 2,1 a 2,3 $\mathrm{Nm}^{3} / \mathrm{kg}$ combustible b.s.s.c, mostrándose similar a otros estudios con CSR, pero menor que en otros, por tanto, estas diferencias indican que el combustible CSR gasificado influye en la producción de gas de proceso [64, 108, 109, 110]. El haber mantenido la producción de gas constante se debe a que la mayor contribución en la producción de gas corresponde al agente gasificante, habiéndose utilizado aire para todos los combustibles. No obstante, ninguna variación significativa ha podido observarse debido a que el ER empleado en los ensayos de gasificación fue el mismo, evitando cualquiera diferencia en la producción de gas, puesto que un aumento del ER originaría un aumento en la producción de gas.

En la Figura 5.7, se observa la evolución de la eficiencia de gasificación en frio y la conversión de carbono en las mezclas combustibles, es decir: con la cantidad de lodo añadido. La eficiencia de gasificación en frío mostró valores de 35 a $54 \%$, incrementándose con la cantidad de lodo presente en las mezclas combustibles. La eficiencia resultó ser baja para M1, mezcla con bajo contenido en lodo (5\%), incrementándose hasta un $54,3 \%$ para M4, mezcla con un contenido medio en lodo (35\%), asemejándose a otros estudios con CSR y CDR [109, 110, 218].

La caracterización de las mezclas combustibles mediante análisis inmediato mostró un alto contenido en materia volátil, por tanto elevada reactividad, transformándose de inmediato las partículas sólidas en gas, sin embargo, la adición de lodo redujo sensiblemente este contenido. Se puede extrapolar que un mayor tiempo de residencia en el reactor podría haber originado un aumento de la EFG al favorecerse reacciones en fase gaseosa propias del proceso de gasificación, pero existía una limitación en el diseño del gasificador, siendo su altura de $3 \mathrm{~m}$, menor que los empleados en otras investigaciones con gasificadores de lecho burbujeante operando de manera autotérmica [109].

No obstante, el caudal de aire de gasificación necesitaría haberse reducido con el objeto de alcanzar un mayor tiempo de residencia en el reactor. Este hecho no pudo probarse debido a que el sistema de alimentación, inicialmente diseñado para tratar lodos de depuradora, condicionó la cantidad de combustible a alimentar. Por tanto, no fue posible operar con menores caudales de aire, ya que también hubiera sido necesario operar con menores cantidades de combustible para un logar un mismo ER, y en estas condiciones, ya ensayadas, se produjeron atascos debidos a la formación de bóvedas que impidieron la operación continua en el gasificador.

La conversión de carbono, que arrojó valores desde 31 hasta 54\%, aumentó con el contenido en lodo de las mezclas combustibles, pero siguió siendo inferior a otros estudios con CSR [109, 110]. El caudal de aire, agente gasificante, se mantuvo constante durante los ensayos de gasificación a las mezclas combustibles para estudiar la influencia de la proporción del lodo en parámetros tales como la conversión de carbono, ya que un incremento en el aporte de aire hubiera favorecido la conversión de las partículas sólidas de combustible en un producto gaseoso. 


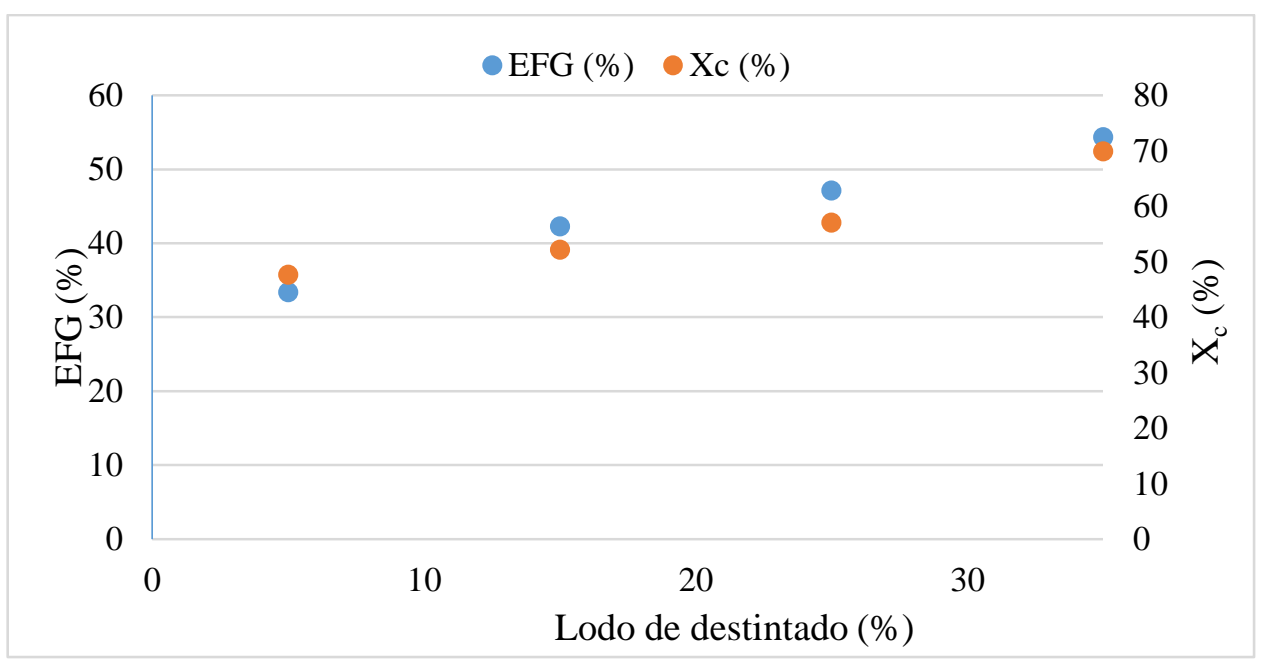

Figura 5.7. EFG y conversión de carbono para las mezclas combustibles en el gasificador de LFB para los CSR de origen industrial.

\subsubsection{Alquitranes y contaminantes minoritarios}

\section{$\underline{\text { Alquitranes }}$}

En la Figura 5.8 se representan los alquitranes medidos en base a la clasificación propuesta por el ECN, ver Tabla 5.1. Todos los compuestos indicados en la Tabla 5.1 fueron determinados, a excepción de aquellos que no pudieron detectarse por estar por debajo del límite de detección del analizador o que fue imposible su determinación al carecer de los patrones correspondientes.

En la Figura 5.5, se muestran los compuestos que se incluyen en las clases II, III, IV y V. Los alquitranes que se muestran son los compuestos que se incluyen en las clases II, III, IV y V, a excepción del cresol y la quinolina, clase II, el estireno, clase III, el bifenil, clase IV, y el perileno, clase V, que no fueron analizados al no disponerse de los patrones correspondientes. No obstante, la mayoría de los compuestos incluidos en la clasificación del ECN sí que pudieron medirse.

En la Figura 5.8 se observa la evolución de las clases en las que se dividen los alquitranes. Las clases IV y V, correspondientes a componentes poliaromáticos, experimentaron una reducción paulatina, a medida que se incrementó la cantidad de lodo añadida en el combustible, pasando de 10,8 a $6,1 \mathrm{~g} / \mathrm{Nm}^{3}$ para la clase IV y de 1,2 a $0,4 \mathrm{~g} / \mathrm{Nm}^{3}$ para la clase $\mathrm{V}$. Además, la clase III también sufrió una ligera reducción en su contenido, pasando de 7,5 a 4,8 g/ $\mathrm{Nm}^{3}$. Por contra, la clase II no mostró un comportamiento regular, sino aleatorio, con independencia de la cantidad de lodo añadido a la mezcla combustible.

Para los ensayos realizados se observó que el contenido total de alquitranes disminuyó a medida que los CSR tuvieron una mayor proporción de lodo de destintado. La mezcla M1 arrojó un valor de 20,2 g/ $\mathrm{Nm}^{3}$ (46,7 g/ $\mathrm{kg}$ b.s.s.c.), la mezcla M2 dio un valor de $16,6 \mathrm{~g} / \mathrm{Nm}^{3}\left(35,5 \mathrm{~g} / \mathrm{kg}\right.$ b.s.s.c.), la mezcla M3 tuvo un valor de $14,9 \mathrm{~g} / \mathrm{Nm}^{3}(33,5 \mathrm{~g} / \mathrm{kg}$ b.s.s.c.) y la mezcla M4 mostró un valor de $11,5 \mathrm{~g} / \mathrm{Nm}^{3}$ (25,1 $\mathrm{g} / \mathrm{kg}$ b.s.s.c.), respectivamente. 
Los resultados son difícilmente comparables, ya que no existen ensayos en lechos fluidizados burbujeantes con combustibles similares [117]. Sin embargo, estos valores son menores que los mostrados por otros CSR con alto contenido en material plástico y textil [108] y semejantes para CSR con alto contenido en material plástico y cenizas gasificados en lechos fluidizados burbujeantes a nivel de laboratorio, o a nivel de planta piloto $[64,109,110]$.

Algunos estudios mostraron una mayor reducción de alquitranes en CSR a partir de mezclas de materiales celulósicos y plásticos que con material plástico solamente [109], incluso con material de lecho como el olivino que ha demostrado ser una medida primaria aconsejable en la reducción de alquitranes en CDR con alto contenido en material plástico [218, 220]. Sin embargo, según el tipo de CDR empleado se ha observado que la actividad catalítica del olivino se reduce o desaparece cuando se utilizan residuos derivados de actividades domésticas y diferentes tipos de envases plásticos [218].

Estos datos de alquitranes totales, corresponden a la clasificación que indica el ECN, así que su comparación está supeditada a las especies analizadas. Los alquitranes totales mostrados aquí se corresponden con las clases del I al V, no con la clase I, gravimétricos o no detectables por cromatografía. Cabe recordar que los rechazos del papelote y del pulpado tienen un alto contenido tanto en materiales plásticos, como celulósicos, lo cual le confiere al combustible unas características especiales. Además, en función de la cantidad de lodo de destintado añadido, el contenido en fibras, talco, caolín, arcillas, carbonato cálcico y partículas de tinta puede verse aumentado.

Los valores de alquitranes totales son difícilmente comparables al no existir estudios de gasificación referidos a residuos de la industria papelera semejantes a estos. No obstante, existen algunos investigadores que han estudiado la viabilidad de la gasificación de residuos semejantes, mezcla $80 \%$ material plástico y $20 \%$ material celulósico, en un lecho fluidizado burbujeante, obteniendo un contenido en alquitranes totales mayor, pero tal vez sea debido a su mayor contenido en material plástico [210]. El mayor contenido en alquitranes corresponde a la clase IV, aquellos que condensan a bajas temperaturas, como ocurre en otros estudios con CSR, siendo menor en contenido la clase $\mathrm{V}$, aquellos que condensan a mayor temperatura [12].

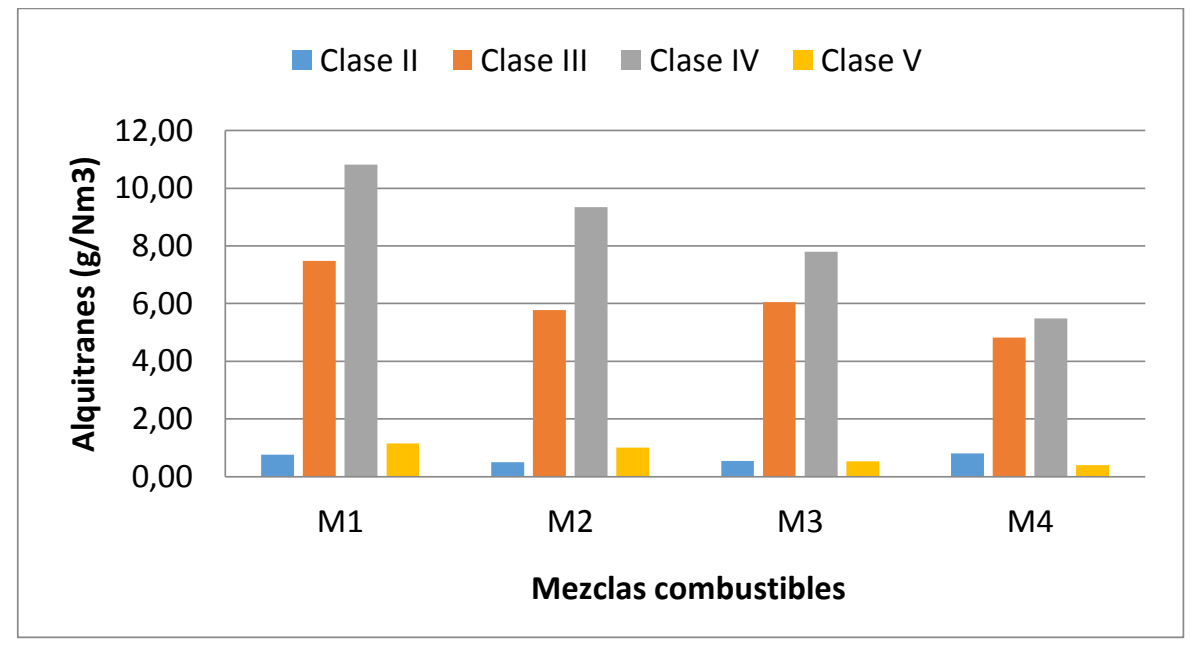

Figura 5.8. Alquitranes según clasificación del ECN en el gasificador de LFB para los CSR de origen industrial. 
Los alquitranes totales también fueron determinados teniendo en cuenta la clasificación de la EPA. Estos mostraron el mismo comportamiento que se observó en la Figura 5.8, según la clasificación del ECN. Se produjo una reducción de su cuantía en función de la cantidad de lodo de la mezcla combustible. El orden de magnitud del contenido en alquitranes difiere, ya que no fueron contabilizadas las mismas especies en ambas clasificaciones. Las mezclas M1, M2, M3 y M4 mostraron unos valores de $10,0 \mathrm{~g} / \mathrm{Nm}^{3}$ (23,1 g/kg b.s.s.c.), $8,7 \mathrm{~g} / \mathrm{Nm}^{3}$ (18,6 g/kg b.s.s.c.), $7,2 \mathrm{~g} / \mathrm{Nm}^{3}$ (16,2 g/kg b.s.s.c.) y 5,7 $\mathrm{g} / \mathrm{Nm}^{3}(12,4 \mathrm{~g} / \mathrm{kg}$ b.s.s.c. $)$, respectivamente.

\section{$\underline{\text { Contaminantes minoritarios }}$}

En los procesos de gasificación, atmósfera reductora, la concentración de especies minoritarias de azufre o nitrógeno no se hallan en sus formas oxidantes en el gas de proceso. Por tanto, en lugar de encontrar especies de azufre y nitrógeno en forma de óxidos $\left(\mathrm{SO}_{2}, \mathrm{NO}_{\mathrm{x}}\right)$, su aparición ocurre en forma de especies reducidas, es decir: $\mathrm{NH}_{3}$ y $\mathrm{H}_{2} \mathrm{~S}$. Ambas especies fueron medidas junto al gas de proceso durante la gasificación de las mezclas combustibles, ver Tabla 5.6, pero la posible formación de $\mathrm{HCN}$ no fue contemplada.

El contenido en $\mathrm{H}_{2} \mathrm{~S}$ experimentó una reducción al gasificar los CSR con un mayor contenido de lodo de destintado, variando de $108 \mathrm{ppm}$ a $72 \mathrm{ppm}$. No obstante, la presencia de ciertos elementos en las cenizas, potasio y calcio, tienen un efecto importante sobre la formación de $\mathrm{H}_{2} \mathrm{~S}$, reduciéndolo, ya que puede llegar a formarse $\mathrm{K}_{2} \mathrm{~S}$. Sin embargo, a temperaturas superiores a $700{ }^{\circ} \mathrm{C}$, caso de la gasificación, y la existencia de cloro y silicio, se reduce la formación de $\mathrm{K}_{2} \mathrm{~S}$ en forma sólida, facilitando la formación de $\mathrm{H}_{2} \mathrm{~S}$ [221]. Además, el bajo contenido en $\mathrm{H}_{2} \mathrm{~S}$ podría explicarse con la presencia de calcio, que podría retener el azufre formando CaS en forma sólida [64].

Respecto al contenido de $\mathrm{NH}_{3}$ del gas de proceso se observó que su valor para todas las mezclas se aproximó a $250 \mathrm{ppm}$, a excepción de la mezcla $\mathrm{M} 4$. El valor de $\mathrm{NH}_{3}$ para esta mezcla fue de $562 \mathrm{ppm}$, a pesar de que en el análisis elemental del combustible no se observó prácticamente diferencia, siendo tal vez debido a que parte del nitrógeno se encontraba como HCN durante la gasificación del resto de combustibles. Generalmente, un incremento de la temperatura de gasificación en combustibles ricos en material plástico y textiles deriva en un incremento de la concentración de HCN [108], como ocurriría para estos combustibles, ya que la mezcla M4, es la de mayor contenido en lodo y, por tanto, la de menor contenido en rechazos

\begin{tabular}{|l|c|c|c|c|}
\hline CSR & M1 & M2 & M3 & M4 \\
\hline $\mathrm{H}_{2} \mathrm{~S}(\mathrm{ppm})$ & 108 & 82 & 81 & 72 \\
\hline $\mathrm{NH}_{3}(\mathrm{ppm})$ & 250 & 275 & 263 & 562 \\
\hline
\end{tabular}

Tabla 5.6. Concentración de especies minoritarias en el gas de proceso para los CSR de origen industrial $\left(\mathrm{NH}_{3} ; \mathrm{H}_{2} \mathrm{~S}\right)$.

Algunos halógenos como cloro o flúor están presentes de forma significativa en los residuos de origen industrial [223]. Para los CSR a estudio solamente se determinó el cloro, ya que la presencia de flúor en los combustibles se demostró irrelevante tras el análisis elemental. La determinación se basó en el hecho de que el cloro se vaporiza rápidamente a temperaturas elevadas, reaccionando inmediatamente con vapor de agua para formar $\mathrm{HCl}$ [222]. El contenido en cloro se determinó a través de un tren de 
muestreo en base a un método no-isocinético para la determinación de $\mathrm{HCl}, \mathrm{HBr}, \mathrm{HF}$, $\mathrm{Cl}_{2}$ y $\mathrm{Br}_{2}$, siendo analizados por cromatografía iónica.

Los valores de cloro medidos como $\mathrm{HCl}$ en disolución ácida fueron de $130 \mathrm{mg} / \mathrm{Nm}^{3}$ para la mezcla M1, 94,1 mg/ $\mathrm{Nm}^{3}$ para la mezcla $\mathrm{M} 2,54,3 \mathrm{mg} / \mathrm{Nm}^{3}$ para la mezcla M3 y $22,7 \mathrm{mg} / \mathrm{Nm}^{3}$ para la mezcla M4, respectivamente. Se observó, por tanto, una reducción del contenido en cloro determinado en disolución ácida con el aumento de la cantidad de lodo en el combustible. Al contrario, el contenido en cloro determinado en disolución básica $\left(\mathrm{Cl}_{2}\right)$ mostró un aumento con la cantidad de lodo añadida al combustible, aumentando de $3,2 \mathrm{mg} / \mathrm{Nm}^{3}$ a $12,4 \mathrm{mg} / \mathrm{Nm}^{3}$, ver Tabla 5.7 .

Globalmente, se observó una reducción de la concentración de cloro a medida que se aumentó el contenido en lodo del combustible. Este hecho puede deberse a la presencia de metales alcalinos en las cenizas, como muestran los análisis de las cenizas de los combustibles, lo que afecta al equilibrio $\mathrm{KCl} / \mathrm{HCl}$, ya que provoca una reducción en la concentración de $\mathrm{HCl}$ [34]. Además, las fracciones residuales con alto contenido en material celulósico gozan de elevados valores de calcio, potasio y magnesio, típicos de la biomasa, pudiendo formarse compuestos como $\mathrm{CaCl}_{2}$ o $\mathrm{MgCl}_{2}$ por reacción de $\mathrm{HCl}$ con $\mathrm{CaO}$ y $\mathrm{MgO}[109,143]$.

\begin{tabular}{|l|c|c|c|c|}
\hline & M1 & M2 & M3 & M4 \\
\hline $\mathrm{HCl}$ ácido $\left(\mathrm{mg} / \mathrm{Nm}^{3}\right)$ & 130,3 & 94,1 & 54,3 & 22,7 \\
\hline $\mathrm{Cl}_{2}$ básica $\left(\mathrm{mg} / \mathrm{Nm}^{3}\right)$ & 3,2 & 5,1 & 6,6 & 12,4 \\
\hline
\end{tabular}

Tabla 5.7. Análisis de cloro de los CSR de origen industrial.

Los datos obtenidos en el muestreo del gas para los CSR arrojaron valores muy bajos de la presencia de cloro en el gas de proceso, siendo los porcentajes de cloro en el gas respecto al cloro del combustible: $1,6 \%$ para $\mathrm{M} 1, \%$ para $\mathrm{M} 2,0,9 \%$ para $\mathrm{M} 3$ y $0,5 \%$ para M4. Este hecho se debe a que para la determinación de cloro se utilizó un método no-isocinético, siendo transportada la alícuota de gas de proceso hasta el tren de muestreo a través de una manguera calefactada, $400{ }^{\circ} \mathrm{C}$, que afectó a la retención del cloro tanto en medio ácido como en básico por parte del tren de muestreo y a la dilución de la ceniza del combustible. No obstante, las cenizas recogidas durante el ensayo se analizaron, ver Tabla 5.8, mostrando una elevada presencia de cloro, siendo los porcentajes de cloro en las cenizas respecto al cloro del combustible los siguientes: $69 \%$ para M1, 82,2\% para M2, 87\% para M3 y 78,2\% para M4, valores próximos a estudios previos donde se fijó en torno al 75\% el cloro retenido en las cenizas [226].

\subsubsection{Cenizas de proceso}

En la Tabla 5.8 se muestran los análisis de las cenizas recogidos en los procesos de gasificación de los CSR para la determinación de cloro. Además, se incluyen los análisis del lecho utilizado durante los ensayos.

El análisis de las cenizas tras los ensayos de gasificación de los CSR muestra un contenido significativo de carbono, próximo al 4\%. El contenido en cloro resultó ser elevado en las cenizas, con valores de 6,1 a 13,8\%. Esto indica que el cloro se concentra en las partículas de menor tamaño, y que las partículas más finas, volantes, concentran una parte importante de las pérdidas de $\mathrm{Cl}$. Respecto a los metales encontrados en las 
cenizas, estos análisis arrojaron un elevado contenido en aluminio, 7-13\%, y calcio, 21$31 \%$.

Respecto al lecho, se observa un elevado contenido en calcio, 6,3\%, y un contenido relativamente alto en cloro, $1,7 \%$. Esto indica que parte del cloro del combustible se deposita en el lecho a través de cenizas o inquemados.

\begin{tabular}{|l|c|c|c|c|c|}
\hline CSR & M1 & M2 & M3 & M4 & Lecho \\
\hline \multicolumn{4}{|l|}{ Composición (\% en peso; b.s.) } \\
\hline $\mathrm{C}$ & 4,2 & 4,2 & 4,6 & 3,8 & $<1$ \\
\hline $\mathrm{H}$ & 0,5 & 0,4 & 0,4 & 0,4 & $<0,4$ \\
\hline $\mathrm{N}$ & 0,15 & 0,4 & 0,5 & 0,06 & $<0,05$ \\
\hline $\mathrm{Cl}$ & 13,76 & 7,57 & 6,11 & 9,4 & 1,72 \\
\hline $\mathrm{Al}$ & 8,5 & 13 & 7,5 & 7.2 & 0,81 \\
\hline $\mathrm{Ba}$ & 0,13 & 0,1 & 0,086 & 0,061 & 0,022 \\
\hline $\mathrm{Ca}$ & 24 & 21 & 27 & 31 & 6,3 \\
\hline $\mathrm{Fe}$ & 1,4 & 3,4 & 1,2 & 0,81 & 0,81 \\
\hline $\mathrm{K}$ & 0,66 & 0,79 & 0,38 & 0,47 & 0,023 \\
\hline $\mathrm{Mg}$ & 0,95 & 0,68 & 0,96 & 1,1 & 0,29 \\
\hline $\mathrm{Mn}$ & 0,044 & 0,066 & 0,039 & 0,031 & 0,009 \\
\hline $\mathrm{Na}$ & 0,85 & 1,5 & 0,55 & 0,51 & 0,26 \\
\hline $\mathrm{P}$ & 0,4 & 0,58 & 0,16 & 0,16 & 0,070 \\
\hline $\mathrm{S}$ & 0,35 & 0,38 & 0,33 & 0,39 & 0,086 \\
\hline $\mathrm{Si}$ & 6,3 & 10 & 9,2 & 8,1 & 38 \\
\hline $\mathrm{Sr}$ & 0,049 & 0,055 & 0,047 & 0,049 & 0,016 \\
\hline $\mathrm{Ti}$ & 1,1 & 0,79 & 0,66 & 0,51 & 0,19 \\
\hline $\mathrm{Zn}$ & 0,094 & 0,16 & 0,15 & 0,072 & 0,035 \\
\hline
\end{tabular}

Tabla 5.8. Cenizas de los CSR de origen industrial tras los ensayos de gasificación.

El material de lecho empleado en los ensayos de las mezclas combustibles no se cambió hasta la finalización de los mismos. Tras finalizar los ensayos, éste fue extraído para toma de muestra y ser pesado, obteniéndose un valor de $53 \mathrm{~kg}$, próximo a los $50 \mathrm{~kg}$ de arena de sílice introducidos al inicio de los ensayos. Por tanto, la cantidad de sólidos y cenizas aportados al lecho tras cada ensayo puede considerarse no significativa. Además, se observó que la ceniza recogida en el ciclón, que fue menor de la que se debió recoger en base a los análisis de laboratorio debido a su tamaño de partícula, mostró un contenido en carbono tras su análisis, próximo al 4\%, lo que pudo originar una reducción de la conversión de carbono. La ceniza más volante no pudo ser recogida porque fue expulsada del gasificador con el gas de proceso, suponiendo un $27 \%$ del total, siendo el tamaño mínimo de recogida de partículas sólidas de $100 \mu \mathrm{m}$.

\subsubsection{INFLUENCIA DEL TIPO DE GASIFICADOR}

Tras el estudio del potencial de las mezclas, obtenidas a partir de corrientes residuales de la industria papelera, como combustibles en un proceso térmico de gasificación en lecho fluidizado burbujeante, se decidió investigar su posible uso como combustible en un proceso de gasificación en lecho fluidizado circulante. 
La viabilidad del proceso de gasificación en lecho fluidizado circulante se controló mediante una serie de parámetros clave como son: composición de gas, contenido en alquitranes, contenido en cloro, producción de gas, poder calorífico, eficiencia de la gasificación en frío y conversión de carbono. El estudio de viabilidad del proceso de gasificación se realizó en el gasificador de lecho fluidizado circulante definido en el apartado 2.5.2. Este estudio llevó a cabo con la mezcla combustible de menor contenido en cenizas, M1, ya que ésta se podría acumular en el lecho o en la rama de retorno, dificultando la circulación de sólidos.

En un futuro convendría ampliar este estudio al resto de mezclas combustibles, aunque fuera necesaria la inclusión de un sistema de extracción de cenizas en continuo durante la operación. En este caso, se investigó el comportamiento de las variables anteriormente citadas en función de la variación de ER. Se realizaron diferentes ensayos preliminares, con objeto de seleccionar el rango óptimo de operación en el gasificador. Al igual que ocurriera en gasificador de lecho fluidizado burbujeante, se simularon condiciones de operación típicas en un gasificador de lecho fluidizado industrial, es decir: operando de manera autotérmica usando aire como agente gasificante y arena como material de lecho [64].

El inventario de sólidos usado fue de $125 \mathrm{~kg}$, siendo usada arena de sílice con una granulometría $428 \mu \mathrm{m}$. El aporte extra de calor al inicio de cada ensayo fue suministrado mediante un quemador de propano hasta alcanzar la temperatura de ignición del combustible, como se hizo en los ensayos con el lecho fluidizado burbujeante.

El caudal de agente gasificante se mantuvo prácticamente constante durante el proceso de gasificación, alcanzándose unas velocidades de $3,1 \mathrm{~m} / \mathrm{s}$ a $3,9 \mathrm{~m} / \mathrm{s}$, de manera que se permitiera una circulación de sólidos adecuada. Cabe recordar que la salida del gasificador tiene forma abrupta, por tanto, se produce un retorno elevado de partículas sólidas al lecho denso, sobre todo a través de las paredes del reactor, provocando una reducción de la cantidad neta de partículas que salen del reactor y, por tanto, recogidas por el ciclón y depositadas en la rama de retorno.

A pesar de que el caudal de aire usado como agente gasificante y de fluidización se mantuvo prácticamente constante, permitiendo una fluidización semejante en cada prueba, la cantidad de combustible y aire tuvieron que ser variadas debido a la necesidad de establecer diferentes valores de ER en cada experimento, afectando a la tasa de alimentación (TA). Las TA alcanzadas dueron de 1074 a $1423 \mathrm{~kg} / \mathrm{m}^{2} \mathrm{~h}$. Las temperaturas alcanzadas en el lecho variaron en función de la cantidad de aire y combustible alimentados, encontrándose ligadas al ER al ser variables dependientes. Los valores de las temperaturas del lecho variaron entre 750 y $870{ }^{\circ} \mathrm{C}$. No obstante, se consiguió que la el proceso de gasificación fuera homogéneo al encontrarse el reactor prácticamente a la misma temperatura.

\subsubsection{Composición del gas y poder calorífico}

La Figura 5.9 muestra la evolución en la composición del gas de proceso en función del ER seleccionado para cada ensayo. El análisis del gas de proceso se llevó a cabo mediante un FTIR y un FID como ocurrió para los ensayos en la unidad burbujeante. 
La influencia del ER en la composición del gas fue importante, ya que proporcionó un aumento moderado del contenido en $\mathrm{CO}_{2}$ al aumentar el valor de ER de 11,8-12,2\% y un descenso para el resto de compuestos del gas de proceso. El contenido en $\mathrm{H}_{2}$ y CO disminuyeron al aumentar ER, pasando de 3,8-2,7\% y de 6,9 a 5,6\%, respectivamente. $\mathrm{El} \mathrm{CH}_{4}$ se mantuvo prácticamente constante hasta que se modificó drásticamente el valor de ER hasta 0,49, momento en el cual su valor se redujo desde un $4,8 \%$ hasta un $1,9 \%$. Además, el contenido en $\mathrm{C}_{2} \mathrm{H}_{4}$ se redujo al aumentar ER, de $3 \%$ a $0,9 \%$ y el contenido en $\mathrm{C}_{2} \mathrm{H}_{6}$ se mostró constante para cada valor de ER, en torno a 0,1-0,2\%, no obstante, su contribución al poder calorífico fue testimonial debido a su bajo contenido en el gas de proceso. Los resultados y las tendencias son semejantes a otros estudios para CSR en lechos fluidizados circulantes [63, 113, 114].

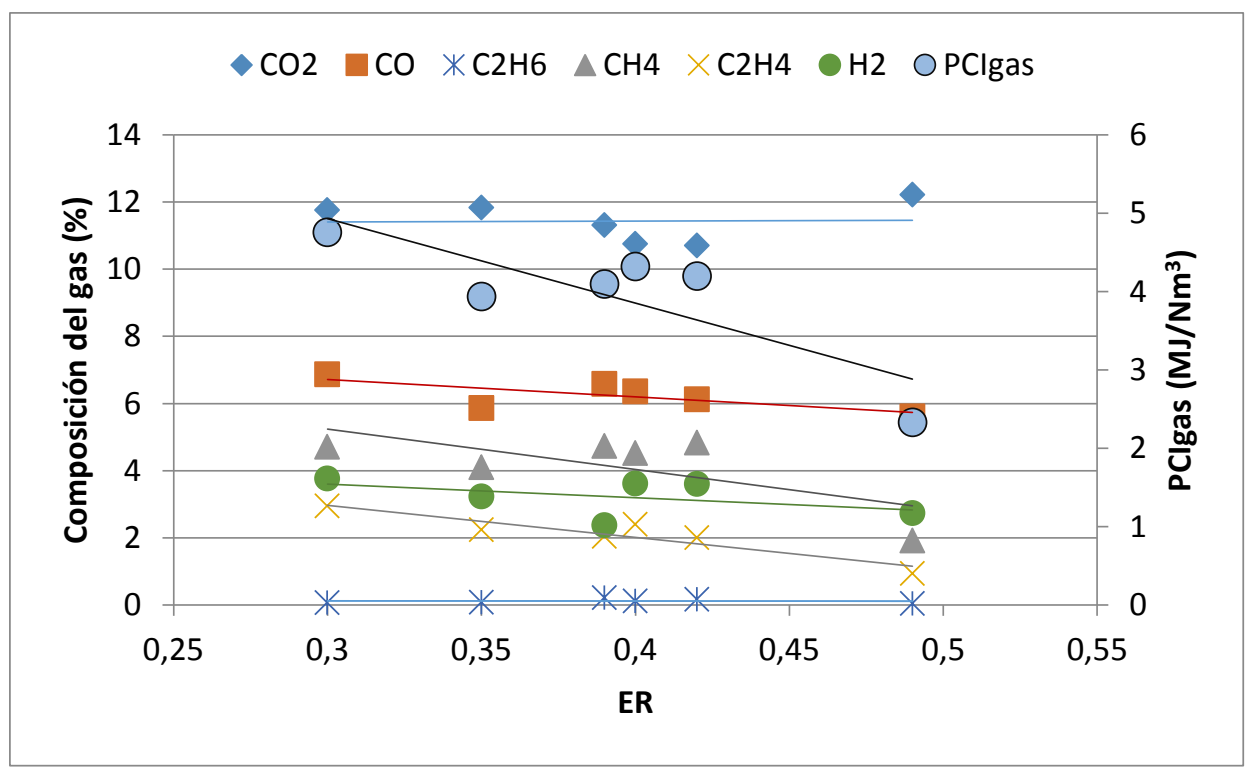

Figura 5.9. Composición del gas en función del ER en el gasificador de LFC para el CSR de origen industrial M1.

El poder calorífico inferior del gas de proceso mostró valores de 4,76 a 2,3 $\mathrm{MJ} / \mathrm{Nm}^{3}$, ver Figura 5.9, que disminuyeron al aumentar ER. Esta disminución se ve favorecida al aumentar las reacciones de oxidación, generándose más $\mathrm{CO}_{2}$ en detrimento de $\mathrm{H}_{2}$ y $\mathrm{CO}$. El poder calorífico mostrado es similar a estudios de gasificación empleando aire como agente gasificante $[63,113]$.

\subsubsection{Producción de gas, eficiencia en frío de la gasificación y conversión de carbono}

La producción de gas se puede observar en la Figura 5.10. La producción de gas aumentó al aumentar ER. El aumento fue de 3,3 a 4,9 $\mathrm{Nm}^{3} / \mathrm{kg}$ s.s.c. Este aumento tiene sentido puesto que la mayor contribución a la producción de gases viene por parte del agente gasificante. 


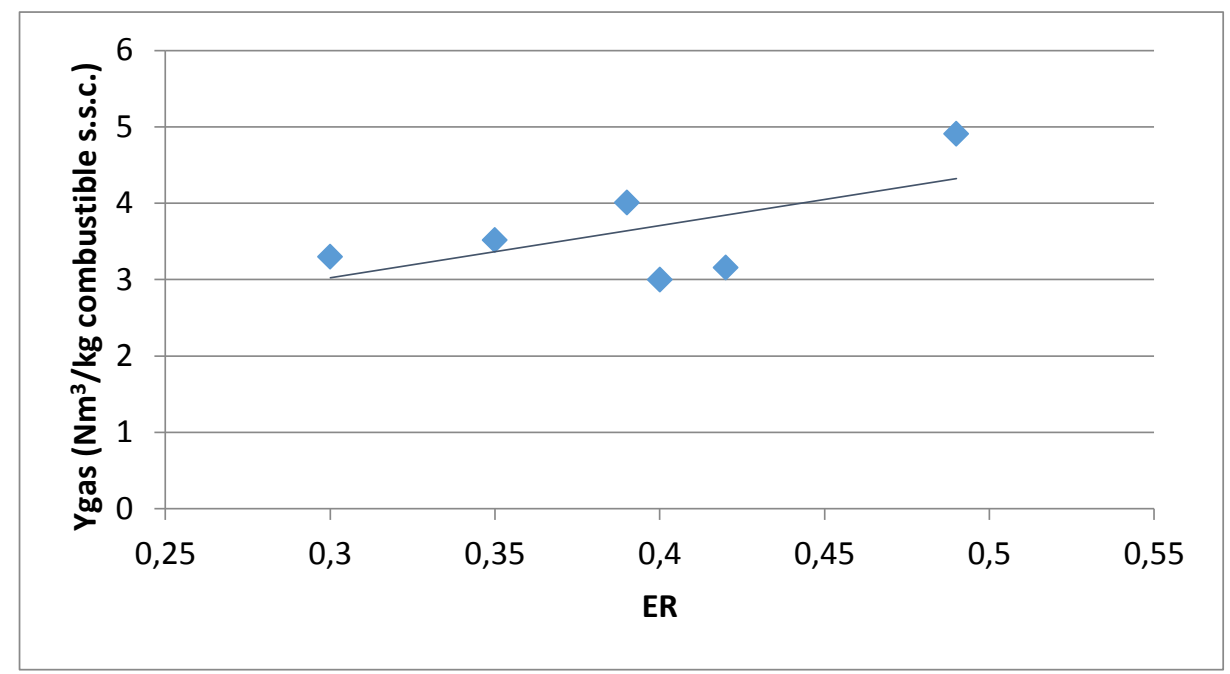

Figura 5.10. Producción de gas en función del ER en el gasificador de LFC para el CSR de origen industrial M1.

En la Figura 5.11 se representa la evolución de la eficiencia en frío y de la conversión de carbono en función del ER.

La EFG arrojó valores de 50-62 \% para un valor de ER entre 0,3 y 0,42. Sin embargo, el valor de EFG descendió drásticamente hasta un valor de 36,9\% para un de ER de 0,49, ya que se redujo su poder calorífico inferior en una gran cuantía. Por tanto, puede decirse que los valores de EFG se mantuvieron aproximadamente constantes en torno a un valor de 50-62\% como consecuencia de que el aumento de la producción de gas compensó la disminución del poder calorífico al aumentar ER.

La conversión de carbono, con valores de $71-82 \%$, se incrementó al aumentar ER, ver Figura 5.11. Esto puede ser debido a que un mayor aporte de aire facilitó la conversión del combustible hacia productos gaseosos. Esta tendencia, respecto a la conversión de carbono y EFG, es similar a la encontrada en otros estudios sobre gasificación de CSR $[113,114]$.

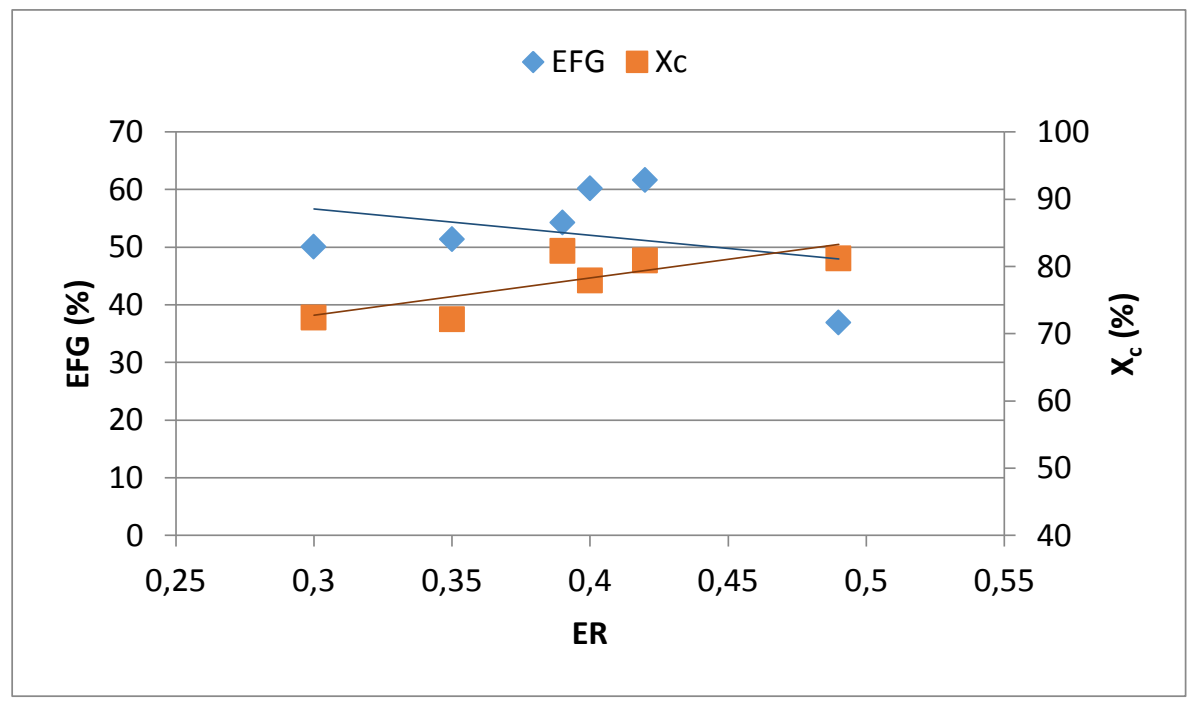

Figura 5.11. EFG y conversión de carbono en función del ER en el gasificador de LFC para el CSR de origen industrial M1. 


\subsubsection{Alquitranes y contaminantes minoritarios}

\section{Alquitranes}

En la Figura 5.12 se representan los alquitranes medidos en base a la clasificación propuesta por el ECN, ver Tabla 5.1. Todos los compuestos indicados en la Tabla 5.1 fueron determinados, a excepción de aquellos que no pudieron detectarse por estar bajo el límite de detección del analizador o que fue imposible su determinación al carecer de los patrones correspondientes, como ocurrió con la clase II, donde ningún componente pudo ser determinado. Respecto al resto de clases, únicamente no pudieron ser determinados el estireno de la clase III y el perileno de la clase IV, respectivamente, al carecer de los patrones correspondientes.

En la Figura 5.12 se observa la evolución de las clases en las que se dividen los alquitranes. Las clases IV y $\mathrm{V}$, correspondientes a componentes poliaromáticos, experimentaron una reducción a medida que se incrementó ER, pasando de 10 a 4,8 $\mathrm{g} / \mathrm{Nm}^{3}$ para la clase IV y de 1,6 a $0,1 \mathrm{~g} / \mathrm{Nm}^{3}$ para la clase $\mathrm{V}$. La contribución de la clase II fue irrelevante, menor de $0,1 \mathrm{~g} / \mathrm{Nm}^{3}$.

En comparación a la medida de alquitranes para la mezcla M1 en la unidad burbujeante, estos valores resultaron bastante menores en cuanto a la clase III de alquitranes. Por tanto, son difícilmente comparables estos resultados. Sin embargo, si nos ceñimos a la clasificación que hace la EPA, los resultados fueron de un orden de magnitud semejante y, por tanto, más extrapolables. Se produjo un descenso del contenido en alquitranes con el aumento de ER, mostrando unos valores de $11,4 \mathrm{~g} / \mathrm{Nm}^{3}$ (37,6 g/kg b.s.s.c.), 7,1 $\mathrm{g} / \mathrm{Nm}^{3}$ (28,5 g/kg b.s.s.c.), $4,9 \mathrm{~g} / \mathrm{Nm}^{3}$ (24,1 g/kg b.s.s.c.), respectivamente. Para la mezcla M1, en la unidad burbujeante, la cantidad de alquitranes medidos para un $\mathrm{ER}=0,2$ fue de $10,0 \mathrm{~g} / \mathrm{Nm}^{3}$. La cantidad de alquitranes determinados fueron semejantes a los obtenidos en lechos fluidizados circulantes usando CSR como combustible o residuos $[111,113,114]$.

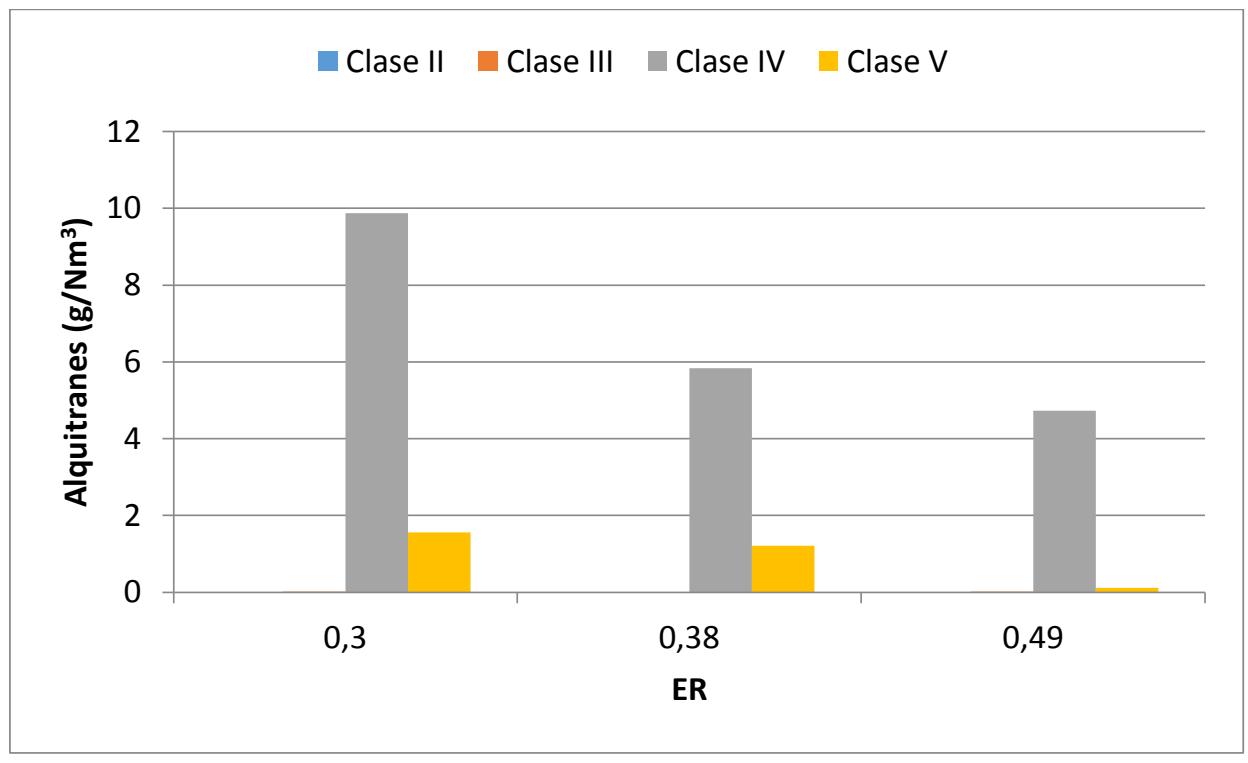

Figura 5.12. Alquitranes según clasificación ECN en el gasificador de LFC para el CSR de origen industrial M1. 


\section{Componentes minoritarios}

En la Figura 5.13 se muestran los valores de $\mathrm{NH}_{3}$ y $\mathrm{H}_{2} \mathrm{~S}$ en el gas de proceso en función del ER. Ambas especies fueron medidas junto al gas de proceso durante la gasificación de las mezclas combustibles, pero la posible formación de $\mathrm{HCN}$ no fue contemplada.

El contenido de $\mathrm{NH}_{3}$ del gas de proceso se mantuvo en valores próximos a 198 y 121 ppm, aunque descendiendo ligeramente al aumentar ER, salvo para un ER de 0,49, donde mostró un fuerte descenso hasta el valor de $55 \mathrm{ppm}$. La medida del contenido en $\mathrm{NH}_{3}$ puede estar subestimada, ya que al incrementarse la temperatura de gasificación en combustibles ricos en material plástico y textiles puede aumentarse la concentración de $\mathrm{HCN}[108,225]$. Respecto al contenido en $\mathrm{H}_{2} \mathrm{~S}$, éste mostró un descenso a medida que se incrementó ER, pasando de valores de 143 a 80 ppm.

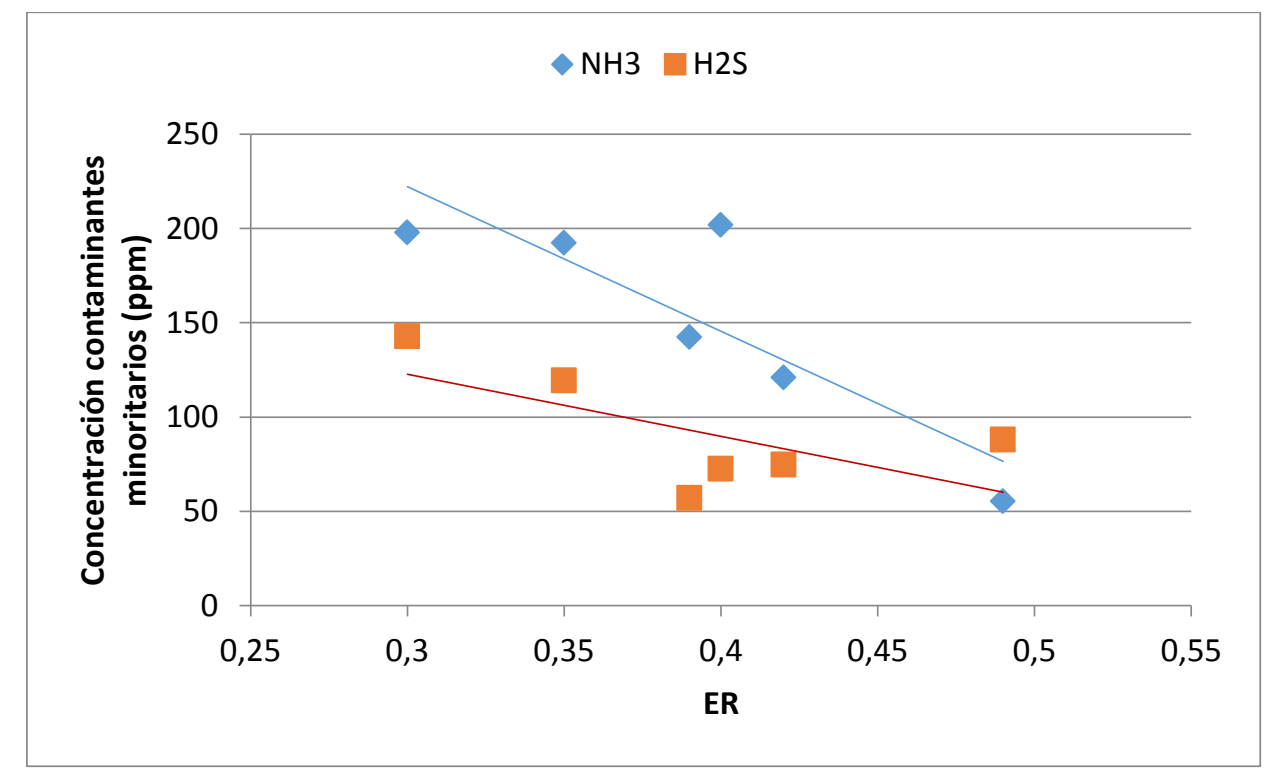

Figura 5.13. Concentración de contaminantes minoritarios en el gas de proceso del gasificador de LFC para el CSR de origen industrial M1.

En la Tabla 5.9 se pueden observar los valores de cloro determinado mediante un método no-isocinético para la determinación de $\mathrm{HCl}, \mathrm{HBr}, \mathrm{HF}, \mathrm{Cl}_{2}$ y $\mathrm{Br}_{2}$ tras su análisis por cromatografía iónica. Las valores de cloro medidos como $\mathrm{HCl}$ en disolución ácida fueron de $763,9 \mathrm{mg} / \mathrm{Nm}^{3}$ y $545,4 \mathrm{mg} / \mathrm{Nm}^{3}$, mientras que los valores de cloro medidos en disolución básica fueron de $59,6 \mathrm{mg} / \mathrm{Nm}^{3}$ y $42,3 \mathrm{mg} / \mathrm{Nm}^{3}$ para un ER de 0,35 y 0,49 , respectivamente. Se observó una reducción del contenido en cloro determinado tanto en disolución ácida, como en disolución básica, con el aumento de ER. En comparación con los valores obtenidos en el contenido en cloro en disolución ácida para la unidad burbujeante, la diferencia de concentración de $\mathrm{HCl}$ mostrado en la unidad circulante, pudo ser debida a la volatilización del cloro inorgánico proveniente de sales de $\mathrm{NaCl}$ y $\mathrm{KCl}$, ya que se transforman en $\mathrm{HCl}$ a temperaturas superiores a $800{ }^{\circ} \mathrm{C}$ [107].

\begin{tabular}{|l|c|c|}
\hline ER & $\mathrm{HCl}\left(\mathrm{mg} / \mathrm{Nm}^{3}\right)$ & $\mathrm{Cl}_{2}\left(\mathrm{mg} / \mathrm{Nm}^{3}\right)$ \\
\hline 0,35 & 763,9 & 59,6 \\
\hline 0,49 & 545,4 & 42,3 \\
\hline
\end{tabular}

Tabla 5.9. Análisis de cloro en función del ER. 
La determinación de cloro se llevó a cabo a través del citado método no-isocinético, de manera que una alícuota del gas de proceso fue llevada desde la salida del gasificador hasta el tren de muestreo, enfriándose el gas durante el trayecto. El porcentaje de cloro del combustible gasificado que acompañó al gas de proceso y el que permaneció en las cenizas fueron determinados mediante los datos reflejados en la Tabla 5.9 referidos a la concentración de cloro en el gas, y la Tabla 5.10 referida a la concentración de cloro en las cenizas.

Los datos obtenidos en el muestreo del gas para un $E R=0,35$ reflejaron que el 13,5\% del cloro del combustible se encontraba en el gas de proceso, mientras que el 73,5\% del cloro del combustible fue a parar a las cenizas como fue determinado en el balance de cloro, siendo del mismo orden de magnitud al mostrado en las instalaciones del ECN para la determinación de cloro en las cenizas del proceso de gasificación de biomasa, donde el $75 \%$ del cloro del combustible fue recogido en las cenizas [226].

El resto del cloro se puede haber depositado en el lecho y en las cenizas volantes que acompañan al gas de proceso. En el muestreo del gas para un $\mathrm{ER}=0,49$, se observó que el 9,8\% del cloro del combustible se encontraba en el gas de proceso, mientras que el $84,7 \%$ del cloro del cloro del combustible se alojó en las cenizas.

\subsubsection{Cenizas de proceso}

En la Tabla 5.10 se muestran los análisis de las cenizas recogidas en los procesos de gasificación del CSR de origen industrial M1 tras el muestreo de cloro.

El análisis de las cenizas tras los ensayos de gasificación de los CSR muestra una importante reducción del contenido en carbono en función del ER desde un 16,1\% hasta un $6,4 \%$. Esto se debe a las partículas sólidas que acompañan a la ceniza y que se depositan en el ciclón secundario. El contenido en cloro resultó ser elevado en las cenizas, con valores próximos a 10,2\%. Respecto a los metales encontrados en las cenizas, estos análisis arrojaron un elevado contenido en aluminio, 14-17\%, calcio, 21$16 \%$ y silicio, $7,7-9,1 \%$. 


\begin{tabular}{|l|c|c|}
\hline CSR M1 & ER=0,35 & ER=0,49 \\
\hline \multicolumn{2}{|c|}{ Composición (\% } & en peso; $\boldsymbol{b . s .}$ ) \\
\hline $\mathrm{C}$ & 16,1 & 6,4 \\
\hline $\mathrm{H}$ & 0,6 & $<0,4$ \\
\hline $\mathrm{N}$ & 0,23 & 0,29 \\
\hline $\mathrm{Cl}$ & 10,25 & 10,21 \\
\hline $\mathrm{Al}$ & 14 & 17 \\
\hline $\mathrm{Ba}$ & 0,14 & 0,12 \\
\hline $\mathrm{Ca}$ & 21 & 16 \\
\hline $\mathrm{Fe}$ & 2,2 & 2,2 \\
\hline $\mathrm{K}$ & 0,57 & 0,46 \\
\hline $\mathrm{Mg}$ & 0,7 & 0,52 \\
\hline $\mathrm{Mn}$ & 0,067 & 0,11 \\
\hline $\mathrm{Na}$ & 0,92 & 0,93 \\
\hline $\mathrm{P}$ & 0,51 & 0,44 \\
\hline $\mathrm{S}$ & 0,28 & 0,19 \\
\hline $\mathrm{Si}$ & 7,7 & 9,1 \\
\hline $\mathrm{Sr}$ & 0,062 & 0,051 \\
\hline $\mathrm{Ti}$ & 2,2 & 1,3 \\
\hline $\mathrm{Zn}$ & 0,17 & 0,07 \\
\hline
\end{tabular}

Tabla 5.10. Cenizas del ciclón secundario del CSR industrial M1 tras los ensayos de gasificación. 


\section{CAPÍTULO VI. RESUMEN DE RESULTADOS Y CONCLUSIONES}

\subsection{RESUMEN DE RESULTADOS}

Esta tesis ha pretendido evaluar la viabilidad técnica del proceso de gasificación de residuos con contenido en material plástico mediante la producción de CSRs a partir de residuos de origen doméstico e industrial. Este proceso ha sido definido en varias etapas: caracterización fracciones residuales de partida, preparación del combustible, caracterización y clasificación en base a la normativa europea sobre los CSR y viabilidad técnica del CSR en un proceso de gasificación en lecho fluidizado.

\section{Caracterización de las fracciones residuales de partida}

La primera etapa consistió en la recogida y análisis de las muestras de cada una de las fracciones residuales a tratar.

\section{Residuo de origen doméstico}

- La caracterización de los rechazos mostró humedades superiores al $20 \%$ (necesidad de secado), un cierto contenido en cloro a tener en cuenta (corrosión en instalaciones), un elevado contenido en materia volátil (reactividad), un bajo riesgo de sinterización (altas temperaturas de fusibilidad) y un alto contenido en ceniza, superior al $20 \%$, que podría haber dificultado la operación durante el proceso de gasificación.

- Las fracciones de film y plástico mixto fueron descartadas por sus bajas densidades a granel, inferiores a $5 \mathrm{~kg} / \mathrm{m}^{3}$, y por el exceso de humedad, $40 \%$, de plástico mixto, lo que supondría un gasto adicional en secado. Además, su generación en comparación con los rechazos de envases es baja, solamente un $19 \%$.

- El análisis de la densidad a granel de las fracciones de rechazo mostró la necesidad de un proceso de compresión por peletizado, ya que el combustible a alimentar en un lecho fluidizado requiere de unas determinadas características físicas, siendo un pélet con un adecuado valor de densidad a granel óptimo para estas instalaciones.

○ rechazo de biometanización $\left(120 \mathrm{~kg} / \mathrm{m}^{3}\right)$

○ rechazo de envases $\left(42 \mathrm{~kg} / \mathrm{m}^{3}\right)$

\section{Residuo de origen industrial}

La caracterización de los rechazos y los lodos mostró:

- Humedades superiores al $40 \%$ y $30 \%$ (necesidad de secado), respectivamente.

- Los rechazos mostraron un poder calorífico inferior de $26.6 \mathrm{MJ} / \mathrm{kg}$, un alto contenido en materia volátil de $82,5 \%$ y un contenido medio en ceniza, alrededor del $9 \%$, sin embargo, la cantidad de ceniza de los lodos se elevó alrededor del $40 \%$. 
- Bajo riesgo de sinterizado: elevado contenido en óxido de calcio, alrededor del $45 \%$ en los rechazos y del $17 \%$ en los lodos, que reduce la posible formación de sinterizados.

- El contenido en cloro en los rechazos, tal vez debido a trazas de PVC, fue relativamente alto, $1,3 \%$, con lo que es un aspecto a vigilar por la posible corrosión que puedan sufrir las instalaciones donde sea usado.

- El análisis de la densidad a granel mostró la necesidad de un proceso de compresión por peletizado, ya que la densidad a granel del rechazo fue solamente de $100 \mathrm{~kg} / \mathrm{m}^{3}$.

\section{Preparación del combustible}

La segunda etapa consistió en la eliminación de impurezas y la densificación de las fracciones rechazo para cada uno de los CSR a preparar. Las principales conclusiones para los CSR producidos son:

\section{Residuos de origen doméstico}

- La eliminación de impurezas del CSR fue del 12,4\% en la fracción rechazo orgánica y $5,5 \%$ en el rechazo de envases.

- El estudio del consumo energético durante la densificación demostró que el mayor gasto energético correspondió al acondicionamiento del residuo, molienda fina, $195 \mathrm{kWh} / \mathrm{T}$, mientras que el gasto energético en la densificación fue dependiente de la relación de compresión de la matriz plana, aumentando de 53 a $83 \mathrm{kWh} / \mathrm{T}$ para una RC: $37-40 \mathrm{~mm}$. Además, aparecieron fundidos de material plástico a temperaturas de salida del material superiores a $60{ }^{\circ} \mathrm{C}$, que se alcanzaron con $\mathrm{RC}=40 \mathrm{~mm}$.

- El estudio de las propiedades físicas del peletizado mostró una reducción del índice de durabilidad con el aumento de RC de 37 a $40 \mathrm{~mm}$, pasando de un valor de 97 a 93\%. Las matrices planas con RC inferior a $37 \mathrm{~mm}$ produjeron un peletizado de muy bajo índice de durabilidad, se deshacía con facilidad al tacto. Los pélets producidos fueron de $8 \mathrm{~mm}$ de diámetro, y mostraron unos valores de índice de durabilidad de $96,8 \%$ y una densidad a granel de $540 \mathrm{~kg} / \mathrm{m}^{3}$, que resultaron adecuados para su manejo en los sistemas de alimentación de las instalaciones de gasificación.

\section{Residuos de origen industrial}

- El estudio del consumo energético durante la densificación de las mezclas combustibles mostró un mayor consumo energético para el acondicionamiento del residuo, molienda fina, entre $245-277 \mathrm{kWh} / \mathrm{T}$, que para la densificación, que fue de 67-84 kWh/T, sin embargo, no se encontró una relación directa con la cantidad de lodo añadido a las mezclas, por tanto, el consumo energético fue semejante para todas y cada una de las mezclas. La RC fue de $40 \mathrm{~mm}$, pudiendo usarse al no encontrarse fundidos de material plástico.

- El estudio de las propiedades físicas del peletizado mostró un valor del índice de durabilidad próximo al $98 \%$ para todas las mezclas. Sin embargo, la densidad a granel se modificó de 420 a $510 \mathrm{~kg} / \mathrm{m}^{3}$ en función de la carga de lodo añadida, 5 a $35 \%$. 
- El estudio de la humedad en el índice de durabilidad y la densidad a granel determinó que ambas se reducían cuando la humedad del material de partida superaba el 10\%, empeorando las características del pélet.

\section{Caracterización y clasificación de los CSR}

La tercera etapa consistió en la caracterización y clasificación del combustible según la normativa europea UNE-EN 15359:2011. Las principales conclusiones fueron:

- La caracterización del combustible de origen doméstico mostró un combustible con un contenido de humedad de $8,8 \%$, una cantidad elevada de cenizas $21,1 \%$, una elevada cantidad de materia volátil $75,5 \%$, un poder calorífico inferior de 23 $\mathrm{MJ} / \mathrm{kg}$ y un contenido en biomasa del $45 \%$. Además, se evaluó el riesgo de sinterización, que resultó ser bajo, debido al alto contenido en óxido de calcio, $28 \%$, y el bajo contenido de óxido de sodio y potasio, $4 \%$ y $5 \%$, respectivamente, en las cenizas. Este hecho fue confirmado mediante la determinación de diversos índices de sinterización y de las temperaturas características de fusión. Por tanto, se ha conseguido un combustible que cumple la normativa y especificaciones técnicas necesarias para categorizarlo como CSR de origen doméstico, siendo su código de clase 231.

- Los análisis termogravimétricos del CSR mostraron la existencia de dos periodos de degradación a través de las curvas TG/DTG. La primera etapa, correspondiente a materiales celulósicos se produjo en el rango de temperaturas de $220-380{ }^{\circ} \mathrm{C}$ y la segunda etapa de degradación ocurrió entre $380-540{ }^{\circ} \mathrm{C}$ debido a los materiales plásticos. Las energías de activación se estimaron aplicando el método de Coats-Redfern. Los valores de energía de activación, factor pre-exponencial y orden de reacción para la degradación de los materiales celulósicos fueron 31,2 $\mathrm{kJ} / \mathrm{mol}, 2,5 \times 10^{6} \mathrm{~min}^{-1}$ and 4. La segunda etapa de degradación fue la correspondiente al material plástico, siendo los parámetros cinéticos 55,9 $\mathrm{kJ} / \mathrm{mol}, 2,7 \times 10^{12} \mathrm{~min}^{-1}$ and 1,5 , respectivamente.

- La caracterización de las mezclas combustibles de origen industrial mostraron las siguientes variaciones en función de la cantidad de lodo añadido, 5-35\%:

- Contenido en humedad prácticamente constante, en torno al $3 \%$.

- Reducción del contenido en cenizas $17 \%$ al $28,3 \%$.

- Reducción de materia volátil del 75,2\% al 66,7\%.

○ Reducción del poder calorífico inferior de 25 a $18.9 \mathrm{MJ} / \mathrm{kg}$.

- Aumento del contenido en biomasa del $18 \%$ al $25 \%$.

- El riesgo de sinterización, resultó ser bajo, debido al incremento de los óxido de calcio y magnesio en las cenizas del $28 \%$ al $40 \%$ y del $1,3 \%$ al $1,9 \%$, respectivamente, y al descenso del contenido de óxido de sodio desde un $3,5 \%$ hasta un $0,54 \%$ y de potasio desde un $1,8 \%$ hasta un $0,47 \%$ en las cenizas. Este hecho fue corroborado mediante la determinación de diversos índices de sinterización y de las elevadas temperaturas de fusión.

- Los análisis termogravimétricos de los CSR mostraron la existencia de tres periodos de degradación a través de las curvas TG/DTG. La primera etapa, correspondiente a materiales celulósicos se produjo en el rango de temperaturas de $200-360{ }^{\circ} \mathrm{C}$. La segunda etapa de degradación ocurrió entre $360-530{ }^{\circ} \mathrm{C}$ debido a los materiales plásticos, y la tercera etapa de 
degradación entre 580-720 ${ }^{\circ} \mathrm{C}$ se debió a los aditivos del lodo de destintado. Las energías de activación se estimaron aplicando métodos no isotérmicos (Coats-Redfern, KAS y FOW). En la primera y en la segunda etapa, las energías de activación fueron de 140-160 kJ/mol para materiales celulósicos y de $50-80 \mathrm{~kJ} / \mathrm{mol}$ para materiales plásticos, respectivamente.

Esta caracterización demostró que los cuatro CSR son susceptibles de poderse adherir a la normativa y especificaciones técnicas necesarias para categorizarlos como CSR de origen doméstico, siendo sus códigos de clase $251 ; 251 ; 341 ; 341$, en función de la carga de lodo añadida.

\section{Viabilidad de la gasificación de los CSR en lechos fluidizados}

La cuarta etapa consistió en el estudio de la viabilidad técnica del proceso de gasificación utilizando los CSR de origen doméstico e industrial como combustibles. Las principales conclusiones fueron:

- En el proceso de gasificación del CSR de origen doméstico en lecho fluidizado burbujeante se trabajó en operación autotérmica con lo cual la temperatura media del lecho aumentó al hacerlo el ER, ya que es función de éste. Se utilizaron distintos inventarios de sólidos. Inicialmente se probó con $25 \mathrm{~kg}$, lo que significó que el ER solo pudiera variarse entre 0,12 y 0,17 . Estos ensayos demostraron que la producción de gas y la conversión de carbono aumentaron con el incremento de ER, permaneciendo prácticamente constante la EFG. La segunda tanda de ensayos se realizó aumentando el inventario de sólidos a 50 $\mathrm{kg}$, máximo permitido por la instalación, con lo cual el ER pudo variarse de 0,19 a 0,23, lo que significó en un aumento de la producción de gas, de la conversión de carbono y un descenso de los alquitranes totales y del PCI a medida que aumento ER. Estos ensayos transcurrieron sin problemas de sinterización, ni acumulación de cenizas en el lecho, por tanto, resultaron satisfactorios.

- En el proceso de gasificación de los CSR de origen industrial en lecho fluidizado burbujeante se trabajó en operación autotérmica, pero se mantuvo constante ER, 0,20, para los cuatro CSR. El estudio comparativo de los CSR mostró un aumento del PCI, de 4,3 a 5,7 MJ/ $\mathrm{Nm}^{3}$, debido al aumento del contenido en $\mathrm{CH}_{4}$ del gas de proceso con el aumento de la proporción de lodo en el combustible. La producción de gas se mantuvo constante al no variar ER, ya que su valor depende en gran medida de la cantidad de aire suministrado. La EFG mostró valores de 35 a 54\%, incrementándose con la cantidad de lodo presente en las mezclas combustibles, al igual que ocurrió para la conversión de carbono, que aumento de la misma forma de 48 a $78 \%$. El contenido total de alquitranes disminuyó a medida que la mezcla combustible tuvo una mayor proporción de lodo de destintado, de $20,2 \mathrm{~g} / \mathrm{Nm}^{3}$ a $11,5 \mathrm{~g} / \mathrm{Nm}^{3}$ según la clasificación del ECN, y $10,0 \mathrm{~g} / \mathrm{Nm}^{3}$ a $5,7 \mathrm{~g} / \mathrm{Nm}^{3}$ según la clasificación de la EPA. Los componentes minoritarios como el cloro y $\mathrm{H}_{2} \mathrm{~S}$ disminuyeron en función de la carga de lodo en las mezclas, mientras que el $\mathrm{NH}_{3}$ permaneció constante, salvo para la mezcla de mayor contenido en lodo. Los ensayos demostraron la viabilidad de este CSR como combustible. Contrariamente a lo que se pensó inicialmente, estos ensayos resultaron más positivos para los CSR de mayor carga de lodo, controlándose mejor el proceso y sin problemas de acumulación de ceniza, ya que ésta fue recogida por un ciclón posterior al gasificador. No se detectaron problemas de 
aglomeración o sinterizado del combustible con el material de lecho. El PCI obtenido fue relativamente alto para gasificación con aire en operación autotérmica, pero no se pudo trabajar con un ER mayor a 0,20, por tanto, el contenido total en alquitranes superó al obtenido en el gasificador lecho fluidizado circulante donde el ER varió de 0,3 a 0,49.

- El estudio de su viabilidad en lechos fluidizados circulantes tuvo un paso previo, al emplear modelos a temperatura ambiente para mejorar las condiciones operacionales para esta tecnología. Se seleccionó el material de lecho a emplear en la unidad circulante, $428 \mu \mathrm{m}$, así como se solucionaron los problemas de circulación debidos a la válvula no-mecánica de control de sólidos. Este estudio resultó en un incremento de la circulación de sólidos de la unidad circulante al gasificar el CSR M1, con las modificaciones de la aireación en la rama de retorno de sólidos.

- La viabilidad del proceso de gasificación de los CSR de origen industrial solamente fue estudiada para el CSR con menor contenido en cenizas para evitar la puesta en funcionamiento de un sistema de extracción de cenizas. El proceso empleo aire como agente gasificante en operación autotérmica, por lo tanto, la temperatura media del lecho fue función del ER seleccionado. Los ensayos se realizaron con un valor de ER: 0,3-0,49, lo que resultó en un incremento de la producción de gas y de la conversión de carbono, por el contra, el PCI se redujo desde 4,8 a 2,3 MJ/Nm${ }^{3}$. Respecto al EFG, éste se mantuvo constate alrededor de $50-62 \%$, a excepción de un $37 \%$ con $\mathrm{ER}=0,49$. Los alquitranes totales descendieron con el aumentar ER, según la clasificación de la EPA de 11,4 $\mathrm{g} / \mathrm{Nm}^{3}$ a $4,9 \mathrm{~g} / \mathrm{Nm}^{3}$. Respecto a los componentes minoritarios el $\mathrm{NH}_{3}$ del gas de proceso se mantuvo en valores próximos de 198 a 121 ppm, mientras que el cloro y el $\mathrm{H}_{2} \mathrm{~S}$ disminuyeron su concentración al aumentar ER. Los ensayos demostraron la viabilidad de este CSR como combustible, la ceniza que se generó durante el ensayo fue recogida por un ciclón sin causar problemas operacionales. Además, no se detectó ni aglomeración, ni sinterizado del combustible con el material de lecho. El PCI obtenido fue semejante al obtenido con otros combustibles en operaciones autotérmicas, siendo el ensayo óptimo a un $\mathrm{ER}=0,3$ con $4,8 \mathrm{MJ} / \mathrm{Nm}^{3}$.

\subsection{CONCLUSIONES}

El Empleo de residuos para la producción de combustibles aptos para su aprovechamiento energético en instalaciones de lecho fluidizado ha resultado satisfactorio. Las principales conclusiones de la evaluación de la viabilidad técnica del proceso de gasificación de residuos con elevado contenido en material plástico son:

- Producción de un combustible derivado de residuos con origen doméstico, se produjo un combustible con el código clase 231, correspondiente a la clasificación estipulada en la normativa para los CSR. Este combustible mostró un bajo contenido en mercurio, moderado de cloro y alto poder calorífico inferior de acuerdo a su clasificación, lo que permite afirmar que el empleo de este CSR tiene un bajo riesgo ambiental, reducido impacto de la corrosión en las instalaciones y un potencial uso como combustible para recuperación energética. Los periodos de operación estable en el gasificador de lecho fluidizado burbujeante mostraron su idoneidad como combustible en una planta 
de gasificación operada de manera autotérmica a semejanza de una planta industrial.

- Producción de combustible derivado de residuos con origen industrial, se obtuvieron cuatro combustibles con los siguientes códigos de clase: 251;251; $341 ; 341$, en función de la carga de lodo añadida. Este combustible mostró un bajo contenido en mercurio, lo que implica un bajo riesgo ambiental de acuerdo a las especificaciones técnicas de la normativa para los CSR. La dilución provocada por el lodo en las mezclas que dieron lugar a cada uno de los cuatro CSR redujo el poder calorífico, siendo moderado, pero apto para su viabilidad como combustibles en procesos de gasificación, ya que es semejante al de una biomasa convencional. Además, está dilución, hizo que el contenido en cloro bajara apreciablemente sin necesidad de un tratamiento previo al papelote. Los cuatro CSR fueron ensayados en el gasificador de lecho fluidizado burbujeante operado de manera autotérmica con óptimos resultados tras sendos periodos estables de operación, donde se demostró su idoneidad como combustible en una planta de gasificación. Además, el CSR M1, menor contenido en lodo, fue gasificado en una planta piloto de lecho fluidizado burbujeante con resultados muy prometedores al aumentar la conversión de carbono y el poder calorífico del gas de proceso.

- Este estudio ha mostrado la aplicabilidad de las fracciones residuales de los residuos no susceptibles de reciclaje en la producción de combustibles secundarios. La producción de CSR, en forma de pélets, adecuados para recuperación energética es un hecho que puede abrir nuevas expectativas en la gestión de residuos evitando su eliminación o depósito en vertedero.

\subsection{FUTUROS TRABAJOS}

Tras analizar los resultados obtenidos en este estudio, existe un amplio margen para la realización de futuros trabajos.

Respecto a los CSR, se podrían enfocar este estudio hacia otros residuos no peligrosos que pudieran ser susceptibles de transformación para su uso en instalaciones de gasificación de lecho fluidizado:

- Ampliar el estudio a la producción de CSR de origen industrial, ya que existen gran variedad de procesos industriales que generan abundantes residuos que actualmente se llevan a vertedero. En este sentido, siguiendo la línea de investigación actual, residuos con alto contenido en material plástico, se podrían estudiar: residuos de vehículos fuera de uso (VFU), neumáticos fuera de uso (NFU), residuos plásticos de uso agrícola, residuos de construcción y demolición, y en general, cualquier residuo industrial que posea un elevado contenido de material plástico.

- Ampliar el estudio a la producción de CSR de origen comercial.

- Estudio comparativo con otras plantas de tratamiento de residuos sólidos, con el objeto de comparar la caracterización y composición de otros CSR obtenidos en función de la zona geográfica y sus sistemas de recogida de residuos. 
En cuanto al proceso de gasificación, se podrían implementar nuevas líneas de trabajo:

- Ampliar el estudio de gasificación a los CSR de la industria papelera, es decir: realizar el mismo estudio que se llevó a cabo para la mezcla M1, con las mezclas M2, M3 y M4.

- Ampliar el estudio de gasificación a los CSR de origen doméstico, es decir, su utilización como combustible en la planta piloto de lecho fluidizado circulante.

- Rediseño del gasificador de lecho fluidizado burbujeante para permitir un aumento del inventario de sólidos, ya que permitiría aumentar el aporte de aire, incrementando el ER.

- Optimización y mejora del lecho fluidizado burbujeante, que permita el empleo de métodos primarios de gasificación con objeto de reducir el contenido total de alquitranes. Estas medidas podrían centrarse en:

- Utilización de diferentes materiales de lecho como olivino o dolomita.

- Utilización de aires secundarios (rediseño del gasificador).

- Utilización de otros agentes gasificantes: aire-vapor, aire enriquecidovapor o aire enriquecido.

- Estudio de los tratamientos del gas producido en función de su aplicación: producción eléctrica en vertederos, producción eléctrica in situ en plantas industriales, e incluso la canalización del gas, ya sea para la producción de energía térmica del gas por combustión directa para su empleo en redes de calor, o el aprovechamiento del gas en instalaciones a tal efecto. Además, la transformación química del gas de proceso posibilitando la generación de combustibles líquidos y productos químicos (DME, metanol, bioetanol) requieren un grado de limpieza adecuado del gas. Estos productos se utilizan para la producción de combustibles para automoción y transporte, productos químicos y plásticos, combustible para su inyección en gaseoductos, etc. 


\section{REFERENCIAS}

1. Pacesila, M.; Burcea, S.G.; Colesca, S.E., 2016. Analysis of renewable energies in European Union. Renewable and Sustainable Energy Reviews 56, 156-170.

2. Andreas, J.J.; Burns, C.; Touza, J., 2017. Renewable Energy as a Luxury? A Qualitative Comparative Analysis of the Role of the Economy in the EU's Renewable Energy Transitions During the 'Double Crisis'. Ecological Economics 142, 81-90.

3. Khanama, T.; Rahmana, A.; Mola-Yudegoa, B.; Pelkonena, P.; Perezc, Y.; Pykäläinena, J., 2017. Achievable or unbelievable? Expert perceptions of the European Union targets for emissions, renewables, and efficiency, 2017. Energy Research \& Social Science 34, 144-153.

4. Berndes, G.; Hoogwijk, M.; van der Broek, R., 2003 The contribution of biomass in the future global. Energy supply: a review of 17 studies. Biomass \& Bioenergy $25,1-28$.

5. Babu, S.P., 2006. Work Shop No. 1: Perspectives on Biomass Gasification. IEA Bionergy Agreement. Task 33: Thermal Gasification of Biomass.

6. McKendry, P., 2002. Energy production from biomass (part 2): conversion technologies. Bioresource Technology 83, 47-54.

7. Campoy Naranjo, M., 2009. Gasificación de biomasa y residuos en lecho fluidizado: estudios en planta piloto. Tesis doctoral, Universidad de Sevilla.

8. Directive 2006/12/EC. Directive on Waste. Available at: <http://eurlex.europa.eu> (accesed on August 2014).

9. Directive 2008/98/EC. Directive on Waste. Available at: <http://eurlex.europa.eu> (accessed on August 2014).

10. Commission Staff Working Paper. Analysis of Options Beyond 20\% GHG Emission Reductions: Member Stateresults, 2012. Available at: http://ec.europa.eu/clima/ policies/package/docs/swd_2012_5_en.pdf (accesed on March 2015).

11. HORIZONTE 20/20, Digital Journal, 2015. Available at: $<$ http://eshorizonte2020.cdti.es/index.asp?MP=87\&MS=718\&MN=2> (accessed on April 2015).

12. Arena, U., 2015. From waste-to-energy to waste-to-resources: the new role of thermal treatments of solid waste in the Recycling Society. Waste Manage. 37, 12.

13. Martínez, C., Cotes, T., Corpas, F.A., 2013. Recovering wastes from the paper industry: development of ceramic materials. Fuel Process. Technol. 103, 117124.

14. Rada, E.C., 2014. Energy from municipal solid waste. WIT Trans. Ecol. Environ. 190, 945-957

15. Ionescu, G., Rada, E.C., Ragazzi, M., Marculescu, C., Badea, A., Apostol, T., 2013. Integrated municipal solid waste scenario model using advanced pretreatment and waste to energy processes. Energy Convers. Manage. 76, 10831092.

16. Martínez, T.G., Bräutigam, K.-R., Seifert, H., 2012. The potential of a sustainable municipal waste management system for Santiago de Chile, including energy production from waste. Energy Sustain. Soc. 2, 1-14.

17. Premakumara, D.G.J., Abe, M., Maeda, T., 2011. Reducing municipal waste through promoting integrated sustainable waste management (ISWM) practices in Surabaya city, Indonesia. WIT Trans. Ecol. Environ. 144, 457-468. 
18. Singh, J., Laurenti, R., Sinha, R., Frostell, B., 2014. Progress and challenges to the global waste management system. Waste Manage. Res. 32 (9), 800-812.

19. Ciudin, R., Isarie, C., Cioca, L., Petrescu, V., Nederita, V., Rainieri, E., 2014. Vacuum waste collection system for a historical city centre. U.P.B. Sci. Bull., Series D 76 (3), ISSN 1454-2358.

20. Petrescu, V., Ciudin, R., Isarie, C., Nederita, V., 2010. Environmental engineering education-waste management in Romania, World Transitions in Engineering and Technology Education, Volume 8, Number 1, Published by World Institute for Engineering and Technology Education (WIETE), ISSN 1446-2257, pp. 107110, pg. 4.

21. Rada, E.C. and Ragazzi, M., 2014. Selective collection as a pretreatment for indirect solid recovered fuel generation. Waste Manage. 34 (2), 291-297.

22. Directive 1999/31/EC. Directive on Landfill of Waste 1999/31/EC. (accessed 01.08.14).

23. Kwak, T.-H., Maken, S., Lee, S., Park, J.-W., Min, B.-R. and Yoo, Y. D, 2006. Environmental aspects of gasification of Korean municipal solid waste in a pilot plant. Fuel 85, 2012-2017.

24. Park, J.W., Shin, H.C., 2001. Surface emission of landfill gas from solid waste landfill. Atmos. Environ. 35, 3445.

25. Zamorano, M., Perez Perez, J.I., Aguilar Paves, I., Ramos Ridao, A., 2007. Study of the energy potential of the biogas produced by an urban waste landfill in Southern Spain. Renewable and Sustainable Energy. Reviews 11, 909-922.

26. Bidart, C., Fröhling, M., Schultmann, F., 2013. Municipal solid waste and production of substitute natural gas and electricity as energy alternatives. Appl. Therm. Eng. 51, 1107-1115.

27. Waste360, Digital Journal, 2015. Available at: http://www.waste360.com/mag/waste_landfills_small_big (accessed on April 2015).

28. Morris, M., Waldheim, L., 1998. Energy recovery from solid waste fuels using advanced gasification technology. Waste Manage. 18, 557-564.

29. Handbook for compost marketing, 2015. Available at: http://www.biowastescow.eu (accesed on January 2018).

30. ECN (European Compost Network), Digital Journal 2018.Available at: https://www.compostnetwork.info (accessed on January 2018).

31. Bosmans, A., Vanderreydt, I., Geysen, D., Helsen, L., 2013. The crucial role of Wasteto-Energy technologies in enhanced landfill mining: a technology review. J. Clean. Prod. 55, 10-23.

32. Cimpan C. and Wenzel, H., 2013. Energy implications of mechanical and mechanical-biological treatment compared to direct waste-to-energy. Waste Manag. 33, 1648-1658.

33. Rada, E.C., Ragazzi, M., Ionescu, G., Merler, G., Moedinger, F., Raboni, M., Torretta, V., 2014. Municipal Solid Waste treatment by integrated solutions: energy and environmental balances. Energy Procedia 50, 1037-1044.

34. Ma, W., Hoffmann, G., Schirmer, M., Chen, G. and Rotter, V.S., 2010. Chlorine characterization and thermal behaviour in MSW and RDF. Journal of Hazardous Materials 178, 489-498.

35. Vesilind, P.A., Uhl, M.E., Gullet, B.K. and Elsevier, E, 1983. Characterization of refuse-derived fuels by large-scale continuous calorimetry. Waste Manage. and Research 147-155. 
36. Belgiorno, V., De Feo, V.G., Della Rocca, C. and Napoli, R.M.A., 2003. Energy from gasification of solid wastes. Waste Manage. 23, 1-15.

37. Monte, M.C., Fuente, E., Blanco, A., Negro, C., 2009. Waste management from pulp and paper production in the European Union. Waste Manage. 29 (1), 293308.

38. Preliminary Statistics 2016, CEPI.

39. Ahmadi, B., Al-Khaja, W., 2001. Utilization of paper waste sludge in the building construction industry. Resour. Conserv. Recycl. 32 (2), 105-113.

40. Frías, M., Rodríguez, O., Sánchez de Rojas, M.I., 2015. Paper sludge, an environmental sound alternative source of MK-based cementitious materials. A review. Constr. Build. Mater. 74, 37-48.

41. Yan, S., Sagoe-Crentsil, K., Shapiro, G., 2011. Reuse of de-inking sludge from wastepaper recycling in cement mortar products. J. Environ. Manage. 92 (8), 2085-2090.

42. ASPAPEL, Association of Spanish Pulp, Paper and Cardboard Manufacturers, 2017. Available at: <http://www.aspapel.com> (accessed on June 2017).

43. Alter, H., 1987. The history of refuse-derived fuels. Resour. Conser. 15, 251-275.

44. ASTM E856-83. Standard Definitions of Terms and Abbreviations Relating to Physical and Chemical Characteristics of Refuse Derived Fuel, 2004.

45. European Commissin-Directorate General Environment. Refuse derived fuel, current practice and perspectives (B4-3040/2000/306517/MAR/E3). Final report. WRc Ref: CO5087-4, July 2003.

46. Evaluation of Dutch and Finnish situation of energy recovery from biomass and waste, 2000. Technology Review, National Technology Agency.

47. Ciceri, G., 2011. Il combustibili solidi secundari (CSS) e la nuova normativa nazionale. Ecomondo, Ricerca Sitema energético.

48. BGS ev. Available at: <http://bgs-ev.de/> (Accesed 17/06/2017).

49. Rada, E.C., 2012. Biodegradability of landfilled MSW in EU: past, present and future. J. Bioremed. Biodegrad 3, 22.

50. Rada, E.C., Andreottola, G., 2012. RDF/SRF: which perspective for its future in the EU. Waste Manage. 32 (6), 1059-1060.

51. Velis C.A., Longhurst P.J., Drew G.H., Smith R., Pollard S.J.T., 2010. Production and quality assurance of solid recovered fuels using mechanical biological treatment (MBT) of waste: a comprehensive assessment. Crit Rev Environ Sci Technol 40(12), 9791105.

52. UNE-EN 15357:2012. Combustibles sólidos recuperados: Terminología, definiciones y descripciones. Available at: <www.aenor.es>

53. UNE-EN 15359:2012. Combustibles sólidos recuperados: Especificaciones y clases. Available at: <www.aenor.es>

54. UNE-EN 15440:2012. Combustibles sólidos recuperados: Métodos para la determinación del contenido en biomasa. Available at: <www.aenor.es>

55. Séverin, M., Velis, C.A., Longhurst, P.J., Pollard, S.J.T., 2010. The biogenic content of process streams from mechanical-biological treatment plants producing solid recovered fuel. Do the manual sorting and selective dissolution determination methods correlate? Waste Manage. 30 (7), 1171-1182.

56. European Recovered Fuel Organisation (ERFO). Available at: <ww.erfo.es> (accessed on March 15).

57. Recuperación de residuos en fábricas de cemento y protección del clima. Fundación CEMA, 2014. 
58. Recuperación energética de residuos en fábricas de cemento y salud ambiental. Fundación CEMA, 2014.

59. Guía de Métodos de medición y Factores de emisión del sector cementero en España. Oficemen, 2014.

60. IDEA, 2011. Available at: <http//www.idae.es> (acessed 17/6/2017)

61. Leckner, B., 2014. Process aspects in combustion and gasification Waste-toEnergy (WtE) units. Waste Manage. 37, 13-25.

62. Arena, U., 2012. Process and technological aspects of municipal solid waste gasification. A review. Waste Manage. 32, 625-639.

63. Dunnu, G., Panopoulos, K.D., Karellas, S., Maier, J., Touliou, S., Koufodimos, G., Boukis, I., 2012. The solid recovered fuel Stabilitat characteristics and fluidised bed gasification tests. Fuel 93, 273-283.

64. Pinto, F., André, R.N., Carolino, C., Miranda, M., Abelha, P., Direito, D., Perdikaris, N., Boukis, I., 2014. Gasification improvement of a poor quality solid recovered fuel (SRF). Effect of using natural minerals and biomass wastes blends. Fuel 117, 1034-1044.

65. Vounatsos, P., Agraniotis, M., Grammelis, P., Kakaras, E., Skiadi, O., Zarmpoutis, T., 2014. Refuse-derived fuel classification in a mechanical-biological treatment plant and its valorization with techno-economic criteria. Int. J. Environ. Sci. Technol. 12 (3), 1137-1146.

66. Puig-Arnavat, M.; Bruno, J.C.; Coronas, A., 2010. Review and analysis of biomass gasification models. Renewable and Sustainable Energy Reviews 14, 2841-2851.

67. Shabbar, S.; Janajreh, I., 2013. Thermodynamic equilibrium analysis of coal gasification using Gibbs energy minimization method. Energy Conversion and Manage. 65, 755-763.

68. Kern, S.; Pfeifer, C.; Hofbauer, H., 2013. Gasification of lignite in a dual fluidized bed gasifier-Influence of bed material particle size and the amount of steam. Fuel Processing Technology 111, 1-13.

69. Sánchez López, I., 2014. Análisis comparativo de las tecnologías de valorización de residuos basadas en la gasificación, Congreso Nacional de Medio Ambiente (Conama).

70. Pohorely, M., Vosecký, M., Hejdová, P., Punčochář, M., Skoblja, S., Staf, M., Vošta, J., Koutský, B., Svoboda, K., 2006. Gasification of coal and PET in fluidized bed reactor. Fuel 85, 2458-2468.

71. Van Huynh, C.; Kong, S.C., 2013. Combustion and $\mathrm{NO}_{\mathrm{x}}$ emissions of biomassderived syngas under various gasification conditions utilizing oxygen-enriched-air and steam. Fuel 107, 455-464.

72. Baratieri, M., Baggio, P., Bosio, B., Grigiante, M. and Longo, G.A., 2009. The use of biomass syngas in IC engines and CCGT plants: a comparative analysis. Applied Thermal Engineering 29, 3309-3318.

73. Vélez, J.F., Chejne, F., Valdés, C.F., Emery, E.J. and Londoño, C.A., 2009 Cogasification of Colombian coal and biomass in fluidized bed: an experimental study. Fuel 88, 424-430.

74. Basu, P., 2006. Combustion and Gasification in Fluidized Beds. Taylor and Francis, USA

75. Kawaguchi, K., Miyakoshi, K. and Momonoi, K., 2002. Studies on the pyrolysis behaviour of gasification and melting systems for municipal solid waste. Journal of Material Cycles and Waste Manage. 4, 102-110. 
76. De Souza-Santos, M.L., 2002. Solid Fuels Combustion and Gasification. Marcel Dekker, Inc.

77. BIOENERGY, Task 33. Thermal gasification of biomass. Available at: <http://www.ieatask33.org/content/thermal_gasification> (accessed on April 2015).

78. Higman, C. and Burgt, M., 2003. Gasification, $1^{\text {st }}$ Ed. Elsevier Gulf Professional. Publishing, Boston.

79. Hatzilyberis, K.S., 2011. Design of an indirect heat rotary kiln gasifier. Fuel Processing Technology 92, 2429-2454.

80. Agrowaste, 2017. Available at:<http://www.agrowaste.eu> (Accesed 17/06/2017)

81. Ruiz, J.A., Juárez, M.C., Morales, M.P., Muñoz, P., Mendívil, M.A., 2013. Biomass gasification for electricity generation: Review of current technology barriers. Renewable and Sustainable Energy Reviews 18, 174-183.

82. Basu, P., 2010. Biomass gasification and Pyrolysis. Taylor and Francis, USA.

83. Slapak, M.J.P., van Kasteren, J.M.N., Drinkenburg, A.A.H., 2000. Design of a process for steam gasification of PVC waste. Resources, Conservation and Recycling 30, 81-93.

84. Rahman, M.H., Bi, X.T., Grace, J.R., Lim., C.J., 2017. Measurement of solids circulation rate in a high-temperature dual fluidized bed pilot plant Powder Technology 316, 658-669.

85. Aroraa, P., Hoadley, A.F.A., Mahajani, S.M., Ganeshc, A., 2017. Compartment model for a dual fluidized bed biomass gasifier. Chemical Engineering Research and Design 117, 274-286.

86. Tremel, A., Becherer, D., Fendt, S., Gaderer, M., Spliethoff, H., 2013 Performance of entrained flow and fluidised bed biomass gasifiers on different scales. Energy Conversion and Manage. 69, 95-106.

87. Zhao, Y., Sun, S., Zhou, H., Sun, R., Tian, H., Luan, J. and Qian, J., 2010. Experimental study on sawdust air gasification in an entrained-flow reactor. Fuel Process. Technol. 91, 910-914.

88. Janajreh, I., Raza, S.S. and Valmundsson, A.S., 2013. Plasma gasification process: Modeling, simulation and comparison with conventional air gasification. Energy Convers. and Manage. 65, 801-809.

89. Gomez, E., Amutha-Rania, D., Cheesemanb, C.R., Deeganc, D., Wisec, M. and Boccaccinia, A.R., 2009. Thermal plasma technology for the treatment of wastes: A critical review. Journal of Hazardous Materials 161, 614-626.

90. Mountouris, A., Voutsas, E. and Tassios, D., 2008. Plasma gasification of sewage sludge: Process development and energy optimization. Energy Conversion and Manage. 49, 2264-2271.

91. Guo, Y., Wang, S., Huelsman, C.M. and Savage P.E., 2013. Products, pathways, and kinetics for reactions of indole under supercritical water gasification conditions. Journal of Supercritical Fluids 73, 161- 170.

92. Castello, D., Kruse A., Fiori, L., 2013. Biomass gasification in supercritical and subcritical water: The effect of the reactor material. Chemical Engineering Journal 228, 535-544.

93. Bernocco, D., Bosio, B. and Arato, E., 2013. Feasibility study of a spouted bed gasification plant. Chemical engineering research and design 91, 843-855.

94. Ruoppolo, G., Miccio, F., Brachi, P., Picarelli, A. and Chirone, R., 2013. Fluidized Bed Gasification of Biomass and Biomass/Coal Pellets in Oxygen and Steam Atmosphere. Chemical Engineering Transations, Vol. 32. 
95. Hasler, Ph., Buehler, R. and Nussbaumer, Th., 1998. Evaluation of gas cleaning technologies for biomass gasification. Biomass for energy and industry, 10th European Conference and Technology Exhibition, June 8-11, Wurzburg (Germany).

96. Couto, N. D., Silva, V. B. and Rouboa, A., 2016. Thermodynamic Evaluation of Portuguese municipal solid waste gasification. Journal of Cleaner Production 139, 622-635.

97. Higman, C. State of the gasification industry: Worlwide Gasification Database 2016 update in Gasification and Syngas Technologies Conference Vancouver $19^{\text {th }}$ October, 2016.

98. National Energy Technology Laboratory. US Department of Energy, 2016. Available at: <http: Iwww.netl.doe.gov> (accessed on March 2018).

99. Asadullah, M., 2014. Barriers of commercial power generation using biomass gasification gas: A review. Renewable and Sustainable Energy Reviews, 29 (0), 201-215.

100. Spath, P.L. and Dayton, D.C., 2003. Preliminary screening- Technically and economic assessment of synthesis gas to fuels and chemicals with emphasis on the potential for biomass-derived syngas. National Renewable Laboratory, NREL/TP510-34929.

101. Ruiz, E. and Sánchez, J.M., 2014. Purificación y acondicionamiento del gas de gasificación de biomasa. Boletín Grupo Español del Carbón, nº 33.

102. Review of Technologies for Gasification of Biomass and Wastes Final report NNFCC project 09/008. A project funded by DECC, project managed by NNFCC and conducted by E4Tech on June 2009.

103. Hofbauer, H., Rauch, Ripfel-Nitsche, K., 2007. Report on Gas Cleaning for Synthesis Applications Work Package 2E: "Gas treatment" Deliverable: 2E-3 University of Vienna, Technology Institute of Chemical Engineering.

104. Fu, H.Z., Ho Y.S., Sui, Y.M., Li, Z.S., 2010. A bibliometric analysis of solid waste research during the period 1993-2008. Waste Manage. 30, 2410-2417.

105. Li, Y., Zhao, X., Li, Y., Li, X., 2015. Waste incineration industry and development policies in China. Waste Manage. 46, 234-241.

106. Leckner, B., 2013 Atmospheric (Non-Circulating) Fluidized Bed Combustion, Chapter 14 in Fluidized-Bed Technologies for Near-Zero Emission Combustion and Gasification (Ed. F. Scala), Woodhead Publishing Ltd., Cambridge, UK, ISBN:0 857095412.

107. Montané, D., Abelló, S., Farriol, X., Berrueco, C., 2013. Volatilization characteristics of solid recovered fuels (SRFs). Fuel Process. Technol. 113, 90-96.

108. Recari, J., Berrueco, C., Abelló, S., Montané, D., Farriol, X., 2016. Gasification of two solid recovered fuels (SRFs) in a lab-scale fluidized bed reactor: Influence of experimental conditions on process performance and release of $\mathrm{HCl}, \mathrm{H}_{2} \mathrm{~S}, \mathrm{HCN}$ and $\mathrm{NH}_{3}$. Fuel Processing Technology 142, 107-114.

109. Arena, U., Di Gregorio, F., 2014. Energy generation by air gasification of two industrial plastic wastes in a pilot scale fluidized bed reactor. Energy 68, 735-743.

110. Arena, U., Di Gregorio, F., 2016. Fluidized bed gasification of industrial solid recovered fuels. Waste Management 50, 86-92.

111. Siedlecki, M., de Jong, W., 2011. Biomass gasification as the first hot step in clean syngas production process-gas quality optimization and primary tar reduction measures in a $100 \mathrm{~kW}$ thermal input steam-oxygen blown gasifier. Biomass Bioenergy 35 (1), 840-862. 
112. Meng, X., de Jong, W., Fu, N., Verkooijen, A.H.M., 2011. Biomass gasification in a $100 \mathrm{~kW}$ th steam-oxygen blown circulating fluidized bed gasifier: effects of operational conditions on product gas distribution and tar formation. Biomass Bioenergy 35 (7), 2910-2924.

113. Van der Drift, A., van Doorn, J., Vermeulen, J.W., 2001. Ten residual biomass fuels for circulating fluidized-bed gasification. Biomass Bioenergy 20 (1), 45-56.

114. Granatstein, D.L., 2003. Case of Study on Waste-Fuelled Gasification Project, Greve in Chianti, Italy. IEA Bioenergy Task 36 Report.

115. Liu, K., Ma, X.Q., Min, H.M., 2012. Experimental and kinetic modeling of oxygen enriched air combustion of paper mill sludge. Waste Manage. 30 (7), $1206-1211$.

116. Xie, Z., Ma, X., 2012. The thermal behaviour of the co-combustion between paper sludge and rice straw. Bioresour. Technol. 146, 611-618.

117. Ouadi, M., Brammer, J.G., Kay, M., Hornung, A., 2013. Fixed bed downdraft gasification of paper industry wastes. Appl. Energy 103, 692-699.

118. ECN, 2017. <http://www.thersites.nl/tardewpoint.aspx> (Accesed 17/6/2017)

119. CEN/TS 15439: 2006. Biomasa gasification-Tar and particles in product gasesSampling and análisis, European Comitee for Standarization, 2006.

120. Osipovs, S., 2008. Sampling of benzene in tar matrices from biomass gasification using two different solid-phase sorbents. Analytical and Bioanalytical Chemistry 391(4), 1409-1417.

121. Ortiz, I., 2015. Caracterización de contaminantes orgánicos generados en la gasificación de residuos. Tesis doctoral, Universidad Complutense.

122. Milne, T.A., Abatzoglou, N., Evans, R.J., 1998. Biomass Gasifier Tars: Their Nature, Formation and Conversion, Golden, CO, USA. Available at: <http://www.nrel.gov/docs/ fy99osti/25357.pdf>.

123. Van Paasen and Kiel, J.H.A., 2004. Tar formation in a fluidised-bed gasifier: impact of fuel properties and operating conditions, Petten. Available at: <https://www.ecn. nl/publications/ECN-Ce04-013>.

124. Houben M. P., 2004. Analysis of tar removal in a partial oxidation burner. $\mathrm{PhD}$ thesis, Technische Universiteit Eindhoven.

125. Gredinger, A., Schweitzer, D., Dieter, H., Scheffknecht, G., 2014. Online Tar Monitoring via FID - Laboratory and Pilot Plant Experiments of an Advanced Online Tar Analyzer Prototype. 22 ${ }^{\text {nd }}$ European Biomass Conference and Exhibition.

126. Zwart, R.W.R. Gas cleaning downstream biomass gasification. Status Report 2009. Energy research Centre of the Netherlands (ECN), Unit Biomass, Coal and Environmental Research.

127. Chiemchaisri, C., Charnook, B., Visvanathan, C., 2010. Recovery of plastic wastes from dumpsite as refuse-derived fuel and its utilization in small gasification system. Bioresour. Technol. 101, 1522-1527.

128. Wagland, S.T., Kilgallon, P., Coveney, R., Garg, A., Smith, R., Longhurst, P.J., Pollard, S.J.T., Simms, N., 2011. Comparison of coal/solid recovered fuel (SRF) with coal/ refuse derived fuel (RDF) in a fluidised bed reactor. Waste Manage. 31, $1176-1183$.

129. Ceamanos, J., Mastral, J.F., Millera, A., Aldea, M.E., 2002. Kinetics of pyrolisis of high density polyethylene: Comparison of isothermal and dynamic experiments. J. Anal. Appl. Pyrolysis 65 (2), 93-110. 
130. Singh Chouhan, A.P., Singh, N., Sharma, A.Q., 2013. A comparative analysis of kinetic parameters from TGDTA of Jatropha curcas oil, biodiesel, petroleum diesel and B50 using different methods. Fuel 109, 217-224.

131. Slopiecka, K., Bartocci, P., Fantozzi, F., 2012. Thermogravimetric analysis and kinetic study of poplar wood pyrolysis. Appl. Energy 97, 491-497.

132. Aboulkas, A., El Harfi, K., El Bouadili, A., Nadifiyine, M., Benchanaa, M., Mokhlisse, A., 2009. Pyrolysis kinetics of olive residue/plastic mixtures by nonisothermal thermogravimetry. Fuel Process. Technol. 90 (5), 722-728.

133. Determination of hydrogen halide and halogen emissions from stacionary sources non-isokinetic method (Method 26). Avaliable at: <www.prtr_es.es> (accessed March 2015).

134. RD 653/2003 sobre incineración de residuos ECA/OCA. Registro estatal de emisiones y fuentes contaminantes. Available at: 〈www.prtr_es.es $>$ (acceso en Marzo de 2015).

135. Aranda Usón, A., Ferreira, G., Zambrana Vásquez, D., Zabalza Bribián, I., Llera Sastresa, E., 2012. Estimation of the energy content of the residual fraction refused by MBT plants: a case study in Zaragoza's MBT plant. Journal of Cleaner Production, Volume 20 (1), Pages 38-46.

136. Aracil, I., Font, R., Conesa, J.A., 2005. Semivolatile and volatile compounds from the pyrolysis and combustion of polyvinyl chloride. J. Anal. Appl. Pyrolysis 74, 465-478.

137. Sarc, R., Lorber, K.E., 2013. Production, quality and quality assurance of refuse derived fuels (RDFs). Waste Manage. 33 (9), 1825-1834.

138. Alonso, A., Sánchez, J., 2010. Estudio de viabilidad para fabricación de combustible sólido recuperado de residuos urbanos procedentes de plantas de tratamiento mecánico-biológico. Conama10 Congreso Nacional del Medio ambiente. Feasibility study for production of solid recovered fuel from municipal solid waste from mechanical biological treatment plants. CONAMA 10, National Congress of the Environment.

139. Hernandez-Atonal, F.D., Ryu, C., Sharifi, V.N., Swithenbank, J., 2007. Combustion of refuse-derived fuel in a fluidised bed. Chem. Eng. Sci. 62, 627635.

140. Ruiz Celma, A., Cuadros, F., López-Rodriguez, F., 2012. Characterization of pellets from industrial tomato residues. Food Bioprod. Process. 90 (4), 700-706.

141. Obidzinski, S., 2012. Analysis of usability of potato pulp as solid fuel. Fuel Processing Technology 94, 67-74.

142. Colley, Z., O. O. Fasina, D. Bransby, and Y. Y. Lee. 2006. Moisture effect on the physical characteristics of switchgrass pellets. American Society of Agricultural and Biological Engineers 49(6): 1845-1851.

143. Corella, J., Toledo, J.M., Molina, G., 2008. Performance of $\mathrm{CaO}$ and $\mathrm{MgO}$ for the hot gas clean up in gasification of chlorine-containing (RDF) feedstock. Bioresour. Technol. 99 (16), 7539-7544.

144. Lehtikangas, P., 2001. Quality properties of pelletised sawdust, logging residues and bark. Biomass Bioenergy 20 (5), 351-360.

145. Dunnu, G., Maier, J., Scheffknetch, G., 2010. Ash fusibility and compositional data of solid recovered fuels. Fuel 89, 1534-1540.Fernández, M.J., Carrasco, J.E., 2005. Comparing methods for predicting the sintering of biomass ash in combustion. Fuel 84, 1893-1900. 
146. Contreras, M.L., García-Frutos, F.J., Ramos, R., Sanz, D., Bahillo, A., 2015. Trace metals removal through a catalytic hybrid filter during cofiring of different biomass waste materials. Fuel 150, 538-547.

147. Gray, R. J. and Moore, G. F., 1974. Burning the sub-bituminous coals of Montana and lryoming in langc uitility boilers, ASblE paper 74-IVA/FV-1.

148. Ramos Casado, R., Arenales Rivera, J., Borjabad García, E., Escalada Cuadrado, R., Fernández Llorente, M., Bados Sevillano, R., Pascual Delgado, A., 2016. Classification and characterisation of SRF produced from different flows of processed MSW in the Navarra region and its co-combustion performance with olive tree pruning residues. Waste Manage. 47, 206-216.

149. Mangut, V., Sabio, E., Gañán, J., Al-Kassir, A., González, J.F., Ramiro, A., González, C.M., Román, S., 2006. Thermogravimetric study of the pyrolysis of biomass residues from tomato processing industry. Fuel Process. Technol. 87, $109-115$.

150. Cai, J., Wang, Y., Zhou, L., Huang, Q., 2007. Thermogravimetric analysis and kinetics of coal/plastic blends during co-pyrolysis in nitrogen atmosphere. Fuel Process. Technol. 89, 21-27.

151. Liu, K., Pan, W.P., Riley, J.T., 2000. A study of chlorine behavior in a simulated fluidized bed combustion system. Fuel 79, 1115-1124.

152. Altarawneh, M., Dlugogorski, B.Z., Kennedy, E.M., Mackie, J.C., 2009. Mechanisms for formation, chlorination, dechlorination and destruction of polychlorinated dibenzo-p-dioxins and dibenzofurans (PCDD/Fs). Progr Energy Combust Sci 35, 245-274.

153. Ramos, A., Monteiro, E., Silva, V., Rouboa, A., 2018. Co-gasification and recent developments on waste-to-energy conversion: A review. Renewable and Sustainable Energy Reviews 81, 380-398.

154. Hu, B., Huanga, Q., Buekensa, A., Yong Chia, Yana, J., 2017. Co-gasification of municipal solid waste with high alkali coal char in a threestage gasifier. Energy Conversion and Management 153, 473-481.

155. Mediavilla Ruiz, I., Esteban Pascual, L.S., Fernández Llorente, M.J., Pérez Ortiz, P., Carrasco García, J.E., 2007. $15^{\text {th }}$ European Biomass Conference \& Exhibition, Berlin, Germany, 7-11 May 2007.

156. Lin, K.S., Wang, H.P., Liu, S.H., Chang, N.B., Huang, Y.J., Wang, H.C., 1999. Pyrolysis kinetics of refuse-derived fuel. Fuel Process. Technol. 60 (2), 103-110.

157. Hilber, Th., Martense, M., Maier, J., Scheffknetch, G., 2007. A method to characterise the volatile release of solid recovered fuels (SRF). Fuel 86 (1-2), 303-308.

158. Cozzani, V., Petarca, L., Tognotti, L., 1995. Devolatilization and pyrolysis of refuse derived fuels: characterization and kinetic modelling by a thermogravimetric and calorimetric approach. Fuel 74 (6), 903-912.

159. Shah, J., Jan, M.R., Mabood, F., Jabeen, F., 2010. Catalytic pyrolysis of LDPE leads to valuable resource recovery and reduction of waste problems. Energy Convers. Manage. 51 (12), 2791-2801.

160. Kim, Y.D., Yang, C.W., Kim, B.J., Kim, K.S., Lee, J.W., Moon, J.H., Yang, W., Yu, T.U., Lee, U.D., 2013. Air blown gasification o woody biomass in a bubbling fluidized gasifier. Applied energy, 112, 414-420.

161. Li, X.T., Grace, J.R., Lim, C.J., Watkinson, A.P., Chen, H.P. and Kim, J.R., 2004. Biomass gasification in a circulating fluidized bed. Biomass and Bioenergy, 26, 171-193. 
162. Li, D., Ray, M.B., Ray, A.K. and Zhu, J. A., 2013. Comparative study on hydrodynamics of circulating fluidized bed riser and downer. Powder Technology, 247, 235-259.

163. Levenspiel, O., Kunii, D., Fitzgerald, T., 1968. The processing of solids of changing size in bubbling fluidized beds. Powder Technology, 2, 87-96.

164. Greval, N.S., Saxena, S.C., 1980. Comparison of commonly used correlations for minimum fluidization velocity of small solid particles. Powder Technol. 26, 229234.

165. Lippens, B.C., Mulder, J., 1993. Prediction of the minimum fluidization velocity. Powder Technol. 75, 67-78.

166. Hannes, J.P. Mathematical modelling of circulating fluidized bed combustion. ISBN 3-88817-002-8.

167. Bin, A. K., 1994 Prediction of the minimum fluidization velocity. Powder Technol. 81, 197-199.

168. Fletcher, J.V., Deo, M.D. and Hanson, F.V., 1992. Re-examination of minimum fluidization velocity correlations applied to Group B sands and cooked sands. Powder Technol. 69, 147-155.

169. Subramani, H.J., Mothivel Balaiyya, M.B. and Miranda, L.R., 2007. Minimum fluidization velocity at elevated temperatures for Geldart's group-B particles. Experimental Thermal and Fluid Science 32, 166-173.

170. Thonglimp, V.Hiquily, N., Laguerie, C., 1984 Vitesse minimale de fluidisation et expansion des couches fluidisées par un gaz. Powder Technol. 38, 233-253.

171. Coltters, R. and Rivas, A.L., 2004. Minimum fluidization velocity correlations in particulate systems. Powder Technol., 147, 34-48.

172. Multhipase Flow FACE 8, 2006. Institute of Energy Flow Technology.

173. Cheng, N. S., 2008. Comparison of formulas for drag coefficient and settling velocity of spherical particles. Powder Technol. doi: 10.1016/j.powtec.2008.07.006

174. Gabitto, J., Tsouris, C., 2008 Drag coefficient and shettling velocity for particles of cylindrical shape. Powder Technol. 183, 314-322.

175. Di Felice, R. and Kehlenbeck, R., 2000. Sedimentation velocity of solids in finite size vessels. Chemical Engineer Technol. 23, 12.

176. Yang, W.C., 1998. A model for the dynamics of a circulating fluidized bed loop, $2^{\text {nd }}$ International Conference on Circulating Fluidized Beds. Pergamon Press, pp. 181-191.

177. Yan, C., Fan, Y., Lu, C., Zhang, Y., Liu, Y., Cao, R., Gao, J. and Xu, C., 2009. Solids mixing in a fluidized bed riser. Powder Technol. 193, 110-119.

178. Tommey, R., Johsntone , H.F., 1952. Two phase theory. Chem. Engng. Prog. 48, 220.

179. Van Deemter, J.J., 1961. Mixing and contacting in gas-solid fluidized beds. Chemical Engineering Science Vol. 13, pp. 143-154.

180. Makkawi, Y.T., Ocone, R., 2011. Mass Transfer in Fluidized Bed Drying of Moist Particulate, Mass Transfer in Multiphase Systems and its Applications, Prof. Mohamed El-Amin (Ed.), ISBN: 978-953-307- 215-9, InTech.

181. Almendros-Ibañez, J.A., Pallarés, D., Johnsson, F., Santana, D., 2010. Voidage distribution around bubbles in a fluidized bed: Influence of throughflow. Powder Technol. 197, 73-82.

182. Pallarés, D. and Johnsson, F., 2006. Macroscopic modelling of fluid dynamics in large-scale circulating fluidized beds. Progress in Energy and Combustion Science, 32, 539-569. 
183. Grace, J.R. and Clift, R., 1974. On the two-phase theory of fluidization. Chemical Engineering Science Vol. 29, pp. 327-334.

184. Johnsson, F., Andersson, S. and Leckner, B. Expansion of a freely bubbling fluidized bed. Powder Technology, 68 (1991) 117-123.

185. Johansson, A., Johnsson, F., Leckner, B., 2007. Solids back mixing in CFB boilers. Chemical Engineering Science 1, 561-573.

186. Johnsson, F., Zhang, W. and Leckner, B. Characteristics on the formation of particle wall layers in CFB boilers. $2^{\text {nd }}$ International Conference on Multiphase Flow 1995, Kyoto.

187. Pallarés, D.J. and Johnsson, F. Fluyddynamic modelling of large CFB units. Proc. $7^{\text {th }}$ Conference on Circulating Fluidized Beds, Niagara Falls, Canada, May 5-8, 2002.

188. Kunii, D. and Levenspiel, O., 1997. Circulating fluidized-bed reactors. Chemical Engineering Science 52(15), 2471-2482.

189. Kunii, D. and Levenspiel, O., 1991. Fluidization engineering, $2^{\text {nd }}$ Ed., Butterworth-Heinemann, Boston.

190. Gomez-Barea, A., Leckner, B., 2010. Modeling of biomass gasification in fluidized bed. Progress in Energy and Combustion Science 36, 444-509.

191. Löffler, G., Kaiser, S., Bosch, K. and Hofbauer, H., 2003. Hydrodynamics of a dual fluidized bed gasifier. Part I: simulation of a riser with gas injection and diffuser. Chemical Engineering Science, 58, 4197-4213.

192. Kaiser, S., Löffler, G., Bosch, K. and Hofbauer, H., 2003. Hydrodynamics of dual fluidized bed gasifier. Part II: simulation of solid circulating rate, pressure loop and stability. Chemical Engineering Science 58, 4215-4223.

193. Colokyan, M., Levenspiel, O., 1984. Elutriation from fluidized beds. Powder Technol. 38, 223-232.

194. Adánez, J., Gayán, P., García-Labiano, F., de Diego, L.F., 1994. Axial voidage profiles in fast fluidized beds. Powder Technol. 81, 259-268.

195. Smolders, K. and Baeyens, J., 1997. Elutriation of fines from gas fluidized beds: mechanisms of elutriation and effect of freeboard geometry. Powder Technol. 92, 35-46.

196. Harris, A.T., Davidson, J.F., Thorpe, R.B., 2003. Influence of exit geometry in circulating fluidized-bed risers. AIChe Journal, Vol. $49 \mathrm{~N}^{\mathrm{o}} 1$.

197. Van der Meer, E.H., Thorpe, R.B., Davidson, J.F., 2000. Flow patterns in the square cross-section riser of a circulating fluidised bed and the effect of riser exit design. Chemical Engineering Science 55, 4079-4099.

198. Bai, D.R., Jin, Y., Yu, Z.Q., and Zhu, J.X., 1992. The axial distribution of the cross sectional averaged voidage in fast fluidized beds. Powder Technol. 71, 5158.

199. Gupta, A.V.S.S.K.S., Reddy, B.V., 2005. Bed to wall heat transfer modelling in the top region of a CFB riser column with abrupt riser exit geometries. International Journal of Heat and Mass Transfer 48, 4307-4315.

200. Bricout, V., Louge, M. Y., 2004. Measurements of cyclone performance under conditions analogous to pressurized circulating fluidization. Chemical Engineering Science 59, $3059-3070$.

201. Avci, A., Karagoz, I., 2003. Effects on flow and geometrical parameters on the collection eficiency in cyclone separators. Aerosol Science 34, 937-955.

202. Gimbun, J., Chuah, T.G., Fakhru'l-Razi, A., Choong, T. S.Y., 2005. The influence of temperature and inlet velocity on cyclone pressure drop: a CFD study. Chemical Engineering and Processing 44, 7-12. 
203. Beeckemans, J.M., Morin, B., 1987. The effect of particulate solids on pressure drop across a cyclone. Powder Technol. 52, $227-232$.

204. Cortés, C. and Gil, A., 2007. Modeling the gas and particle flow inside cyclone separators. Progress in Energy and Combustion Science, 33, 409-452.

205. Zhao, B., 2009. Modeling pressure drop coefficient for cyclone separators: A support vector machine approach. Chemical Engineering Science 64, 4131 - 4136.

206. Basu, P., Cheng, L., 2000. An analysis of loop seal operations in a circulating fluidized bed. Trans IChemE, Vol. 78, Part A.

207. Knowlton, T. Non-mechanical control of solids flow in chemical looping systems. Particulate Solid Research, Inc.NETL 2011. Workshop on Multiphase Flow Science, August 16 -18, 2011 Pittsburgh, PA.

208. Basu, P. and Butler, J., 2009. Studies on the operation of loop-seal in circulating fluidized bed boilers. Applied energy 86, 1723-1731.

209. Butler, W., Basu, P. Effect of horizontal passage length on solid recycle through a loop-seal in a circulating fluidized bed. 2007 ECI Conference on the $12^{\text {th }}$ International Conference on Fluidization-New Horizons in Fluidization Engineering.

210. Cheng, L., Basu, P., 1999. Effect of pressure on loop seal operation for a pressurized circulating fluidized bed. Powder Technol. 103, 203-211.

211. Kuramoto, M., Kunii, D. and Furusawa, T., 1986. Flow of dense fluidized particles through an opening in a circulation system. Powder Technol. 47, 141149.

212. Kim, S.W., Kim, S.D., 2002. Effects of particle properties on solids recycle in loop-seal of a circulating fluidized bed. Powder Technol. 124, 46-84.

213. Yang, W.C., Knowlton, T.D., 1993 L-valve equations. Powder Technol. 77, 4954.

214. Geldart, D., Jones, P., 1991. The behaviour of L-valves with granular powders. Powder Technol. 67, 163-174.

215. Arena, U., Langeli C.B., Cammarota, A., 1998. L-valve behaviour with solids of different size and density. Powder Technol. 98, 231-240.

216. Terasaka, K., Akashi, S., Tsuge, H., 2002. Development of a J-shaped pneumatic valve to control the solid particle circulation rate in a circulating fluidized bed. Powder Technol. 126, 13-21.

217. Mastellone, M. L., Zaccariello, L., Arena, U., 2010. Co-gasification of coal, plastic waste and wood in a bubbling fluidized bed reactor. Fuel 89, 2991-3000.

218. Arena, U., Zaccariello, L., Mastellone, M.L., 2010. Fluidized bed gasification of waste-derived fuels. Waste Manage. 30, 1212-1219.

219. Aznar, M.P., Caballero, M.A., Sancho, J.A., Francés, E., 2006. Plastic waste elimination by co-gasification with coal and biomass in fluidized bed with air in pilot plant. Fuel Processing Technol. 87, $409-420$.

220. Mastellone, M.L., Arena, U., 2008. Olivine as a tar removal catalyst during fluidized bed gasification of plastic waste. AIChE Journal 54, 1656-1667.

221. Bläsing, M., Zini, M., Müller,M., 2013. Influence of feedstock on the release of potassium, sodium, chlorine, sulfur, and phosphorus species during gasification of wood and biomass shells. Energy Fuel 27, 1439-1445.

222. Woolcock, P.J., Brown, R.C., 2013. A review of cleaning technologies for biomass-derived syngas. Biomass Bioenergy 52, 54-84.

223. Moilanen, A., 2006. Thermogravimetric Characterisations of Biomass and Waste for Gasification Processes. VTT Publication 607, Espoo, Finland, p. 25. 
224. Pérez López, Virginia, 2015. Estudio de la reducción de alquitranes en procesos de gasificación de lodos de E.D.A.R. Tesis doctoral, Universidad de Valladolid.

225. Tchapda, A.H., Pisupati, S.V., 2014. A review of thermal co-conversion of coal and biomass/ waste, Energy 7, 1098-1148.

226. Van Paasen, S.V.B., Cieplik, M.K., Phokawat, N.P., 2006. Gasification on nonwoody biomass. Economic and technical perspectives of chlorine and sulphur. Removal from product gas, ECN-C-06-032.

227. Pérez López, V., 2015. Estudio de la reducción de alquitranes en procesos de gasificación de lodos de EDAR. Tesis doctoral, Universidad de Valladolid.

228. Yaque Sánchez, A., 2013. Combustibles sólidos recuperados y combustibles derivados de residuos. TFM, Universidad de Sevilla.

229. DIARIO DE ALMERIA, 2017. Disponible en: www.diariodealmeria.es (acceso 17 de abril)

230. BOLSAS Y MERCADOS, 2017. Dispnible en: https://www.bolsasymercados.es (acceso 17 de abril)

231. INTEREMPRESAS, 2017. Disponible en: https://www.interempresas.net (acceso 17 de abril)

232. RETEMA, 2017. Disponible en: https://www.retema.es (acceso 17 de abril)

233. EMGRISA, 2017. Disponible en: https://www.emgrisa.es (acceso 17 de abril)

234. RECIPLASA, 2017. Disponible en: https://www.reciplasa.es (acceso 17 de abril)

235. MADRID, 2017. Disponible en: https://www.madrid.es (acceso 17 de abril)

236. CTR Mediterraneo, 2017. Disponible en: https://www.ctrmediterraneo.es (acceso 17 de abril)

237. SOGAMA, 2017. Disponible en: https://www.sogama.es (acceso 17 de abril)

238. FCC, 2017. Disponible en: https://www.fcc.es (acceso 17 de abril)

239. PROMSA, 2017. Disponible en: https://www.promsa.es (acceso $17 \mathrm{de}$ abril)

240. FERROVIAL, 2017. Disponible en: https://www.ferrovial.es (acceso 17 de abril) 
ANEXOS 


\section{ANEXO I. Determinación de la velocidad de mínima fluidización}

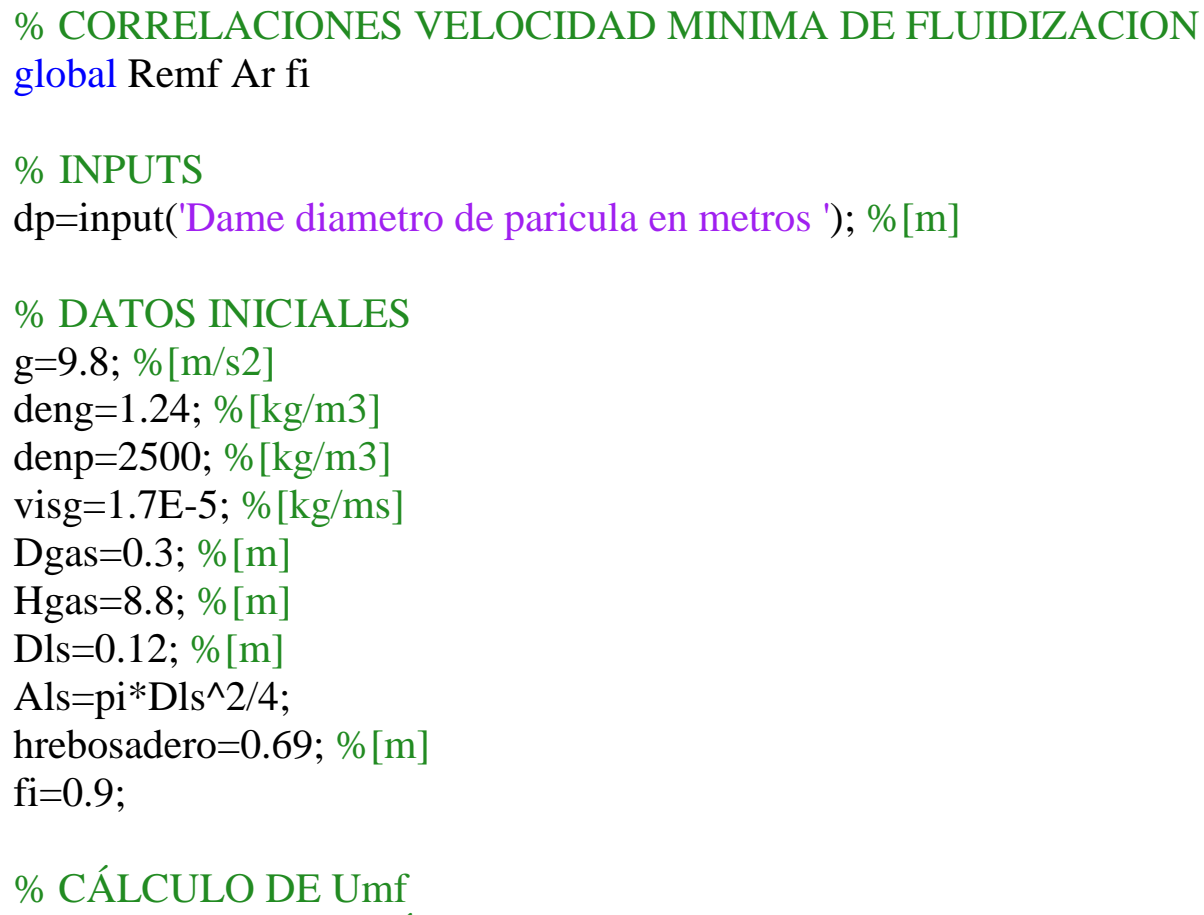


$\%$ Saxena et Vogel

$\operatorname{Remf}=\operatorname{sqrt}\left(25.28^{\wedge} 2+\operatorname{Ar}^{*} 0.0571\right)-25.28 ; \% \operatorname{Remf}$

umf=Remf*visg/(dp*deng); \%umf

elseif cor $==7$

$\% \mathrm{~J}$. Reina

$\operatorname{Remf}=\operatorname{sqrt}\left(48^{\wedge} 2+\mathrm{Ar}^{*} 0.045\right)-48 ; \% \operatorname{Remf}$

umf=Remf*visg/(dp*deng); \% umf

$\%$ Correlaciones de la forma $\mathrm{Remf}=\mathrm{C} 1 * \mathrm{Ar}$

elseif cor $==8$

$\%$ Rowe et Henwood

Remf $=8.1 \mathrm{e}-3 * \mathrm{Ar} ; \% \operatorname{Remf}$

umf $=$ Remf* ${ }^{*}$ isg/(dp*deng); \%umf

elseif cor $==9$

$\%$ Frantz

Remf $=1.065 \mathrm{e}-3 * \mathrm{Ar} ; \% \operatorname{Remf}$

umf=Remf*visg/(dp*deng); \%umf

elseif cor $==10$

$\%$ Davies et Richardson

Remf $=7.8 \mathrm{e}-4 * \mathrm{Ar} ; \% \operatorname{Remf}$

umf=Remf*visg/(dp*deng); \%umf

elseif cor $==11$

$\%$ Doichev et Akhamov

$\operatorname{Remf}=1.08 \mathrm{e}-3 * \mathrm{Ar}^{\wedge} 0.947 ; \% \operatorname{Remf}$

umf $=$ Remf*visg/(dp*deng); \%umf

$\%$ Otras correlaciones

elseif cor $==12$

$\%$ Baeyens et Geldart

$\mathrm{xO}=2$;

Remf=fzero('bayensgeldart',xo);

umf $=((9.125 \mathrm{e}-4) *(($ denp-

deng $\left.\left.)^{\wedge} 0.934\right)^{*}\left(\mathrm{~g}^{\wedge} 0.934\right)^{*}\left(\mathrm{dp}^{\wedge} 1.8\right)\right) /\left(\left(\operatorname{visg}^{\wedge} 0.87\right)^{*}\left(\operatorname{deng}^{\wedge} 0.066\right)\right)$;

elseif cor $==13$

$\%$ Miller et Logwinuk \%Ar=1429*Remf^1.063 De la forma de ecuacion de ergun umf $=\left(\left(0.00125^{*} \mathrm{dp}^{\wedge} 2\right)^{*}\left((\text { denp-deng })^{\wedge} 0.9\right)^{*}\left(\text { deng }^{\wedge} 0.1\right)^{*} \mathrm{~g}\right) /($ visg $)$;

Remf $=\mathrm{dp} *$ umf*deng/visg;

elseif cor $==14$

$\%$ Leva, Shirai et Wen

umf $=\left(7.39 *\left(\mathrm{dp}^{\wedge} 1.82\right)^{*}\left((\text { denp-deng })^{\wedge} 0.94\right)\right) /\left(\right.$ deng $\left.^{\wedge} 0.06\right)$;

Remf $=$ dp*umf*deng/visg;

elseif cor $==15$

$\%$ Leva

$\mathrm{umf}=\left((7.169 \mathrm{e}-4)^{*}\left((\text { denp-deng })^{\wedge} 0.94\right)^{*}(\mathrm{~g})^{*}\left(\mathrm{dp}^{\wedge} 1.82\right)\right) /\left(\left(\operatorname{visg}^{\wedge} 0.88\right)^{*}\left(\operatorname{deng}^{\wedge} 0.06\right)\right)$;

Remf $=\mathrm{dp} *$ umf*deng/visg;

elseif cor $==16$

$\%$ Pillai et Raja Rao

umf $=\left((7.01 \mathrm{e}-4) *\left(\mathrm{dp}^{\wedge} 2\right) *(\right.$ denp-deng $\left.) * \mathrm{~g}\right) /($ visg $)$;

Remf $=\mathrm{dp}^{*} \mathrm{umf}^{*}$ deng/visg;

elseif cor $==17$ 
$\%$ Broadhurst et Becker

$\operatorname{Remf}=\left(\operatorname{Ar} /\left(\left(2.425^{*}\left(\operatorname{Ar}^{\wedge}(-0.85)\right)^{*}\left((\text { denp/deng })^{\wedge} 0.13\right)\right)+37.7\right)\right)^{\wedge} 0.5$;

umf $=$ Remf*visg/(dp*deng);

elseif cor $==18$

$\%$ Goroshko, Rozembaum et Todes

$\operatorname{Remf}=\operatorname{Ar} /\left(1400+\left(5.2 *\left(\operatorname{Ar}^{\wedge} 0.5\right)\right)\right)$;

umf $=$ Remf*visg/(dp*deng);

elseif cor $==19$

$\%$ Bena

$\operatorname{Remf}=\left((1.38 \mathrm{e}-3)^{*} \mathrm{Ar}\right) /\left((\mathrm{Ar}+19)^{\wedge} 0.11\right)$;

umf $=$ Remf*visg/(dp*deng);

elseif cor $==20$

$\%$ Riba, Routie et Couderc

$\operatorname{Ar}=\left(\left(\mathrm{dp}^{\wedge} 3\right)^{*}\left(\text { deng }^{\wedge} 2\right)^{*} \mathrm{~g}\right) /\left(\operatorname{visg}^{\wedge} 2\right)$;

$\mathrm{Mv}=($ denp-deng $) /$ deng;

$\operatorname{Remf}=(1.54 \mathrm{e}-2)^{*}\left(\operatorname{Ar} 2^{\wedge} 0.66\right) *\left(\mathrm{Mv}^{\wedge} 0.7\right)$;

umf $=$ Remf*visg/(dp*deng);

elseif cor $==21$

$\%$ Lamas

$\mathrm{Mv}=($ denp-deng $) /$ deng;

$\operatorname{Remf}=(12.56 \mathrm{e}-2) *\left(\mathrm{Ar}^{\wedge} 0.523\right) *\left(\mathrm{Mv}^{\wedge} 0.66\right)$;

umf $=$ Remf*visg/(dp*deng);

elseif cor $==22$

$\%$ R. Coltters

Kcolt=9.7119e-7;

alfacolt $=0.84268$;

umf $=$ Kcolt* $\left(\left(\left(\left(\mathrm{dp}^{\wedge} 2\right)^{*}(\text { denp-deng })^{*} \mathrm{~g}^{*}\left((\text { denp/deng })^{\wedge} 1.23\right)\right) /(\text { visg })\right)^{\wedge}\right.$ alfacolt $)$;

Remf $=\mathrm{dp}^{*}$ umf $^{*}$ deng/visg;

$\%$ Schiller

else

break

end

$\%$ POROSIDAD MINIMA DE FLUIDIZACION

$\%$ Se calcula con la ecuación de Ergun

\%Cálculo emf (Porosidad de mínima fluidización)

$\mathrm{xg}=0.6$;

$\mathrm{emf}=$ fzero('ergun',xg);

$\%$ DATOS DE SALIDA

fprintf('Velocidad minima de fluidizacion $\% .2 \mathrm{f} \mathrm{m} / \mathrm{s}$ Porosidad de minima fluidizacion $\% .2 \mathrm{fln}$ ',umf,emf) 


\title{
ANEXO II. Determinación de la velocidad terminal
}

\author{
\% VELOCIDAD TERMINAL
}

\% Se calcula a partir de correlaciones de literatura tanto el diametro de partícula adimensional como la velocidad terminal adimensional para obtener la velocidad terminal

\% Este programa me sirve para comparar las correlaciones para el cálculo de velocidad terminal que se han encontrado en diferentes artículos

$\%$ Datos de entrada

dp=input('dame diametro de particula ');

$\%$ Propiedades fluido y particula

$\mathrm{g}=9.8 ; \%[\mathrm{~m} / \mathrm{s} 2]$

deng $=1.24 ; \%[\mathrm{~kg} / \mathrm{m} 3]$

denp $=2500 ; \%[\mathrm{~kg} / \mathrm{m} 3]$

visg=1.7E-5; \% $[\mathrm{kg} / \mathrm{ms}]$

$\%$ Determinacion velocidad terminal

$\%$ Diametro de particula adimensional

$\left.\mathrm{dp} 1=\mathrm{dp}^{*}\left(((\text { deng*(denp-deng }) * \mathrm{~g}) /\left(\operatorname{visg}^{\wedge} 2\right)\right)^{\wedge}(1 / 3)\right)$;

$\%$ Velocidad terminal adimensional (correlaciones en literatura)

velocidadterminal=input('Dame la correlación para velocidad terminal');

if velocidadterminal $==1$

ut $1=\left(\left(18 / \mathrm{dp} 1^{\wedge} 2\right)+\left((2.335-1.744 * 0.95) /\left(\mathrm{dp} 1^{\wedge} 0.5\right)\right)\right)^{\wedge}-1$;

$\%$ Correlacion de Haider and Levenspiel $(\operatorname{Re}<3 \mathrm{e} 5)$

elseif velocidadterminal $==2$

ut $1=\left(\left(\left(18 / \mathrm{dp} 1^{\wedge} 2\right)^{\wedge} 0.898 *((0.936 * \mathrm{dp} 1+1) /(\mathrm{dp} 1+1))\right)+((0.317) /(\mathrm{dp} 1))^{\wedge} 0.449\right)^{\wedge}-1.114 ;$

$\%$ Correlacion de Brown and Lawler $(\operatorname{Re}<2 \mathrm{e} 5)$

elseif velocidadterminal $==3$

ut $1=\left(\left(\left(2.33^{*}\left(\mathrm{dp} 1^{\wedge} 0.054\right)\right)-\left(1.53^{*}\left(\mathrm{dp} 1^{\wedge}(-0.048)\right)\right)\right)^{\wedge} 13.3\right) / \mathrm{dp} 1 ;$

$\%$ Correlacion Kan and Richardson $(\operatorname{Re}<3 e 5)$

elseif velocidadterminal $==4$

ut1 $=\left(\left(18 / \mathrm{dp} 1^{\wedge} 2\right)^{\wedge} 0.824+((0.321) /(\mathrm{dp} 1))^{\wedge} 0.412\right)^{\wedge}-1.214$;

$\%$ Correlacion de Turton and Clark $(\operatorname{Re}<2 \mathrm{e} 5)$

elseif velocidadterminal $==5$

ut $1=\left(\left(\left(\operatorname{sqrt}\left(14.51+1.83 *\left(\mathrm{dp} 1^{\wedge} 3 / 2\right)\right)-3.81\right)\right)\right) / \mathrm{dp} 1$;

$\%$ Correlacion de Zigrang and Silvester $(\operatorname{Re}<3 \mathrm{e} 5)$

elseif velocidadterminal $==6$

$\mathrm{z}=\log 10(\operatorname{sqrt}((4 * \mathrm{dp} 1 \wedge 3) / 3))$;

ut $1=\left(10^{\wedge}\left(-1.38+1.94 * z-0.086 * \mathrm{z}^{\wedge} 2-0.0252^{*} \mathrm{z}^{\wedge} 3+9.19 \mathrm{e}-4^{*} \mathrm{z}^{\wedge} 4+5.35 \mathrm{e}-4 * \mathrm{z}^{\wedge} 5\right)\right) / \mathrm{dp} 1$;

$\%$ Correlacion de Turian et al. $(\operatorname{Re}<1.5 \mathrm{e} 5)$

elseif velocidadterminal $==7$

$\mathrm{y} 1=1 /\left(\left(\left(0.055^{*} \mathrm{dp} 1^{\wedge} 2\right)^{\wedge}(-10)\right)+\left(0.126^{*} \mathrm{dp}^{\wedge} 1.256\right)^{\wedge}(-10)+\left(0.518^{*} \mathrm{dp}^{\wedge} 0.8\right)^{\wedge}(-\right.$

$\left.10)+\left(1.826 * \mathrm{dp}^{\wedge} 0.5\right)^{\wedge}(-10)\right)$;

$\mathrm{y} 2=\left(2.834 * \mathrm{dp} 1^{\wedge} 0.422\right)^{\wedge} 10+\left(1.633 * \mathrm{dp} 1^{\wedge} 0.5\right)^{\wedge} 10$;

$\mathrm{y} 3=\left(3 \mathrm{e}-22 * \mathrm{dp} 1^{\wedge} 7\right)^{\wedge} 10$

$\mathrm{y} 4=\left(3393 * \mathrm{dp} 1^{\wedge}(-0.352)\right)^{\wedge} 10+\left(2.582^{*} \mathrm{dp} 1^{\wedge} 0.5\right)^{\wedge} 10$; 


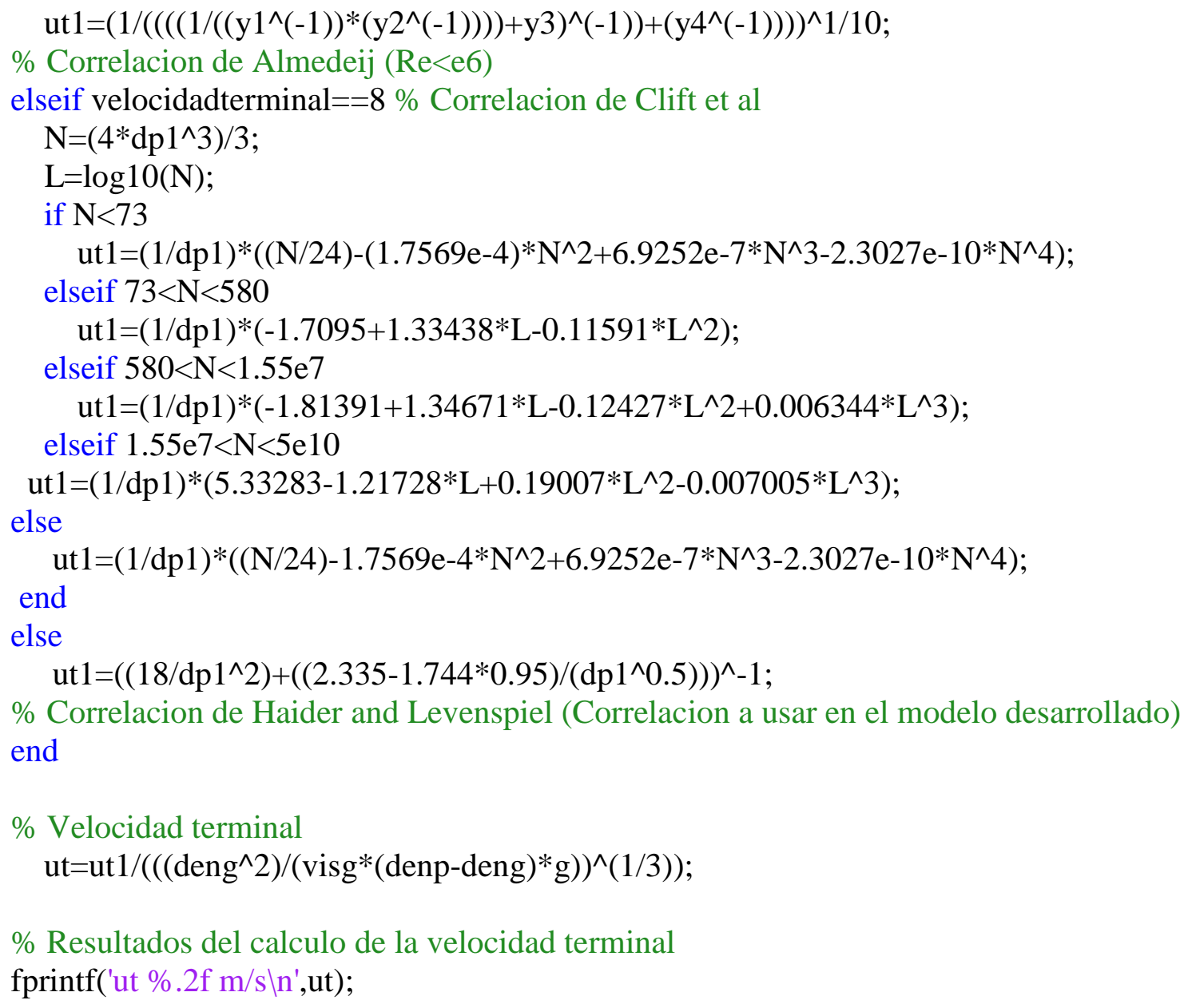




\section{ANEXO III. Simulación gasificador de LFC con válvula loop-seal}

\% Modelo fluido-dinámico que permite el cálculo de las caidas de presión y $\%$ cantidad de sólidos que se tienen a lo largo de un gasificador de lecho

\%fluido circulante

global Remf Ar edz einft a hdz denp g Agas usa Dgas fs fi

\%Inputs

Msist=input('Dame cantidad de sólidos en el sistema '); \%[kg]

ur=input('Dame velocidad en el riser '); \%[m/s]

ubottom=input('Dame la velocidad en el bottom '); \%[m/s]

uls=input('Dame la velocidad en el loop-seal '); \%[m/s]

$\%$ Datos iniciales

$\mathrm{g}=9.8 ; \%[\mathrm{~m} / \mathrm{s} 2]$

deng $=1.24 ; \%[\mathrm{~kg} / \mathrm{m} 3]$

$\mathrm{dp}=428 \mathrm{E}-6 ; \%[\mathrm{~m}]$

denp $=1450 ; \%[\mathrm{~kg} / \mathrm{m} 3]$

visg $=1.7 \mathrm{E}-5 ; \%[\mathrm{~kg} / \mathrm{ms}]$

Dgas $=0.3 ; \%[\mathrm{~m}]$

Hgas $=8.8 ; \%[\mathrm{~m}]$

Dls $=0.12 ; \%[\mathrm{~m}]$

Als $=$ pi $^{*} \mathrm{Dls}^{\wedge} 2 / 4$;

hrebosadero $=0.69 ; \%[\mathrm{~m}]$

fi $=0.9$;

\%ZONA DENSA

\%Cálculo umf (Velocidad de fluidización)

Agas $=$ pi $^{*} \operatorname{Dgas}^{\wedge} 2 / 4 ; \%$ Área gasificador

$\mathrm{Ar}=\mathrm{dp}^{\wedge} 3^{*}$ deng $*(\text { denp-deng })^{*} \mathrm{~g} / \mathrm{visg}^{\wedge} 2 ; \%$ Arquimedes

$\operatorname{Remf}=\operatorname{sqrt}\left(27.2^{\wedge} 2+\mathrm{Ar}^{*} 0.0408\right)-27.2 ; \% \operatorname{Remf}$

umf=Remf*visg/(dp*deng); \%umf

\%Cálculo emf (Porosidad de mínima fluidización)

$\mathrm{xg}=0.3$;

emf=fzero('ergun',xg);

\%Cálculo de edz (Porosidad de la zona densa)

$\mathrm{N}=1$;

$\mathrm{rob}=\left(1+\left(\left(\left(1.3 *(0.15+\text { ubottom-umf })^{\wedge}(1 / 3)\right) /(0.26+(0.7 * \exp (-3.3 * \mathrm{dp} * 1000)))\right) \ldots\right.\right.$

$\left.\left.*(\text { ubottom-umf })^{\wedge}(-0.8)\right)^{*}\left(\mathrm{~N}^{\wedge}(0.47)\right)\right)^{\wedge}(-1)$;

$\%$ Fraccion burbuja en la zona densa

edz=rob+(1-rob)*emf; \%Porosidad en la zona densa

denlecho $=(1-$ edz $) *$ denp;

$\%$ Cálculo ut (Velocidad terminal)

$\mathrm{dp} 1=\mathrm{dp} *\left(\text { deng } *(\text { denp-deng })^{*} \mathrm{~g} / \mathrm{visg}^{\wedge} 2\right)^{\wedge} 1 / 3$;

ut $1=\left(\left(18 / \mathrm{dp} 1^{\wedge} 2\right)+(2.335-1.744 * 0.95) / \mathrm{dp} 1^{\wedge} 0.5\right)^{\wedge}-1$;

ut $=$ ut $1 /\left(\text { deng }^{\wedge} 2 / \text { visg }^{*}(\text { denp-deng })^{*} \mathrm{~g}\right)^{\wedge} 1 / 3$; 
disp(ut)

\%ZONA DE TRANSPORTE_sin zona de splash

$\%$ Constante de la zona de chapoteo

$\% \mathrm{C}=10 ; \%[\mathrm{~m}-1]$ Loffler at al. 2003

$\% \mathrm{k}=\mathrm{C}^{*} \mathrm{ut} / \mathrm{ubottom} ; \%$ [constante de decaimiento]

$\%$ einfs $=1 ; \%$ [einfinito zona splash]

$\%$ Constante zona de transporte

$\mathrm{K}=8.6$;

$\mathrm{a}=\mathrm{K} /\left((\text { ur-ut })^{\wedge} 2^{*} \operatorname{Dgas}^{\wedge} 0.6\right) ; \%$ Löffler et al. 2003

Kinf $=0.011 *$ denp*((1-ut/ur $\left.)^{\wedge} 2\right) ; \%$ Colakyan and Levenspiel 1984

einft=1-(Kinf/(denp*(ur-ut))); \%[einfinito zona de transporte]

$\mathrm{Re}=\mathrm{dp} *$ deng*ubottom/visg;

Ret=dp*deng*ut/visg;

$\operatorname{deninf}=(1-\text { einft })^{*}$ denp;

dencero $=1.25 *$ deninf; $\%$ Densidad de la suspensión a la salida del freeboard

\%CICLÓN

\%Cálculo pérdida de carga en el ciclón, depende de su geometría

$\mathrm{Kc}=25$;

$\mathrm{APc}=\mathrm{Kc}^{*}$ deng*ur^${ }^{\wedge}$;

\%LOOP-SEAL

\% Reparto en el loop-seal es 0,5 ya que Asp=Adc y el caudal de sólidos

$\%$ desplazado es muy pequeño (arrastre de gas despreciable)

$\%$ Rls $=0.5$;

$\% \mathrm{R} 1 \mathrm{~s}=\mathrm{Qdc} / \mathrm{Q} 1 \mathrm{~s}$

$\mathrm{N}=1$;

robls $=\left(1+\left(\left(\left(1.3 *(0.15+\text { uls-umf })^{\wedge}(1 / 3)\right) /(0.26+(0.7 * \exp (-3.3 * \mathrm{dp} * 1000)))\right) \ldots\right.\right.$

$\left.\left.*(\text { uls-umf })^{\wedge}(-0.8)\right)^{*}\left(\mathrm{~N}^{\wedge}(0.47)\right)\right)^{\wedge}(-1)$; \% Fraccion burbuja en el loop-seal

els $=\left((1 \text {-robls })^{*}\right.$ emf $)+$ robls; \% Porosidad en el loop-seal

$\%$ Standpipe, recycling chamber

APsp $=(1-\text { els })^{*}$ denp $*$ hrebosadero*g;

Msp=(1-els)*denp*hrebosadero*Als;

$\%$ Inicio bucle

APriser $=11 ; \%$ Es un valor inicial para iniciar la condición que se indica $\%$ en el bucle while

APriserbalance $=0 ; \%$ Es un valor inicial para iniciar la condición que $\%$ se indica en el bucle while

\%Suposición inicial hdz(altura zona densa)

$\mathrm{hdz}=0.4$

while abs(APriser-APriserbalance $)>=1$;

hdz=hdz+0.00001; \% Valor de hdz para iterar hasta obtener solución 
\%ZONA DENSA

$\mathrm{Mdz}=(1-\mathrm{edz}) *$ denp*hdz*Agas;

$\mathrm{APdz}=(1-\mathrm{edz}) * \mathrm{denp} * \mathrm{hdz}^{* \mathrm{~g}}$;

\%ZONA TRANSPORTE

APtz=quadl('perdidacargatz',hdz,Hgas);

Mtz=quadl('masatz',hdz,Hgas);

$\%$ Pérdida de carga por fricción

if ur>ut

$\mathrm{S} 1=0.0126$

$\mathrm{S} 2=0.979$;

else

$\mathrm{S} 1=0.0410$

$\mathrm{S} 2=-1.021$

end

usa $=1 ; \%$ Velocidad descendente en el annulus

$\mathrm{fs}=\mathrm{S} 1 *\left((1-\mathrm{edz}) / \mathrm{edz}{ }^{\wedge}(3)\right)^{*}((1-\mathrm{edz}) * \operatorname{Ret} / \mathrm{Re})^{\wedge} \mathrm{S} 2$;

APfrtz=quadl('perdidacargafrtz',hdz,Hgas);

$\%$ Balance al riser

Mriser $=$ Mdz+Mtz;

APriser $=A P d z+A P t z+A P f r t z$;

disp(APriser)

$\%$ Downcomer, supply chamber

Mdc=Msist-Mriser-Msp;

hdc $=\mathrm{Mdc} /((1-\mathrm{els}) *$ denp*Als $)$;

APdc $=(1-$ els $) *$ denp $*$ hdc $* \mathrm{~g}$;

\%Flujo de circulación de sólidos

$\mathrm{kb}=0.3 ; \%$ Parámetro que indica una salida abrupta en ángulo recto,

$\%(J o h n s s o n$ and Leckner 1995)

b=2;\% Parámetro que expresa la relación entre la densidad media en una

\%sección y la que hay en el core del riser, (Zhang et al. 1993) sobre CFBs

$\mathrm{Fs}=($ dencero*(ur-ut)*Agas $) /\left(\mathrm{b}^{*}(1+\mathrm{kb})\right) ; \%[\mathrm{~kg} / \mathrm{s}]$

$\mathrm{Gs}=\mathrm{Fs} /$ Agas $\% \%[\mathrm{kgm} 2 / \mathrm{s}]$

\%Conexión riser-ciclón

\%Cálculo pérdida de carga (Patience et al. 1990)

APconexionrc $=\mathrm{Gs} *\left(2.84+0.0108 * \mathrm{ur}^{\wedge} 2\right)$;

\% Tubería de recirculación

\%Cálculo pérdida de carga, considerando

\%correctamente distribuido al sólido en la tuberia de recirculación

$\%$ (Cheng et al. 1998)

Ltuberiarecirculacion $=1.2$;

Htuberiarecirculacion $=1.5$;

frs $=2.9$;

if $3 \mathrm{e} 3<\operatorname{Re}<1 \mathrm{e} 5$

frg $=0.0791 * \operatorname{Re}^{\wedge}(-0.25)$;

elseif $1 \mathrm{e} 5<\operatorname{Re}<1 \mathrm{e} 8$ 


$$
\text { frg }=0.0008+0.0552 * \operatorname{Re}^{\wedge}(-0.237)
$$

else

$$
\operatorname{frg}=0
$$

end

erp $=1-(($ Fs*Als $) /(\operatorname{sqrt}(2 * 9.8 *$ Htuberiarecirculacion $) *$ denp $))$;

APtuberiarecirculacion $=\left(\left((1 \text {-erp })^{*}\right.\right.$ denp-erp*denp $) \ldots$

*9.8*Ltuberiarecirculacion* $\sin (25)) / 1$;

APfrtuberiarecirculacion $=\left(\left(2 * \mathrm{frg} * 9.8 *\right.\right.$ Ltuberiarecirculacion*uls $\left.\left.{ }^{\wedge} 2\right) / \mathrm{Dls}\right) / \ldots$

$((2 *$ frs*Fs*Als*( $\operatorname{sqrt}(2 * 9.8 *$ Htuberiarecirculacion $)) \ldots$

$*$ Ltuberiarecirculacion)/Dls);

$\%$ Balance al sistema

APriserbalance=APdc-APc-APsp-APconexionrc;

disp(APriserbalance)

end

fprintf('APdc \%.2f kPa Mdc \%.2f kg $\backslash n$ ',APdc/1000,Mdc)

fprintf('APsp \%.2f kPa Msp \%.2f kg \n',APsp/1000,Msp)

fprintf('APdz \%.2f kPa Mdz \%.2f kg \n',APdz/1000,Mdz)

fprintf('APtz \%.2f kPa Mtz \%.2f kg\n',APtz/1000,Mtz)

fprintf('APfrtz \%.2f kPa\n',APfrtz/1000)

fprintf('APriser \%.2f kPa Mriser \%.2f kg $\backslash n$ ',APriser/1000,Mriser)

fprintf('APc \%.2f kPa APconexionrc \%.2f kPaln',APc/1000,APconexionrc/1000)

fprintf('hdz \%.2f m hdc \%.2f m\n',hdz,hdc)

fprintf('Gs \%.2f kg/m2s Fs \%.2f kg/m2s\n',Gs,Fs)

fprintf('denlecho $\% .2 \mathrm{f} \mathrm{kg} / \mathrm{m} 2 \mathrm{~s}$ dencero $\% .2 \mathrm{f} \mathrm{kg} / \mathrm{m} 2 \mathrm{~s}$ ',denlecho,dencero)

\% Gráfica de presiones a lo largo del gasificador

Presionloopseal $=[(1000+$ APc + APconexionrc + APriser $) / 1000 \quad(1000+$ APdc-APsp $) / 1000$ $(1000+\mathrm{APdc}+\mathrm{APconexionrc}) / 1000 \quad 1 \quad 1 \quad(1000+\mathrm{APc}+\mathrm{APconexionrc}) / 1000$ $(1000+$ APc+APconexionrc+APtz)/1000 (1000+APc+APconexionrc+APriser)/1000];

Alturaloopseal=[0 $1.30 .7 \mathrm{hdc} 8.88 .8 \mathrm{hdz} 0]$;

Presionriser $=[(1000+\mathrm{APc}+\mathrm{APconexionrc}) / 1000$

$(1000+$ APc+APconexionrc+APtz)/1000 (1000+APc+APconexionrc+APriser)/1000];

Alturariser $=[8.8 \mathrm{hdz} 0]$;

Presionciclon=[1 (1000+APc+APconexionrc)/1000];

Alturaciclon=[8.8 8.8];

plot(Presionloopseal,Alturaloopseal,'r',Presionriser,Alturariser,'g',Presionciclon,Alturaci clon,'b')

xlabel('Presión $(\mathrm{kPa})$ ');

ylabel('Altura (m)');

legend('Válvula no mecánica (Loopseal)','Lecho rápido (Riser)','Ciclón');

$\%$ Se observa que un aumento de presion en el riser es compensado por un

\%aumento de altura en el downcomer.

function $[\mathrm{fx}]=\operatorname{ergun}(\mathrm{x})$

global Remf Ar fi

$\mathrm{fx}=\left(\left(\left(1.75 * \operatorname{Remf}^{\wedge} 2\right)\right) /((\mathrm{x} . \wedge 3) * \mathrm{fi})\right)+\left(((150 *(1-\mathrm{x}) * \operatorname{Remf})) /\left((\mathrm{x} . \wedge 3)^{*}\left(\mathrm{fi}^{\wedge} 2\right)\right)\right)-\mathrm{Ar}$; 
end

function [f2] $=$ masatz $(\mathrm{s})$

global einft edz a hdz denp Agas

$\mathrm{f} 2=\left(\left((1-\right.\right.$ einft $)-\left((\right.$ edz-einft $\left.\left.) * \exp \left(-\mathrm{a}^{*}(\mathrm{~s}-\mathrm{hdz})\right)\right)\right) *$ denp*Agas $)$;

end

function $[\mathrm{f} 1]=$ perdidacargatz $(\mathrm{x})$

global edz einft a hdz denp $\mathrm{g}$

$\mathrm{f} 1=\left(\left((1-\right.\right.$ einft $\left.)-\left((\text { edz-einft })^{*} \exp \left(-\mathrm{a}^{*}(\mathrm{x}-\mathrm{hdz})\right)\right)\right) *$ denp*g);

end

function $[\mathrm{f} 3]=$ perdidacargafrtz $(\mathrm{r})$

global usa Dgas fs denp einft edz a hdz

$\mathrm{f} 3=\mathrm{fs}^{*}\left(\left(\mathrm{usa}^{\wedge} 2\right) / 2\right)^{*}\left(4 /\left(\right.\right.$ Dgas $\left.\left.^{\wedge} 2\right)\right) *$ denp $^{*}\left((1-\right.$ einft $)-\left((\right.$ edz-einft $\left.\left.) * \exp \left(-\mathrm{a}^{*}(\mathrm{r}-\mathrm{hdz})\right)\right)\right)$; end 


\section{ANEXO IV. Granulometría de las cenizas volantes del CSR de origen doméstico}

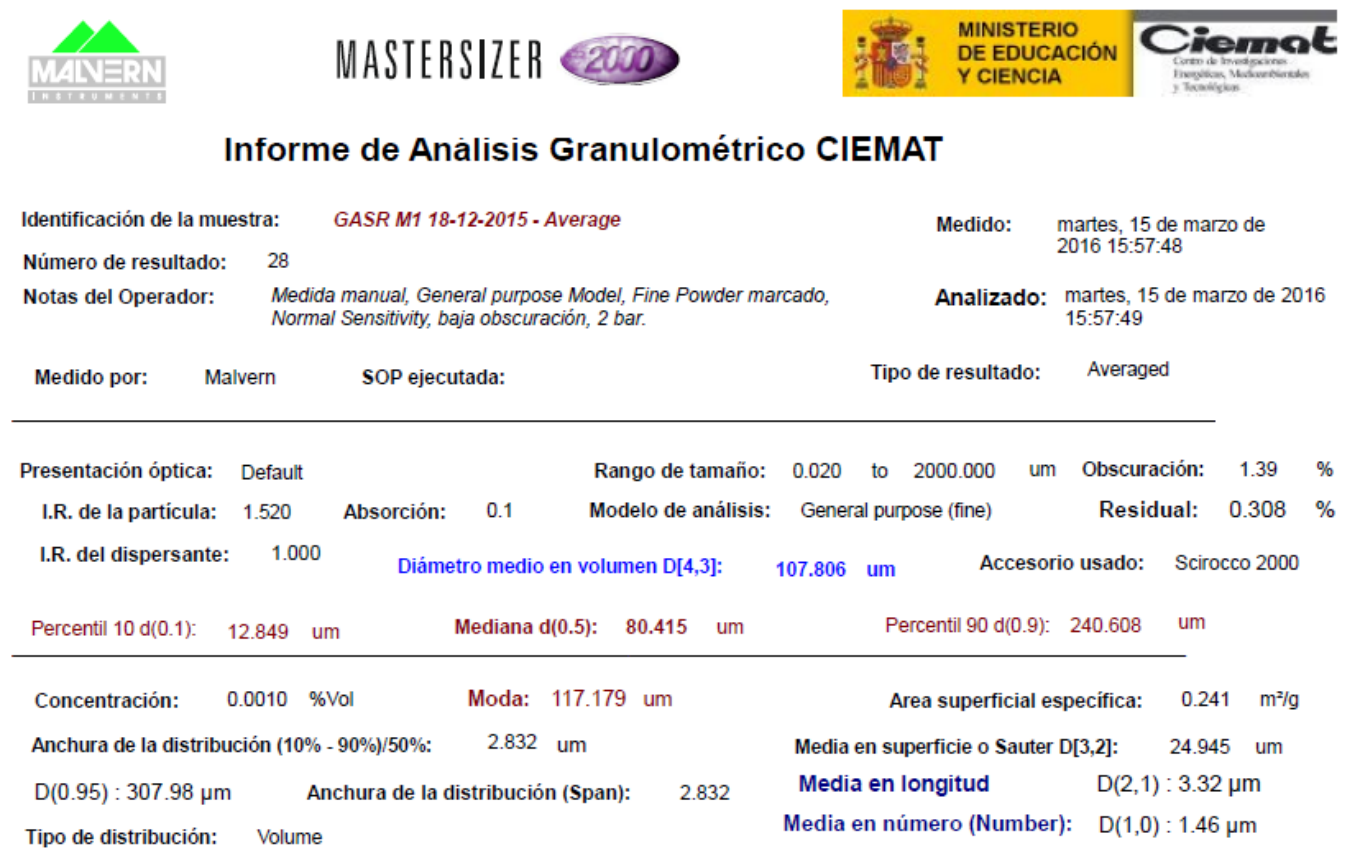

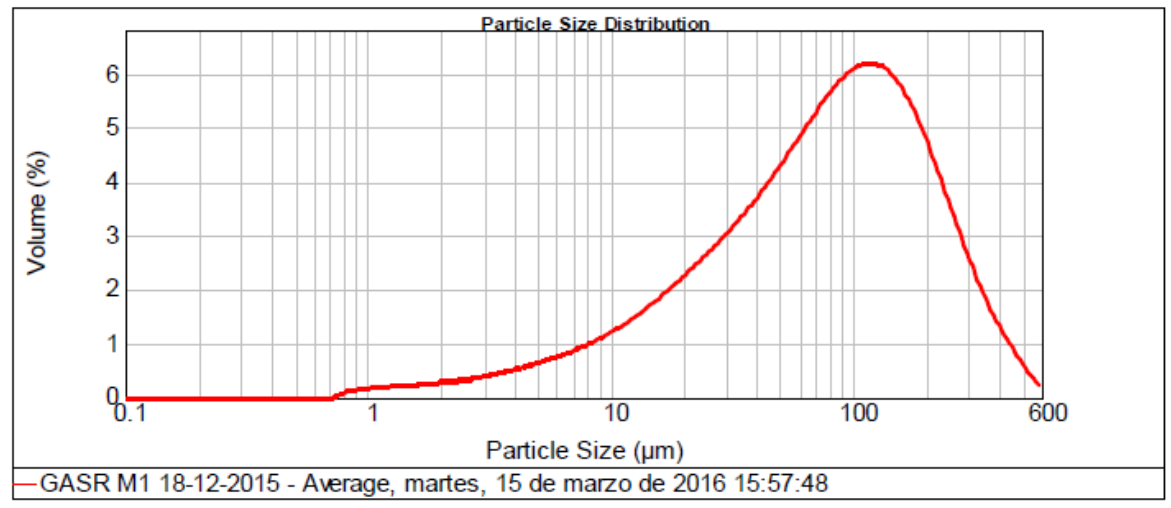

\begin{tabular}{|c|c|c|c|c|c|c|c|c|c|c|c|}
\hline Size $(\mu \mathrm{m})$ & Vol Under \% & \begin{tabular}{|l} 
Size $(\mu \mathrm{m})$ \\
\end{tabular} & Vol Under $\%$ & \begin{tabular}{|l|} 
Size $(\mu \mathrm{m})$ \\
\end{tabular} & Vol Under \% & Size $(\mu \mathrm{m})$ & Vol Under \% & \begin{tabular}{|l|l} 
Size $(\mu \mathrm{m})$ \\
\end{tabular} & Vol Under $\%$ & \begin{tabular}{|l} 
Size $(\mu \mathrm{m})$ \\
\end{tabular} & Vol Under \% \\
\hline 0.020 & 0.00 & 0.142 & 0.00 & 1.002 & 0.23 & 7.008 & 5.47 & 50238 & 34.63 & 3355.656 & 96.97 \\
\hline 0.022 & 0.00 & $0.15 e$ & 0.00 & 1.125 & 0.36 & 7.962 & 6.17 & 56.308 & 38.00 & 309.052 & 98.13 \\
\hline 0.025 & 0.00 & 0.178 & 0.00 & 1.262 & 0.51 & 8.934 & 6.94 & 63248 & 41.62 & 447.744 & 98.88 \\
\hline 0.028 & 0.00 & 0.200 & 0.00 & 1.416 & 0.67 & 10.024 & 7.80 & 70.983 & 45.51 & 502.377 & 20.56 \\
\hline 0.032 & 0.00 & 0.224 & 0.00 & 1.589 & 0.85 & 11.247 & 8.76 & 79.621 & 49.63 & 563.677 & 90.89 \\
\hline 0.036 & 000 & 0.252 & 0.00 & 1.783 & 1.03 & 12.619 & 9.82 & 89.337 & 53.98 & 632.456 & 10000 \\
\hline 0.040 & 0.00 & 0.283 & 0.00 & 2000 & 1.23 & 14.159 & 11.01 & 100237 & 58.50 & 709.627 & 10000 \\
\hline 0.045 & 0.00 & 0.317 & 0.00 & 2244 & 1.44 & 15.887 & 12.33 & 112408 & 63.13 & 796.214 & 10000 \\
\hline 0.050 & 0.00 & 0.356 & 0.00 & 2518 & 1.88 & 17.825 & 13.79 & 128.191 & 67.79 & 893.367 & 100,00 \\
\hline 0.056 & 0.00 & 0.390 & 0.00 & 2825 & 1.24 & 20.000 & 15.40 & 141.580 & 72.39 & 1002.374 & 10000 \\
\hline 0.083 & 0.00 & 0.448 & 0.00 & 3.170 & 223 & 22.440 & 17.17 & 158.868 & 76.83 & 1124.683 & 100000 \\
\hline 0.071 & 0.00 & 0.502 & 0.00 & 3.567 & 255 & 25.179 & 19.11 & 178250 & 81.00 & 1281.915 & 100.00 \\
\hline 0.030 & 0.00 & 0.564 & 0.00 & 3.291 & 281 & 28.251 & 21.21 & 200000 & 84.81 & 1415.882 & 10000 \\
\hline 0.089 & 0.00 & 0.632 & 0.00 & 4.477 & 3.32 & 31.088 & 23.49 & 224.404 & 88.18 & 1588.656 & 100000 \\
\hline 0.100 & 0.00 & 0.710 & 0.00 & 5.024 & 3.77 & 35.586 & 25.86 & 251.785 & 21.08 & 1782.502 & 10000 \\
\hline 0.112 & 0.00 & 0.796 & 0.02 & 5.637 & 4.28 & 30.005 & 28.63 & 282508 & 83.50 & 2000.000 & 10000 \\
\hline 0.126 & 0.00 & 0.883 & 0.12 & 6.325 & 4.84 & 44.774 & 31.51 & 316.979 & 86.45 & & \\
\hline
\end{tabular}




\section{MASTERSIZER 2000

Informe de Análisis Granulométrico CIEMAT

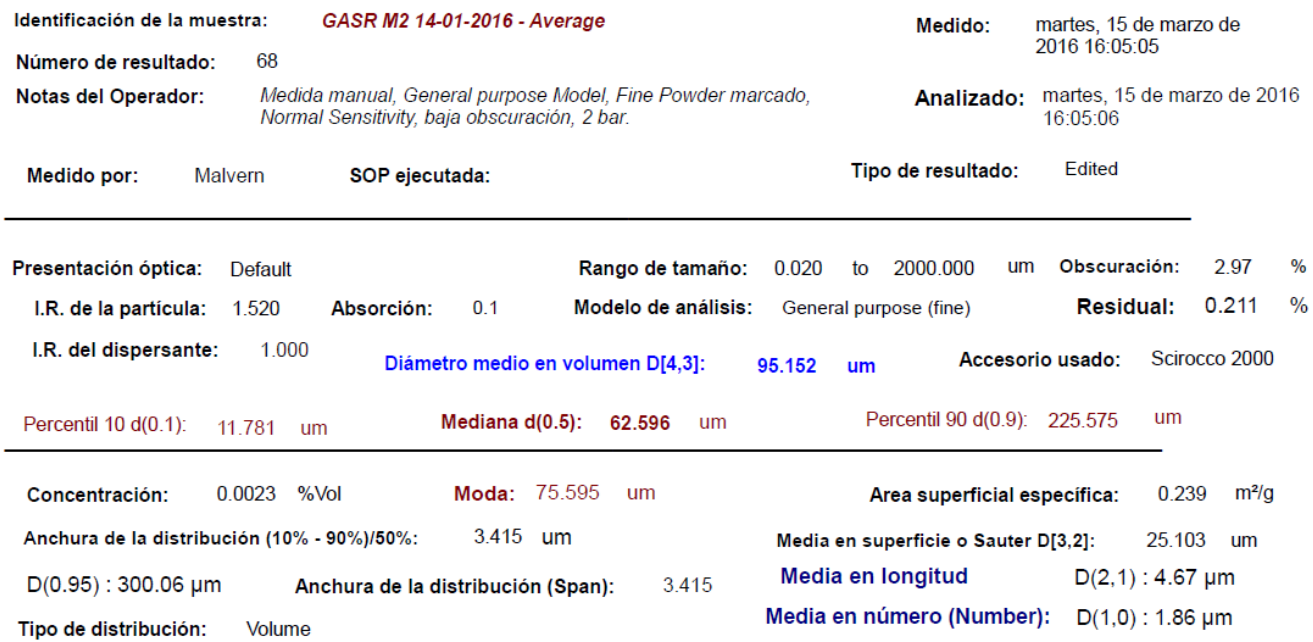

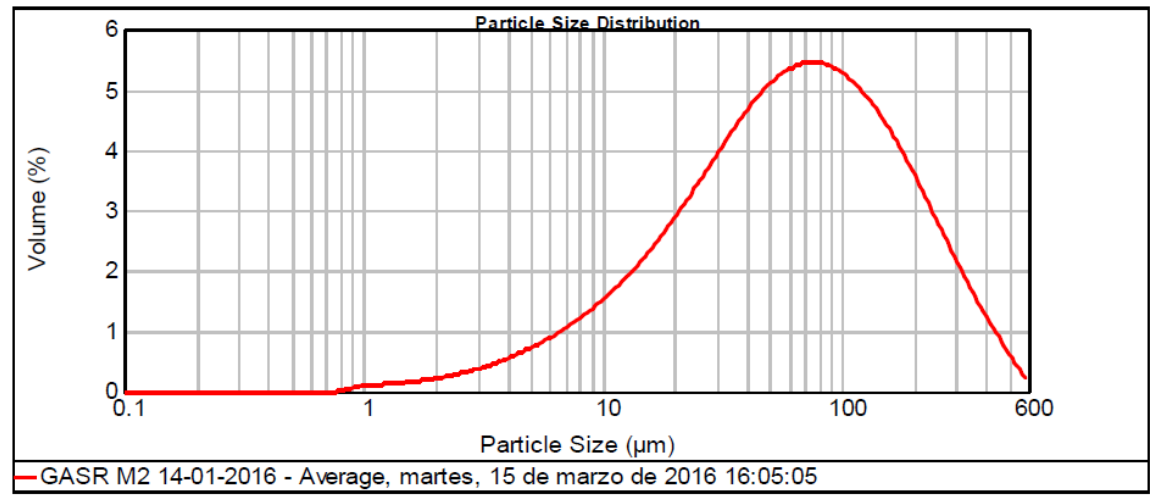

\begin{tabular}{|c|c|c|c|c|c|c|c|c|c|c|c|}
\hline Size $(\mu \mathrm{m})$ & Vol Under \% & Size $(\mu \mathrm{m})$ & Vol Under \% & Size $(\mu \mathrm{m})$ & Vol Under \% & \begin{tabular}{|l|} 
Size $(\mu \mathrm{m})$ \\
\end{tabular} & Vol Under \% & Size $(\mu \mathrm{m})$ & Vol Under \% & Size $(\mu \mathrm{m})$ & Vol Under \% \\
\hline 0.020 & 0.00 & 0.142 & 0.00 & 1.002 & 0.09 & 7.096 & 5.34 & 50.238 & 42.42 & 355.656 & 97.09 \\
\hline 0.022 & 0.00 & 0.159 & 0.00 & 1.125 & 0.16 & 7.962 & 6.20 & 56.368 & 46.34 & 399.052 & 98.16 \\
\hline 0.025 & 0.00 & 0.178 & 0.00 & 1.262 & 0.25 & 8.934 & 7.17 & 63.246 & 50.36 & 447.744 & 98.98 \\
\hline 0.028 & 0.00 & 0.200 & 0.00 & 1.416 & 0.35 & 10.024 & 8.25 & 70.963 & 54.45 & 502.377 & 99.56 \\
\hline 0.032 & 0.00 & 0.224 & 0.00 & 1.589 & 0.47 & 11.247 & 9.47 & 79.621 & 58.56 & 563.677 & 99.89 \\
\hline 0.036 & 0.00 & 0.252 & 0.00 & 1.783 & 0.60 & 12.619 & 10.83 & 89.337 & 62.65 & 632.456 & 100.00 \\
\hline 0.040 & 0.00 & 0.283 & 0.00 & 2.000 & 0.75 & 14.159 & 12.35 & 100.237 & 66.68 & 709.627 & 100.00 \\
\hline 0.045 & 0.00 & 0.317 & 0.00 & 2.244 & 0.93 & 15.887 & 14.04 & 112.468 & 70.60 & 796.214 & 100.00 \\
\hline 0.050 & 0.00 & 0.356 & 0.00 & 2.518 & 1.13 & 17.825 & 15.91 & 126.191 & 74.38 & 893.367 & 100.00 \\
\hline 0.056 & 0.00 & 0.399 & 0.00 & 2.825 & 1.37 & 20.000 & 17.98 & 141.589 & 77.97 & 1002.374 & 100.00 \\
\hline 0.063 & 0.00 & 0.448 & 0.00 & 3.170 & 1.66 & 22.440 & 20.25 & 158.866 & 81.34 & 1124.683 & 100.00 \\
\hline 0.071 & 0.00 & 0.502 & 0.00 & 3.557 & 1.99 & 25.179 & 22.75 & 178.250 & 84.47 & 1261.915 & 100.00 \\
\hline 0.080 & 0.00 & 0.564 & 0.00 & 3.991 & 2.37 & 28.251 & 25.48 & 200.000 & 87.33 & 1415.892 & 100.00 \\
\hline 0.089 & 0.00 & 0.632 & 0.00 & 4.477 & 2.81 & 31.698 & 28.44 & 224.404 & 89.89 & 1588.656 & 100.00 \\
\hline 0.100 & 0.00 & 0.710 & 0.00 & 5.024 & 3.33 & 35.566 & 31.63 & 251.785 & 92.15 & 1782.502 & 100.00 \\
\hline 0.112 & 0.00 & 0.796 & 0.00 & 5.637 & 3.91 & 39.905 & 35.04 & 282.508 & 94.10 & 2000.000 & 100.00 \\
\hline 0.126 & 0.00 & 0.893 & 0.02 & 6325 & 458 & 44.74 & 38.65 & 316979 & 9575 & & \\
\hline
\end{tabular}




\section{MASTERSIZER 2000 MINISTERIO \\ Y CIENCIA \\ Cipent \\ (2000}

MANERN

Informe de Análisis Granulométrico CIEMAT

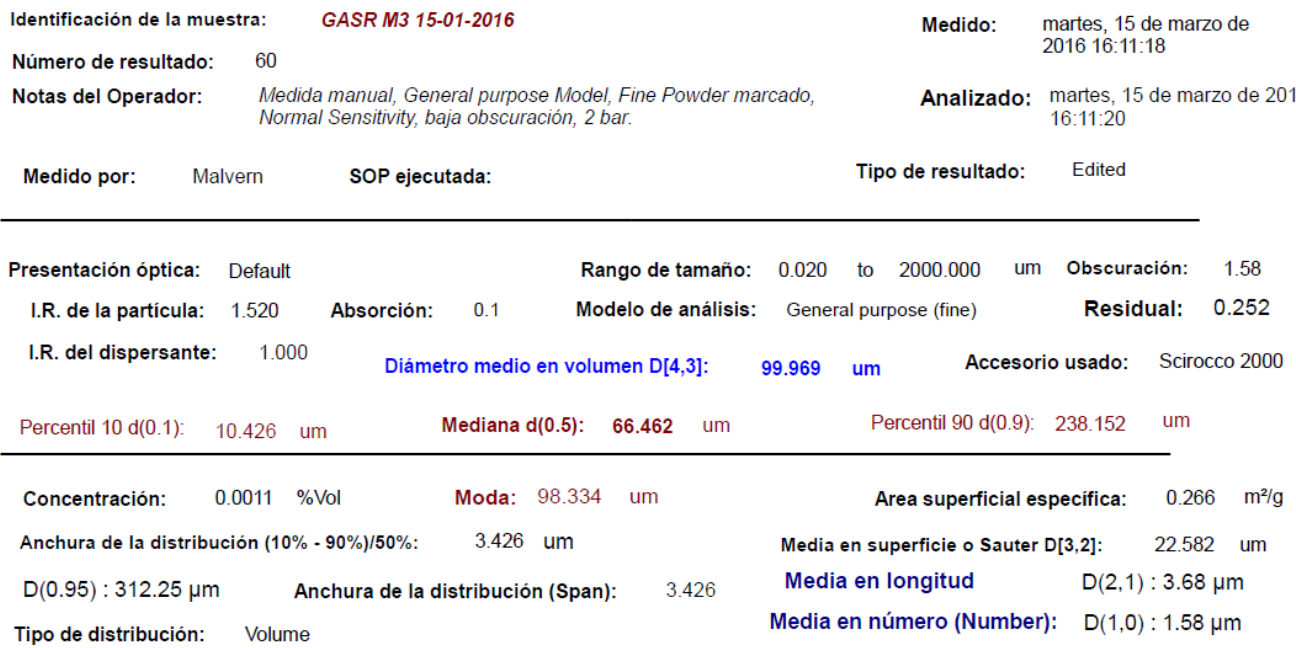

Tipo de distribución: Volume Media en número (Number): $D(1,0): 1.58 \mu \mathrm{m}$

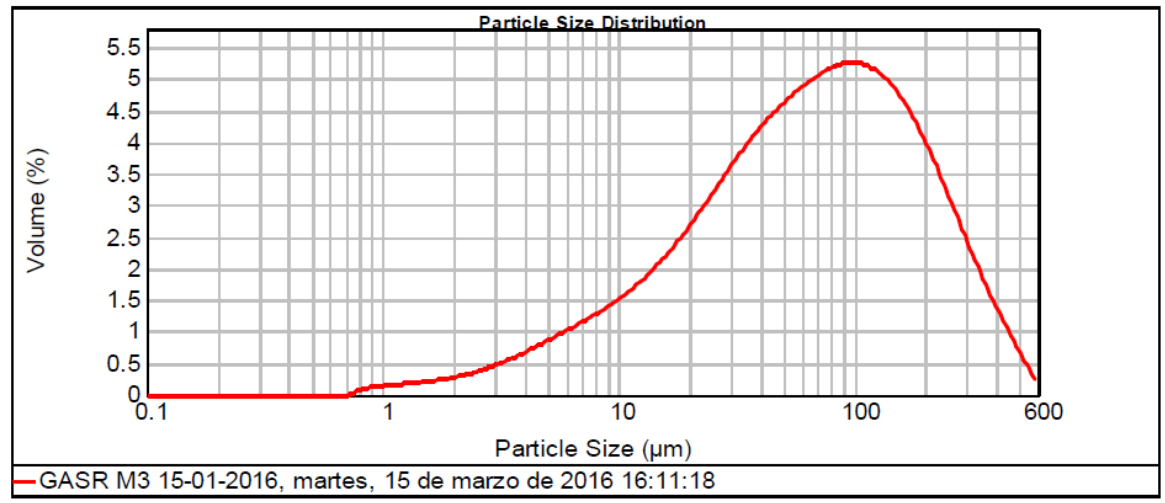

\begin{tabular}{|c|c|c|c|c|c|c|c|c|c|c|c|}
\hline \begin{tabular}{|l|} 
Size $(\mu \mathrm{m})$ \\
\end{tabular} & \begin{tabular}{|l|l|} 
Vol Under $\%$ \\
\end{tabular} & \begin{tabular}{|l|l} 
Size $(\mu \mathrm{m})$ \\
\end{tabular} & Vol Under \% & \begin{tabular}{|l|} 
Size $(\mu \mathrm{m})$ \\
\end{tabular} & Vol Under \% & \begin{tabular}{|l|} 
Size $(\mu \mathrm{m})$ \\
\end{tabular} & Vol Under \% & \begin{tabular}{|l|l} 
Size $(\mu \mathrm{m})$ \\
\end{tabular} & Vol Under \% & \begin{tabular}{|l|l} 
Size $(\mu \mathrm{m})$ \\
\end{tabular} & \begin{tabular}{|l|} 
Vol Under \% \\
\end{tabular} \\
\hline 0.020 & 0.00 & 0.142 & 0.00 & \begin{tabular}{|l|}
1.002 \\
\end{tabular} & 0.20 & 7.096 & 6.59 & 50.238 & 41.17 & 355.656 & 96.74 \\
\hline 0.022 & 0.00 & 0.159 & 0.00 & 1.125 & 0.31 & 7.962 & 7.51 & 56.368 & 44.72 & 399.052 & 97.94 \\
\hline 0.025 & 0.00 & 0.178 & 0.00 & 1.262 & 0.44 & 8.934 & 8.51 & 63.246 & 48.39 & 447.744 & 98.85 \\
\hline 0.028 & 0.00 & 0.200 & 0.00 & 1.416 & 0.58 & 10.024 & 9.60 & 70.963 & 52.16 & 502.377 & 99.50 \\
\hline 0.032 & 0.00 & 0.224 & 0.00 & 1.589 & 0.74 & 11.247 & 10.80 & 79.621 & 56.02 & 563.677 & 99.88 \\
\hline 0.036 & 0.00 & 0.252 & 0.00 & 1.783 & 0.91 & 12.619 & 12.11 & 89.337 & 59.95 & 632.456 & 100.00 \\
\hline 0.040 & 0.00 & 0.283 & 0.00 & 2.000 & 1.11 & 14.159 & 13.54 & 100.237 & 63.91 & 709.627 & 100.00 \\
\hline 0.045 & 0.00 & 0.317 & 0.00 & 2.244 & 1.33 & 15.887 & 15.13 & 112.468 & 67.87 & 796.214 & 100.00 \\
\hline 0.050 & 0.00 & 0.356 & 0.00 & 2.518 & 1.59 & 17.825 & 16.87 & 126.191 & 71.76 & 893.367 & 100.00 \\
\hline 0.056 & 0.00 & 0.399 & 0.00 & 2.825 & 1.89 & 20.000 & 18.79 & 141.589 & 75.56 & 1002.374 & 100.00 \\
\hline 0.063 & 0.00 & 0.448 & 0.00 & 3.170 & 2.25 & 22.440 & 20.90 & 158.866 & 79.19 & 1124.683 & 100.00 \\
\hline 0.071 & 0.00 & 0.502 & 0.00 & 3.557 & 2.66 & 25.179 & 23.22 & 178.250 & 82.62 & 1261.915 & 100.00 \\
\hline 0.080 & 0.00 & 0.564 & 0.00 & 3.991 & 3.13 & 28.251 & 25.74 & 200.000 & 85.78 & 1415.892 & 100.00 \\
\hline 0.089 & 0.00 & 0.632 & 0.00 & 4.477 & 3.68 & 31.698 & 28.46 & 224.404 & 88.65 & 1588.656 & 100.00 \\
\hline 0.100 & 0.00 & 0.710 & 0.00 & 5.024 & 4.29 & 35.566 & 31.38 & 251.785 & 91.18 & 1782.502 & 100.00 \\
\hline 0.112 & 0.00 & 0.796 & 0.02 & 5.637 & 4.98 & 39.905 & 34.48 & 282.508 & 93.38 & 2000.000 & 100.00 \\
\hline 0.126 & 0.00 & 0.893 & 0.10 & 6.325 & 5.75 & 44.774 & 37.75 & 316.979 & 95.22 & & \\
\hline
\end{tabular}

